\title{
Besitzwechsel und sozialer Wandel
}

Lebensläufe und sozioökonomische Entwicklungen im südlichen Böhmerwald, 1640-1840

Hermann Zeitlhofer 
Besitzwechsel und sozialer Wandel 


\section{SOZIAL- UND WIRTSCHAFTSHISTORISCHE STUDIEN}

Institut für Wirtschafts- und Sozialgeschichte

Universität Wien

\section{Gegründet von}

Alfred Hoffmann und Michael Mitterauer

Herausgegeben von

Carsten Burhop, Markus Cerman, Franz X. Eder, Josef Ehmer, Peter Eigner, Thomas Ertl, Erich Landsteiner und

Andrea Schnöller

Wissenschaftlicher Beirat:

Birgit Bolognese-Leuchtenmüller

Ernst Bruckmüller

Alois Ecker

Herbert Knittler

Andrea Komlosy

Michael Mitterauer

Andrea Pühringer

Reinhard Sieder

Hannes Stekl

Dieter Stiefel

Band 36 
Hermann Zeitlhofer

\section{BESITZWECHSEL UND SOZIALER WANDEL}

Lebensläufe und sozioökonomische Entwicklungen im südlichen Böhmerwald, 1640-1840

Böhlau Verlag Wien Köln Weimar 


\section{FWF $\boldsymbol{F}_{\text {Derwssenschatstsonds }}$}

\section{The research was funded by the Austrian Science Fund (FWF): PUB 117-V16}

Bibliografische Information der Deutschen Nationalbibliothek:

Die Deutsche Nationalbibliothek verzeichnet diese Publikation in der

Deutschen Nationalbibliografie; detaillierte bibliografische Daten sind im Internet über http://dnb.d-nb.de abrufbar.

(C) 2014 by Böhlau Verlag Ges.m.b.H., Wien Köln Weimar

Wiesingerstraße 1, A-1010 Wien, www.boehlau-verlag.com

Alle Rechte vorbehalten. Dieses Werk ist urheberrechtlich geschützt.

Jede Verwertung außerhalb der engen Grenzen des Urheberrechtsgesetzes ist unzulässig.

Lektorat: Dr. Andrea Schnöller, Wien

Satz: Michael Rauscher, Wien

Druck und Bindung: Prime Rate, Budapest

Gedruckt auf chlor- und säurefrei gebleichtem Papier

Printed in the EU

ISBN 978-3-205-79565-0 


\section{INHALTSVERZEICHNIS}

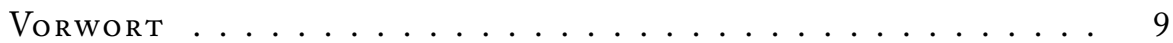

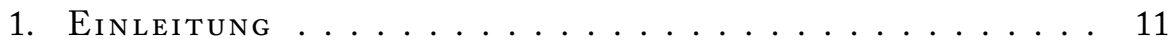

1.1 Der Besitztransfer als zentrale Erklärungsvariable

in der sozialhistorischen Forschung . . . . . . . . . . . . . . 11

1.2 Fragestellungen der Arbeit . . . . . . . . . . . . . . 26

1.3 Lokale Fallstudie als Methode . . . . . . . . . . . . . . . . 28

2. Untersuchungstegion und Quellen . . . . . . . 31

2.1 Das Untersuchungsgebiet:

Die Pfarre Kapličky in der südböhmischen Herrschaft Vyšší Brod . . 31

2.2 Die Datengrundlage . . . . . . . . . . . . . . . . . . 36

2.2.1 Der Familienkataster . . . . . . . . . . . . . . . . 37

2.2.2 Die Grundbücher . . . . . . . . . . . . . . . . . . . 41

2.2.3 Das Ausnehmerbuch . . . . . . . . . . . . . . . . 46

2.2.4 Die staatlichen Quellen: Bevölkerungsverzeichnis und Kataster . . . . . . . . . . . . . . . . . 47 47

2.3 Die Gutsherrschaft des Klosters Vyšší Brod . . . . . . . . . . . . 49

3. Die Ausgangslage um i 650 und Fragen der sozialen

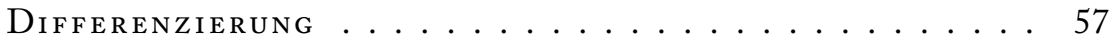

3.1 Die demographischen Folgen des Dreißigjährigen Krieges . . . . . 58

3.2 Sozialstruktur und Grundbesitz nach dem Dreißigjährigen Krieg: das Bild der staatlichen Kataster . . . . . . . . . . . . . . . . 71

3.3 Soziale Kategorisierung in den staatlichen Katastern . . . . . . . . 78

3.4 Haus und Haushalt $\ldots \ldots \ldots$

3.5 Eine mögliche soziale Differenzierung $\ldots \ldots \ldots \ldots$

4. Die Vielfalt der Regionalen und lokalen Ö́onomie . . 86

4.1 Ackerbau und Viehzucht . . . . . . . . . . . . 86

4.2 Das Landhandwerk . . . . . . . . . . . . . . . . . . . . 91 
4.3 Die Mischökonomie im Schatten der Landwirtschaft _. . . . . . . 95

4.4 Zur Bedeutung der Holzwirtschaft in der Region . . . . . . . . . . . 100

4.5 Flachsanbau und -verarbeitung . . . . . . . . . . . . . . . . . . 104

4.6 Weitere gewerbliche Einkommensformen im südlichen

Böhmerwald . . . . . . . . . . . . . . . . . 111

5. Agrarentwicklung und Sozialer Wandel:

ZUR FLEXIBILITÄT TRADITIONALER LÄNDLICHER

Geselloschaften . . . . . . . . . . . . . . . 116

5.1 Eine statische vorindustrielle ländliche Gesellschaft? . . . . . . . . . 116

5.2 Wesentliche Charakteristika des lokalen Agro-Systems:

Landnutzung und Feldsysteme . . . . . . . . . . . . . . . . . 120

5.3 Demographisches Wachstum von der Mitte des 17. bis zur Mitte des

19. Jahrhunderts . . . . . . . . . . . . . . . . . . . . . . . 124

5.4 Die Entwicklung der sozialen Differenzierung von der Mitte des

17. bis ins 19. Jahrhundert . . . . . . . . . . . . . . . 127

5.5 Die Etablierung neuer Anwesen . . . . . . . . . . . . . . . . . . 132

5.6 Die dominikalen Zinsreuter: eine zweite Kategorie von Land . . . . 138

5.7 Folgen des Siedlungsausbaus: Wachstum der Agrarproduktion . . . . 146

6. Besitzrechte, Mobilität und Siedlungsausbau . . . . . . . 152

6.1. Der frühneuzeitliche Siedlungsausbau im südlichen Böhmerwald . . 152

6.2 Mobilität und Migration im südlichen Böhmerwald . . . . . . . . . . 157

6.3 Zur Entwicklung der Besitzrechte in der Region . . . . . . . . . . . 168

6.3.1 Die Entstehung der Leiberpacht im 18.Jahrhundert . . . . . . 171

7. Die Praktiken des Besitzwechisels . . . . . . . . . . . . 174

7.1 Die Prinzipien der Besitzweitergabe im südlichen Böhmerwald . . . 174

7.2 Die Rolle der Herrschaft beim Besitzerwechsel . . . . . . . . . . . . 180

7.3 Die „Wehrungen“ und Variationen in der Aufteilung der

Kaufsumme . . . . . . . . . . . . . . . . . . . . 184

7.4 Muster des Besitztransfers in Kapličky . . . . . . . . . . . . . . . 192

7.4.1 Die Unteilbarkeit der Güter als Konstante . . . . . . . . . . . 193

7.5 Die Besitzdauer . . . . . . . . . . . . . . . . . . . . 195

7.6 Die Besitznachfolger: Kinder, Verwandte, Fremde? . . . . . . . . . . 200

7.6.1 Zur Rekonstruktion von Besitzerfolgen und

Verwandtschaftsbeziehungen . . . . . . . . . . 200

76.2 Empirische Ergebnisse: zunehmende land-family bond . . . . . 205

7.6.3 Geschlecht und Geburtsrang der Nachfolger . . . . . . . . . . 212 
7.6.4 Witwen und Interimsbesitzer . . . . . . . . . . . . . . . . 219

7.7 Besitztransfermuster im regionalen Vergleich . . . . . . . . . . 227

7.8 Der Wandel der räumlichen Stabilität bei der Haus besitzenden

Bevölkerung . . . . . . . . . . . . . . . 232

7.9 Typen unterschiedlicher Strategien des Besitzerwerbs und -erhalts . . 238

8. Die Heirat : ein , soziales Privileg' der Besitzenden?

European Marriage Pattern, ,Vollstellen'-Theorie, und die lokalen VerhäLttisse . . . . . . . . . . . . . 243

8.1 Die Persistenz der,Vollstellentheorie' in der deutschsprachigen Forschung . . . . . . . . . . . . . . . . 245

8.2 Heirat und Stelle in Kapličky . . . . . . . . . . . . . . . . . . . 249

8.2.1 Zum Wandel der Heiratsmuster in Südböhmen . . . . . . 250

8.2.2 Was ist eine,Stelle'? . . . . . . . . . . . . . . . . . 253

8.3 Der Besitztransfer als Regulativ im Nischenmodell . . . . . . . . 256

8.4 Die Rolle der Herrschaft bei der Eheschließung . . . . . . . . . 259

8.5 Die Bedeutung des Gesindedienstes für das Heiratsalter . . . . . . . 262

8.6 Optionen und Strategien statt Mechanismen . . . . . . . . . . 264

8.7 Auswirkungen auf die Sozialstruktur: die Lebenswege

der, weichenden' Geschwister . . . . . . . . . . . . . . 265

9. Das Ausgedinge: Privileg der ländlichen

Oberschichten oder sozialer Abstieg?

Erzwungener Rückzug oder strategischer Wechisel? . . 272

9.1 Zur Verbreitung des Ausgedinges in der Pfarre Kapličky . . . . . . 275

9.2 Das Ausgedinge und die familialen Kontinuitäten . . . . . . . . 283

9.3 Arbeit und Alter bei der hausbesitzenden und der landlosen

Bevölkerung: Die Erwerbstätigkeit im Alter zwischen eigenem

Besitz und den Zwängen einer, Ökonomie des Auskommens' . . . . 289

9.3.1 Arbeit im Alter bei der haus- und grundbesitzenden

Bevölkerung . . . . . . . . . . . . . . . . . 293

9.3.1.1 Besitzweitergabe zu Lebzeiten: das Ausgedinge als

Vorwegnahme des modernen Ruhestandes?

Die Arbeits- und Erwerbstätigkeit der Ausnehmer . . 293

9.3.1.2 Die Wirtschaftsführung bis zum Tod . . . . . . . . 300

9.3.2 Arbeit im Alter bei den Besitzlosen: eine Ökonomie des

Auskommens . . . . . . . . . . . . . 303

10. Zusammenfassung und Schlussfolgerungen $\ldots \ldots \ldots$ 
11. Quellen - und Literaturverzeichnis . . . . . . . . . . 318

12. Verzeichnis der Tabellen, Graphiken und Karten . . . 369

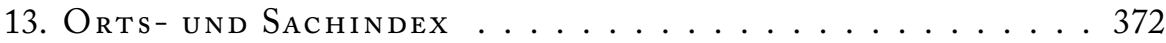




\section{VORWORT}

Das vorliegende Buch ist im Kern eine überarbeitete Fassung meiner an der Universität Wien entstandenen Dissertation. Allerdings ist die aus unterschiedlichen Gründen erst mit großer Verzögerung zustande gekommene Publikation gegenüber dem damals eingereichten Manuskript nicht nur stark überarbeitet - an einigen Stellen deutlich gekürzt, an anderen erweitert -, sondern in mehreren $\mathrm{Ab}$ schnitten auch thematisch wesentlich verbreitert. Zahlreiche in der Zwischenzeit auf Basis einer Überarbeitung von Teilen der Dissertation publizierte Aufsätze wurden für die vorliegende Druckfassung nochmals modifiziert und eingearbeitet. Bedingt auch durch den zeitlichen Abstand beeinflussten mehrere in den letzten Jahren neu hinzugekommene Forschungsinteressen die Überarbeitung der Dissertation stark. Die vorliegende Version enthält so auch jeweils eigene Kapitel zu den Themen Migration und Erwerbstätigkeit im Alter - zwei Forschungsthemen, die mich erst in den Jahren nach Abschluss der Dissertation intensiv beschäftigten.

Die Dissertation entstand im Kontext des langjährigen internationalen Forschungsprojektes ,Soziale Strukturen in Böhmen' in dem österreichische, tschechische, britische und deutsche Institutionen zusammenarbeiteten und in dem ich mehrere Jahre lang mitarbeiten durfte. Die Einbindung in dieses Forschungsprojekt erlaubte mir, meine Fragestellungen und deren methodische Umsetzung in enger Anbindung an den internationalen aktuellen Forschungsstand zu entwickeln. Dafür danke ich insbesondere den Projektleitern Josef Ehmer und Michael Mitterauer.

Ich bin den Mitarbeiterinnen und Mitarbeitern des Projektes für die langjährige Zusammenarbeit, vielfältige Unterstützung sowie für zahlreiche inhaltliche Diskussionen zu Dank verpflichtet. Josef Grulich, der ebenfalls eine südböhmische Herrschaft bearbeitete, hat mir besonders beim manchmal nicht einfachen Zugang zu den regionalen Archiven geholfen. Ihm gilt auch mein Dank für unsere mehrere Jahre währende inhaltliche Kooperation zur Sozialgeschichte Südböhmens. Alena Pazderová und Lenka Matušiková habe ich für die ganz hervorragende Betreuung im staatlichen Zentralarchiv in Prag zu danken. Dana Štefanová und Alice Velková danke ich besonders für die wichtigen inhaltlichen Diskussionen über unsere gemeinsamen Themenbereiche Ausgedinge und Besitztransfer. Sheilagh Ogilvie hat mich mit wichtigen inhaltlichen Ratschlägen sehr unterstützt. Für einen regen in- 
haltlichen Austausch danke ich ganz besonders Markus Cerman, mit dem ich in der Intensivphase des Projektes eng zusammenarbeitete.

Erich Landsteiner habe ich nicht nur für die ersten Hinweise auf die von mir gewählte Untersuchungsregion, sondern auch für sein Bemühen um die schlussendliche Publikation des Buches zu danken. In verschiedenen Stadien des langjährigen Projektes habe ich von Robert Luft, Jürgen Schlumbohm und Manfred Thaler sowie auch von Gudrun Hopf und Werner Lausecker wertvolle inhaltliche Unterstützung erhalten, ganz besonders gilt dies aber für Josef Ehmer und Eduard Maur. Für wichtige Kommentare danke ich außerdem Heinz Berger, Georg Fertig, David R. Green, Michael Kopsidis, Margareth Lanzinger und Richard Wall ( $\dagger$ ).

Ohne die Finanzierung des ursprünglichen gemeinsamen Forschungsprojektes durch das österreichische Bundesministerium für Wissenschaft und der Volkswagen-Stiftung, Hannover, wäre das Forschungsvorhaben nicht möglich gewesen. Finanzielle Unterstützung durch die Gewährung von Stipendien und Tagungsteilnahmen leisteten außerdem die Aktion Österreich-Tschechische Republik und die Österreichische Forschungsgemeinschaft.

Ich danke dem Státní oblastní archiv in Třeboň für die guten Arbeitsbedingungen während meines viele Wochen währenden Archivaufenthalts. Dem Kloster Vyšší Brod habe ich für die ausnahmsweise erteilte Erlaubnis zur zweiwöchigen Benutzung des Archivs besonders zu danken.

Für das Lesen zahlreicher Kapitel der Arbeit während sehr verschiedener Stadien des Buches danke ich Birgit Reischl und Gudrun Hopf. Mein Dank geht außerdem an Andrea Schnöller für das sorgfältige Lektorat und Magda Oberreiter für die Überarbeitung des Literaturverzeichnisses. Für die Aufnahme des Buches in die Reihe "Sozial- und wirtschaftshistorische Studien“ danke ich dem Institut für Wirtschafts- und Sozialgeschichte der Universität Wien, insbesondere aber Josef Ehmer. Ursula Huber betreute das Buch vonseiten des Verlages. 


\section{EINLEITUNG}

1. 1 Der Besitztransfer als zentrale Erklärungsvariable in der sozialhistorischen Forschung

Die zentrale Fragestellung dieser Studie bezieht sich auf die Zusammenhänge zwischen der Weitergabe von Haus und Landbesitz von Generation zu Generation und den demographischen, ökonomischen und sozialen Entwicklungen in der ländlichen Gesellschaft der frühen Neuzeit. Am Beispiel einer lokalen Fallstudie über die zur Klosterherrschaft Vyšší Brod (Hohenfurth) gehörige Pfarre Kapličky (Kapellen) im südlichen Böhmerwald, einem Gebiet, in dem das Prinzip der Unteilbarkeit der Güter vorherrschte, werden die Praktiken der Weitergabe von Hausund Landbesitz und deren Folgen für die Entwicklung der lokalen Gesellschaft bzw. für die soziale Position der beteiligten Personen analysiert.

Worin liegt die Bedeutung einer Untersuchung der lokalen Besitztransfermuster in der frühen Neuzeit? „The pure case of impartibility will result in co-residential stem family households, celibacy, and out-migration. " ${ }^{1}$ Dieses Zitat entstammt einem in der internationalen sozialhistorischen Forschung seit mehreren Jahrzehnten als klassisch bewerteten und dementsprechend häufig zitierten Artikel von Lutz Berkner und Franklin Mendels aus den 1970er Jahren zum Themenbereich ,bäuerliche Erbschaftspraktiken im vorindustriellen Europa'. Die zitierte Aussage kann in mehrfacher Hinsicht als typisch für die damalige Forschungsliteratur angesehen werden und ist gleichzeitig doch überaus bemerkenswert. Sie bezieht sich zunächst auf einen (angenommenen) regionalen Typus der Praxis der ,ungeteilten Vererbung' des Besitzes (,impartible inheritance') an eine einzige Person - in Abgrenzung zu einem anderen regionalen Typus, bei dem die Teilung des Grundbesitzes (und manchmal selbst des Hauses) unter allen Nachkommen (,partible inheritance') üblich war. Bemerkenswert erscheint mir zunächst, dass Berkner und Mendels mit der zitierten Aussage suggerieren, dass der internationalen sozialhistorischen Forschung ihrer Zeit die regional höchst vielfältigen lokalen Praktiken der Besitzweitergabe sowie deren Folgen für die gesellschaftliche Entwicklung bekannt gewesen wären. Tatsächlich lagen zu dieser Zeit aber beinahe

1 Berkner/Mendels, Inheritance Systems, 213. 
keine empirischen historischen Fallstudien zum genannten Themenkomplex vor. Ebenso bemerkenswert, aber keineswegs untypisch für den lange Zeit dominanten Diskurs der Forschung, ist die Behauptung eindeutiger und kausaler Folgewirkungen bestimmter regionaler Muster, die Mechanismen - ja, eine Determiniertheit der gesellschaftlicher Entwicklung - unterstellen.

,Erbe' und ,Erbschaft' sind - abseits der Rechtsgeschichte - erst in jüngster Zeit zu einem wichtigen Forschungsthema in verschiedenen Zweigen der Geschichtswissenschaften geworden. Die angenommenen regionalen Unterschiede in den normativen Konzepten des Erbrechts und der,bäuerlichen Erbgewohnheiten spielen allerdings seit vielen Jahrzehnten in verschiedenen Theorieansätzen der Sozialgeschichte eine große Rolle. Die Annahme, dass in den regional vorherrschenden Praktiken der Besitzweitergabe die entscheidenden Ursachen für eine Vielzahl an sozialhistorischen Entwicklungen abzulesen seien, hat eine lange und sehr erfolgreiche Tradition in der sozialhistorischen und historisch-demographischen Literatur zur frühen Neuzeit. Erbrecht und Besitztransfer bilden zum Teil bis in jüngste Zeit eine zentrale Erklärungsvariable für die Unterschiede in der sozialen und demographischen Entwicklung einzelner Regionen. In zahlreichen Theorien und Forschungsansätzen wurde und wird ein enger Zusammenhang von Besitztransfer, Heiratsverhalten, demographischer Reproduktion und sozialer Differenzierung hergestellt. Erbschaft wird als zentrale Steuerungskategorie dörflichen Lebens angesehen. ${ }^{2}$

In der sozialhistorischen Forschung sind die Annahmen, dass Haus- und Landbesitz in den ländlichen vormodernen Gesellschaften Europas eher innerhalb der Familie vererbt als über anonyme Märkte verkauft wurden, sehr alt und blieben lange Zeit weitgehend unhinterfragt. ${ }^{3}$ Die Besitznachfolge wurde demgemäß in der Literatur überwiegend mit Termini wie ,ländliche Erbschaftspraxis' abgehandelt. ${ }^{4}$ Dichotome Konzepte vom ,Markt' einerseits, der ,Familie', ,Verwandtschaft und der ,Erbschaft ${ }^{\star}$ andererseits waren in den unterschiedlichen theoretischen Traditionen der Forschung tief verwurzelt. Volkskundler und Agrarsoziologen des 19. Jahrhunderts haben ebenso, wie anthropologische Konzeptionen des 20. Jahrhunderts, an der Festschreibung von bipolaren Vorstellungen von der traditionellen, immobilen, an der Subsistenz orientierten ,bäuerlichen Gesellschaft ${ }^{\star}-$

2 Langbein, Geerbte Dinge, 20.

3 Vgl. zu den folgenden Seiten auch meinen Aufsatz: Zeitlhofer, Land, Family and the Transmission of Property, bes. 519-523.

4 Daher waren in Studien zur, ländlichen Erbschaftspraxis‘ auch Begriffe wie ,family strategies` oder ,stem families‘ weit verbreitet. Vgl. zu diesen Begriffen etwa: Baud/Engelen, Introducion; Moch, Family Strategy; Viazzo/Lynch, Anthropology; Berkner, Stem Family und Arrizabalaga, The Stem Family in the French Basque Country. 
ohne Marktbeziehungen sowohl in der Produktion als auch in der Tradierung von Grund und Boden - einerseits und der modernen, kapitalistischen, mobilen, gewinnorientierten ,Industriegesellschaft ${ }^{\star}$ andererseits, mitgewirkt. ${ }^{5}$ Zahlreiche Autoren haben dabei - im Kontrast zum frühzeitig individualistischen und marktorientierten England - insbesondere die ,familistischen' bäuerlichen Gesellschaften Kontinentaleuropas als Orte gesehen, wo Land- und Hausbesitz von Generation zu Generation innerhalb der Familie weitervererbt wurde: ${ }^{6}$,At one extreme stands the relatively undifferentiated economy of family farms and rural crafts and services. Economic activity is largely a family affair in which labour is applied to capital in the family's control. Access to the means of production is mainly through inheritance (or by marriage to an heir); kinship plays an important role in marriage decisions and other property transactions ... ${ }^{7}$

Teils aufgrund der Vorstellung einer traditionalen, stark an verwandtschaftlicher Abstammung orientierten Mentalität, teils wegen der Annahme eines ,anderen“ (manchmal auch als, irrational' bezeichneten) ökonomischen Verhaltens der traditionellen Bauern des europäischen Kontinents, schien es, dass nur durch Erbschaft, nicht aber durch Marktbeziehungen Land akkumuliert werden konnte. ${ }^{8}$ Der Dualismus zwischen Landmarkt einerseits und der familialen Weitergabe durch Vererbung andererseits hat insbesondere in der englischen sozialhistorischen Forschung eine lebhafte Debatte ausgelöst. Bestand bei einem Landmarkt die Assoziation mit modernen Gesellschaften, wurde (und wird) ein starker ,Land-Family Bond' oft als charakteristisch für mittelalterliche und vorindustrielle Gesellschaften gesehen. ${ }^{9}$ Für die vorindustriellen Gesellschaften Kontinentaleuropas fehlten dagegen bis in die jüngste Zeit - trotz der immer wieder behaupteten Annahme einer starken ,Land-Family Bond' - empirische Studien, die überprüft hätten, wie verbreitet die Weitergabe des Landes innerhalb der Familie in Zentraleuropa tatsächlich war. ${ }^{10}$

5 Vgl. Grassby, Kinship and Capitalism, 1-3.

6 Macfarlane, The Origins of English Individualism; Schofield, Family Structure.

7 Schofield, Family Structure, 285.

8 Zahlreiche Studien sahen vorindustrielle bäuerliche Gesellschaften als auf einer von modernen Verhältnissen deutlich abweichenden, moralischen Ökonomie basierend an. Vgl. Popkin, The Rational Peasant, 5 : ,Peasants are anti-market ... [they] dislike buying and selling.' Für zahlreiche ähnliche Beispiele siehe auch: Ogilvie, Zur ökonomischen Welt der Untertanen in Böhmen.

9 Vgl. etwa Sreenivasan, The land-family bond; Razi, Myth; Razi, The erosion of the family-land bond. Siehe auch: Mitson, The significance of kinship networks, und Whittle, Individualism and the familyland bond.

$10 \mathrm{Vgl}$. jedoch Schlumbohm, The land-family bond, für eine nordwestdeutsche Gesellschaft. Er kam zu dem Schluss, dass die ländlichen Grundbesitzer zwar häufig das Land ihrer Vorfahren bewirtschafteten, es aber keineswegs immer oberste Priorität war, das ererbte Land innerhalb der Familie zu erhalten. 
Trotz des weitgehenden Fehlens empirischer Studien zu den Praktiken des Besitztransfers in der Vormoderne, verleiteten fest gefügte Vorannahmen die Fachliteratur lange Zeit zu weit reichenden Schlussfolgerungen. ${ }^{11}$ Zunächst wurde eine Dichotomie zwischen zwei Formen des Besitztransfers angenommen: nämlich der ungeteilten Weitergabe an eine Person (,Anerbenrecht $t^{\circ}$ ) einerseits, andererseits der gleichen Aufteilung von Haus und Boden an alle Anspruchsberechtigten (,Realteilung ).Von diesem dualen Modell ausgehend, wurden zumeist zahlreiche kausale Zusammenhänge hergestellt.

Die Dynamik der Bevölkerungsentwicklung, der Verlauf des sozialstrukturellen Wandels in einer Region, die Formen des familialen Zusammenlebens, die Höhe des Heiratsalters und der Umfang der (insbesondere saisonalen) Migration, etc. wurden oft in direkter Abhängigkeit vom jeweiligen Typus des Besitztransfers gesehen. Beispielsweise habe die ungeteilte Weitergabe zu höheren Zölibats- und Abwanderungsraten und zu einer sozialen Polarisierung der Gesellschaft geführt, Realteilung dagegen zu einem starken Bevölkerungswachstum und einheitlichem Kleinbesitz. Häufig wurde etwa angenommen, dass die Unteilbarkeit der Güter zu einer deutlichen sozialen Polarisierung der regionalen Gesellschaft in eine kleine, aber konstante Anzahl an großen bäuerlichen Anwesen einerseits sowie zu einer stark anwachsenden Schicht völlig landloser Haushalte andererseits geführt habe, da jeweils nur ein Kind in den Genuss eines Großteils des Familienerbes gekommen wäre, während die anderen nichts oder nur deutlich geringere Anteile erhalten hätten. Außerdem wurde Regionen mit Unteilbarkeit der Güter ein vergleichsweise geringes Bevölkerungswachstum aufgrund hoher Ledigenanteile und eines im Durchschnitt hohen Heiratsalters - da die präsumptiven Erben mit der Heirat bis zum Zeitpunkt der Besitzübergabe gewartet hätten - zugesprochen. Die Unteilbarkeit der Güter hätte auch die permanente Auswanderung eines Teils derer, die keine Aussicht auf das Erbe von Land gehabt hätten, gefördert. Gebiete mit Realteilung dagegen wurden als Regionen mit sehr starkem Bevölkerungswachstum betrachtet. Die gleiche Aufteilung des Erbes hätte es mehreren Kindern erlaubt, zu heiraten und eine Familie zu gründen; allerdings hätte Realteilung auch zu einem Vorherrschen von Klein- und Kleinstbauern - von nicht überlebensfähigen „Zwergbetrieben“ - und

11 Vgl. als eine Ausnahme aber die frühe Fallstudie über die Auswirkungen der beiden unterschiedlichen Systeme: Mayer, Anerben- und Teilungssystem. Besonders bemerkenswert erscheint an diesem Buch, das aufgrund empirischer Vergleiche für liberale Agrarreformen und gegen eine gesetzliche Aufrechterhaltung ,bäuerlicher Besitzgrößen ' eintritt, also tendenziell für die Realteilung Partei ergreift, dass der Reihenherausgeber (und ehemalige Lehrer des Autors) im Vorwort der Studie gegen deren Ergebnisse und für die Vorteile des Anerbenrechtes argumentiert. 
damit tendenziell zur Verarmung geführt. Die saisonale Arbeitswanderung der vielen Kleinstbesitzer, die nicht von ihrem Land allein leben konnten, sei typisch für Regionen mit Realteilung gewesen. ${ }^{12}$

Auch in anderer Hinsicht wurden manchmal kausale Zusammenhänge zwischen dem behaupteten dualen Modell der Besitzweitergabe und der ökonomischen Entwicklung in einer Region hergestellt. So wurde etwa angenommen, dass die Praxis der Realteilung in Regionen mit einer besonders intensiv betriebenen Landwirtschaft eingeführt worden wäre. Andere Autoren wandten dagegen ein, dass umgekehrt die Realteilung als Motor einer Intensivierung der landwirtschaftlichen Produktion gewirkt habe. ${ }^{13}$

Weitreichende sozialstrukturelle Folgewirkungen wurden manchmal auch aus Teilaspekten des Besitztransfers, wie den Unterschieden zwischen Ältesten- oder Jüngstenerbfolge (Majorat und Minorat), ${ }^{14}$ abgeleitet. Eine systematische Bevorzugung entweder der Ältesten- oder der Jüngstenerbfolge bei der Nachfolgeregelung hätte die Länge des ,sozialen Generationenabstandes' bestimmt und damit Auswirkungen auf die durchschnittliche Besitzdauer auf den Anwesen gehabt. Darüber hinaus hätte dies möglicherweise auch das Heiratsalter des nachfolgenden Kindes sowie die zeitliche Dauer des Altenteils und damit die personelle Haushaltskonstellation beeinflusst. Häufig, aber nicht immer, sei es zur Herausbildung regional vorherrschender Traditionen gekommen.

In der deutschsprachigen Forschungstradition, insbesondere in der Theorie der vorindustriellen ,agrarischen Bevölkerungsweise', 15 dominierte lange Zeit die Ansicht, dass unter den Bedingungen der Unteilbarkeit der Güter die Heiratschan-

12 Vgl. etwa Habakkuk, Family Structure and Economic Change; Berkner, Inheritance, Land Tenure and Peasant Family Structure; Berkner/Mendels, Inheritance Systems, 209, 213, 223; Pfister, Bevö1kerungsgeschichte, 27, 56f.; Trossbach, Bauern, 36; Marschalk, Bevölkerungsgeschichte Deutschlands, 22f. Vgl. auch Haan, In the shadow of the tree, 171, und Hippel, Auswanderung. Für eine Kritik an den Vorstellungen eines Zusammenhangs von demographischem Wachstum und Migrationsraten siehe Ehmer, Migration und Bevölkerung. Für eine Neuinterpretation des Zusammenhangs von Besitzweitergabe und Migration siehe Wegge, To Part or not to Part.Vgl. auch Duroux, Emigration, Gender, and Inheritance. Die Vorstellung, dass Verarmung und Auswanderung ursächlich auf die Realteilung - die hier sogar als ,fehlerhafte Ackerverfassung bezeichnet wird - zurückzuführen seien, findet sich etwa bereits bei: List, Die Ackerverfassung, bes. 113.

13 Vgl. Mathieu, From Ecotypes to Sociotypes, 70f.; Brakensiek, Generationengerechtigkeit, hier $17 \mathrm{f}$.

14 Zum Majorat, der Erbfolge, die den jeweils ,Erstgeborenen des Mannesstammes ' bevorzugt - eine Rechtstradition, die sich in zahlreichen Gebieten des heutigen Deutschland vor allem seit dem 17.Jahrhundert mehr und mehr verbreitet, siehe: Vedder, Majorate. ,Majorat' ist gegenüber ,Primogenitur' der treffendere Ausdruck, da ,Primogenitur' das Prinzip des ,Erstgeborenen in der ältesten Abstammungslinie' bezeichnet.

15 Mackenroth, Bevölkerungslehre. 
cen der Geschwister des Hofübernehmers nur sehr gering waren. Dies hätte das Bevölkerungswachstum wesentlich gebremst. Häufig wurde auch zur Erklärung des European Marriage Pattern eine enge Kausalität zwischen den Formen des Besitztransfers und den Heiratsmöglichkeiten der Menschen hergestellt. ${ }^{16}$ Andere Autoren dagegen waren in der Interpretation der Folgen des Besitztransfers vorsichtiger. Für John Hajnal, auf den das überaus erfolgreiche Konzept des European Marriage Pattern zurückgeht, schien die Frage, wie Heirat und Besitzweitergabe konkret zusammenhingen, noch erklärungsbedürftig: „To understand the effect on the frequency of marriage and age of marriage (...) we should know (...) the various arrangements by which land was passed on. ${ }^{\text {17 }}$

In der deutschsprachigen Literatur weit verbreitet ist die Gleichsetzung aller Formen der ungeteilten Weitergabe von Land und Haus an eine Einzelperson mit dem Anerbenrecht. ${ }^{18}$ Dies suggeriert, dass auch in der frühen Neuzeit ein formalisiertes Erbrecht bestanden habe. Bis weit ins 18. Jahrhundert hinein bestimmten jedoch nicht staatliche Rechtsvorschriften, sondern lokale Normen und Gebräuche die Praxis der Besitzweitergabe. Unter ,Anerbenrecht' versteht man jedoch ein kodifiziertes Erbrecht, bei dem die Bevorzugung eines einzelnen Kindes als Haupterbe gesetzlich fixiert ist. Häufig war die Auswahl dieses Haupterben (dem ,Anerben') unter den Kindern, dem der gesamte Land- und Hausbesitz übergeben werden sollte, bereits durch den Geburtsrang bestimmt. ${ }^{19}$ In vielen Fällen stellt die Verwendung des Terminus, Anerbenrecht' auch für die frühmoderne Zeit einen Anachronismus dar, da diese Rechtsform in manchen Gebieten erst im 19. oder auch im 20. Jahrhundert implementiert wurde. ${ }^{20}$ Keineswegs aber sind alle lokalen Praktiken der Unteilbarkeit des Besitzes in der Vergangenheit mit der klaren Bevorzugung einer Einzelperson, wie dies im Anerbenrecht bestimmt ist, vergleichbar. Inzwischen liegen auch für Mitteleuropa einige Fallstudien vor, die nicht die regional vorherrschenden Normen, sondern

16 Häufig wurde das Muster später Heirat mit der angeblich eisernen ,Kette zwischen Erbschaft und Fortpflanzung, (Tilly/Tilly, Agenda) begründet. Daran schlossen auch die Überlegungen in der Theorie der Proto-Industrialisierung an, vgl. Kriedte/Medick/Schlumbohm, Industrialisierung, $122 \mathrm{ff}$. Kritisiert wurde dieser behauptete Zusammenhang etwa bei Ehmer, Heiratsverhalten, bes. 62-82; Schlumbohm, Micro-History and the Macro-Models, und Fertig, Marriage and economy, bes. $268 \mathrm{f}$.

17 Hajnal, European marriage patterns, 134.

18 Vgl. etwa: Bürger, Bäuerliche Liegenschaftsübertragung; Sauermann, Hofidee und bäuerliche Familienverträge; Rödel, Entwicklung, 32; Pfister, Bevölkerungsgeschichte, 27, 56.

19 Schlumbohm, Lebensläufe, 379-81; Mooser, Ländliche Klassengesellschaft.

20 Dies war etwa in vielen Gebieten im Osten des heutigen Österreich der Fall, wo das Anerbenrecht erst 1938 mit der Annexion Österreichs durch das nationalsozialistische Deutschland durchgesetzt wurde. Vgl. Feigl, Erbrecht, 177-78. 
die tatsächliche Praxis der Besitzweitergabe in der frühen Neuzeit untersuchen. Die empirischen Studien zu den konkreten Praktiken von Erbschaft und Besitzweitergabe in der vorindustriellen Gesellschaft haben einige dieser Vorannahmen, wie etwa die dichotome Sichtweise von ungeteilter und geteilter Besitzweitergabe zum Teil in Frage gestellt. ${ }^{21}$ Cole und Wolf etwa, die zwei benachbarte Dörfer im Norden Italiens untersuchten (eines, in dem das System der Unteilbarkeit der Güter favorisiert wurde und eines, in dem die Teilbarkeit vorherrschte) fanden heraus, dass beide Systeme in der Praxis sehr ähnliche soziale und demographische Konsequenzen nach sich zogen. Die Heiratsmuster oder auch die durchschnittliche Größe der Anwesen waren in beiden untersuchten Gemeinden relativ ähnlich. Ähnliche Umweltbedingungen ließen es hier auch unter den Bedingungen der Realteilung geboten erscheinen, eine tatsächliche Aufteilung des Landes häufig zu vermeiden. Einige kulturanthropologische Studien sehen diese unterschiedlichen Prinzipien daher nur mehr als sekundäre Variable der Anpassung an ökologische Faktoren. ${ }^{22}$ Die Zweiteilung in Realteilung und Anerbenrecht vernachlässigte die historisch beträchtliche Vielfalt an Zwischenformen. Häufig sahen die lokalen Normen auch bei ungeteilter Besitzweitergabe keine eindeutige Bevorzugung eines Kindes gegenüber seinen Geschwistern, wie dies beim kodifizierten Anerbenrecht der Fall ist, vor. Bisher gibt es aber nur wenige Studien, die die historisch hohe Vielfalt an Zwischenformen von Teilbarkeit und Unteilbarkeit explizit thematisieren. In vielen historischen Studien wurden einfach die im 19. oder frühen 20. Jahrhundert in Bezug auf die Besitzweitergabe bestehenden Rechtsverhältnisse auf die lokalen und regionalen Gewohnheiten der Erbpraxis während der frühen Neuzeit rückprojiziert. Die Vorstellung einer starren, über die Zeit scheinbar unveränderlichen regionalen Verbreitung der Systeme von Teilbarkeit und Unteilbarkeit blockierte dabei bis in die letzten Jahrzehnte des 20. Jahrhunderts die sozialhistorische Forschung. ${ }^{23}$ Übersehen wurde dabei, dass die regionale Verbreitung des Grundprinzips der Unteilbarkeit, bzw. Teilbarkeit der Anwesen selbst einem Wandel unterlag. ${ }^{24}$

21 Cole/Wolf, The Hidden Frontier; Sabean, Property; Schlumbohm, Lebensläufe.

22 Cole/Wolf, The Hidden Frontier; Viazzo, Upland Communities, 93-99, 258-85. Vgl. Haan, In the shadow of the tree, $156 \mathrm{ff}$.

23 Jahrzehntelang wurde eine kartographische Darstellung über die ,Verbreitung bäuerlicher Vererbungsformen' in Zentraleuropa, die sich erstmals in einer 1939 publizierten Bonner Dissertation findet, auch international vielfach zitiert. Vgl. ausführlich zur Geschichte der weitgehend kritiklosen Rezeption dieser weder methodisch noch wissenschaftsgeschichtlich problemfreien Karte: Rouette, Erbrecht und Besitzweitergabe.

24 Bis heute existieren zu diesem Themenkomplex nur wenige Studien. Vgl. jedoch zur Ausbreitung der Unteilbarkeit in Hohenlohe während des 15. und 16. Jahrhunderts: Robisheaux, Rural Society. 
Bis heute ist die empirische Basis zu den in der historischen Literatur behaupteten kausalen Zusammenhängen von Besitztransferformen mit der demographischen, ökonomischen und sozialstrukturellen Entwicklung in einer Region schmal. Die in den letzten Jahren entstandenen Studien zu den Praktiken des Besitztransfers und zu den Erbschaftspraktiken haben weitgehend darauf verzichtet, die seit langer Zeit behaupteten Zusammenhänge von Besitztransfer und gesellschaftlicher Entwicklung zu überprüfen. ${ }^{25}$ Zahlreiche aktuelle Arbeiten zeigen eher die Bedeutung individueller und familialer Strategien bei der Besitznachfolge auf und weisen insbesondere nach, dass die Verhaltensweisen der frühneuzeitlichen ländlichen Bevölkerung nicht durch Rechtsnormen determiniert wurde, sondern dass diese vielfach umgekehrt die existierenden Normen sehr variabel und flexibel einsetzte. ${ }^{26}$ Weitere Forschungen zur Besitzweitergabe in historischen Perioden behandeln jeweils unterschiedliche Aspekte - sei es die Bedeutung von,Gender ' für die Besitznachfolge, oder die Frage, ob ein Landmarkt existierte oder nicht. Die Stärke oder Schwäche der familialen Bindung an den Grundbesitz oder die Frage nach den sozialen oder demographischen Folgen der Weitergabepraktiken zählten dagegen zumeist nicht zu den bevorzugten Themen der Arbeiten der letzten Jahre. ${ }^{27}$

Die neuere Literatur hat aber etwa gezeigt, dass Landmärkte in den vorindustriellen ländlichen Gesellschaften Zentraleuropas nicht völlig abwesend waren. ${ }^{28} \mathrm{Die}$ Vorstellung einer immobilen, in sich ruhenden traditionalen bäuerlichen Gesellschaft beruht im Wesentlichen auf Missverständnissen, die durch die unkritische Übernahme der Sichtweisen bürgerlicher Aufklärer und staatlicher Bürokraten zustande kamen..$^{29}$ Es gibt Fallstudien, die zeigen, dass Häuser und Land oft gekauft und verkauft wurden und der Grundbesitz oft an nicht-verwandte Personen weitergegeben wurde. ${ }^{30}$ Manche Autoren haben diese Ergebnisse dazu veranlasst, den Markt und die Familie nicht mehr als Gegensatz, sondern als stark miteinan-

25 Vgl. aber zur Neuinterpretation des Zusammenhangs unterschiedlicher Systeme der Besitzweitergabe und der sozialen und ökonomischen Entwicklung am Beispiel Frankreichs: Béaur, Land transmission.

26 Medick/Sabean, Interest and Emotion; Sabean, Property; Levi, Das immaterielle Erbe; Schlumbohm, Lebensläufe. Für einen Überblick über Theorien von Erbschaft und Nachfolge vgl. Haan, In the shadow of the tree.

27 Vgl. etwa die Beiträge in: Fauve-Chamoux /Arrizabalaga, Family transmission; Prass/Schlumbohm/ Beaur/Duhamelle, Ländliche Gesellschaften in Deutschland. Für eine Studie, die einen Wandel in der ,land-family bond' im Zeitverlauf feststellt, siehe Clarke, The ,land-family bond'.

28 Vgl. nun insbesondere: Fertig, Äcker, Wirte, Gaben; Cerman, Bodenmärkte und ländliche Wirtschaft, 125-48; Brakensiek, Grund und Boden - eine Ware?

29 Cerman, Rural Economy and Society, 48. Interessant ist, dass diese Mythen in der französischsprachigen Forschung wesentlich früher als in der deutschsprachigen überwunden wurden. Vgl. Beaur/ Schlumbohm, Einleitung, 25.

30 Sieder/Mitterauer, The reconstruction. 
der verwoben zu betrachten. David Sabean etwa, geht davon aus, dass ,der Markt innerhalb einer durch die Verwandtschaft strukturierten Welt existierte . ${ }^{31}$ Andere Autoren verwiesen auf die mehrfach anzutreffende rechtliche Zweiteilung des bäuerlichen Landes, mit einem Teil, der nur als eine Einheit weitervererbt werden konnte, und einem anderen Segment an Land, das offen für Teilungen und den Landmarkt war. ${ }^{32}$ Jedenfalls zeigen die Fälle eines Kaufes und Verkaufes der Anwesen zwischen den Generationen, dass die in zahlreichen Studien gängigen Begrifflichkeiten, wie ,Erbschaft' oder ,Markt', zur Bezeichnung der Besitzerabfolgen nicht unproblematisch sind. Ein weiterer Schwerpunkt neuerer Studien lag auf der Analyse geschlechtsspezifischer Unterschiede in den Besitzweitergabepraktiken. Den Vorstellungen einer starken familialen Tradition in Kontinentaleuropa implizit ist die männliche Dominanz in der Nachfolge. Zur Aufrechterhaltung der Kontinuität der männlichen Abstammungslinie (oder auch nur des Familiennamens) seien männliche Kinder in der Nachfolge deutlich bevorzugt worden. Mehrere Studien haben inzwischen allerdings gezeigt, dass Töchter keineswegs immer systematisch gegenüber ihren Brüdern benachteiligt wurden. ${ }^{33}$,The relationship between gender and inheritance is definitely not as clear-cut as earlier anticipated. ${ }^{34}$ Lediglich einzelne, überwiegend dem Bereich der Mikro-Geschichte zuzurechnende sozialhistorische Forschungen der letzten Jahre versuchten in ihren Untersuchungen auch einige der lange Zeit unhinterfragt angenommenen Aussagen der Makro-Theorien (European Marriage Pattern, agrarische Bevölkerungsweise, etc.) zu den Zusammenhängen von Besitzweitergabe und gesellschaftlicher Entwicklung, die sich zumeist implizit auf die Mikroebene konkreter Haushalte und Lebensläufe beziehen, auch tatsächlich empirisch zu überprüfen..$^{35}$

Die Modi der Weitergabe des ländlichen Besitzes von einer Generation zur nächsten waren vor allem im 19. und frühen 20. Jahrhundert ein großes Thema politischer Debatten. ${ }^{36}$ Aus den angeblich grundlegend unterschiedlichen Prinzipien

31 Sabean, Property, 413 (meine Übersetzung). Vg1 auch die Formulierungen auf Seite 412: ,How resources are distributed and redistributed has everything to do with family dynamics, and the market is not an independent mechanism but can be an instrument of family strategies in competition with each other'.

32 Cerman, Bodenmärkte und ländliche Wirtschaft; Brakensiek, Grund und Boden - eine Ware?; Robisheaux, Rural Society and the Search for Order.

33 Duroux, The temporary migration; Arrizabalaga, Female primogeniture.

34 Fauve-Chamoux/Arrizabalaga, Family transmission, 185.

35 Vgl. etwa Schlumbohm, Lebensläufe und Schlumbohm, Micro-History and the Macro-Models, sowie die Arbeiten von Georg Fertig, etwa: Fertig, Lokales Leben, 319-325; Fertig, Heirat; Fertig/Fertig, Bäuerliche Erbpraxis.

36 Béaur/Schlumbohm, Einleitung, 21. 
der Teilung von Land und Haus in gleiche Anteile oder der ungeteilten Besitzweitergabe an eine Einzelperson wurden immer wieder moralische, ideologische und politische Schlussfolgerungen abgeleitet. Trotz des Fehlens einer ausreichenden empirischen Evidenz spielte das Bild eines unzerstörbaren Bandes zwischen ,Familie' und ,Land' im soziologischen, rechtlichen und politischen Denken über bäuerliche Verhaltensweisen in vorindustrieller Zeit seit der Mitte des 19.Jahrhunderts immer wieder eine zentrale Rolle. Die Ideologie des unteilbaren ,bäuerlichen Erbhofs', der auf der Drei-Generationen-Familie, der Weitergabe innerhalb der familialen Abstammungslinie und der klaren Bevorzugung der männlichen Besitznachfolger beruhte, war nicht zuletzt auch ein Schlüsselelement in der völkischen Ideologie des Nationalsozialismus. ${ }^{37}$ Im deutschsprachigen Raum hatte die Höherbewertung der Unteilbarkeit der Anwesen bei einer gleichzeitigen Verurteilung der gleichwertigen Aufteilung des Landbesitzes unter allen Kindern bereits davor eine lange Traditionslinie, die aber auch eine Entwicklung erkennen lässt. So bezeichnete etwa der Volkskundler und Familiensoziologe Wilhelm Heinrich Riehl zur Mitte des 19. Jahrhunderts die Grundbesitzer, die die Unteilbarkeit ihres Landes praktizierten, als die Bauern der ,guten Art“, denen er die Realteilung übenden, von ihm als, entartet' bezeichneten Bauern Südwestdeutschlands gegenüberstellte. Diese Dichotomie wurde dann im frühen 20. Jahrhundert vom Bevölkerungssoziologen Gunther Ipsen ethnisch gedeutet: das "germanische“ Bauerntum sei dadurch zu charakterisieren, dass es die Höfe nicht teilt, die Praxis der Teilung bäuerlicher Anwesen sei dagegen ein Kennzeichen des slawischen Bauerntums. ${ }^{38}$ Bereits die deutschen Nationalökonomen August von Miaskowski und Max Sering, deren Arbeiten als Ausgangspunkt der Diskussionen über bäuerliches Erbrecht in Deutsch-

37 In der nationalsozialistischen Terminologie wurde daraus ein Band zwischen, Blut und Boden'. Siehe dazu ausführlicher Schlumbohm, The land-family bond, bes. 462, sowie die dort zitierte Literatur.

38 Ipsen stellt in seinem 1933 publizierten und später sehr einflussreichen Aufsatz ,Bevölkerung der ,germanischen Agrarverfassung,, in der ,die Stellenzahl grundsätzlich festliegt', also die Höfe nicht geteilt werden, eine, slawische Agrarverfassung' gegenüber, die geprägt sei von einer ,Armee elender Zwergbauern` oder ,kümmerlicher Kleinbauern`. Vgl. dazu genauer: Ehmer, Bevölkerungsgeschichte, hier bes. $61 \mathrm{f}$. Ipsen ignoriert an dieser Stelle die auch in seiner Zeit zumindest teilweise bekannte hohe kleinräumige Vielfalt zwischen Gebieten mit Unteilbarkeit und solchen mit Realteilung und verwendet den ansonsten häufig für südwestdeutsche Realteilungsgebiete gebrauchten Begriff, Zwergbauern für den slawischsprachigen Raum. Vgl. dazu auch Fertig/Fertig, Bäuerliche Erbpraxis 168, 170. Auch wenn solche, völkischen' Wertungen ganz überwiegend der Vergangenheit angehören, finden sich in der Literatur der zweiten Hälfte des 20. Jahrhunderts explizit positive Wertungen der mit dem Anerbenrecht angeblich einhergehenden Ungleichbehandlung der Kinder. Begründet wird dies nun mit der Natürlichkeit einer Hierarchie innerhalb einer sozialen Ordnung. Vgl. Sauermann, Hofidee und bäuerliche Familienverträge, 59: ,Dem Anerbenrecht lag die Überzeugung zu Grunde, dass menschliches Zusammenleben nur in einer hierarchisch geordneten Gesellschaft möglich sei.‘ 
land gelten können, waren Anwälte der Unteilbarkeit der bäuerlichen Anwesen gewesen. Dabei verbanden sich zwei Ideen: einerseits wurde der Erhalt der größeren und mittleren Bauerngüter gegenüber einem Aufgehen im weit verbreiteten Kleinbesitz per se als positiver gesellschaftlicher Wert gesehen, andererseits erschien auch die Erhaltung des Grundbesitzes innerhalb der Familie als anstrebenswert. ${ }^{39}$ Den Hintergrund für diese Bewertung bildete die Vermutung, dass größere Betriebe effizienter als kleinere seien. ${ }^{40}$ Außerhalb des deutschen Sprachraumes dagegen wurde die Praxis der Realteilung überwiegend weitaus positiver beurteilt als die Unteilbarkeit. Vielfach galt und gilt die Aufteilung des (Land-)Besitzes zu gleichen Teilen unter allen Kindern als, gerechter - und wurde manchmal auch als ,demokratischer' bezeichnet. ${ }^{41}$

Bei der Analyse historischer Muster der Besitzweitergabe ist zunächst zu betonen, dass Erbschaft und Besitznachfolge nicht identisch und daher analytisch voneinander zu trennen sind. Jack Goody und andere Anthropologen betonen, dass die Weitergabe von Besitz an Grund und Boden vor allem auch die Nachfolge in der Betriebsführung bedeutet. Wie andere Anthropologen sieht er insbesondere das Element der ,Sukzession“; ,Erbe“ dagegen ist für ihn als Weitergabe von Gütern von Todes wegen (mortis causa) definiert. ${ }^{42}$ Erbansprüche wurden und werden in fast allen Gesellschaften mit Blutsverwandtschaft oder affinaler (Heirats-)Verwandtschaft begründet. Die Nachfolge in der Leitung eines (bäuerlichen) Anwesens dagegen erfordert nicht zwingend eine verwandtschaftliche Verbindung; dagegen erscheint die körperliche, geistige und ökonomische Eignung zur Leitung eines Betriebes, bzw. zur Übernahme eines ,Amtes‘ entscheidend. In Gebieten mit Unteilbarkeit der Anwesen konnte es deshalb potenziell zu einem Konflikt zweier - auch von den bäuerlichen Besitzern selbst vertretener - Prinzipien kommen, nämlich zwischen dem Wunsch, den Familienbesitz an alle Nachkommen weiterzugeben und dem Wunsch, ihn intakt und ungeteilt zu erhalten. Es konnten sich daher zum Teil regional unterschiedliche Systeme entwickeln, die entweder die Integrität des Hofes

39 Miaskowski von, Das Erbrecht; Sering, Vererbung. Vgl. dazu insbesondere: Schlumbohm, Mächtige Mythen, und Schlumbohm, The land-family bond.

40 Fertig/Fertig, Bäuerliche Erbpraxis, $165 f$.

41 Während der Amerikanischen Revolution vertrat etwa Thomas Jefferson die Meinung, dass nur die Praxis der Teilbarkeit der Güter eine Voraussetzung für eine stabile republikanische Politik wäre. Vgl. Ditz, Property and Kinship, 163 ff. Der französische Soziologe Emmanuel Todd ging in den 1980er Jahren sogar so weit, die beiden Idealtypen ,Realteilung' und, ungeteilte Besitzweitergabe' mit einer gesellschaftlichen Entwicklung in Richtung, Liberalität' und ,Gleichheit' bzw. zu ,Ungleichheit' und ,Totalitarismus' zu verbinden. Vgl. Haan, In the shadow of the tree, $167 f$.

42 Goody, Inheritance, Property, and Women; siehe auch: Wetherell/Plakans, Intergenerational transfers hier 334; Haan, In the shadow of the tree, 154. 
präferierten, oder die Integrität der verwandtschaftlichen Abstammungslinie. ${ }^{43}$ Es ist auch argumentiert worden, dass im deutschsprachigen Raum der frühen Neuzeit die Besitzweitergabe ländlicher Anwesen de facto in einem Übergangsbereich von Erbe und Nachfolge zu verorten sei, da die ländlichen Besitzer unter den Bedingungen der Feudalgesellschaft nicht in vollem Eigentum ihrer Anwesen standen. Erbe habe dabei überall die Tendenz gezeigt, alle Kinder gleichmäßig auszustatten, während man im Falle der Nachfolge in zahlreichen Regionen dazu tendierte, die Rolle des den Hof führenden „Arbeitspaares“ nur an ein Paar zu geben. ${ }^{44}$ Der Besitzerwechsel auf einem Anwesen kann nur dann als Teil einer ,Erbpraxis' gesehen werden, wenn er tatsächlich als ,Vererbung', als Teil eines Erbschaftsprozesses, erfolgt. Der in der deutschsprachigen Forschung bis heute gängige Terminus ,Erbschaftspraxis' als Synonym bzw. als Oberbegriff für alle Formen von Besitzwechsel und Betriebsnachfolge auf den ländlichen Anwesen der Vormoderne verschleiert diese wichtige Differenzierung. Ob die Besitznachfolge als Vererbung innerhalb von Familie und Verwandtschaft durchgeführt wurde oder nicht, war nur zum Teil durch regional unterschiedliche Traditionen bedingt, war je nach Zeitraum wandelbar und unterlag auch zahlreichen anderen Faktoren. In der vorliegenden Studie werden systematisch nur die Praktiken der Besitzweitergabe analysiert; die verschiedenen, zum Teil überaus komplexen Prozesse von Erbe und Erbschaft spielen dabei zum Teil zwar eine Rolle, werden jedoch nicht systematisch diskutiert. ${ }^{45}$

Durch Vererbung und Sukzession reproduzieren sich gesellschaftliche Verhältnisse mit all ihren Differenzierungen und Ungleichheiten aufs Neue. Beide sind zwangsläufig Momente des Wandels und der Veränderung, gleichzeitig sollen sie aber häufig der Sicherung von Bestehendem dienen. Üblicherweise ist das gesellschaftliche Interesse daran, dass soziale Rollen, Funktionen und soziale Verhältnisse fortbestehen, hoch. Da Individuen aber verschieden sind, birgt der Übergang einer Funktion, eines Amtes (oder von Besitz und Status generell) von einer Person zu einer anderen immer die Gefahr von Diskontinuität in sich. ${ }^{46}$ Autoren, wie Jack Goody und Pierre Bourdieu, analysieren Besitzweitergabe und Vererbung daher vor allem als Taktiken und Strategien, durch die Status, Macht und symbolisches Kapital aufrechterhalten werden sollen. ${ }^{47}$

43 Segalen, Die Familie, 97-101.

44 Fertig/Fertig, Bäuerliche Erbpraxis, 164.

45 Erst in den letzten Jahren hat sich im deutschsprachigen Raum eine intensivere Erforschung der verschiedenen Formen und sozialen Logiken von Erbschaft, Mitgift, Heiratsgut, etc. etabliert. Vg1. etwa Gottschalk, Eigentum; Lanzinger, Das gesicherte Erbe; Lanzinger, Generationengerechtigkeit; bereits klassisch ist die Studie: Levi, Das immaterielle Erbe.

46 Lettke, Vererbungsabsichten, $97 f$.

47 Goody, Strategies; Haan, In the shadow of the tree, $160 \mathrm{ff}$. 
Ohne Zweifel stehen die Entwicklung der (Ungleich-)Verteilung des Landbesitzes innerhalb einer lokalen Gesellschaft und die jeweiligen Modi der Weitergabe des Besitzes von einer Generation zur nächsten innerhalb der ländlichen vorindustriellen Gesellschaften in einem - jeweils näher zu bestimmenden - Zusammenhang. Land war die wichtigste Nahrungs- und Erwerbsgrundlage im frühneuzeitlichen Europa. Die jeweiligen Wege und Mechanismen, die auf lokaler Ebene den Zugang zu Land und Landnutzung regelten, waren für das Entstehen sozialer Unterschiede von großer Bedeutung. Erbschaft und Nachfolge können außerdem das Problem bereits bestehender sozialer Ungleichheit in einer Gesellschaft potenzieren, wenn manche sehr viel erhalten, andere aber gar nichts. ${ }^{48}$ Dennoch sind nicht nur in der historischen Forschung, sondern auch in der Soziologie Studien, die nach den Zusammenhängen von Vererbung und gesellschaftlicher Kontinuität bzw. dem sozialen Wandel suchen, selten. ${ }^{49}$ Beim Modell der Unteilbarkeit des Landbesitzes wird allgemein nicht nur von einer Entwicklung hin zu einer stark ausgeprägten sozialen Ungleichheit innerhalb der Gesellschaft ausgegangen, sondern auch von einer starken Ungleichheit in den Lebenschancen zwischen den Geschwistern. Bis heute in der Literatur weit verbreitet ist die Annahme, dass bei Einzelnachfolge im Besitz - im Gegensatz zur egalitären Behandlung unter den Bedingungen der Realteilung - ein Kind alles (oder fast alles) erbte und die Geschwister des Besitznachfolgers wenig bis nichts. Diese hätten bloß ein frühzeitiges Verlassen des elterlichen Haushaltes und den sozialen Abstieg in die ländliche Unterschicht zu erwarten gehabt. ${ }^{50}$ Die „nachgeordnete Versorgung“ der weichenden Geschwister sei eine „Funktion der Stabilität des bäuerlichen Besitzes“ und der Preis des Anerbenrechtes gewesen. ${ }^{51}$ Der Forschungsstand zu den Fragen, wie groß die Unterschiede in der (Ungleich-)Behandlung der Geschwister unter den Bedingungen der Unteilbarkeit tatsächlich waren und wie sich dies in ihren Lebenswegen und in ihrer sozialen Positionierung widerspiegelte, ist bis heute ungenügend.

Die Frage der (Ungleich-)Behandlung der Kinder führt indirekt auch zur Frage nach der Position von Frauen im System der Besitznachfolge. Denn nur wenn diese eine ausreichend starke Position hatten, hatten etwa Kinder aus zweiter Ehe zumindest auch theoretisch die Chance auf die Nachfolge. Während in einigen osteuropäischen Gebieten Frauen gänzlich von der Nachfolgeregelung ausgeschlossen waren, ${ }^{52}$ lassen sich für zentraleuropäische Gebiete je nach Re-

48 Vgl. dazu die Bemerkungen am Beispiel gegenwärtiger Gesellschaften bei: Hansert, Erbschaft, 143.

49 Vgl. allerdings mehrere Studien in: Lettke (Hg.), Erben.

50 Vgl. etwa:Trossbach, Bauern, 37; Ebeling/Klein, System, $32 \mathrm{f}$.

51 Mooser, Ländliche Klassengesellschaft, 195, 198.

52 Vgl. Kaser, Macht. 
gion zwei unterschiedliche Entwicklungen im Ehegüterrecht erkennen: einerseits Gütertrennung zwischen den Ehepartnern, andererseits eheliche Gütergemeinschaft. In beiden Fälle konnten Frauen, zumindest im Status der Verwitwung auch Anwesen und Höfe leiten und im Besitz haben. Diese Differenzierung hatte dennoch eine Reihe sehr unterschiedlicher Konsequenzen. Bei Gütertrennung leitete der Ehemann das Anwesen - egal ob dieses aus dem Besitz seiner Vorfahren oder der seiner Frau stammte. Nach dem Ende der Ehe allerdings konnte das Gut faktisch nur in der jeweiligen Herkunftslinie weitergegeben werden. Der eingeheiratete Teil konnte diese in der Regel nicht durch eine Zweitheirat weiterführen und später etwa an die Kinder aus dieser zweiten Ehe weitergeben. Die Gütergemeinschaft des Besitzerpaares bedeutete dagegen eine deutliche Aufwertung der erbrechtlichen Stellung der Frau. ${ }^{53}$ Starb der Ehemann, konnte die Frau das Anwesen als Witwe auf längere oder kürzere Zeit alleine führen; sie konnte sich außerdem nach Belieben wiederverehelichen und das Anwesen dann an Kinder aus der zweiten Ehe weitergeben, unabhängig davon, ob sie das Anwesen ursprünglich in die Ehe eingebracht hatte oder ihr erster Mann. Aufgrund der demographisch, unsicheren Lebenszeit' in der Vormoderne waren Wiederverehelichungen - und damit häufig auch Besitzweitergaben über Wiederverehelichungen - zum Teil überaus häufig. ${ }^{54}$

Auch die Herausbildung scharfer Zäsuren im Lebenslauf wird dem Prinzip der Unteilbarkeit zugeschrieben. Während Realteilung allgemein als ein Prozess sukzessiven Erbens im Lebenslauf beschrieben wird, gehen viele Autoren im Falle der Unteilbarkeit der Güter von einem einmaligen Akt aus: dem Zeitpunkt der Übernahme des Anwesens (durch den/die Nachfolger), bzw. der Übergabe durch den/ die Vorgänger. Demgegenüber betonen andere Autoren, dass es auch unter diesen Bedingungen im Lebenslauf mehrfach Momente des Ressourcenerwerbs gab, da auch zum Zeitpunkt der Heirat häufig Ressourcen weitergegeben wurden. ${ }^{55}$ Ferner war die Möglichkeit eines zusätzlichen Erbteils von entfernten Verwandten sicherlich nicht prinzipiell ausgeschlossen. Jedenfalls scheinen unter den Bedingungen der Unteilbarkeit oftmals zwei Momente im Lebenslauf des Einzelnen bedeutsam: der des Antritts der Besitznachfolge und der des Rückzugs aus der Führung des Anwesens. Beiden Momenten wird in der vorliegenden Studie deshalb breiter Raum gewidmet. Dabei wird insbesondere die in der Literatur weit verbreitete

53 Vgl. Langer-Ostrawsky/Margareth Lanzinger, Begünstigt - benachteiligt?; Mitterauer, Formen, 314; Feigl, Erbrecht, 64.

54 Vgl. etwa Mitterauer, Formen, 312f. In diesen Konstellationen konnte es häufig zu Konflikten im Anspruch auf die Besitznachfolge zwischen den Kindern aus erster und zweiter Ehe kommen.

55 Hohkamp, Wer will erben?, 331. 
Meinung, dass Besitzantritt und Heirat zeitlich und kausal zusammenfielen und beide einander bedingten, kritisch hinterfragt.

Besitzweitergabe und Vererbung sind Modi, wodurch zwischenmenschliche Beziehungen wesentlich strukturiert werden. ${ }^{56}$ Unabhängig von der in der Literatur kontrovers diskutierten Frage nach der historischen Bedeutung des Landmarktes, kommt den Generationenbeziehungen in vorindustriellen Gesellschaften jedenfalls eine hohe Bedeutung zu. Angesichts ihres personell zumeist relativ geringen Umfangs war in vielen west- und mitteleuropäischen Haushalten und Familienwirtschaften die Alterskonstellation ihrer Mitglieder von großer Bedeutung. War die Arbeitsfähigkeit des die Wirtschaft führenden Paares, etwa aufgrund von Alter oder Krankheit, nicht mehr gewährleistet, war ein Rückzug der Inhaber bereits zu Lebzeiten und die Weitergabe der Wirtschaftsführung an einen Nachfolger möglich. In diesem Aspekt scheint der Ursprung der in vielen Gebieten häufigen Besitzerwechsel zu Lebzeiten (inter vivos) zu liegen. Der Transfer der Güter zwischen den Generationen konnte sowohl der Sicherung von Kontinuität als auch von Reziprozität dienen. Die Bedeutung des Rückzugs der Besitzenden zu Lebzeiten - sowohl für die Nachfolger als auch für die Abtretenden selbst - konnte unterschiedlichen sozialen Logiken unterliegen. Erfolgte dieser aufgrund allmählich nachlassender Arbeitsfähigkeit oder eher auf Druck der nächsten Generation? Oder handelte es sich eher um einen Austausch zwischen den Generationen? Wurde Versorgung im Alter gegen Besitznachfolge getauscht?

Im Unterschied zu zahlreichen afrikanischen Gesellschaften wurde und wird in Europa und Asien Besitz vorwiegend von Älteren an Jüngere - in vertikaler Linie, und nicht lateral - weitergegeben. Erst dadurch konnte die Möglichkeit eintreten, dass kein Nachfolger vorhanden oder dieser noch zu jung war, um die Nachfolge anzutreten. Bei einer Weitergabe in den Seitenlinien waren dagegen weitaus häufiger Personen am Leben und in übernahmefähigem Alter. Für Goody stellt dies eine wichtige Voraussetzung dafür dar, dass in europäischen Gesellschaften taktische Überlegungen und Elemente der Planung des Besitztransfers eine wichtige Rolle spielten. ${ }^{57}$

Trotz der häufigen Herleitung sehr unterschiedlicher demographischer, ökonomischer und sozialer Entwicklungen aus der simplen, dichotomen Unterscheidung der beiden Prinzipien der Unteilbarkeit und der Teilbarkeit von landwirtschaftlichem Besitz, ist in der Literatur implizit doch immer auch die Wichtigkeit bestimmter (insbesondere rechtlicher und politischer) Rahmenbedingungen der Erb- und Besitzweitergabepraktiken gesehen worden - wenn

56 Medick/Sabean, Einleitung, 19.

57 Goody, Strategies, $6 \mathrm{ff}$. 
auch zumeist nur in ungenügendem Maße. Im Wesentlichen wurden in diesem Zusammenhang bloß unterschiedliche Formen des bäuerlichen Besitzrechtes angeführt; im Falle der frühen Neuzeit auch der jeweilige Charakter der feudalen Herrschaftsverhältnisse. Ungeteilte Besitzweitergabe etwa trat häufig in Regionen mit einer starken Stellung des Grundherren auf. Die Grundherren hatten in Bezug auf die Besitzweitergabepraktiken ihrer Untertanen Eigeninteressen, die sie durchzusetzen trachteten. Diese Interessen lagen vor allem in der Erhaltung der Leistungs- und Abgabenfähigkeit der Hofeinheiten, daraus scheint das Prinzip der Unteilbarkeit der Güter ableitbar. Nicht nur die Grundherren, auch die Bauern selbst hatten manchmal allerdings den Wunsch, ihren Besitz „... intakt [zu] wissen, um die materielle Grundlage für den Fortbestand der Familie zu gewährleisten. " ${ }^{58}$ Sie konnten insbesondere dann ein Interesse an der Bevorzugung eines einzelnen Nachfolgers haben, wenn dieser im Gegenzug im Haus verblieb und ihre Altersversorgung übernahm. ${ }^{59}$ Den Übergabepraktiken kam vor allem dann eine hohe Bedeutung zu, wenn den Menschen ein Handlungsspielraum offen stand, wenn sie ausreichend gefestigte Besitz- oder Nutzungsrechte an dem von ihnen bewirtschafteten Land hatten, um die Auswahl des Besitznachfolgers (mit-)bestimmen zu können. Es bleibt noch zu erforschen, welche Rolle den Generationenbeziehungen in Regionen ohne Weitergaberechte zukam, bzw. welche Bedeutung der Besitztransfer unter den Bedingungen sehr schwacher Nutzungsrechte hatte. ${ }^{60}$

\subsection{Fragestellungen der Arbeit}

Ziel der vorliegenden Studie über die südböhmische Pfarre Kapličky, in der das Prinzip der Unteilbarkeit der Güter beim Besitztransfer herrschte, ist neben einer Analyse der lokalen Praktiken der Weitergabe von Land- und Hausbesitz auch die Untersuchung der Folgen dieser Regelungen auf die lokale gesellschaftliche Entwicklung. Dabei sollen die in der Literatur noch immer verbreiteten stark verallgemeinernden Aussagen kritisch hinterfragt werden. Selbst bei sehr günstigen Bedingungen der freien Vererbbarkeit der Güter, wie etwa beim ,Erbzinsrecht', blieb etwa eine prinzipielle Eingriffsmöglichkeit der Gutsherrschaft aufrecht. Umgekehrt blieben aber auch unter den Bedingungen einer ,verschärften Erbuntertänigkeit', wie sie sich in Böhmen seit dem späten 16.

58 Cole/Wolf, Die unsichtbare Grenze, 230.

59 Goody, Erbschaft, 105.

60 Vgl. dazu die Überlegungen bei Plakans, Retirement, bes. $150 f$. 
Jahrhundert herausbildete, Handlungsspielräume der Untertanen beim Besitztransfer erhalten. ${ }^{61}$

Abseits der politischen und rechtlichen Bedingungen konnten auch andere Faktoren von entscheidendem Einfluss auf die tatsächlichen lokalen Praktiken der Besitzweitergabe sein. So sind etwa die demographischen und ökonomischen Rahmenbedingungen als von außen einwirkende Faktoren von großer Bedeutung. Diese wurden in der Forschung bisher aber nur selten berücksichtigt. Wie häufig kam es in einer Gesellschaft der frühen Neuzeit vor, dass mehrere Kinder den Zeitpunkt der Übergabe erlebten, sodass etwa für die Eltern eine Wahlmöglichkeit zwischen jüngstem und ältestem Sohn bestand? Waren die demographischen Bedingungen überhaupt derart, dass eine Planung der Besitzweitergabe, eine Verfolgung bestimmter Strategien in Bezug auf die Nachfolge möglich war? War nicht der Tod in diesen Gesellschaften viel zu häufig mitten im Leben ein überraschender Gast? Welche Rolle spielten Familie und Verwandtschaft in der Praxis der Besitzweitergabe? War es demographisch und ökonomisch möglich, die Anwesen in der Familie zu vererben? Ermöglichten es die ökonomischen Umstände den Haus- und Hofinhabern tatsächlich, einer Familienwirtschaft längerfristig vorzustehen und damit an Kontinuitäten in der Besitzerfolge zu denken, oder zwangen ökonomische Krisen, Ernteausfälle und der feudale Abgabendruck, etc. ohnehin die meisten Bauern de facto in einen Status kurzfristiger ,Bewirtschafter eines Anwesens, das sie gar nicht besaßen? Welche Rolle spielte die Weitergabe über Wiederverehelichung eines Teils des Inhaberpaares? War es ein Ziel, familiale Kontinuitäten auf den Anwesen sicherzustellen, oder wurde etwa danach getrachtet, Land und Anwesen möglichst Gewinn bringend zu verkaufen? Gab es dabei Unterschiede zwischen den wohlhabenden und den ärmeren Anwesen? Änderten sich die Positionen der bei der Weitergabe beteiligten Personen, etwa der Ehefrau und der Kinder? Bedeutete die Bevorzugung eines Einzelnachfolgers de facto einen Ausschluss der weiblichen Besitznachfolge? Oder konnten Töchter zwar die Nachfolge antreten, jedoch nur dann, wenn kein (geeigneter) Sohn vorhanden war?

Ganz grundsätzlich wird zu fragen sein, wie sehr das Modell der Unteilbarkeit der Güter bei Besitztransfer in der Praxis tatsächlich eingehalten wurde. Erlaubte eine regional gültige Norm Ausnahmen? Gab es trotzdem Teilungen von Anwesen, oder kam es zur Abtrennung einzelner Parzellen? Waren diese so häufig, dass die Norm nicht die zu erwartenden gesellschaftlichen Folgen bewirkte? In welchem Maße trugen schließlich die Praktiken der Besitzweitergabe zum sozialen und demographischen Wandel bei? Verhinderte ein rigide gehandhabtes Prinzip

61 Vgl. zur,verschärften Erbuntertänigkeit' als Terminus für eine spezifische Ausformung von, Gutsherrschaft': Cerman, Gutsherrschaft vor dem,Weißen Berg. 
der Einzelnachfolge jedes demographische Wachstum? Führte dieses Prinzip zu einer über die Zeit stabil bleibenden Zahl an Anwesen? Oder war es schließlich irrelevant, da abseits des Besitztransfers andere Wege für die Etablierung von Haushalten und Familien bestanden? Was bedeutete es in dieser Gesellschaft, ,Besitzer zu werden? Konnte unter den Bedingungen der Gutsherrschaft auch während der Dauer der Hausinhaberschaft noch weiterer Landbesitz akkumuliert werden? 62 War die Position des ,Besitzers' überhaupt attraktiv? Hatte der Besitztransfer nur für eine Minderheit der untersuchten Gesellschaft eine wichtige Bedeutung, da viele in diese Prozesse gar nie involviert waren? All diese Fragen werden in der vorliegenden Studie angesprochen und manche sehr ausführlich diskutiert.

\subsection{Lokale Fallstudie als Methode}

Die vorliegende Arbeit versteht sich als lokale empirische Fallstudie, die die Frage nach den vermuteten Zusammenhängen zwischen Besitztransfer, Heiratsverhalten, Reproduktion und Bevölkerungswachstum neu stellt und die Praktiken der Weitergabe von Haus und Landbesitz eng in den Kontext der regionalen Gesellschaft einbettet. Da die Praktiken, Muster und Modalitäten der Besitzweitergabe nicht losgelöst von rechtlichen, politischen, institutionellen, ökonomischen und demographischen Rahmenbedingungen analysiert werden können, widmet die Studie der Darstellung dieser Faktoren in mehreren Kapiteln breiten Raum. ${ }^{63}$ Einerseits beeinflussten diese Rahmenbedingungen die Praktiken der Besitzweitergabe, andererseits wurden die Rahmenbedingungen auch von diesen Praktiken (in einem näher zu analysierenden Ausmaß) mitbestimmt. Die vorliegende Arbeit versteht sich nicht als Ortsgeschichte, sondern als Fallstudie. Der Ort der Untersuchung ist nicht Gegenstand der Untersuchung. ${ }^{64}$ Die eher geringe Bedeutung der Region (oder der untersuchten Pfarre) selbst würde kaum eine langjährige intensive Beschäftigung der Forschung rechtfertigen: „Hohenfurts Geschichte ist einfach und arm an Ereignissen“, ist in der ältesten Monographie über Vyšší Brod zu lesen. ${ }^{65}$ Mit der mikrohistorischen Methode der genauen Betrachtung einer zahlenmäßig und räum-

62 Diese Überlegungen wieder nach: Plakans, Retirement, bes. 151.

63 Mehrfach wurden Arbeiten zum Besitztransfer und zu den familialen Strategien gerade wegen der fehlenden Einbindung ihrer Befunde in die regionalen ökonomischen und sozialen Rahmenbedingungen kritisiert. Vgl. Medick/Sabean, Emotionen, 49 im Bezug auf die Arbeiten Bourdieus. Einen Mangel an ausreichender Einbettung der Studien zu den vorindustriellen Landmärkten in Europa in den sozialen und ökonomischen Kontext beklagt auch: Bavel van, Organization, 46.

64 Eine Formulierung, die auf Clifford Geertz zurückgeht, vgl. Medick, Mikro-Historie, 51.

65 Mikowec, Cisterzienserstift Hohenfurt, 12. 
lich kleinen Einheit, wie einer Pfarre, können vielmehr die ,klassischen' Fragen der Sozialgeschichte neu gestellt und zum Teil in der Literatur gängige Thesen erstmals tatsächlich empirisch überprüft werden. ${ }^{66}$

Die mikrohistorische Zugangsweise untersucht die Bedeutung sozialer Phänomene in ihren lokalen Kontexten und stützt sich nicht auf eine isolierte Quelle, sondern arbeitet mit einer Vielzahl an unterschiedlichem Quellenmaterial. Diese Vorgangsweise führt dabei häufig auch zur Problematisierung und Hinterfragung von einigen in der Literatur weit verbreiteten und scheinbar sehr eindeutigen, überhistorischen' Konzepten, die sich im regionalen und zeitgebundenen Kontext teilweise als weniger eindeutig als erwartet herausstellen: Was ist etwa im südlichen Böhmerwald des 17. Jahrhunderts ein Haushalt? Wie lässt sich dieser analytisch von einem Haus abgrenzen? Unter welchen Bedingungen gilt ein Gebäude als selbstständiges Haus? Wie lassen sich Bauern und wie ländliche Unterschichten definieren? Erst die Analyse unterschiedlichen Quellenmaterials aus demselben Ort der Untersuchung zeigt, wie verschieden interpretierbar manche der in der makrohistorischen Forschung lange Zeit unhinterfragt verwendeten Kategorien für die auf der regionalen Ebene agierenden Beamten, Pfarrer, die die uns vorliegenden historischen Quellen produzierten, zum Teil waren, bzw. wie schwierig die lokalen Verhältnisse jeweils in überregionale Terminologien zu übersetzen waren.

Der mikrohistorische Ansatz erlaubt es, manche Fragestellungen sowohl quantitativ wie zum Teil auch qualitativ zu bearbeiten. Neben der Herausarbeitung von Regeln und Durchschnittswerten konnten zumindest ansatzweise auch die „normalen Ausnahmen"67, die Handlungsoptionen und -logiken der Menschen in den Blick genommen werden. Die in dieser Arbeit mehrfach präsentierten Einzelfälle dienen daher nicht der bloßen Illustration, sondern sollten vielmehr neue Einsichten in mögliche Zusammenhänge erlauben.

66 Vgl. zur Relevanz des mikrohistorischen Ansatzes auch die Überlegungen bei: Sabean, Property, 10. Während die internationale Historische Demographie methodisch ein Vorläufer der Mikrogeschichte war, wurde letztere lange Zeit von der deutschen Bevölkerungsgeschichte abgelehnt. Schon der Ahnherr der deutschsprachigen Demographie, Johann Peter Süßmilch, hätte nämlich betont, dass sich ,in kleinen Gesellschaften und Dörfern ... auch nicht leicht was ordentliches wahrnehmen“ lasse, wie Köllmann, Bevölkerungsgeschichte, 20, in Abgrenzung zur Mikrogeschichte bemerkt.

67 Ein aus der italienischen Mikrogeschichte (E. Grendi) stammender Begriff, vgl. Medick, Weben, 34 und Medick, Mikro-Historie, 47. 


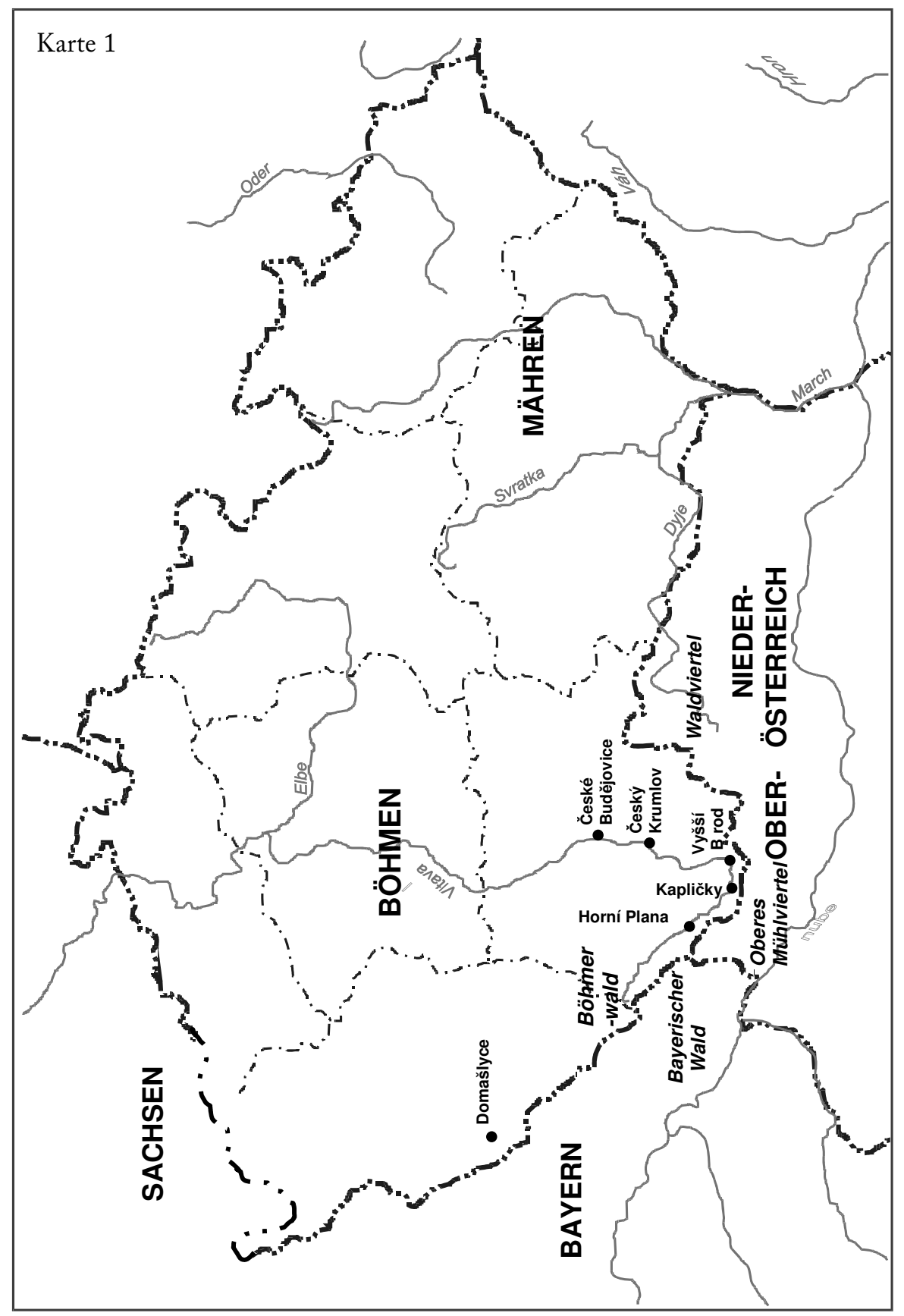

Anm.: Gezeichnet vom Autor nach einem Entwurf von Miroslava Melkesová und Zdeněk Melkes. 


\section{UNTERSUCHUNGSREGION UND QUELLEN}

\subsection{Das Untersuchungsgebiet:}

Die Pfarre Kapličky in der südböhmischen Herrschaft Vyšší Brod

Die zentrale Untersuchungseinheit der vorliegenden Studie bildet die im südlichen Böhmerwald an der österreichischen Grenze gelegene, zur Gutsherrschaft des Zisterzienserklosters Vyšší Brod/Hohenfurth gehörige Pfarre Kapličky/Kapellen (siehe Karte 1, S. 30).

Die Gründung des Klosters Vyšší Brod im Jahre 1259 geht auf eine Stiftung von Wok von Rosenberg/Rožmberk, einem Angehörigen des mächtigsten Adelsgeschlechtes im mittelalterlichen Südböhmen, zurück. ${ }^{1} \mathrm{~W}$ ie in anderen Regionen auch hatten die Zisterzienser von Vyšší Brod zur Zeit der Gründung des Klosters, die vom oberösterreichischen Kloster Wilhering aus erfolgte, weitgehend unbesiedeltes Land rund um den gleichnamigen Hauptort erhalten, das sie in der Folge rodeten. ${ }^{2}$ Die Siedlungen in der Umgebung von Vyšší Brod wurden erst ab der Mitte des 13. Jahrhunderts gegründet. Überwiegend handelte es sich dabei um Weiler und nur vereinzelt um Dörfer. Der Ort Kapličky selbst gehörte dabei zu den allerersten Gründungen in der Region, er wird bereits im Urbar des Klosters von 1278, dem ältesten Urbar Böhmens, erwähnt. ${ }^{3}$

Im Laufe des Mittelalters war das Herrschaftsgebiet infolge von adeligen Schenkungen und Zukäufen kontinuierlich vermehrt worden, sodass es am Beginn der Neuzeit neben einer territorial geschlossenen Einheit im äußersten Süden mehrere über ganz Südböhmen verstreute kleinere Besitzungen, einzelne untertänige Dörfer und einzelne Häuser in zu anderen Herrschaften gehörenden Dörfern umfasste.Im 16. und 17. Jahrhundert gehörten zur Herrschaft Vy̌̌ší Brod zwei Marktorte - neben dem gleichnamigen Ort auch der Markt Hořice/ Höritz - und eine große Anzahl an Dörfern und Einzelhöfen, die in neun (1530)

1 Vgl. zur Geschichte des Klosters und zur Entwicklung seines Herrschaftsgebietes: Kaindl, Zisterzienserstift Hohenfurt, und Proschko, Cistercienser-Stift Hohenfurth.

2 Vy̌šši Brod war die achte Klostergründung der Zisterzienser in Böhmen. Zu den Zisterzienserklöstern in Böhmen, siehe z. b. Čechura, Monastères cisterciens.

3 Zum Urbar von 1278 vgl. Čechura, Nejstarší český urbár. 
bzw. 21 (1651) Gerichten zusammengefasst wurden. Die Berní rula aus dem Jahre $1654^{4}$ verzeichnete (inklusive der wenigen verödeten) 824 Häuser; das herrschaftliche Urbar des Jahres 1530 hatte 917 Hausstätten, darunter auch 19 Weinbauern in Niederösterreich, aufgelistet. ${ }^{5}$ Im Jahre 1797 sind in einer Liste 1.135 Häuser als zur Herrschaft gehörig erwähnt. ${ }^{6}$ Aufgrund der territorialen Zersplitterung des Herrschaftsgebietes wurden in der vorliegenden Studie keine Analysen für das gesamte Herrschaftsgebiet durchgeführt, obwohl bei manchen Fragestellungen (etwa zur wirtschaftlichen und sozialstrukturellen Entwicklung) - über das Pfarrgebiet von Kapličky hinaus - das gesamte, südlich der Moldau liegende, geschlossene Gebiet der Herrschaft rund um den Zentralort berücksichtigt wurde. Bei einigen anderen Fragestellungen dagegen werden zum Teil weit über das Herrschaftsgebiet hinausgehend Ansiedlungen und Regionen in die Analyse miteinbezogen.

Der Ort Vyšší Brod, zugleich der Hauptort der Herrschaft, liegt am rechten Ufer der Moldau/Vltava etwa an jener Stelle, an dem der Fluss seine bisherige Richtung ändert und nach Norden weiterfließt. Vor Vyšší Brod - nach mancher Definition am östlichen Endpunkt des Böhmerwaldes gelegen - bahnt sich die Moldau ihren Weg von Westen nach Osten durch sehr felsiges und steil abfallendes Gebiet. Das Gebiet der Pfarre Kapličky erstreckte sich westlich von Vyšší Brod relativ weit in die Ausläufer des Böhmerwaldes und gehörte zum territorialen Kerngebiet der Herrschaft. Die Grenzen der Pfarre bildeten im Norden die Moldau - die gleichzeitig auch eine Herrschaftsgrenze bildete - und im Süden die Landesgrenze zum oberösterreichischen Mühlviertel. Im Westen grenzte sie an die Pfarren Přední Výtoň/Vorder-Heuraffl und Rychnůvek/Deutsch Reichenau, die den südlichsten Teil der großen Herrschaft Český Krumlov bildeten (bzw. auch an den zum Gebiet des ebenfalls zu Vyšší Brod gehörigen Meierhofs Zadní Výtoň/ Hinter-Heuraffl, der gegen Ende des 18. Jahrhunderts zu einem Dorf umgewandelt wurde, das danach aber Teil der Pfarre Přední Výtoň war); im Osten schloss sich die Pfarre Vyšší Brod an.

4 Národní archiv (NA) Praha, Fond Berní rula (BR) 2, fol. 822-828.

5 Die Quelle wurde editiert als: Schmidt, Urbar. Viele Ansiedlungen der Pfarre Kapličky werden erstmals in dieser Quelle erwähnt.

6 Quelle: Archiv Klašter Vyšší Brod, Karton č. 397, Publikum 5/2 : verzeichniß deshier kreises gefindlichen orthschaften؛ Vyšší Brod kann damit als eine mittelgroße Herrschaft bezeichnet werden. Die zweite südböhmische Zisterzienserherrschaft Zlatá Koruna war mit 146 Anwesen im Jahre 1654 deutlich kleiner. Die benachbarte Herrschaft Český Krumlov dagegen war weitaus größer. Sie hatte im Jahre 1844 über 51.000 Einwohner, die in einer Stadt, fünf Marktorten und 294 Dörfern lebten. Vgl. Kubíková, Panstvi Vy̌̌ší Brod, 206 und Paleczek, Modernisierung, 245. Zum Vergleich der Größe böhmischer Herrschaften siehe: Purš, Struktur und Dynamik. 
Die Pfarre Kapličky als eigentliche Untersuchungsregion umfasste zur Zeit des Urbars von 1530 zwölf Ansiedlungen, gegen Ende des 18. Jahrhunderts jedoch 15. Während mit Hvěsta/Stern (um 1610) und Nové Domky/Neuhäuseln (im Jahre 1690) zwei Ansiedlungen neu gegründet worden waren, hatte sich Hŕbítek (Hundsruck) allmählich aus zwei bereits zu Ende des 16. Jahrhunderts bestehenden Kleinhäusern am Ortsrand des Pfarrortes zu einer eigenständigen Siedlung entwickelt. Die Weiler umfassten um 1700 mit Ausnahme des Pfarrortes nicht mehr als drei bis zehn Häuser. Kapličky selbst sowie etwa die Hälfte der Pfarrsiedlungen lagen auf einem Hochplateau im Süden des Pfarrgebietes (auf über 900 Meter Seehöhe) sehr nahe zur österreichischen Grenze. Das Dorf Kapličky war unmittelbar an der Wasserscheide (zwischen Nordsee und Schwarzem Meer) gegründet worden. Von den beiden Bächen, die unweit des Dorfes entspringen, fließt einer in die Moldau, der andere jedoch in die Kleine Mühl (in Oberösterreich), die in die Donau mündet. ${ }^{7}$ Die nördliche Hälfte des Pfarrgebiets bestand in einem steil nach Norden zur Moldau hin abfallenden Gebiet, das bis ins 20. Jahrhundert eine weitgehend geschlossene und kaum besiedelte Waldfläche blieb, innerhalb der bloß die Ansiedlung Lindberg/Lipová lag. Von Kapličky aus ostwärts - einen kleinen Bach entlang, hinunter zum Hauptort Vyšší Brod - lagen die Weiler Krásná Pole, Hodoň, Mnichovice und Martinkov sowie - weiter nördlich - das von Kapličky schon weit entfernte Vyšína (manchmal auch Pošlak genannt), welches Ende des 18. Jahrhunderts zum deutlich näher gelegenen Vyšší Brod umgepfarrt wurde. Direkt an der Moldau, die die lange Nordgrenze der Pfarre bildete, bestand mit Ausnahme einiger am rechten Ufer der Moldau gelegener Häuser der Ansiedlung Loučovice/Kienberg, die - anders als die Häuser am linken Ufer - ebenfalls zur Herrschaft Vyšši Brod und zum Teil zur Pfarre Kapličky gehörten, ${ }^{8}$ und dem erst 1690 gegründeten Dorf Nové Domky/Neuhäuseln keine einzige Ansiedlung.

7 Märten, Heimatkunde, 156.

8 Lange Zeit existierte im zur Herrschaft Vyšší Brod gehörenden Teil von Loučovice nur das Haus eines von der Herrschaft angestellten Fischers; um 1840 bestanden dann vier Anwesen, die zu Vyšší Brod und zur Pfarre Kapličky gehörten. Beim Großteil der in dieser Studie durchgeführten Untersuchungen wurden die Häuser von Loučovice - allesamt auf dominikalem Grund gelegen - nicht (!) berücksichtigt. Die anderen Häuser des Dorfes Loučovice waren unter den Herrschaften Rožmberk, Český Krumlov und dem Gut Rímov (Rimau) des Krumauer Jesuitenkollegs aufgeteilt. Vgl. Schacherl, Kienberg. 
Tabelle 1: Häuser- und Einwohnerzahl der Dörfer und Weiler der Pfarre Kapličky im 19. Jahrhundert (anhand älterer publizierter Literatur)

\begin{tabular}{lccc}
\hline & Häuser 1843 & Einwohner 1843 & Einwohner 1890 \\
\hline Kapličky (Kapellen) & 23 & 220 & 189 \\
Adámky (Abdank) & 5 & 45 & 35 \\
Dobřín (Dobring) & 14 & 125 & 94 \\
Frantoly (Frauenthal) & 13 & 138 & 108 \\
Hodoň (Hornschlag) & 14 & 139 & 136 \\
Hřbítek (Hundsruck) & 5 & 41 & 33 \\
Hvězda (Stern) & 4 & 31 & 29 \\
Krásná Pole (Schönfelden) & 14 & 123 & 121 \\
Lhota (Stift) & 5 & 35 & 41 \\
Mlýnská (Mühldorf) & 4 & 43 & 28 \\
Lipová (Lindberg) & 12 & 79 & 100 \\
Martinkov (Martetschlag) & 9 & 65 & 62 \\
Mnichovice (Minichschlag) & 9 & 71 & 46 \\
Vyšína (Poschlag) & 13 & 85 & 89 \\
Nové Domky/Neuhäuseln & 15 & 119 & 192 \\
\hline Summe: & 159 & 1.288 & 1.303 \\
\hline
\end{tabular}

Quelle: Palacký, Popis království Českého; Märten, Heimatkunde, 132-134.

Anmerkung: Die Tabelle berücksichtigt - wie dies in der vorliegenden Studie durchgehend der Fall ist auch das Dorf Vyšína, das jedoch nur bis 1787 zur Pfarre gehörte.

Bereits publizierte Einwohnerzahlen für jede einzelne Ansiedlung der Pfarre liegen bisher erst für das Ende des Untersuchungszeitraums, bzw. für die Periode danach, vor (Tabelle 1). Die dem klassischen Werk von Palacký entnommenen Angaben zur Häuserzahl erweisen sich für beinahe jedes Dorf und jeden Weiler als etwas höher als die Zahl der in den Grundbüchern angeführten Häuser (vgl. Kapitel 3.2, 3.4 und 5.4). Tabelle 1 zeigt aber auch, dass das jüngste, erst während der frühen Neuzeit gegründete Dorf Nové Domky allmählich zur größten Ansiedlung der Pfarre anwuchs sowie dass die während der zweiten Hälfte des 19. Jahrhunderts für die meisten Dörfer rückläufigen Einwohnerzahlen (vergleiche 1843 und 1890) einen deutlichen Hinweis auf die wirtschaftlich überaus schwierige Situation im südlichen Böhmerwald während der Phase der anderswo in Mitteleuropa stattfindenden Industrialisierung geben. 
Nach dem Zweiten Weltkrieg wurde die große Mehrheit der fast ausschließlich deutschsprachigen Bevölkerung der Pfarre vertrieben. ${ }^{9}$ Eine Mehrheit der Ansiedlungen der Pfarre lag außerdem innerhalb eines in den 1950er Jahren zum militärischen Sperrgebiet erklärten, drei Kilometer breiten Grenzstreifens entlang der Grenze zu Österreich, aus dem die Bevölkerung vollständig abgesiedelt wurde. Der Großteil der Anwesen innerhalb dieses Sperrgebietes wurde bis zum Juni 1959 vollständig geschleift. ${ }^{10}$

Die Pfarre Kapličky wurde vor allem aufgrund des ausgezeichneten Quellenbestandes (ein vollständig erhaltener Bestand an Grundbüchern sowie eine im Wesentlichen bereits vorliegende, vollständige Familienrekonstitution, etc.) für eine vertiefende Studie ausgewählt. Gleichzeitig sicherte auch die geschlossene Zugehörigkeit der Pfarre zur Herrschaft einen einheitlichen Quellenbestand für alle Dörfer. ${ }^{11}$ Darüber hinaus erschien sie als eine im Vergleich zur Pfarre Vyšší Brod, die ebenfalls alle vorgenannten Bedingungen erfüllte, deutlich kleinere Pfarre den Arbeitsaufwand einigermaßen in Grenzen zu halten: Während die Pfarre Vyšší

9 Im Jahre 1947 lebten in Kapličky 200 Personen, im Jahre 1930 waren dagegen 2.536 Bewohner gezählt worden. Vgl. Schusser, Pfarrei. Vgl. auch die kurze Ortsgeschichte: Michel/Schusser/Paloušová, Kapličky.

10 Bei einigen Dörfern, wie etwa dem Hauptort der Pfarre selbst, erinnert heute nur mehr eine hölzerne Hinweistafel an die ehemalige Siedlung. Heute existieren - wenn auch mit einer im Vergleich zu den beiden Jahrhunderten davor deutlich reduzierten Häuserzahl - unter anderem noch die Pfarrdörfer Nové Domky, Lipová, und Martinkov. Allerdings befindet sich auch das an der Moldau gelegene Nové Domky heute nicht mehr an seiner ursprünglichen Stelle, sondern wurde nach der Aufstauung der Moldau - ebenfalls Ende der 1950er Jahre - an höher gelegener Stelle neu errichtet. Wüstungen sind heute die ehemaligen Pfarrorte: Adámky, Dobřín, Frantoly, Hodoň, Hřbítek, Hvězda, Kapličky, Krásná Pole, Lhota, und Mlýnská.

11 Ein Umstand, der ansonsten nur auf zwei weitere der insgesamt 16 zum Kirchenpatronat des Klosters Vyšší Brod gehörenden Pfarren zutraf. Vgl. Ladenbauer, Das Sociale Wirken, 150. Anzumerken ist auch, dass sich die Grenzen der Pfarre Kapličky im Laufe des Untersuchungszeitraums änderten: das Dorf Vyšína kam im Jahre 1787 im Zuge der Josefinischen Pfarrreformen von Kapličky zur Pfarre Vyšší Brod. Weitere Veränderungen in der Pfarrzugehörigkeit, die Dörfer Martínkov und Mnichovice betreffend, erfolgten dagegen erst während der 1850er Jahre. Vgl. dazu neben den Matrikenbüchern auch: Statní Archiv v Třeboni. Die beiden im späten 18. Jahrhundert gebildeten Steuergemeinden Schönfelden und Minichschlag waren (auch im 19. Jahrhundert) weitgehend mit dem Pfarrgebiet identisch (sie inkludierten Minichschlag und Martetschlag, aber nicht Vyšína; doch zählte auch der kleine zur Pfarre Vyšší Brod gehörige Weiler Valdov/Waldau hinzu). Der Unterschied hinsichtlich Häuser- und Einwohnerzahl zwischen der Pfarre Kapličky und den beiden Steuergemeinden war nur gering. Palacký nennt 1843 für die Pfarre 163 Häuser und 1.303 Einwohner (inklusive der vier Häuser in Loučovice), Sommer, Königreich Böhmen, 176-78, nennt 1840149 Häuser (ohne Loučovice); die Catastral-Schätzungs-Elaborate, ein Beiwerk des sogenannten ,Stabilen Katasters ‘ählt für die beiden Gemeinden im Jahre 1846159 Häuser und 1.367 Einwohner. Quelle: Palacký, Popis království Českého. 
Brod im Jahre 1860 eine Einwohnerzahl von etwa 3.600 Personen hatte, wies Kapličky im selben Jahr lediglich 1.306 Einwohner auf. ${ }^{12}$

\subsection{Die Datengrundlage}

Die vorliegende Studie ist in ihrem Kern eine Lokalstudie, die auf einer Vielzahl an lokalen Quellenbeständen einer ländlichen Pfarre beruht, fallweise aber über die Grenzen der Pfarre hinausblickt und insbesondere Daten für andere Teile der Herrschaft Vyšší Brod berücksichtigt. Die empirische Basis der zentralen Kapitel zum Besitzwechsel, Ausgedinge und zum Zusammenhang von Heirat und Besitzübernahme beruht weitgehend auf der namentlichen Verknüpfung von Informationen über Einzelpersonen aus mehreren Quellen (,nominative record linkage'). $\mathrm{Zu}$ diesen miteinander verknüpften Quellen zählen neben den Grundbüchern, die sämtliche Besitzerwechsel verzeichneten (systematisch ausgewertet für die Jahre 1637-1840/48), ${ }^{13}$ ein zur Mitte des 19. Jahrhunderts erstelltes Familienregister (Familienrekonstitution - rodový katastr) ${ }^{14}$, sowie alle Eintragungen für diese Pfarre aus einem herrschaftsweit geführten Ausnehmerbuch (kniha výménkářská) (1699_ 1738). ${ }^{15}$ Alle diese Informationen wurden zu einer häuserorientierten Datenbank zusammengefasst. Zumindest für das Gebiet der Pfarre Kapličky (zum Teil auch über das Pfarrgebiet hinausgehend) wurden die entsprechenden Abschnitte aus den folgenden landesweit in Böhmen vorliegenden seriellen Quellenbeständen erhoben: dem Soupis poddaných podle viry (einem Haushalts- und Bevölkerungsverzeichnis aus dem Jahre 1651) ${ }^{16}$, des Berní rula (1653/54) genannten ältesten böhmischen Steuerkatasters sowie dessen Revisitation (Revisitace) (1682) ${ }^{17}$, und des Tereziánský katastr (Fassion 1713) ${ }^{18}$. Neben zahlreichen verschiedenen patrimonialen Quellen,

12 Trajer, Historisch-statistische Beschreibung.

13 SOA Třeboň, fond C Vyšší Brod, PK č. 453, 464, 465, 475, 479, 480 und 553.

14 SOA Třeboň, Sbírka. Ich danke dem Archiv für die teilweise Mikroverfilmung des Rodovyý katastr.

15 SOA Třeboň, fond C Vyšší Brod, PK, č. 565.

16 NA Praha, Soupis poddaných. Die Quelle wurde auch ediert. Vgl. die den Bechiner Kreis, der den

Großteil Südböhmens umfasste, betreffenden Bände Kokošková/Sedláčková/Zahradníková, Soupis poddanych.

17 NA Praha, Fond Berní rula (BR) 2, fol. 822-828; BR 30, fol. 271-279. Auch die Berní rula ist für einige Regionen Böhmens ediert. Zur älteren summarischen Edition der Quelle vgl. Doskočil, Berni rula.

18 NA Praha, TK 684, fol. 43-67, 232, 234. Die Okkularvisitation des TK (1720-25) erwies sich im vorliegenden Fall als mangelhaft und unvollständig und wurde deshalb hier kaum benutzt. Berücksichtigt wurden weiters die sogenannten Endelaborate und die herrschaftlichen Bekenntnistabellen. Zur summarischen Edition vgl. Chalupa, Tereziánský katastr český. 
die jeweils bei ihrer Nennung im Text gesondert zitiert werden, wurden außerdem zahlreiche Materialien für die untersuchte Pfarre des auch ,Stabiler Kataster genannten Franziszeischen Katasters verwendet. ${ }^{19}$

Die methodische Vorgangsweise einer Datenverknüpfung auf der Ebene konkreter Individuen ermöglichte die Bearbeitung einer Reihe von Fragestellungen unter Einbettung der untersuchten Phänomene in den breiteren Kontext der lokalen Gesellschaft. In der Sozialgeschichte der tschechischen Länder stellen Lokalstudien auf Basis einer Verknüpfung unterschiedlicher Quellentypen bis heute eine rare Ausnahme dar. ${ }^{20}$ Die weiteren herangezogenen Quellen aus dem staatlichen Zentralarchiv in Prag, den Kloster-, Bezirks- und Kreisarchiven wurden jeweils nur gesondert analysiert.

\subsubsection{Der Familienkataster}

Das hier benützte Familienbuch (rodový katastr) der Pfarre Kapličky stellt eine weitgehend nach den Prinzipien der ,modernen“ historisch-demographischen, aber bereits im 19. Jahrhundert erstellte Familienrekonstitution dar. ${ }^{21}$ Es handelt sich dabei um eine seltene und wertvolle Quelle, die den Zeitraum vom Beginn der Matrikenführung zur Mitte des 17. Jahrhunderts ${ }^{22}$ bis in die Mitte des 19. Jahrhunderts umfasst und zum Teil bis ins 20. Jahrhundert weitergeführt wurde. In der vorliegenden Studie wurde diese Quelle nur für einige ausgewählte historisch-demographische Fragestellungen herangezogen und nicht umfassend statistisch ausgewertet, sondern weitaus häufiger für Datenverknüpfung (etwa mit den Grundbüchern) und für die Analyse des verwandtschaftlichen Beziehungsgeflechtes der Pfarrbewohner genutzt. Der rodový katastr von Kapličky wurde im Jahre 1850 vom damaligen Pfarrer, Pater Benedikt Holzbauer, erstellt. ${ }^{23}$ Dieses

19 NA Praha, SK. Die patrimonialen Quellen der ehemaligen Herrschaft Vyšší Brod konnten nur geringfügig ausgewertet werden, da diese kurz nach Beginn meiner Forschungsarbeiten vom Staatlichen Gebietsarchiv Třeboň an das Zisterzienserkloster zurückgegeben wurden und dann jahrelang nicht, bzw. in den Folgejahren nur äußerst begrenzt öffentlich benutzbar waren. Vgl. dazu: Répásová, Das Archiv des Zisterzienserstiftes Hohenfurt.

20 Vgl. z.B. Horsky/Maur, Die Familie, 9.

21 Vgl. dazu auch das ausführliche Kapitel zur Quellenkritik in meiner ungedruckten Dissertation: Zeitlhofer, Besitztransfer.

22 Taufbücher ab 1642, Trauungsbücher ab 1643 und Sterbebücher ab 1663.

23 Die Familienkataster von Vyšší Brod sind ihrem Entstehungszusammenhang nach daher nicht im Kontext der vor allem in Deutschland häufig vorkommenden und durch das NS-Regime im besonderen Maße propagierten Ortssippenbücher zu sehen, von denen es auch einige in der Tschechischen Republik gibt. Vgl. als Überblick vor allem Weiss/Münchow, Bestandsverzeichnis, sowie Böser, Ortssippenbücher. Siehe auch die quellenkritische Auseinandersetzung mit diesen Materialien innerhalb 
frühe Familienbuch ist kein Einzelfall, vielmehr existieren heute zumindest für insgesamt neun der ehemals zur Kirchenpatronatsverwaltung des Klosters Vyšší Brod gehörigen Pfarren derartige Quellen. Die Entstehungszeit der Familienkataster von Vyšší Brod reicht bis ins ausgehende 18. Jahrhundert zurück. Die erste derartige Arbeit, die Pfarre Priethal/Přidolí (bei Český Krumlov) betreffend, wurde vom aus Schlesien stammenden Pater Stephan Lichtblau, als Mitglied des Klosters Bibliothekar und Archivar und später auch Prior, bereits 1789 fertiggestellt. Es handelt sich dabei sicherlich um einen der frühesten Versuche einer systematischen Rekonstitution der Familien auf Basis der Kirchenbücher. Nach seinem methodischen Vorbild entstanden dann weitere Familienregister im Einzugsgebiet des Klosters, der rodový katastr der Pfarre Kapličky ist dabei der jüngste der erhalten gebliebenen. ${ }^{24}$

Die Zusammenstellung des rodový katastr von Kapličky ist sehr sorgfältig und genau. Bei jedem einzelnen Sterbe-, Trauungs- oder Geburtseintrag wurde auch die Belegstelle des Originaleintrags im jeweiligen Kirchenbuch genannt. Natür-

der historisch-demographischen Forschung bei: Knodel, Ortssippenbücher, und Knodel/Shorter, The Reliability.

24 Vgl. als Überblick zu den rodové katastry vor allem Psíková, Rodové katastry. Diese sind im SOA Třeboň unter den Matrikenbeständen der jeweiligen Pfarren aufbewahrt. Pater Lichtblau war an der Erstellung mehrerer dieser Quellen beteiligt. Vgl. zu ihm und seiner Arbeitsweise: Gottsmich, Zur Erhaltung. Siehe auch das Verzeichnis der zahlreichen weiteren ungedruckten, teilweise auch lokalhistorischen Arbeiten von Stephan Lichtblau bei: Pavel, Gelehrte, Schriftsteller, Künstler, 353-55. Offenbar hatten die Zisterzienser von Vyšší Brod aber noch für weitere Pfarren derartige Familienregister erstellt. In einer Übersicht der Matrikenbestände der von den Nationalsozialisten 1938 an Oberösterreich angegliederten südböhmischen Gebiete verzeichnete Georg Grüll auch für die Vyšší Brod benachbarte Pfarre Malšiny ein solches Familienbuch, das heute im Archiv von Třeboň nicht vorhanden ist. Vgl. Grüll, Matrikeln in Oberdonau, 12. Hingewiesen sei außerdem darauf, dass Grüll selbst ebenfalls eine Familienrekonstitution - für die oberösterreichische Pfarre Pergkirchen - durchführte. Vgl. Weiss, Bestandsverzeichnis, 438. In Böhmen existiert - abgesehen von der Region um Vyšší Brod - ein rodový katastr auch für das Pfarrgebiet des Klosters Břevnov in Prag, der auch bereits historisch-demographisch ausgewertet wurde. Vgl. dazu Čánová/Horská, Obyvatelstvo und Horská, Index; das Material von Vy̌šši Brod wurde dagegen erstmals von mir für die Forschung genutzt. Weshalb die Mönche des Klosters diese mühevollen, langwierigen Arbeiten durchführten, lässt sich nicht mit Sicherheit klären. Ende des 18. Jahrhunderts waren alle Pfarren verpflichtet worden, einen alphabetischen Index zu den Matriken anzulegen. Dass das Kloster Vyšší Brod nicht nur diesen geforderten Index anlegte, sondern darüber hinaus alle Familien rekonstruierte, hatte wohl auch mit sozialer Kontrolle zu tun. Es lag im Interesse der Kirche, zu überprüfen, ob Brautleute nicht zu nahe miteinander verwandt waren. Der Verfasser des Bandes für Kapličky, Pater Benedict Holzbauer, hebt in der - nur mehr fragmentarisch erhaltenen - Einleitung den Aspekt der Rekonstruktion der Abstammung für die seelsorgerische Arbeit gesondert hervor. Das Moment der bürokratischen Erleichterung für die seelsorgliche Arbeit betont auch Lanzinger, die in ihrer Studie ebenfalls eine im (späten) 19. Jahrhundert erstellte Familienrekonstitution verwendet. Vgl. Lanzinger, Das gesicherte Erbe, 47. 
lich wurden im Zuge mehrerer (stichprobenartiger) Überprüfungen der Qualität dieses Materials dennoch einige Fehler und problematische Zusammenstellungen - aber auch Lücken - gefunden, die im Korrekturprozess nur zum Teil gelöst werden konnten. ${ }^{25}$ Alle genannten Probleme geben keinen Anlass, der Qualität der Quelle generell zu misstrauen. Der Vergleich mit den anderen verwendeten Quellen der Pfarre machte insgesamt nur sehr wenige Widersprüche sichtbar. Die hohe Qualität der südböhmischen Familienkataster zeigt sich auch darin, dass - wie Gottsmich, der selbst Pater des Klosters war, schreibt - zu Beginn des 20 Jahrhunderts die Pfarrer von Vyšší Brod für ihre seelsorgliche Tätigkeit

25 Erhoben wurden die Daten des Rodový katastr mit Hilfe des Datenbankprogrammes kleio in einem quellennahen Format. Der Gefahr einzelner Fehler war sich auch Pater Benedikt Holzbauer bereits bewusst gewesen, hatte er doch auf der ersten Seite, neben einer Erläuterung der Funktionsweise des Familienregisters geschrieben: „Daß manche Fehler und Verschreibungen vorkommen, gesteht der Verfasser im Voraus ein, rechnet aber im vollen Vertrauen auf brüderliche Nachsicht seines /P:T/hw: E Nachfolger, umso mehr, da Jeder das mühsame Zusammenstellen aus alten, schwer leserlichen und mani geführten Matrizen leicht einsehen kann und wird“ (SOA Třeboň, Sbírka). Zeitliche Lücken, die sicherlich auch in den Originalmatriken auftraten, finden sich insbesondere bei den Tauf- und den Sterbeeinträgen: Bei den ab Jänner 1642 geführten Taufen gab es zwischen dem 20.11.1645 und dem 26. 10. 1648 keinerlei Einträge. Bei den zu dieser Zeit im selben Buch geführten Trauungen findet sich diese Lücke interessanterweise nicht. Bei den ab März 1663 geführten Sterbeeinträgen gibt es eine Periode von fast zwei Jahren ohne Einträge (vom 9.3.1698 bis 1.1.1700). Derartige Probleme mit Perioden fehlender Einträge sind in der historisch-demographischen Forschung wohl bekannt. Die von Jürgen Schlumbohm für die Familienrekonstitution von Belm verwendeten Sterbebücher wiesen im 17. Jahrhundert eine zeitliche Lücke von immerhin 17 Jahren auf. Vgl. Schlumbohm, Lebensläufe, 34. Er führte daher keine Berechnungen zur Mortalität im 17. Jahrhundert durch. Ansonsten konnten keine Perioden mit fehlenden Einträgen im rodový katastr von Kapličky festgestellt werden. Damit ist dieser weit vollständiger als die heute für die Pfarre erhaltenen Original-Kirchenbücher, von denen seit der Mitte des 19. Jahrhunderts offenbar einige verloren gegangen sind: Die Sterbematriken sind für Kapličky heute nur mehr für den Zeitraum von 1716 bis 1785 vollständig erhalten. Danach liegen diese nur mehr für den Ort Kapličky, nicht aber für die gesamte Pfarre vor. Auch bei den beiden anderen Kirchenbüchern fehlt heute der Zeitraum von 1696 bis 1716 völlig. Vgl. SOA Třeboň, Sbírka. Allerdings fehlen im Familienregister bei Beginn der Familien mit dem Anfangsbuchstaben ,N, einige wenige Seiten. Verloren sind dadurch die Informationen zu maximal einem halben Dutzend Familien, die sich auf den gesamten Untersuchungszeitraum verteilen. Ein weiteres Problem des rodový katastr von Kapličky stellen die nach dem Abschluss der Familienrekonstitution im Jahre 1850 durchgeführten Nachträge dar. Offensichtlich war zunächst versucht worden, das Buch systematisch fortzuführen. Einzelne Einträge finden sich sogar noch in den 1930er Jahren. Je größer die zeitliche Entfernung von der Mitte des 19. Jahrhunderts ist, desto unzuverlässiger erscheint aber die Weiterführung des Bandes. Spätere Einträge beschränkten sich nicht auf zeitlich nach 1850 liegende Ereignisse, in einigen Fällen wurden auch Daten für die Zeit vor 1850 nachgetragen. Ganz überwiegend müssen diese Nachträge als falsch bezeichnet werden. So haben diese Nachträge etwa zu einer irrtümlichen doppelten Erfassung von etwa einem Dutzend Sterbeeinträgen geführt. 
prinzipiell die vorhandenen Familienregister und nicht die Originalmatriken verwendeten. ${ }^{26}$

Die Gefahr, dass durch die Fokussierung auf Kirchenbücher als zentrale Quelle bestimmte Personengruppen aufgrund eines anderen konfessionellen Bekenntnisses aus der Lokalstudie ausgeschlossen werden, dürfte im Falle der Pfarre Kapličky nicht gegeben sein. ${ }^{27}$ Personen jüdischen Glaubens gab es bis ins 19. Jahrhundert in der kleinen Pfarre mit großer Wahrscheinlichkeit nicht. ${ }^{28}$ Auch Personen evangelischer Konfession sind zumindest zwischen 1642 und dem späten 18. Jahrhundert auszuschließen. Die Rekatholisierung im Zuge der Gegenreformation war in dieser Herrschaft - im Gegensatz zu weiten Teilen Böhmens - bereits in den 1620er Jahren abgeschlossen. ${ }^{29}$

Der rodový katastr von Kapličky listet alle Familien in alphabetischer Reihenfolge nach dem Anfangsbuchstaben des Familiennamens auf. Das folgende Fallbeispiel 1 zeigt Struktur und Aufbau der Quelle (in einer vereinfachten Darstellung) am Beispiel einer ausgewählten Familie. Die Daten wurden besonders quellennah mit dem Datenbankprogramm KLEIO erhoben.

Fallbeispiel 1: Datensatz einer Familie

unit $\$ E 16 / 110$

$m \$$ Edelbauer/Adalbert $/ m / I / M i n i c h s c h l a g / 19.5 .1821 / a b=E 45$

elt \$Martin/m/I/Poschlag

fr $\$$ Maria/Krepper/w/9.4.1828/ab=K243

elt \$Thomas/m/Fischer/Minichschlag

$k \$$ Maria/w/23.8.1785/15.11.1817/27.5.1863/fst=lM/fam $=N 280$

enkel\$Thomas/m/1.3.1815//24.8.1849/

$k \$$ Marianna/w/25.1.1787/26.2.1821/30.4.1856/fam $=H 438$

26 Vgl. Gottsmich, Zur Erhaltung, 43.

27 Wie in jeder anderen Familienrekonstitution auch sind allerdings sehr mobile Bevölkerungsgruppen zwangsläufig unterregistriert.

28 In den Beilagen des Theresianischen Katasters des Jahres 1713 wurde erwähnt, dass es im Herrschaftsgebiet von Vyšší Brod keine Personen jüdischen Glaubens gebe, vgl. NA Praha, TK Spisy 619, fol. 69. In der benachbarten Kleinstadt Rožmberk, für die ebenfalls ein Rodový katastr vorliegt, hatte die jüdische Gemeinde dagegen eine sehr lange zurückreichende Tradition. Vgl. dazu: Kurrein, Rosenberg. Auch im ebenfalls zur Herrschaft Rožmberk gehörigen Frymburk existierte im 19. Jahrhundert eine kleine jüdische Gemeinde, vgl. Märten, Heimatkunde, 165.

29 Vgl. dazu: Schmidt, Gegenreformation. Im späten 16. Jahrhundert dagegen war der Protestantismus auch in der Klosterherrschaft Vyšší Brod weit verbreitet. Für das Jahr 1588 wird von mindestens 720 Protestanten berichtet. Vgl. Kaindl, Zisterzienserstift Hohenfurt, 53. 
$k \$$ Joseph $/ m / 12.10 .1788 / / 11.8 .1816$

$k \$$ Andreas $/ \mathrm{m} / 24.11 .1790 / / 26.1 .1856$

$k \$$ Gregor $/ \mathrm{m} / 25.2 .1793$

$k \$$ Katharina/w/20.3.1796

$k \$ J o h a n n / m / 1.12 .1798 / / 2.9 .1837$

$k \$$ Anastasia/w/22.3.1801/5.3.1828//fam $=M 366$

$k \$$ Rosina/w/4.9.1803//2.1.1806

Zur Erläuterung: Die ausgewählte Familieneinheit (unit) bezieht sich auf die Familie ,Edelbauer' mit der Identifikationsnummer E16, die auf Seite 110 im Familienkataster zu finden ist. Die Familie besteht aus dem Mann (m), der Frau (fr), den Eltern der Ehepartner (elt), den Kindern (k) sowie fallweise (fst=1M; Familienstand: ledige Mutter) auch den unehelichen Kindern der Töchter (enkel), die jeweils direkt nach ihrer Mutter verzeichnet wurden. Nach dem Namen der Person wurde jeweils deren Geschlecht genannt. Im Falle des Mannes sowie der Eltern beider Ehepartner ist auch eine berufliche/soziale Bezeichnung („I“ für Inwohner, bzw.: Fischer) sowie der Wohnort (Minichschlag) angeführt. Bei Mann und Frau finden sich die Sterbedaten und die Nummern ihrer Herkunftsfamilien ( $a b=E 45)$ verzeichnet. Nur bei den Kindern werden nach ihrem Geschlecht jeweils alle Vitaldaten in der Reihenfolge Taufdatum/Heiratsdatum/Sterbedatum genannt. Falls es einen Heiratseintrag gibt, ist auch ein Verweis auf die Familie, in die sie geheiratet hatten, zu finden (z. b. fam=N280). Fehlt der Heiratseintrag dagegen, ist - wie im Falle des Enkel Thomas das Feld zwischen Tauf- und Sterbeeintrag leer $(/ /)$. Bei dieser Anordnung fehlen damit zu einer vollständigen Rekonstitution der Familien, wie sie aus der Forschung bekannt ist, lediglich die Angaben zu Taufe und Heirat der Eltern. Diese Informationen können aber über die Verweisnummer leicht aus deren jeweiliger Herkunftsfamilie gewonnen werden.

\subsubsection{Die Grundbücher}

Grundbücher dienten im Rahmen der Grund- (bzw. Guts-)herrschaft zur Kontrolle und Evidenzhaltung von Besitzerwechseln der untertänigen Anwesen bzw. des dazugehörigen Landes. ${ }^{30}$ Die Anlage derartiger Bücher stand in Südböhmen offenbar in einem engen Zusammenhang mit der Einführung des erblichen Besitzrechtes im späten 16. Jahrhundert (vgl. dazu genauer Kapitel 6.3). Für die vor-

30 Winkelbauer, Grundherrschaft, 72-73. Vgl. zur (regional eingeschränkten) Verbreitung dieser Quelle im deutschsprachigen Raum während der frühen Neuzeit: Neschwara, Grundbuch. 
liegende Studie wurden beginnend mit dem ältesten, noch als „Kaufbuch“"31 bezeichneten Grundbuch, das Aufzeichnungen ab dem Jahre 1587 enthält, sämtliche Besitzübertragungen auf dem Pfarrgebiet bis zum Ende der Grundherrschaft im Jahre 1848 erhoben. ${ }^{32}$ In der Pfarre Kapličky wurden die Grundbücher getrennt nach den jeweiligen Dorfgerichten geführt; zumeist waren die Dörfer und Weiler der Pfarre in zwei Gerichten zusammengefasst, sodass jeweils auch zumindest zwei Grundbücher gleichzeitig existierten. Zur Führung der Aufzeichnungen waren faktisch (nicht rechtlich!) nicht nur herrschaftliche Verwalter, sondern wohl auch die einzelnen Dorfrichter befugt. ${ }^{33}$ Die Besitzungen und Nutzungsrechte der sogenannten Dominikalisten ${ }^{34}$, die nicht auf rustikalem Land, sondern auf herrschaftlichem Grund angesiedelt waren, wurden nicht in den Grundbüchern, sondern in eigenen herrschaftsweit geführten Büchern verzeichnet.

Ein Grundbucheintrag dient vornehmlich der Dokumentation der wesentlichen Eckdaten eines Besitzerwechsels. Dieser war im Untersuchungsgebiet immer in der Form eines Kaufvertrages gestaltet. Erst durch den Eintrag ins Grundbuch erlangt ein solcher Kaufvertrag seine rechtliche Gültigkeit. Festgehalten wurden im Grundbuch zumindest folgende Informationen: Name des Käufers, Name des Verkäufers, Umschreibung des Kaufobjektes, der Kaufpreis und das Datum des Grundbucheintrags (zumindest eine Jahresangabe). Das eigentliche Kaufobjekt wurde in der Periode vor der exakten Vermessung und Parzellierung allen Grund und Bodens in der Habsburgermonarchie (also vor dem Josefinischen, resp. dem Franziszeischen Kataster) im Wesentlichen mit dem Hinweis auf den Verkäufer sowie formelhafter Zusätze (etwa: dessen anwesen mitsamt aller dazugehörigen Gründe; oder: dessen Anwesen, wie es ,mit Rain und Stein umfangen') identifiziert.

Der Inhalt der Aufzeichnungen in den Grundbüchern der Herrschaft Vy̌šši Brod unterlag im Untersuchungszeitraum, der sich über zwei Jahrhunderte erstreckt, aber einem nicht unbedeutenden Wandel. Tatsächlich systematisch in den Grundbüchern verzeichnet sind die Ergebnisse vielfältiger, oft sehr komplexer und langwie-

31 SOA Třeboň, fond C Vyšší Brod, PK č. 445.

32 Weiters wurden die folgenden Grundbücher benützt: SOA Třeboň, PK č. 453, č. 465, č. 479, č. 480, č. 475 , č. 464, č. 553.

33 Dies geht aus den Eintragungen in den Grundbüchern selbst hervor, die häufig zwar von einem herrschaftlichen Verwalter unterschrieben waren, aber zum Teil auch in Formulierungen, wie "geschehen im Gerichtshaus Minichschlag“, etc. - in einigen Fällen mit Unterschrift des Dorfrichters - bestanden. Dass die Dorfrichter deshalb offiziell zur selbstständigen Führung der Grundbücher befugt gewesen wären, scheint daraus aber nicht ableitbar. Da in der Regionalliteratur dieses Recht einzelner Marktorte besonders hervorgehoben wurde, erschiene es ungewöhnlich, wenn auch die Dörfer eine derartige Befugnis gehabt hätten. Vgl. Schmidt, Siedlungs-Geschichte, 49, 52.

34 Vgl. dazu Kapitel 6. 
riger Aushandlungen zwischen den jeweils beteiligten Personen und Personengruppen. Ein Besitzerwechsel war zumeist nicht bloß auf ein Rechtsgeschäft zwischen zwei beteiligten Personen (Käufer und Verkäufer) beschränkt, sondern konnte mit einem weiteren Rechtsgeschäft im Zuge einer Heirat (Heiratsverträge), eines Todesfalls (Verlassenschaftsabhandlung), eines Nutzungs- und Versorgungsvorbehalts der abtretenden Verkäufer (Ausgedingeverträge), Legate für Dritte, und Testamente, etc. in Verbindung stehen. Während des 17. Jahrhunderts wurden alle diese Vereinbarungen noch gemeinsam mit dem eigentlichen Besitzerwechsel ebenfalls in den Grundbüchern verzeichnet. Wichtig zu erwähnen ist, dass bis etwa zur Mitte des 18. Jahrhunderts in den Grundbüchern auch eine genaue Dokumentation der Abzahlung der vereinbarten, in jährlichen Raten zu leistenden Kaufsumme durch den neuen Inhaber erfolgt. Eintragungen, wie : Käufer erlegt 169810 fl.' belegen daher, dass die Häuser und der landwirtschaftliche Grund tatsächlich gegen Bezahlung realer Geldsummen verkauft wurden (und die vereinbarten Kaufpreise daher keine bloß fiktive ,Gegenrechnung - zur Abgeltung der Ansprüche von Familienmitgliedern - bei einer eigentlich bargeldlosen Weitergabe der Anwesen darstellten) und erlauben die Rekonstruktion von Tempo und Umfang der tatsächlich erfolgten Bezahlung des Kaufobjektes. Sicherlich aus Gründen einer besseren Übersichtlichkeit und Auffindbarkeit der verzeichneten Informationen wurden nach und nach immer mehr der - die eigentliche Besitzübertragung nur begleitenden - Verträge und Aufzeichnungen in gesondert geführte Bücher ausgelagert, sodass um 1800 überwiegend nur mehr der eigentliche Akt des Besitzerwechsels vermerkt ist. Anstelle der ausgelagerten Informationen enthält das Grundbuch dann immer mehr Verweise auf die jeweiligen, in anderen Büchern eingetragenen, in direktem Zusammenhang mit der Besitzübertragung stehenden Rechtsverträge. ${ }^{35}$

Die in den Grundbüchern im Zusammenhang mit dem Besitzerwechsel angeführten Informationen variieren auch in anderer Hinsicht stark. Bis ins 19. Jahrhundert hinein wurde jeweils nur der männliche Käufer genannt. Erst mit Einführung der Gütergemeinschaft durch das Josefinische Gesetzbuch (1787) werden zeitverzögert ab etwa 1810 häufig beide Ehepartner als gemeinsame Besitzer der Anwesen verzeichnet. In der Periode davor sind die Namen der Frau, bzw. der noch lebenden Kinder des Inhabers nur dann genannt, wenn der Besitzerwechsel nach dem Tod des männlichen Inhabers, also im Zuge einer Verlassenschaftsab-

35 So finden sich im Bestand der Grundbücher für Kapličky ab dem späten 18. Jahrhundert neben eigenen Verzeichnissen von Verlassenschaften und Ausgedingeverträgen (erhalten nur für 1699 bis 1738; siehe unten), auch separate Bücher, die etwa die jährlichen Ratenzahlungen bei Häuserkäufen dokumentierten, und eigene Häuserkaufkontraktprotokolle (ab 1779). Diese Bestände konnten - mit Ausnahme des ,Ausnehmerbuches' hier nicht ausgewertet werden. 
handlung, erfolgte. In den restlichen Fällen musste auf die Verknüpfung mit dem Familienkataster zurückgegriffen werden.

Eine Angabe zum Verwandtschaftsverhältnis zwischen altem und neuem Besitzer findet sich im Grundbuch häufig. War der neue Besitzer der Sohn des Vorgängers, so wird dies durchgängig auch im Grundbuch vermerkt. Andere verwandtschaftliche Verbindungen wurden aber, wie eine stichprobenartige Überprüfung anhand der Familienrekonstitution ergab, bloß fallweise und nicht in allen Fällen angegeben, sodass eine Rekonstruktion auch naher Verwandtschaftsverhältnisse lediglich auf Basis der Grundbücher problematisch wäre. Schwiegersöhne etwa wurden überwiegend, aber nicht durchgehend als solche ausgewiesen. Von den im gesamten Untersuchungszeitraum insgesamt 19 Fällen, in denen ein Stiefsohn des Vorbesitzers die Besitznachfolge antrat, waren nur zwölf als solche im Grundbuch ausgewiesen worden, bei den anderen sieben erbrachte erst die Verknüpfung mit dem Familienkataster Hinweise auf ein Verwandtschaftsverhältnis. Die im Folgenden angeführte Besitzerabfolge (Fallbeispiel 2) eines Anwesens stellt ein auf die Grundinformationen Kaufdatum, Name, Kaufsumme und Verwandtschaftsverhältnis zum Vorbesitzer reduziertes Beispiel aus der Grundbuchdatei dar. ${ }^{36}$

\section{Fallbeispiel 2: Besitzerfolge des Hofes Kapličky Nr. 8}

Inh\$ vor 1614/Hans/Preininger

Inh\$ 13.5.1614/Hans/Weisgrammer/60

Inh\$18.5.1627/Georg/Weisgramer

Inh $\$ 0.0 .1647 / \mathrm{Jacob} /$ Zanner $/ 240$

Inh $\$ 0.0 .1648 / \mathrm{Joachim} / \mathrm{Iglboeck} / 187$

Inh \$ 0.0.1650/Thomas/Iglboeck/215/vw=s

Inh \$ 0.0.1665/Reichard/Reisch1/160

Inh $\$ 25.6 .1675 / \mathrm{Gerg} /$ Preinfalckh $/ 160$

Inh\$19.12.1690/Balthauser/Stockinger/250.30/vw=e

Inh\$ 0.0.1692/Nicolai/Thurnberger/312.49/vw=w

Inh $\$ 23.1 .1721 /$ Andre/Thurnberger/312/vw=s

Inh $\$ 17.8 .1743 /$ Bernhard/Huetter/312

Inh $\$ 19.6 .1773 /$ Mathias/Hutter/510/vw=s

Inh $\$ 7.6 .1787 /$ Gregor/Post1/500

Inh \$18.2.1831/Albert/Post1/900/vw=s

36 Die angegebene Hausnummer ist nicht die vom Staat im späten 18. Jahrhundert eingeführte Konskriptionsnummer, sondern eine von mir aufgrund der Reihenfolge der Erwähnung im Grundbuch von 1639 vergebene fiktive Ordnungsnummer. 
Anmerkung: Bei jedem Inhaber des Anwesens (inh) ist zunächst das Datum des Besitzantritts (13.5.1614), dann dessen Name (Hans/Weisgrammer) und danach die Kaufsumme (60) in Gulden angeführt. Falls ein Verwandtschaftsverhältnis (vw) zum jeweiligen direkten Vorbesitzer genannt wurde oder mittels Familienkataster rekonstruiert werden konnte, ist dieses angeführt. Als Kürzel des jeweiligen Verwandtschaftsverhältnisses dient „„“ für Sohn, „e“ für Schwiegersohn, „w“ steht für ,Heirat der Witwe des Vorbesitzers'.

Seit 1637 wurden die Grundbücher von Kapličky großteils (i.e. im Falle der bereits zu dieser Zeit existierenden Anwesen, nicht aber für die später gegründeten) nach dem sogenannten Realfoliensystem, bei dem für jedes Haus mehrere aufeinander folgende Blätter reserviert sind, geführt. Dies erleichterte die beinahe lückenlose Rekonstruktion der Besitzerfolgen sämtlicher Häuser der Pfarre, die in der vorliegenden Studie für den Zeitraum von 1640 bis 1840 lückenlos gelang) wesentlich. Weiter zeitlich zurück (bis gegen Ende des 16. Jahrhunderts) konnten die Besitzerfolgen dagegen nur mehr für einen Teil der Häuser rekonstruiert werden.

In der vorliegenden Studie erfolgte nur eine systematische Analyse der eigentlichen Besitzübertragung, also der Ergebnisse recht komplexer Aushandlungsprozesse, nicht aber eine Analyse aller damit im Zusammenhang stehenden Binnentransfers innerhalb der beteiligten Personen und Familien. Die Muster der Weitergabe von Haus und Land, nicht die Praktiken der Verteilung allen Erbes (d. h. sämtlicher materieller Güter, wie sie in Nachlassinventaren verzeichnet, oder in Testamenten festgelegt sind) standen im Zentrum des Interesses. ${ }^{37}$ Nachlässe und Testamente wurden daher ebenso wenig wie Heiratsverträge erhoben, die Aufschluss über die lokalen Praktiken der gegenseitigen Reichung von Heiratsgut und Widerlage zwischen den Ehepartnern (und deren Herkunftsfamilien) und damit auch eine stärker geschlechtsspezifische Orientierung erlauben würden. ${ }^{38}$

Ebenfalls im Bestand der Grundbücher von Vyšší Brod befindet sich ein, für die vorliegende Studie auch ausgewertetes, herrschaftsweit geführtes sogenanntes ,Reuterbuch' (ab 1731). ${ }^{39}$ Dabei handelt es sich um ein Verzeichnis, das die von den Untertanen - neben ihren ,Rustikalgründen“ - zusätzlich von den Herrschaftsgründen zugepachteten Parzellen auflistet.

37 Ein eigenes Buch, das Heiratsverträge und Testamente verzeichnet, ist für das Untersuchungsgebiet erst ab 1782 erhalten.

38 In den letzten Jahren hat sich auch im deutschsprachigen Raum ein eigenes Forschungsfeld etabliert, das sich der Rekonstruktion der sehr komplexen und kleinräumig überaus unterschiedlichen Systeme von Mitgift- und Vererbungspraktiken widmet. Vgl. etwa Lanzinger, Das gesicherte Erbe; Gottschalk, Eigentum.

39 SOA Třeboň, fond C Vyšší Brod, PK č. 556. 


\subsubsection{Das Ausnebmerbuch}

Wie bereits erläutert, findet sich im Bestand der Grundbücher der ehemaligen Herrschaft Vyšší Brod auch ein herrschaftsweit geführtes Ausnehmerbuch (kniha výměnkářská), in dem Altenteilerverträge für den Zeitraum von 1699 bis 1738 verzeichnet sind. ${ }^{40}$ Diese Quelle umfasst mehrere hundert Ausnahmevereinbarungen, erhoben und systematisch ausgewertet wurden hier jedoch nur die die Pfarre Kapličky betreffenden Informationen. Wie indirekt aus den Grundbüchern zu schließen ist, waren sowohl in der Zeit nach 1738 als auch bereits vor 1699 derartige separate Ausnehmerbücher geführt worden, diese gelten heute aber als verloren. Im Zeitraum bis etwa in die 1660er Jahre waren die Ausgedingeverträge bei den einzelnen Übergabeverträgen noch in den Grundbüchern mitverzeichnet worden. Gerade um die Mitte des 17. Jahrhunderts waren derartige Verträge aber offenbar nicht sehr zahlreich, sodass Aussagen über das Ausgedinge im 17. Jahrhundert nur auf der Basis von recht geringen Fallzahlen getroffen werden können.

Die Gründe für die Führung eines solchen Buches sind unbekannt. Eine plausible Annahme ist, dass es sich bei diesem Buch lediglich um eine aufgrund der Häufigkeit der Ausnehmervereinbarungen erfolgte Ausgliederung aus den örtlichen Grundbüchern, in welchen diese in Böhmen üblicherweise mitverzeichnet wurden ${ }^{41}$, in ein herrschaftsweit geführtes Buch handelt. Es gibt aber auch andere mögliche Erklärungen für die Führung eines speziellen Verzeichnisses der Ausgedingeverträge. Anders als die Grundbücher, die zum Teil auch von den Dorfrichtern geführt wurden, wurde das Ausnehmerbuch vom Kloster Vyšší Brod selbst erstellt. Dies ist aus dem immer wiederkehrenden Schlusssatz der Eintragungen „actum Closter Hochenfurth Ao: ..." ersichtlich. Einmal fand sich auch die Formulierung vom „Herrschaft Hohenfurther Ausnehmerbuch“. ${ }^{42}$ Das Kloster kontrollierte offenbar die Besitzübergabe und den Rückzug der Untertanen aufs Ausgedinge und achtete wohl insgesamt auf ein stabiles Funktionieren dieser Institution, die im ländlichen Bereich ja wesentliche Versorgungsfunktionen erfüllte. Diese Rolle der Herrschaft vermag auch den für das frühe 18. Jahrhundert erstaunlich hohen Verschriftlichungsgrad derartiger Regelungen und Arrangements im Untersuchungsgebiet zu erklären und scheint den in der Literatur häufig postulierten engen Konnex der Entstehung des Ausgedinges mit den Interessen der Grund-

40 SOA Třeboň, fond Vyšší Brod, PK, č. 565.

41 Nach Horáček, Das Ausgedinge, 6 wird das Ausgedinge erst durch die Eintragung in die öffentlichen

Grundbücher ein Obligationsvertrag.

42 Archiv Kláštera Vyšší Brod, kart. č. 414. 
herrschaft zu bestätigen, wonach „der Grundherr daran interessiert war, ältere Bauern durch körperlich leistungsfähige Söhne und Töchter zu ersetzen“43

Bei den einzelnen Ausnehmerverträgen findet sich jeweils ein Verweis auf den entsprechenden Akt der Besitzübertragung im Grundbuch (mit Angabe der Folio). Umgekehrt findet sich auch im Grundbuch ein Verweis auf die Eintragung im Ausnehmerbuch. ${ }^{44}$ Bereits dieser Aufbau der beiden Quellen bestätigt die Bindung des Ausgedinges an das Haus und nicht an einzelne Personen. Trotz einzelner sehr umfangreich gehaltener Verträge war der Großteil der verzeichneten Vereinbarungen recht knapp gehalten. Gerade bei den ärmeren Häusern wurde manchmal mit einigen wenigen Zeilen das Auslangen gefunden. Anstelle etwa die einzelnen zu reichenden Nahrungsmittel - wie in vielen aus dem 19. Jahrhundert bekannten Beispielen - detailliert zu nennen, wurde häufig bloß allgemein die Versorgung beim Haus festgehalten.

\subsubsection{Die staatlichen Quellen: Bevölkerungsverzeichnis und Kataster}

Das Soupis poddaných podle viry (auf Deutsch: ,Verzeichnis der Untertanen nach dem Glauben') aus dem Jahre $1651^{45}$ ist eine Bevölkerungszählung, die im Zuge der Rekatholisierung nach dem Dreißigjährigen Krieg erhoben wurde. Die gesamte Bevölkerung wurde namentlich und nach Haushalten geordnet unter Angabe ihres Alters, Familienstandes, der Position im Haushalt und ihrem religiösen Bekenntnis verzeichnet. Weitere Angaben, wie etwa Beruf und Herkunftsort der Personen, sind nur unvollständig angeführt. Obwohl die geplante landesweite Erhebung scheiterte, liegt diese Quelle für etwa die Hälfte aller Einwohner Böhmens vor. Als ein in seinem Aufbau durchaus mit späteren Volkszählungen vergleichbares Verzeichnis, das (weitgehend) alle Personen einer Region (und nicht nur ausgewählte Bevölkerungsgruppen) verzeichnete, stellt das soupis poddaných eine europaweit beinahe einzigartige Quelle der frühen Neuzeit dar. Die Qualität der Erhebung, generell vor allem

43 Gaunt, Formen, 158.

44 Durch diese Verweise in den Grundbüchern ist ersichtlich, dass sowohl in der Zeit nach 1738 als auch einige Jahre vor 1699 separate Ausnehmerbücher geführt wurden, diese sind heute allerdings nicht mehr auffindbar. Aussagen über das Ausgedinge im 17. Jahrhundert können daher nur aufgrund der einzelnen, vollständig in den Grundbüchern des 17. Jahrhunderts verzeichneten Ausgedinge-Verträge getroffen werden.

45 NA Praha, Soupis poddaných. Das Soupis poddaných wurde aufgrund des Streubesitzes nicht für die gesamte Herrschaft Vyšší Brod erhoben, sondern nur für den territorial geschlossenen Bereich rund um den Hauptort (konkret für die Gerichte: Studánky, Kapličky, Horní Drkolná, Herbertov, Jílovice, Lachovice und Slupečná - sowie für die beiden Marktorte Vyšší Brod und Hořice). Das Sample beinhaltet Informationen zu 2.316 Personen. 
hinsichtlich der Genauigkeit der Altersangaben sowie für mehrere Gebiete auch hinsichtlich ihrer Vollständigkeit ist sehr differenziert zu beurteilen. ${ }^{46}$ Für zahlreiche Herrschaften, darunter auch Vyšši Brod, wurden die Kinder vor dem Beichtalter nicht verzeichnet. ${ }^{47}$ Obwohl dies die Möglichkeiten der Analyse einschränkt, bietet diese Quelle, die sicherlich eine der ältesten Bevölkerungserhebungen Zentraleuropas darstellt, eine einzigartige Möglichkeit zur Untersuchung der Bevölkerungs-, Haushalts- und Familienstrukturen für die Zeit unmittelbar nach dem Dreißigjährigen Krieg.

Die ebenfalls landesweit erhobene Berní rula der Jahre 1653/5448 und deren Revisitation, im Falle von Vy̌šsi Brod für das Jahr 1682,49 sowie der Tereziánský katastr des Jahres $1713^{50}$ und dessen Revisitation (Okularvisitation des Tereziánský katastr 1720-1725) sind in ihrer Struktur als Steuerkataster zu werten. Als solche erfassen sie lediglich die Inhaber von Betriebseinheiten (Bauernhöfen, Handwerkerbetrieben etc.). Sie enthalten neben dem Namen des Inhabers und dessen sozialer Position detaillierte Angaben zur Aussaat (aufgeschlüsselt nach Winter-, Sommersaat und Brache bzw. nach Bodenqualität) und zur Viehzahl jeder besteuerbaren Einheit sowie auch zu allen weiteren agrarischen und gewerblichen Einkommensmöglichkeiten (z.B. Waldbesitz, Ausübung eines Handwerks oder eines agrarischen Nebenerwerbs usw.). In der Regel wurden die Kataster mit jeder neuen Erhebung genauer. Für die untersuchte Herrschaft standen de facto allerdings nur drei Steuererhebungen zur Verfügung, da in diesem Fall gerade die allgemein als die genaueste aller Erhebungen eingestufte, nämlich die Okularvisitation nicht im Original erhalten ist. Von dieser existiert lediglich im Endelaborat des Tereziánský katastr des Jahres $1757^{51}$ eine unvollständige Abschrift, die nur die besitzenden Häuser auflistet und bei diesen außerdem nur Angaben zur Aussaat und zum Gewerbe nennt, nicht aber etwa den Viehbestand.

Während die zuvor genannten Materialien lediglich für die Pfarre Kapličky erhoben wurden, wurden die staatlichen Quellen (Kataster und Bevölkerungsverzeichnis) auch für zahlreiche weitere Dörfer aus dem territorial geschlossenen Kerngebiet der Herrschaft sowie für den Marktort Vyšší Brod erfasst. ${ }^{52}$

46 Vgl. zum Folgenden auch die umfangreichen quellenkritischen Ausführungen bei Cerman/Matušíková/Zeitlhofer, Rozbor. Vgl. außerdem die kurze quellenkritische Abhandlung: Cerman/Zeitlhofer, Fragestellungen.

47 Matušíková/Pazderová, Alterszusammensetzung.

48 NA Praha, BR 2, fol. 822-828.

49 NA Praha, BR 30, fol. 271-279.

50 NA Praha, TK 684, fol. 43-67, 232, 234.

51 NA Praha, TK 46.

52 Die maschinenlesbaren Datensätze der Kataster haben folgende Größe: 1653/54: 247 Anwesen; 
Erhoben wurden weiters auch einige ausgewählte Informationen aus den Beständen der beiden späteren Kataster - des Josefinischen aus den 1780er Jahren und des Franziszeischen aus der ersten Hälfte des 19. Jahrhunderts. ${ }^{53}$ Beide Quellen sind in ihrer Struktur nicht mehr mit ihren Vorläufern (Berní rula und Theresianum) vergleichbar, sondern weitaus detaillierter, und konnten deshalb selbst für die kleine ausgewählte Pfarre nicht vollständig erhoben werden. Alle weiteren in der vorliegenden Arbeit verwendeten Quellenbestände werden bei ihrer Nennung im Text beschrieben.

\subsection{Die Gutsherrschaft des Klosters Vyšší Brod ${ }^{54}$}

Zum Zisterzienserkloster Vyšší Brod gehörte während der frühen Neuzeit eine im böhmischen Vergleich als mittelgroß zu bezeichnende Herrschaft. Einige der entsprechend neuerer Definitionen ${ }^{55}$ - wesentlichen Kennzeichen einer,Gutsherrschaft' waren in diesem südböhmischen Grenzgebiet, entlang der Grenzlinie zum System der Grundherrschaft, im 17. und 18. Jahrhundert voll ausgebildet, während sich die Klosterherrschaft in anderen typischen Merkmalen davon unterschied.

Die Herrschaftsökonomie des Klosters entsprach weitgehend dem Typus einer Gutswirtschaft. Der zeitliche Verlauf der Etablierung einer auf der Robot basierenden Eigenwirtschaft in Vyšší Brod spricht aber eher gegen die in der Literatur traditionelle Betonung des Dreißigjährigen Krieges als Zäsur. Entsprechend der lange Zeit vorherrschenden Lehrmeinung, sei es in Böhmen - insbesondere seit der Schlacht am Weißen Berg im Jahre 1620 und der, Verneuerten Landesordnung“

1682: 254 Anwesen; 1713: 326 Anwesen. Die staatlichen Quellen wurden mit den zentralen Materialien der vorliegenden Studie (Grundbücher, Altenteilerverträge, Familienrekonstitution) nicht systematisch verbunden. In die „Meta“-Datenbank übernommen wurde lediglich die Angabe zur Aussaat und zum Besitz an Zugvieh der Anwesen im Jahre 1713 als Indikatoren einer ökonomischer Differenzierung der Anwesen (vgl. unten). Ansonsten wurden die im Folgenden beschriebenen Erhebungen lediglich isoliert ausgewertet.

53 NA Praha, Josefinsky Katastr (JK) 2963, Obec Krasné Pole; NA Praha, Stabilní Katastr (SK) Dupl. 183; Dupl. 190; SK 221 Operat; SK 323 Operat.

54 Bei diesem Kapitel handelt es sich um eine überarbeitete und deutlich erweiterte Fassung des entsprechenden Abschnitts in: Zeitlhofer, Vielfalt, 15-18.

55 Vgl. etwa Cerman, Gutsherrschaft. Vgl. auch Cerman, Soziale Differenzierung, bes. 174-177. Vgl. als Forschungsüberblick zur,Gutsherrschaft': Kaak, Gutsherrschaft; zur,Grundherrschaft' siehe: Blickle, Grundherrschaft. Eine wichtige Ursache dieser veränderten Einschätzung zwischen der älteren und der neueren Literatur liegt bei einer anderen Akzentuierung in der Definition der Konzepte,Gutsherrschaft' und ,Grundherrschaft'. Für den Vorschlag, die beiden gegensätzlichen Modelle ,Grund-, und,Gutsherrschaft' zugunsten differenzierterer Konzepte aufzulösen, siehe Holenstein, Bauern. 
von 1627 - zu einer grundlegend neuen Entwicklung hin zu einer ,ostelbischen Gutsherrschaft' (manchmal, insbesondere in der englischsprachigen Literatur auch als ,second serfdom/zweite Leibeigenschaft' bezeichnet) gekommen. Das System einer auf der, Robot' basierenden Eigenwirtschaft der Gutsherren sei in dieser Zeit deutlich ausgebaut worden. Dies habe eine wesentliche Verstärkung des Zugriffs der Obrigkeiten auf die Arbeitskraft der Untertanen bewirkt und hätte gleichzeitig eine Beschneidung der rechtlichen Freiheiten der Untertanen (Restriktion der Mobilität, etc.) herbeigeführt. Die Hauptursachen dieser Entwicklung wurden vorwiegend in sinkenden Agrarpreisen und einem drastischen Arbeitskräftemangel gesehen. ${ }^{56} \mathrm{Im}$ Kontrast dazu wurde in der tschechischen Historiographie die adelige Wirtschaft in der Periode vor der Schlacht am Weißen Berg, insbesondere im 15. und 16. Jahrhundert, als ,westeuropäisch“, manchmal sogar als „proto-kapitalistisch " (da überwiegend auf Lohnarbeit beruhend) beschrieben. ${ }^{57}$ Kritiker einer Überbewertung des Dreißigjährigen Krieges als Zäsur und der Größe der herrschaftlichen Meierhöfe als Gradmesser betonen, dass es sich bei dieser Entwicklung nicht um Innovationen zur Mitte des 17. Jahrhunderts handelte. Vielmehr sind schon für das 16. Jahrhundert für zahlreiche Regionen Böhmens Ansätze zum Ausbau der obrigkeitlichen Eigenwirtschaften zu erkennen. Eduard Maur und Markus Cerman charakterisieren die Entwicklung in Böhmen als, verschärfte Erbuntertänigkeit..$^{58}$

Zwar baute auch das Kloster Vyšší Brod seine Eigenwirtschaft insbesondere während und nach dem Dreißigjährigen Krieg deutlich aus, indem etwa Lehensgüter angekauft und als Vorwerke weitergeführt wurden. ${ }^{59}$ Der Kritik an einer Überbewertung dieser Zäsur ist aber zuzustimmen: In Vyšši Brod kehrte man lediglich zu einer bereits während des Mittelalters stark ausgeprägten herrschaftseigenen Ökonomie zurück. Die Erhöhung der Zahl der von der Herrschaft selbst bewirtschafteten Gutshöfe ${ }^{60}$ basierte beinahe ausschließlich auf der Rückführung von zum Teil im 14., zum Teil aber auch erst zur Mitte des 16. Jahrhunderts verpachteten oder verkauften, aber bereits seit dem Hochmittelalter bestehenden Meierhöfen in den Besitz der Herrschaft. ${ }^{61}$ Auch der für das Jahr 1374 quellenmäßig

56 Vgl. diese Sichtweise bei Hroch/Petrán, Krise, 126 ff, Klíma, Probleme, hier 220 ff; Klíma, Economy, 35 ff; Kann/Zděnek, Peoples, 23-29.

57 Čechura, Struktur.

58 Vgl. Cerman, Gutsherrschaft, und Maur, Gutsherrschaft, bes. $103 \mathrm{ff}$.

59 Schmidt, Urbar; Kaindl, Zisterzienserstift Hohenfurt, 62.

60 Um 1374 sieben Höfe, 1530 sechs, um 1600 drei bis vier, 1651 sieben, 1713 neun, 1749 zehn, vgl. Millauer, Viehzucht, 223-224; Schmidt, Urbar; NA Praha, Soupis poddaných; NA Praha, TK, Spisy 619, fol. 1-30 und NA Praha, ED.

61 Lediglich einer der Meierhöfe des Jahres 1749 war eine Neugründung aus den 1590er Jahren. Im Ver- 
fassbare Viehbestand der Eigenbetriebe lässt auf eine hohe Bedeutung der Regiewirtschaft im Mittelalter schließen, wie dies für mittelalterliche Zisterzienserklöster nicht untypisch erscheint. ${ }^{62}$

Jahrzehntelang hatte insbesondere die marxistisch-orientierte Forschung Ostmitteleuropas beim Kriterium einer Zuordnung zur,Gutsherrschaft' ein zu starkes Augenmerk auf den Umfang der „herrschaftlichen Regiewirtschaft“ und die Höhe der von den Untertanen zu leistenden Arbeitsdienste gelegt und andere Definitionsmerkmale außer Acht gelassen. ${ }^{63}$ Westliche deutschsprachige Historiker, wie Friedrich Lütge, hatten überwiegend dagegen diese Ansätze als zu ökonomisch zurückgewiesen und in Anschluss an Otto Brunner bereits in den 1950er Jahren auf die sozialen und rechtlichen Merkmale von ,Herrschaft' als zentrale Definitionskriterien von ,Gutsherrschaft' verwiesen, wozu unter anderem zählten: der allmähliche Aufbau territorial geschlossener Gebietskomplexe durch die Grundherren, der Zusammenfall von Grund- und Gerichtsherrschaft bei einem Herrn, die Existenz von Aufkaufs- und Absatzmonopolen sowie von Mobilitätsbeschränkungen für die Untertanen und weitere verpflichtende Arbeitsdienste wie der Waisen- und Gesindezwangsdienst. ${ }^{64}$ Wenn man mit Landsteiner davon ausgeht, dass jede Durchsetzung erhöhter Arbeitsdienste für die Untertanen ebenfalls auf außerökonomischem Zwang, also Herrschaft, beruhte, erscheinen die Gegensätze dieser beiden unterschiedlichen Traditionslinien in der Sicht auf ,Gutsherrschaft ${ }^{\text {‘ }}$ allerdings weniger stark als häufig angenommen. ${ }^{65}$

Als geistliche Herrschaft war Vyšší Brod bis 1822 in der Herrschaft Český Krumlov inkorporiert, bei der auch die Gerichtsbarkeit lag. Das Kloster hatte nicht, wie die meisten böhmischen Herrschaften, die hohe Gerichtsbarkeit über seine Untertanen inne. ${ }^{66}$ Außerdem bildete das Herrschaftsgebiet keinen tatsäch-

gleich mit anderen Regionen Böhmens erfolgte diese Reorientierung eher spät, vgl. Cerman, Gutsherrschaft, bes. $101 \mathrm{ff}$. Auch die Verpachtung von Meierhöfen um die Wende zur Neuzeit war hier im böhmischen Vergleich bereits deutlich verspätet erfolgt. Vgl. Čechura, Bauernschaft, 293.

62 Die bei Millauer, Viehzucht, genannten Zahlen erlauben für vier Höfe des Klosters einen Vergleich des Viehbestandes der Jahre 1374 und 1819. Dabei zeigt sich, dass in jedem Meierhof im Jahr 1819 etwa um 50 Prozent mehr Rinder als 1374 gehalten wurden; dafür war die im 14. Jahrhundert übliche Pferdehaltung aufgegeben worden. Vgl. dazu die Tabelle in: Zeitlhofer, Besitztransfer, 46.

63 Harnisch, Gutsherrschaft.

64 Anders als etwa in Bayern hatten in Böhmen die Grundherrn bereits im ausgehenden Spätmittelalter ganz überwiegend auch die Gerichtsbarkeit über ihre Untertanen inne. Vgl. dazu ausführlich Maur, Gutsherrschaft, 64, sowie Cerman, Diss., $107 \mathrm{ff}$ und die Beiträge in: Peters, Gutsherrschaftsgesellschaften.

65 Landsteiner, Demesne. Hier findet sich auch eine ausführlichere Darstellung der Traditionslinien dieser beiden unterschiedlichen Sichtweisen auf Gutsherrschaft und Gutswirtschaft.

66 Obwohl sie sich bereits seit 1677 darum bemüht hatte, erlangte die Klosterherrschaft erst 1822 durch 
lich territorial völlig geschlossenen Gebietskomplex. Dies war bloß im Kerngebiet der Herrschaft südlich der Moldau (in der Umgebung des Klosters) gegeben. In diesem Gebiet hatte auch während des Spätmittelalters, ähnlich wie im Falle vieler anderer böhmischer Herrschaften, ein Prozess der territorialen Abrundung stattgefunden. So waren etwa im Jahr 1500 die Dörfer des Gerichtes Studánky/Kaltenbrunn in der unmittelbaren Umgebung von Vyšší Brod an die Herrschaft gefallen. Nur die beiden hier gelegenen Pfarren Vyšší Brod und Kapličky gehörten vollständig zur Herrschaft. Bereits die Dörfer der direkt im Norden (jenseits der Moldau) anschließenden Pfarre Malšiny/Malsching waren auf fünf verschiedene Herrschaften, darunter auch Vyšši Brod, aufgeteilt, wobei die Herrschaftsgrenzen zum Teil auch durch die einzelnen Dörfer gingen; gleiches traf auch auf den Ort Loučovice an der Moldau zu, der sich nicht nur auf fünf Herrschaften aufteilte, sondern auch auf vier Pfarren und (im 19. Jahrhundert) auf drei Gemeinden. ${ }^{67}$ Die Pfarre Hořice bildete - mitsamt den zum Pfarrgebiet gehörigen Dörfern - eine in einiger Entfernung nordwestlich vom Kerngebiet der Herrschaft gelegene abgeschlossene Enklave innerhalb der sehr großen Herrschaft Český Krumlov/Böhmisch Krumau. Alle weiteren Besitzungen des Klosters sind als Streubesitz zu bewerten. Diese territoriale Zersplitterung des Herrschaftsbesitzes war innerhalb Böhmens zwar sicherlich eine Ausnahme, völlig ungewöhnlich war diese aber nicht. Gerade in Südböhmen hatten sich neben den wenigen, territorial sehr großen geschlossenen Herrschaftskomplexen auch kleine Güter mit Streubesitz gehalten. Da und dort waren einzelne Dörfer, manchmal auch nur einzelne Häuser, vom Komplex einer großen Herrschaft ausgenommen und einer anderen Obrigkeit untertänig. So hatte beispielsweise das oberösterreichische Stift Schlägl die Grundherrschaft über zwei an der Moldau liegende Dörfer in der Nähe von Horní Plana/Oberplan inne. ${ }^{68}$ Für die betroffene kleine Minderheit der neuzeitlichen Bevölkerung Südböhmens hatte dies zur Folge, dass Grund-, Gerichts-, und Pfarrherr nicht identisch waren. In aller Regel war dies für die Untertanen von Vorteil.

Auch einige der sonst in Böhmen weit verbreiteten Abgaben oder Monopolstellungen fehlten in der Herrschaft Vyšši Brod oder wurden erst relativ spät eingeführt. Der sogenannte Mühlzwang etwa, in benachbarten Gebieten bereits im 16. Jahrhundert eingeführt, bestand erst seit $1701 .{ }^{69}$ Die Einführung mehrerer neuer

die Loslösung von Český Krumlov ihre volle Selbstständigkeit und damit unter anderem auch die volle Patrimonialgerichtsbarkeit über ihre Untertanen. Vgl. Kaindl, Zisterzienserstift Hohenfurt, 79, $112 \mathrm{f}$.

67 Vgl. etwa Irsigler, Turmberg, 112f. Vgl. auch Kapitel 2.1.

68 Schmidt, Siedlungs-Geschichte, 42; Pröll, Schlägl, 298.

69 Archiv Kláštera Vyšší Brod, kniha č. 245 (Zinsregister 1712). In den benachbarten Herrschaften der Rožmberk wurde der Mühlzwang dagegen bereits in den 1590er Jahren eingeführt. Vgl. Essl, 
Abgaben nach dem Dreißigjährigen Krieg lässt sich nicht zuletzt am langjährigen (erfolglosen) Widerstand der Untertanen ablesen. Das Kloster Vyšší Brod hatte unter anderem versucht, eine Abgabe auf das Erlernen eines Handwerks einzuführen, wie mehreren Beschwerdebriefen zahlreicher Dörfer aus dem Jahre 1654 $\mathrm{zu}$ entnehmen ist. ${ }^{70}$ Abgaben für die Ausübung eines Gewerbes, wie dies etwa im Falle nordböhmischer Weber dokumentiert ist, ${ }^{71}$ lassen sich in der Herrschaft Vyšší Brod dagegen nicht nachweisen. Die Zinsregister der Jahre 1643 und 1712 nennen nur die traditionellen, überwiegend seit dem Hochmittelalter bestehenden Forderungen, wie Hauszins, ,Fleischgeld“, ,Kuchldienst', etc., aber auch etwa Wiesenzinse. ${ }^{72}$ Die Robotforderungen gegenüber den Zugvieh besitzenden Untertanen erstreckten sich nach deren eigenen Angaben zu Beginn des 18. Jahrhunderts auf bis zu vier Tage pro Woche. ${ }^{73}$ Die Handrobot der Häusler und Inwohner betrug dagegen laut herrschaftlichen Verzeichnissen aus den Jahren 1675-1677 durchgehend weniger als 20 Tage pro Jahr. ${ }^{74}$ Auch die Untertanen der beiden Marktorte der Herrschaft hatten im 18. Jahrhundert nur fünf Tage pro Jahr Robot zu leisten. ${ }^{75}$ Insbesondere die Dörfer des Gerichtes Studánky, die erst im Jahre 1500 von der Herrschaft Český Krumlov zur Herrschaft Vyšší Brod gekommen waren, versuchten in den 1650er und 1660er Jahren erfolglos die Erhöhung der Robotforderungen mit verschiedensten Mitteln abzuwehren. Das Kloster stiftete darauf hin den als Rädelsführer des Protestes erachteten Grundbesitzer Hans Zanner aus Studánky ab - worauf das Gericht Studánky wiederum mit mehreren Beschwerdebriefen an die Bechiner Kreishauptmannschaft reagierte. ${ }^{76}$ Laut Urbar aus dem Jahre 1530 war die Robotverpflichtung zu jener Zeit gering gewesen, sie belief sich bei den meisten Häusern auf weniger als zehn Tage im Jahr. Zu einer ersten allge-

Krumau, 279. Die Berechtigungen der Untertanen, selbst Bier zu brauen, dagegen wurden spätestens zur Wende zum 17. Jahrhundert abgeschafft. Vgl. Schmidt, Brauwesen bes. 315.

70 Archiv Kláštera Vyšší Brod, Kart. č. 405, 47/5. So wurde etwa vom 1644 geborenen Mathias Iglpeck, einem Bauernsohn aus Kapličky und späteren Kleinhäusler in Hřbitek, im Jahre 1663 eine Abgabe von fünf Gulden und 30 Kreutzer auf die Erlernung des Weberhandwerks gefordert. In den Grundbüchern von Kapličky ließ sich die Einforderung dieser Abgabe lediglich in zwei Fällen nachweisen, sie wurde wohl wieder abgeschafft. Eine derartige Abgabe lässt sich in Böhmen sonst kaum nachweisen.

71 Vgl. Cerman, Proto-Industrialisierung.

72 Archiv Klaštera Vyšší Brod, kniha 237 (Zinsbuch beim Kloster Hohenfurth, 1643); kniha 245 (,Zins buech bey dem löblichen stüfft undt closter Hochenfurth rändtambt, wie solche jährlich in empfang gebracht undt ordentl: verechnet werden', 1712).

73 Kienzl, Geschichte, 32; Kaindl, Zisterzienserstift Hohenfurt, 75, $92 \mathrm{f}$.

74 Archiv Kláštera Vyšší Brod, kart. č. 397, Publikum 5/3.

75 NA Praha, ED.

76 NA Praha, NM H 115/1. 
meinen Anhebung der Robot war es aber, wie zuvor in der Domäne der Rožmberk, bereits während der zweiten Hälfte des 16. Jahrhunderts gekommen. Die zu dieser Zeit für einen Großteil der untertänigen Dörfer durchgeführte Umwandlung eines eingeschränkten Besitzweitergaberechtes der untertänigen Güter (,Totenfälligkeit') in emphyteutisches Besitzrecht (Erbzinsrecht) war von einer Verdoppelung der bisherigen Abgaben und einer Anhebung der Robotforderung begleitet. ${ }^{77}$

Die Widerständigkeit gegen die Robot flammte noch öfter auf: 1723 legte das Gericht Kapličky bei der Statthalterei in Prag eine Beschwerde wegen überhöhter Robotforderungen durch die Herrschaft ein und nahm sich zu diesem Zweck einen Prokurator. Sie hätten während der Sommermonate jeden Tag Robot zu leisten und im Winter für den Wegfall der Robot 173 Gulden zu zahlen. ${ }^{78}$ Als im Zuge der Erstellung der Revisitation des Theresianischen Katasters während der ersten Hälfte der 1720er Jahre staatliche Beamte die Dörfer aufsuchten, ergriff wiederum das Gericht Studánky die Gelegenheit, um Beschwerde gegen die Robotforderungen zu erheben. ${ }^{79}$ Die Untertanen legten dabei den staatlichen Beamten Urkunden vor, die beweisen sollten, dass sie vor dem Jahr 1500 von jeglicher Robot befreit gewesen wären. ${ }^{80}$ Während der zweiten Hälfte des 17. Jahrhunderts kam es - wie die Grundbücher zeigen - in einzelnen Fällen auch wegen schlechter Wirtschaftsführung zur Abstiftung von Bauern. Eine Praxis, die sich im 18. Jahrhundert nicht mehr nachweisen lässt.

Die Gutswirtschaft des Klosters blieb während der gesamten frühen Neuzeit bedeutend; dies betraf nicht nur die ausgedehnte Forstwirtschaft, sondern auch die Viehzucht. Für das Jahr 1711 hatte das Kloster als Viehbestand in seinen Eigenbetrieben unter anderem 54 Ochsen und 193 Kühe deklariert. ${ }^{81}$ Eine Abkehr vom System einer ausgeprägten herrschaftlichen Eigenwirtschaft erfolgte nur sehr

77 Vgl. Schmidt, Agrar- und Colonisationsgeschichte. Bereits für das Jahr 1609 sind auch Konflikte der Herrschaft mit Untertanen von weiter im Landesinneren gelegenen Dörfern (z. B. Lipanovice/ Linden, nordwestlich von České Budějovice [Budweis]) um die zu leistende Robot dokumentiert. Vgl. Schmidt, Urbar, 269.

78 Kaindl, Zisterzienserstift Hohenfurt, 92f. Die Gegendarstellung der Herrschaft sprach von zwei Tagen Robot pro Woche im Durchschnitt und davon, dass die Bewohner von Kapličky oft schwächliche Kinder oder alte Leute zur Verrichtung der Robotarbeit sandten.

79 NA Praha, TK Spisy 619, fol. 66. Vgl. dazu auch Kienzl, Geschichte, 32.

80 Eine ähnliche Argumentation gegen die Robotverpflichtung wurde in Südböhmen häufig von den Untertanen angewandt, vgl. am Beispiel des Dorfes Rychnůvek im Jahre 1750: Himl, Vrchnost a venkované, 654. Diese Beispiele verdeutlichen jedenfalls das beträchtliche Wissen frühneuzeitlicher Bewohner scheinbar abgelegener Walddörfer um zeitlich weit zurückreichende Auseinandersetzungen bezüglich ihrer Rechte und Pflichten sowie deren Geschick in der Benutzung geeigneter staatlicher und ständischer Rechtsmittel.

81 Archiv Kláštera Vyšší Brod, kart. č. 410. 
allmählich. Zwar wurden die für die herrschaftseigene Ökonomie benötigten Arbeitskräfte zu jeder Zeit aus einer Kombination von Lohnarbeit, Robotverpflichtung und Gesindebeschäftigung ${ }^{82}$ rekrutiert; der Höhepunkt der Bedeutung der Robotarbeit dürfte aber in die zweite Hälfte des 17. Jahrhunderts fallen. Erst mit der landesweiten Aufhebung der Robot in den 1780er Jahren löste das Kloster zahlreiche seiner Meierhöfe auf, und verkaufte die verparzellierten Gründe an Untertanen. ${ }^{83}$ Wie zu zeigen sein wird, hatte dies auch deutliche Auswirkungen auf die Familienwirtschaften der untertänigen Bauern.

Hinweise auf eine Zurückdrängung der Robot zugunsten der Lohnarbeit lassen sich in Teilbereichen der herrschaftlichen Ökonomie aber deutlich früher finden. Darauf verweist nicht nur die um 1690 beginnende Ansiedlung vertraglich verpflichteter Lohnarbeiter für die Waldwirtschaft, etwa mit der Gründung des Holzfällerdorfes Nové Domky, die explizit die Robotarbeit in diesem Bereich ersetzen sollte, sondern vermutlich auch der Umstand, dass zahlreiche Untertanen bereits im frühen 18. Jahrhundert ihre Robotverpflichtungen mit Geld abgelöst hatten. Die Untertanen der Dörfer des Gerichtes Stift (das etwa die Hälfte der Dörfer der Pfarre Kapličky umfasste) zahlten etwa 1712 anstelle des Pflügens im Meierhof ,Gaishof' (bei Vyšší Brod) 26 Gulden jährlich. ${ }^{84}$

Die Robotpflichten belasteten nicht alle Untertanen der Herrschaft in gleichem Maße. Wie bereits angedeutet, unterschied sich deren Ausmaß nach sozio-ökonomischer Position des Haushalts sehr gravierend. Ledige Personen schuldeten, wie in anderen Regionen auch, keine Fron. Die Robotpflicht betraf allerdings alle Personen, die einen eigenen Haushalt führten, und damit auch landlose Inwohner und Ausnehmer. ${ }^{85}$

Neben der Robot war auf den herrschaftlichen Regiegütern insbesondere ein hoher Bedarf an Lohnarbeit vorhanden. Für die landarme und landlose Bevölkerung der Region war diese Verdienstmöglichkeit bei der Gutsherrschaft (als eine unter mehreren Einkommensmöglichkeiten) essenziell. Besonders während der

82 Das Bevölkerungsverzeichnis von 1651 führt zahlreiche auf den herrschaftlichen Meierhöfen lebende Gesindepersonen an.

83 Neuerlich erfolgte diese Umstellung im innerböhmischen Vergleich relativ spät. In der Herrschaft Liberec in Nordböhmen hatte die Aufösung der Eigenbetriebe bereits in den 1720er Jahren begonnen. Vgl. Cerman, Gutsherrschaft und untertäniges Gewerbe, 15. Auch in der benachbarten südböhmischen Herrschaft Český Krumlov war zumindest ein Meierhof bereits im 17. Jahrhundert und ein weiterer im Jahre 1727 aufgelöst und der Grund an Bauern verkauft worden. Vgl. Gallistl, Heimatkunde, $219 \mathrm{ff}$.; Jordan, St. Thomas-Wittingshausen, 15.

84 Archiv Kláštera Vyšší Brod, kniha 245, nr. 11.

85 Im Vergleich dazu war es etwa in Bayern rechtlich umstritten, ob sich diese Verpflichtung der Haushalte auch auf Inwohner bezog. Vgl. Blickle, Scharwerk, 410. 
Einbringung und der Verarbeitung der Ernte wurden zusätzlich zu den Robotleistenden zahlreiche Taglöhner benötigt. Dies zeigen etwa herrschaftliche Quellen des 17. Jahrhunderts, die zahlreiche Inwohner der Region als ,Hofdrescher' bezeichnen (vgl. auch Tabelle 19). ${ }^{86}$

Als kirchliche Herrschaft hob das Kloster Vyšší Brod von den Untertanen auch den Zehent ein. Da die Zehentbücher für die Zeit nach dem Dreißigjährigen Krieg beinahe geschlossen erhalten sind, würde dies theoretisch eine ausgezeichnete und seltene Möglichkeit bieten, die Ernteerträge der untertänigen Wirtschaften im Zeitverlauf zu rekonstruieren. Tatsächlich war es aber bereits im 15. und 16. Jahrhundert vereinzelt zur Herabsetzung des Zehents, ${ }^{87}$ bzw. zur Umwandlung in fix feststehende Geldabgaben gekommen ${ }^{88}$ sodass eine Berechnung der Erträge wohl nur für bestimmte Perioden und einzelne Dörfer möglich wäre. Das mit dem Jahr 1683 beginnende Zehentbuch für mehrere Dörfer der Pfarre Kapličky ${ }^{89}$ dokumentiert aber immerhin einen gerade in diesen Jahren stattfindenden Wandel weg von der bisher üblichen Abgabeform ganzer Getreidebündel direkt vom Feld hin zur Abgabe des Zehents in „Körnern“, also des bereits gedroschenen und gereinigten Getreides in Säcken. Dies dokumentiert einen wichtigen Rationalisierungsschritt der gutsherrschaftlichen Eigenbetriebe und gleichzeitig einen Auslagerungsprozess mehrerer Arbeitsschritte von der herrschaftlichen Ökonomie hin zu den bäuerlichen Betrieben. Für den Gutsbetrieb selbst bedeutete dies in der Folge eine Reduzierung des Bedarfs an Lohnarbeit oder an Robotleistungen.

86 Vgl. die ähnliche Argumentation bei: Trossbach, Gutsherrschaft, 50 .

87 Schmidt, Urkunden.

88 Sehr häufig vor allem in den entfernter liegenden Dörfern, vgl. Proschko, Cistercienser-Stift Hohenfurth, 24; Schmidt, Stritschitzer Sprachinsel, 392.

89 Archiv Kláštera Vyšší Brod, kniha č. 242. 


\section{DIE AUSGANGSLAGE UM 1650 UND FRAGEN DER SOZIALEN DIFFERENZIERUNG}

Das Bevölkerungsverzeichnis (Soupis poddaných) des Jahres 1651 zählte für die Dörfer der Pfarre Kapličky 383 Personen: 186 Männer und 197 Frauen. Wie bei zahlreichen anderen Herrschaften Südböhmens nennt die Quelle keine Kinder vor dem Beichtalter (mit ca. 10 Jahren). Aufgrund von Vergleichswerten aus anderen Gebieten Böhmens zum Anteil der Kinder unter zehn Jahren an der Gesamtbevölkerung lässt sich für die Pfarre Kapličky eine Einwohnerzahl von etwa 500 Personen im Jahre 1651 schätzen. ${ }^{1}$

Die Haushaltsstrukturen in den ländlichen Gebieten der Herrschaft Vyšší Brod sind laut Soupis poddaných im Jahre 1651 von sehr hohen Anteilen an mitlebenden Inwohnern und Inwohnerfamilien und von hohen Anteilen an Gesindepersonen gekennzeichnet. In den Dörfern der Herrschaft lebten knapp 30 Prozent aller Familien im Inwohnerstatus, in der Pfarre Kapličky lag dieser Anteil noch höher. Im innerböhmischen und im internationalen Vergleich sind diese Werte als sehr hoch einzustufen. ${ }^{2}$ Die Vermutung, dass es nach dem Dreißigjährigen Krieg zu einem Rückgang oder gar Verschwinden der landlosen Familien gekommen wäre, weil diese verödete Bauernwirtschaften übernehmen konnten, ${ }^{3}$ lässt sich weder für die Herrschaft Vyšší Brod noch für andere Regionen Südböhmens bestätigen. Ein großer Teil der Inwohner war verheiratet. Dass beinahe 20 Prozent der Bevölkerung im Alter von über 10 Jahren im Dienst standen, verweist auf den vorherrschenden Typus der regionalen Ökonomie (Viehzucht und der im Jahresverlauf einen hohen Arbeitskräftebedarf erfordernde Flachsanbau), der - aufgrund relativ geringer saisonaler Schwankungen im Arbeitskräftebedarf der Familienwirtschaften - Beschäftigungsverhältnisse in hausrechtlicher Abhängigkeit begünstigte. ${ }^{4} 1651$ be-

1 Quelle: NA Praha, SM R 109/45. Zu dieser Zahl gelangt man, wenn man - wie durch andere Studien auf der Basis dieser Quelle vielfach belegt - einen Anteil der Nicht-Kommunikanten an der Gesamtbevölkerung von etwa 30 Prozent annimmt. Vgl. etwa Schreiber, Elbogner Kreis.

2 Siehe zur Diskussion über die Höhe des Inwohner- und Gesindeanteils in mehreren südböhmischen Herrschaften vor und nach dem Dreißigjährigen Krieg: Grulich/Zeitlhofer, Lebensformen.

3 Klima, Länder.

4 Vgl. grundlegend zu den Zusammenhängen von Viehzucht und Gesindebeschäftigung bzw. von Taglöhnergesellschaften und beispielsweise überwiegend vom Ackerbau lebenden Bauern: Mitterauer, Formen. 
schäftigte mehr als die Hälfte der Anwesen in den Dörfern der Herrschaft Vyšší Brod Gesindepersonen - ein Anteil, der von kaum einer anderen Region Böhmens zu dieser Zeit erreicht wurde. ${ }^{5}$ In Vyšší Brod trug freilich auch der deutliche Überhang der bäuerlichen Anwesen, die eher als die Kleinbesitzer Gesinde benötigten, zu den insgesamt hohen Durchschnittswerten bei den Gesindezahlen bei.

\subsection{Die demographischen Folgen des Dreißigjährigen Krieges}

Die außergewöhnlich günstige Quellensituation mit einem für zahlreiche Gebiete Böhmens vorliegenden Bevölkerungsverzeichnis für die Mitte des 17. Jahrhunderts hat in der tschechischen Historiographie bereits früh zu zahlreichen, überwiegend als regionale historisch-demographische Fallstudien angelegten Auswertungen dieser Quelle aus dem Jahre 1651 geführt. Nur selten waren die älteren Studien an Fragestellungen zu den Haushaltsstrukturen interessiert gewesen. Die historisch-demographischen Analysen der Bevölkerungszählung von 1651 hatten trotz beachtlicher regionaler Unterschiede in den Tendenzen einige übereinstimmende Ergebnisse erbracht, die ganz überwiegend als Abbild der Folgen des Dreißigjährigen Krieges interpretiert wurden. Als Anzeichen solcher Kriegsfolgen wurden unter anderem das - im Vergleich mit den überwiegend aus späterer Zeit stammenden west- und zentraleuropäischen Vergleichsdaten - geringe durchschnittliche Alter der lokalen Bevölkerungen, eine unausgeglichene Geschlechterproportion mit einem deutlichen Übergewicht der Frauen und auffallend geringe Anteile bestimmter Altersgruppen (z.B. bei den Altersgruppen der 15-19-Jährigen und bei den über 50-Jährigen) genannt. ${ }^{6}$ Schätzungen zum durch den Krieg verursachten Bevölkerungsverlust gehen für Böhmen im Landesdurchschnitt von einem Drittel bis zu 40 Prozent des Vorkriegsstandes aus. ${ }^{7}$ Gegenüber den älteren Interpretationen hat Markus Cerman auf Basis einer Analyse von fünf böhmischen Herrschaften die Bedeutung des Dreißigjährigen Krieges als ausschließliche Erklärung des Bevölkerungsaufbaus von 1651 zurückgewiesen und betont, dass viele dieser Muster auch als Folgen von Migrationen bzw. von regionalen ökonomischen Besonderheiten gedeutet werden könnten. ${ }^{8}$

Die Zusammensetzung der ländlichen Bevölkerung der Herrschaft Vyšší Brod im Jahre 1651, wie sie anhand des Soupis poddaných sichtbar wird, zeigt überwie-

5 Vgl. die Zahlen bei: Maur, Gesinde, 124.

6 Vgl. etwa Fügedi, Demographic landscape, 47-58; Maur, Structure démographique, 29-98.

7 Vgl. Klima, Economy, 37; Hroch/Petran, Länder, 970; Hoensch, Geschichte.

8 Cerman, Bohemia, 168. 
gend Ähnlichkeiten mit den Ergebnissen aus anderen Regionen Böhmens, weist dennoch aber einige Besonderheiten auf. Die hohen Verheiratetenanteile und ein hoher Prozentsatz an (im Haus oder Haushalt mit lebenden) verheirateten Inwohnern finden sich in vielen Regionen Böhmens zu dieser Zeit. ${ }^{9}$ Die Altersstruktur von Kapličky - wie auch der gesamten Herrschaft Vyšší Brod sowie einiger anderer Gebiete Südböhmens - zeichnet sich im Jahre 1651 aber selbst im innerböhmischen Vergleich dieser Zeit durch außergewöhnlich geringe Anteile an alten Menschen aus (vgl. die Tabellen 2, 3 und 4).

Tabelle 2: Altersaufbau der Bevölkerung der Pfarre Kapličky im Jahr 1651

\begin{tabular}{lrrrrc}
\hline & \multicolumn{4}{c}{ Weiblich } & \multicolumn{2}{c}{ Männlich } \\
& $\mathrm{N}$ & $\%$ & $\mathrm{~N}$ & $\%$ & Gesamt-\% \\
\hline $10-19$ & 82 & 41,6 & 53 & 28,5 & 35,2 \\
$20-29$ & 69 & 35,0 & 53 & 28,5 & 31,9 \\
$30-39$ & 35 & 17,8 & 47 & 25,3 & 21,4 \\
$40-49$ & 9 & 4,6 & 17 & 9,1 & 6,8 \\
$50-59$ & 2 & 1,0 & 12 & 6,5 & 3,7 \\
$60+$ & 0 & 0,0 & 4 & 2,1 & 1,0 \\
\hline & 197 & 100,0 & 186 & 100,0 & $100,0(\mathrm{~N}=383)$ \\
\hline
\end{tabular}

Quelle: NA Praha, SM R 109/45.

Tabelle 3: Altersaufbau der Bevölkerung des Marktes Vyšší Brod im Jahr 1651

\begin{tabular}{lccccc}
\hline & Weiblich & \multicolumn{3}{c}{ Männlich } \\
& $\mathrm{N}$ & \multicolumn{1}{c}{$\%$} & $\mathrm{~N}$ & $\%$ & Gesamt-\% \\
\hline $10-19$ & 79 & 38,3 & 53 & 33,8 & 36,4 \\
$20-29$ & 62 & 30,1 & 32 & 20,3 & 25,9 \\
$30-39$ & 35 & 17,0 & 30 & 19,1 & 17,9 \\
$40-49$ & 20 & 9,7 & 29 & 18,5 & 13,5 \\
$50-59$ & 5 & 2,4 & 8 & 5,1 & 3,6 \\
$60+$ & 5 & 2,4 & 5 & 3,2 & 2,8 \\
\hline & 206 & 100,0 & 157 & 100,0 & $100,0(\mathrm{~N}=363)$ \\
\hline
\end{tabular}

Quelle: NA Praha, SM R 109/45.

9 Vgl. dazu die Daten aus anderen böhmischen Regionen bei: Cerman, Bohemia. 
Tabelle 4: Altersaufbau der Bevölkerung der Dörfer der Herrschaft Vyšší Brod im Jahr 1651

\begin{tabular}{lrrrrc}
\hline & \multicolumn{2}{c}{ Weiblich } & \multicolumn{2}{c}{ Männlich } \\
& $\mathrm{N}$ & $\%$ & $\mathrm{~N}$ & $\%$ & Gesamt-\% \\
\hline $10-19$ & 282 & 36,1 & 224 & 29,5 & 32,8 \\
$20-29$ & 260 & 33,2 & 192 & 25,3 & 29,3 \\
$30-39$ & 137 & 17,5 & 175 & 23,1 & 20,2 \\
$40-49$ & 65 & 8,3 & 90 & 11,9 & 10,1 \\
$50-59$ & 32 & 4,1 & 48 & 6,3 & 5,2 \\
$60+$ & 6 & 0,8 & 30 & 4,0 & 2,3 \\
\hline & 782 & 100,0 & 759 & 100,0 & $100,0(\mathrm{~N}=1541)$ \\
\hline
\end{tabular}

Quelle: NA Praha, SM R 109/45.

Anm. Eine Person wurde wegen fehlender Altersangabe ausgeschlossen. Die Tabelle beinhaltet alle Personen, die in den erhobenen Dörfern der Herrschaft wohnten; nicht berücksichtigt sind neben den beiden Marktorten der Herrschaft auch die Meierhöfe. Von den als im Jahre 1651 in den Meierhöfen lebenden verzeichneten 55 Personen war lediglich eine älter als 50 Jahre.

In der Herrschaft Vyšší Brod waren 1651 etwa zwei Drittel der verzeichneten Personen jünger als 30 Jahre. Trotz des Fehlens von Kindern unter zehn Jahren lag der Anteil der Personen im Alter von 60 oder mehr Jahren überall unter drei Prozent; würden auch die fehlenden Kinder hinzugerechnet werden, läge dieser Anteil noch weit deutlicher darunter. War diese Altersstruktur eine Folge des Dreißigjährigen Krieges?

Im Falle von Südböhmen ist die Quellenlage in mancher Hinsicht noch günstiger als in anderen Regionen Böhmens, da nicht nur für einige Gebiete die Zählung von 1651 erhalten geblieben ist, sondern darüber hinaus für einige wenige Orte auch Bevölkerungsverzeichnisse aus der Zeit vor dem Dreißigjährigen Krieg existieren. Auch wenn für keinen einzigen Ort (Süd-)Böhmens beide Verzeichnisse - die eine direkte Gegenüberstellung erlauben würden - erhalten sind, scheint ein Vergleich des Bevölkerungsaufbaus verschiedener südböhmischer Regionen vor und nach dem Krieg für die umstrittenen Thesen der durch den Krieg bedingten besonderen demographischen Struktur Böhmens im Jahre 1651 äußerst nützlich. Eine systematische Analyse und Gegenüberstellung der beiden Herrschaften Vyšší Brod und Chýnov im Jahre 1651 mit den drei Listen der Herrschaften Prachatice/ Prachatitz 1585, Třeboň/Wittingau 1586 und Libějovice/Libejitz 1607 zeigte bei zahlreichen demographischen Kennzahlen die hohen Ähnlichkeiten der beiden 
Perioden auf. ${ }^{10}$ Sowohl die Population des Jahres 1651 als auch die zu Ende des 16. Jahrhunderts lässt sich als extrem jung bezeichnen. Der Median des Alters (der Bevölkerung über 11 Jahre) lag in allen untersuchten Samples bei 25 Jahren außer in Prachatice, wo dieser bei 26 Jahren lag (Tabelle 5). Auch die Anteile der verschiedenen Altersgruppen zeigen keine signifikanten Differenzen zwischen den beiden Perioden (vgl. Tabelle 6). Von einer allgemeinen „Schwächung der jüngeren Jahrgänge" nach dem Krieg, wie von Hroch/Petran behauptet, ${ }^{11}$ kann nicht die Rede sein. Differenziert man nach den einzelnen Siedlungstypen innerhalb der Herrschaften, ergeben sich jedenfalls deutlichere Unterschiede als im diachronen Vergleich. Zum Teil war die dörfliche Bevölkerung im Durchschnitt deutlich jünger als diejenige der Städte und Marktorte.

Tabelle 5: Das Alter der Bevölkerung in südböhmischen Regionen des 16. und 17. Jahrhunderts (ab 12 Jahren)

\begin{tabular}{lccc}
\hline & Durchschnitt & Median & Anzahl \\
\hline Prachatice Stadt 1585 & 28,9 & 24 & 565 \\
Prachatice Vorstadt & 31,9 & 30 & 341 \\
Prachatice Dörfer & 27,3 & 23 & 131 \\
Třeboň Marktorte 1586 & 28,5 & 26 & 319 \\
Stadt Lomnice nad Lužnicí & 29,1 & 26 & 495 \\
Stadt Veselí & 29,7 & 27 & 366 \\
Třeboň Dörfer 1586 & 26,6 & 23 & 1.024 \\
Libějovice 1607 & 27,2 & 25 & 1.685 \\
Chýnov Markt 1651 & 30,9 & 28 & 166 \\
Ratibořské Hory Markt & 28,9 & 29 & 189 \\
Chýnov Dörfer & 26,6 & 25 & 1.080 \\
Vy̌ší Brod Markt 1651 & 28,0 & 26 & 347 \\
Hořice & 27,1 & 26 & 342 \\
Vy̌ší Brod Dörfer & 27,7 & 25 & 1.498 \\
\hline
\end{tabular}

Quelle: Grulich/Zeitlhofer, Lebensformen, 44.

Anm.: Da das Alter, ab dem Kinder verzeichnet waren, je nach Verzeichnis unterschiedlich war, wurden generell nur Personen ab einem Alter von 12 Jahren berücksichtigt. Der diachrone Vergleich bleibt dadurch gewährleistet. Die Städte Lomnice und Veselí waren Teil der Herrschaft Třeboň, Ratibořské Hory gehörte zur Herrschaft Chýnov.

10 Vgl. zum Folgenden ausführlich: Grulich/Zeitlhofer, Lebensformen.

11 Hroch/Petran, Krise, 98. 
Tabelle 6: Altersaufbau der Bevölkerung in südböhmischen Regionen des 16. und 17. Jahrhunderts

\begin{tabular}{lccccccc}
\hline & \multicolumn{2}{c}{ bis 24 Jahre } & \multicolumn{2}{c}{ 25-59 Jahre } & \multicolumn{2}{c}{60 und älter } & über 60 Jahre \\
& $\mathrm{m}$ & $\mathrm{f}$ & $\mathrm{m}$ & $\mathrm{f}$ & $\mathrm{m}$ & $\mathrm{f}$ & alle \\
\hline Prachatice Stadt 1585 & 44,4 & 57,8 & 49,2 & 38,7 & 6,4 & 3,5 & 4,8 \\
Prachatice Vorstadt & 33,1 & 37,0 & 60,0 & 58,7 & 6,9 & 4,3 & 5,6 \\
Prachatice Dörfer & 49,3 & 56,3 & 47,7 & 39,0 & 3,0 & 4,7 & 3,8 \\
Třeboň Marktorte 1586 & 37,8 & 36,6 & 58,0 & 61,7 & 4,2 & 1,7 & 2,8 \\
Lomnice nad Lužnicí & 41,7 & 46,7 & 55,2 & 46,3 & 3,1 & 7,0 & 5,3 \\
Veselí & 39,6 & 41,1 & 56,2 & 58,4 & 4,2 & 0,5 & 2,2 \\
Třeboň Dörfer 1586 & 50,4 & 53,4 & 47,6 & 44,6 & 2,0 & 2,0 & 2,0 \\
Chýnov Markt 1651 & 38,0 & 37,9 & 53,5 & 58,9 & 8,5 & 3,2 & $3,8^{*}$ \\
Chýnov Dörfer & 41,3 & 51,3 & 57,8 & 47,2 & 0,9 & 1,5 & $0,8^{*}$ \\
Ratibořské Hory Markt & 24,3 & 51,2 & 71,4 & 48,8 & 4,3 & 0,0 & $1,1^{*}$ \\
Vyšší Brod Markt 1651 & 44,8 & 51,8 & 51,9 & 46,7 & 3,3 & 2,5 & $2,0^{*}$ \\
Vy̌ší Brod Dörfer & 41,2 & 55,5 & 54,7 & 43,7 & 4,1 & 0,8 & $1,7^{*}$ \\
Hor̆ice & 39,8 & 51,8 & 59,0 & 48,2 & 1,2 & 0,0 & $0,4^{*}$ \\
\hline
\end{tabular}

* Der Anteil an der Gesamtbevölkerung wurde berechnet mit Hilfe eines geschätzten Prozentwertes für die fehlenden Kinder. Dabei handelt es sich um einen in der tschechischen Historiographie gebräuchlichen ,empirischen Erfahrungswert' für das Verzeichnis von 1651. Dieser geht von einem Anteil der Nicht-Kommunikanten an der Gesamtbevölkerung von 30,8 Prozent aus.

Quelle: Grulich/Zeitlhofer, Lebensformen, 44.

Auffallend ist der besonders geringe Anteil an alten Menschen (ab 60 Jahren) in allen bekannten südböhmischen Bevölkerungsverzeichnissen des 16. und 17. Jahrhunderts. Dies gilt für beide Geschlechter, besonders aber für die Frauen. Dieses Phänomen war keineswegs auf die Herrschaft Vyšší Brod in der Periode nach dem Dreißigjährigen Krieg beschränkt. Im Jahre 1651 fehlten in mehreren Orten (Hořice na Šumavě, Ratibořské Hory und in den Dörfern von Chýnov) alte Menschen beinahe völlig. Der Anteil der Frauen in den höheren Altersgruppen (Tabelle 7) war innerhalb Böhmens sehr unausgewogen: In einigen Gebieten bildeten sie die Mehrheit in dieser Altersgruppe, in anderen - wie in Vyšší Brod - bestand eine klare Dominanz der Männer. ${ }^{12}$

12 Ein deutliches Übergewicht der Männer wurde auch bereits bei Maur, Problémy demografické, 848 festgestellt. 
Auch die in einzelnen Alterskohorten signifikante Geschlechterproportion in der Periode nach dem Krieg war kein neues Phänomen. Der aus zahlreichen Studien für viele Regionen Böhmens im Jahre 1651 bekannte Frauenüberhang (zumeist etwa 80 bis 90 Männer auf 100 Frauen) $)^{13}$, der in der Altersgruppe der 15-29-Jährigen noch weit deutlicher war, bestand auch bereits im 16. Jahrhundert (vgl. Tabelle 7) und lässt sich überdies für einzelne Gebiete Böhmens auch noch mehrere Jahrzehnte nach dem Krieg nachweisen. ${ }^{14}$ Es handelt sich um ein Merkmal, das auch in anderen europäischen Regionen der vorindustriellen Zeit zu finden ist. ${ }^{15}$ Dies kann daher nicht, wie häufig behauptet wurde, mit der Abwesenheit von Männern, die 1651 noch außerhalb des Landes in Söldnertruppen gedient hätten, erklärt werden. ${ }^{16}$

Tabelle 7: Geschlechterproportion in südböhmischen Regionen des 16. und 17. Jahrhunderts (Anzahl der Männer auf 100 Frauen; nur Personen ab 12 Jahren)

\begin{tabular}{lrcc}
\hline & alle & 15-29 Jahre & 50 und älter \\
\hline Prachatice Stadt 1585 & 79,4 & 60,1 & 97,5 \\
Prachatice Vorstadt & 85,3 & 63,9 & 96,3 \\
Prachatice Dörfer & 104,7 & 90,9 & 116,7 \\
Třeboň Marktorte 1586 & 81,3 & 61,2 & 121,4 \\
Lomnice nad Lužnicí & 82,0 & 71,0 & 60,0 \\
Veselí & 85,8 & 70,5 & 136,4 \\
Třeboň Dörfer 1586 & 95,3 & 79,1 & 121,9 \\
Chýnov Markt 1651 & 74,7 & 88,1 & 91,7 \\
Ratibořské Hory Markt & 58,8 & 42,9 & 128,6 \\
Chýnov Dörfer & 100,0 & 84,4 & 125,0 \\
Vyšší Brod Markt 1651 & 77,9 & 46,8 & 130,0 \\
Hořice & 94,3 & 66,7 & 500,0 \\
Vyšší Brod Dörfer & 96,8 & 72,1 & 205,3 \\
\hline
\end{tabular}

Quelle: Grulich/Zeitlhofer, Lebensformen, 45.

Der vor wie nach dem Krieg durchgängig feststellbare stärkere Frauenüberhang in den Städten im Vergleich zu den Dörfern stellte ein allgemeines Kennzeichen vor-

13 Cerman, Bohemia, 159-161; Horský/Sedláčková/Seligová, demographisches Regime, 72-75.

14 Cerman, Bohemia, 160.

15 Vgl. etwa Schluchter, Gösgeramt, $57 \mathrm{f}$.

16 Fügedi, Demographic Landscape, 56; Maur, Problemy demografické, 849. 
industrieller Städte dar und ist auf die besseren Erwerbschancen für Frauen in den Städten zurückzuführen. In manchen Dörfern war die Geschlechterproportion dagegen beinahe ausgeglichen. Die für die Zeit vor dem Krieg ermittelten Werte mahnen zur Vorsicht gegenüber einer vorschnellen Interpretation der Auswirkungen des Krieges. In den Dörfern der Herrschaft Třeboň war der Altenanteil 1651 mit 3,3\% sogar höher als im Jahre $1586 .{ }^{17}$ Sicherlich stellt die auch von der tschechischen Historischen Demographie mehrfach betonte häufige Rundung der Altersangaben in den verwendeten Quellen (im Wesentlichen Vielfache von fünf und sechs) ein Problem dar, das bei der Interpretation berücksichtigt werden muss. ${ }^{18}$ Für die in den hier analysierten Samples festgestellten geringen Altenanteile bieten systematische Rundungen der Altersangaben (etwa auf 50 Jahre), wie dies für einzelne andere Gebiete betont wurde ${ }^{19}$, jedenfalls keine ausreichende Erklärung. In Prachatice 1585 lag der Bevölkerungsanteil der 50-Jährigen oder Älteren nur etwa bei zehn Prozent, in den Dörfern der Herrschaft Třeboň lag selbst dieser Anteil bei weniger als fünf Prozent. In einer Forschungszusammenfassung nannte Josef Ehmer als Ergebnis der allermeisten für West- und Nordwesteuropäische Regionen durchgeführten Studien zum Anteil der alten Menschen an der Gesamtbevölkerung in vorindustrieller Zeit einen Wert von 5-10\%. ${ }^{20}$ In den südböhmischen Gebieten wurden diese Anteile eindeutig nicht erreicht, und zwar weder vor noch nach dem Krieg. Auch für die Herrschaft Hluboká 1651 lag der entsprechende Wert nur bei 1,7\%. ${ }^{21}$ In den Dörfern der Herrschaft Třeboň war der Altenanteil 1651 mit 3,3\% sogar höher als im Jahre 1586.22 Es gibt Anzeichen dafür, dass die Anteile der älteren Bevölkerung in manchen Gebieten Südböhmens auch noch im 18. Jahrhundert deutlich unter

17 Berechnet nach: Jan Horský/Miloš Sládek, Rodinné, 86.

18 Vgl. dazu die systematischen Analysen des Bevölkerungsverzeichnisses von 1651 bei: Cerman/ Matušíková/Zeitlhofer, Rozbor.

19 So die These von Maur, der für das Jahr 1651 in vielen Herrschaften ebenfalls recht geringe Anteile der über 59jährigen fand, gleichzeitig aber für manche Gebiete recht hohe Anteile der über 49jährigen (zum Teil über 15\%) feststellen konnte, vgl. Maur, Populacní, 53; ders., Problémy demografické, 861.

20 Vgl. Ehmer, Sozialgeschichte, 205f. Auch für Jahr 1651 lassen sich in manchen Gebieten Böhmens relativ hohe Altenanteile feststellen, so etwa für die Herrschaft Dymokury mit einem Anteil von 9\%, vgl. Rumlová, Demografická, 198. Andererseits wiesen auch die ländlichen Regionen der beiden nordböhmischen Herrschaften Frýdlant und Liberec im Jahre 1651 lediglich einen Anteil der Bevölkerung von 60 Jahren oder mehr von 3,0 Prozent bzw. 3,1 Prozent auf. Quelle: Eigene Berechnungen auf Basis der Datensätze der Wiener Datenbank zur Familiengeschichte. Vgl. dazu auch Cerman, Bohemia.

21 Berechnet nach Čapek, Soupis obyvatel, 14.

22 Berechnet nach Horský/Sládek, Rodinné, 86. 
5 Prozent blieben. ${ }^{23}$ Dies wirft die Frage auf, ob die Lebenserwartung im frühneuzeitlichen Südböhmen deutlich geringer war als in anderen Gebieten Europas? Waren die Lebensbedingungen der Menschen hier vom 16. bis zum 18. Jahrhundert um so viel schlechter als anderswo? Diese Frage muss aufgrund des Fehlens entsprechender Quellen derzeit leider unbeantwortet bleiben.

Die geringen Unterschiede im Altersaufbau der Bevölkerungen vor und nach dem Dreißigjährigen Krieg bedeuten jedenfalls nicht, dass die Bevölkerungsverluste infolge des Krieges in dieser Region gering gewesen wären. An den verwendeten Quellen und Methoden der bisher vorliegenden Studien ist aber Kritik zu üben. Der bisherige Forschungsstand zum demographic impact of the war beruht weniger auf den Angaben des Soupis poddanych als vor allem auf dem um 1654 ebenfalls landesweit in Böhmen erhobenen ersten Steuerkataster (Berní rula), in dem neben den abgabepflichtigen Anwesen auch die verödeten Häuser angeführt wurden. Sehr viele Studien über das Ausmaß der demographischen Verluste durch den Dreißigjährigen Krieg beruhten, da Kirchenbücher aus dieser Zeit nur sehr selten erhalten sind, auf Schätzungen, die auf dem Anteil der im Jahr 1654 als verödet verzeichneten Häuser im Jahre 1654 basierten. ${ }^{24}$ Dieser Indikator wurde mit dem Multiplikator einer angenommenen durchschnittlichen Haushaltsgröße zum wahrscheinlichen Ausmaß des Bevölkerungsverlusts hochgerechnet. Ein Rückschluss von der Entwicklung der Zahl der bewohnten Häuser auf den Bevölkerungsrückgang kann aber in mehrfacher Hinsicht zu einer Fehleinschätzung führen:25 Damit ist nichts über die zahlenmäßige Entwicklung der in vielen $\mathrm{Ge}$ bieten sehr zahlreichen Familien ohne Hausbesitz ausgesagt. In einigen Herrschaften Südböhmens, darunter Třeboň und Chynov, gab es auch nach dem Krieg trotz vieler leer stehender Häuser zahlreiche landlose Inwohnerfamilien. ${ }^{26}$ Zweitens, ist auch ein Rückgang der Häuserzahl nicht notwendigerweise als Kriegsfolge zu interpretieren. Für České Budějovice/Budweis lässt sich zeigen, dass die Zahl der

23 Vgl. die Daten bei Dudáček, Age Structure, 116f für das Jahr 1753.

24 Vgl. etwa Placht, Lidnatost a společenská; Hoensch, Geschichte, 235.

25 Vgl. auch die Kritik an dieser Vorgangsweise bei: Theibault, Demography, 10. Eine ähnliche Kritik an einer Schätzung der Bevölkerungsverluste basierend auf Häuserzahlen am Beispiel von Niederösterreich bei: Landsteiner/Weigl, Krieg und lokale Gesellschaft, bes. 231f.

26 Für die Herrschaft Chýnov lässt sich feststellen, dass 165485 der 540 Häuser und Höfe (knapp 16 Prozent) leer standen, obwohl die drei Jahre zuvor erstellte staatliche Zensusliste etwa fünf Prozent der Gesamtbevölkerung als junge (unter 40 Jahre alte) verheiratete Inwohnerpaare ohne Land- und Hausbesitz ausgewiesen hatte. Quelle: Eigene Berechnungen auf Basis der in der ,Wiener Datenbank zur europäischen Familiengeschichte‘ vorliegenden maschinenlesbaren Datensätze (Soupis poddaných 1651 und Berní rula 1654). 
Häuser bereits einige Jahrzehnte vor dem Krieg rückläufig war ${ }^{27}$; für Böhmen insgesamt wird ein Bevölkerungsrückgang seit etwa 1600 angenommen. ${ }^{28}$ Ein weiterer Grund für die Ähnlichkeit der demographischen Strukturen in Südböhmen vor und nach dem Krieg liegt darin, dass auch die Periode des späten 16. Jahrhunderts nicht von Mortalitätskrisen verschont blieb. So hinterließ vor allem das Seuchenund Pestjahr 1582/83 auch in Südböhmen deutliche Spuren. ${ }^{29}$

Eine Berücksichtigung anderer Quellen zeigt, wie problematisch die Einschätzung der demographischen Folgen des Krieges ausschließlich auf Basis der in der Berní rula angegebenen Häuserzahlen ist. Nach der Zahl der,verödeten' Häuser im Jahre 1653/54 erscheint die Herrschaft Vyšší Brod, wie manch andere Region Südböhmens, als vom Krieg eher gering betroffen. ${ }^{30}$ 1653/54 waren hier nur 14 Anwesen (von insgesamt mehr als 800) als,verödet' angeführt, 1652 waren es noch 41 gewesen. Die höchste Zahl an unbewirtschafteten Anwesen war hier mit 77 Häusern bereits in der Mitte der 1630er Jahre zu verzeichnen. ${ }^{31}$ Die verödeten Häuser lagen aber überwiegend nicht im Zentralgebiet der Herrschaft, sondern weiter im Landesinneren. ${ }^{32}$ Aus mehreren für die Pfarre Kapličky erhaltenen Zählungen geht klar hervor, dass hier während des Dreißigjährigen Krieges jeweils nur einzelne bäuerliche Anwesen (vorübergehend) unbewirtschaftet blieben (Tabelle 8). 1654 gab es dagegen in der Pfarre keine verlassenen Anwesen mehr. ${ }^{33}$ Vereinzelt kam es in der Nähe von Kapličky sogar während des Krieges (in den 30er und 40er Jahren) zur Gründung von neuen, wenn auch sehr kleinen Ansiedlungen. ${ }^{34}$

27 Kropaček et al., Encyklopedie, 322.

28 Hroch/Petrán, Krise, 94; Placht, Lidnatost a společenská.

29 Petraň, Poddaný, 172, 175.

30 Die bei Slavik, Böhmens Beschreibung, 56, angeführten Zahlen deuten auf einen besonders geringen (bis keinen) Verödungsgrad in den dem Böhmerwald nahen Gebieten Südböhmens hin, wie etwa in den Orten Horní Plana/Oberplan und Chvalšiny/Kalsching. Zahlreiche wüste Häuser finden sich innerhalb Südböhmens dagegen in den weiter östlich und weiter im Landesinneren gelegenen Gebieten.

31 Kaindl, Zisterzienserstift Hohenfurt, 64.

32 So befanden sich unter den in den Jahren zwischen 1651 und 1653 insgesamt 29 neu errichteten Anwesen der Herrschaft (vgl. Tabelle 10) allein 15 im Marktort Hořice. Vgl. Kubíková, Panstvi Vyšší Brod, 201.

33 Vgl. Archiv Kláštera Vyšší Brod, Kart. č. 397, 5/3.

34 Vgl. Schmidt, Siedlungs-Geschichte, 41. 
Tabelle 8: Entwicklung der Häuserzahl der Dörfer und Weiler der Pfarre Kapličky

\begin{tabular}{lrrrrrrrr}
\hline & 1530 & 1623 & 1629 & 1643 & 1652 & $1653 / 54$ & 1682 & 1713 \\
\hline Kapličky & 13 & 10 & 11 & 15 & 13 & 11 & 15 & 21 \\
Mlýnská & $2(+1)$ & 2 & 2 & 3 & - & 2 & 3 & 3 \\
Adámky & 3 & 2 & 2 & 4 & 2 & 3 & 3 & 6 \\
Dobř́n & 7 & 6 & 6 & 6 & 7 & 6 & 6 & 8 \\
Hodoň & 7 & 5 & 6 & 8 & 7 & 6 & 9 & 10 \\
Krásná Pole & 6 & 6 & 5 & 7 & 7 & 6 & 7 & 7 \\
Lhota & 2 & 2 & 2 & 2 & 2 & 2 & 2 & 2 \\
Lipová & 5 & 5 & 5 & 6 & 5 & 5 & 5 & 8 \\
Martinkov & 5 & 5 & 5 & 5 & 5 & 5 & 5 & 5 \\
Mnichovice & 5 & 5 & 5 & 5 & $2(+3)$ & 5 & 5 & 6 \\
Hvězda & - & - & - & 3 & - & 3 & 3 & 3 \\
Frantoly & 7 & 7 & 7 & 7 & 8 & 7 & 7 & 7 \\
\hline Vyš́na & 5 & 5 & 5 & 5 & 5 & 6 & 6 & 8 \\
Nové & - & - & - & - & - & - & - & 9 \\
Domky & & & & & & & & \\
\hline Summe: & 68 & 60 & 61 & 76 & 66 & 67 & 76 & 103 \\
\hline
\end{tabular}

Quellen: NA Praha, BR 2, BR 30, TK 684; Archiv Kláštera Vyšší Brod, kart. 397, Publ. 5/2 und 5/3; Archiv Kláštera Vyšší Brod, kniha č. 237; Schmidt, Urbar.

Anmerkung: Nové Domky wurde erst 1690 gegründet; Hvězda etwa um 1610. Die Siedlung Hřbítek zählte im Untersuchungszeitraum noch zu Kapličky. Mlýnská wurde 1652 offenbar bei Kapličky mitgezählt. Das ebenfalls zur Pfarre gehörige Haus in Loučovice (im frühen 18. Jahrhundert: zwei) ist in manchen Quellen nicht erwähnt und wurde hier daher jeweils nicht berücksichtigt

Für 1713 sind auch die im Besitz der Gemeinde befindlichen, bewohnten Häuser genannt. Zahlen in Klammer beziehen sich auf gerade leer stehende Anwesen. Der 1530 und 1643 ebenfalls verzeichnete Pfarrhof wurde nicht gewertet.

Dennoch kann nicht behauptet werden, dass das Zentralgebiet der Herrschaft von Sterbewellen verschont blieb. In den Sterbematriken der Pfarre Vy̌šš Brod, die bereits seit 1622 - allerdings mit Lücken in den Jahren zwischen 1624 und 1631 sowie zwischen 1634 und 1638 - geführt wurden, sind für die Jahre 1640 und 1649 jeweils etwa doppelt so viele Todesfälle wie in den anderen Jahren der vierten und fünften Dekade des 17. Jahrhunderts verzeichnet. ${ }^{35}$ Eine noch weitaus heftigere Mortalitätskrise

35 Berechnet nach: SOA Třeboň, Sbírka jihočeských matrik, Farní úřad Vy̌̌ší Brod č. 2. Auch in den 
dürfte es aber bereits im Jahre 1625 gegeben haben, von der die Region um Vyšší Brod sicherlich auch betroffen war. Nachweisbar ist dies anhand der einzigen aus diesen Jahren für Südböhmen erhaltenen Sterberegister (seit 1624) für die nahe Kleinstadt Rožmberk/Rosenberg an der Moldau. 1625 sind in dieser nach ihrer Einwohnerzahl vermutlich mit Vyšší Brod vergleichbaren Pfarre 278 Todesfälle verzeichnet. Alleine im August dieses Jahres wurden 71 Personen begraben; im Juli 40 und im September 55. Für die relativ kleine Pfarre bedeutete dies sicherlich einen immensen Bevölkerungsverlust. In anderen Phasen des 17. Jahrhunderts waren dagegen in Rožmberk häufig nur 30 bis 40 Menschen pro Jahr zu Grabe getragen worden. ${ }^{36}$ Zwar fehlen die Sterbematriken aus dieser Zeit in allen anderen Pfarren Südböhmens, wir können aufgrund der Dimension dieser demographischen Krise dennoch mit Sicherheit davon ausgehen, dass diese auch andere Regionen - wie etwa die nahe Herrschaft Vyšší Brod - nicht unberührt ließ. Die Ursache der hohen Sterblichkeit in diesen Jahren dürfte das Auftreten der Pest gewesen sein. Die Jahre 1625 und 1626 werden für Böhmen allgemein als Pestjahre beschrieben. ${ }^{37}$ Auch für Chvalšiny im Böhmerwald wird 1625 vom Auftreten der Pest gesprochen. ${ }^{38}$ Die Ausbreitung der Pest darf wohl als Folge der Kriegswirren dieser Zeit gesehen werden.

Mehrfach war die Region um Vyšší Brod und Kapličky von Soldaten geplündert und verwüstet worden. In den Jahren 1624 und 1625 wurde Vyšší Brod von mehreren durchziehenden Regimentern geplündert, wobei auch das Kloster in Brand gesetzt und die Brunnen und Wasserleitungen des Ortes zerstört wurden. 1645 wurde der Ort nochmals von schwedischen Truppen geplündert. Kapličky war im Jahre 1627 von im nahen österreichischen Bad Leonfelden stationierten bayerischen Truppen massiv verwüstet worden. Das ebenfalls nahe gelegene Přední Výtoň wurde noch im Jahre 1648 Opfer von durchziehenden plündernden Truppen. ${ }^{39}$ Ebenso muss die unmittelbare Nachkriegszeit für dieses Gebiet als sehr schwierig bezeichnet werden. Patrimoniale Quellen sowie die Grundbücher zeigen, dass in den ersten Jahren nach dem Krieg Armut, Hunger und eine zum Teil

Matriken der Pfarre Rožmberk ist eine Sterblichkeitsspitze um 1650 zu erkennen. Für das nahe Gebiet des oberösterreichischen Stiftes Schlägl wird für 1649/50 vom Auftreten der Pest mit zahlreichen Toten berichtet. Vgl. Pröll, Schlägl, 259; Wasmayr, Ulrichsberg, 421.

36 Für die Überlassung der Daten zur Pfarre Rožmberk danke ich Josef Grulich. Vgl. auch die Erwähnung dieser Krise bei: Waltenberger, Rosenberg, 106f. Im Jahre 1713 gab es in Rožmberk zirka 1.500 Kommunikanten, demnach also etwa 1.700 bis 1.800 Einwohner. Quelle: NA Praha, APA I, sign. B14/22, fol. 125 .

37 Vgl. Dokupil/Fialová/Maur/Nesládková, Přirozená, 65. Von einer Seuche im Jahre 1625 wird auch für Wien berichtet. Vgl. Weigl, Residenz, 65.

38 Vgl. Schläger, Kalsching, 28.

39 Gottsmich/Pils, Hohenfurt, 19, 36. 
massive Verschuldung unter der Haus und Grund besitzenden Bevölkerung sehr weit verbreitet waren. Zahlreiche Bauern waren gezwungen, ihre Höfe bereits nach wenigen Jahren wieder aufzugeben. Mathias Stockinger etwa, Inhaber der Taverne von Kapličky sowie eines dazugehörigen kleinen bäuerlichen Anwesens im Ausmaß von zehn böhmischen Strich (etwas mehr als vier Hektar) Ackerland, musste zwischen Mitte Mai und Mitte August 1649 von der Verwaltung des Klosters immer wieder mit Brot versorgt werden. ${ }^{40}$

Graphik 1: Durchschnittliche jährliche Zahl der Taufen, Begräbnisse und Eheschließungen pro Dekade, Pfarre Vyšší Brod 1610-1699

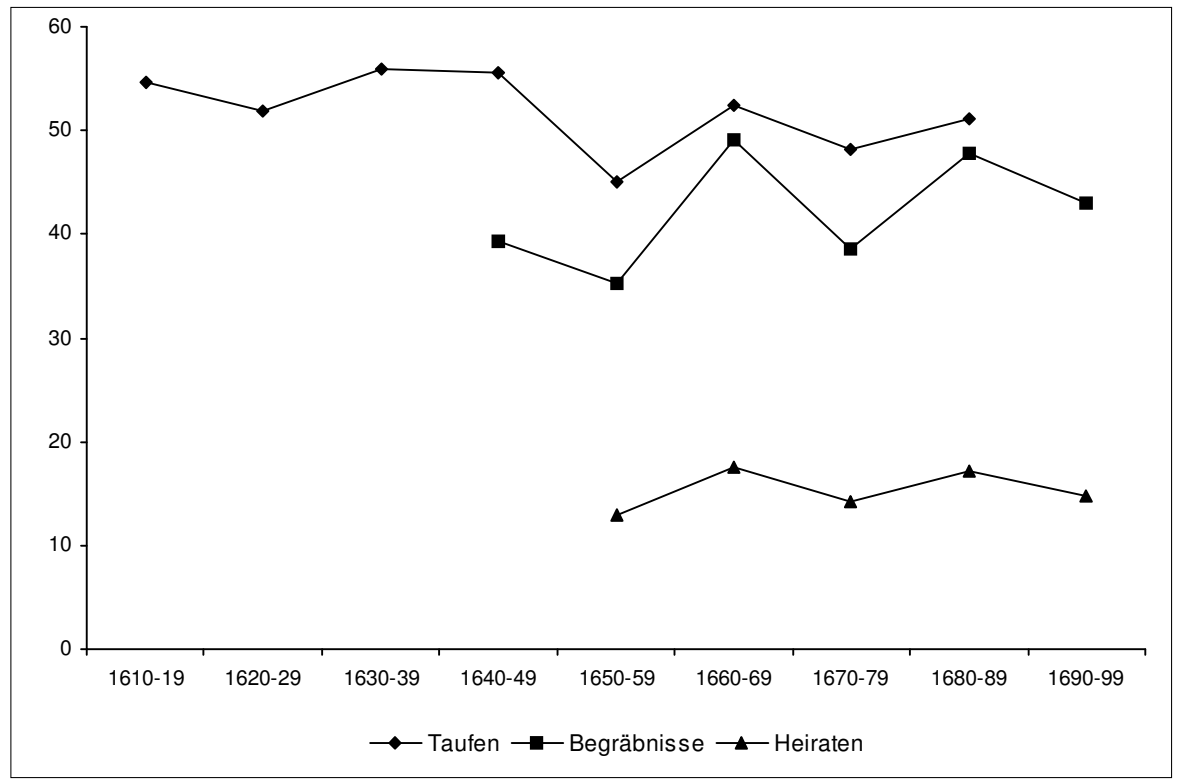

Quelle: SOA Třeboň, Sbírka jihočeských matrik, Farní úřad Vyšší Brod, kniha č. 2 und č. 3.

Anm.: Bei den Taufeinträgen wurde aufgrund der Lücke zwischen 1696 und 1699 (keinerlei Einträge) für die 1690er Jahre kein Durchschnitt ermittelt. Die Sterbeverzeichnisse sind vor 1639 nur für einzelne Jahre erhalten. Der Durchschnittswert für die Heiraten der 1650er Jahre bezieht sich quellenbedingt nur auf die Jahre 1654-59.

Die Matriken der Pfarre Vy̌ší Brod, die - soweit vorhanden - für das 17. Jahrhundert aggregativ ausgewertet wurden (Graphik 1), zeigen eine Häufung über-

40 Dies wurde im Grundbuch mit der Anmerkung, so das closter künfftig ein zunehmen 4fl.48x' festgehalten. Quelle: SOA Třeboň, fond C Vyšší Brod, PK č. 453, fol. 164. 
durchschnittlich geburtenstarker Jahre in den Perioden 1637-40 und 1644/45 bzw. $1647 / 48$. Dieser Befund fügt sich gut zum bereits erwähnten geringen Durchschnittsalter der Bevölkerung im Jahre $1651 .{ }^{41}$ Der in der Graphik vermittelte Eindruck einer in den letzten Jahrzehnten des Jahrhunderts stagnierenden Zahl an jährlichen Geburten ist ungewöhnlich und könnte bei aller Vorsicht als Folge des wieder deutlich steigenden Durchschnittsalters potenzieller Eltern gedeutet werden.

Das bisher nur in sehr groben Zügen rekonstruierbare Bild der demographischen Situation im südlichen Böhmerwald während und nach dem Ende des Dreißigjährigen Krieges zeigt, dass die Entwicklung der Zahl bewohnter und bewirtschafteter Häuser und Höfe als isolierte Quelle nur ein sehr unsicherer Indikator für den demographic impact des Krieges ist, der auch eine deutliche Fehleinschätzung der Bevölkerungsverluste durch den Krieg bewirken kann. Hohe Sterblichkeitsratsraten, verursacht wohl durch das Auftreten der Pest, konnten signifikante demographische Auswirkungen haben - wie eine sehr junge Altersstruktur im Jahr 1651 (vgl. Tab. 6) -, ohne dass es deshalb zu einem hohen Anteil völlig verlassener und leerstehender Anwesen kommen musste. In anderen Gebieten wiederum scheinen die Verluste an Menschen geringer gewesen zu sein als es die überlieferten Zahlen an verödeten Hofstellen vermuten lassen. ${ }^{42}$ Es bedarf demnach einer neuen Einschätzung der durch den Krieg und dessen Begleiterscheinung verursachten demographischen Verluste in Böhmen. Wenn in manchen Regionen Zentraleuropas noch Jahrzehnte später zahlreiche Bauernhöfe unbewirtschaftet waren, wie dies in manchen Gebieten Böhmens und Bayerns der Fall war, ist dies nicht unbedingt als direkte Kriegsfolge zu interpretieren, sondern könnte auch verschiedene andere Ursachen haben. ${ }^{43}$ Zukünftige Studien sollten in ihrer Beurteilung wesentlich vorsichtiger sein und trotz der Existenz der beiden außergewöhnlichen landesweiten Quellen aus der Mitte des 17. Jahrhunderts weitere Quellen nicht ignorieren. ${ }^{44}$

Graphik 1 zeigt außerdem, dass das hohe Bevölkerungswachstum der zweiten Hälfte des 17. Jahrhunderts jedenfalls zu einem Gutteil auf kontinuierlich hohe

41 In jedem einzelnen dieser acht Jahre waren zumindest 60 Taufen zu verzeichnen. Für die Pfarre Kapličky ließen sich solche Berechnungen nicht durchführen, da der Familienkataster aggregative Auszählungen nicht erlaubt. Ein Blick in die Originalmatriken der Pfarre bestätigt aber die starke Präsenz junger Ehepaare mit vielen Kindern im Jahre 1651. Die 1640er Jahre waren durch deutlich höhere Trauungsziffern als die nachfolgenden Jahre gekennzeichnet. In den sieben Jahren vor dem Bevölkerungsverzeichnis 1651 (1644-1650) gab es 39 Eheschließungen, in den danach folgenden sieben Jahren dagegen nur 32. Vgl. SOA Třeboň, Sbírka jihočeských matrik, Farní úřad Kapličky č. 1.

42 So die Argumentation bei Roeck, Bayern, 440f.

43 So auch die Einschätzung von Schlögl, Bauern, 113.

44 Vgl. auch Cerman/Maur, Entwicklung, bes. $107 \mathrm{ff}$. 
Geburtenüberschüsse zurückgeführt werden kann. In keiner Dekade übertraf die Zahl der Sterbefälle diejenige der Geburten. Dieses Ergebnis steht im Einklang mit dem bereits häufig auf überregionaler Ebene festgestellten - in den nördlichen Landesteilen übrigens noch deutlicher als in den südlichen -besonders starken demographischen Wachstum in Böhmen während der zweiten Hälfte des 17. Jahrhunderts. ${ }^{45}$ In Vyšší Brod fielen mehrere besonders geburtenstarke Jahre (mit jährlich zumindest 60 Taufen) noch in die Spätphase des Dreißigjährigen Krieges (so die Jahre: 1637-40, 1644,1645, 1647 und1648). Auch in den Jahren 1657, 1658 sowie 1666, 1684 und 1690 wurde jeweils der Wert von 60 Taufen überschritten. ${ }^{46}$ Insgesamt sollten die in der Graphik ausgewiesenen Zahlen aber ohne weitere vertiefende Studien nicht überbewertet werden.

\subsection{Sozialstruktur und Grundbesitz nach dem Dreißigjährigen Krieg: das Bild der staatlichen Kataster}

Zur Mitte des 17. Jahrhunderts, zur Zeit der Anlage der böhmischen Steuerrolle (Berní Rula) in den Jahren 1653/54, stellte sich die Pfarre Kapličky als überaus ,bäuerlich' geprägte Gesellschaft dar, die aber dennoch eine differenzierte Sozialstruktur aufwies. 82 Prozent der verzeichneten Anwesen der Pfarre wurden als ,bäuerlich' bezeichnet, nur ganz wenige Häuser dagegen den Kategorien für kleinund unterbäuerliche Anwesen (Chalupner und Gärtner ${ }^{47}$; ab 1682 auch: Häusler) zugewiesen. Ganz ähnlich war das Bild auch noch zur Zeit der sogenannten, Revisitation' im Jahre 1682 - die gleichsam den Versuch einer Neufassung des Katasters von 1653/54 darstellt (vgl. Tabelle 9). Erstmals sind 1682 auch die weitgehend landlosen Häusler verzeichnet.

45 Vgl. etwa Maur, Gutsherrschaft; Cerman/Maur/Zeitlhofer, Wirtschaft; Cerman, Bohemia. Mortalitätskrisen hatten ein regional sehr differenziertes Verbreitungsgebiet. Beispielsweise trat die Pest in der Zeit um 1680 in verschiedenen Orten Südböhmens, wie in Hořice oder Oberhaid, oder auch in Niederösterreich und im oberösterreichischen Mühlviertel teilweise sehr massiv auf. In Vy̌š̌i Brod, Kapličky oder etwa in Český Krumlov ist diese anhand der Zahl der Sterbefälle dagegen ebenso wenig nachweisbar wie in Nordost-Böhmen. Vgl. Essl, Krummau, 352, 431; Grüll, Pergkirchen, 134; Sandgruber, Leben und Lebensstandard, 172f.; Dokupil, Gebietssterblichkeit, 84.

46 Die Zahl von 81 Geburten des Jahres 1612 wurde im 17. Jahrhundert nie wieder erreicht.

47 ,Chalupner' und,Gärtner' stellen in Böhmen während der frühen Neuzeit häufig anzutreffende soziale Kategorien für kleinbäuerliche und landarme Anwesen dar. Anders als ,Gärtner' war, Chalupner' ein auch im südlichen Böhmerwald gebräuchlicher Terminus, der im Laufe des 18. Jahrhunderts aber allmählich verschwindet. 
Tabelle 9: Sozialstrukturelle Differenzierung in der Pfarre Kapličky 1653/54 und 1682 (Quellenkategorien)

\begin{tabular}{lccccc}
\hline & & 1654 & & & 1682 \\
& $\mathrm{~N}$ & $\%$ & $\mathrm{~N}$ & $\%$ \\
\hline Bauern & 55 & 82,1 & 55 & 72,4 \\
Chalupner & 7 & 10,4 & 8 & 10,5 \\
Gärtner & 5 & 7,5 & 9 & 11,8 \\
Häusler & - & 0,0 & 4 & 5,3 \\
\hline Summe & 67 & 100,0 & 76 & 100,0 \\
\hline
\end{tabular}

Quelle: NA Praha, BR 2; BR 30, fol. 271-279.

Anm: Der Theresianische Kataster von 1713 nennt für diese Herrschaft keine sozialen Kategorien und kann daher diesbezüglich nicht ausgewertet werden.

Ganz ähnlich wie in Kapličky war die Verteilung der sozialen Kategorien auch in den anderen Dörfern der Herrschaft Vyšší Brod: Beinahe drei Viertel der verzeichneten Güter der gesamten Herrschaft wurden nach den summarischen Angaben der Berní Rula im Jahre 1653/54 als bäuerlich bezeichnet, etwa 15 Prozent als Gärtner und weniger als 10 Prozent als Chalupner. Lediglich unter den wenigen in den letzten Jahren vor der Erhebung neu errichteten Anwesen war der Anteil der unterbäuerlichen Gruppen deutlich stärker (vgl. Tabelle 10).

Tabelle 10: Differenzierung der Anwesen nach sozialer Kategorie in der Berní Rula, Herrschaft Vyšší Brod 1653/54

\begin{tabular}{lrrcc}
\hline & $\mathrm{N}$ & $\%$ & $\begin{array}{c}\text { Davon seit 1651 } \\
\text { neu angesiedelt }\end{array}$ & Noch wüst \\
\hline Bauern & 617 & 76,2 & 14 & 10 \\
Chalupner & 70 & 8,6 & 3 & 2 \\
Gärtner & 123 & 15,2 & 12 & 2 \\
\hline Summe & 810 & 100,0 & 29 & 14 \\
\hline
\end{tabular}

Quelle: NA Praha, BR 2, fol. 871.

Anm.: Diese Auswertung bezieht sich auf das gesamte Herrschaftsgebiet; auch die beiden Marktorte sind inkludiert.

Die Tendenzen zu einer sozialen Polarisierung der lokalen Gesellschaft erscheinen in diesem Gebiet im Vergleich mit anderen Regionen Böhmens im 17.Jahrhundert als sehr gering. Für zahlreiche andere Herrschaften Böhmens vermitteln die staatlichen Kataster dagegen ein völlig gegensätzliches Bild der sozialstrukturellen Dif- 
ferenzierung. Insbesondere in einigen Gebieten Nordböhmens war die ländliche Sozialstruktur sehr früh von den unterbäuerlichen und landarmen/-losen Bevölkerungsgruppen der Chalupner und Gärtner geprägt. Zum Teil bildeten die landarmen Anwesen zur Mitte des 17. Jahrhunderts dort bereits eine deutliche Mehrheit der untertänigen Bevölkerung. In den Dörfern der Herrschaften Frýdlant und Liberec etwa stellten im Jahre 1654 die Bauern (im Vergleich zu den Chalupnern und Gärtnern) jeweils weniger als 30 Prozent aller Anwesen. ${ }^{48}$ In einzelnen Regionen Böhmens waren die unterbäuerlichen Anwesen selbst im 14. Jahrhundert bereits gegenüber den Bauern in der Mehrzahl gewesen. ${ }^{49}$ Manchmal wird ein hoher Anteil an landarmer oder landloser Bevölkerung auch als Kennzeichen der ,ost-elbischen Gutsherrschaftsregionen' der frühen Neuzeit gewertet, da die Gutsherrschaft selbst oft einen hohen Bedarf an Lohnarbeitern hatte. ${ }^{50}$ Umso erstaunlicher erscheint daher zunächst die starke Dominanz der Bauern in der Herrschaft Vyšší Brod.

Innerhalb Südböhmens dagegen war Vyšší Brod sicherlich keine Ausnahme. Ganz ähnlich stellte sich die Verteilung der sozialen Gruppen in zahlreichen anderen Gebieten der Region dar. In den Herrschaften Chýnov ${ }^{51}$ und Zlatá Koruna ${ }^{52}$ zählten im Jahr 1654 jeweils etwa zwei Drittel der Häuser zu den Bauern; etwa ein Viertel waren Gärtner und jeweils knapp mehr als 10 Prozent wurden als Chalupner bezeichnet. Im zur Herrschaft Český Krumlov gehörigen Marktort Černá wurden 16 Bauern, aber nur zwei Gärtner genannt. ${ }^{53}$ Eine sehr deutliche Dominanz der bäuerlichen Anwesen lässt sich in dieser Region außerdem auch in früherer Zeit auf der Basis patrimonialer Quellen belegen. Das Urbar der Vyšší Brod benachbarten Herrschaft Rožmberk aus dem Jahre 1598 nannte neben 719 „Hausgesessenen“ lediglich 114 Chalupner und einzelne Inleute. ${ }^{54}$ Während des 17 . Jahrhunderts war innerhalb Südböhmens die sozialstrukturelle Differenzierung - abgesehen von den Marktorten ${ }^{55}$ - offenbar nur in den wenigen, zu dieser Zeit bereits bestehenden

48 Vgl. Cerman, Diss. und Cerman, Klassenstruktur, 217; Cerman/Štefanová, Wirtschaft, 75; Štefanová, Erbschaftspraxis, 34 .

49 Cerman, Ursprünge, bes. 350 .

50 Melton, Gutsherrschaft, $334 f$.

51 Grulich, Aspekte, 23f.

52 Vgl. Kubíková, Panstvi Vy̌šś Brod, 206.

53 Doskočil, Berní rula, 61.

54 Schmidt, Urbar Rosenberg, 429.

55 Auch die meisten Anwesen wohl aller Marktorte Südböhmens waren nicht gänzlich vom agrarischen Kontext losgelöst. Die allermeisten Häuser hatten auch landwirtschaftlichen Besitz. Trotzdem waren die Bestiftungen hier kleiner als in den Dörfern, sodass zumeist die unterbäuerlichen Gruppen zahlenmäßig überwogen. In Vyšší Brod etwa standen 1653/54 den 21 Bauern 63 Chalupner und Gärtner gegenüber; in Hořice waren es ebenfalls 21 Bauern und 35 Chalupner und Gärtner. Vgl. Kubíková, 
Holzfällersiedlungen des Böhmerwaldes signifikant anders. Nur in solchen Orten finden sich hohe Anteile an landarmen Häusern. In der der Pfarre Kapličky unmittelbar benachbarten, aber zur Herrschaft Český Krumlov gehörigen Ansiedlung Přední Výtoň (in den Verzeichnissen des 17. Jahrhunderts wird dieser Ort noch „Waldt- und Holtzknecht“ genannt) etwa wurden 1654 nur fünf Bauern, aber 18 Gärtner, angeführt. Im Jahr 1682 dann fünf Chalupner und 18 Gärtner. ${ }^{56}$ Auch in der weiter westlich anschließenden, von proto-industrieller Leinenweberei geprägten Pfarre Rychnůvek bildeten die unterbäuerlichen Anwesen im 17. Jahrhundert eine Mehrheit. ${ }^{57} \mathrm{Im}$ weiter nordwestlich im Böhmerwald gelegenen Ort Kašperské Hory (Bergreichenstein) im heutigen Bezirk Klatovy (Klattau) stellten im Jahr 1654 die Gärtner mit 56 der 104 verzeichneten Häuser die Mehrheit. ${ }^{58}$

Die für die Mitte des 17. Jahrhunderts innerhalb Böhmens erkennbaren deutlichen großräumigen Unterschiede in der quantitativen Stärke der landarmen Bevölkerungsgruppen zwischen den ,südlicheren' und den ,nördlicheren' Kreisen Böhmens blieben - trotz eines überall beobachtbaren Anwachsens der landarmen Bevölkerungsgruppen - auch im 18. Jahrhundert bestehen, wie die verschiedenen Erhebungen im Zuge der Erstellung des Theresianischen Katasters zeigen. ${ }^{59}$

Die sozialen Kategorien sagen noch nichts über die Größe der landwirtschaftlichen Betriebe aus. Insbesondere Rainer Beck hat am bayerischen Beispiel sehr anschaulich gezeigt, wie sehr sich in einer frühneuzeitlichen ländlichen Bevölkerung die Besitzgrößenverteilung und die zeitgenössische soziale Terminologie im Laufe der Zeit in unterschiedliche Richtungen entwickeln konnten und schließlich kaum mehr Übereinstimmungen aufwiesen. ${ }^{60}$ Einen Anhaltspunkt für die Größe der Anwesen können die in den Katastern genannten Angaben zur Aussaat der einzelnen Anwesen (die in böhmischen Strich angegeben sind) geben. ${ }^{61}$ Die Verteilung der Aussaatzahlen des Jahres 1654 zeigt - trotz der Ungenauigkeiten durch die feststellbaren Tendenz zur Rundung der Angaben, wie die Häufungen der Fall-

Panstvi Vyšší Brod, 201. In Horní Plana gab es neben 19 Bauern 43 Chalupner und Gärtner. Quelle:

Doskočil, Berní Rula, 60.

56 NA Praha, BR 2, fol. 702f., BR 30, fol. $100 f$.

57 In den Jahren 1653/54 wurden 67 Bauern, 66 Chalupner und 26 Gärtner sowie acht leer stehende ehemals bäuerliche Anwesen verzeichnet. Quelle: Doskočil, Berní Rula, 61f. Im Jahr 1682 finden sich dagegen: 88 Bauern, 69 Chalupner und 26 Gärtner. Vgl.: NA Praha, BR 2, fol. 86-101. Demnach waren hier in der zweiten Hälfte des 17. Jahrhunderts weitere Grund besitzende Anwesen hinzugekommen, während die Zahl der landarmen Anwesen stagnierte.

58 Blau, Kreuz, 255.

59 Vgl. dazu Cerman/Maur, Entwicklung, bes. 106f.

60 Beck, Unterfinning, $224 \mathrm{ff}$.

61 Ein böhmischer Strich entsprach etwa $2.850 \mathrm{~m}^{2} ; 3,5$ böhmische Strich sind somit ca. einem Hektar gleichzusetzen. 
zahlen bei 18 und 21 Strich zeigen - für die Pfarre Kapličky eine graduelle und keine schroffe Abstufung in den Besitzgrößen der einzelnen Häuser (Tabelle 11). ${ }^{62}$ Trotz der nominell sehr starken Dominanz der,Bauern' waren die landwirtschaftlichen Betriebseinheiten von recht unterschiedlicher Größe. In den Dörfern der Herrschaft Vyšši Brod wiesen die Bauern eine Aussaatfläche zwischen sieben und 39 böhmischen Strich ${ }^{63}$ auf, die Chalupner hatten zwischen drei und zehn Strich und die Gärtner weniger als drei Strich. Innerhalb der Grund besitzenden und selbst innerhalb der als ,Bauern' bezeichneten Anwesen gab es damit recht deutliche Unterschiede. Dagegen wurden in nordböhmischen Herrschaften prinzipiell nur Anwesen ohne Aussaat als Gärtner klassifiziert. ${ }^{64}$

In der Pfarre Kapličky verfügte im Jahr 1654 kein einziges Haus über mehr als 10 Hektar Ackerland. Der höchste angegebene Wert belief sich auf 30 Strich Aussaat (ca. 8,6 Hektar). Von den 67 Anwesen, die im Steuerkataster aufscheinen, bewirtschafteten 39 (58 Prozent) zwischen fünf und zehn Hektar Ackerland (ab 18 Strich), 23 (34,5 Prozent) zwischen zwei und fünf Hektar und fünf Anwesen (7,5 Prozent) weniger als ein Hektar Ackerland. Die Differenzierung innerhalb der Grund besitzenden Güter war ausgeprägt, im Vergleich mit manchen anderen Regionen Böhmens gab es allerdings keine sehr großen bäuerlichen Betriebe. In der Region überwog eindeutig eine kleinbetriebliche landwirtschaftliche Struktur, während in zahlreichen anderen Regionen Böhmens laut den Angaben der Berní Rula häufig auch deutlich größere landwirtschaftliche Anwesen anzutreffen waren. ${ }^{65}$ Auffällig ist, dass es in Kapličky überhaupt keine Anwesen mit einer Aussaat in der Größenordnung zwischen drei und sieben Strich (zwischen einem und zwei Hektar) gab, auch in den anderen Dörfern der Herrschaft kamen Wirtschaften dieser Größenordnung nur sehr selten vor. Aus diesen Angaben zur Getreideaussaat lässt sich erkennen, dass das in der Region vertretene Spektrum der Grundbesitzgrößen einerseits von Landbesitz, der ausreichte, eine Familie davon zu ernäh-

62 Die auffällige Häufung einzelner Werte in der Tabelle zeigt, dass es sich bei diesen Angaben nur um grobe Schätzungen handelt.

63 Allerdings verfügten nur elf der insgesamt 160 verzeichneten Häuser mit Grundbesitz über mehr als 30 Strich; nur eines davon wies 39 Strich auf. Etwa die Hälfte der genannten größeren Anwesen der Herrschaft lagen im kleinen Dorf Těchoraz (Zichraß) südöstlich von Vyšší Brod. Der größte Hof der Herrschaft dürfte aber die Einschichte Mörixhof (gelegen in der ansonsten zur Herrschaft Rožmberk gehörigen Pfarre Frymburk) gewesen sein. 1713 verfügte dieser über 12, 6 Hektar Ackerland und hielt unter anderem fünf Ochsengespanne und ein Pferd. Vgl. NA Praha, TK 684, fol. 113. Der Hof lag an einem dem Kloster gehörigen Fischteich.

64 Cerman, Klassenstruktur, 224. Dagegen wurden im Marktort Vyšší Brod selbst einzelne Häuser mit weniger als drei Strich noch zu den Chalupnern gerechnet.

65 Vgl. etwa Matušíková, Entwicklung, 63f. Siehe auch: Cerman, Klassenstruktur, 225; Cerman/Maur, Entwicklung. 
ren, über Besitzgrößen, die eine Nebenbeschäftigung erforderlich machten, bis zu einer nur minimalen Landausstattung der Häuser reichte.

Tabelle 11: Verteilung der gesamten Aussaat, Pfarre Kapličky 1653/54

\begin{tabular}{ccc}
\hline Aussaat in Strich & Anzahl der Anwesen & kumulative Prozent \\
\hline 0,0 & 1 & 1,5 \\
0,5 & 3 & 6,0 \\
2,0 & 1 & 7,5 \\
7,0 & 5 & 14,9 \\
8,0 & 2 & 17,9 \\
9,0 & 1 & 19,4 \\
10,0 & 1 & 20,9 \\
10,5 & 1 & 22,4 \\
12,0 & 1 & 23,9 \\
13,0 & 2 & 26,8 \\
15,0 & 4 & 32,8 \\
16,0 & 6 & 41,8 \\
18,0 & 12 & 59,7 \\
19,0 & 2 & 62,6 \\
20,0 & 2 & 65,6 \\
21,0 & 10 & 80,6 \\
22,0 & 1 & 82,1 \\
23,0 & 1 & 83,6 \\
24,0 & 2 & 86,5 \\
25,0 & 1 & 88,0 \\
27,0 & 2 & 91,0 \\
30,0 & 67 & 100,0 \\
\hline Summe & &
\end{tabular}

Quelle: NA Praha, BR 2, fol. 822-828.

Beinahe alle im Jahre 1654 verzeichneten Anwesen der Pfarre Kapličky verfügten außerdem über Zugvieh (drei Viertel der Häuser hatten sogar mindestens zwei Gespanne an Ochsen). Am oberen Ende des sozialen Spektrums standen einige Anwesen mit drei Ochsengespannen, ein einziges hatte vier. Das Zugvieh wurde nicht allein für die Bewirtschaftung der im Eigenbesitz der Untertanen befindlichen Flächen benötigt, sondern zum Teil auch für die zahlreichen Frondienste auf den herrschaftlichen Meierhöfen gehalten. Bestandteil der feudalen Ordnung war die genaue Festlegung, welches Anwesen zur, großen Robot' verpflichtet war - also ein 
Gespann Zugvieh für die Fron auf den herrschaftlichen Feldern abzustellen hatte - und welches Haus lediglich zur ,Handrobot' verpflichtet war. Obwohl sicherlich Grundbesitz als Kategorie sozialer Differenzierung - der Acker als der ,Ort, wo die soziale Ordnung als soziale Ungleichheit immer wieder hergestellt wurde ${ }^{66}$ - nicht unterschätzt werden darf, wird aus den zuvor genannten Gründen in Tabelle 12 eine soziale Differenzierung der Gesellschaft auf Basis der Zugviehhaltung versucht. ${ }^{67}$ Die Zugviehhaltung bei den Anwesen wies infolge der gutsherrschaftlichen Bedingungen im Zeitverlauf eine sehr hohe Konstanz auf. Zwischen 1654, 1682 und 1713 waren es immer dieselben 62 Häuser, die Zugvieh hielten. Erst um die Mitte des 18. Jahrhunderts kamen drei weitere hinzu. Aufgrund der Bedeutung der Differenzierung innerhalb des gutsherrlichen Systems in ,spannfähige Bauern“ einerseits und ,nicht-spannfähige‘ Häuser andererseits, kann der Zugviehhaltung ein sehr hoher Stellenwert im sozialen dörflichen Gefüge zugesprochen werden.

Tabelle 12: Sozialstrukturelle Entwicklung, Pfarre Kapličky 1654-1713 (nach Zugvieh)

\begin{tabular}{lrrrrrc}
\hline & \multicolumn{2}{c}{$1653 / 54$} & \multicolumn{2}{c}{1682} & \multicolumn{2}{c}{1713} \\
Anwesen & $\mathrm{N}$ & $\%$ & $\mathrm{~N}$ & $\%$ & $\mathrm{~N}$ & $\%$ \\
\hline mit zwei oder mehr Gespannen & 51 & 73,1 & 51 & 67,1 & 42 & 41,6 \\
mit einem Gespann & 11 & 16,4 & 11 & 14,5 & 20 & 19,8 \\
ohne Zugvieh & 5 & 7,5 & 14 & 18,4 & 39 & 38,6 \\
\hline Summe & 67 & 100,0 & 76 & 100,0 & 101 & 100,0 \\
\hline
\end{tabular}

Quellen: NA Praha, BR 2; BR 30; TK 684.

Der Zusammenhang zwischen sozialer Kategorisierung in den staatlichen Quellen und dem verzeichneten Land- und Viehbesitz der Anwesen lässt sich auch anders ausdrücken: 1654 verfügten die 62 als ,bäuerlich' bezeichneten Anwesen über Besitzgrößen zwischen zwei und zehn Hektar Ackerland und hielten zumindest ein Gespann an Zugvieh. Die fünf ,landarmen“ Häuser verfügten jeweils über weniger als ein Hektar Ackerland und hatten kein Zugvieh. Die untere Grenze der Zugviehhaltung lag damit in Kapličky deutlich niedriger als etwa im bayerischen Unterfinning, wo Zugvieh nur für die eigene bäuerliche Wirtschaftsführung und kaum

66 Wunder, Acker, 18.

67 Als Zugvieh wurden lediglich Ochsengespanne gewertet. Pferde kamen 1654 in der Pfarre nicht vor; im Jahre 1713 wurden die fünf Pferde nicht unbedingt von den rein landwirtschaftlichen Betrieben der Pfarre gehalten (sondern etwa von einem Müller und einem Wirt). 
für Frondienste benötigt wurde. In Unterfinning hielten erst Anwesen ab etwa zehn Hektar Eigenbesitz ein Ochsengespann. ${ }^{68}$ Im Jahre 1654 wurden lediglich sechs Inhaber der verzeichneten Anwesen von Kapličky als Handwerker bezeichnet; sie gehörten aber überwiegend nicht zur Gruppe der kleinen Grundbesitzer.

\subsection{Soziale Kategorisierung in den staatlichen Katastern}

Der spezifischen ,Logik' der Quelle, nämlich der eines in erster Linie an Grundbesitz interessierten Steuerkatasters, entsprechend, wurde in den Katastern nur die Haus besitzende Bevölkerung und nicht alle Familien der Pfarre verzeichnet. ${ }^{69}$ Aus dem Vergleich mit den Grundbüchern ergibt sich, dass es um 1653/54 außerdem auch einzelne weitere landlose Häuser in der Pfarre gab, die im Kataster nicht erfasst wurden. ${ }^{70}$ Ein ,nominative record linkage' (Verknüpfung von Informationen aufgrund von Namensgleichheit aus unterschiedlichen Quellen) mit anderen Materialien erlaubt eine Kritik der Kataster als Quelle für die sozialstrukturelle Differenzierung der Bevölkerung und relativiert das von den Steuerkatastern gezeichnete Bild einer von Grund besitzenden Familien geprägten Gesellschaft in Kapličky in mehrfacher Hinsicht. Die zentralen Angaben in den staatlichen Katastern des 17. Jahrhunderts zum sozialen Status der einzelnen Häuser stellten von staatlichen Behörden generierte, auf einer Schätzung der jährlichen Aussaat beruhende Kategorien (in böhmischen Strich) dar. Die verzeichnete Haus besitzende Bevölkerung wurde dabei in die drei Gruppen der Bauern, Chalupner und Gärtner eingeteilt. Dieses zum Teil regional auch neu eingeführte, künstlich geschaffene Schema einer sozialen Kategorisierung konnte sich von den lokal üblichen - oder auf den einzelnen Herrschaften gebräuchlichen - sozialen Klassifikationsschemata manchmal deutlich unterscheiden und stand bisweilen auch im Widerspruch zu diesen. ${ }^{71}$ Während die Erhebungen des 17. Jahrhunderts dabei den Strich tatsächlich als

68 Vgl. Beck, Unterfinning, $236 \mathrm{ff}$.

69 Dies trifft im Falle Vyšší Brods auch für die Theresianische Fassion des frühen 18. Jahrhunderts zu. In manchen anderen Regionen Böhmens verzeichnete diese Quelle - da im Unterschied zu den Katastern des 17. Jahrhunderts nun auch versucht wurde, das Gewerbe zu erfassen - erstmals auch Inwohner.

$70 \mathrm{Vgl}$. dazu weiter unten.

71 Wie sich zeigen lässt, wurden in den patrimonialen Quellen zum Teil zwar dieselben sozialen Termini wie in den staatlichen Katastern verwendet, zahlreiche Häuser wurden dabei aber unterschiedlich klassifiziert. Die von der Gutsherrschaft erstellten Verzeichnisse wiesen im Vergleich mit den Katastern von 1654 und 1682 daher tendenziell höhere Anteile an Chalupnern auf. Vgl. dazu ausführlicher Zeitlhofer, Vielfalt, $21 f$. 
Hohlmaß - als die Menge an Aussaat - anwendeten, wurde dieser in den Theresianischen Katastern des 18. Jahrhunderts als Flächenmaß - als die Fläche, die mit einem Strich Aussaat besät werden konnte - verstanden. ${ }^{72}$ Sowohl die regionale als auch die zeitliche Vergleichbarkeit der Angaben sind daher nur begrenzt möglich. In manchen Regionen, so in Vyšší Brod und anderen Teilen Südböhmens, schuf das landesweit vorgegebene Schema den erhebenden Behörden derart schwerwiegende Probleme, dass schließlich im Theresianischen Kataster (1713) für diese Herrschaft auf eine soziale Kategorisierung der Anwesen gänzlich verzichtet wurde.

Das von den Katastern gezeichnete Bild der sozialen Zusammensetzung der Dörfer von Kapličky ist in mehrfacher Hinsicht zu differenzieren. Zunächst variiert der Grad der Erfassung der existierenden Anwesen je nach Verzeichnis. Die Berní rula von 1654 etwa hatte mit 67 Anwesen keineswegs alle in der Pfarre existierenden Häuser genannt. Aus den Grundbüchern ergibt sich dagegen für dieses Jahr eine Anzahl von etwa 72 bis 74 Häusern in der Pfarre. Mehrere der kleinen Anwesen blieben unberücksichtigt. ${ }^{73}$ Hinter den differierenden Angaben zur Häuserzahl steht aber auch das Problem, dass es in dieser Region zahlreiche separate Wohngebäude gab, die keine selbstständigen Anwesen bildeten.

Dazu zählten außer Nebengebäuden bei Bauernhöfen, die von Ausnehmern oder Inwohnern bewohnt wurden, ${ }^{74}$ auch mehrere Häuser im Besitz der Dorfgemeinden, in denen etwa die Viehhirten der Dorfgemeinden und von der Herrschaft angestellte Revierjäger wohnten. ${ }^{75}$ Bis 1723 war auch das Haus des Schmiedes im Dorf Kapličky im Eigentum der Dorfgemeinde. Eigene Häuser für Inwohner gab es im gesamten Böhmerwald in großer Zahl, wie auch in einigen angrenzenden Gebieten Oberösterreichs oder in nordböhmischen Regionen. ${ }^{76}$

Würde neben den in separaten Häusern wohnenden Familien die gesamte Gruppe aller Inwohner berücksichtigt, so relativiert sich der Eindruck einer so-

72 Vgl. dazu ausführlicher Cerman/Matusiková/Zeitlhofer, Rozbor. Bei den Angaben zur Getreideaussaat handelt es sich ebenfalls nur um sehr grobe Schätzungen mit einer deutlichen Präferenz für bestimmte Zahlenabfolgen (Häufungen der Vielfachen der Zahlen 5 und 6). Lediglich die letzte Erhebung, die Okularvisitation der 1720er Jahre, dürfte hier deutlich glaubwürdigere Angaben liefern. Für Vyšší Brod ist diese jedoch nur in einer unvollständigen Abschrift erhalten.

73 Bei einzelnen Anwesen ist das genaue Gründungsjahr nicht im Grundbuch angeführt. Die Berní rula hatte aber zumindest fünf der zweifellos zu dieser Zeit bestehenden Kleinhäuser nicht berücksichtigt. Ein Zinsregister der Herrschaft aus dem Jahre 1643 hatte für die Pfarre Kapličky 76 Häuser verzeichnet, von denen aber einzelne um 1651/54 nicht bewohnt waren. Vgl. Archiv Klašter Vyšší Brod, kniha č. 237.

74 Ähnlich auch in nordböhmischen Regionen. Vgl. Cerman, Proto-Industrialisierung.

75 Zur Mitte des 17. Jahrhunderts gab es in der Pfarre zumindest drei Häuser im Besitz der Gemeinde, im 18. Jahrhundert phasenweise mindestens zehn.

76 Cerman, Proto-Industrialisierung, $173 f$. 
zial nur gering differenzierten, bäuerlichen Gesellschaft nochmals deutlich. In den Dörfern der Herrschaft Vyšší Brod lebten laut Soupis poddaných im Jahre 1651 knapp 30 Prozent aller Familien im Inwohnerstatus, in der Pfarre Kapličky lag dieser Anteil noch höher. Im innerböhmischen und im internationalen Vergleich sind diese Werte als sehr hoch einzustufen. ${ }^{77}$ Die Vermutung, dass es nach dem Krieg zu einem Rückgang oder Verschwinden der landlosen Familien gekommen wäre, weil diese verödete Bauernwirtschaften übernehmen konnten, ${ }^{78}$ lässt sich weder für die Herrschaft Vy̌šši Brod noch für andere Regionen Südböhmens bestätigen.

Hinter der Bezeichnung „Inwohner" verbargen sich freilich sehr unterschiedliche Lebensverhältnisse. Zum Teil war der Inwohnerstatus eine lebenszyklische Phase, da etwa auch Altenteiler und verwitwete Personen dazu gezählt wurden. Dazu kamen die Bewohner der zahlreichen Gemeindehäuser (Viehhirten, etc.) oder vom Taglohn lebende Personen. Manche Menschen lebten lebenslang in diesem Status, andere nur für wenige Jahre. ${ }^{79}$ Ein großer Teil der Inwohner war verheiratet.

\subsection{Haus und Haushalt}

Obwohl - oder gerade weil - die Quellenlage für die Mitte des 17. Jahrhunderts besonders dicht ist, ist die Zahl der Häuser in der Pfarre nicht eindeutig feststellbar. Vergleicht man mehrere Verzeichnisse, so zeigt sich, wie problematisch die Begriffe ,Haus' und ,Haushalt' sind: Sie werden in den einzelnen Quellen unterschiedlich verwendet, und die Einheiten sind nicht klar abgegrenzt. Neben dem Soupis poddaných, ${ }^{80}$ existiert durch Zufall für die Pfarre Kapličky auch ein im selben Jahr vom örtlichen Pfarrer erstellter status animarum. Es handelt sich dabei überhaupt um den einzigen ,echten', erhalten gebliebenen Status animarum für Kapličky. ${ }^{81}$

77 Siehe zur Diskussion über die Höhe des Inwohner- und Gesindeanteils in mehreren südböhmischen Herrschaften vor und nach dem Dreißigjährigen Krieg: Grulich/Zeitlhofer, Lebensformen. Die bei Mitterauer, Formen, 194-197 für eine Vielzahl an österreichischen Pfarren des 17. bis frühen 20. Jahrhunderts genannten Inwohneranteile liegen beinahe durchgängig unter den Werten für Kapličky.

78 Klima, Länder; ders., Class Structure, $195 f$.

79 Vgl. Kapitel 8.7.

80 NA Praha, SM, R 109/45, Bech. 5.

81 Archiv Klaštera Vyšší Brod, Kart. č. 219. Ein ähnliches Verzeichnis, das allerdings vergleichsweise wenige Informationen (keine Familiennamen und keine Altersangaben) enthält, existiert auch für das Jahr 1652. Aus späterer Zeit ist dagegen für die Pfarre Kapličky kein einziges Personenstandsverzeichnis erhalten. Lediglich die Bevölkerung des Dorfes Vyšína befindet sich im Status animarum der Pfarre Vyšší Brod aus dem Jahre 1798, da dieses Dorf in der Zwischenzeit die Pfarrzugehörigkeit gewechselt hatte. 
Die beiden Verzeichnisse listen mit wenigen Ausnahmen dieselben Personen auf, und die Zahl der Ehepaare ist nahezu deckungsgleich. Sie werden jedoch zu unterschiedlichen Haushaltseinheiten zusammengefasst, die in ihrer Anzahl erheblich differieren. Wenn man den Kataster von 1654 mit den Grundbüchern vergleicht, ergibt sich ebenfalls eine leichte Abweichung in der Häuserzahl (Tabelle 13).

Tabelle 13: Anzahl der Häuser, Haushalte und Ehepaare in der Pfarre Kapličky in verschiedenen Verzeichnissen

\begin{tabular}{lllll}
\hline Haushaltsliste (Staat) & $1651:$ & 81 Haushalte/107 Ehepaare & & \\
Haushaltsliste (Pfarrer) & $1651:$ & 61 Haushalte/104 Ehepaare & & \\
Kataster & $1654:$ & 67 Häuser & $1713:$ & 101 Häuser \\
Grundbücher & $1651 / 1654:$ & $70-72$ Häuser $^{82}$ & $1840:$ & 119 Häuser \\
\hline
\end{tabular}

Quellen: NA Praha, SM, R 109/45, Bech. 5, BR 2, TK 684; Archiv Kláštera Vyšší Brod, Kart. č. 219; SOA Třeboň, fond C Vyšší Brod, Pozemkové Knihy.

Die staatliche Bevölkerungszählung von 1651 nennt für Kapličky insgesamt 107, eine Liste des Pfarrers aus demselben Jahr 104 Ehepaare. Während der Pfarrer Zisterzienserpater Mathias Marck aber 61 Haus besitzende Familien zählte und alle anderen Familien unter die Inwohner reihte, kam die Zählung des Soupis poddaných dagegen auf eine Zahl von 81 Haushalten.

Diese Abweichungen zeigen deutlich, dass die Art der Erfassung von Häusern und Haushalten vom Kontext abhing, in dem die jeweilige Quelle erstellt wurde ${ }^{83}$, und sie veranschaulichen die Schwierigkeit einer eindeutigen Definition von Haushalt, auf die auch schon andere Autoren hingewiesen haben. ${ }^{84}$ Dass in Kapličky die Angaben zur Zahl der Häuser und Haushalte so stark differieren, liegt auch daran, dass es hier separate Wohngebäude gab, die keine selbstständigen Anwesen bildeten. Viele Bauernhöfe hatten Nebengebäude, in denen - wie bereits erwähnt - Altenteiler oder Inwohner lebten; hinzu kamen die Wohnhäu-

82 Die Zahl der in den Grundbüchern verzeichneten Häuser lässt sich für diesen Zeitraum nicht exakt angeben, weil bei einzelnen Anwesen das Gründungsjahr nicht angeführt ist.

83 Dies bekräftigt nachdrücklich die Berechtigung von Berkners bereits früh geäußerter Skepsis gegenüber einer kritiklosen Übernahme der Haushaltsdefinition aus den Quellen. Vgl. Berkner, Use and misuse. Vgl. auch: Ders.,The Stem family, 405. Ähnlich auch Sabean, Property, 99.

84, „...] denn der Begriff der Haushaltung ist ein so vager und schwer bestimmbarer, daß er selbst der modernen Statistik die größten Schwierigkeiten entgegenstellt“. Banck, Bevölkerungszahl, 308, zit. nach: Rödel, Statistik, 20 f. Vgl. auch Schnyder-Burghartz, Lebensformen, 85; Van der Linden, Household history, 164 . 
ser etwa der Gemeindehirten oder des Gemeindeschmieds, die den Dorfgemeinden gehörten. Die Unterscheidung zwischen Haus und Haushalt - also zwischen selbstständigen Häusern und solchen, die nicht als selbstständige Einheit galten - war dabei nicht immer eindeutig. In Einzelfällen wechselten Häuser sogar ihren Status. Ein 1639 im Dorf Lipová errichtetes Altenteilerhaus wurde in den Grundbüchern ab 1641 als selbstständiges Anwesen geführt, ab 1695 galt es dann wieder als bäuerliches Nebengebäude. Das zum bäuerlichen Anwesen Kapličky Nr. 4 gehörige Inwohnerhaus Hřbítek Nr. 2 wurde 1668 an eine Kleinhäuslerfamilie verkauft; der Eintrag ins Grundbuch erfolgte aber erst 1696.85 Auch der Schneider Zacharias Wabra in Kapličky ist bereits im Zinsregister des Jahres 1643 als Besitzer eines Kleinhauses genannt und zahlte laut diesem Verzeichnis einen Hauszins. Er ist auch in den folgenden Jahren gelegentlich als im Dorf wohnhaft nachweisbar. Sein Haus wird jedoch erst in seinem Todesjahr $1679 \mathrm{im}$ Grundbuch eingetragen - zu dem Zeitpunkt, als es von seinem Sohn Michael gekauft wurde. ${ }^{86}$

Hausbesitz war also in dieser Region zur Mitte des 17. Jahrhunderts offenbar kein zentrales soziales Differenzierungskriterium. Ähnliche Probleme mit der Unterscheidung zwischen Häusern und Haushalten sind auch aus anderen Regionen dokumentiert: Für die schweizerische Pfarre Langnau etwa liegt ein vom Pfarrer erstellter Status animarum aus dem Jahre 1763 vor, in dem 458 Häuser und 575 Haushalte verzeichnet sind. Im Jahr darauf fand in der Schweiz eine Volkszählung statt, die für diesen Ort derselbe Pfarrer durchführte. Bei dieser wurde nach der Zahl der „Feuerstätten“ gefragt. Der Pfarrer nannte 475 Feuerstätten für die Pfarre, hatte aber mit diesem Begriff offenbar selbst Probleme, da er eine Beschreibung seiner Definition von „Feuerstätte“ beifügte. ${ }^{87}$ In der Forschung wird in letzter Zeit öfter darauf hingewiesen, dass die lokalen Behörden, Beamte oder Pfarrer in der von ihnen verwendeten Begrifflichkeit unsystematisch, schwankend und teilweise widersprüchlich vorgingen. ${ }^{88}$ Die Grenzen innerhalb des Hauses und die vielschichtigen graduellen Abstufungen an jeweils unterschiedlicher Einbindung verschiedener Personen in das Haus/den Haushalt werden in den weiteren Kapiteln der vorliegenden Studie noch mehrfach zur Sprache kommen. Die Grenzen bzw. die Verbindungen zwischen Menschen und Anwesen, Familien und Haushalten basierten oft auf vertraglich abgesicherten Rechten und Ansprüchen und

85 Vgl. SOA Třeboň, fond C Vyšší Brod, PK č. 453, fol. 360.

86 Archiv Kláštera Vyšší Brod, kniha 237 (Zinsregister 1643); SOA Třeboň, fond C Vyšší Brod, PK č. 453 , fol. 357.

87 Bietenhard, Langnau, $174 f$.

$88 \mathrm{Vgl}$. Béaur/Schlumbohm, Einleitung, 26. 
können zumeist nicht auf Basis einer Haushaltstypologie erkannt werden, sondern nur nach Heranziehung zusätzlicher Quellen. ${ }^{89}$

\subsection{Eine mögliche soziale Differenzierung}

Trotz aller Problematik der zeitgenössischen sozialen Kategorisierungen der Anwesen wird in der vorliegenden Arbeit mehrfach eine Unterteilung der Haus besitzenden Bevölkerung in unterschiedliche soziale Gruppen vorgenommen. Eine solche Differenzierung erscheint im Falle bestimmter Fragestellungen aus rein pragmatischen Gründen nötig. Im vorliegenden Fall erscheint es als relativ einfach, bestimmte entscheidende soziale Trennlinien zwischen den einzelnen Häusern der untersuchten Pfarre zu erkennen. Eine solche Grenze dürfte vor allem in Relation zu den Obrigkeiten (Herrschaft, Pfarrer, Staat) bestanden haben. Für die Pfarre Kapličky lassen sich über einen langen Zeitraum hinweg 62 Häuser von allen anderen Anwesen abgrenzen. Es waren dies diejenigen Häuser, die voll im feudalen System integriert waren. In vielen Verzeichnissen der Herrschaft wurden lediglich diese Häuser genannt, zahlreiche Abgaben an die Herrschaft (,Fleischgeld“, Kuchlgeld') aber auch der Zehent an den Pfarrer oder die Unterhaltsleistungen für den Schullehrer wurden ausschließlich von diesen 62 Anwesen und nicht von den anderen geleistet. ${ }^{90}$ Auch der Pfarrer von Kapličky orientierte sich bei der Erstellung der Seelenbeschreibung des Jahres 1651 offenbar an dieser Einteilung und bezeichnete lediglich die 61 Grund besitzenden Häuser (ein Haus im Dorf Adámky war zu dieser Zeit gerade kurzfristig unbewohnt) als selbstständige Einheiten, während er alle anderen Familien zu den Inwohnern zählte (siehe oben). Gleichzeitig war dies auch lange Zeit die Zahl der Zugvieh haltenden Anwesen: zwischen 1654 und 1713 waren es immer dieselben 62 Häuser in der Pfarre, die Zugvieh hielten (vgl. Tab. 12). Im 17. und frühen 18. Jahrhundert waren auch nur diese 62 Häuser der Herrschaft gegenüber zur Leistung der wöchentlichen, „großen“ Robot mit Zugvieh verpflichtet, während alle anderen Anwesen nur,Handdienste‘ zu leisten hatten.,Große Robot' bedeutete die Verpflichtung, der Grundherrschaft etwa für drei Tage pro Woche eine volle Arbeitskraft sowie ein Ochsengespann zur Verfügung zu stellen. Die unterbäuerlichen Haushalte leisteten dagegen keine Spannrobot, sondern - wie einzelne erhalten gebliebene Verzeichnisse zeigen - kaum zwei Tage

89 Vgl. dazu auch die ausführliche Diskussion an einem lokalen Fallbeispiel bei: Lanzinger, Das gesicherte Erbe, bes. 269-73.

90 Archiv Kláštera Vyšší Brod, č. 219 (Pfarrarchiv Kapličky); kniha 237 (Zinsregister 1643). 
Handrobot im Monat. ${ }^{91}$ In einem Verzeichnis des Jahres 1749 wurden dagegen 65 Häuser als zur ,großen Robot' verpflichtet genannt, da nun auch die drei Dominikalisten des kleinen Dorfes Hvězda/Stern einbezogen waren. ${ }^{92}$ Zumindest für die zweite Hälfte des 17. Jahrhunderts entsprach die Differenzierung in Zugvieh haltende und andere Anwesen auch sehr klar der Verteilung der Ackerfläche. Wer mehr als zwei Hektar Ackerland bewirtschaftete, benötigte offenbar ein Ochsengespann, die anderen nicht. Nicht zu verwechseln ist diese Differenzierung dagegen mit einer Unterscheidung in Landbesitzer einerseits und Landlose andererseits. In der untersuchten Region sind diese beiden Gruppen nicht klar voneinander abgrenzbar. ${ }^{93}$ Über die 62 Anwesen hinaus verfügten auch die meisten kleineren Häuser in unterschiedlichem Ausmaß über geringen Grundbesitz.

Aus all den genannten Gründen werden diese 62 Häuser in der vorliegenden Arbeit hinkünftig ,Bauern' oder ,Grund besitzende Anwesen' genannt, alle anderen Häuser jedoch als ,landarm` oder , unterbäuerlich' eingestuft. Gegen dieses hier kreierte Modell einer für einen Zeitraum von etwa zwei Jahrhunderten fixen Zuordnung der Anwesen in „Bauern“ einerseits und „unterbäuerliche“ Anwesen andererseits lassen sich natürlich mehrere Einwände vorbringen: dieses Schema berücksichtigt weder die teilweise recht beachtlichen Veränderungen in den $\mathrm{Be}$ sitzgrößen über den Zeitverlauf - insbesondere den allgemein feststellbaren allmählichen Zuwachs an Landbesitz bei fast allen Anwesen, noch den untertänigen Besitz an Wiesen (über die keine Flächenangaben vorliegen), noch die zusätzlich zum eigentlichen ,Rustikalland' der untertänigen Güter von der Herrschaft gepachteten Flächen (siehe dazu unten). Gerade das Ausmaß der Letzteren unterlag aber mitunter einem deutlichen Wandel im Zeitverlauf. Auch sind die in Einzelfällen vorkommenden $\mathrm{Zu}$ - oder Verkäufe einzelner Grundparzellen in diesem Schema nicht berücksichtigt. Einen wertvollen Indikator für mögliche soziale Differenzierungen der lokalen Praktiken und Verhaltensweisen bietet diese Unterscheidung dennoch.

91 Die Handrobot der unterbäuerlichen Bevölkerung lag - wie mehrere Verzeichnisse aus den 1670er Jahren zeigen - bei unter 20 Tagen im Jahr. Vgl., Verschreibung der in denen Closter Hohenfurtherischen Herrschafftsgerichten befindenten Inleuth', 1675-1677, Archiv Klaštera Vyšší Brod, Kart. č. 397, Publikum 5/3.

92 Die direkt an der oberösterreichischen Grenze gelegenen Häuser von Hvězda stellten eine gewisse Ausnahme dar: sie besaßen anders als viele andere Kleinhäuser auch ein wenig Ackerland und hatten zusätzlich auch von benachbarten oberösterreichischen Herrschaften Pachtgründe in Bewirtschaftung. Zumindest phasenweise hielten sie auch Zugvieh, wie einzelne Übergabeverträge zeigen.

93 Eine Vielzahl an graduellen Abstufungen zwischen Landbesitz, Landarmut und Landlosigkeit, die keine klaren Trennlinien zulassen, wird auch für andere vorindustrielle Gesellschaften betont. Vgl. etwa: Landsteiner/Langthaler, Ökotypus, $204 f$. 
Freilich sollte die hier gewählte Unterteilung in ,bäuerliche“ und ,unterbäuerliche“ Anwesen nicht als Zuschreibung eines sozialen Status missverstanden werden.

Der soziale Status im Dorf hatte auch viel mit der „Ehre“ und dem Prestige von Personen und Familien zu tun. Dieses stellte ein symbolisches Kapital dar, das unter Umständen auch von einer Generation zur nächsten vererbbar war und keinesfalls mit dem jeweiligen ökonomischen Kapital korrelieren musste. ${ }^{94}$ Über Prestige und Ehre geben aber die hier untersuchten Materialien keinerlei Auskunft. Auch kann diese Unterscheidung nicht ohne weiteres mit der Differenz zwischen, Armut' und ,Reichtum' gleichgesetzt werden. ${ }^{95}$ Aus den genannten Gründen sollte auch Abschied genommen werden von der Sicherheit und Geradlinigkeit konventioneller und dichotomer Schichtungsmodelle, tatsächlich gab es in vorindustriellen ländlichen Gesellschaften viele Dimensionen sozialer Ungleichheit. ${ }^{96}$

94 Vgl. dazu etwa: Schnyder, Unterschiede, bes. 160, 165.

95 Die Differenz von, arm ' und ,reich` erscheint für manche Gesellschaften der vorindustriellen Zeit außerdem nur von sekundärer Bedeutung gewesen zu sein. Vgl. dazu etwa: Theibault, German Villages, $101 \mathrm{ff}$.

96 Simplifizierte Schichtungsmodelle erscheinen heute als typisch für die Sozialgeschichtsschreibung der 1960er und 1970er Jahre, obwohl sich auch zu dieser Zeit Kritik an derartigen Modellen findet, vgl. etwa: Schissler, Agrargesellschaft, 43f: „Bei der Problematik der sozialen Schichtung von vorindustriellen, agrarischen Gesellschaften macht sich die Tendenz zur Dichotomisierung in den Modernisierungstheorien ... besonders nachteilig bemerkbar." Zit. nach Mooser, Ländliche Klassengesellschaft, 369 . 


\title{
4. DIE VIELFALT DER REGIONALEN UND LOKALEN ÖKONOMIE ${ }^{1}$
}

\author{
4. 1 Ackerbau und Viehzucht
}

Die naturräumlichen Bedingungen für den Ackerbau waren in dem von starken Höhenunterschieden - einige Dörfer der Pfarre lagen auf 800 bis 900 Meter Seehöhe -, einem rauen Klima und humusarmen Böden geprägten Gebiet nicht besonders günstig. Um Vyšší Brod - und noch viel mehr galt dies für das höher gelegene Kapličky - war das Klima wesentlich rauer als in den größeren Städten Südböhmens, wie etwa České Budějovice und Český Krumlov. Häufige Nordostwinde und Schnee bis Ende April beschränkten den Getreidebau. Roggen und Hafer wurden zumeist bei allen Grund besitzenden Anwesen angebaut, Weizen dagegen gedieh in den höheren Regionen des Böhmerwaldes kaum und wurde im Pfarrgebiet von Kapličky im 17. und 18. Jahrhundert nicht angebaut. Hafer diente vorwiegend nicht als Futter für Pferde, die nur in geringer Zahl gehalten wurden, sondern entweder zum Verkauf oder auch als menschliche Nahrung. Die wichtigste Getreidesorte der Region war der für seine große Resistenz gegen Nässe und Winterkälte im nordalpinen Raum besonders geschätzte Roggen. ${ }^{2}$ Das Saatgut-Ertragsverhältnis von Roggen lag hier zur Mitte des 17. Jahrhunderts im überregionalen Vergleich aber extrem niedrig. ${ }^{3}$ Aufgrund des bis weit

1 Siehe dazu bereits den kurzen Überblick: Zeitlhofer, Vielfalt, 18-20.

2 Roggen war seit dem Mittelalter im gesamten ostmitteleuropäischen Raum eine besonders geschätzte Kulturpflanze, während er für das mediterrane Klima weniger gut geeignet war. Vgl. Mitterauer, Roggen.

3 Das Kloster deklarierte zur Mitte des 18. Jahrhunderts für etwa 70 Prozent der eigenbewirtschafteten Anbaufläche lediglich einen Ertrag von 1:2, vgl. NA Praha, ED, i. č. 193, Kart. č. 20, und lag damit sogar noch unter den bereits überaus bescheiden wirkenden Angaben von 1:4 in anderen böhmischen Regionen, bzw. im südbayerischen Raum. Auch Nenning, Materialien, 154, nennt für die Region zu Beginn des 19. Jahrhunderts lediglich einen Ertrag von 1:3 bzw. 1:4. Ähnlich geringe Ertragsverhältnisse werden außerdem für das angrenzende oberösterreichische Mühlviertel im 18. Jahrhundert angegeben. Vgl. Steinmaß1, Massenarmut 22f. Vgl. dagegen die Zusammenstellung durchschnittlicher Ernteerträge in verschiedenen europäischen Ländern um 1800 bei: Cerman, Rural Economy, 52. 
ins Frühjahr vorhandenen Schnees winterte in Kapličky nicht selten selbst der Roggen aus. ${ }^{4}$

Unter den weiteren Kulturpflanzen war besonders der Flachs (siehe ausführlicher weiter unten) in der Region verbreitet, wenn auch flächenmäßig insgesamt weniger bedeutend. Nur sehr selten nachweisbar ist dagegen der Mais, der den Grundbüchern zufolge um 1749 im nahe der Moldau gelegenen Dorf Vyšína gepflanzt wurde. ${ }^{5}$ In den eher ebenen Regionen der Herrschaft, namentlich in der weiter im Landesinneren gelegenen Pfarre Hořice, wurde im 17. Jahrhundert außerdem viel Kraut angebaut, das in der nahen lokalen Residenzstadt Český Krumlov auf den Markt gebracht wurde. ${ }^{6}$ Der Anbau von Kraut für den Eigenbedarf wird mehrfach auch für die Pfarre Kapličky hervorgehoben. ${ }^{7}$ Nahe des Klosters Vyšší Brod sowie auch in drei weiter östlich gelegenen Dörfern der Herrschaft wurde zu Beginn des 18. Jahrhunderts auch Hopfen gepflanzt. ${ }^{8}$

Die Intensität des Bodenbaus bewegte sich zunächst im zu erwartenden Rahmen, wenn auch früh vereinzelt Ansätze einer Verdichtung erkennbar sind. Der Anteil der Brache an der gesamten Aussaatfläche der Wirtschaften betrug in der Pfarre Kapličky nach den Angaben der Berní Rula im Jahre 1654 bei etwa 74 Prozent aller verzeichneten Häuser der Pfarre zwischen 25 und 33 Prozent. Bei zehn Anwesen, überwiegend größeren Bauern, lag dieser Anteil über 33 Prozent, bei sechs Häusern jedoch unter 25 Prozent. Die beiden Kleinbesitzer des Dorfes Adámky hatten einen Bracheanteil von lediglich zwölf bzw. 14 Prozent. Im Jahre 1682 hatte sich an dieser Verteilung relativ wenig geändert, nunmehr waren es aber lediglich vier Häuser mit einem Brachenteil von weniger als 25 Prozent. ${ }^{9}$ Aus diesen Zahlen lässt sich folgern, dass Häuser mit geringerem Grundbesitz diesen

4 Nenning, Materialien, 153.

5 Hinweise auf einen Maisbau finden sich aber ansonsten für das Pfarrgebiet nur sehr selten.

6 In der Berní Rula von 1653/54 wurde für Hořice angemerkt, dass die Bewohner neben dem nebenberuflichen Spinnen und Weben auch dadurch Geld verdienten, dass sie ,Krauthäupel auf dem Wagen in die Stadt Krumau bringen. Sie säen mehr Kraut und deshalb ist die Aussaat an Getreide geringer („teželi v hlavavkach na ffasunky do města Krumlova vozi a tim sa zice mnoho zeli, menši nejverky magi, mohou obstatni, puda dobra žitna"). Quelle: NA Praha, BR 2, fol. 817-20.

7 Vgl. NA Praha, TK 684, Rustik.fasse. 43/8, fol. 44-48.

8 Es waren dies die Dörfer Hörmanschlag, Kainretschlag und Buggaus (in der Region zwischen Malonty und Rychnov nad Malší gelegen). Quelle: Archiv Kláštera Vyšší Brod, kniha 245 (Zinsregister 1712). Im Ort Vyšší Brod selbst bestand während der frühen Neuzeit eine vom Kloster geführte Brauerei; im 16. Jahrhundert hatten auch zahlreiche Bürger des Marktortes Braugerechtigkeiten inne gehabt, die ihnen später jedoch von der Herrschaft entzogen wurden. Vgl. dazu Schmidt, Geschichte des Brauwesens.

9 Quelle: NA Praha, BR 2; BR 30; Für das Jahr 1713 konnten derartige Berechnungen nicht durchgeführt werden, da in der Quelle keine Gesamtaussaat genannt wurde. 
auch intensiver bewirtschafteten als die größeren Anwesen. Kleinbesitz musste gezwungenermaßen optimal genützt werden. Andererseits war das Land der größeren Besitzer häufig von sehr unterschiedlicher Qualität. Neben besseren Böden bewirtschafteten gerade die größeren Anwesen auch weit abgelegene Flächen - im Gegensatz zu den Kleinhäuslern, die oft nur über direkt bei ihrem Anwesen gelegenen Grundbesitz verfügten - von manchmal nur geringer Qualität, die immer wieder mehrere Jahre lang brach liegen mussten, um die Böden nicht zu erschöpfen. ${ }^{10}$

Mehr Bedeutung als dem Ackerbau kam in der Pfarre der Viehzucht (vor allem von Ochsen und Kühen) zu. Rinder züchtende Kleinbauern bestimmten die Wirtschaft in den hügeligen bis gebirgigen Gebieten des südlichen Böhmerwaldes wesentlich mit, auch wenn die Viehhaltung manchmal aus dem Grund als unbedeutend beschrieben wurde, weil die Kühe der Region angeblich kleinwüchsig waren. ${ }^{11}$ Die Bedeutung der Viehhaltung in der Herrschaft Vyšší Brod und in der Pfarre Kapličky lässt sich einerseits an der Hartnäckigkeit ermessen, mit der auch noch das kleinste Anwesen darum bemüht war, zumindest eine Kuh zu halten, andererseits vor allem aber an den zumindest in bestimmten Zeitperioden relativ hohen Viehzahlen der Bauern sowie an der Bedeutung der Viehweide in jedem Dorf. Besonders in den Jahren unmittelbar nach dem Dreißigjährigen Krieg fallen bei mehreren Bauern der Pfarre relativ hohe Rinderzahlen auf. Im Jahre 1654 wurden gleich bei mehreren Anwesen der Pfarre mehr als 15 Stück Großvieh (Ochsen, Kühe und Jungrinder) genannt. Zwei Bauern im Dorfe Hodoň betrieben in Ansätzen auch eine Art Almwirtschaft. Auf einer dem Dorf nahe gelegenen Hochwiese inmitten der herrschaftlichen Wälder hatten sie Stallungen und hielten dort während des Sommers ihr gesamtes Vieh. ${ }^{12}$ Einige Formulierungen in der Marktordnung von Vyšší Brod aus dem Jahre 1608 deuten darauf, dass um diese Zeit die Weideflächen für das Vieh zu Ungunsten des Getreidebaus ausgedehnt worden waren; im 16. Jahrhundert dürfte zum Teil auch in der als Weidefläche genutzten Brache Getreide angebaut worden sein. ${ }^{13}$

10 Der Josephinische Kataster verzeichnet etwa am äußeren Rand der Flur des Pfarrdorfes (in Richtung der Allmenden der Dörfer Krasné Pole und Adámky) mehrere solcher Trischfelder, die zum Teil für drei Jahre, zum Teil auch für siebe Jahren brach lagen. Vgl. NA Praha, JK 2963 Obec Krasné Pole (vgl. etwa die Parzellen rund um die Parzellennummer 400).

11 So Nenning, Materialien, 154. Dagegen betont ein Reisebericht aus dem frühen 19. Jahrhundert die ,ergiebige Viehzucht' im südlichen Böhmerwald. Vgl. Blau, Böhmerwaldreise.

12 Dies wird im ansonsten romanhafte Züge tragenden Buch von Tobner, Zigeunerwald, 8 beschrieben. Da der Autor, selbst ein Mitglied des Konvents des Zisterzienserklosters Vyšší Brod, die Bewohner der Dörfer und deren Wirtschaftsweisen sicherlich sehr gut kannte, erscheint diese Angabe glaubhaft.

13 Siehe den Abdruck der Marktordnung bei: Schlesinger, Dorfweisthümer, 326. 
Einen vorübergehenden Rückgang in der Viehhaltung im beginnenden 18. Jahrhundert legen möglicherweise die im Theresianischen Kataster von 1713 genannten Viehzahlen nahe. Nun hielt kein einziges Anwesen im Pfarrgebiet (genauso in allen Dörfern der Herrschaft südlich der Moldau) mehr als drei Kühe. ${ }^{14}$ Die Haltung zumindest einer Kuh bildete allerdings auch für die landarmen Häuser der Region eine ganz wesentliche Voraussetzung einer ,eigenständigen' Existenz. Von den 67 im Jahre 1654 im Kataster genannten Häusern verfügte nur ein einziges über keine Kuh, 1682 hielten alle Anwesen zumindest eine, wenngleich fünf davon ihre Kühe nur "gemietet" hatten (Tabelle 14). ${ }^{15}$ Erst 1713 finden sich sieben Häuser ohne Kuhhaltung, dabei handelte es sich durchgängig um Häuser, die erst während der zweiten Hälfte des 17. Jahrhunderts gegründet worden waren. Beinahe alle Anwesen verfügten im Jahre 1654 über Zugvieh (drei Viertel der Häuser verfügten sogar über mindestens zwei Gespanne). ${ }^{16}$ Mehrere Anwesen hatten drei Ochsengespanne, ein einziges vier. Im Marktort Vyšší Brod hielt zwar ebenfalls ein hoher Anteil der Häuser eine Kuh, an der Verbreitung der Zugviehhaltung lässt sich jedoch erkennen, dass wohl nur etwa 30 Prozent der Anwesen des Ortes eine ,eigentliche' Landwirtschaft besaßen (vgl. Tabelle 15 und 16). Nur Haushalte, die Zugvieh hielten, können als tatsächlich eigenständige Landwirtschaft gelten, da alle anderen Grundbesitzer auf die Bestellung ihrer Felder mit fremden Gespannen (gegen eine Arbeitsleistung oder gegen Bezahlung) angewiesen waren. Das Zugvieh wurde nicht allein für die Bewirtschaftung der im Eigenbesitz der Untertanen befindlichen Flächen benötigt, manchmal wurde ein Gespann wohl auch speziell für die Frondienste auf den herrschaftlichen Meierhöfen gehalten. Die Zugviehhaltung war aus diesen Gründen, wie auch der Vergleich der Kataster von 1654 und 1713 zeigt, sehr stabil im Zeitverlauf (vgl. Tabelle 12). Die minimale Besitzgröße, ab der Zugvieh benötigt wurde, ist in dieser Region recht eindeutig festzulegen. Wer mehr Ackerfläche als etwa sieben Strich (ca. zwei Hektar) besaß, benötigte Zugvieh; Häuser mit weniger Grundfläche dagegen nicht.

14 Letztlich muss aber offen bleiben, ob diese Zahlen allerdings tatsächliche Veränderungen in der Wirtschaftsführung widerspiegeln, oder aber lediglich das Resultat unterschiedlicher Erfassungsweisen in den Quellen sind.

15 Die Differenzierung in eigene und gemietete Tiere ist eine Besonderheit der Revisitation der Berní Rula von 1682.

16 Als Zugvieh wurden nur Ochsengespanne, nicht aber Pferde gewertet. Im Gegensatz zu den nordböhmischen Regionen unterschied die Berni rula hier nach Pferden und Ochsen. In Kapličky wurden nur sehr wenige Pferde gehalten, im Jahr 1713 etwa wurden fünf genannt. Wie für das angrenzende Mühlviertel festgestellt wurde, war die Pferdehaltung im 16. Jahrhundert wesentlich stärker verbreitet als in späterer Zeit - etwa im frühen 19. Jahrhundert. Vgl. Knittler, Pferd oder Ochse, 163. 
Tabelle 14: Die Milchkuhhaltung bei den Anwesen der Pfarre Kapličky (1653/54 und 1682)

\begin{tabular}{ccccc}
\hline Anzahl der Kühe & $\begin{array}{c}\text { Anzahl der } \\
\text { Anwesen 1654 }\end{array}$ & $\begin{array}{c}\text { Prozentanteil } \\
\text { (an den genann- } \\
\text { ten Anwesen) }\end{array}$ & $\begin{array}{c}\text { Anzahl der } \\
\text { Anwesen 1682 }\end{array}$ & $\begin{array}{c}\text { Prozentanteil } \\
\text { (an den genann- } \\
\text { ten Anwesen) }\end{array}$ \\
\hline 0 & 1 & 1,5 & 5 & 6,9 \\
1 & 1 & 1,5 & 29 & 40,3 \\
2 & 24 & 35,8 & 25 & 34,7 \\
3 & 21 & 31,3 & 12 & 16,7 \\
4 & 17 & 25,4 & 1 & 1,4 \\
5 & 3 & 4,5 & 0 & 0,0 \\
\hline Summe & 67 & 100,0 & 72 & 100,0 \\
\hline
\end{tabular}

Quelle: NA Praha, BR 2, fol. 822-828; BR 30, fol. 271-279.

Tabelle 15: Die Milchkuhhaltung bei den Anwesen des Marktes Vy̌šši Brod (1653/54 und 1682)

\begin{tabular}{ccccc}
\hline Anzahl der Kühe & $\begin{array}{c}\text { Anzahl der } \\
\text { Anwesen 1654 }\end{array}$ & $\begin{array}{c}\text { Prozentanteil } \\
\text { (an den genann- } \\
\text { ten Anwesen) }\end{array}$ & $\begin{array}{c}\text { Anzahl der } \\
\text { Anwesen 1682 }\end{array}$ & $\begin{array}{c}\text { Prozentanteil } \\
\text { (an den genann- } \\
\text { ten Anwesen) }\end{array}$ \\
\hline 0 & 14 & 16,5 & 23 & 26,7 \\
1 & 44 & 51,8 & 51 & 59,3 \\
2 & 25 & 29,4 & 9 & 10,5 \\
3 & 2 & 2,4 & 3 & 3,5 \\
\hline Summe & 85 & 100,0 & 86 & 100,0 \\
\hline
\end{tabular}

Quelle: NA Praha, BR 2; BR 30.

Im Vergleich mit manchen anderen böhmischen Gutsherrschaften - auch in Südböhmen -, in denen die Schafhaltung aufgrund der verbreiteten Tuchproduktion überaus bedeutend war, erscheint die Zahl der gehaltenen Schafe in der Pfarre als gering. ${ }^{17}$ Sie wurde von gut der Hälfte der Grund besitzenden Anwesen betrieben. Interessant erscheint die hohe Konstanz der Schafhaltung. In allen drei staatlichen

17 In der ersten Hälfte des 19. Jahrhunderts wurden in Böhmen kontinuierlich zwischen einer Million und 1,6 Millionen Schafe gehalten. Vgl. die Zahlen bei: Stamm, Forstwirtschaft, 181f; siehe auch: Stark, Niedergang, 431. 
Zählungen $(1654,1682,1713)$ waren es jeweils 36 (bzw. 1654: 37) Höfe, die Schafe hielten. Unterschiede zwischen den Dörfern, etwa aufgrund der topographischen Lage, ließen sich dabei nicht erkennen. Auffallend ist jedoch, dass Schafe nur auf Anwesen gehalten wurden, deren Besitzer als Bauern bezeichnet wurden und nicht in landarmen Häusern. Dies deutet wohl darauf hin, dass durch Schafhaltung Weiden von schlechterer Qualität genutzt werden konnten - Land, das überwiegend im Besitz der größeren Anwesen war. Weiter verbreitet war in der Pfarre die Haltung von Schweinen, wenn auch jeweils in geringer Stückzahl. ${ }^{18}$ Ziegen werden lediglich vom Theresianischen Kataster des Jahres 1713 bei einzelnen der neu errichteten Kleinhäuser genannt.

Tabelle 16: Anzahl des Zugviehs pro Anwesen, Markt Vyšší Brod $1653 / 54$ und 1682

\begin{tabular}{ccccc}
\hline $\begin{array}{c}\text { Zugvieh } \\
\text { (Anzahl) }\end{array}$ & $\begin{array}{c}\text { Anzahl der } \\
\text { Anwesen 1654 }\end{array}$ & Prozent & $\begin{array}{c}\text { Anzahl der } \\
\text { Anwesen 1682 }\end{array}$ & Prozent \\
\hline 0 & 58 & 68,2 & 58 & 67,4 \\
1 & 1 & 1,2 & - & 0,0 \\
2 & 7 & 8,2 & 8 & 9,3 \\
4 & 19 & 22,4 & 18 & 20,9 \\
6 & - & 0,0 & 2 & 2,3 \\
\hline Summe & 85 & 100,0 & 86 & 100,0 \\
\hline
\end{tabular}

Quelle: NA Praha, BR 2; BR 30.

\subsection{Das Landhandwerk}

Insgesamt basierte der Großteil der untertänigen Wirtschaften in der Region auf einer breit gefächerten Mischökonomie, wobei vor allem Holzwirtschaft und Flachsverarbeitung über Jahrhunderte hinweg einen hohen Stellenwert als zusätzliche Einkommensmöglichkeiten zur Landwirtschaft hatten. In einigen Häusern wurde aber auch ein Handwerk betrieben. $\mathrm{Zu}$ den größeren Grundbesitzern der Pfarre gehörten zur Mitte des 17. Jahrhunderts die fünf Mühlenbesitzer der Pfarre. Lediglich die Mühle in Lipová war ab dem Jahre 1657 landlos, da in diesem Ausnahmefall der landwirtschaftliche Grundbesitz und die Mühlwerkstatt in

18 Die Schweinemast expandierte im Allgemeinen erst mit dem Kartoffelanbau. Vgl. Brakensiek, Agrarreformen, 430. 
zwei Betriebseinheiten getrennt worden waren. ${ }^{19}$ Anders als in manchen Gebieten Böhmens, in denen zumindest nach dem Dreißigjährigen Krieg alle Mühlen im Besitz der Gutsherrschaft waren ${ }^{20}$, gab es in dieser Region Südböhmens während der frühen Neuzeit kontinuierlich sowohl untertänige als auch im Besitz der Herrschaft befindliche Mühlen. ${ }^{21}$ Die Getreidemühlen der Pfarre waren recht bescheiden, sie verfügten jeweils nur über einen ,Gang' (i. e. ein Mahlwerk). Auch die geringen Zahlen an bei den Mühlen gehaltenen Schweinen (die von den Mahlabfällen genährt wurden) zeigen, dass die Mühlen sicherlich nicht kontinuierlich ausgelastet waren. ${ }^{22}$ Seit 1701 war ihnen ein fixer Kundenkreis zugesprochen, da die Häuser der Pfarre durch den ,Mühlenzwang der Herrschaft jeweils einer bestimmten Mühle zugeteilt waren, bei der diese ihr Getreide mahlen lassen mussten. Allerdings hatten die Mühlen der Region typischerweise neben der Mühle und der Landwirtschaft noch weitere Einkommen. Drei der Mühlen der Pfarre verfügten (zumindest) im 17. und 18. Jahrhundert zusätzlich auch über eine Brettersäge. ${ }^{23}$ Bei der seit 1657 landlosen Mühle von Lipová wurde seit dem frühen 18. Jahrhundert eine Ölpresse betrieben und bei der Mühle in Mlýnska bestand neben der Brettersäge (offenbar nur kurzzeitig um 1840) eine Leinwandbleiche. ${ }^{24}$ Viel bedeutender war dagegen die seit etwa der Mitte des 18. Jahrhunderts bei der Mühle in Lhota betriebene Leinen- und Garnbleiche (vgl. unten). Auch zur Mahlmühle in Loučovice gehörten eine Brettersäge sowie ab etwa 1828 auch ein Hammerwerk (siehe ebenfalls weiter unten).

Wie sich im Vergleich mit anderen Quellen zeigt, nennen die staatlichen Kataster - abgesehen von den Müllern - aus unterschiedlichen Gründen nur bestimmte, keineswegs aber alle ausgeübten Handwerke und Gewerbe (Tabelle 17). Hinweise auf weitere gewerbliche Tätigkeiten lassen sich aber aus zahlreichen anderen Quel-

19 Dieser Fall stellt den einzigen im gesamten Untersuchungszeitraum dar, bei dem eine Betriebseinheit im Zuge eines Besitzerwechsels geteilt wurde. Vgl. SOA Třeboň, fond C Vyšší Brod, PK č. 453, fol. 211.

20 Ich danke Markus Cerman für diesen Hinweis zur Situation in den von ihm untersuchten nordböhmischen Herrschaften Liberec und Frýdlant.

21 Diese waren, wie etwa die ,Herrschaftliche Saagmühl' bei Vyšší Brod, oft ungleich größer als die untertänigen Getreidemühlen der Region. Die genannte obrigkeitliche Mühle wurde im Jahr 1750 an den Sohn des bisherigen Betreibers verkauft. Vgl. SOA Třeboň, fond C Vyšší Brod, PK č. 480, fol. 116.

22 In anderen Regionen verfügten die Mühlen des 18. Jahrhunderts häufig über drei oder auch vier Mahlgänge. Vgl. dazu den Abschnitt bei Beck, Unterfinning 257-61.

23 Bei der so genannten,Weymühl' in Martinkov wurde schon 1530 eine Brettersäge betrieben. Vgl. Schmidt, Urbar, 172.

24 Diese wird erwähnt bei: Sommer, Königreich Böhmen, 178. Im Zinsregister des Jahres 1712 ist bei dieser Mühle außerdem eine Tuchwalke erwähnt. Vgl. Archiv Kláštera Vyšší Brod, kniha 245, Nr. 17. Sowohl die Walke als auch die spätere Bleiche dürften aber nur wenig bedeutend gewesen sein, da beide in weiteren Quellen, insbesondere in den Grundbüchern, keine Erwähnung fanden. 
len gewinnen. In einigen Fällen finden sich in den Verlassenschaften des 17. Jahrhunderts etwa Verweise auf spezifische Handwerkzeuge, die die verstorbenen Besitzer hinterlassen hatten. Insbesondere im Pfarrdorf Kapličky selbst scheint tatsächlich bei einer Mehrheit der Häuser ein Handwerk ausgeübt worden zu sein: für die Zeit um 1654 lassen sich hier neben dem im Kataster genannten Wagner und dem Weber auch die nicht genannten Berufe Wirt, Schuster, Schneider, Zimmermann und Schmied zweifelsfrei nachweisen. Der Schmied etwa findet sich nicht im Kataster genannt, da er seine Werkstätte nur gepachtet hatte und diese sich - ähnlich wie dies auch in Bayern häufig der Fall war - (bis 1723) im Besitz der Dorfgemeinde befand. ${ }^{25}$

Tabelle 17: Berufsangaben in den Staatlichen Katastern, Pfarre Kapličky (1654-1713)

\begin{tabular}{lccc}
\hline Berufe & 1654 & 1682 & 1713 \\
\hline Müller & 5 & 5 & 5 \\
Weber & 1 & - & - \\
Wagner & 2 & - & 5 \\
Schneider & - & 1 & 2 \\
Zimmermann & - & 1 & - \\
Schindelmacher & - & 1 & 1 \\
Schuster & - & - & 88 \\
keine Angabe & 59 & 68 & 101 \\
\hline Summe & 67 & 76 &
\end{tabular}

Quelle: NA Praha, BR 2, fol. 822-828; BR 30, fol. 271-279; TK 684, fol. 43-67.

Mit Ausnahme der Müller war das klassische Landhandwerk, insbesondere das zunftmäßig organisierte, in den Dörfer Südböhmens und des südlichen Böhmerwaldes relativ schwach vertreten. Die Zunftgewerbe waren ganz überwiegend in den Städten und Marktorten Südböhmens angesiedelt. In den südböhmischen Marktorten, wie etwa in Vyčší Brod, war die Zahl der genannten Handwerker und Gewerbetreibenden dementsprechend deutlich höher als in den Dörfern. Für Vyšší Brod, das zu Beginn des 18. Jahrhunderts etwa 100 Häuser zählte, verzeichneten die ältesten Manufakturtabellen Böhmens aus dem Jahre 1753 genau 60 Gewer-

25 Im bayerischen Gerichtsbezirk Landsberg saß im frühen 18. Jahrhundert jeder zweite Hufschmied auf einer Gemeindeschmiede. Vgl. Beck, Unterfinning, 267. 
betreibende (Tabelle 18). Neben den Webern und Töpfern, die regional besonders stark vertreten waren, sind für den Marktort die klassischen Sparten des traditionellen Handwerks vom Bäcker und Fleischhauer bis zum Schuhmacher zu nennen. Anders als in den Dörfern spielten die Holz verarbeitenden Gewerbe im Marktort keine besondere Rolle.

Tabelle 18: Berufe im Marktort Vyšší Brod (1654-1753)

\begin{tabular}{lcccc}
\hline Berufe & 1654 & 1682 & 1713 & 1753 \\
\hline Müller & 1 & - & - & 1 \\
Weber & 11 & 8 & 12 & 6 \\
Wagner & - & 1 & 3 & 1 \\
Töpfer/Hafner & 8 & 6 & 6 & 5 \\
Schmied & 3 & 3 & 3 & 2 \\
Sattler & - & 1 & - & 1 \\
Schneider & 7 & 6 & 12 & 6 \\
Bäcker & 5 & 8 & 8 & 7 \\
Brauer & 7 & 7 & 3 & - \\
Fleischhauer & 3 & 6 & 5 & 5 \\
Binder & 1 & 4 & 4 & 1 \\
Schuhmacher & 3 & 9 & 5 & 9 \\
Gerber & 1 & 4 & 6 & 2 \\
Zimmermann & 1 & 1 & 4 & 2 \\
Maurer & - & - & 3 & 1 \\
Steinmetz & - & - & 2 & 1 \\
Stricker & - & - & 2 & 3 \\
Sonstige/K.A. & 34 & 22 & 101 & 7 \\
\hline Summe & 85 & 86 & & 60 \\
\hline & & & 23 & \\
\hline
\end{tabular}

Quelle: NA Praha, BR2; BR 30; TK 684; SB.UZLA, inv. č. 189, fol. 18.

Die Zünfte entstanden in Südböhmen mit wenigen Ausnahmen überwiegend im 16., teilweise auch erst im 17. und 18. Jahrhundert. ${ }^{26} \mathrm{Im}$ Allgemeinen waren diese territorial organisiert.

26 Für die Marktorte Vyšší Brod und Hořice, aber auch für Rožmberk und Kaplice (bei den beiden letzteren mit jeweils einer ins 15. Jahrhundert zurückreichenden Ausnahme) sind die ältesten Zunftorganisationen jeweils ins 16. Jahrhundert zu datieren. Nur in der zentralen Residenzstadt Český 
War nur eine geringe Zahl von Produzenten vorhanden, wurden alle Mitglieder eines Gewerbes des gesamten Herrschaftsbereichs zu einer Zunft zusammengefasst. Häufiger bestand jedoch - wie auch in der Herrschaft Vyšší Brod - für jeden Marktort einer Herrschaft jeweils eine eigene Zunftorganisation, bei der dann auch einzelne Handwerker aus den Dörfern der umliegenden Pfarren Mitglied waren. Mit Ausnahme weniger Branchen, wie etwa der Leinenweberei oder der Töpferei, scheint die Einführung einer Zunftorganisation eher die Zurückdrängung des bisher existierenden Landhandwerks bewirkt zu haben.

\subsection{Die Mischökonomie im Schatten der Landwirtschaft}

Ein Grund für die Nichterwähnung mancher Gewerbetätigkeit in den staatlichen Katastern ist darin zu sehen, dass vieles nicht als zunftmäßig organisiertes $\mathrm{Ge}-$ werbe, sondern als gewerblicher Nebenerwerb (etwa neben der Landwirtschaft), oder konkreter im Rahmen einer Mischökonomie neben mehreren anderen Einkommen ausgeübt wurde. Wie sich diese unterschiedlichen Formen einer Mischökonomie am Beispiel einzelner Häuser darstellten, sei an den folgenden beiden sehr unterschiedlichen Fällen veranschaulicht:

Zum Anwesen des Josef Viehböck, seit 1712 Besitzer im Dorf Mlynská, gehörten Ackerflächen im Ausmaß von etwa 20 böhmischen Strich (ca. sieben Hektar). Neben neun Äckern hatte er zwei Wiesen in Besitz, von denen laut Theresianischem Kataster 1713 acht zweispännige Fuhren Heu geerntet werden konnten, sowie eine geringe Waldfläche. An Viehstand wurde 1713 verzeichnet: vier Ochsen, drei Kühe, ein Galtvieh, drei Schweine und zwei Schafe. 1654 waren noch 18 Stück an Großvieh (Ochsen, Kühe, Galtvieh) angeführt worden. Zum Anwesen gehörten überdies eine Mühle mit einem Gang und eine kleine Brettersäge. Über einen langen Zeitraum wurde außerdem auch ein von der benachbarten oberösterreichischen Herrschaft Waxenberg gepachtetes Zinsgereut (von unbekannter Größe) bewirtschaftet. Zu Beginn des 18. Jahrhunderts wurde bei diesem Haus auch relativ viel Flachs angebaut und sicherlich auch hier versponnen. Josef Viehböcks Vater Gregor hatte sich bei der Übergabe des Anwesens 1712 immerhin vorbehalten, jährlich etwa ein Viertel Hektar Flachs anzubauen. Die Einkommensquellen die-

Krumlov sowie im Markt Trhově Sviny/Schweinitz bestanden bereits im 15. Jahrhundert bei mehreren Gewerben Zünfte. Vgl. dazu die Studie von Schmidt, Zünfte. Siehe dazu auch: Čechura, Cechy rožmberských und Čechura, Rozvoj cechù. Neben den klassischen zunftmäßigen Gewerben gab es in Südböhmen auch einzelne eher selten anzutreffende Zunftorganisationen, so etwa die Mälzer- und Bierbrauerzunft in Rožmberk. Vgl. Schmidt, Brauwesen, $305 f$. 
ses sicherlich zu den wohlhabendsten Anwesen der Pfarre zählenden Hauses waren demnach überaus vielfältig.

Im selben Zeitraum hatte Mathias Nagl das Haus Hodoň Nr. 9 inne. Sein Vater Augustin hatte vor 1680 der Dorfgemeinde ein kleines Grundstück abgekauft und darauf ein Haus errichtet. Laut den Angaben der Theresianischen Fassion 1713 gehörten weder Wiesen noch Äcker zum Anwesen, lediglich ein kleiner Obstgarten. An Viehstand war bloß eine Kuh verzeichnet. Wovon Mathias Nagl und seine Frau lebten, ist nicht vollständig zu eruieren. Allgemein geben die Quellen über die Lebensgrundlagen der Unterschichten nur sehr unzureichend Auskunft. Als die beiden 1728 das Haus übergaben, hatten sie aber ihre landwirtschaftliche Basis deutlich vergrößert, da nun auch zwei herrschaftliche Zinsgereuter angeführt wurden. Der 1695 verstorbene Vater Augustin Nagl war Binder und Schindelmacher gewesen und hatte auch etwas Leinwand hinterlassen, hatte also möglicherweise auch selbst gewebt. Auch gegen Ende des 18. Jahrhunderts wurde das Haus von einem Landhandwerker, einem Zimmermann, bewohnt. Bei diesem Haus ist von einer kontinuierlichen Kombination von Handwerk (und/oder unterschiedlichen Formen von Lohnarbeit und heimgewerblicher Tätigkeit) mit einer auf herrschaftlichem Pachtland betriebenen Kleinstlandwirtschaft auszugehen.

In beiden Fällen, sowohl beim bäuerlichen wie auch beim unterbäuerlichen Anwesen, ist auffällig - und dies ist für die untersuchte Region sehr typisch -, dass neben dem eigentlichen untertänigen Grund und Boden von sehr vielen Anwesen auch eine zweite Kategorie an Land, sogenannte ,Zinsgereuter' oder ,Zinsreut', bewirtschaftet wurde. Dabei handelte es sich um relativ neu gerodete, im Eigenbesitz einer Herrschaft befindliche Flächen, die jährlich gegen eine geringe Pacht an die Untertanen vergeben wurden. Wie zu zeigen sein wird, waren diese Flächen in der Praxis jedoch oft auch über viele Jahrzehnte an dasselbe Haus verpachtet und diese vergrößerten die agrarische Basis zahlreicher Häuser beträchtlich (zu den ,Zinsgereutern' siehe ausführlich Kapitel 5.6).

In allen drei Katastern kamen Berufsangaben nur selten vor. Die drei erhalten gebliebenen Handrobotverzeichnisse der Jahre 1675 bis 1677 (vgl. Tabellen 19 und 20) nennen aber für mehrere landarme und landlose Personen der Pfarre konkrete Berufsbezeichnungen. In diesen Listen werden vor allem Inwohner - aber auch die in dieser Periode noch wenig zahlreichen Häusler der Pfarre - genannt: eben diejenigen Untertanen, die nicht zur Spannrobot (wie die Bauern), sondern nur zur Handrobot verpflichtet waren. Am Beispiel des Verzeichnisses für das Jahr 1677, das nicht nur das Gebiet der Pfarre Kapličky (die Gerichte Mnichovice und Lhota) umfasst, sondern ein größeres Territorium innerhalb der Herrschaft, lässt sich die recht hohe Bedeutung der herrschaftlichen Eigenbetriebe und die verschiedenen Formen der Holzverarbeitung für den Lebensunterhalt der landarmen Bevölke- 
rung dokumentieren, obwohl bei vielen keine spezifische Angabe eines Berufes verzeichnet ist. Kleinräumig differenziert betrachtet, zeigen sich dennoch einige Unterschiede. Die sogenannten „Hofdrescher“, also Personen, die saisonal als Taglöhner in den obrigkeitlichen Meierhöfen beschäftigt waren, waren vor allem in den Dörfern nahe des Hauptortes Vyšší Brod angesiedelt (so etwa in Studánky und Př́sanov); rund um den Hauptort der Herrschaft befanden sich die meisten Meierhöfe. Holzknechte und generell in Holz verarbeitenden Gewerben beschäftigte Personen wohnten dagegen häufiger in den waldreicheren Regionen der Herrschaft, wie etwa in der Pfarre Kapličky (vgl. Tabelle 20). Auch diese Verzeichnisse machen freilich nur einen weiteren kleinen Ausschnitt der verschiedenen Einkommensquellen der landarmen Bevölkerung der Region sichtbar.

Tabelle 19: Berufsangaben im Handrobotverzeichnis 1675 (Gerichte Mnichovice und Lhota)

\begin{tabular}{lcc}
\hline & N & $\%$ \\
\hline Holzknecht & 8 & 17,0 \\
Schindelmacher & 4 & 8,5 \\
Hofdrescher & 2 & 4,3 \\
Maurer & 1 & 2,1 \\
Schneider & 2 & 4,3 \\
Schuster & 1 & 2,1 \\
Leinweber & 1 & 2,1 \\
Tagwerker & 7 & 14,9 \\
Häusler & 4 & 8,5 \\
Inwohner & 9 & 19,1 \\
Ausnehmer & 1 & 2,1 \\
untauglich/alt & 7 & 14,9 \\
\hline Summe & 47 & 100,0 \\
\hline
\end{tabular}

Quelle: Archiv Kláštera Vyšší Brod, kart. č. 397, 5/3.

Anm.: Die Gerichte Mnichovice und Lhota waren weitgehend identisch mit der Pfarre Kapličky. 
Tabelle 20: Berufsangaben im Handrobotverzeichnis 1677 (alle Gerichte der Herrschaft Vyšší Brod)

\begin{tabular}{|c|c|c|c|c|c|c|c|c|c|}
\hline & 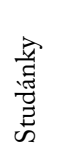 & 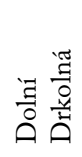 & 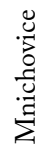 & 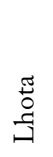 & 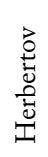 & 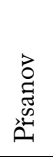 & 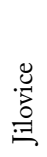 & 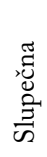 & $\begin{array}{l}\text { : } \\
\text { ğ } \\
\text { की }\end{array}$ \\
\hline Holzknecht & & & 1 & 4 & & & & 1 & 6 \\
\hline Schindelmacher & & & 1 & 3 & & & & & 4 \\
\hline Schwingenmacher & & & & & 1 & & & & 1 \\
\hline Garbelmacher & & & & 1 & & & & & 1 \\
\hline Zimmermann & 1 & 2 & & & 1 & & & 1 & 5 \\
\hline Hofdrescher & 6 & & 2 & 1 & & 7 & 3 & 1 & 20 \\
\hline Maurer & 1 & & & & & 2 & 1 & 2 & 6 \\
\hline Schneider & & & 1 & 1 & & & & & 2 \\
\hline Schuster & & & 1 & & & & & & 1 \\
\hline Leinweber & & 1 & & 1 & & & 1 & & 3 \\
\hline Müller & & & & 1 & & & & & 1 \\
\hline Schmied & & & & & & & 1 & & 1 \\
\hline Fleischhacker & 1 & & & & & & & & 1 \\
\hline Hüter & 1 & & & 1 & & & & & 2 \\
\hline Tagwerker & & 14 & 8 & 11 & & 1 & 6 & 8 & 48 \\
\hline Bettler & & & & 1 & & & & & 1 \\
\hline untauglich/alt & & & 1 & 2 & 1 & & & & 4 \\
\hline o. A. & 11 & 1 & 2 & & 8 & 2 & & & 24 \\
\hline Summe & 21 & 18 & 17 & 27 & 11 & 12 & 12 & 13 & 131 \\
\hline
\end{tabular}

Quelle: Archiv Kláštera Vyšší Brod, kart. č. 397, 5/3.

Anmerkung: Unter, Garbelmacher' ist ein Produzent hölzerner Futter- oder Mistgabeln zu verstehen.

Der bedeutende Schriftsteller Adalbert Stifter, selbst aus der Region stammend, beschrieb in seiner Novelle ,Der Waldgänger' im Jahr 1847 die ökonomischen Tätigkeiten eines zwischen Lipno nad Vltavou (Lippen) und Kobylnice (Goblenz) - keine fünf Kilometer vom hier untersuchten Pfarrdorf Nové Domky entfernt wohnhaften unterbäuerlichen Ehepaares folgendermaßen:

„(...) er war ein Holzhauer, trieb auch bei Gelegenheit, wenn Nachfrage darnach war, Kohlenbrennerei, und wenn die Scheite auf der Moldau geschwemmt wurden, war er mit einer Stange bei der Teufelsmauer [i.e. der felsige, nicht flößbare Ab- 
schnitt der Moldau, der die Nordgrenze der Pfarre Kapličky bildete, H. Z.] unten, und half lenken, die ausgestoßenen hineinwerfen, die säumigen in das Fahrwasser bringen, und die gespreizten und verstrickten lüften. Das kleine Weibchen war immer zu Hause, wirthschaftete, oder that auf dem Kraut- oder Kartoffelfelde, was nothwendig war." 27

Die Kombination der hier erwähnten Tätigkeiten war sicherlich für viele Menschen der Region zu dieser Zeit charakteristisch. Christoph Mörxbauer etwa, zwischen 1664 und 1696 Hausbesitzer und Inhaber einer kleinen Mühle ohne Landbesitz in Lipova, wurde 1676 in einer herrschaftlichen Quelle als Holzknecht bezeichnet, 1677 dann wieder als Müller. ${ }^{28}$ Insgesamt ist davon auszugehen, dass im Untersuchungsgebiet bereits zu Beginn des 18. Jahrhunderts ein sehr hoher Prozentsatz der Bevölkerung zu ihrer Existenzsicherung zumindest zum Teil auch auf Lohnarbeit angewiesen war.

Die hohe Bedeutung außeragrarischer Einkommensformen in der Pfarre zeigt sich dann besonders zur Mitte des 19. Jahrhunderts. Im Jahre 1846 betrieben laut den Beilagen zum Franziszeischen Kataster von den insgesamt 315 ,Wohnparteien“ der beiden Gemeinden Krasné Pole und Mnichovice insgesamt 65 (oder 20,6 \% von allen) eine Landwirtschaft, neun weitere lebten ausschließlich von einem Gewerbe. Etwas mehr als drei Viertel aller Wohnparteien der Pfarre waren dagegen auf Tätigkeiten außerhalb der Landwirtschaft und des traditionellen Landhandwerks angewiesen (vgl. Tabelle 21). Dabei ist in erster Linie sicherlich an diverse Tätigkeiten im Textilgewerbe, an Lohnarbeit in der Land- und Forstwirtschaft und an heimgewerbliche Tätigkeiten in der Holzverarbeitung zu denken. Es wäre aber dennoch falsch, diese Zahlen vorschnell als Indikatoren für ein völliges Fehlen jeglicher Landanbindung bei der großen Mehrheit der Bevölkerung der Region zu nehmen. Ein marginaler Grundbesitz war - wie zu zeigen sein wird - auch bei den allermeisten Kleinhäuslern gegeben. Vielmehr geben diese Zahlen eine vage Vorstellung davon, wie viele Menschen von ihrem Grundbesitz leben konnten und wie viele nicht. Unter ,Wohnparteien“ sind im vorliegenden Falle wohl ,Haushalte` zu verstehen, wobei zu bedenken ist, dass sicherlich auch Altenteiler-Haushalte und ,unvollständige Familienformen' (etwa eine allein stehende Inwohnerin mit Kind) als separate Einheiten gezählt wurden.

27 Stifter, Waldgänger, 24.

28 Archiv Klaštera Vyšší Brod, Kart. č. 397, 5/3. 
Tabelle 21: Einkommen der,Wohnparteien, der Gemeinden Krasné Pole und Mnicovice im Jahre 1846

\begin{tabular}{lrc}
\hline & $\mathrm{n}$ & $\%$ \\
\hline Landwirtschaft (ausschließlich) & 60 & 19,0 \\
Gewerbe (ausschließlich) & 9 & 2,9 \\
Landwirtschaft und Gewerbe & 5 & 1,6 \\
keines von beiden/„Tagwerker“ & 241 & 76,5 \\
\hline Summe & 315 & 100,0 \\
\hline
\end{tabular}

Quelle: SK Dupl. 183, Nr. 26 ; SK Dupl. 190, § 3.

\subsection{Zur Bedeutung der Holzwirtschaft in der Region}

Der Wald bildete sowohl für die Ökonomie des Zisterzienserklosters als auch für die ländliche Bevölkerung der Region bis ins 20. Jahrhundert auf überaus vielfältige Weise eine zentrale ökonomische Quelle. Bereits von weniger waldreichen Dörfern der frühen Neuzeit, wie dem bayerischen Unterfinning, hieß es, dass der Wald, die vielfältigste Ressource, die das Dorf hatte [war]. Er bot Nahrung für Mensch und Vieh, bot das Material sich zu wärmen und sich zu behausen ${ }^{29}$. Noch deutlich stärker galt dies für die waldreichen Gebiete des südlichen Böhmerwaldes. Neben dem - häufig kleinen - Waldbesitz der Bauern boten die ausgedehnten Wälder im Besitz der Herrschaft vor allem für die unterbäuerlichen Schichten auf sehr vielfältige Weise Arbeits- und Erwerbsmöglichkeiten. Mehrere Bevölkerungsverzeichnisse des 17. Jahrhunderts für die Pfarre Kapličky nennen zahlreiche Holzknechte. ${ }^{30}$ Schon in Urkunden des 15. Jahrhunderts werden in den herrschaftlichen Wäldern tätige Holzfäller erwähnt. ${ }^{31}$ Der Handel mit Holz aus den herrschaftlichen Wäldern setzte bereits früh ein. Im 16. Jahrhundert sorgten vor allem die zahlreichen Bauten und der zu dieser Zeit in Blüte stehende Bergbau in der benachbarten Herrschaft Český Krumlov für eine hohe Nachfrage. ${ }^{32}$ Als billigster Transportweg bot sich die Moldau an. Dem Kloster kam hier zugute, dass der Fluss erst ab Vyšší Brod flößbar war. Oberhalb von Vyšší Brod bildete die Čertova Stěna/Teufelsmauer (ein mehrere Kilometer langes, unbefahrbares steiniges Flussbett zwischen Loučovice und Vyšší

29 Beck, Unterfinning, 62.

30 NA Praha, Soupis poddaných; Archiv Kláštera Vyšší Brod, Kart. č. 397, 5/3.

31 Mičanová, Deutsche Urkunden, 70. Hier die Abschrift der entsprechenden Urkunde.

32 Nachweisbar ist die Holzschwemme auf der Moldau seit 1545. Vgl. Huyer, Holzschwemme. 
Brod mit starkem Höhenunterschied) ein unpassierbares Hindernis. Trotz zahlreicher Regulierungsversuche und Sprengungsarbeiten zwischen 1725 und dem Ende des 19. Jahrhunderts gelang es nie, dieses Hindernis zu überwinden. Seit Mitte des 16. Jahrhunderts konnte aber in diesem Abschnitt der Moldau, der die Nordgrenze der Pfarre Kapličky bildete, zumindest Scheitholz geschwemmt werden. In diesem Fall wurde das Holz in den oberhalb gelegenen Herrschaftswäldern zerhackt und danach moldauabwärts geschwemmt. Sogenanntes, Langholz' dagegen wurde geflößt, musste aber westlich von Loučovice in der Schwebe von Lipno/Lippen aus dem Fluss genommen und auf dem Landweg bis nach Vyčší Brod transportiert werden, um danach im Fluss weiter moldauabwärts geschwemmt zu werden. Berichtet wird, dass in den Sommermonaten häufig 200 Holzfuhren pro Tag auf dem Landweg entlang der Moldau unterwegs waren. ${ }^{33} \mathrm{Im}$ Jahr 1791 wurde mit dem Bau des Schwarzenberger Schwemmkanals begonnen, der die europäische Wasserscheide zwischen Nordsee und Schwarzem Meer in diesem Gebiet überwand und das Flößholz noch oberhalb der Pfarre Kapličky auf oberösterreichisches Gebiet umleitete, wo es schließlich seinen Weg in die Donau fand. ${ }^{34}$ An der ab diesem Zeitpunkt nochmals stark zunehmenden Bedeutung von Holzverarbeitung und -hande ${ }^{35}$ hatte die Herrschaft Vyšší Brod dadurch keinen direkten Anteil mehr. Indirekt begünstigte diese Entwicklung allerdings sicherlich den in der zweiten Hälfte des 19. Jahrhunderts erfolgten Aufstieg des jahrhundertelang sehr kleinen, an der Nordgrenze der Pfarre Kapličky gelegenen Dorfes Loučovice zu einem der ganz wenigen Industriestandorte im südlichsten Teil Böhmens. ${ }^{36}$

Im Zuge des Aufschwungs der Flößerei, wie der Forstwirtschaft allgemein, entstanden im südlichen Böhmerwald in der Zeit nach dem Dreißigjährigen Krieg zahlreiche Holzfällerdörfer, ${ }^{37}$ darunter 1690 auch das Dorf Nové Domky auf dem Gebiet der Pfarre Kapličky. Die Anlage des Dorfes Nové Domky, der einzigen ,echten' Dorfgründung in der Herrschaft Vyšší Brod nach der Mitte des 17. Jahrhunderts, direkt in der sogenannten ,Schwebe von Lipno' war kein Zufall. ${ }^{38}$ Angesiedelt wurden «verpflichtete Holzfäller», die vor allem bei der Holzschwemme

33 Blau, Hausindustrie (Bd.1), 79 ff. Vgl. auch Saitz, Krumau, 42-46 und Märten, Heimatkunde, 250f..

34 Vgl. Scheufler, Flößerei; Komlosy (Hg.), Industrie-Kultur, 175; Praxl, Dreiländerberg.

35 Die Herrschaft Český Krumlov hatte während der ersten Hälfte des 19. Jahrhunderts mehrere Holzhändler angestellt, darunter ist etwa 1841 auch eine ,Theresia Schero, Holzversilberin zu Linz' genannt. Vgl. Hochfürstlich Schwarzenberg'scher Schematismus, $35 \mathrm{f}$.

36 Hier war ab 1886 eine Zellulosefabrik mit phasenweise bis zu 350 Arbeitern in Betrieb. Vgl. Schusser, Papírny Vltavský mlýn. Ab etwa 1900 bestand noch ein zweiter - auf die Herstellung von Pappe spezialisierter - Betrieb im Ort.

37 Vgl. Kapitel 6.1.

38 Märten, Heimatkunde, 157; Willkomm, Böhmerwald, 251. 
auf der Moldau und in den herrschaftlichen Wäldern benötigt und im Stücklohn bezahlt wurden. ${ }^{39}$ Davor war die Holzfößerei als Robotarbeit der Dorfbewohner aus der nahen Umgebung erfolgt. Die Bewohner von Nové Domky baten allerdings bereits im Jahre 1717 den Abt von Vyšší Brod, sie von der «zwiederen» Arbeit des Holzfällens und -schwemmens zu befreien ${ }^{40}$ - ein Indiz dafür, dass sie ausreichend alternative Einkommensmöglichkeiten sahen. In dieser Zeit herrschte bei der Holzschwemme und -verarbeitung offenbar hoher Arbeitskräftemangel. Jedenfalls ist überliefert, dass es im Jahre 1698 zwischen den Herrschaften Vyšší Brod und Rožmberk zu einem Konflikt kam, da Vy̌šś Brod versucht hatte, einen der Herrschaft Rožmberk untertänigen Holzknecht aus Loučovice abzuwerben. ${ }^{41}$

Für die Pfarre wie für die Region werden immer wieder zahlreiche typische ,Waldberufe' genannt. ${ }^{42}$ Wie bereits erwähnt, waren Holz verarbeitende Gewerbe und Handwerkszweige (etwa Schindelmacher, Wagner, Binder) unter den dörflichen Untertanen von Kapličky im 17. Jahrhundert weit verbreitet. Zum Teil finden sich darunter auch relativ spezialisierte Tätigkeiten: so 1654 ein Erzeuger von hölzernem Geschirr, zwischen 1675 und 1677 einige Spindelmacher ${ }^{43}, 1783$ ein Uhrmacher und um 1840 spezialisierte Flachsbrechel-, Hechel- und Spinnradmacher. ${ }^{44}$ In mehreren Orten der benachbarten Herrschaft Český Krumlov wurde die Holzschuherzeugung lange Zeit hindurch hausindustriell betrieben. Die Produkte wurden im Landesinneren Böhmens und in Wien verkauft. 1860 wurden allein im Gerichtsbezirk Chvalšiny/Kalsching 22 Holzschuhhändler gezählt. ${ }^{45}$ Die Herrschaft profitierte hier in besonderer Weise auch durch den Verkauf des geeigneten Holzes an die Produzenten. ${ }^{46}$ "Beinahe jedes Haus ist in diesem Theile Böhmens eine Werkstätte für Holzgegenstände, die Schnitzbank ist ein hier nir-

39 So Saitz, Krumau, 35. Ob die Entlohnung dieser Holzarbeiter dem Marktlohn entsprach, kann nicht beantwortet werden.

40 Irsigler, Turmberg, 285.

41 Vgl. die Schilderung bei: Huyer, Holzschwemme, 38.

42 Für das neu besiedelte Gebiet des sogenannten ,Freiwaldes‘ im nahen nordöstlichen Mühlviertel listet eine ,Bereitung` aus dem Jahre 1615 zahlreiche Berufe auf, die nachdrücklich die Bedeutung des Waldes als Einkommensquelle hervorhebt. Bei einer Häuserzahl von 114 werden unter anderem genannt: 25 Köhler, 12 ,Waldwaren-Erzeuger' (unterschiedliche hölzerne Arbeitsgeräte, etc.), acht Schindelmacher, sechs Glasmacher, sechs Holzfäller, vier Jäger, drei ,Aschenbrenner' (Erzeugung von Pottasche für die Glasproduktion). Vgl. Grüll, Walde, 210.

43 Archiv Kláštera Vyšší Brod, Kart. č. 397, 5/3. Die bereits erwähnten Handrobotverzeichnisse nennen 1675 für das Dorf Přisanov zwei und 1676 für den Marktort einen ,Spiller'. Laut Palla, Lexikon, 424, scheint diese Bezeichnung auf die Herstellung hölzerner Spindeln zu verweisen.

44 Sommer, Königreich Böhmen, 174.

45 Blau, Hausindustrie (Bd. 1), 241.

46 Vgl. Zeithammer, Land, 140; Essl, Krummau, 555. Stamm, Forstwirtschaft, 256. 
gend vermißtes Hausgeräth», heißt es in einer Darstellung des 19. Jahrhunderts. ${ }^{47}$ Die Erzeugung von Holzschuhen, Holzdrähten, Zündhölzern, die Handschindelund Spielwarenerzeugung, die Produktion von Holzgeschirr und -geräten und von Siebrändern und die Tischlerei waren im 19. Jahrhundert im südlichen Böhmerwald jeweils mit lokal unterschiedlichen Schwerpunkten weit verbreitet. ${ }^{48}$ Manche dieser Tätigkeiten hatten eine lange zurückreichende Tradition. Über die Herrschaft Český Krumlov wird bereits für das frühe 17. Jahrhundert die Bedeutung der Verarbeitung von Buchenholz zu landwirtschaftlichen Arbeitsgeräten betont. ${ }^{49}$ Das Schindelmachen zählte im 17. Jahrhundert zu einer häufigen Beschäftigung unter der Inwohnerbevölkerung der Region. Einige Dörfer des südlichen Böhmerwaldes waren auch verpflichtet, jährlich eine bestimmte Anzahl an Holzschindeln als herrschaftliche Abgabe zu erzeugen. ${ }^{50}$

Die Glaserzeugung als ein mit dem Holzreichtum der Region eng verbundenes Gewerbe spielte dagegen, anders als in vielen benachbarten südböhmischen Herrschaften, in der Herrschaft Vyšší Brod nach dem Dreißigjährigen Krieg keine Rolle mehr. Ortsbezeichnungen und Flurnamen verweisen aber auf die Existenz von Glashütten in der Region um Kapličky und Vyšší Brod im Spätmittelalter (Meierhof Glashof beim Marktort Hor̆ice). ${ }^{51} \mathrm{Zu}$ Ende des 18. Jahrhunderts bildete der Böhmerwald eine der zentralen Produktionsstätten der Glaserzeugung in Europa ${ }^{52}$ Eine Sonderform der Glasverarbeitung bestand im Dorf Pohoři/Buchers im südlichsten Teil der weiter östlich gelegenen Herrschaft Nové Hrady bzw. im unmittelbar angrenzenden österreichischen Dorf Sandl, wo jeweils heimgewerblich (für überregionale Märkte, so etwa in Kroatien) die Hinterglasmalerei und auch die Herrgottschnitzerei betrieben wurden. ${ }^{53}$

47 Vgl. Koch, Holzindustrien, 467.

48 Vgl. den detaillierten Überblick: Zeithammer, Land, 132-143.

49 Blau, Hausindustrie (Bd. 1), 235.

50 Dies war etwa im nahe von Frymburk gelegenen Dorf Platten der Fall, dessen Bewohner laut Urbar von 1598 verpflichtet waren, der Herrschaft Rožmberk jährlich 1.000 Holzschindeln gegen einen Preis von 30 Groschen pro Stück zu liefern. Schmidt, Urbar Rosenberg, 48; Vgl. auch Essl, Krummau, 705. Die manuelle Erzeugung von Holzschindeln hielt sich im Böhmerwald auch noch nach Einführung der Maschinen-Spindel in der zweiten Hälfte des 19. Jahrhunderts. Vgl. Zeitlhammer, Land, $132 \mathrm{ff}$.

51 Im Pfarrdorf Mlýnská lässt sich 1579 eine Glashütte nachweisen. Vgl. Schmidt, Urbar, 174; Blau, Glasmacher; Fröhlich, Glashütten, 91.

52 Der Böhmerwald - und hier insbesondere die Herrschaft Vimperk - bildete seit dem 17. Jahrhundert das Produktionszentrum für böhmisches Glas, dessen Veredelung in nordböhmischen Regionen erfolgte. In den Glasfabriken der Herrschaft Nové Hrady arbeiteten zu Ende des 18. Jahrhunderts ca. 800 Arbeiter. Vgl. dazu die Arbeiten Winkelbauers, etwa: Winkelbauer, Glaserzeugung, aber auch: Svoboda, Trade, 111f.; Stark, Niedergang, 435; Zeithammer, Land, 144-165.

53 Vgl. Blau, Hausindustrie (Bd. 2), 276f.; Märten, Heimatkunde, 165. 


\subsection{Flachsanbau und -verarbeitung ${ }^{54}$}

Die größte Bedeutung unter den außeragrarischen Erwerbsformen kam in der Region des südlichen Böhmerwaldes aber kontinuierlich der Textilverarbeitung, bzw. deren Vorstufen, der Flachs- und Garnproduktion, zu. Die Flachsverarbeitung war in der Region infolge günstiger naturräumlicher Voraussetzungen vermutlich bereits seit der Besiedlung von großer Bedeutung. Die proto-industrielle Entwicklung im südlichen Böhmerwald verlief dennoch deutlich nach dem Typus einer «agrarischheimgewerblichen Verflechtung»(W. Mager). ${ }^{55}$ Flachsanbau und Garnerzeugung waren jahrhundertelang integraler Bestandteil beinahe aller Familienwirtschaften. Flachs wurde nicht nur von den Grund besitzenden Häusern, sondern auch von Inwohnern und Ausnehmern - und teilweise selbst vom Gesinde - angebaut und von Angehörigen beiderlei Geschlechts zu Garn versponnen. ${ }^{56}$ Abgesetzt wurden Flachs und Garn zu einem Gutteil im nahen österreichischen Mühlviertel. ${ }^{57}$ Anders als bei der Garnproduktion lässt die Bedeutung der Leinenweberei im Laufe der frühen Neuzeit stärkere Konjunkturen erkennen. Die Berní Rula des Jahres 1654 merkte bei 85 der 108 verzeichneten Dörfer der Herrschaft Vyšší Brod an, dass diese zusätzlich zur Landwirtschaft auch vom Spinnen und Weben lebten. Um 1700 und danach sind dagegen kaum Hinweise auf die Leinenweberei zu finden. Die Manufakturtabellen des Jahres 1768 weisen für die Herrschaft Vyšší Brod erneut 72 Weber aus. ${ }^{58}$ Es ist daher ein ähnlicher Entwicklungsverlauf der Leinenweberei wie im nahen Mühlviertel anzunehmen, mit einem ersten Höhepunkt im späten 16. und während des 17. Jahrhunderts und einer neuerlichen Expansion ab der zweiten Hälfte des 18. Jahrhunderts. ${ }^{59}$ Weit bedeutender war die Leinenweberei im nur wenige Kilometer weiter westlich gelegenen südlichen Teil der Herrschaft Český Krumlov. Die ältesten böhmischen Manufakturtabellen von 1753 verzeichneten 680 Leinenweber im große Teile Südböhmens umfassenden Bechiner Kreis (Tabelle 22). Etwa 500 von diesen fanden sich allein in der Herrschaft Český Krumlov,

54 Der Abschnitt beruht auf Teilen meiner beiden bereits publizierten Aufsätze: Zeitlhofer, Flachs, sowie Zeitlhofer, Heimgewerbe. Vgl. aber weiterführend dort die in manchen Aspekten wesentlich detaillierteren Ausführungen.

55 Vgl. Mager, Protoindustrialisierung. Die Art der „Verflechtung“ von Landwirtschaft und textilem Heimgewerbe war regional aber jeweils sehr unterschiedlich. Vgl. auch Kriedte/Medick/Schlumbohm, Sozialgeschichte. Vgl. dazu auch: Medick, Weben, 156. Vgl. dazu auch Pfister, Household.

56 Die Inwohner bauten sowohl um 1713 als auch um 1815 auf den Feldern der Bauern ihren Flachs an, vgl. Nenning, Materialien, 154.

57 NA Praha, TK, Spisy 619, fol. 65.

58 Archiv Kláštera, Vyšší Brod, Kart. č. 410, V/4 (Abschrift).

59 Hoffmann, Wirtschaftsgeschichte, $181 \mathrm{ff}$; Marks, Leinengewerbe. 
überwiegend in den gebirgigen Regionen des südlichen Böhmerwaldes, so etwa um Horní Planá (Oberplan), Dolní Vltavice (Unterwuldau) und Rychnůvek (Deutsch Reichenau). Über Horní Planá etwa wird berichtet, dass „... hier die Leinenweberei, wie nirgend anders, im Schwunge [war], hatte fast jedes Haus seinen eignen Webstuhl oder deren mehrere“. ${ }^{60} \mathrm{Zu}$ Beginn des 19. Jahrhunderts wurden in der Region der sogenannten ,Neuen Welt', einem hoch gelegenen Spätkolonisationsgebiet im Dreiländereck von Böhmen, Bayern und Österreich, allein 5,000 Handwebstühle gezählt. ${ }^{61}$ Deutlich geringer war die Bedeutung der Weberei dagegen lange Zeit in der Herrschaft Vyšší Brod. ${ }^{62}$

Tabelle 22: Orte mit der höchsten Anzahl an Leinenwebern in den südböhmischen Bezirken Český Krumlov und Kaplice im Jahre 1753*

\begin{tabular}{lrlr}
\hline Dorf Rychnůvek & 136 & Markt Kaplice & 14 \\
Dorf Kammený Újezd & 43 & Stadt Český Krumlov & 12 \\
Markt Horní Planá & 35 & Markt Frymburk & 10 \\
Markt Chvalšiny & 35 & Markt Nové Hrady & 10 \\
Markt Dolní Vltavice & 20 & Stadt Rožmberk & 9 \\
Markt Hořice na Šumavě & 15 & Markt Rožmitál & 7 \\
& & Markt Vyšší Brod & 6 \\
\hline
\end{tabular}

* Die Quelle nennt nicht alle Weber, sondern lediglich die Manufakturisten. Kammený Újezd gehörte zum Bezirk České Budějovice, die Weber waren aber der Zunft von Přidolí (im Bezirk Český Krumlov) inkorporiert.

Quelle: NA Praha, SB.UZLA, i. č. 189

Das Untersuchungsjahr 1753 ist insofern von besonderem Interesse, als dieser Zeitpunkt knapp vor der allgemein starken Aufschwungphase der Weberei in der Habsburgermonarchie liegt, die in den 1760er Jahren begann. Orte, die bereits vor 1760 von der Weberei geprägt waren, verfügten möglicherweise über eine bis ins 16. Jahrhundert zurückreichende Tradition. Der danach auch im südlichen Böhmerwald folgende Aufschwung sei nur am Beispiel einiger weniger Zahlen illustriert: Um 1790 betrug die Zahl der Webstühle in der Herrschaft Český Krumlov

60 Jordan, Oberplan, 28.

61 Vgl. Kaindl, Zisterzienserstift Hohenfurt, 32. Kleinhanns, Leinenweberei, 12. Zur Bedeutung der Leinenweberei auf der bayerischen Seite der Grenze siehe: Kreiner, Wirtschaftsleben.

62 Auch die Theresianische Fassion von 1713 verzeichnete für alle Dörfer der Herrschaft lediglich 21 Weber. 
$898^{63}, 1841$ ebenfalls ca. 900. Für den gesamten Budweiser Kreis werden für das Jahr 17891.298 Webermeister und 1.705 Webstühle genannt. ${ }^{64}$ Die besondere räumliche Konzentration auf den südwestlichen Teil des Kreises blieb demnach aufrecht. Auch Schaller nannte in seiner Topographie Böhmens das Weben als wichtige Einkommensquelle der Bevölkerung lediglich bei den Herrschaften Rožmberk, Vyšší Brod und für die Dörfer Dolní Vltavice und Rychnůvek in der Herrschaft Český Krumlov, nicht aber etwa bei den Herrschaften Nové Hrady und Zlatá Koruna. ${ }^{65}$

$\mathrm{Zu}$ belegen ist die starke Zunahme der Leinenweberei aber auch am Beispiel des Marktes Vyšší Brod. 1768 werden auf dem Herrschaftsgebiet des Klosters 72 Weber (Manufakturisten) genannt, wovon lediglich acht im Marktort, 26 in Hořice, 38 aber in den Dörfern ansässig waren. ${ }^{66}$ Eine Anfang der 1780er Jahre entstandene Liste der Zunftmeister des Marktes Vyšší Brod verzeichnete dagegen 44 Mitglieder, 19 im Marktort selbst, 25 in den zum Zunftbezirk gehörenden Dörfern. Besonders hervorzuheben ist an dieser Quelle, dass sie nun auch die Frauen als Zunftmitglieder ausweist. Nach den Namen der männlichen Meister wurde jeweils angeführt: „und sein Haußfraw “ ${ }^{67}$ Die Weber von Vyšší Brod erzeugten laut Manufakturtabelle von 1753 relativ schmale Gewebe mit einer Breite von 1,25 Wiener Ellen, dementsprechend klein waren auch deren Webstühle. Vermutlich war der vergleichsweise geringe ökonomische Wert der kleinen und einfachen Webstühle mit ein Grund dafür, dass in den zahlreichen untersuchten Quellen der Pfarre Kapličky - wie den Übergabeverträgen, etc. - kaum je Webstühle genannt wurden.

Besonders gut lässt sich die Konjunktur der Textilproduktion ab der zweiten Hälfte des 18. Jahrhunderts an den Händlern dokumentieren. Im Jahre 1753 wurden für den Budweiser Teil des Bechiner Kreises vier Leinenhändler genannt. Alle vier waren in Chvalšiny ansässig und handelten nach Prag. Ein größerer Prager Leinenhändler lässt sich im Jahre 1709 auch in den Quellen für das Dorf Sviníhlavy östlich von Rožmberk nachweisen. ${ }^{68}$ Insgesamt sicherlich wichtiger war aber, besonders um 1800, der - zum Teil über Mühlviertler Händler vermittelte - Verkauf nach Süden und Osten. Der aus Frymburk stammende Großverleger J. P.

63 Záloha, Průmyslove, 150. Die Zahl der hierin inkludierten Schafwoll- und Baumwollweber war wohl nur gering.

64 Blau, Hausindustrie (Bd 2), 68.

65 Vgl. Schaller, Topographie, 132-191.

66 Archiv Klastera Vy̌šśí Brod, kart. č. 410, V/4 (Abschrift der Manufakturtabelle).

67 SOkA Č. Krumlov, C-84, Cech tkalců V. Brod, kniha č. 6. „verzeichnuß der lebendigen meister, und meisterin alhier, in marckt hochenfurth der leinweber" (undatiert).

68 Anhand einer Verlassenschaft eines Ausnehmers, dem der Händler noch 117 Gulden für verkauftes Leinen schuldete, Archiv Klastera Vyšší Brod, kart. č. 414, unpag. 
Löffler aus Weissenbach im Mühlviertel ist etwa ab den 1780er Jahren als Gläubiger in den Grundbüchern von Kapličky zu belegen. ${ }^{69}$ Mit letzterem durch Heiratsbeziehungen mehrfach verwandt waren die Greipl aus Frymburk, die wichtigste Leinenhändlerfamilie des südlichen Böhmerwaldes. Dem 1740 geborenen Bäckersohn Adalbert Greipl gelang hier, vermutlich vor allem durch bedeutende Leinwandlieferungen an das österreichische Heer während des siebenjährigen Krieges, der Aufstieg zum Großhändler. Sein Sohn Matthias hatte bereits Warenlager in Wien, Prag, Pest, Verona, Triest, Mantua und Mailand. Über den Hafen Triest ging vor allem Segeltuch auch nach Übersee. Allein auf den Märkten im ungarischen Raab verkaufte Greipl in den Jahren 1801/02 Webwaren im Wert von über 100.000 Gulden. Im Jahre 1803 belief sich ein einziger Auftrag einer Prager Firma an das Handelshaus Greipl auf 28.000 Gulden. Die Greipl - die „Fugger“ des Böhmerwaldes ${ }^{70}$ - verlegten die Weber der Umgebung, in erster Linie in der Pfarre Rychnůvek, und besaßen in und um Frymburk neben ihrem dreistöckigen Wohnhaus zahlreiche Gebäude, die der Endfertigung (Bleiche, Mange, etc.) dienten. Das Handelshaus beschäftigte noch in den 1840er Jahren mehrere hundert Weber und kam erst ab den 1850er Jahren durch die Konkurrenz der Baumwolle allmählich in die Krise. Die Greipl waren nur eine unter zahlreichen Leinenhändlerfamilien des südlichen Böhmerwaldes, wenn auch während der ersten Hälfte des 19. Jahrhunderts mit Abstand die bedeutendste. Allein in Frymburk gab es um 1770 noch zwei weitere Leinenhändler, die ebenfalls die Märkte in Wien belieferten. ${ }^{71}$

Ein Beleg für Ansätze einer Verlagsproduktion in Vy̌šś Brod findet sich für 1788. In diesem Jahr schloss die Weberzunft von Vyšší Brod mit dem „k.k. Garnsammlungs-Commando zu Goldenkronn in Böhmen“ einen Kontrakt über eine Lieferung von 222 Stück Leinwand binnen vier Monaten. ${ }^{72}$ Die Zunft ging also eine Verlagsbeziehung mit dem Militär ein (sie musste das Garn aus Zlatá Koruna selbst abholen und danach die fertige Leinwand dort abliefern). Es gibt allerdings keine Anzeichen für ein längeres Bestehen dieser Handelsverbindung. Das „Garnsammlungs-Commando“ dürfte in dem seit dem Jahre 1785 aufgehobenen ehemaligen Kloster Zlatá Koruna stationiert gewesen sein. Das Gebäude stand jedenfalls nicht, wie manchmal zu lesen, bis zur Einrichtung einer Baumwollspinnerei durch Anton B. Joss in den Jahren 1800/1801 leer ${ }^{73}$, vielmehr wurde dort

69 Vgl. zu diesem Komlosy, Industrie-Kultur, 199-202.

70 Liedl, Greiplähnl.

71 Vgl. Praxl, Leinwandhandlung, passim und Dolzer, Stifter-Kreise.

72 SOkA Č. Krumlov, C-84, Cech tkalců V. Brod, Spisy II/12, 18.1.1788.

73 So in Komlosy, Industrie-Kultur, 161. 
schon sehr bald nach der Aufhebung des Klosters eine Leinwandbleiche errichtet - laut Gallistl im Jahre 1789. ${ }^{74}$ Bereits 1787 erschien aber ein Zeitungsartikel, der von einer Garnproduktion im Klostergebäude berichtet. ${ }^{75}$ Die Bleiche wurde im Jahre 1808 aufgelöst. ${ }^{76}$

Der entscheidende Weg des Aufstiegs vom lokalen Weber oder Händler zum großen Unternehmer führte in dieser Zeit, wie auch das Beispiel Greipl zeigt, über den Besitz der zentralisierten Endfertigungsstätten (Bleiche, Appretur, etc.). Gegen Ende des 18. Jahrhunderts gab es laut den Manufakturtabellen in Südböhmen eine hohe Anzahl an Leinen- und Garnbleichen, die vor allem entlang der Moldau zwischen Frymburk und Vyšší Brod konzentriert waren. In Vyšší Brod existierten um 1790 neben der einzigen Kommerzialbleiche des Budweiser Kreises auch insgesamt 28 Hausbleichen. ${ }^{77} \mathrm{Im}$ wichtigen Weberort Horní Planá dagegen wurde offenbar bis in die 1820er Jahre nur wenig gebleicht. Die Endfertigung der hier erzeugten Waren fand vielmehr häufig in der genannten Region um FrymburkVyšší Brod und im Mühlviertel statt. ${ }^{78}$

Im südlichen Böhmerwald war die Flachsverarbeitung überwiegend Bestandteil einer gemischten bäuerlichen Ökonomie und auch für die landarme Bevölkerung nur eine Teilzeitbeschäftigung. Die meisten Familien kombinierten verschiedene Einkommensformen. In den höher gelegenen, gebirgigen Regionen des westlichen Böhmerwaldes, in denen ein hinreichendes agrarisches Standbein häufig fehlte, kombinierten viele Holzfäller ihre Arbeit in den großen herrschaftlichen Wäldern oft mit der Leinenweberei. In diesen Regionen, in denen die Weberei intensiver betrieben wurde, waren die durchschnittlichen landwirtschaftlichen Besitzgrößen deutlich kleiner als in den weiter südlich gelegenen, wo das Flachsspinnen überwog. Da das Garnspinnen fast immer lediglich ein Zusatzeinkommen bot, und keinen eigenen Beruf darstellte, ist diese Produktionsform oft nur schwer nach-

74 Gallistl, Heimatkunde, 110f., spricht von zwei Bleichen im Ort - eine im ehemaligen Kloster und eine in der Kirche St. Margareth; auch Novotný, Rozmíštění, 32, nennt für 1790 zwei Bleichen im Ort.

75 Errichtung einer ärarischen Garnfabrik im Kloster Goldenkron. K.K. Prager Oberpostamtszeitung 101 (Hg. Schönfeld), Praha 1787. Trotz einiger Anstrengungen konnte an keiner Bibliothek ein Exemplar dieser Zeitung aufgefunden werden.

76 Záloha, Průmyslove, 148.

77 Novotný, Rozmíštění, 32. Wenn Schreyer, Fabriken (Bd. 1), 53-57 in seiner Übersicht der Kommerzialbleichen Böhmens, wie auch in den meisten anderen Abschnitten seines Buches (über das Weben, etc.), Südböhmen nicht erwähnt, so lag dies wohl an dem Umstand, dass er, wie er selbst im Vorwort betont, ein besonderer Kenner des nordböhmischen Textilgewerbes war; die gewerbliche Produktion in Südböhmen hat er dagegen offenbar völlig ignoriert.

78 Essl, Oberplan, 144. Anhand der Grundbücher von Vyšší Brod (vgl. PK č. 475) kann nachgewiesen werden, dass auch in der Nähe von Kapličky für Horní Planá gebleicht wurde. 
zuweisen. Während beispielsweise der Steuerkataster von 1654 für die Dörfer der Herrschaft Vyšši Brod beinahe nie Berufsbezeichnungen wie „Weber“ oder „Spinner" nennt, wird in den summarisch pro Dorf angeführten Kommentaren beinahe durchgehend angeführt, dass die Bewohner neben ihrer wenig ertragreichen Landwirtschaft vor allem auch vom Garnspinnen und (im geringeren Maße) der Weberei lebten. Ein Chronist, der selbst in Vyšší Brod lebte und 1820 eine kurze „Topographie von Vyšší Brod“ veröffentlichte, bezeichnete Flachs als „Hauptbedürfnis eines Jeden“79.

In der zweiten Hälfte des 18. und der ersten Hälfte des 19. Jahrhunderts war Garnspinnen in Vyšší Brod und Umgebung so sehr verbreitet, dass es mindestens drei verschiedene Garnarten gab, die in großen Mengen hergestellt wurden und die für die Region als typisch angesehen werden können. Zunächst wurde, wie in vielen anderen südböhmischen Regionen, das gewöhnliche, von Leinwebern benötigte Leinengarn in großen Mengen produziert. Abnehmer dafür waren nicht nur die südböhmischen Weber, sondern vor allem auch jene der benachbarten österreichischen Weberregion des Oberen Mühlviertels. Daneben wurden im Raum Vyšší Brod und östlich davon allerdings auch große Mengen des von Bandwebern verwendeten Zwirns erzeugt. Dieser wurde nicht in der Region verkauft, sondern vorwiegend in den Zentren der Bandweberei wie Domašlyce (Taus) in Westböhmen und Groß-Siegharts im österreichischen Waldviertel. ${ }^{80}$ Schließlich wurde in Vyšší Brod in der ersten Hälfte des 19. Jahrhunderts außerdem noch eine spezielle, grobe Garnsorte in großen Mengen produziert, die von Kerzenziehern verwendet wurde. Für den Anfang des Jahrhunderts wird sogar berichtet, dieses Produkt sei die Haupteinnahmequelle der Stadt Vyšší Brod gewesen. Abgesetzt wurde diese Sorte Garn sowohl in verschiedenen Regionen des heutigen Österreich als auch in Bayern und innerhalb Böhmens. ${ }^{81}$

Die Bedeutung der Flachsverarbeitung in der Region lässt sich auch an der Existenz einer Reihe spezifischer, mit dieser Tätigkeit in Zusammenhang stehender Berufsgruppen, wie der bereits erwähnten spezialisierten Spindel-, Brechel-

79 Nenning, Materialien, 154. Die hohe Bedeutung des Garnspinnens in der Region während der frühen Neuzeit (so insbesondere im 16. und 17. Jahrhundert), wird etwa auch durch die zahlreich dokumentierten und oft viele Jahre andauernden Konflikte zwischen den Weberzünften der südböhmischen Marktorte um das Garn aus den jeweils umliegenden Dörfern unterstrichen. Vgl. dazu Zeitlhofer, Flachs.

80 Die Kleinstadt Domašlyce war mit einer Zahl von 970 für das Jahr 1808 ausgewiesenen Bandwebern der wichtigste Produktionsstandort der Bandweberei in Böhmen. In Niederösterreich war Groß-Siegharts, welches freilich weitaus geringere Produzentenzahlen aufwies, das Zentrum der Bandweberei. Vgl. Mužík, Obyvatelstvo; Meinharter/Ofner, Produktionsformen.

81 Blau, Hausindustrie (Bd. 2), 66; Nenning, Materialien, 155. 
und Spinnradmacher, ermessen. Im 19. Jahrhundert gab es im südlichen Böhmerwald nicht nur den Beruf des Leinenhändlers, sondern auch jeweils spezialisierte Flachssamenhändler, Flachshändler (wie beispielsweise den Vater des berühmten Schriftstellers Adalbert Stifter in Horní Plana), sowie eigene Garnhändler. ${ }^{82}$

Die kurze Vegetationsperiode des Flachses passte hervorragend zu den klimatischen Verhältnissen der Region, dem rauen Klima mit häufig langen Wintern. Im Mittelgebirge des Böhmerwaldes gedieh Flachs wesentlich besser als im südböhmischen Flachland. ${ }^{83}$ Im südlichen Böhmerwald wurde Flachs überwiegend erst im Mai angebaut und konnte bereits nach etwa 13 Wochen geerntet werden. Flachs wurde in der Region im Rahmen der Dreifelderwirtschaft zum Teil auch als Bestandteil der üblichen Fruchtfolge, häufiger aber - wie auch Kraut oder Hirse - in der Brache gesät. ${ }^{84}$ Dagegen war die Kartoffel in Kapličky - sobald sie sich in der Region durchgesetzt hatte - stärker als Bestandteil der Fruchtfolge etabliert. ${ }^{85}$ Die Praxis, einen Teil der Brache nicht ungenutzt zu lassen, sondern mit Flachs zu bebauen, deutet auf einen früh erfolgten Intensivierungsschritt hin. Die Beispiele belegen überdies, dass auch ,Flurzwang' eine Änderung der Fruchtfolge zuließ. Allerdings stand der Anbau von Flachs damit in Konkurrenz zur Viehzucht, da eine geringere Brache auch eine verminderte Weidefläche für Vieh bedeutete. Entschärft wurde dieses Problem dadurch, dass in der Region einerseits ausreichend Weideflächen vorhanden waren und der Flachs andererseits nur sehr geringe Anbauflächen benötigte.

Die Flachsverarbeitung war in den saisonalen Rhythmus der bäuerlichen Agrarproduktion eingebettet. ${ }^{86}$ Die zum Teil vom Wachstum der Vegetation abhängigen, aufeinander folgenden Arbeitsschritte führten im Jahresverlauf zu mehreren Phasen einer erhöhten Arbeitsintensität. Dazu zählten nicht nur die Ernte und das Garnspinnen, sondern bereits die Arbeitsschritte in den ersten Wochen nach dem

82 Während in der Stadt Vyšší Brod in den 1760er Jahren nur ein einziger Garnhändler gezählt wurde, waren es 1815 vier; 1841 wurden für die gesamte Herrschaft 19 Garnhändler genannt. Vgl. Blau, Hausindustrie (Bd. 2); Nenning, Materialien.

83 Vgl. dazu die Auflistung durchschnittlicher Hektarerträge für unterschiedliche Regionen bei: Zeithammer, Land, $50 \mathrm{f}$.

84 Blau, Hausindustrie (Bd. 2), 5; Schacherl, Flachsbau, 105; Stark, Ackerbau, 23. Zeithammer betont, dass die Kleinbesitzer Flachs und Kartoffel in der Brache, die Bauern diese jedoch als Teil der Fruchtwechselwirtschaft anbauen würden. Vgl. ders., Land, 119.

85 Bei Äckern 2. Klasse (von drei) bestand folgende Fruchtfolge: 1. Jahr: Roggen, 2. Jahr: 7/10 Hafer, 3/10 Kartoffel, 3. Jahr: 4/10 Flachs, 6/10 Brache. Lediglich bei Äckern 3. Güteklasse wurden zwei Zehntel der Brache mit Kartoffel bebaut. Quelle:, Nachweisung der Endresultate des rectificirten Arbeits- und Natural-Aufwandes bei den Kulturgattungen der Gemeinde Muenichschlag', 30. 4. 1850, NA Praha, SK Duplikat 183, Nr. 31.

86 Vgl. dazu detailliert am Beispiel einer deutschen Leinenregion: Schlumbohm, Fluctuations. 
Anbau, insbesondere das mehrfach nötige Jäten. Während die Aussaat des Samens im Süden Männerarbeit war, in anderen Teilen des Böhmerwaldes aber eher von Frauen getätigt wurde ${ }^{87}$, war das besonders zeitintensive Jäten überall Frauenarbeit. Während des Frühjahrs musste das Jäten mehrfach wiederholt werden und dauerte bei größeren Anbauflächen jeweils mehrere Wochen. ${ }^{88}$ Berichte über die hohe Arbeitsintensität beim Spinnen von Garn sind aus zahlreichen Regionen bekannt und lassen sich auch in diesem Fall belegen. ${ }^{89}$

Die spezifischen Formen der Einbindung der Flachsverarbeitung in die bäuerliche Arbeitsorganisation waren neben der Bedeutung der Viehzucht ein weiterer Grund für vergleichsweise hohe Gesindezahlen bei den Bauern der Region. Ein Vergleich mehrerer böhmischer Bevölkerungsverzeichnisse aus dem Jahr 1651 zeigte, dass die Region um Vyšší Brod die höchsten Gesindezahlen pro Haushalt aufwies. Etwa zwanzig Prozent der Bevölkerung im Alter von zehn Jahren oder mehr arbeiteten als Gesinde. ${ }^{90}$

Leinenweberei und Flachsverarbeitung erreichten in der Herrschaft Vyšší Brod insgesamt nicht jene Stärke, um zu einer völligen Umwälzung der sozialen Verhältnisse in der Region zu führen. Kennzeichnend blieb vielmehr, ähnlich wie im österreichischen Waldviertel, die „Durchdringung traditioneller bäuerlicher Familienstrukturen durch das Element der Hausindustrie“. ${ }^{91}$ Da während des 19. Jahrhunderts im südlichen Böhmerwald - ähnlich wie in zahlreichen anderen europäischen Leinenregionen - der Übergang zur mechanisierten industriellen Produktion scheiterte und die südböhmische Leinenweberei stattdessen einen langwierigen De-Industrialisierungsprozess durchlief, ist die Geschichte der Textilerzeugung in dieser Region heute weitgehend vergessen.

\subsection{Weitere gewerbliche Einkommensformen im südlichen Böhmerwald}

In Teilen der Herrschaft Vyšší Brod war ein weiteres Gewerbe, das zum Teil auch als Zulieferer für die Glashütten der Region fungierte, lange Zeit von hoher Be-

87 Blau, Hausindustrie (Bd. 2), 8.

88 Schacherl, Flachsbau; Blau, Hausindustrie (Bd. 2), 11.

89 So heißt es z.B. über das Dorf Breitenberg im nahen Dreiländereck zwischen Bayern, Böhmen und Oberösterreich: „Den Hauptnahrungszweig der Einwohner bildet ganz unstreitig der Flachsbau (...). Was Hände und Füße nur ein wenig regen kann, muss bis in die späte Nacht hinein spinnen." (Praxl, Dreiländerberg, 74).

90 Vgl. Kapitel 8.5.

91 Mitterauer, Formen, 237. 
deutung: das Handwerk der Töpfer und Hafner. ${ }^{92}$ Die Zunft dieses Handwerks war zwar, wie bei den anderen Gewerben der Region auch, im Marktort Vyšší Brod angesiedelt, zahlenmäßig dominierten zumindest im 17. und 18. Jahrhundert aber deutlich die Töpfer aus dem zur Pfarre Vyšší Brod gehörigen, vergleichsweise großen Dorfes Studánky/Kaltenbrunn. In allen drei staatlichen Katastern (1654, 1682, 1713) wurden für dieses Dorf jeweils zehn Töpfer/Hafner genannt (Tabelle 23). Das Urbar des Jahres 1530 nennt für das Dorf Studánky sieben Hafner. Neben den vielfach in größerer Zahl anzutreffenden Webern bildeten damit die Töpfer von Studánky eine Ausnahme zu den ansonsten stark in den Marktorten konzentrierten Gewerben Südböhmens. ${ }^{93}$

Tabelle 23: Berufsangaben in den Staatlichen Katastern, Dorf Studánky (1654-1713)

\begin{tabular}{lccc}
\hline Berufe & 1654 & 1682 & 1713 \\
\hline Müller & 1 & 1 & 1 \\
Weber & 1 & 3 & - \\
Töpfer/Hafner & 10 & 10 & 10 \\
Schmied & 1 & 2 & 1 \\
Sattler & 1 & 1 & - \\
Wirt & 1 & - & - \\
Schneider & - & 2 & - \\
Zimmermann & - & - & 1 \\
Keine Angabe & 18 & 14 & 20 \\
\hline Summe & 33 & 33 & 33 \\
\hline
\end{tabular}

Quelle: NA Praha, BR2; BR 30; TK 684.

Der Rohstoff für die Töpfer kam aus der nahen Umgebung. An zahlreichen Orten der Pfarre Vyšší Brod war die Erde tonhältig, besonders etwa im an der österrei-

92 Töpferton wurde in den Glashütten etwa für Behälter gebraucht, vgl. Winkelbauer, Glaserzeugung, 250. Bei der Errichtung einer Glashütte im oberösterreichischen Schlägl wurde etwa eine größere Zahl an Töpfen aus Vyšší Brod und der Region Weitra (in Niederösterreich) angefordert, vgl. Krinzinger, Glashütten. Auch in einigen anderen Orten Südböhmens, etwa in der südböhmischen Bezirkshauptstadt Kaplice, war die Töpferei traditionell recht bedeutend, vgl. Blau, Hausindustrie (Bd. 1), 10; Schmidt, Zünfte, $446 f$.

93 Dies wird auch in der Zunftordnung der Töpfer der Herrschaft aus dem Jahre 1554 ersichtlich, mit der Studánky nach lange andauernden Konflikten als einzigem Dorf - neben dem Hauptort - die Ausübung des Gewerbes erlaubt wurde. Vgl. Schmidt, Zünfte, 445f. 
chischen Grenze südlich von Studánky gelegenen kleinen Dorf Mlýnec/Lahrenbecher. Der Holzreichtum der Region kam diesem brennholzintensiven Gewerbe entgegen. Wie in zahlreichen anderen Regionen auch, übte die Mehrheit der Hafner ihr Gewerbe neben der Landwirtschaft aus. Nicht nur in Studánky, sondern auch in zahlreichen anderen Regionen Zentraleuropas verfügten die Töpfer und Hafner häufiger als andere Handwerker über ein relevantes Ausmaß an landwirtschaftlichem Grundbesitz und hielten Kühe. ${ }^{94} 1654$ zählten fünf der Hafner von Studánky zu den Bauern des Dorfes. Bauern konnten leichter als kleine unterbäuerliche Anwesen die Töpferei betreiben, da sie Platz für eine größere Feuerstelle und (aufgrund der Feuergefahr) einen hohen Rauchfang benötigten; daneben konnten sie Gesindepersonen als Hilfskräfte gut gebrauchen. Die Kachelöfen produzierenden Hafner bildeten gleichsam eine Elite unter den Töpfern. ${ }^{95}$ Erzeugt wurde daneben aber unter anderem auch relativ billiges Geschirr. ${ }^{96}$ Abgesetzt wurden die Tonwaren aus Studánky auf den Jahrmärkten der Umgebung, so etwa im nahen oberösterreichischen Bad Leonfelden. ${ }^{97}$ Südböhmische Töpferwaren, auch die aus Kaplice, wurden während der frühen Neuzeit sehr häufig in Ober- und Niederösterreich gehandelt, davon zeugen auch lange andauernde Konflikte um deren Jahrmarktteilnahme, wie etwa in Freistadt. ${ }^{98}$ Darüber hinaus verkauften die Frauen der Hafnermeister die produzierten Waren in Eigenregie in den umliegenden Dörfern der Region. Die überlieferte Erneuerung eines Zunftprivilegs für dieses Gewerbe aus dem Jahre 1779 spricht etwa von den „Häfentragerinnen, die ins Gey gehen“. ${ }^{99}$ In den Berichten der Handelskammer Budweis lassen sich in den 1850er Jahren im Gerichtsbezirk Vyšší Brod zwei spezialisierte Töpfergeschirrhändler nachweisen. ${ }^{100}$

In manchen Gegenden Südböhmens war in verschiedenen historischen Perioden auch der Bergbau von hoher Bedeutung. Für das Spätmittelalter und insbesondere das 16. Jahrhundert ist etwa der Abbau von Gold und Silber in der Herrschaft

94 Vgl. etwa Endres, Uckermark, 220 und Kahle, Hausindustrie, 26 ff., der dies für mehrere Regionen in Thüringen und Galizien feststellt.

95 Vgl. allgemein zur Geschichte des Töpferhandwerks und der Vielfalt seiner Produkte: Reith, Das alte Handwerk, 230-234; zur Geschichte der Töpfer von Studánky siehe auch: Schusser, Ofensetzer.

96 So waren etwa die in der Milchverarbeitung als Behälter verwendeten, irdenen Weidlinge' eine Hafnerware. Vgl. Beck, Handwerkliche Produktion, 173.

97 Kienzl, Geschichte, 26, 50.

98 Trachtová, Zünfte, 127-130. Vg1. auch Winkelbauer, Glaserzeugung, 250; für das späte 19. Jahrhundert: Exner, Hausindustrie, 86.

99 Archiv Kláštera Vyšší Brod, kart. č. 405, 47/1.

100 Jahresbericht der Handelskammer Budweis, Tabelle 16. 
Český Krumlov zu erwähnen ${ }^{101}$, für das 19. Jahrhundert dann vor allem der Abbau von Graphit bei Černá v Pošumavi/Schwarzbach sowie in einigen Orten in dessen näherer Umgebung. Im 19. Jahrhundert galt Černa immerhin als die bedeutendste Graphitabbaustätte Europas. ${ }^{102}$ Auch die Eisenverarbeitung hatte in der Region einige Relevanz. Zahlreiche Hammerwerke entstanden entlang der südböhmischen Flüsse - etwa entlang des Flusses Malše/Maltsch in der Herrschaft Nové Hrady. Die besondere Gründungsphase der unter anderem auch Äxte und Sägen erzeugenden Hämmer gerade in den 1780er Jahren war sicherlich eine Folge des besonderen Aufschwungs der Holzverarbeitung in der Region. ${ }^{103}$ Bereits seit 1623 existierte nur wenige Kilometer östlich von Vyšší Brod nahe des Ortes Cetviny/ Zettwing ein Sensenhammer. ${ }^{104}$ In der Herrschaft Vy̌šsí Brod selbst bestand zumindest seit dem frühen 16. Jahrhundert der sogenannte Steindlhammer an der Moldau bei Čertová Stena (in unmittelbarer Nähe des Pfarrdorfes Vyšina). ${ }^{105}$ In der Einschichte Pramhof, wenige Kilometer Moldau abwärts von Vyšší Brod gelegen, existierte im Jahre 1654 ein Eisenhammer. ${ }^{106} \mathrm{Im}$ Jahr 1824 wurde auch in Loučovice auf einem zur Pfarre Kapličky gehörigen Grundstück eine Hammerschmiede, laut Grundbuch ein ,Hackenhammer', errichtet. ${ }^{107}$

101 Im 16. Jahrhundert war der Silberabbau an mehreren Orten Südböhmens von Relevanz. Vgl. Balling, Bergbau, hier 106,116. Um 1780 kam es sogar vorübergehend zu einer neuerlichen kurzen Blüte des Goldabbaus rund um den zur Herrschaft Vyšší Brod gehörigen Marktort Hořice, die auch von einer Zuwanderung einiger Bergleute aus Kutná Hora/Kuttenberg begleitet wurde. Vgl. Essl, Krummau, 431.

102 Wenzig/Krejči, Böhmerwald, 265, 351. In den 1870er Jahren arbeiteten in den Graphitbergwerken Südböhmens rund 1000 Bergleute. Der Hauptabbau auf Graphit erfolgte seit 1811durch das Fürstenhaus Schwarzenberg - als der Gutsherrschaft der Region -, die zu diesem Zwecke eng mit dem Abnehmer des Rohstoffes, der Firma Hardtmuth kooperierte, die ihren Unternehmenssitz aus diesem Grund von Wien nach České Budějovice verlegt hatte; daneben gab es aber im Laufe des 19. Jahrhunderts auch einige genossenschaftliche Bauerngesellschaften, die jeweils mehrere Jahrzehnte lang den Graphitabbau betrieben und dadurch zu relativem Wohlstand gelangten, so etwa in den Dörfern Stuben und Mugrau. In Letzterem wurde im Jahre 1846 von 12 dem Fürsten Schwarzenberg untertänigen Bauern eine Gesellschaft zum Abbau von Graphit gebildet. Die Wohlhabenheit dieser Bauern sei an ihren bereits seit den 1830er Jahren gemauerten Steinhäusern und an den stattlichen landwirtschaftlichen Nebengebäuden ablesbar gewesen. Vgl. dazu: Anonymus, Graphitbergbau, 88-92; Balling, Bergbau, 116; Blau, Hausindustrie (Bd. 2), $234 \mathrm{ff}$.

103 Auch auf bayerischer Seite brachte die stark an Bedeutung gewinnende Holzschlägerung in der zweiten Hälfte des 18. Jahrhunderts einen Aufschwung für die Eisenhämmer. Vgl. Praxl, Dreiländerberg, 85 .

104 Novotný, Rozmíštění, hier 51f.; Teichl, Herrschaft, 423.

105 Vgl. Schmidt, Siedlungs-Geschichte, 59.

106 Kubiková, Panství Vyšší Brod, 204; Blau, Hausindustrie (Bd.1), 79.

107 SOA Třeboň, fond C Vy̌šśí Brod, PK, č. 553, fol. 36. Der Inhaber Mathias Foisner hatte hier bereits seit 1789 eine Mühle und eine Säge betrieben. 
Wie gezeigt wurde, bedarf die in der Literatur öfter zu findende Einschätzung, dass Südböhmen im Gegensatz zu anderen Teilen Böhmens auch in vorindustrieller Zeit eine ,rückständige', von der Landwirtschaft geprägte Region gewesen sei, einer Revision. ${ }^{108}$ Es handelt sich dabei offenbar um eine Rückprojektion späterer Verhältnisse. In einem Aufsatz über die regionale Verteilung der proto-industriellen Gewerbe in Böhmen erwähnt etwa der Wirtschaftshistoriker Milan Myška den südböhmischen Raum überhaupt nicht, anhand der seinem Aufsatz beigefügten Karte zeigt sich dagegen nicht nur der Norden sondern auch der Süden als gewerbereich: verzeichnet sind etwa zahlreiche Leinenbleichen, Papiermühlen, Glasund Eisenhütten. ${ }^{109}$ Während der frühen Neuzeit und bis weit ins 19. Jahrhundert war der südliche Böhmerwald keineswegs ausschließlich von der Landwirtschaft geprägt. Auch das Tal der Lužnice/Lainsitz an der südböhmisch-niederösterreichischen Grenze wurde für die vorindustrielle Zeit als „regelrechte Gewerberegion" bezeichnet. ${ }^{110}$ Diese Einschätzung kann auch auf zahlreiche andere Gebiete des südlichen Böhmerwaldes ausgedehnt werden. Erst als im 19. Jahrhundert der Übergang zur Industrialisierung in den meisten Branchen weitgehend fehlschlug, kam es zur Re-Agrarisierung Südböhmens.

Im südlichen Böhmerwald waren mit der Flachsverarbeitung und den verschiedenen Formen der Holzverarbeitung relativ gute Nebenerwerbsmöglichkeiten für die landarme Bevölkerung vorhanden. Im Umkreis von etwa 30 Kilometern Entfernung von Vyšší Brod und Kapličky lagen außerdem sowohl zahlreiche Eisenhämmer und Glashütten als auch der Graphitabbau von Černá. Im Hinblick auf die Einkommensmöglichkeiten für die während der frühen Neuzeit zahlenmäßig zunehmenden landarmen Bevölkerungsgruppen ist daher eine sehr hohe Vielfalt an außeragrarischen und gewerblichen Produktionssparten zu betonen.

108 So auch: Komlosy, Grenze, bes. 236f.

109 Myška, Proto-Industrialisierung.

110 Komlosy, Fluß, 104. Hier waren die Glaserzeugung, die Baumwollweberei, die Eisenerzeugung sowie Mühlen, Sägewerke und Gerbereien weit verbreitet. 


\section{AGRARENTWICKLUNG UND SOZIALER WANDEL: ZUR FLEXIBILITÄT TRADITIONALER LÄNDLICHER GESELLSCHAFTEN ${ }^{1}$}

\subsection{Eine statische vorindustrielle ländliche Gesellschaft?}

Die traditionale ländliche Agrargesellschaft wurde lange Zeit als statisch und wachstumsfeindlich beschrieben. Erst durch den Einfluss exogener Faktoren und den Abbau institutioneller Hemmnisse sei Wachstum ermöglicht worden. Einem raschen Wachstum der agrarischen Produktion und einer Bevölkerungszunahme wären in vorindustrieller Zeit dieselben strukturellen Faktoren entgegengestanden. Sie lassen sich im Wesentlichen mit dem Begriff der, traditionalen Agrarverfassung umschreiben. ${ }^{2}$ Feudale Strukturen hätten Investitionen der bäuerlichen Untertanen in eine Produktionsausweitung erschwert, die Entfaltung eines Bodenmarktes gehemmt und die Einführung neuer Kulturpflanzen behindert. Die untertänige Ökonomie beruhte auf einer fest gefügten Ordnung der Flur, in der Elemente individueller und kollektiver Wirtschaftsführung (Flurzwang und Allmendenbewirtschaftung) miteinander verbunden waren. Kollektive dörfliche Nutzungsformen hätten Änderungen in der Besitzverteilung, individuelle Produktionsumstellungen oder einen Siedlungsausbau verhindert. "Gruppenbezogene Privilegien gaben ihren Nutznießern den Anreiz (und die Macht), jeden Wandel zu verhindern“. ${ }^{4}$

1 Bei diesem Kapitel handelt es sich um eine überarbeitete und stellenweise stark erweiterte Version meines Aufsatzes Zeitlhofer, Wandel. Für wertvolle Hinweise danke ich Michael Kopsidis und Georg Fertig.

2 ,Die Erforschung der Landwirtschaft [war] lange Zeit durch den Blick auf die Agrarverfassung erschwert', wie Christof Dipper, Übergangsgesellschaft, 559, bemerkte. Aus der Fülle an älterer verfassungsgeschichtlicher Literatur sei hier nur auf Brunner, Haus, 107 verwiesen, in dessen Sichtweise bäuerliche Gesellschaften vom „Neolithikum bis ins 19. Jahrhundert“ vom Strukturwandel nur „wenig berührt" wurden. Dem Bild einer statischen vorindustriellen ländlichen Gesellschaft kam und kommt, meist in Kontrast zu ,dynamischen' (Proto-)Industrialisierungsprozessen, in unterschiedlichen Forschungstraditionen eine zentrale Rolle zu.

3 Selbst die sehr innovative Studie von Rainer Beck, Unterfinning, zeichnet im Hinblick auf die „Ordnung des Raumes“ im vorindustriellen Dorf ein überaus statisches Bild: diese war „festgefügt“ (85), „Veto“ stand ,gegen Veto“(83).

4 Ogilvie, Institutionen, 130. 
Speziell in Gebieten mit Gutsherrschaft hätten außerdem verschiedene Formen rechtlicher Unfreiheit (Beschränkungen der Bewegungsfreiheit, herrschaftlicher Ehekonsens, ungünstige Besitzrechte, etc.) sowohl Produktionssteigerungen als auch demographisches Wachstum begrenzt. ${ }^{5}$

In traditioneller Sichtweise korrespondierten statische vormoderne ländliche Ökonomie und Flurverfassung auch mit einer starren demographischen, Ordnung. Die Institutionen der traditionalen Agrarverfassung hätten in (west-)europäischen vorindustriellen Gesellschaften Bevölkerungszahl und agrarische Ressourcen durch die Bindung von Heirat und Fortpllanzung an den Zugang zu Landbesitz aufeinander abgestimmt. ${ }^{6}$ Dadurch wäre ein rasches Bevölkerungswachstum, das die vorhandenen ökonomischen Kapazitäten der traditionalen Agrarwirtschaft ,überfordert" und zur „Unterschreitung der Konsumnorm“7 geführt hätte, verhindert worden. Erst die - überwiegend staatlich durchgeführten - Agrarreformen des späten 18. und frühen 19. Jahrhunderts hätten die ,alte Ordnung، aufgebrochen und damit Wachstum ermöglicht. Insbesondere den Teilungen der Allmenden wurde dabei eine zentrale Rolle zugesprochen: Dies hätte zu einem markanten Siedlungsausbau und einem rapiden Anwachsen der ländlichen Unterschichten und durch die Vergrößerung der individuell genutzten Flächen zu einer intensiveren Bewirtschaftung geführt. ${ }^{8}$

Die neuere agrarhistorische Forschung hat inzwischen allerdings die Bedeutung der Agrarreformen relativiert ${ }^{9}$ und für zahlreiche europäische Regionen nachgewiesen, dass über lange Zeiträume hinweg auch unter Beibehaltung des institutionellen Rahmens der traditionalen Landwirtschaft eine kontinuierliche Steigerung

5 Grund- und Gutsherrschaft gelten als „Haupthemmnis rationeller landwirtschaftlicher Produktion“ (Münch, Lebensformen, 52). Vgl. dagegen die differenzierte Diskussion der Auswirkungen dieser Aspekte auf das Agrarwachstum bei: Zimmermann, Traditionalismus, $228 \mathrm{f}$. An neuerer Literatur, die zum Teil auch eine Neubewertung der Frage persönlicher und ökonomischer Unfreiheit unter den Bedingungen der Gutsherrschaft vornimmt, vgl. neben Peters, Gutsherrschaft, etwa Cerman, ProtoIndustrialisierung.

6 Mackenroth, Bevölkerungslehre, 421-432. Für eine ausführliche Kritik an diesen Annahmen siehe Kapitel 7, sowie: Ehmer, Heiratsverhalten, 64-67; Fertig, Heirat.

7 Mackenroth, Bevölkerungslehre, 428.

8 Vgl. etwa Mooser, Ländliche Klassengesellschaft, 127f. und Mager, Protoindustrialisierung, 466.

9 Vgl. besonders: Brakensiek, Gemeinheitsteilungen; Friedeburg, Taglöhner. Georg Fertig, Gemeinheitsteilungen, zeigt, dass Allmendteilungen nicht durchgeführt wurden, weil die Grenzen des möglichen Wachstums spürbar geworden wären, sondern weil sie staatlich gewollt und für individuelle Interessenten von Vorteil waren. Brakensiek, Agrarreformen, 431f. zeigt darüber hinaus, dass sich die Intention der preußischen Gemeinheitsteilungen, nämlich Mobilität in den Bodenmarkt zu bringen, nicht erfüllte, weil die Bauern das neu hinzugekommene Land einfach in ihren Besitz integrierten und keinen Handel damit trieben. 
der agrarischen Produktion möglich war. Dieser Befund gilt für ganz unterschiedliche Agrarverfassungen und deutet darauf hin, dass der institutionelle Rahmen der alteuropäischen Landwirtschaft vor den Agrarreformen wesentlich flexibler und anpassungsfähiger war als bisher angenommen. Spielräume für eine Steigerung der agrarischen Produktion bestanden etwa in den Möglichkeiten, die dörfliche Produktion an veränderte Nachfrage- und Marktbedingungen anzupassen oder den Anteil individuell bewirtschafteter Flächen auszudehnen. ${ }^{10}$ Davon unabhängig haben andere Studien gezeigt, dass zahlreiche frühneuzeitliche Agrargesellschaften bereits vor den Agrarreformen ein starkes und kontinuierliches demographisches Wachstum aufwiesen, das überwiegend von einem deutlichen Anstieg des Anteils der landarmen Bevölkerungsgruppen getragen wurde, sodass diese oft bereits während der frühen Neuzeit zahlenmäßig die Mehrheit unter den ländlichen Anwesen bildeten. ${ }^{11}$

Die bisher weitgehend unverbundenen Ergebnisse neuerer agrarhistorischer und historisch-demographischer Studien geben Anlass, die Zusammenhänge von Demographie und Ökonomie in vorindustrieller Zeit neu zu überdenken. Bedingten demographisches und ökonomisches Wachstum einander gegenseitig? Von Malthus bis Mackenroth wurde das Verhältnis zwischen Bevölkerung und agrarischen Ressourcen als einseitige Kausalkette - der Nahrungsspielraum begrenzte die Bevölkerungszahl - gedacht, nicht als ein wechselseitiger Prozess. ${ }^{12}$ Eine Steigerung des agrarischen Outputs war freilich eine Vorbedingung dafür, um eine wachsende Bevölkerungszahl ernähren zu können. Weniger klar scheint dagegen der Einfluss demographischen Wachstums auf die agrarische Produktion. Entscheidend war vor allem, in welcher Form und in welchem Ausmaß diese Entwicklung zu zusätzlichen Arbeitskräften im Agrarsektor führte. ${ }^{13}$ Wachstum im vorindustriellen Agrarsektor war eher arbeits- als kapitalintensiv. ${ }^{14}$ Arbeit und Arbeitsintensivierung bildeten die zentralen produktionstechnischen Faktoren, die den Agrarproduzenten in ausreichendem Maße zur Verfügung standen. Produktionssteigerungen konnten vor allem durch Ausdehnung der Anbauflächen (wofür

10 Vgl. für deutsche Regionen etwa Kopsidis, Entwicklung; Enders, Uckermark, besonders 585-591.

11 Vgl. etwa Kriedte, Spätfeudalismus, 179-181; Trossbach, Bauern, 36-44; Schlumbohm, Lebensläufe; Beck, Unterfinning; Ehmer, Heiratsverhalten, 68; für Böhmen vor allem Cerman, Ursprünge. Siehe dazu auch Kapitel 5.4.

12 Vgl. Gehrmann, Verhältnis, 32.

13 Sofern ländliche Unterschichten nicht nur Arbeitskräfte, sondern auch landwirtschaftliche Produzenten waren, konnten sie manchmal auch Träger der Innovationen und der agrarischen Intensivierung sein. Vgl. Zimmermann, Traditionalismus, 235 f. Vgl. andererseits zu den von Großbauern ausgehenden Tendenzen eines ,Bauernkapitalismus', Trossbach, Bauern, 65.

14 Vgl. Kopsidis, Entwicklung, 132. 
zusätzliche Arbeitskräfte benötigt wurden) oder aber durch eine Steigerung der Arbeitsleistung pro Arbeitskraft erzielt werden.

Durch das allmählich sichtbar werdende, auch den traditionalen Agrargesellschaften innewohnende Veränderungspotenzial erscheint manchen Autoren nunmehr das Bild einer ,starren“ Agrarverfassung eher als „ein ins Objekt projizierter Ausdruck gedanklicher Erstarrung "15 der Verfechter dieser Sichtweise. Dennoch ist für vormoderne Gesellschaften weiterhin „sozialregulativen Normen viel Gewicht ${ }^{\text {"16 }}$ beizumessen, wenn sich auch deren Bedeutung nicht generalisieren lässt. Letztendlich bestimmte der konkrete lokale institutionelle und konjunkturelle Rahmen die Entscheidungen der agierenden Wirtschaftssubjekte und nicht irgendwelche angenommenen allgemeinen Prinzipien einer wie auch immer definierten ,Wirtschaftsordnung. Im Folgenden wird am Beispiel der Pfarre Kapličky der Zusammenhang zwischen Agrar- und Bevölkerungswachstum über zweihundert Jahre (1640 - 1840) für eine Agrarverfassung untersucht, die sich als eine relativ milde Form der Gutsherrschaft bezeichnen lässt. Folgende leitende Fragestellungen stehen dabei im Vordergrund:

1. Welche Institutionen der Agrarverfassung erlaubten bei günstigen ökonomischen Rahmenbedingungen eine Ausdehnung der Nutzflächen und Behausungen selbst bei einer im Prinzip äußert rigiden Regelung des Zugangs zu Landbesitz wie in Kapličky?

2. Welche ökonomischen Faktoren führten zu einer dichteren Besiedlung und Nutzflächenausdehnung? Erfolgte die zunehmende Besiedlungsdichte in einem kontinuierlichen Prozess oder vollzog sie sich in Schüben mit langen Stagnationsphasen?

3. Welche Beziehungen bestanden in Kapličky zwischen demographischer Expansion und Agrarentwicklung? Waren grundlegende Änderungen des institutionellen Rahmens überhaupt notwendig, damit die landwirtschaftliche Erzeugung mit dem Bevölkerungswachstum Schritt hielt? Deuten demographische Indikatoren darauf hin, dass es zu sinkendem Lebensstandard kam als Zeichen für eine „Überforderung“ der überkommenen Ordnung?

4. Welche Rolle spielten ländliche Unterschichten, welche die Bauern im Wandel der Agrarproduktion? Ermöglichten es die institutionellen Rahmenbedingungen den Unterschichten, auch als Agrarproduzenten tätig zu werden, oder wiesen sie diesen lediglich eine Rolle als unselbstständige Arbeitskräfte zu?

15 Vgl. Trossbach, Anthropologie, 195.

16 Mathieu, Agrargeschichte. 


\subsection{Wesentliche Charakteristika des lokalen Agro-Systems: Landnutzung und Feldsysteme}

Die traditionale Agrarverfassung mit gutswirtschaftlichen Strukturen ${ }^{17}$ und kollektiven dörflichen Nutzungsformen (Flurzwang und Allmendennutzung) als wesentlichste Kennzeichen blieb in der Region bis weit ins 19. Jahrhundert hinein bestehen und müsste der älteren Theorie folgend den Möglichkeiten zum Siedlungsausbau und zur Veränderung der Landnutzung enge Grenzen gesetzt haben. Spätestens seitdem die Verödungen in Folge des Dreißigjährigen Krieges beseitigt waren, befand sich - wie auch in anderen Teilen Böhmens - das gesamte Land in der Pfarre geteilt in herrschaftliches Dominikalland einerseits und untertäniges Rustikalland andererseits. Die Abgrenzung von Dominikal- und Rustikalland wurde während des 17. und frühen 18. Jahrhunderts endgültig festgeschrieben und vom frühneuzeitlichen Staat überwacht. ${ }^{18}$ An dieser Verteilung änderte sich in der Regel nichts mehr.

Der bei Weitem größte Grundbesitzer in der Pfarre war das Zisterzienserkloster als Gutsherrschaft. Dieses Dominikalland des Klosters bestand in erster Linie aber aus Wald, an dem die Untertanen nur geringe Flächen innehatten. Die Gutsherrschaft hatte in der Regel kein Interesse daran, Teile ihres Dominikallandes in untertäniges Rustikalland umzuwidmen, weil diese Umwidmung nicht mehr rückgängig gemacht werden konnte. Die bäuerlichen Anwesen bildeten eine unteilbare Einheit aus Haus, Landbesitz und verschiedenen Nutzungsrechten am Gemeindegrund. Teilungen der bäuerlichen Betriebseinheiten ließ die Gutsherrschaft nicht zu, da ihre Ökonomie wesentlich auf Abgaben und Spannrobot der Grund besitzenden Untertanen beruhte.

In den Höhenlagen des Böhmerwaldes bestimmte der Wald das Landschaftsbild. Ungeachtet der seit dem Mittelalter mit je nach Zeitperiode unterschiedlicher Intensität bis ins späte 19. Jahrhundert immer wieder vorangetriebenen Rodungstätigkeit im südlichen Böhmerwald blieb die Pfarre Kapličky immer überaus waldreich. Die dem Stabilen Kataster aus der ersten Hälfte des 19. Jahrhunderts beiliegenden Grundparzellenprotokolle für die beiden Steuergemeinden Krasné Pole (Schönfelden) und Mnichovice (Münichschlag), die mit dem Gebiet der Pfarre annähernd identisch waren, ${ }^{19}$ belegen die Dominanz des Waldes, der noch zu die-

17 Vgl. Kapitel 2.3 und Zeitlhofer, Vielfalt, bes. 15-18.

18 Dies war auch eine wichtige Ursache für die Anlage der drei ältesten böhmischen Steuerkataster. Das Rustikalland war dadurch unantastbar. In den Beilagen des Katasters von 1713 werden etwa umstrittene Zuordnungen und Parzellengrößen aufgelistet und mit den Angaben in den früheren Erhebungen abgeglichen.

19 Der kleine, nicht zu Kapličky, sondern zur benachbarten Pfarre Vyšší Brod gehörige Weiler Valtov war Teil der Gemeinde Mnichovice. Dagegen fehlte der 1787 von der Pfarre abgetrennte Ort Vyšina, 
ser Zeit etwa die Hälfte der Fläche einnahm, und geben darüber hinaus bereits einen ersten Eindruck von den lokalen Wirtschaftsformen. Von einer Gesamtfläche der beiden Gemeinden im Ausmaß von 6.345 Joch waren knapp 973 Joch Äcker (15,3 \%), 1.215 Joch Wiesen (19,1 \%), 989 Joch Weiden (15,6 \%) und 3.057 Joch Wald (48,2\%). Der Rest verteilte sich auf Hausgründe und -gärten, Teiche, Sümpfe und Ödungen $(1,2 \%) .{ }^{20}$ In der zweiten Hälfte des 17. Jahrhunderts wäre diese Verteilung mit Sicherheit noch weitaus deutlicher zugunsten des Waldes ausgefallen, da in der Zwischenzeit viel Wald gerodet worden war. In anderen mitteleuropäischen Dörfern der frühen Neuzeit überwog dagegen der Anteil von Wiesen und Ackerland deutlich. ${ }^{21}$

Das Kloster besaß in erster Linie Wald, an dem die Untertanen nur geringe Flächen innehatten. Anhand des Anteils des Waldes an der Gesamtfläche der Pfarre lässt sich der Besitzanteil der Herrschaft für die erste Hälfte des 19. Jahrhunderts auf etwa 40 Prozent schätzen. ${ }^{22}$ Nach dem Theresianischen Kataster von 1713 hatten auch 36 untertänige Anwesen der Pfarre einen geringen eigenen Waldbesitz, außerdem besaßen manche Dorfgemeinden kleine Waldflächen. Das Ackerland dagegen war weitgehend im Besitz der Untertanen. Zur Mitte des 17. Jahrhunderts wurde von beinahe allen Anwesen der Pfarre Ackerbau betrieben. Neben dem Individualbesitz der Untertanen war ein kleinerer Teil des Rustikallandes, überwiegend Weiden, im Eigentum der Dorfgemeinden. Diese Flächen setzten sich jeweils aus einer kleineren, direkt in der Ansiedlung (oft im Ortskern) gelegenen Weidefläche und der größeren, eigentlichen Allmende zusammen, die abseits des Ortes lag. Die auf Rustikalland befindlichen Wiesen wurden nur zum Teil individuell, häufiger jedoch in gemeinsamer Bewirtschaftung des Dorfes als Weideland genutzt. ${ }^{23}$

Die Dörfer der Pfarre waren überwiegend hochmittelalterliche Rodungsdörfer mit Gemengelage. Wie in zahlreichen anderen Regionen auch, wurde eine Dreifelderwirtschaft mit Flurzwang und einer gemeinsamen Viehweide auf den brachlie-

der nur um wenige Häuser größer als Valtov war, sodass sich $\mathrm{Zu}$ - und Abschlag von Gebietsteilen im Ergebnis in etwa ausglichen.

20 Quellen: NA Praha, Stabilní katastr (SK) 323: ,Ausweis über die Benutzung des Bodens. Steuergemeinde Schönfelden' (1827); NA Praha, SK 221: ,Grundparzellenprotokoll der Steuergemeinde Muenichschlag' (1827).

21 Im bayerischen Dorf Unterfinning betrug Anfang des 18. Jahrhunderts der Anteil des Waldes lediglich etwa 30\% der Gemarkung. Vgl. Beck, Unterfinning, 52, 60, 62.

22 Genauere Angaben zum Anteil des herrschaftlichen Besitzes liegen nur für das gesamte Herrschaftsgebiet (hier lag der Anteil bei etwa 20 Prozent), nicht aber gesondert für die Pfarre vor. Die herrschaftsweite Verteilung ist nicht direkt auf Kapličky übertragbar, da in den anderen, weniger waldreichen Teilen der Herrschaft der Anteil des dominikalen Eigenbesitzes deutlich geringer war.

23 Vgl. auch Schlögl, Krise, 163. 
genden Feldern sowie der Allmende betrieben. ${ }^{24}$ Die gemeinschaftliche Beweidung der Felder erforderte einen aufeinander abgestimmten Beginn der Feldarbeiten sowie eine saisonale Abgrenzung (Einzäunung) der Weideflächen von den Äckern und Wiesen. In der Region um Vyšší Brod war die Einzäunung der Brache laut tradierter Marktordnung jährlich bis spätestens ,Georgi' (23. April) vorgeschrieben. ${ }^{25}$ Wie ein Blick in den sogenannten ,Stabilen Kataster ${ }^{6}$ der 1820er Jahre, der alle Feldparzellen einzeln verzeichnete, zeigt, war die Flur speziell in den Dörfern der Gemeinde Krasné Pole sehr abgeschlossen. In den hier gelegenen Dörfern (wie Kapličky, Dobřin, etc.) gab es keinen einzigen außerhalb der Gemeinde wohnenden Parzellenbesitzer. In den näher zu Vyšší Brod gelegenen Dörfern wie etwa in Martinkov dagegen, kamen auch einige außerhalb der Gemeinde wohnende Parzelleninhaber, darunter etwa Bürger aus dem Marktort Vyšší Brod, vor. ${ }^{26}$

Die Allmenden bildeten das materielle Rückgrat der Gemeinden. ${ }^{27}$ Allmendgründe gab es in der Region in großer Zahl. Die zahlreichen kleinen Weiler der Pfarre lagen zum Teil in größerer Entfernung voneinander. Bedingt durch diese Siedlungsstruktur hatte - mit Ausnahme der drei kleinsten Ansiedlungen, die jeweils nur aus zwei oder drei Anwesen bestanden - jeder Weiler seine eigene Allmende. Mehrere Weiler beschäftigten auch eigens angestellte Viehhirten. Die Häuser der Hirten standen oft direkt auf dem Gemeindegrund und damit häufig weit außerhalb des Dorfes. ${ }^{28}$ Nutzungsrechte an der Allmende waren insbesondere für die kleinen Anwesen von hoher Bedeutung, da sie die Ungleichverteilung des Besitzes in der Flur etwas ausglichen. Selbst marginale Nutzungsrechte konnten für die Existenz der landarmen Dorfbevölkerung überlebenswichtig sein. Nicht völlig zu klären ist, in welchem Maß die unterbäuerlichen Hausbesitzer von Kapličky Zugang zur Dorfallmende hatten. Aus der Region finden sich jedenfalls mehrere Hinweise dafür, dass sie zumindest begrenzte Nutzungsrechte hatten und selbst landlose Inwohnerfamilien nicht immer gänzlich ausgeschlossen blieben. So wurde etwa im nahen Frymburk im Jahre 1672 beschlossen, dass Inwohner und Ausnehmer jeweils nur eine Kuh und ein Kalb zur Viehweide treiben durften. ${ }^{29}$ Auch im zur selben Herrschaft gehörigen Marktort Hořice wurde den Inwohnern die Haltung einer Kuh erlaubt - sie mussten allerdings dafür bezahlen. ${ }^{30}$ In der Pfarre scheint es - anders als in manchen anderen Regionen des südlichen

24 Vgl. grundlegend dazu etwa Winkelbauer, Grundherrschaft, $60 \mathrm{ff}$.

25 Vgl. dazu Blau, Hausindustrie (Bd.1), 201.

26 NA Praha, SK 221 Operat.

27 Trossbach, Bauern, 26.

28 Blau, Hausindustrie (Bd.1), $178 f$.

29 Vgl. Stark, Abhängigkeitsverhältnisse, hier 372.

30 Archiv Klaštera Vyšší Brod, Kart. č. 405, 46/3: ,Markordnung Höritz (3. 6. 1720). 
Böhmerwaldes - keine Wälder im Besitz der Gemeinde gegeben zu haben. Die Viehweide in den überaus großen herrschaftlichen Wäldern des Böhmerwaldes war dafür bis weit ins 19. Jahrhundert verbreitet. ${ }^{31}$

Infolge der hohen Bedeutung der Allmendenutzung hatten die Dorfgemeinden ein großes Interesse an einer Beschränkung der Häuserzahl. Jedes zusätzliche Anwesen mit Besitz an Großvieh hätte einen zusätzlichen Mitbenützer der Dorfallmenden bedeutet und jede Verkleinerung der Weideflächen hätte potenziell den Viehbestand der existierenden Anwesen gefährdet. Entsprechend selten kam dies vor. Das Ausbleiben der Teilung der Allmenden in Kapličky wäre in traditioneller Sichtweise der Sozialgeschichte als Anzeichen eines nur mäßigen sozialen Wandels und nur bescheidener Produktionssteigerungen in der lokalen Landwirtschaft zu werten. Die Allmendebewirtschaftung bestand in der Pfarre zumindest bis in die zweite Hälfte des 19. Jahrhunderts. ${ }^{32}$ Die in anderen Regionen Zentraleuropas seit der zweiten Hälfte des 18. Jahrhunderts teilweise durchgeführten Gemeinheitsteilungen hatten - je nach ihrem Charakter - auf die einzelnen sozialen Gruppen im Dorf ganz unterschiedliche und zum Teil gegensätzliche Auswirkungen. ${ }^{33}$ Im nahen Horní Plana hatten bei der Aufteilung eines großen Teils der Allmende im Jahr 1827 auch die landarmen Häusler Anteile erhalten. ${ }^{34}$ Für die Region um Kapličky gibt es Hinweise darauf, dass der Flurzwang bis weit ins 19. Jahrhundert bestehen blieb. Aus Vyšší Brod wird 1820 berichtet, dass zwar seit kurzer Zeit in geringem Ausmaß Klee angebaut werde, aber die Beweidung der Brache immer noch üblich ist. ${ }^{35}$ Nur langsam und graduell wurde die klassische Dreifelderwirtschaft mit dem Anbau neuer Zwischenfrüchte in der Brache gegen Ende des 18. Jahrhunderts durchbrochen. Dazu dürfte es in diesem Gebiet etwas früher als in den meisten Regionen des heutigen Österreich gekommen sein. Die Kartoffel war

31 Blau, Viehweiden, 3.

32 Im Pfarrdorf Hodoň kam es 1869 zur Aufteilung der Allmende unter den acht Grund besitzenden Anwesen, die drei Häuser mit marginalem Grundbesitz gingen dabei leer aus. Diese Regelung wurde nachträglich in das patrimoniale Grundbuch eingetragen, obwohl dieses eigentlich nur bis zur Aufhebung der Grundherrschaften um 1848/1850 geführt wurde. Vgl. SOA Třeboň, fond C Vyšší Brod, PK č. 475 .

33 Vgl. dazu den sehr informativen Vergleich des Verlaufs und der Auswirkungen von Allmende-Teilungen in verschiedenen deutschsprachigen Regionen bei Weitensfelder, Interessen, 31-38. Vgl. außerdem die detaillierten Fallstudien zu Norddeutschland: Fertig, Gemeinheitsteilungen und Brakensiek, Agrarreformen. Siehe außerdem: Zückert, Allmende.

34 Essl, Oberplan, 31f. Ebenso erhielten im bei Horní Plana gelegenen Dorf Stuben auch die kleinen Besitzer bei der Aufteilung der Hutweiden zu Beginn des 19. Jahrhunderts Anteile. Vgl. Essl, Krummau, 717. In Volary dagegen wurden die Hutweiden im Jahr 1810 nur unter den weideberechtigten Altbürgern geteilt. Vgl. Praxl, Holzhäuser, 146.

35 Nenning, Materialien, 154. 
in der Region wohl bereits in den 1770 er Jahren relativ verbreitet ${ }^{36}$ und bildete seit dem frühen 19. Jahrhundert eine sehr wichtige Nahrungsgrundlage der Bevö1kerung. In Kapličky wurden Kartoffeln und Flachs zum Teil aber nicht als Zwischenfrucht, sondern als Bestandteil der Fruchtfolge ausgesät. Nach den Angaben des Stabilen Katasters zur Mitte des 19. Jahrhunderts bestand bei Äckern der 2. Klasse (von drei) folgende Fruchtfolge: 1. Jahr: Roggen, 2. Jahr: 7/10 Hafer, 3/10 Kartoffel, 3. Jahr: 4/10 Flachs, 6/10 Brache. Lediglich bei Äckern 3. Güteklasse wurden zwei Zehntel der Brache mit Kartoffeln belegt. ${ }^{37}$ Klee wurde um Vyšší Brod ab etwa 1800 angebaut. ${ }^{38}$ Noch 1893 forderte ein Agrarreformer für den südlichen Böhmerwald die Aufhebung des in manchen Orten weiterhin bestehenden Flurzwangs. ${ }^{39}$

\subsection{Demographisches Wachstum von der Mitte des 17. bis zur Mitte des} 19. Jahrhunderts

In der Pfarre Kapličky vollzog sich während der frühen Neuzeit innerhalb der überlieferten Agrarverfassung mit ihren institutionell verankerten Begrenzungen ein markantes demographisches Wachstum. Die Einwohnerzahl der Pfarre erhöhte sich ebenso wie die Zahl der Familien deutlich. Um 1650 zählte die Pfarre Kapličky vermutlich nur etwas mehr als 500 Einwohner (im Jahre 1651 wurden 383 Personen gezählt, die älter als zehn Jahre waren), ${ }^{40}$ im Jahre 1860 waren es dagegen 1.306 Einwohner. ${ }^{41}$ Die Entwicklung der Einwohnerzahlen der Pfarre lässt sich für die vorstatistische Periode anhand der Verzeichnisse der, Kommunikanten“ - d. h. der ,beichtfähigen' Personen der Pfarre (also unter Ausschluss aller Kinder

36 Dies lässt sich für Orte in der nahen Umgebung belegen. Vgl. Fischer, Naturereignisse, 6; Wasmayr, Ulrichsberg, 462f., 472f. Um 1830 waren die Anbauflächen für die Kartoffel in Böhmen weitaus größer als in den meisten Gebieten Österreichs. Die frühesten Belege der Kartoffel im heutigen Österreich finden sich überwiegend im an Südböhmen unmittelbar angrenzenden Mühlviertel. Vgl. Sandgruber, Kartoffeln, 166.

37 Quelle: NA Praha, SK Duplikat 183, Nr. 31: ,Nachweisung der Endresultate des rectificirten Arbeitsund Natural-Aufwandes bei den Kulturgattungen der Gemeinde Muenichschlag' (30. 4.1850).

38 Nenning, Materialien, 154.

39 Anderegg, Verhältnisse, 31.

40 Das Soupis poddaných des Jahres 1651 (NA Praha, SM R 109/45) verzeichnete bei dieser Herrschaft keine Kinder vor dem Erstkommunionsalter (ca. mit 10 Jahren).

41 Trajer, Historisch-statistische Beschreibung, 260; 1880 zählte Kapličky 1.329 Einwohner. Für die Pfarre Vyšší Brod sind die Angaben zur Einwohnerzahl zahlreicher: 1713: ca. 1990, 1815: 2.528, 1860: 3.636, und im Jahr 1880: 3.740 Einwohner. Quelle: NA Praha, APA I, sign. B14/22, fol. 177; Nenning, Materialien, 154; Trajer, Beschreibung, 251; Mardetschläger, Budweis, 225-231. 
unter etwa zehn Jahren) - nur annähernd rekonstruieren. Erst für die zweite Hälfte des 19. Jahrhunderts liegen dann Angaben zur gesamten Einwohnerzahl der Pfarre vor. Die Verzeichnisse der Kommunikanten zeigen einen sehr deutlichen Anstieg der Einwohnerzahlen während der frühen Neuzeit (Graphik 2). ${ }^{42}$ Die Verwendung von Indexzahlen in Graphik 2 ermöglicht dabei eine Vergleichbarkeit des demographischen Wachstums in der Pfarre mit dem in der benachbarten Pfarre Vyšší Brod. Dieser Vergleich zeigt für Kapličky ein deutlich stärkeres Wachstum. Bis in die 1690er Jahre konnte die Entwicklung in Vyšší Brod noch mit Kapličky Schritt halten, der neuerliche, kontinuierliche Aufwärtstrend im 18. Jahrhundert (nach einigen Jahren der Stagnation) fiel in der Pfarre des Marktortes aber weit schwächer aus als in der Pfarre Kapličky. Sicherlich beruht der Unterschied auch auf der stärkeren Siedlungstätigkeit in der waldreichen Pfarre Kapličky. Für Kapličky ist zwischen 1651 und dem späten 18. Jahrhundert damit wohl mehr als eine Verdoppelung der Bevölkerungszahl festzustellen, bis zur Mitte des 19. Jahrhunderts eine Verdreifachung. In Vyšší Brod stieg die Kommunikantenzahl innerhalb von etwa 130 Jahren um mehr als die Hälfte an. Diese Ergebnisse deuten auf ein selbst im interregionalen Vergleich mit stark wachsenden Kommunen beachtliches Bevölkerungswachstum hin. ${ }^{43}$ Es gab ja auch Orte, in denen die Bevölkerungszahl im 18. (und im 19.) Jahrhundert weitgehend stagnierte. ${ }^{44}$ Obwohl das demographische Wachstum in einzelnen Teilen Südböhmens ebenfalls sehr hoch war, so lag es doch im Allgemeinen unterhalb desjenigen in den nördlichen Landesteilen Böhmens. Böhmen insgesamt wies noch während der zweiten Hälfte des 18. Jahrhunderts deutlich höhere Wachstumsraten als etwa Deutschland (in den Grenzen von 1871) oder Österreich (in den heutigen Grenzen) auf. Erst im frühen 19. Jahrhundert ging dieser Vorsprung Böhmens verloren. ${ }^{45}$

42 Die Zahlen nach den Meldungen der Pfarrer an den Prager Erzbischof: NA Praha, Archiv pražského arcibiskupství (APA) I, B, Vicariat Crumlov.

43 Im norddeutschen Kirchspiel Belm kam es zwischen 1662 und 1858 zu etwas mehr als einer Verdoppelung der Einwohnerzahl. Vgl. Schlumbohm, Lebensläufe, 49; ders., Micro-History and the Macro-Models. Im württembergischen Neckarhausen verdreifachte sich die Einwohnerzahl beinahe zwischen 1700 und 1870. Vgl. Sabean, Property, 41,

44 Beispiele dafür sind etwa das württembergische Laichingen oder Innichen in Südtirol. Vgl. Medick, Weben, 305f.; Lanzinger, Das gesicherte Erbe, $179 \mathrm{ff}$.

45 Vgl. Maur, Gutsherrschaft, 213; Cerman/Maur/Zeitlhofer,Wirtschaft. Vgl. dazu die Daten bei: Dipper, Übergangsgesellschaft, 61 . 
Graphik 2: Die Entwicklung der Zahl der ,Kommunikanten' in den Pfarren Kapličky und Vyšší Brod in ausgewählten Jahren (Index: $1651=100)$

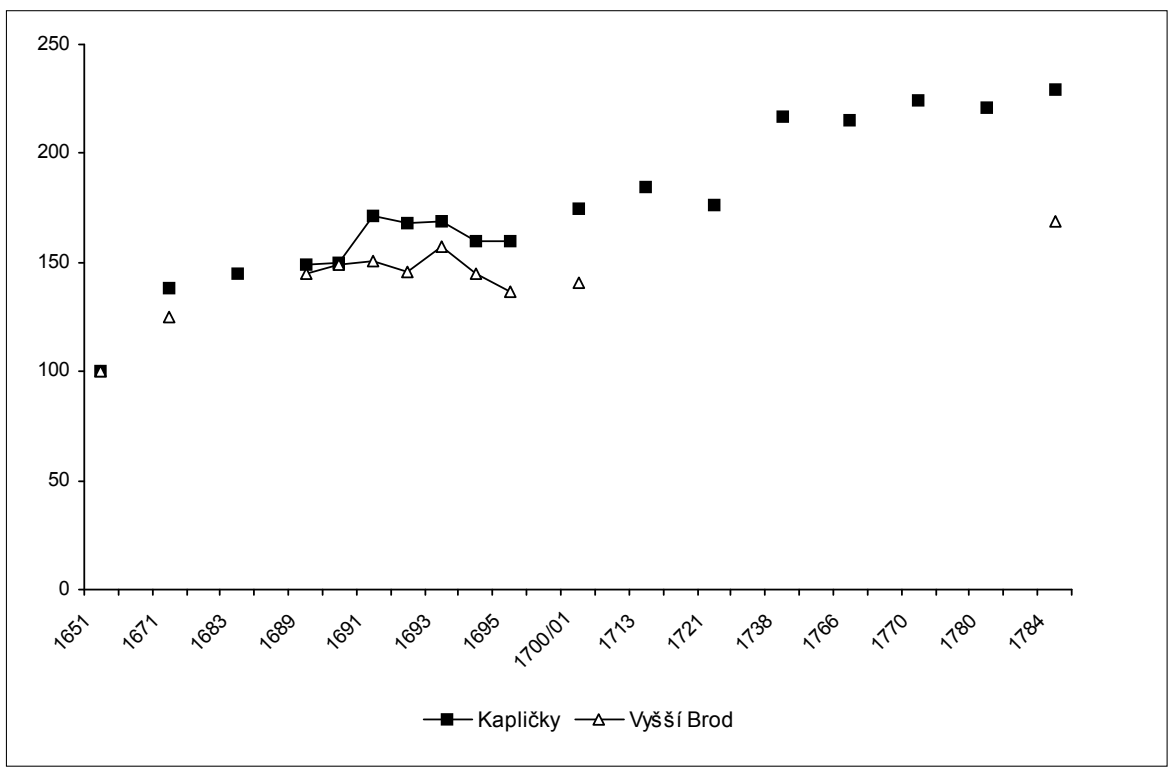

Quelle: NA Praha, APA I, B. Consignatio paschalis. Vicariat Český Krumlov.

Anmerkung: Die Pfarrer waren angehalten, ihrem Erzbischof jährlich Bericht über die Zahl der, Kommunikanten' (d. h. Personen ab einem Alter von etwa 10 Jahren) in ihrer Pfarre zu melden. Auf dieser Basis lässt sich eine vorsichtige Schätzung der gesamten Einwohnerzahl einer Pfarre durchführen. Die Überlieferung dieser Daten weist für alle Pfarren Lücken auf. Für die Pfarre Vy̌šśi Brod konnten nur wenige Berichte gefunden werden. In der Graphik sind die jährlich aufeinander folgenden Werte mit einer durchgehenden Linie verbunden.

In beiden Pfarren weist die Zahl der Kommunikanten zwischen etwa 1691 und 1695 eine rückläufige Tendenz auf, deren Ursache unklar ist. Für die Pfarre Kapličky ist dies umso überraschender als hier um 1690/91 zahlreiche neue Anwesen errichtet wurden. Für Kapličky lässt sich letztlich nicht klären, ob es sich um demographische Krisenjahre mit erhöhter Sterblichkeit handelte, da die Sterbebücher von Kapličky für die Zeit vor 1716 heute verloren sind. Im Familienkataster der Pfarre finden sich allerdings - wenn auch mit einer kurzen Lücke - Sterbeeinträge aus dieser Zeit. ${ }^{46}$ Die jährliche Auswertung der Sterbematriken von Vyšší Brod zeigt, dass die Jahre 1694 und 1695 zwei überdurchschnittlich starke Sterbejahre waren.

46 Vgl. Kapitel 2.2. 
Für 1694 sind 68 Todesfälle verzeichnet und für 1695 55. Eine ähnliche Spitze ist in diesen Jahren auch in der Pfarre Rožmberk zu erkennen. ${ }^{47}$

\subsection{Die Entwicklung der sozialen Differenzierung von der Mitte des 17. bis ins 19. Jahrhundert}

Während der frühen Neuzeit nahm in der Pfarre die Zahl der Familien, die über wenig oder kein Land verfügten oder aber nicht einmal ein Kleinhaus ihr Eigen nannten, deutlich zu. Die Häuserzahl in der Pfarre Kapličky lag nach den Eintragungen in den Grundbüchern zur Mitte des 17. Jahrhunderts bei etwa 70 (vgl. Kapitel 3.4), im Jahre 1797 aber bei 115 und um 1840 bei 119. Die Zunahme der Häuserzahl in der Pfarre von der Mitte des 17. Jahrhunderts bis in die erste Hälfte des 19. Jahrhunderts wie das demographische Wachstum basierten beinahe ausschließlich auf dem Anwachsen der Zahl der landarmen Häuser sowie der landlosen Familien ohne Haus. War der Anteil der landarmen und landlosen Familien bereits zur Mitte des 17. Jahrhunderts hoch gewesen (vgl. Kapitel 3.2), so wandelte sich die Pfarre bis ins frühe 19. Jahrhundert zu einer zahlenmäßig deutlich von diesen Gruppen dominierten Gesellschaft. Trotz der Zunahme der Zahl der landarmen Häuser gab es weiterhin immer auch Familien ohne Hausbesitz, wie sich am Vergleich der Zahl der Häuser mit der Zahl der verheirateten Paare, die von etwa 107 im Jahr 1651 auf 142 im Jahr 1783 anstieg, ablesen lässt. ${ }^{48}$ Die Entwicklung in der untersuchten Pfarre war damit keineswegs außergewöhnlich, sondern scheint vielmehr einem in vielen zentraleuropäischen Regionen beobachtbaren Trend gefolgt $\mathrm{zu}$ sein. ${ }^{49}$

Das Wachstum der landarmen Schichten ging dabei kaum zu Lasten der bäuerlichen Flur. Durchwegs wurden in der Pfarre alle neu errichteten Häuser zunächst mit keinem oder nur mit sehr bescheidenem Landbesitz ausgestattet. Andererseits blieb die Besitzstruktur aller Grund besitzenden Häuser trotz mancher Veränderungen im Ausmaß der bewirtschafteten Flächen im Wesentlichen unangetastet. Unter den Bedingungen der Unteilbarkeit der Güter (siehe unten) blieb die Zahl der Grund besitzenden Anwesen weitgehend stabil, die Zahl der landarmen bzw.

47 Ich danke Josef Grulich für die Einsicht in seine Datenauswertung. Für Vyšší Brod ist diese Mortalitätskrise zur Mitte der 1690er Jahre jedenfalls nicht an der durchschnittlichen Sterbezahl pro Dekade ablesbar (vgl. Kapitel 3.1, Graphik 1). Vermutlich glichen sich in diesem Fall die jährlich sehr stark schwankenden Sterbeziffern im 17. Jahrhundert im Dekadendurchschnitt beinahe wieder aus.

48 Archiv Klaštera Vyšší Brod, Kart. č. 219, Nr. III.

49 Vgl. etwa Pierenkemper, Ländliche Sozialstruktur, 318f.; Trossbach, Bauern, 36f. 
landlosen Häuser erfuhr dagegen eine deutliche Zunahme. ${ }^{50}$ Anhand der drei Kataster von 1654, 1682 und 1713 lässt sich auch feststellen, dass es immer dieselben 62 Häuser - sämtlich mit mehr als einem Hektar Ackerland - waren, die Zugvieh hielten, daher ihre Felder selbst bestellen konnten und der Herrschaft zu Spanndiensten verpflichtet waren (vgl. dazu auch Kapitel 3. 2). ${ }^{51}$ Dieses Resultat fügt sich daher gut zu den Ergebnissen anderer Mikrostudien, die ebenfalls ein deutliches Anwachsen unterbäuerlicher Anwesen bei einer gleichzeitigen Stagnation der Zahl der größeren Grundbesitzer feststellten. ${ }^{52}$ Markus Cerman hat für eine nordböhmische Region sogar festgestellt, dass die Zahl der Bauern zwischen 1381 und der Mitte des 18. Jahrhunderts weitgehend konstant blieb. ${ }^{53}$

Die sozialstrukturelle Entwicklung in der Herrschaft Vyšší Brod in der Zeit von der Mitte des 17. bis ins beginnende 18. Jahrhundert muss kleinräumig aber sehr differenziert betrachtet werden. In der Pfarre Kapličky war der Anteil der unterbäuerlichen Häuser höher als in den meisten anderen Dörfern der Herrschaft. In der benachbarten Pfarre Vyšší Brod blieb zwischen 1654 und 1713 die Zahl der in den Steuerverzeichnissen genannten Güter beinahe völlig konstant. Wie zu zeigen sein wird, korrelierte das Wachstum der Zahl der Häuser teilweise auch mit topographischen Gegebenheiten.

Trotz des starken Anwachsens der Häuserzahl in Kapličky wie in anderen Teilen des südlichen Böhmerwaldes blieb der Anteil der Inwohner an der Gesamtbevölkerung in der Pfarre wie auch in vielen anderen Teilen der Region auch im 18. Jahrhundert hoch. Im Jahre 1783 lebte etwa in jedem dritten Haus der Pfarre Kapličky neben der Besitzerfamilie auch eine Inwohnerfamilie. ${ }^{54}$ In manchen Regionen Südböhmens dominierten unter den ländlichen Unterschichten quantitativ eher die Inwohner als die landarmen Kleinbesitzer. In der Vyšší Brod benachbarten Herrschaft Český Krumlov stellten 1718 die Bauern zwar gut zwei Drittel der Anwesen, die größte soziale Gruppe bildeten aber die Inwohner: bei ca. 2. 600 Anwesen sind mehr als 2. 700 Mietparteien nachweisbar (Tabelle 24). ${ }^{55} \mathrm{Im}$ Ort

50 Vgl. für Kapličky aber den Ausnahmefall der Aufteilung der Grundflächen eines bäuerlichen Anwesens in drei neue Einheiten in den 1830er Jahren in Kapitel 7.4.1.

51 Bis zur Mitte des 18. Jahrhunderts erhöhte sich die Anzahl der spannpflichtigen Anwesen allerdings auf 65 .

52 Vgl. etwa Schlumbohm, Lebensläufe, 55; Friedeburg, Tagelöhner, 51-53; Cerman, Diss., 212, 221.

53 Cerman, Diss., 202.

54 Hier wurden nur Inwohner und keine Altenteiler gezählt. Das Abgabenverzeichnis des Pfarrers von Kapličky aus dem Jahre 1783 (Archiv Kláštera Vyšší Brod, kart. č. 219, Nr. III) nennt neben den Haushaltsvorständen lediglich männliche Inwohner und Altenteiler. Mit Hilfe der Familienrekonstitution ließ sich aber die Zahl der verheirateten Inwohner eruieren.

55 Vgl. Essl, Krummau, 252. 
Nové Hrady wurden 1769 bei einer Zahl von 92 Häusern 131 Familien gezählt. ${ }^{56}$ 1843 kamen im gesamten Budweiser Kreis auf 100 Häuser etwa 174 Wohnparteien. ${ }^{57}$ Das Merkmal hoher Anteile an Familien ohne Hausbesitz in der Region kann als Indikator für die spezifische Entwicklung der regionalen Sozialstrukturen gelten, die einer starken Zunahme neuer Anwesen zum Teil doch Grenzen setzte. ${ }^{58}$ Typisch für die Region blieben daher nicht alleinstehende (verwitwete) Personen im Inwohnerstatus, sondern eine hohe Zahl an ,vollständigen Inwohnerfamilien“ (Ehepaare mit Kindern). In anderen Regionen führte dagegen die Errichtung zahlreicher neuer Anwesen im 18. Jahrhundert zu einem erheblichen Rückgang gerade der Zahl der verheirateten Inwohner. ${ }^{59}$

Tabelle 24: Sozialstrukturelle Gliederung in den Dörfern der Herrschaft Český Krumlov, 1718

\begin{tabular}{lcc}
\hline & Anzahl & Prozent \\
\hline Bauern & 1.657 & 63,9 \\
Chalupner & 639 & 24,7 \\
Gärtner & 296 & 11,4 \\
\hline Summe & 2.592 & 100,0 \\
\hline sowie „Mietparteien“ & 2.723 &
\end{tabular}

Quelle: Essl, Krumau, 252.

Auf mannigfache Weise konnten die Übergänge zwischen Inwohnern und anderen landlosen und landarmen Bevölkerungsgruppen fließend sein. Obwohl eigentlich eine haus- und grundbesitzlose, zur Miete wohnende Bevölkerungsgruppe mit entweder lebenszyklischem Charakter (Altenteiler, verwitwete Mutter) oder im Status vertraglich gebundener Aushilfsarbeiter der Bauern, kam es im südlichen Böhmerwald sehr häufig vor, dass diese in separaten Häusern wohnten, ihren eigenständigen Beruf ausübten und ein kleines Stück Land bewirtschafteten: „(...) im südlichen Böhmen sehr häufig gegen Überlassung eines Feldstückes

56 Teichl, Stadt, 104.

57 Berechnet nach: Schnabel, Grundkräfte, $488 \mathrm{f}$.

58 Der hohe Inwohneranteil ist andererseits auch auf das verbreitete Muster der Besitzweitergabe zu Lebzeiten beider Ehepartner zurückzuführen. Vgl. Kapitel 7.6.

59 Vgl. etwa: Mitterauer, Vorindustrielle Familienformen, für Salzburg in der zweiten Hälfte des 18. Jahrhunderts. 
zum Legen der Kartoffeln übernimmt der Mietsmann die Pflicht, zu bestimmter oder unbestimmter Zeit eine Anzahl von Arbeitstagen auf Geheiß dem Bauern zur Verfügung zu stellen." ${ }^{60}$ In der Pfarre Kapličky etwa wohnten kontinuierlich zahlreiche Inwohner nicht im bäuerlichen Hofverband mit, sondern in eigenen Häusern. Viele Bauern verfügten hier über ein Nebengebäude (einige hatten auch mehrere), das sie vermieteten, wenn dieses gerade nicht für Ausnehmer benötigt wurde. Im Dorf Hodoň etwa gab es im Jahr 1840 laut Stabilem Kataster elf Hausbesitzer, aber 17 bewohnbare Häuser. Neben dem Gemeindehaus hatten drei Bauern jeweils ein weiteres bewohnbares Nebenhaus und ein Hausbesitzer hatte zwei derartige Nebengebäude. ${ }^{61}$ Auch zum Haus Kapličky Nr. 9 gehörten - wie den Angaben in den Grundbüchern mehrfach zu entnehmen ist - wohl während des gesamten 18. Jahrhunderts zwei Inwohnerhäuser. Eines dieser beiden Inwohnerhäuser verfügte laut den Angaben des Josephinischen Katasters aus dem Jahre 1787 auch über eine „Hausgartenwiese“ und kann damit nicht als gänzlich landlos gelten. ${ }^{62}$ Die für den Böhmerwald typischen Inwohnerhäuser waren klein, noch im 19. Jahrhundert durchgehend aus Holz gebaut und nicht vollständig autark: Wasser, Holzvorratsräume und Düngerhaufen mussten zumeist beim Haupthaus mitbenutzt werden. ${ }^{63}$

In separaten Häusern wohnende Inwohner waren auch in vielen anderen Regionen sehr häufig oder zumindest nicht unbekannt, so etwa in Nordböhmen, in Tirol, und sehr häufig in bayerischen und oberösterreichischen Regionen. ${ }^{64}$ Für das oberösterreichische Waizenkirchen im 19. Jahrhundert wird betont, dass ein bis zwei dazugehörige Inwohnerhäuser pro Bauernhaus die Regel gewesen seien. ${ }^{65}$ Dass Inwohnern Felder zur Bewirtschaftung überlassen wurden, kam ebenso nicht nur im südlichen Böhmerwald vor, sondern auch etwa im niederösterreichischen Waldviertel und in Bayern. ${ }^{66}$ Anders ist die Situation der Inwohner dagegen einzustufen, wenn sie sogar Grundstücke besaßen, wie in manchen Marktorten des Böhmerwaldes. In Horní Plana hielten laut Stabilem Kataster von 1827 die 113 Inwohner nicht nur Vieh, sondern verfügten auch über 268 Grundparzellen (davon etwa die Hälfte Äcker). ${ }^{67}$ Ebenso züchteten in Volary die Inwohner Rinder und

60 Zeßner, Arbeitsverhältnis, 234. Diese für die Zeit um 1900 getroffene Feststellung ist ganz sicher auch auf frühere Zeiten übertragbar.

61 NA Praha, SK Duplikat 183 (Gemeinde Muenichschlag).

62 NA Praha, JK 2963 Obec Krasné Pole. „Inwohnerhaus des Albert Mautner“.

63 Vgl. Schramek, Böhmerwald-Bauernhaus, 21f.

64 Cerman, Proto-Industrialisierung, 173f.; Mitterauer, Arbeitsteilung, 38, Huber-Sperl, Inleute, $24 f$.

65 Jungwirth, Familienstrukturen, $116 \mathrm{ff}$.

66 Vgl. Berkner, Social Structure, 173; Komlosy, Fallbeispiel, 312; Huber-Sperl, Inleute, $29 f$.

67 Vgl. Essl, Oberplan, 238. 
besaßen Grundstücke. ${ }^{68}$ Da sie keine Hausbesitzer waren, zählten sie als Inwohner. Für Kapličky ist der Kauf bzw. die Pacht von Land durch Inwohner jeweils im Einzelfall nachweisbar. In manchen Gegenden des südlichen Böhmerwaldes, beispielsweise in der Herrschaft Vimperk, durften Inwohner in den herrschaftlichen Wäldern bis in die Mitte des 19. Jahrhunderts Kartoffel und sogar Getreide anbauen. ${ }^{69}$ Zumindest in einigen Gebieten des südlichen Böhmerwaldes hatten Inwohner, anders als Ausnehmer, aber keinen Zugang zur Gemeindeweide und konnten daher auch kein Großvieh halten. ${ }^{70}$ Im Marktort Hořice war ihnen zu Beginn des 18. Jahrhunderts erlaubt, eine Kuh zu halten, für die Benutzung der Dorfweide hatten sie jedoch zu bezahlen. ${ }^{71}$ Eine besonders deutliche Emanzipation mancher Inwohner von ihrer Wirtsfamilie ist dann nahe liegend, wenn diese einen eigenen, vom Besitzer des Hauses abweichenden Beruf ausübten. In Kapličky war dies mit zahlreichen in den Holz verarbeitenden Berufen tätigen Inwohnern der Fall. ${ }^{72}$ Aus den genannten Gründen konnten die Übergänge zwischen Inwohnern und anderen landarmen Bevölkerungsgruppen fließend sein. ${ }^{73} \mathrm{Im}$ 18. Jahrhundert war der Charakter der Inwohner im südlichen Böhmerwald dann auch deutlich stärker als im 17. Jahrhundert der einer eigenen sozialen Schicht, in der man ein Leben lang verblieb und weniger der einer lebenszyklischen Phase (nach der Verwitwung, nach der Übergabe, oder vor der Verheiratung). ${ }^{74}$ Die relative Stärke der lebenslang zur Miete lebenden, besitzlosen Bevölkerungsgruppe hatte auch mit dem hohen Bedarf an Lohnarbeit in der Region zu tun. Dies wiederum war zu großen Teilen auch durch den Bedarf der Herrschaften an Lohnarbeit für ihre Meierhöfe bedingt (vgl. zu diesen Zusammenhängen auch Kapitel 3). ${ }^{75}$ Josef Blau bezeichnet die Inwohner des Böhmerwaldes schließlich für die Zeit um 1900 nicht nur als eine eigene soziale Schicht, sondern auch als sozial unter dem Gesinde stehend, wie sich etwa durch die Sitzordnung beim Essen oder auch im Fehlen patronaler Verpflichtungen der Bauern gegenüber den Inwohnern ausdrücke. ${ }^{76}$

68 Praxl, Holzhäuser, 147. Die zur Mitte des 19. Jahrhunderts in Volary besonders verbreitete Viehzucht bei den Inwohnern beruhte darauf, dass diese einige Jungtiere von Bauern kauften, um sie zu mästen. Vgl. Kubitschek/Schmidt, Wallern, 86f.

69 John, Beschreibung, 38.

70 Vgl. Stark, Abhängigkeitsverhältnisse, 372 für das nahe Frýmburk.

71 Archiv Kláštera Vyšší Brod, kart. č. 405, 46/3.

72 Vgl. ähnlich auch: Mitterauer, Formen, $205 \mathrm{f}$.

73 So auch Mitterauer, Arbeitsteilung, 38 für österreichische Gebiete.

74 Vgl. dazu auch Kapitel 8.7.

75 Vgl. Stark, Abhängigkeitsverhältnisse, 372.

76 Blau, Inmann, 149. 


\subsection{Die Etablierung neuer Anwesen}

Auch in anderen Regionen Mitteleuropas mit Unteilbarkeit der Güter und feudalen Herrschaftsverhältnissen hatten Dorfkommune und Bauern vielfach nur geringes Interesse an einem sozialen Wandel. In einigen dieser Regionen, etwa in Süddeutschland und Österreich, gab es faktisch jedoch eine Zweiteilung des bäuerlichen Bodens: Neben den unteilbaren, nur gemeinsam mit dem Hof veräußerbaren Flächen in der Dorfflur existierten zahlreiche so genannte ,walzende' Gründe (in Österreich ,Überlandgründe' genannt), die keinen festen Bestandteil der bäuerlichen Einheiten darstellten, sondern von diesen problemlos abtrennbar und frei veräußerbar waren. Gerade diese Gründe stellten in manchen Regionen einen sehr hohen Anteil an der bebaubaren Fläche und bildeten in einer ansonst starren Ordnung der Besitzverteilung ein entscheidendes Reservoir an Land, das auch für die Gründung neuer Anwesen genutzt werden konnte. ${ }^{77}$ In der Pfarre Kapličky fehlten dagegen walzende Grundstücke völlig, und damit scheinbar auch eines der wenigen Elemente der ,Agrarverfassung،, die die Neuerrichtung von Anwesen ermöglicht hätten.

Welche Institutionen der Agrarverfassung erlaubten dennoch eine Ausdehnung der Nutzflächen und Behausungen in der Pfarre? Führten einzelne ökonomische Konjunkturen zu einer Expansion der Siedlungen und Anbauflächen oder verlief dies als kontinuierlicher Prozess? Wie Tabelle 25 zeigt, gab es zwischen 1681 und 1840 lediglich zwei kurze Phasen einer verstärkten Siedlungstätigkeit. ${ }^{78}$ Beide Male waren ökonomische Entscheidungen der Gutsherrschaft ein entscheidender Auslöser. Die erste Phase fällt in die Zeit um 1700 und war quantitativ durch die letzte Dorfgründung dominiert. Die bereits im Spätmittelalter nachweisbare Holzflößerei auf der Moldau erfuhr in dieser Zeit einen bedeutenden Aufschwung. Etwa ab Eintritt des Flusses in das Pfarrgebiet war die Moldau wegen eines mehrere Kilometer langen, starken Gefälles allerdings nie flößbar. ${ }^{79} 1690$ wurde an dieser Stelle das Dorf Nové Domky mit neun Anwesen planmäßig auf dominikalem Grund angelegt. Die neun Häuser erhielten gleich große Grundflächen zur Haltung einer Kuh zugeteilt. ${ }^{80}$ Die ausgegebenen Flächen blieben Dominikalland

77 Im bayerischen Unterfinning bildeten diese Gründe etwa ein Drittel der gesamten Flur, im niederösterreichischen Retzbach sogar 57 Prozent. Vgl. Beck, Unterfinning, 228 f.; Landsteiner/Langthaler, Ökotypus, 192. Vgl. auch Berkner, Social Structure, 172f. und Robisheaux, Rural Society, 83.

78 Auch zwischen 1651/54 und 1680 entstanden etwa zehn neue Häuser. Da deren Entstehungsbedingungen jedoch unzureichend dokumentiert sind (häufig wurden diese Anwesen erst Jahre nach der Gründung im Grundbuch verzeichnet), wird dieser Zeitraum hier nicht behandelt.

79 Vgl. Kapitel 2.1.

80 Laut Schätzung des Theresianischen Katasters (NA Praha, TK 684) belief sich die zugeteilte Fläche pro Haus nur jeweils auf ein böhmisches Viertel (ca. $\left.700 \mathrm{~m}^{2}\right)$. 
und wurden den angesiedelten Holzfällerfamilien gegen einen günstigen jährlichen Zins verpachtet. ${ }^{81}$ Die Herrschaft verlor mit dieser Lösung keine Grundflächen, konnte die bisher auf Robotarbeit beruhende Holzverarbeitung durch die Einführung von Lohnarbeit effizienter gestalten und profitierte vom gesteigerten Holzverkauf.

Tabelle 25: Anzahl der neu errichteten Anwesen in der Pfarre Kapličky auf bäuerlichem, dominikalem und Gemeindeland, 1681-1840

\begin{tabular}{lccc}
\hline & bäuerlich & Gemeinde & dominikal \\
\hline $1681-1700$ & 2 & 1 & 12 \\
$1701-1720$ & 2 & 1 & - \\
$1721-1740$ & 2 & - & - \\
$1741-1760$ & - & - & - \\
$1761-1780$ & - & 1 & - \\
$1781-1800$ & 7 & 4 & 2 \\
$1801-1820$ & - & - & 1 \\
$1821-1840$ & 2 & - & 1 \\
\hline Summe & 15 & 7 & 16 \\
\hline
\end{tabular}

Quellen: SOA Třeboň, C Vyšší Brod, Pozemkové knihy.

Anm.: Bei einzelnen, jedenfalls vor 1700 gegründeten Häusern der Pfarre ist das exakte Datum der Errichtung unbekannt, alle diese bestanden aber vermutlich bereits im Jahr 1680 .

Eine zweite Phase der verstärkten Anlage neuer Anwesen fällt in die Zeit um 1780, in der die Robot in Böhmen allgemein aufgehoben wurde. Das Kloster Vy̌šś Brod behielt nur drei seiner Gutshöfe bei und löste die anderen sieben auf, indem es die zugehörigen Gründe an neu angesiedelte Untertanen aufteilte. ${ }^{82}$ Obwohl keiner dieser Höfe im Pfarrgebiet lag, bewirkte dies nicht nur eine Umstellung der Ökonomie der feudalen Eigenbetriebe, sondern hatte auch Auswirkungen auf die Wirtschaftsweise in allen Dörfern der Herrschaft, auch in denen der Pfarre Kapličky. Für die bäuerlichen Familienwirtschaften bedeutete die Aufhebung der

81 Diese leisteten einen jährlichen Hauszins von drei Gulden, während andere Kleinhäuser bis zu 16 Gulden jährlich zu entrichten hatten. Vgl. Archiv Klaštera Vyšší Brod, kniha 245 : ,Zins buech bey dem löblichen stüfft undt closter Hochenfurth rändtambt, wie solche jährlich in empfang gebracht undt ordentl: verechnet werden', 1712.

82 Kaindl, Zisterzienserstift Hohenfurt, 108. 
Robot den Wegfall der für Gutsherrschaftsgesellschaften typischen „überproportionalen Gespannviehhaltung ${ }^{\text {"83 }}$ sowie einen geringeren Bedarf an permanenten Arbeitskräften im Haushalt. Musste zuvor im Durchschnitt eine halbe Arbeitskraft pro Hof zur Leistung der Robotdienste beschäftigt werden, reichte nach dem Wegfall dieser Verpflichtung in vielen Fällen anstelle einer permanent beschäftigten Gesindeperson die kurzfristige Einstellung eines Taglöhners aus. ${ }^{84}$ Bisher als Zugtiere benötigte Ochsen konnten als Mastvieh gehalten oder durch Milchkühe ersetzt werden. Offenbar verringerte sich das Ausmaß der benötigten kommunalen Weideflächen. Es ist sicher kein Zufall, dass gerade in dieser Zeit mit Krasné Pole der einzige Weiler der Pfarre, der über zwei Allmendeflächen verfügte, einen kleinen Teil einer der beiden Marken auföste und darauf zunächst zwei neue Anwesen (1793 folgte noch ein drittes) errichtet wurden. ${ }^{85}$

Außerhalb dieser beiden Zeitperioden entstanden nur in Einzelfällen neue Häuser. Gerade vom Gemeindeland wurde lange Zeit kaum ein neues Anwesen abgetrennt, insbesondere nicht von der eigentlichen Allmende. Auf kommunalen Flächen im Dorfkern waren während und kurz nach dem Dreißigjährigen Krieg mehrere Häuser errichtet worden, zwischen 1680 und den 1770er Jahren dann nur mehr in zwei Einzelfällen, in denen kommunale Interessen beteiligt gewesen sein dürften: 1695 wurde dem Dorflehrer Michael Hoffmann im Hauptort eine Parzelle für die Errichtung eines Hauses verkauft. Es handelte sich um eine Fläche, auf der bereits in früherer Zeit eine Schule gestanden hatte. ${ }^{86}$ Einige Jahre vor 1710, das exakte Jahr lässt sich nicht ermitteln, konnte sich ebenfalls im Hauptort ein Betreiber des Wagner-Handwerks, an dessen Fertigkeiten die Bauern des Ortes sicher hohen Bedarf hatten, auf Gemeindegrund ansiedeln.

Wenn während des 18. Jahrhunderts ausnahmsweise auf Gemeindegrund ein neues Haus errichtet wurde, dann nur an den schlechter nutzbaren Rändern der Weiden. ${ }^{87}$

83 Trossbach, Bauern, 9.

84 Für Kapličky liegen nur für 1651 systematische Daten zum Gesindeanteil vor. Die spätere Entwicklung kann aber aus Daten für das benachbarte Gericht Studánky indirekt erschlossen werden. 1798 lag hier der Anteil des Gesindes an der Gesamtbevölkerung niedriger als 1651; vor allem wurde weniger männliches Gesinde benötigt. Vgl. ausführlicher Kapitel 8.5.

85 SOA Třeboň, fond C Vyšší Brod, PK č. 475, fol. 54, 55, 61.

86 „ain gereuter der altn schull nechst der kürchen“. SOA Třeboň, fond C Vy̌šś Brod, PK č. 453, unfoliert (Eintrag vom 16.7.1712). Die Gemeinde hatte sich offenbar jahrelang geweigert, Hoffmann eine Bauparzelle abzutreten. Darauf deutet der Umstand, dass er bereits 1687 als Inwohner von einem Bauern ein Stück Ackerland erworben hatte. Es ist dies der einzig nachweisbare Fall eines Landkaufes durch einen Inwohner.

87 Sicherlich konnte es in der prinzipiell ablehnenden Haltung der Gemeinden unter bestimmten Umständen auch Ausnahmen geben. Dies scheint etwa im östlichen Teil Südböhmens gelegenen Herrschaftsdorf Bukovsko (Buggaus) der Fall gewesen zu sein, wenn für dieses Dorf im Theresianischen 
In dieser restriktiven Haltung der Gemeinden ${ }^{88}$ bestand ein wichtiger Unterschied zu anderen Regionen Böhmens. In den nordböhmischen Herrschaften Frýdlant und Liberec etwa war gerade das dörfliche Gemeindeland zentral für die Errichtung neuer Häuser. Hier fand während des 16. und 17. Jahrhunderts ein rapides Wachstum der unterbäuerlichen Anwesen auf Gemeindeland statt. Zur Besiedlung freigegeben wurden dabei in erster Linie Gründe in den Dorfauen mitten im Ort. ${ }^{89}$

Im Gegensatz zu den Dorfgemeinden war die Herrschaft des Klosters Vyšší Brod einer Neuansiedlung von Untertanen auf ihrem Grund weniger abgeneigt. Sie hatte ausgedehnte Besitzungen und durfte sich durch die Ausgabe von Parzellen erhöhte Einnahmen erhoffen. Prinzipiell blieb der von der Herrschaft ausgegebene Grund immer Dominikalland. Die so genannten Dominikalisten hatten ihre Häuser zwar im Eigentum, den Grund erhielten sie dagegen auf Basis unbefristeter Pachtverträge mit jährlich zu leistendem Zins. Im Gegensatz zum emphyteutischen Besitzrecht waren die mit den Dominikalisten geschlossenen Verträge theoretisch jährlich kündbar. Wie die Grundbücher zeigen, kam die Rücknahme zeitlich unbefristet ausgegebener Dominikalgründe in der Praxis allerdings nicht vor. Die Dominikalisten hatten de facto dieselben Freiheiten der Veräußerung und Vererbung ihrer Besitzungen wie die Bauern mit Erbzinsrecht. Eine Emphyteutisierung dieser Anwesen erfolgte aber überwiegend erst im 19. Jahrhundert, bei den Häusern in Nové Domky etwa war dies 1832 der Fall. ${ }^{90}$ Nur in einzelnen Fällen errichtete die Herrschaft während des 18. Jahrhunderts neue Anwesen auch auf Basis von tatsächlich zeitlich befristeten Pachtverhältnissen. In diesen Fällen war die Dauer der Befristung von Beginn ab festgelegt, wobei zumeist eine Regelung auf, drei Leiber' getroffen wurde (und damit üblicherweise eine Befristung auf die Dauer der Lebensspanne zweier Generationen an Inhabern bestand, da nur die Weitergabe an den überlebenden Ehepartner sowie an ein Kind erlaubt war). ${ }^{91}$ In diesen Fällen wurde die vereinbarte Befristung zumeist tatsächlich eingehalten und die Hausparzelle danach eingezogen.

Kataster von 1713 neun der insgesamt 37 Anwesen als, neu errichtete landlose Häuser, die auf Gemeindegrund stehen und auf die Dauer von bloß zwei Leibern (also der Lebensdauer des Inhaberpaares) verpachtet' ausgewiesen sind. Quelle: NA Praha,TK 684.

88 Dies wird auch dadurch illustriert, dass die Gemeinde Martinkov im Jahre 1676 nach der Abtretung einer Fläche für die Errichtung eines Hauses für den herrschaftlichen Revierjäger ihren Verlust durch eine Fläche im nahen herrschaftseigenen, Taschenwald' kompensiert bekam. Vgl. SOA Třeboň, fond C Vyšší Brod, PK č. 453, fol. 354.

89 Vgl. Cerman/Štefanová, Wirtschaft, 78. Vgl. auch Cerman, Diss., 195. Vgl. zum Verhältnis zwischen den Dorfgemeinden und der Gutsherrschaft am Beispiel dieser nordböhmischen Region die ausführliche Studie: Ogilvie, Communities.

90 Kaindl, Zisterzienserstift Hohenfurt, 116.

91 Vgl. dazu genauer Kapitel 6.3.1. 
Als der westlich der Pfarre, aber in unmittelbarer Nähe von Nové Domky gelegene, herrschaftliche Meierhof Heuraffl 1783 aufgelöst wurde, entstanden auf diesem Areal bis Ende des Jahres 178619 Anwesen. Das so entstandene Dorf Zadní Výtoň/Hinter-Heuraffl (der Ortsname nimmt Bezug auf das angrenzende, ältere und zur Herrschaft Český Krumlov gehörige Dorf Přední Výtoň/Vorder-Heuraffl) umfasste mit einem bereits 1781 beim Meierhof errichteten Haus insgesamt zunächst 20 Häuser. Jedem Haus war ein in etwa gleich großer Grundbesitz zugeteilt. Bereits im Jahr 1797 wurden die ursprünglich zur Pacht ,auf drei Leiber' ausgegebenen Anwesen allerdings mittels eines gemeinsamen Vertrags von 24 Hausinhabern mit der Herrschaft, der sich in einer Abschrift erhalten hat, emphyteutisiert. ${ }^{92}$

Vom bäuerlichen Besitz wurden in der Pfarre Kapličky nur dann kleine Flächen abgetrennt und als Bauparzelle verkauft, wenn es sich um landwirtschaftlich ohnehin schlecht nutzbare Flächen handelte. Nähere Beschreibungen dieser Parzellen beim Verkauf belegen dies deutlich: Albert Parth verkaufte Thomas Miesbauer 1791 „sein steinigste mit gestripp verwachsenen grund“ ${ }^{93}$ Es begegnen auch Formulierungen, wie „auf oed grund“94. Da es sich um kleine Flächen mit geringer Bodenqualität handelte, deren Abtrennung die Erträge der bäuerlichen Ökonomie kaum schmälerten, stimmte auch die Herrschaft den Grundabtretungen zu. Manche dieser Bauparzellen waren gänzlich landlos, einige wurden mit etwas Grund ausgestattet. Neben einem Verkauf wurde auch von Bauern zuweilen ein Haus nur zu ,Leiberpacht' ausgegeben. Die Bauern ahmten hier die Vergabeprinzipien der Herrschaft nach, der betreffende Grund verblieb dadurch bei der bäuerlichen Einheit.

Eine weitere Möglichkeit dafür, wie es auf Rustikalland zur Entstehung zusätzlicher Anwesen kommen konnte, zeigt das Beispiel der Mühle im Weiler Lhota: Hier entwickelte sich aus einem traditionellen Betrieb eines Landhandwerkers im Laufe des 18. Jahrhunderts das bei weitem größte Gewerbeunternehmen der Pfarre. Im 17. Jahrhundert wurde beim Anwesen eine der insgesamt fünf Mühlen der Pfarre betrieben, dazu auch eine Brettersäge. Der Müller besaß auch vergleichsweise viel Land, mit einer Aussaat von 23 böhmischen Strich gehörte er 1654 schon zu den größeren Bauern. Etwa zur Mitte des 18. Jahrhunderts dürfte beim Anwesen mit dem Betrieb einer Garn- und Leinenbleiche begonnen worden sein, die offenbar rasch expandierte, sich allmählich aber auch stark verschuldete.

92 Vgl. SOA Třeboň, fond C Vyšší Brod, PK č. 553, lose Beilage. Im Jahr 1860 bestanden bereits 29 Anwesen. Das Gebiet war erst Ende des 16. Jahrhunderts zum Klosterbesitz gelangt. Vgl. Kaindl, Zisterzienserstift Hohenfurt, 55.

93 SOA Třeboň, fond C Vyšší Brod, PK č. 475, fol. 58.

94 SOA Třeboň, fond C Vyšší Brod, PK č. 475, fol. 62. 
Zwischen 1770 und 1800 waren häufig mehr als zehn familienfremde Arbeitskräfte gleichzeitig beschäftigt, wie Auflistungen der zum Zeitpunkt von Besitzerwechseln am Anwesen noch ausstehenden Gesindelöhne im Grundbuch belegen $^{95}$ - eine für die lokalen Verhältnisse außergewöhnlich hohe Beschäftigtenzahl. Dass gerade dieses Anwesen ökonomisch derart expandieren konnte, stand wohl mit seiner verkehrstechnisch günstigen Lage nahe einer kleinen Verbindungsstraße zwischen dem oberösterreichischen Leinenwebergebiet und dem südböhmischen Marktort Frymburk, in dem mehrere Leinenhändler ansässig waren, in Zusammenhang. Siedlungsstruktur und Flurform erleichterten zudem die Produktionsumstellung des Anwesens. Die Ansiedlung Lhota umfasste bis zu diesem Zeitpunkt neben der Mühle nur einen Bauernhof und ein Kleinhaus und hatte keine eigene Allmende. Wie der Inhaber des Betriebes seine Grundflächen nutzte (zum Bleichen wurden große Wiesenflächen benötigt), hatte er nur mit wenigen anderen Personen abzustimmen. Andererseits wurde es mit der Ausdehnung des Betriebes in dem kleinen Weiler rasch notwendig, zusätzliche Arbeitskräfte anzusiedeln. 1790 und 1791 entstanden zwei landlose Anwesen. ${ }^{96}$ In einem Nebengebäude der Mühle wurde außerdem ein Wirtshaus eingerichtet, das dem Betreiber jedoch zunächst nur verpachtet wurde. Wegen Überschuldung zerfiel allerdings der aus Landwirtschaft, Mühle, Sägewerk und Bleiche bestehende komplexe Betrieb bald, obwohl die Herrschaft zu günstigen Bedingungen Kredite gewährte. ${ }^{97}$ Bereits um 1801 wurde die Bleiche, die noch jahrzehntelang nachweisbar ist, an einen von auswärts zugezogenen Inwohner verpachtet. 1817 wurden das Wirtshaus und 1827 schließlich auch Mühle und Brettersäge verkauft, wodurch noch zwei weitere eigenständige Anwesen entstanden.

Beinahe alle Inhaber der neuen Häuser trachteten danach, sich eine zumindest marginale agrarische Subsistenz zu sichern bzw. diese zu vergrößern. Dafür gab es prinzipiell mehrere Möglichkeiten. Der Kleinhäusler und Maurer Andreas Pötscher in Dobřin etwa ließ sich 1740 bei Errichtung seines Anwesens auf dem Grund des Bauern Adam Hutter vertraglich das Recht zusichern, „aine melch kuhe mit $d ß$ haußsitzers seyn rindtvich außzutreibn". ${ }^{98}$

Das beim Generationenwechsel auf den Anwesen strikt eingehaltene Prinzip der Unteilbarkeit der Güter schloss einen Parzellenerwerb auf dem ,Markt‘ nicht

951771 etwa war der ,Lidlohn` von elf Personen ausständig, 1784 von 13 Personen. Da das Gesinde üblicherweise jährlich entlohnt wurde, können diese Angaben als Indikator für die Betriebsgröße dienen. Quellen: SOA Třeboň, fond C Vyšší Brod, PK č. 475, fol. 22 f., PK č. 479, fol. 132.

96 SOA Třeboň, fond C Vyšší Brod, PK č. 475, fol. 57.

97 SOA Třeboň, fond C Vyšší Brod, PK č. 475, fol. 22 f.

98 SOA Třeboň, fond C Vyšší Brod, PK č. 479, fol. 327. 
grundsätzlich aus. Neben Bauparzellen wurden mehrere Male auch kleine Feldparzellen von bäuerlichen Besitzeinheiten abgetrennt und individuell verkauft. Einige landlose Häuser gelangten auf diesem Weg zu Grundbesitz. Der Schneider Michael Wabro beispielsweise, Inhaber eines zunächst landlosen Hauses, das sein Vater noch während des Dreißigjährigen Krieges auf Gemeindegrund errichtet hatte, kaufte 1687 von Georg Zanner, der seit 1677 ein kleinbäuerliches Anwesen in Kapličky besaß und 1713 etwas mehr als vier Hektar Ackerland bewirtschaftete, einen Acker. 1722 kaufte Wabro erneut ein Feld von einem anderen Bauern des Dorfes. ${ }^{99}$

Auffällig ist, dass in der Zeit, in der die Herrschaft Parzellen zum Häuserbau freigab, auch auf Gemeindeboden und auf bäuerlichem Besitz in stärkerem Maße neue Anwesen errichtet wurden. Wenn in Einzelfällen vom bäuerlichen Besitz eine kleine Fläche abgetrennt und darauf ein neues Anwesen angelegt wurde, so stand dahinter eher selten die familiale Strategie, damit einem der Familienmitglieder den Hausbau zu ermöglichen. Lediglich in einem Drittel der Fälle (5 von 15) der Errichtung eines neuen Hauses auf bäuerlichem Grund kam ein „weichender“ Sohn, ein Schwiegersohn oder ein Bruder des Hofbesitzers zur Gründung eines eigenen Anwesens, in den anderen Fällen handelte es sich um Verkäufe an Familienfremde. Für die Neugründungen der Jahre 1780 bis 1800 fällt - wenn man die Kartenmaterialien des Stabilní Katastr aus der ersten Hälfte des 19. Jahrhunderts zugrunde legt - auf, dass vor allem die größeren bäuerlichen Anwesen in den Randlagen ihrer Besitzungen Flächen zum Hausbau abgaben. Möglicherweise benötigten diese, die relativ viel Großvieh besaßen, nach der erfolgten Robotablöse in den 1780er Jahren weniger Zugvieh und daher auch weniger Weideflächen als zuvor.

5.6 Die dominikalen Zinsreuter: eine zweite Kategorie von Land

Weit wichtiger für die Etablierung einer agrarischen Basis der neu entstandenen Anwesen als der selten vorkommende Kauf einzelner Feldparzellen von bäuerlichem Grundbesitz war die Nutzung herrschaftlicher Pachtgründe. Bei diesen meist als ,Zinsreuter' oder ,Zinsgereuther' bezeichneten Flächen handelte es sich um Rodungen aus den großen herrschaftlichen Wäldern, die überwiegend als Wiesen, zum Teil aber auch als Weiden und als Ackerland genutzt wurden. Als Teil des herrschaftlichen Dominikallandes wurden ,Zinsreuter' von den staatlichen Katastern des 17. und frühen 18. Jahrhunderts nicht bzw. nicht im Detail erfasst. ${ }^{100}$

99 SOA Třeboň, fond C Vyšší Brod, PK č. 453, fol. 133, fol. 357.

100 Das Dominikalland der Herrschaften wurde im 18. Jahrhundert mit dem sogenannten Exaequato- 
Die drei vorhandenen staatlichen Kataster sind allerdings die einzigen Quellen, die für das 17. und die erste Hälfte des 18. Jahrhunderts systematische Angaben zur Besitzgröße der untertänigen Anwesen enthalten. Da diese prinzipiell nur Rustikalgründe nennen und alle weiteren, etwa von der Herrschaft gepachteten Flächen, nicht verzeichnen, erschwert dies die Kreierung sozialer Schichtungsmodelle auf Basis der Katasterangaben für all jene Regionen gravierend, in denen es ein bedeutendes Maß an dieser zweiten Landkategorie gab.

In Kapličky, wie generell im südlichen Böhmerwald, war die Bewirtschaftung von Grund und Boden aus herrschaftlichem Besitz aber während der frühen Neuzeit ein entscheidender ökonomischer Faktor, vor allem für die zahlreichen neu errichteten Häuser. Die Theresianische Fassion des Jahres 1713 etwa listet alleine für das Pfarrdorf Kapličky neben den elf, alteingesessenen' Grundbesitzern weitere acht Häuser mit keinem oder nur sehr geringem Grundbesitz auf. Vier von diesen Kleinhäusern verfügten jeweils über einen kleinen Acker, kein einziges der acht Anwesen hatte eine Wiese. Dennoch wurde bei sechs dieser Häuser die Haltung einer Kuh vermerkt. Nur der Bäcker Gottfried Kühschläger und der Schuster Mathias Kern hielten keine Kuh. Woher nahmen allerdings die eine Kuh haltenden Kleinhäusler ohne den Besitz einer Wiese das nötige Winterfutter für ihre Kuh? Die Erklärung findet sich in den summarisch bei jedem Dorf angefügten Angaben: Demnach hatten in Kapličky nicht nur die 11 Angesessenen insgesamt 14 Stück obrigkeitliche Zinsgereuter „in Genuß“, wovon sie 16 zweispännige Fuhren Heu ernteten, sondern auch die acht „Unangesessenen“, womit wohl die Kleinhäusler gemeint waren, verfügten über zusammen drei Zinsreuter, von denen vier Fuhren Heu gewonnen wurden. Vier Fuhren Heu waren nicht besonders viel, bildeten aber doch eine gewisse Basis, um einige Kühe über den Winter zu bringen. ${ }^{101}$

Während der ersten Hälfte des 18. Jahrhunderts hatten sehr viele Pfarrbewohner von der klösterlichen Grundherrschaft solche „Zinsgereuter“, überwiegend Wiesen, gegen einen jährlichen Zins in Pacht. Infolge der Häufigkeit von Pachtgründen gab es de facto kaum Anwesen ohne Anbindung an landwirtschaftlich nutzbare Flächen. Die Bedeutung dieser in der Regel langfristig gepachteten Flächen vor allem für die Ökonomie der landlosen und landarmen Häuser ist nicht zu unterschätzen. Dem Kataster des Jahres 1713 zufolge hatte das Kloster in dieser

rium Dominicale (ED) von staatlicher Seite gesondert erfasst. Siehe für die Herrschaft Vyšší Brod: NA Praha, ED 193, kart. 20.

101 Fraglich ist allerdings, ob mit dieser Menge tatsächlich sechs Kühe über den Winter gebracht werden konnten. Nach den Kalkulationen von R. Beck hätte diese Menge für maximal fünf Kühe gereicht. Vgl. Beck, Unterfinning, 237. 
Pfarre (bei 101 Anwesen) 112 derartige Parzellen verpachtet. ${ }^{102}$ Etwa ein Drittel der Heuernte kam von diesen Flächen. Im gesamten Herrschaftsgebiet waren um 1713415 ,Zinsreuter ${ }^{6}$ an die Untertanen ausgegeben. ${ }^{103}$

In der Region wurde zwischen ,verbrieften', d. h. einem Anwesen per Kontrakt dauerhaft zugeschriebenen, und, unverbrieften' Zinsreutern unterschieden. Beide Typen von herrschaftlichen Pachtgründen wurden bei einem Besitzerwechsel oft gemeinsam mit dem bäuerlichen Besitz weitergegeben, dabei aber in den Grundbüchern separat angeführt. Daher wissen wir, dass ein Großteil der Häuser zusätzlich zum eigentlichen Besitz auch solche Flächen bewirtschaftete - größere Grundbesitzer beinahe ebenso häufig wie landarme. ${ }^{104}$ Eine stichprobenartige Auswertung des ab 1731 (bis Mitte der 1770er Jahre) geführten, Reuterbuches', das alle von der Herrschaft an die Untertanen ausgegebenen Zinsreuter verzeichnet, zeigt zunächst, dass die Herrschaft auch nach Abflauen einer intensiveren Ausgabe neu gerodeter Flächen (um 1710 bis 1715) weiterhin einzelne zusätzliche neu gerodete Flächen aus dem herrschaftlichen Wald verpachtete. ${ }^{105}$ Der untertänige Besitz an solchen neu gerodeten Flächen nahm langsam, aber beständig zu. Hatte das Kloster vom gesamten Gericht Lhota 1732 und in den folgenden Jahren knapp 63 Gulden jährlich eingenommen, waren es ab 1746 mehr als 65 Gulden.

Auch anhand dieser Quelle fällt auf, dass die meisten Zinsreuter jahre- und jahrzehntelang in Pacht desselben Hauses blieben. Johann Hofmann, Inhaber eines eigentlich landlosen Hauses in Hodoň (Nr. 7), etwa bewirtschaftete ein relativ großes Reut (eine Wiese in der Münichschläger Au im Ausmaß von 5 Morgen, von der etwa 2,5 Fuhren Heu geerntet wurden und auf dem zusätzlich etwa ein Drittel Hektar Getreide angebaut wurde). Dieses Reut ging 1743 gemeinsam mit dem Anwesen an seinen Sohn Adam und nach dessen Tod 1757 gemeinsam mit dem Haus an Andreas Prieschl, der die Witwe des Adam geehelicht hatte, und wurde schließlich wieder gemeinsam mit dem Anwesen 1773 dem Mathias Thurnberger zugeschrieben. Nur in einer kleinen Minderheit der Fälle kam es zu anderen Lösungen: Beispielsweise ging nach dem Tod des Nikolaus Sösser, Bauer in Hodoň

102 Dies lässt sich aus den summarischen Angaben pro Dorf errechnen.

103 NA Praha,TK 684, Buděj. 46, Rustik. fasse 43/8, fol. 237. Immerhin auf etwa 70 Hektar von diesen obrigkeitlichen Flächen wurde auch Getreide angebaut. Herrschaftsweit bedeutete dies, dass etwas mehr als 10 Prozent der Heuernte und etwa 2 Prozent der bewirtschafteten Ackerfläche der Untertanen von herrschaftlichem Dominikalgrund kamen.

104 Bei 82 der 119 im Jahre 1840 existierenden Anwesen ist zumindest einmal während der Untersuchungsperiode die Nutzung eines herrschaftlichen Pachtgrundes nachweisbar.

105 SOA Třeboň, C Vyšší Brod, PK č. 556 (,Reuterbuch'). Erhoben wurden sämtliche Einträge für die Dörfer Hodoň, Hřbítek und Hvězda. Für Hodoň etwa wurden - bei 10 Häusern - 16 Zinsreuter geführt, ab 1762 dann 17; in Hřbítek zunächst fünf Zinsreuter, ab 1734 sechs. 
Nr. 6, im Jahr 1733 nur eines der beiden dem Hof zugeschriebenen Zinsreuter an seinen Nachfolger und Sohn Mathias Sösser, nämlich das etwa 2 Morgen umfassende Reut im Kienberger Wald (eine Fuhre Heu). Das größere Wiesenreut ,nechst der altn kohlstatt' (5 Morgen, 6 Fuhren Heu) behielt sich dagegen die Witwe und Ausnehmerin Sybilla Söser für sich. Nach dem Tod der Sybilla 1770 wurde ihr Reut sofort ihrem Enkel Albert, dem Sohn des Mathias, überschrieben. Den Haupthof erhielt Albert dagegen erst nach dem Rückzug des Mathias im Jahr 1779. ${ }^{106}$ In Ausnahmefällen wurden Zinsreuter, anders als beim Rustikalbesitz, offenbar auch von Inwohnern und von nicht-verwitweten Frauen besessen. Ebenfalls unter Hodoň verzeichnet ist etwa das Wiesenreut der Witwe Euphemia Nägelin aus Lipová, das 1748 ihrer Tochter Susanna Nägelin überschrieben wurde und nach dem Tod der Susanna 1755 an Albert Thurnberger, einem landlosen verheirateten Inwohner in Kapličky, kam. ${ }^{107}$ Euphemia Nägelin wurde laut Familienrekonstitution im Alter von 41 Jahren im Jahr 1704 Witwe (sie starb 1747 einen Monat vor ihrem 84. Geburtstag); ihre 1692 geborene Tochter Susanne heiratete offenbar nie, hatte allerdings 1719 ein uneheliches Kind. Das Zinsgereut diente vermutlich sowohl der Euphemia als auch ihrer Tochter als ein wichtiges agrarisches Standbein neben einem uns unbekannten Hauptberuf. Vermutlich wurde vom Ertrag dieser Fläche (angegeben sind 1,5 Fuhren Heu pro Jahr) auch eine Kuh gehalten.

Gerade neu errichtete Anwesen auf bäuerlichem oder Gemeindeland, die zunächst oft weitgehend landlos waren, pachteten überwiegend noch während der Besitzdauer des ersten Inhabers herrschaftlichen Grund hinzu. Beim ersten Besitzerwechsel nach der Gründung eines Anwesens wird in der Regel bereits ein dazugehöriges Zinsreut genannt. Beispielsweise wurde die Gemeindeschmiede von Kapličky 1723 dem bisherigen Pächter für 80 Gulden verkauft. Zum Anwesen gehörten, wie im Kaufvertrag vermerkt, bloß Hausgarten und -wiese. Bei der Weitergabe an den Sohn 1754 ist allerdings auch ein ,herrschaftliches Zinsreuth' dabei, der Sohn hatte daher für das Anwesen bereits 150 Gulden zu bezahlen. ${ }^{108}$

Zinsreuter stellten ein flexibles Element in einem ansonsten eher starren System fixer Grundgrößen dar, das die langfristige Zuordnung der Anwesen in bestimmte Besitzklassen in Frage stellt. Zum Teil wurde die Nutzung herrschaftlicher Pacht-

106 Das Fallbeispiel wurde rekonstruiert nach: SOA Třeboň, C Vyšší Brod, PK č. 556, pag. 275-285 sowie PK č. 465.

107 Im selben Dorf Hodoň ist zwischen 1739 und 1743 außerdem das Zinsreut eines Johann Praitenauer (laut Familienrekonstitution ein verheirateter Inwohner im Dorf Frantoly) verzeichnet. 1734 ging dieses Reut an jemandem aus dem zur Nachbarpfarre Vyšší Brod gehörigen Dorf Bystrá/Schild.

108 SOA Třeboň, fond C Vyšší Brod, PK č. 479, fol. 320 f. In der Region fand der Besitzwechsel prinzipiell in der Form von Kauf und Verkauf statt. Auch leibliche Kinder mussten das elterliche Anwesen kaufen, wobei alle Familienmitglieder gleiche Anteile an der Kaufsumme erhielten. Vgl. Kapitel 7. 
gründe wieder aufgegeben, andererseits kam manchmal ein weiterer hinzu. Einige Anwesen verfügten phasenweise über drei oder mehr herrschaftliche Pachtgründe. Welche Bedeutung diese Veränderungen im Ausmaß der bewirtschafteten Flächen vor allem für landarme Familien hatten, zeigt folgendes Beispiel: Der bereits erwähnte Dorflehrer Michael Hoffmann verstarb 1713, seine Witwe übergab das Haus 1720 an einen Sohn. Im Kaufvertrag wurde angemerkt, dass zwei ,gerünge zinsreuthe" zum Anwesen gehörten. Als Altenteil behielt sich die Witwe vor, auf diesen Flächen drei Gemüsebeete anzulegen sowie etwas Flachs anzubauen. Beim nächsten Besitzerwechsel 1738 konnte sich die ins Altenteil wechselnde Witwe bereits die Nutzung eines halben Zinsreuts vorbehalten. Möglich war diese Vergrößerung der Altenteilerwirtschaft, weil beim Anwesen inzwischen zwei herrschaftliche Wiesen und ein Acker in Pacht waren. 1741 werden allerdings nur mehr ein Acker und eine Wiese genannt. ${ }^{109}$ Auch der Pfarrer von Kapličky vergrößerte im Jahre 1720 seine Landwirtschaft durch ein herrschaftliches Zinsreut. ${ }^{110}$

In Kapličky wurden Zinsreuter nicht nur von der, eigenen' Gutsherrschaft gepachtet, sondern in mehreren Fällen auch von benachbarten südböhmischen oder oberösterreichischen Herrschaften. Bei mehreren Anwesen findet sich ein Hinweis auf ein ,fürstliches Zinsgereuth', also auf Flächen, die im Eigentum der großen benachbarten Güter der Fürsten Schwarzenberg waren. ${ }^{111}$ Die drei Häuser des im Jahre 1610 gegründeten Dorfes Hvězda hatten zwar jeweils ein kleines Stück Acker als Rustikalbesitz zugeteilt erhalten, allerdings keine Wiesen. Diese Häuser hatten daher zahlreiche Zinsreuter nicht nur vom Kloster, sondern auch in Oberösterreich zugepachtet, wie bereits in der Revisitace der Berní rula 1682 angemerkt wurde. Die Pacht von Grundflächen anderer Obereigentümer konnte zum Teil lange Zeit verschwiegen werden. Das direkt an der Grenze zu Oberösterreich gelegene Haus Hvězda Nr. 2 etwa verfügte dem Kataster von 1654 zufolge lediglich über Eigenbesitz im Ausmaß von 0, 5 böhmischen Strich (etwa 1. $400 \mathrm{~m}^{2}$ ). Der

109 SOA Třeboň, fond C Vy̌šší Brod, PK č. 565, fol. 151, fol. 472.

110 Archiv Kláštera Vyšší Brod, kart. 221 und kart. 222 (,Pfarrarchiv Kapellen`). Generell zählten die Pfarrer im südlichen Böhmerwald zu den größeren landwirtschaftlichen Besitzern. Der Pfarrer von Kapličky verfügte 1797 etwa über beinahe 7 Joch Ackerland und 23 Joch Wiesen. Zur Mitte des 17. Jahrhunderts hatte er auch eine kleinere, verlassene Landwirtschaft im Dorf Adámky übernommen. Der Pfarrer von Vyšší Brod bewirtschaftete im 19. Jahrhundert etwa 20 Hektar Grund. Quelle: Gottsmich/Pils, Hohenfurt, 19. Zur Landwirtschaft des Pfarrers von Frýmburk gehörten um 17978 Ochsen, 8 Milchkühe und 27 Schafe. Vgl. dazu: Prügl, Schlägl, 136.

111 Bei der Übergabe des Hofes Dobřin Nr. 1 im Jahre 1749 wurde etwa angemerkt, dass sich beim Anwesen drei fürstliche Zinsgereuter befinden. Das Haus Nr. 4 im selben Dorf wurde 1702 explizit ,ohne das fürstliche Freyreuth` übergeben. Quelle: SOA Třeboň, fond C Vyšší Brod, PK č. 479, fol. 165 . 
beim Besitzerwechsel 1679 genannte Viehstand von 4 Kühen und 4 Kälbern ist angesichts dieses geringen Eigenbesitzes überraschend. Die Erklärung für die hohe Viehzahl findet sich in einem Nachtrag im Grundbuch im Jahre 1747 (acht Jahre nach dem letzten Besitzerwechsel), den vermutlich die ,weichenden' Geschwister des Inhabers eingefordert hatten: Zum Anwesen würden neben ,obrigkeitlichen Zinsreutern' auch solche von oberösterreichischen Herrschaften gehören. Dies sei bisher nicht gemeldet worden. Der Besitzer hatte daraufhin die Ansprüche seiner verwitweten Mutter sowie seiner Geschwister an diesen Gründen finanziell abzugelten. ${ }^{112}$

Zinsreuter lagen außerhalb der Dorfflur im herrschaftlichen Wald und wurden überwiegend individuell und nicht kollektiv bewirtschaftet. Der Ertrag dieser Flächen diente häufig als Winterfutter und trug so zu einer Erhöhung des Viehbestands bei. Anhand der Schätzungen des Katasters von 1713 lässt sich berechnen, dass etwa ein Drittel der Heuernte in Kapličky von den herrschaftlichen Pachtgründen kam. Nach jahrelanger Bewirtschaftung konnte die Bodenqualität der zunächst wenig ertragreichen neu gerodeten Flächen erheblich gesteigert werden, sodass diese zum Teil auch als Ackerland nutzbar waren. ${ }^{113}$ Dies zeigen unter anderem auch die Altenteilerverträge. Die in der Pfarre übliche eigene kleine Landwirtschaft der bäuerlichen Altenteiler war nur auf herrschaftlichen Pachtgründen möglich, da diese nicht zur unteilbaren Besitzeinheit gehörten. Neben dem Winterfutter für die Kuh nutzten die Altenteiler Zinsreuter beinahe durchgängig auch zum Flachsanbau. ${ }^{114}$ Quellenbedingt ist über die Bewirtschaftung der Pachtgründe durch Kleinbesitzer weniger bekannt, es ist aber anzunehmen, dass sie ähnlich wie die Altenteiler wirtschafteten.

Derartiges gerodetes Dominikalland war für die Untertanen relativ günstig zu erhalten. Für einen Morgen Wiese waren um 1730 etwa 10 bis 20 Kreutzer (oder geringfügig mehr) an jährlichem Zins zu bezahlen. Zwar war die Produktivität neu gerodeter Waldflächen zunächst häufig sicherlich nicht besonders hoch, dafür konnten die Ausmaße solcher Grundstücke zum Teil recht beachtlich sein: Martin Kocher hatte etwa um 1660 im nahe gelegenen, besonders waldreichen Gebiet um Loučovice ein einziges Zinsgereut im Ausmaß von ca. acht Hektar in Bewirtschaftung. ${ }^{115}$ Zinsgereuter waren und blieben dauerhaft Teil des Dominikallandes. Für die Gutsherrschaft von Vorteil bei der Ausgabe dieser Pachtgründe war vor allem

112 SOA Třeboň, fond C Vyšší Brod, PK č. 453, fol. 308, č. 479, fol. 302.

1131713 wurden bloß rund drei Hektar herrschaftlicher Zinsreuter mit Getreide bebaut. Berechnet nach: NA Praha, TK 684, fol. 43-67, fol. 232, fol. 234.

114 Vgl. Kapitel 9.6.

115 Irsigler, Turmberg, 282. 
der Umstand, dass derartiges Land im Bedarfsfall - zumindest theoretisch - relativ leicht wieder zurückgenommen werden konnte. In Einzelfällen wurden Zinsreuter vom Kloster aber auch den Pächtern verkauft.

Zinsgereuter waren auch in den benachbarten Herrschaften sehr häufig und lassen sich in Südböhmen zeitlich sehr weit zurückverfolgen. Sie tauchen nicht nur in den Urbaren des 16. Jahrhunderts auf, sondern auch bereits in denen des Spätmittelalters $^{116}$ und bildeten auch die Basis der vor allem im 18. Jahrhundert neu gegründeten Dörfer in der Region (vgl. unten). ${ }^{117}$ In den Schwarzenberger Herrschaften gab es im 18. Jahrhundert reine „Zinsgereuterdörfer“, also Dörfer, deren gesamte landwirtschaftliche Basis aus neu gerodeten herrschaftlichen Gründen bestand. ${ }^{118}$ In der Herrschaft Český Krumlov waren die verpachteten Dominikalgründe derart zahlreich, dass die Herrschaft um 1840 einen eigenen „Zinsgründe-Verrechner“ angestellt hatte. ${ }^{119}$ Die Bürger des Marktortes Frýmburk vergrößerten bereits um 1600 ihren Grundbesitz, indem sie Parzellen im herrschaftlichen Wald kauften. In der Herrschaft Nové Hrady bildete um 1553 der Gereuther- und Hutweidenzins den zweithöchsten Posten unter den Zinseinnahmen der Herrschaft. ${ }^{120}$ In der Herrschaft Tachov/Tachau im Mittleren Böhmerwald dürften zu Beginn des 19. Jahrhunderts kaum 15 Prozent der von den Untertanen bewirtschafteten Flächen dem Rustikalland angehört haben, ganz überwiegend handelte es sich um von der Herrschaft gepachtete und jederzeit kündbare Flächen. Insbesondere die agrarische Basis der im frühen 17. Jahrhundert gegründeten Häuser beruhte auf herrschaftlichen Zinsgründen. ${ }^{121}$ Grüll berichtet für das angrenzende oberösterreichische Mühlviertel, dass die Herrschaften um 1740 verstärkt „Reuter“ aus ihren Forsten an neu errichtete Häuser ausgaben. ${ }^{122}$ Auch in den Spätkolonisationsgebieten auf der Passauer Seite des Böhmerwaldes hatten die neu errichteten Häuser relativ wenig Landbesitz und baten daher von Anfang an um die Zuweisung weiterer „Raumreuter“. ${ }^{123}$

In anderen Regionen Zentraleuropas war neben der Unterscheidung in Rustikal- und Dominikalland auch eine Unterteilung des Rustikallandes in Hausgründe und Überlandgründe, wie in Niederösterreich, oder sogenannte „walzende“

116 Vgl. etwa Henningsen, Besitz, 84f.

117 Saitz, Krumau, 10.

118 Blau, Hausindustrie, (Bd.1), 141.

119 Hochfürstlich Schwarzenberg'scher Schematismus für das Jahr 1846, Wien 1846, 35.

120 Teichl, Stadt, 378 ff.; auch im 18. Jahrhundert waren die verpachteten herrschaftlichen Wiesen noch häufig. Vgl. Buquoy, Grafen, 62.

121 Kuhn, Geschichte (Bd. 2), 253f; Köferl, Tachau, 439. Auch in der nordböhmischen Herrschaft Frýdlant waren von der Herrschaft gepachtete Weiden weit verbreitet. Vgl. Cerman, Diss., 251.

122 Grüll, Bauernhaus, 117.

123 Fegert, ,Fürstenhütte‘, 107; Kuhn, Geschichte, (Bd. 2), 253. 
Flächen, ${ }^{124}$ charakteristisch. Während die Hausgründe nicht vom Haus getrennt verkauft werden konnten, waren die Überlandgründe frei vererb- und verkaufbar. In den genannten Gebieten waren es daher gerade diese Flächen, die ein hohes Maß an Flexibilität und Wandel in die Besitz- und Wirtschaftsverhältnisse der ländlichen Bevölkerung brachten. Auch in den nahen Mühlviertler Herrschaften Freistadt und Schlägl gab es zahlreiche Überlandflächen; ${ }^{125}$ im Gebiet der Pfarre Kapličky waren diese dagegen völlig unbekannt. ${ }^{126}$ Die Zinsgereuter des südlichen Böhmerwaldes bildeten nicht im selben Maße „bewegliche Güter“ wie die Überlände anderswo. ${ }^{127}$ In der Regel wurden diese Pachtgründe langfristig von ein und demselben Hof bewirtschaftet und ganz überwiegend im Falle eines Besitztransfers in den Grundbüchern zwar gesondert erwähnt, aber auch mitsamt den Hausgründen weitergegeben. Ein Handel unter den Untertanen mit Zinsgereutern lässt sich in der Pfarre Kapličky nur in wenigen Fällen nachweisen, was zeigt, dass die durch die Zinsreuter ermöglichte Variabilität der bewirtschafteten Flächen nur selten genutzt wurde. Bei Besitztransfers unter Lebenden hingegen wurden von den Vorbesitzern weit häufiger gerade diese Flächen zurückbehalten, während das Haus mit allen dazugehörigen Gründen ungeteilt weitergegeben wurde. Die Zinsgereuter bildeten so eine zentrale Basis für die in der Region weit verbreitete Kleinlandwirtschaft der Ausnehmer. ${ }^{128}$

Zinsgereuter waren vor allem in den sehr waldreichen Gegenden besonders häufig, hier hatten ja die Herrschaften auch ihren größten Waldbesitz. Im Pfarrgebiet befanden sich etwa sehr viele im hoch und direkt an der österreichischen Grenze gelegenen Sternwald, wie die Grundparzellenverzeichnisse des Josephinischen Katasters zeigen. ${ }^{129}$ Dies bedeutete aber auch, dass Zinsreuter in den Dörfern mit höheren Waldanteilen zahlreicher als in anderen waren. Als eine Folge der unterschiedlichen Bodenreserven kamen sie daher in den meisten Dörfern der Pfarre Kapličky weit häufiger vor als in anderen Gebieten der Herrschaft Vyšší Brod, etwa in den niedriger gelegenen Dörfern um Studanky. Die topographischen Bedingungen hatten also indirekt einen sehr hohen Einfluss auf die regional unterschiedliche sozialstrukturelle Entwicklung.

124 Beck, Unterfinning, 228; Robisheaux, Rural Society, 83. Am Beispiel des Waldviertels Berkner, Social Structure, $172 \mathrm{ff}$.

125 Vgl. etwa Hirsch, Streifzug, 163, und Pröll, Schlägl, 265.

126 Vgl. NA Praha, SK Dupl. 190, § 12.

127 Sie wurden in der Pfarre beispielsweise nie direkt zur Abfindung sogenannter ,weichender Erben verwendet, wie dies bei den Überländern anderswo manchmal der Fall war. Vgl. dazu: Landsteiner, Leben, 98.

128 Vgl. Kapitel 9.6.

129 NA Praha, JK 2963 Obec Krasne Pole, z.B. Nr. 402. 
5.7 Folgen des Siedlungsausbaus: Wachstum der Agrarproduktion

Siedlungsausbau und Ausgabe herrschaftlichen Landes hatten Rückwirkungen auf die Entwicklung der agrarischen Produktion. Zur Mitte des 19. Jahrhunderts wurde in der Pfarre wesentlich mehr landwirtschaftliche Fläche bewirtschaftet als im 17. Jahrhundert. Diese Steigerung beruhte vermutlich in erster Linie auf einer Ausdehnung der Wiesenfläche, da die Zinsreuter vor allem als Wiesen genutzt wurden. ${ }^{130}$ Aber auch die Ackerfläche hatte sich kontinuierlich ausgedehnt (Tabelle 26). Südböhmische Gutsherrschaften stellten außerdem agrarische Ressourcen nicht nur durch die Verpachtung zusätzlicher Grundflächen bereit, sondern auch durch Nutzungsrechte am nicht verpachteten Wald. Viehweide, das Sammeln von Futtergras und ,Waldfruchtbau' in den herrschaftlichen Wäldern war länger als in anderen Regionen verbreitet. ${ }^{131} \mathrm{Im}$ weiter westlich gelegenen Vimperk etwa war es noch Mitte des 19. Jahrhunderts hunderten Inwohnerfamilien gestattet, gegen Bezahlung und versehen mit einem Berechtigungsschein, in den Wäldern der Gutsherrschaft Waldgras als Viehfutter zu sammeln. Bis in die 1840er Jahre war es Landarmen auch erlaubt gewesen, Kartoffeln und Roggen in den Wäldern der Herrschaft anzubauen. Die Herrschaften trachteten danach, von der Waldnutzung durch Untertanen zu profitieren. ${ }^{132}$ In Kapličky verfügten im frühen 19. Jahrhundert wesentlich mehr Familien über ein agrarisches Standbein als zur Mitte des 17. Jahrhunderts. Die bei Häusern mit geringem Grundbesitz tendenziell intensivere Bewirtschaftung des Bodens trug zur Steigerung der landwirtschaftlichen Produktion bei: 1654 betrug der Anteil der Brache an der gesamten Aussaatfläche der Wirtschaften bei etwa 74 Prozent aller verzeichneten Häuser zwischen 25 und 33 Prozent. Bei 10 bäuerlichen Anwesen lag dieser Anteil über 33 Prozent, bei 6 landarmen Häusern jedoch unter 25 Prozent. Die beiden Kleinbesitzer der Siedlung Adámky etwa hatten einen Bracheanteil von lediglich 12 bzw. 14 Prozent. ${ }^{133}$ Änderungen in der agrarischen Produktion werden in der Literatur gerade auch für die kleineren Güter Südböhmens genannt, zentral erscheint dafür eine

130 Über Veränderungen der Wiesenflächen liegen keine systematischen Angaben vor.

$131 \mathrm{Vgl}$. Trossbach, Bauern, $19 \mathrm{f}$. An vielen Orten versuchten die Herrschaften die Waldweide aufgrund forstwirtschaftlicher Interessen zu verbieten, da diese den Holzverkauf beeinträchtigte. Vgl. beispielsweise für die Region um die Saline Hallein: Weiß, Hollersbach, 49.

132 Vgl. John, Beschreibung, 37f. Vgl. auch Praxl, Dreiländerberg, 83, 117. Im südlichen Waldviertel in Niederösterreich war der herrschaftliche Wald als Viehweide derart bedeutend, dass er in einem Banntaiding als ,unser drittes Feld“ bezeichnet wurde. Vgl. Floßmann, Nochilinga, 239. Als Beispiel einer sozialhistorischen Studie zur Geschichte des Waldes siehe: Allmann, Wald.

133 Quelle: NA Praha, BR 2. 1682 war diese Verteilung sehr ähnlich, für das Jahr 1713 konnten derartige Berechnungen nicht durchgeführt werden, da in der Quelle keine Gesamtaussaat genannt wird. 
Verbesserung der Brachlandsysteme. Der Anteil des Brachlandes an der gesamten landwirtschaftlichen Nutzfäche Südböhmens wird für die 1840er Jahre auf nur mehr ein Sechstel geschätzt. ${ }^{134}$ Es gibt einzelne Hinweise darauf, dass in den gebirgigen Regionen des Böhmerwaldes die Wiesen in Hanglage bewässert wurden, wodurch zumindest eine zusätzliche Mahd pro Jahr erzielt werden konnte. ${ }^{135}$ Auch andernorts nutzten die Kleinbesitzer den Boden intensiver und hielten wesentlich mehr Vieh je Hektar Ackerland als die größeren Höfe. ${ }^{136}$ Durch Ausweitung der genutzten Flächen und Intensivierung der Produktion konnte eine deutlich höhere Bevölkerungszahl ernährt werden.

Ein Vergleich des Viehstandes von 1654 und 1846 zeigt insbesondere einen deutlichen Anstieg bei der Kuh- und Schafhaltung (Tabelle 26). 1846 kamen hier 24,7 Kühe auf 100 Einwohner. Erhöht hatte sich jedoch nicht nur die Gesamtzahl der Kühe in der Pfarre, auch - und das war sicherlich in zahlreichen anderen Regionen nicht der Fall - die Zahl der Anwesen, die zumindest eine Kuh hielten, hatte sich zwischen 1654 und 1713 um etwa 50 Prozent auf 94 erhöht. Für die 1840er Jahre können dann etwa 100 Häuser mit Kuhbesitz angenommen werden. ${ }^{137}$ Die Ausdehnung der Milchkuhhaltung auf deutlich mehr Familien brachte sicherlich eine Verbesserung der Ernährungssituation (vor allem bei den Kleinhäuslern) mit sich. Mit dem Besitz einer einzigen Kuh ließ sich jedenfalls im Regelfall der Jahresbedarf einer erwachsenen Person an Milch, Schmalz und Topfen decken. ${ }^{138}$ Milchprodukte bildeten eine wichtige Ergänzung zur ansonsten überwiegend auf Kraut und Rüben ${ }^{139}$ basierenden und somit fett- und proteinarmen Nahrung der ärmeren Bevölkerung in der Region. Als Nebenprodukt ihres Flachsanbaus verfügten die Kleinhäusler und Altenteiler mit dem Leinsamen, der in der Region auch

134 Vondruška, Zemědělská. Neuerdings betont die internationale Forschung zunehmend die Bedeutung der Verbesserung der Bodenqualität für die agrarische Ertragssteigerung während der frühen Neuzeit. So sei der Drainage in der englischen Agrargeschichte möglicherweise eine höhere Bedeutung beizumessen als den üblicherweise in der Literatur hervorgehobenen ,enclosures'. Vgl. Gritt, Good Land.

135 Ubel, Böhmerwald, 43. Für den Bayerischen Wald wird die Bewässerung der Wiesen als üblich dargestellt. Vgl. Fegert, Fürstenhütte, 135.

136 Schlögl, Krise, 143.

137 Für die Zeit nach 1713 sind keine systematischen Daten zum Viehstand der individuellen Anwesen verfügbar. Hinweise in den Grundbüchern legen jedoch nahe, dass bis zum Ende des Untersuchungszeitraums zumindest sieben weitere Anwesen mit Kuhhaltung hinzukamen. In zwei Fällen findet sich dezidiert ein Hinweis auf die Haltung einer Kuh, in fünf weiteren Fällen legt dies die Nutzung einer größeren Wiesenfläche nahe.

138 Vgl. diesbezüglich die Modellrechnung bei Beck, Unterfinning, 237.

139 Vgl. Nenning, Materialien, 155. 
zu Speiseöl verarbeitet wurde, über eine weitere wichtige fettreiche Nahrung. ${ }^{140}$ Es gibt Indikatoren für eine sich während der frühen Neuzeit verbessernde Ernährungssituation sowie für eine Stabilisierung der ökonomischen Verhältnisse in Kapličky. So wie auch für andere Regionen beschrieben, scheint sich, wie die folgenden Tabellen andeuten, die Kombination von Heimarbeit und kleiner Landwirtschaft für die Ernährungssituation und die Lebenserwartung der Bewohner von Kapličky positiv ausgewirkt zu haben. ${ }^{141}$

Tabelle 26: Entwicklung der agrarischen Produktion in der Pfarre Kapličky, 1654-1846

\begin{tabular}{l|c|c}
\hline \multicolumn{2}{c}{ Bebaute Ackerfläche } \\
\hline \multicolumn{2}{c}{ Pfarre Kapličky } & $\begin{array}{c}\text { Gemeinden Mnichovice und } \\
\text { Krasné Pole }\end{array}$ \\
\hline $\begin{array}{l}\text { Summe der gesamten Aussaat } \\
\text { 1654 }\end{array}$ & Rustikalböden 1757 & Ackerfläche 1827 \\
\hline 1.142 Strich (rund 326 ha) & 1.202 Strich (rund 343 ha) & 972,8 Joch (rund 555 ha) \\
\hline \multicolumn{3}{c}{ Viehstand Gemeinde Krasné Pole } \\
Ochsen & 1654 & 1846 \\
Kühe & 128 & 173 \\
Kälber & 123 & 219 \\
Schafe & 149 & 98 \\
Schweine & 85 & 200 \\
\hline
\end{tabular}

Anmerkung: Ein Vergleich der summarischen Angaben der älteren Kataster mit jenen des in der ersten Hälfte des 19. Jahrhunderts erstellten Stabilní katastr (SK) kann nur als Annäherungswert dienen, da letzterer nicht mehr in Pfarren oder Dörfer unterteilte, sondern in Steuergemeinden. Die beiden Steuergemeinden Krasné Pole (Schönfelden) und Mnichovice (Münichschlag) waren nur annähernd mit dem Pfarrgebiet ident, da auch der kleine, nicht zur Pfarre gehörige Weiler Valtov Teil der Gemeinde Mnichovice war. Hingegen fehlte der 1787 von der Pfarre abgetrennte Ort Vyšina, der nur um wenige Häuser größer als Valtov war, sodass sich $\mathrm{Zu}$ - und Abschlag von Gebietsteilen im Ergebnis in etwa ausglichen. Die Ackerfläche 1827 umfasst auch Äcker der Herrschaft, die in den beiden älteren Zählungen nicht inkludiert waren. Die Herrschaft verfügte aber nur über einen kleinen Teil der Ackerflächen - im gesamten Herrschaftsgebiet über etwa 15 Prozent. Für die Steuergemeinde Mnichovice liegen keine Daten zum Viehstand im 19. Jahrhundert vor.

1401712 hatte Veit Kroyher, Müller im Pfarrdorf Lipová, eine Leinsamenpresse errichtet. Vgl. Archiv Klaštera Vy̌̌ší Brod, kniha 245, Nr. 16: ,Zins buech bey dem löblichen stüfft undt closter Hochenfurth rändtambt, wie solche jährlich in empfang gebracht undt ordentl: verechnet werden', 1712.

141 So etwa Mattmüller, Landwirtschaft, für die Basler Landschaft. 
Quellen: ,Ausweis über die Benutzung des Bodens', 1827, NA Praha, SK 323 ;, Grundparzellenprotokoll', 1827, SK 221; ,Catastral-Schätzungs-Elaborat der Steuergemeinde Schönfelden', 1850, NA Praha, SK Dupl. 190, § 4.

In Kapličky lag das mittlere Sterbealter erwachsener Personen (über 15 Jahre) bereits früh relativ hoch und erhöhte sich bei den Männern während des 18. Jahrhunderts um weitere vier Jahre (Tabelle 27). ${ }^{142}$ Bisher vorliegende Daten für andere Regionen verweisen auf ein teilweise deutlich niedrigeres mittleres Sterbealter. ${ }^{143}$ Für das Amt Niedeck im südlichen Niedersachsen etwa wurden Durchschnittswerte des Sterbealters Erwachsener (über 15-jähriger Personen) für den Zeitraum von 1710 bis 1875 von 57,9 Jahren für Männer und 57,0 Jahren für Frauen ermittelt. ${ }^{144}$ In Kapličky ist der deutlich geringere Anstieg des weiblichen Sterbealters wohl auf die durch zunehmenden Flachs- und Kartoffelanbau - beides überwiegend Frauenarbeit - stark steigende Arbeitsbelastung für Frauen zurückzuführen, wie dies in ähnlicher Weise auch bereits für andere Regionen beobachtet wurde. ${ }^{145}$

Auch die ökonomische Situation vieler Anwesen hatte sich während des 18. Jahrhunderts stabilisiert. Mussten während der zweiten Hälfte des 17. Jahrhunderts zahlreiche Haus- und Hofinhaber ihr Anwesen nach relativ kurzer Zeit wieder verkaufen, da es ihnen nicht gelang, ein ausreichendes Einkommen zu erwirtschaften, um sowohl das Überleben der Familie zu gewährleisten als auch allen finanziellen Anforderungen nachzukommen, so erhöhte sich die Besitzdauer im 18. Jahrhundert sowohl bei bäuerlichen Anwesen als auch bei landarmen Häusern deutlich (vgl. Kapitel 7.5).

Obwohl die zentralen Institutionen der traditionalen Agrarverfassung in der Region weitgehend unverändert blieben, fanden während des Untersuchungszeit-

142 Der hier verwendete Indikator des, durchschnittlichen Sterbealters' ist nicht geeignet, um Aussagen zu Veränderungen in der Lebenserwartung der Bevölkerung zu tätigen. Er wird aber auch in der Literatur durchaus als Näherungsmaß für Veränderungen in der Mortalität verwendet. Vgl. Weigl, Ungleichheit, 118f. Auch Schlumbohm, Lebensläufe, 168 berechnete das durchschnittliche Sterbealter, nicht ohne aber auf die geringe Aussagekraft der ermittelten Werte hinzuweisen.

143 Dies zeigen etwa die Daten bei Begemann, Lebensbedingungen, 97 für eine norddeutsche Region im 18. und 19. Jahrhundert und bei Weigl, Ungleichheit, hier 126 für verschiedene Wiener Berufsgruppen, sowie auf Basis von Leichenpredigten für protestantische Mittelschichten im frühen 18. Jahrhundert bei: Paul Münch, Lebensformen, 409 (57 Jahre für Männer und 50 Jahre für Frauen). Dennoch gibt es auch in der Literatur deutliche Hinweise auf eine bereits im frühen 18. Jahrhundert steigende Lebenserwartung. Vgl. dazu etwa: Marschalk, Bevölkerungsgeschichte Deutschlands, 26; Pfister, Bevölkerungsgeschichte, 102f.

144 Vogel, Ungleichheit.

145 Hohe Arbeitsbelastungen für Frauen wurden bisher vor allem im Kontext hoher Säuglingssterblichkeit diskutiert. Vgl. Kaschuba/Lipp, Überleben, 557-562. Vgl. auch Vogel, Ungleichheit, 69. 
raums ein beachtliches demographisches Wachstum, eine Steigerung der agrarischen Produktion und ein sozialstruktureller Wandel statt. Dieser Wandel führte trotz der prinzipiellen Geschlossenheit der Güter nicht zu einer Transformation in eine Gesellschaft, die von einem schroffen Gegensatz zwischen Landbesitzenden und Landlosen geprägt war, sondern zeichnete sich eher durch die ständige Integration neuer, ursprünglich landloser Anwesen aus.

Tabelle 27: Entwicklung des mittleren Sterbealters der erwachsenen Bevölkerung, Pfarre Kapličky (1651-1770)

\begin{tabular}{lcccc}
\hline & Frauen & & Männer \\
Geburtsjahre & mittleres Sterbealter (in Jahren) & N & mittleres Sterbealter (in Jahren) & N \\
\hline $1651-1690$ & 59,9 & 141 & 59,4 & 142 \\
$1691-1730$ & 59,7 & 190 & 60,9 & 207 \\
$1731-1770$ & 60,4 & 210 & 63,8 & 203 \\
\hline
\end{tabular}

Anmerkung: Es wurden nur Personen, die das 15. Lebensjahr überschritten hatten, berücksichtigt. Für später geborene Personen können diese Daten nicht mehr berechnet werden, da nach Fertigstellung der Familienrekonstitution 1850 Nachträge der Sterbedaten nur mehr unvollständig erfolgten und daher jung Verstorbene überrepräsentiert wären.

Quelle: SOA Třeboň, Sbírka jihočeských matrik, Farní úřad Kapličky, kniha č. 9 (,Rodovy katastr',16421931).

Feudale Strukturen wurden und werden als Hemmnis für Steigerungen der landwirtschaftlichen Produktivität während der frühen Neuzeit eingestuft, ganz besonders gilt dies für gutswirtschaftliche Strukturen. Diese Einschätzung trifft zum Teil auch für die Untersuchungsregion zu, dennoch kann die Rolle der Gutsherrschaft nicht durchgängig als bremsend für das Wachstum der agrarischen Produktion bewertet werden. Durch die Ausgabe herrschaftlichen Landes ermöglichte sie eine Ausdehnung der Anbau- und Weideflächen. Faktisch stärkte die Gutsherrschaft dadurch die Tendenzen zu einer Individualisierung der landwirtschaftlichen Produktion. Die Größe der Wälder ermöglichte es, dass unterschiedliche Interessen der Waldnutzung zwischen Herrschaft und Untertanen kaum kollidierten.

Zwar existierten zahlreiche Institutionen, die die Verfügbarkeit von Haus und Land steuerten und begrenzten. Sie funktionierten jedoch nicht nach der Logik, die im Rahmen idealtypischer Modelle zur ,Agrarverfassung" erdacht wurde, sondern boten ausreichend Raum für Modifikationen und Anpassungen an konjunkturelle Entwicklungen. Der Grund dafür ist, dass bäuerliche Gesellschaften keineswegs ,marktfern' existierten. Wegen der Unabwägbarkeiten der zu erwartenden Ernteerträge musste die bäuerliche Ökonomie tendenziell darauf angelegt sein, 
Überschüsse zu produzieren, die - bei guten Erträgen - auf überlokalen Märkten abgesetzt werden konnten. In der Untersuchungsregion findet sich neben Handelsbeziehungen nach außen auch ein (landwirtschaftlicher) Arbeitsmarkt. Als Alternative zum weitgehend fehlenden Bodenmarkt fungierte außerdem ein Markt für Pachtland. Der Arbeitsmarkt und die Verfügbarkeit von Pachtland ermöglichten sowohl Bevölkerungs- als auch Produktionswachstum. Durch das demographische Wachstum standen der Landwirtschaft zusätzliche Arbeitskräfte zur Verfügung; Bevölkerungszunahme und Siedlungstätigkeit ermöglichten eine intensivere Nutzung der vorhandenen Bodenreserven. ${ }^{146}$ Regional unterschiedliche institutionelle Vorbedingungen beeinflussten die Bedingungen für Agrarwachstum maßgeblich. Die Art und Weise, in der sich in dieser Region demographischer und ökonomischer Wandel innerhalb der traditionalen Agrargesellschaft vollzog, war eine spezifische Reaktion auf die konkreten lokalen institutionellen und konjunkturellen Rahmenbedingungen.

146 Vgl. dazu etwa Kopsidis, Leistungsfähigkeit, 330, der davon spricht, dass sich dort, wo ,ein gewisser Grad an Marktintegration existierte, demographische Expansion eingesetzt hatte auch agrarwirtschaftliche, Intensitätsoasen' bildeten. 


\section{BESITZRECHTE, MOBILITÄT UND SIEDLUNGSAUSBAU}

\subsection{Der frühneuzeitliche Siedlungsausbau im südlichen Böhmerwald}

Die in der Pfarre Kapličky während der frühen Neuzeit vergleichsweise starke Siedlungstätigkeit und die kontinuierliche Ausweitung der landwirtschaftlich genützten Flächen war Teil einer insgesamt noch weit bedeutenderen Siedlungstätigkeit in der gesamten Region des Böhmerwaldes. Als größtes zusammenhängendes Waldgebiet Mitteleuropas bildete dieser während der gesamten frühen Neuzeit und noch im 19. Jahrhundert eine bedeutende „Landreserve“, in die beständig weiter vorgedrungen wurde. Die topographischen Gegebenheiten boten hier für die Anlage neuer Siedlungen, die seit dem 16. Jahrhundert auch in den höheren Waldlagen erfolgten, während der frühen Neuzeit wesentlich günstigere Voraussetzungen als in zahlreichen anderen Regionen Europas. Lokal stand die Häufigkeit der Gründung neuer Dörfer dabei in einem engen Zusammenhang mit der Ausdehnung des bisher unbesiedelten Waldes. Wo dieser Waldstreifen, wie etwa entlang der bayerischen Grenze, breiter war, war die ,kolonisatorische“ Tätigkeit naturgemäß intensiver als gegen Süden hin, wo der Streifen bisher ,unberührten` Waldgebietes immer schmäler wurde. ${ }^{1}$ In der bereits in den südlichen Ausläufern des Böhmerwaldes gelegenen Herrschaft Vyšší Brod blieb nur mehr wenig Raum für eine Neukolonisation. Daher entstanden in dieser Herrschaft, abgesehen von der Pfarre Kapličky und der Umwandlung mehrerer herrschaftlicher Meierhöfe in Dörfer in den 1780er Jahren, seit 1530 nur mehr zwei sehr kleine neue Ansiedlungen. ${ }^{2}$ In Kapličky waren außer der bereits erwähnten Gründung des Dorfes Nové Domky 1690 auch die kleine Ansiedlung Hvězda (drei Häuser) im Jahr 1610 sowie die kleine Ansiedlung Hřbítek/Hundsruck erst nach 1500 gegründet worden. Letztere entstand um 1583 dadurch, dass der Weber Stefan Schwentner auf einem Grund des Valentin Strasser, ebenfalls Weber, in der Nähe des Ortes Kapličky ein

1 Vgl. Rubner, Bevölkerung, 559 ff.; Kuhn, Geschichte (Bd. 2), 254 ff.

2 Einerseits das kleine Dominikalistendorf Rossnitzhütten bei Přidolí im späten 16. Jahrhundert (im Kataster 1682 wurden zwei Anwesen genannt), andererseits die ähnlich kleine, zu Ende des 18. Jahrhunderts gegründete Siedlung Loislreut bei Frýmburk. In beiden Fällen konnten tschechische Ortsnamen nicht eruiert werden. Vgl. Schmidt, Siedlungs-Geschichte, 44 ff. 
Häuschen, genannt am Hundsruck, errichtete. ${ }^{3}$ In den höheren Waldlagen und vereinzelt auch entlang der Moldau im südlichen Böhmerwald war dagegen genug Platz, um noch während des 18. Jahrhunderts zahlreiche neue Dörfer zu gründen.

Der Prozess der Neugründung von Dörfern während der frühen Neuzeit wies mehrere Phasen unterschiedlich intensiver Siedlungstätigkeit auf. Die Erschließung von höheren Waldlagen des Böhmerwaldes erfolgte vor allem seit dem späten 17. und im 18. Jahrhundert. ${ }^{4}$ Während die im Spätmittelalter und bis ins frühe 16. Jahrhundert reichende Besiedelung noch agrarischen Charakter hatte, waren die in mehreren Wellen zwischen dem 16. und dem 19. Jahrhundert erfolgten Dorfgründungen prinzipiell nicht-agrarisch geprägt, sondern zum Teil von gewerblichindustrieller Produktion, vor allem aber von der steigenden Bedeutung der Forstwirtschaft getragen.

In der Vyšší Brod benachbarten, sehr großen Herrschaft Český Krumlov fanden bereits während der ersten Hälfte des 17. Jahrhunderts einzelne Dorfgründungen statt. So war das Dorf Glöckelberg (Zvonková), nahe der österreichischen Grenze, 1622, also während des Dreißigjährigen Krieges, gegründet worden. ${ }^{5}$ Die Gründungswelle verstärkte sich ab etwa 1680 und war hier in besonderem Maße von der Holzverarbeitung geprägt. Bis in die 1840er Jahre hinein entstanden zahlreiche neue Ansiedlungen, von denen manche rasch anwuchsen. 6 Das um 1650 gegründete Nová Pec/Neuofen (nahe Glöckelberg) zählte beispielsweise 1653 zwei Häuser, 1689 aber schon 23 und laut dem Endelaborat des Theresianischen Katasters vom Jahre 175727 Anwesen. $^{7}$

Ebenfalls um etwa 1680 begann auch die Siedlungswelle in der Herrschaft Nové Hrady, die allerdings erst ab 1770 mit Einführung des Systems der Leiberpacht deutlich an Intensität gewann. ${ }^{8} \mathrm{Um} 1670$ hatte auch das oberösterreichische Stift Schlägl, das auf böhmischer Seite der Grenze kleinere Besitzungen hatte, das Dorf Gaisleiten (Kozí Stráň) bei Dolní Vltava gegründet. ${ }^{9}$ Ab etwa 1720/30 begann eine

3 Schmidt, Urbar, 174. Noch vor 1600 kam ein zweites Haus hinzu, sodass sich daraus bis ins 18. Jahrhundert eine eigenständige Ansiedlung entwickelte.

4 Ortmeyer, Bauernhäuser, 28; Zeithammer, Land, 104f.; Willkomm, Böhmerwald, 99.

5 Auch das in dieser Herrschaft, direkt an der Grenze zur Pfarre Kapličky gelegene kleine Kappeler Waldhäuser scheint noch während des Dreißigjährigen Krieges gegründet worden zu sein. Vgl. Schmidt, Siedlungs-Geschichte, 41. Diese Beispiele von Siedlungsgründungen in Phasen hoher demographischer Verluste sind ein deutliches Indiz gegen die Gültigkeit weit verbreiteter malthusianischer Sichtweisen, wonach die zunehmende soziale Differenzierung als Folge eines ,demographischen Drucks' betrachtet wird. Vgl. ähnlich: Cerman, Rural Economy, $59 f$.

6 Vgl. etwa: Zeithammer, Land, 104f.; Ortmeyer, Bauernhäuser, 28; Saitz, Krumau, 35.

7 Essl, Krummau, 628, 668.

8 Vgl. Blau, Hausindustrie, (Bd.1), 61ff; Teichl, Herrschaft, $10 \mathrm{f}$.

9 Schmidt, Siedlungs-Geschichte, 42; Pröll, Schlägl, 298. 
Phase der Dorfgründungen auch in der Herrschaft Vimperk. Besonders zahlreiche Dorfgründungen erfolgten gegen Ende des 18. Jahrhunderts, vor allem in den 1790er Jahren. ${ }^{10}$ Sowohl in Vimperk als auch in der Herrschaft Český Krumlov stand dies in einem engen Zusammenhang mit der Errichtung des Schwarzenbergischen Schwemmkanals. ${ }^{11}$ In den 1780er Jahren wurden im, dem Böhmerwald gegen Budweis hin vorgelagerten Blanský Les (Plansker Wald), der um 1700 noch unbesiedelt war, insgesamt acht Dörfer neu angelegt und damit eine ganze Gemeinde, genannt Johannesthal, neu gegründet. Die Bewohner lebten in der Folge vor allem von der Holzschuherzeugung. ${ }^{12}$

Ab etwa 1790 wurden auch Moorlandschaften urbar gemacht und besiedelt. So wurde etwa das Dorf Julienhain (Hranice) in der Herrschaft Nové Hrady in diesem Jahr gegründet; zu Beginn des 19. Jahrhunderts auch die beiden Dörfer Fleissheim (Horní Borkova) und Mayerbach (Dolní Borkova) bei Dolní Vltavice in der Herrschaft Český Krumlov. ${ }^{13}$ Erst in den Jahren 1830 bis 1833 erfolgte die Gründung der Dörfer Friedrichsau (Bedřichov) und Bocksberg in der Gemeinde Světlík, ebenfalls auf Moorgründen. ${ }^{14}$

Allein in der Herrschaft Český Krumlov waren so zwischen 1620 und der Mitte des 19. Jahrhunderts insgesamt 47 Dominikalistendörfer neu entstanden, ${ }^{15}$ in der Herrschaft Nové Hrady in diesem Zeitraum 23 Dörfer und in der Herrschaft Vimperk bis Ende des 18. Jahrhunderts zumindest sieben Siedlungen. ${ }^{16}$

Auf bayerischer Seite des Böhmerwaldes wurde die sogenannte „Neue Welt“ (beim Dreiländereck Österreich, Bayern, Böhmen) ab etwa 1670 besiedelt. 1683 bestanden hier bereits 64 Häuser. ${ }^{17}$ Über die Anlage der in der Nähe dieses Gebietes um 1698/99 planmäßig neu errichteten Siedlung Zwölfhäuser liegt inzwischen eine detaillierte Studie vor. ${ }^{18}$ Besonders der ebenfalls zu dieser Zeit gegründete Ort Breitenberg wuchs wegen der hier betriebenen Holztrift sowie der sich ausbreitenden Leinenweberei im 18. Jahrhundert stark an: die Pfarre zählte um 1800 beinahe 5.000 Einwohner. ${ }^{19}$

10 Vgl. John, Beschreibung, bes. 19-21; Essl, Krummau, 670f.

11 Rubner, Bevölkerung, $560 \mathrm{f}$.

12 Blau, Hausindustrie, (Bd.1), 239.

13 Essl, Krummau, 708f.

14 Lausecker, Skizzen, 65.

15 Berger, Wittingshausen, 64.

16 Siehe den nach Herrschaften geordneten Überblick zur frühneuzeitlichen Siedlungstätigkeit bei:

Blau, Hausindustrie, (Bd.1), 61-66; Zeithammer, Land, 104f; Teichl, Herrschaft, 382 ff.; John, Beschreibung, $19 \mathrm{ff}$.

17 Praxl, Dreiländerberg, 71f.; Hackel, Besiedlungsverhältnisse, 57.

18 Fegert, Zwölfhäuser.

19 Vgl. Praxl, Dreiländerberg, 77. 
Für das oberösterreichische Mühlviertel wird eher das 16. Jahrhundert als Rodungszeitalter gesehen. In der Herrschaft Schlägl wurden etwa zwischen 1459 und 1526 rechts der Mühl sieben neue Dörfer mit insgesamt 65 Anwesen angelegt. ${ }^{20}$ Im relativ nahe der Herrschaft Vyšší Brod gelegenen, sogenannten ,Freiwald‘ bei Freistadt erfolgte die letzte Rodungswelle an der Wende vom 16. zum 17. Jahrhundert. Ohne herrschaftliche Planung entstanden hier bis 1615 insgesamt 113 Häuser. ${ }^{21}$ Lediglich im Gebiet der Herrschaft Schlägl wurde auch auf Mühlviertler Seite der Grenze die Siedlungstätigkeit nach 1700 noch intensiv fortgesetzt. Ab etwa 1767 entwickelte sich z.B. eine neue Siedlung am Klafferbach. ${ }^{22}$

Ganz überwiegend handelte es sich bei den Neugründungen von Siedlungen auf böhmischer Seite der Grenze um Grund und Boden, der in herrschaftlichem Besitz - also Dominikalland - war (im Gegensatz zum Rustikalland der Untertanen). Die Neuangesiedelten wurden deshalb auch Dominikalisten genannt. Sie hatten zwar ihr Haus in Eigenbesitz, den Grund und Boden aber entweder befristet oder auf unbestimmte Zeit in Pacht. Der allergrößte Teil der Neuangesiedelten - dies gilt selbst noch für die Dorfgründungen des frühen 19. Jahrhunderts - wurde auch mit einem geringen Grundbesitz, etwa mit einem Strich Ackerland und einer Wiese in den Auen, ausgestattet. ${ }^{23}$ Im relativ großen, im Jahr 1793 beim Plöckensteinersee (Plešné jezero) errichteten Dorf Hirschbergen (Jeleni Vrchy) bekam jedes Haus fünf Joch Pachtgrund sowie das „Grasrecht“ im herrschaftlichen Wald zugeteilt, sodass alle Besitzer zwei Kühe halten konnten. ${ }^{24} \mathrm{Im}$ bereits erwähnten Julienhain erhielt jedes der Häuser ca. drei Joch Grund zugesprochen. ${ }^{25}$ In vielen der neu gegründeten Dörfer des südlichen Böhmerwaldes wurden Waldarbeiter und Holzfäller angesiedelt, die zumeist von Beginn an auch vertraglich zu jeweils genau bestimmten Holzarbeiten verpflichtet waren. Die zunehmende Bedeutung der Moldauschwemme machte die Ansiedlung ständiger Arbeitskräfte nötig. ${ }^{26}$

Obwohl im Böhmerwald seit den ersten Rodungen im Hochmittelalter im Prinzip beständig eine Siedlungstätigkeit stattfand und sich etwa auch im 16. Jahrhundert mehrere Gründungen neuer Dörfern nachweisen lassen, gab es auch Perioden, in denen der Siedlungsausbau offenbar kaum oder nur äußerst langwierig vonstattenging. Dies scheint etwa während des Spätmittelalters der Fall gewesen zu sein. Berichtet wird, dass sich die Anlage des kleinen Dorfes Fridava (Friedau)

20 Wasmayr, Ulrichsberg, $77 f$.

21 Vgl. Grüll, Walde, 209.

22 Vgl. Pröll, Schlägl, 298, sowie Praxl, Dreiländerberg, 85.

23 Vgl. etwa Schmidt, Siedlungs-Geschichte, 60, Essl, Krummau, 708f., Teichl, Herrschaft, 413.

24 Praxl, Dreiländerberg, 117.

25 Teichl, Herrschaft, 413.

26 In der Herrschaft Český Krumlov hatten diese eine Bezahlung in Akkordlohn. Vgl. Saitz, Krumau, 35. 
an der Moldau im 14.Jahrhundert über 70 Jahre hinzog. ${ }^{27}$ Auch die Gründung des der Pfarre Kapličky unmittelbar benachbarten Dorfes Loučovice (Kienberg) an der Moldau, das bereits 1361 in einer Urkunde als neue Siedlung erwähnt wird und in einem für die Landwirtschaft völlig ungeeigneten Gebiet gelegen ist, kam bis zum Jahr 1600 über einige wenige Häuser nicht hinaus. Vermutlich waren, abgesehen vom sicher bereits länger bestehenden „Fischerbauern“, die um 1600 neu errichteten Dominikalistenhäuser überhaupt die ersten Anwesen des Ortes gewesen. ${ }^{28}$ Für bestimmte Phasen ist wohl nicht nur mit einer Stagnation der Siedlungstätigkeit im südlichen Böhmerwald zu rechnen, mancherorts scheint die Häuserzahl während des 16. Jahrhunderts sogar rückläufig gewesen zu sein, wie einige Beispiele aus der Herrschaft Vyšší Brod zeigen. So bestand das Dorf Jiř́íckov (Irsieglern) im Jahr 1479 aus drei, laut Urbar von 1530 aber nur mehr aus zwei Anwesen. Jílovice (Gillewitz) hatte um 1500 zehn Häuser, 1530 aber nur sieben. Die Gründe der drei anderen Anwesen waren in der Zwischenzeit den sieben verbleibenden zugeschlagen worden. Im Dorf Větrná (Nesselbach) wurde während der zweiten Hälfte des 16. Jahrhunderts eine „Hofstatt“ (kleineres Anwesen) den Hausgründen eines Bauern angegliedert. Auch im zur Pfarre Kapličky gehörigen Dorf Dobřín zählte das herrschaftliche Urbar von 1530 insgesamt acht Anwesen - eine Anzahl, die - wie die Grundbücher zeigen - erst wieder im Jahre 1740 erreicht wurde. ${ }^{29}$

Dominikalistenhäuser finden sich jedoch nicht nur in den während der frühen Neuzeit neu errichteten Dörfern, sondern auch bei Erweiterungen bereits länger bestehender älterer Ansiedlungen, sodass häufig innerhalb ein und desselben Dorfes sowohl Anwesen auf Rustikalland als auch Dominikalisten zu finden waren. Ähnlich wie die Dominikalisten hatten auch einzelne während der frühen Neuzeit auf bäuerlichem Grund angesiedelte Kleinhäusler nur befristete Pachtverträge auf ,drei Leiber' (siehe ausführlicher Kapitel 6.3.1). Nur in seltenen Fällen kam es zu Unklarheiten darüber, ob ein Anwesen als Dominikalistenhaus zu zählen war oder nicht. Dies war etwa im Jahre 1737 im Dorf Valdov (südlich von Studanky) in der Pfarre Vyšší Brod der Fall. Hier war auf einem Grund des Pfarrers von Vyšší Brod das Haus eines gewissen Kaspar Thurmfart errichtet worden. Dieser wurde zunächst als Untertan des Pfarrers angesehen. Da der Pfarrer aber immer ein Pater aus dem Kloster war, wurde auch dieses Haus später zu den Dominikalisten der Herrschaft gezählt. ${ }^{30}$

27 Schmidt, Siedlungs-Geschichte, 42.

28 Die bereits davor hier nachweisbaren Köhler und Holzhauer hatten ihren ständigen Wohnsitz anderswo. Vgl. Schacherl, Kienberg, Schmidt, Siedlungs-Geschichte, 45.

29 Vgl. Schmidt, Urbar, 198 ff. Vgl. die ähnliche Entwicklung in einem westböhmischen Gebiet bei Pangerl, Choden, 233.

30 Kienzl, Geschichte, 102. 
In vielen Fällen dürften die erst während der frühen Neuzeit in Südböhmen entstandenen Dörfer besonders rasch gewachsen sein und sich zu den größeren Ansiedlungen entwickelt haben. Nové Domky etwa hatte um 1860 bereits 19 Häuser und war damit zum zweitgrößten Dorf der Pfarre Kapličky geworden. Eine ähnliche Entwicklung ist auch für die nach dessen Auflösung aus dem herrschaftlichen Gut ,Glashof' entstandene Ansiedlung Skláře/Teutschmannsdorf belegt, die 1860 bereits zum größten Dorf der Pfarre Hořice geworden war. ${ }^{31}$

\subsection{Mobilität und Migration im südlichen Böhmerwald ${ }^{32}$}

Das lange Zeit dominante Bild einer immobilen und sesshaften ländlichen Bevölkerung in vorindustrieller Zeit wurde in den letzten Jahren gründlich revidiert. „Die Bevölkerung des absolutistischen Staates ist grundsätzlich seßhaft" schrieb dagegen noch 1981 ein Sozialwissenschafter. ${ }^{33}$ Beigetragen zur Persistenz solcher Vorstellungen haben „vorschnelle“ Schätzungen von Sozialhistorikern über das Ausmaß der Sesshaftigkeit in vorindustrieller Zeit. So hat etwa P. Goubert angenommen, dass 19,5 von 20 Millionen Franzosen im Ancien Regime an das jeweilige Land, den Boden und das Haus, auf dem sie aufgewachsen waren, gebunden geblieben seien. ${ }^{34}$ Natürlich unterlagen aber auch Mobilität bzw. Immobilität verschiedener Personengruppen einem historischen Wandel. Kürzlich hat etwa G. Fertig an einem südwestdeutschen Fallbeispiel für verheiratete Personen auf Basis der Kirchenbücher eine zunebmende Sesshaftigkeit am Ort während des 18. Jahrhunderts festgestellt. ${ }^{35}$ Auch die Bevölkerung des Südtiroler Marktortes Innichen wird für das 18. Jahrhundert als noch wesentlich mobiler als im 19. Jahrhundert beschrieben. ${ }^{36}$ Neuerdings wird dagegen - in Umkehrung älterer Annahmen - betont, dass die Mobilität während der frühen Neuzeit und während der Frühphase der Industrialisierung in vielen europäischen Ländern und Regionen höher als im 20. Jahrhundert war. ${ }^{37}$ Den älteren, traditionellen Sichtweisen der Forschungsliteratur folgend wäre

31 Vgl. dazu die Zusammenstellung der Häuserzahlen im Jahr 1860 bei: Trajer, Historisch-statistische Beschreibung, 260, 330. Eine ähnliche Entwicklung ist auch in der Pfarre Dolní Vltavice festzustellen.

32 Vgl. zum Folgenden auch die entsprechenden Abschnitte in meinem Aufsatz: Zeitlhofer, Sesshaftigkeit.

33 Tennstedt, Sozialgeschichte, 18.

34 Collins, Mobility, 564.

35 Fertig, Lokales Leben, 258.

36 Lanzinger, Das gesicherte Erbe, 230.

37 Ehmer, Demographie, 19 ff; Ehmer, Alter, 36; Moch, Moving Europeans. Vgl auch Pfister, Bevölkerungsgeschichte, $47 \mathrm{f}$. 
die Untersuchungsregion des südlichen Böhmerwaldes als eine besonders immobile Gesellschaft einzustufen, da sie während der frühen Neuzeit gleich in mehrfacher Hinsicht Bedingungen erfüllte, für die üblicherweise jeweils eine besondere regionale Stabilität angenommen wurde: zum einen handelte es sich um ein Gebiet mit Unteilbarkeit der Güter, für welche die Annahme einer engen Bindung der Bauern an ihren Grund und Boden eine sehr lange Tradition hat, zum anderen um eine sogenannte, Gutsherrschaftsgesellschaft', für die allgemein die Existenz von rigiden Mobilitätsbeschränkungen für die Untertanen betont wurde.

Tatsächlich ging in den böhmischen Ländern mit der schon im 16. Jahrhundert einsetzenden und nach dem Dreißigjährigen Krieg abgeschlossenen vollen Etablierung gutsherrschaftlicher Strukturen eine Einschränkung der Bewegungsfreiheit der Untertanen (Schollenbindung) einher. Das Verlassen der territorial oft geschlossenen Herrschaftskomplexe der Gutsherren war genehmigungspflichtig. ${ }^{38}$ Allerdings war die Handhabung dieser Genehmigungspflicht regional und zeitlich recht unterschiedlich. Die Gutsherrschaften kontrollierten und erschwerten die räumliche Mobilität der Untertanen etwa durch die Ausstellung sogenannter Weglassscheine (,Reisepässe') und in manchen Regionen Böhmens auch durch die regelmäßige Führung von Mannschaftsbüchern, in denen der jeweilige Aufenthaltsort sämtlicher Untertanen der Herrschaft festgehalten wurde. ${ }^{39}$ Allerdings konnten und wollten die Gutsherrn aber die Mobilität ihrer Untertanen - schon um ihre immer auch zu einem Teil auf Lohnarbeit beruhende Eigenwirtschaft nicht zu gefährden - nicht völlig unterbinden. Auch hatten die regional stark variierenden demographischen Folgen des Dreißigjährigen Krieges einen immensen Einfluss auf das Ausmaß der Eingriffe der Gutsherren in die räumliche Mobilität ihrer Untertanen. Auf Gutsherrschaften, in denen es in der unmittelbaren Nachkriegszeit einen bedeutenden ,Menschenmangel' gab, konnte es in den ersten Jahren und Jahrzehnten nach 1648 auch zur erzwungenen Verschiebung ganzer Bevölkerungsgruppen in weitgehend verödete und verlassene Dörfer und Ansiedlungen sowie zu rigide sanktionierten Abwanderungsverboten kommen. ${ }^{40}$ Das illegale, dauerhafte Verlassen der Herrschaft - in den Quellen als ,Entlaufen' bezeichnet - wird in den hier analysierten Grundbüchern speziell zur Mitte des 17. Jahrhunderts mehrfach erwähnt. Zu betonen ist dabei, dass selbst diese Tat nicht zum Verlust

38 Die Einschränkung der Bewegungsfreiheit wird oft auch als eines der Hauptmerkmale der böhmischen ,Erbuntertänigkeit' angesehen. Vgl. Maur, Gutsherrschaft, 104. Vgl. dazu auch Kapitel 1.

39 Für den Kernbereich der Herrschaft (die Region um Vyšší Brod und Kapličky) sind keine „Mannschaftsbücher" erhalten; offenbar wurden keine geführt. Es ist auch nicht anzunehmen, dass die hier als Besonderheit vorhandenen Familienbücher einen Ersatz für die Mannschaftsbücher bildeten, da in diesen nie die Aufenthaltsorte der verzeichneten Personen genannt wurden.

40 Vgl. etwa die Hinweise bei Maur, Gutsherrschaft, 198. 
der Erbansprüche an einem Haus in der Region führte. Vielmehr wurde die dafür vorgesehene Geldstrafe vom zu erwartenden Erbteil abgezogen. Während solche Fälle in der Pfarre Kapličky gelegentlich unter den Kindern der ländlichen Grundbesitzer vorkamen, war ein ,Entlaufen', also eine Flucht aus der Herrschaft, von Grundbesitzern selbst extrem selten. ${ }^{41}$ Mit der während der zweiten Hälfte des 17. Jahrhunderts einsetzenden ökonomischen Erholung und der demographischen Stabilisierung Böhmens dürfte die Haltung der Gutsherren zur Mobilität ihrer Untertanen allerdings wieder differenzierter zu betrachten sein. Die Entlassung aus der Untertänigkeit - also ein permanenter Wegzug - wurde auf wenige Fälle $\mathrm{zu}$ begrenzen versucht ${ }^{42}$, andere Formen der Mobilität dürften dagegen vielfach zunehmend weniger restriktiv gehandhabt worden sein. Für die Entlassung aus dem Untertanenverband wurde ein sogenannter ,Losbrief" verlangt, ein Rechtsanspruch, diesen auch zu erhalten, bestand nicht. ${ }^{43}$ Die ökonomische Diversität vieler Regionen des Landes - darunter auch des südlichen Böhmerwaldes - mit zahlreichen proto- und frühindustriellen Produktionsformen (Eisen- und Glasmanufakturen, ausgeprägten Textilregionen, etc.; vgl. Kapitel 4) schuf saisonbedingt einen hohen Bedarf an Akkord- und Taglohnarbeitern, der unter anderem auch durch mobile Arbeitskräfte gedeckt werden musste. Trotz des bisher sicher ungenügenden Forschungsstandes zur Migration während der frühen Neuzeit ist jedenfalls die Existenz unterschiedlicher Wanderungsbewegungen in den ländlichen Regionen Böhmens durchaus belegt. ${ }^{44}$ Die Ausstellung der im Falle einer

41 Der Fall des 1721 , entlaufenen` Grundbesitzers Georg Lachenwitzer aus dem Dorf Frantoly, der seine Frau und mehrere minderjährige Kinder zurückließ, war ein ungewöhnlicher Ausnahmefall. Das Grundbuch nennt eine hohe Verschuldung als Grund. In der benachbarten Herrschaft Český Krumlov wurde die Flucht aus der Herrschaft ebenfalls mit dem Einzug eines kleinen Teils der Erbschaft bestraft. Interessanterweise betraf dies aber nur die Männer und nicht entflohene Frauen. Vgl. Himl, Die ,armben Leüt', $75 f$.

42 Siehe dazu die empirische Analyse der während des 17. Jahrhunderts kontinuierlich rückläufigen Zahl der,Entlassungen' am Beispiel der ostböhmischen Herrschaft Pardubice bei: Maur, Gutsherrschaft, $107 f$.

43 Für die Herrschaft Vyšší Brod liegen diesbezüglich nur Zahlen für das Jahr 1750 vor. Laut Steuerbekenntnis (NA Praha, ED, i. č. 193, Kart. č. 20) nahm die Herrschaft in diesem Jahr 453 Gulden 55 Kreutzer durch die Ausstellung von Losbriefen ein. Zum Vergleich der Höhe dieser Summe: Für die meisten Häuser der Pfarre Kapličky (auch für solche mit Grundbesitz), die um diese Zeit den Besitzer wechselten, wurde eine (überwiegend deutlich) geringere Summe gezahlt. Vgl. zur rechtlichen Situation der Entlassungen auch: Komlosy, Grenze, 280f.

44 Vgl. die Beispiele bei: Maur, Gutsherrschaft, 78, 105 ff., 120. Erst in jüngster Zeit wird das Thema der Migration im frühneuzeitlichen Böhmen von der Forschung aufgegriffen. Vgl. etwa den Sammelband: Maur/Grulich, Dějiny migrací, sowie die auf einer Analyse von Gerichtsakten basierende Studie, die Einblick in die unterschiedlichen Motive für die ländliche Migration in Südböhmen während der frühen Neuzeit gibt: Grulich, Motivace migrací. 
Verehelichung oder einer Berufsausübung (Gesindedienst, Gesellenwanderung, etc.) außerhalb der Herrschaft benötigten „Pässe“ konnte auch eine willkommene Einnahmequelle für Grundherrn bilden. Generell hinderten die in Böhmen während der frühen Neuzeit herrschenden Mobilitätsbeschränkungen die Menschen nicht, Reisen durch das ganze Land zu unternehmen. ${ }^{45}$ Exakte empirische Studien über die Auswirkungen von Mobilitätsbeschränkungen auf die ländlichen Untertanen in dieser Zeit stehen für Südböhmen noch weitgehend aus. Eine Annäherung an diese Frage kann aber ein Vergleich der Heiratsmobilität in der Herrschaft Chýnov während der zweiten Hälfte des 17. Jahrhunderts mit den Angaben zu den Herkunfts- und Aufenthaltsorten in zwei Bevölkerungszählungen aus dem 16. Jahrhundert bieten. Bei dieser Untersuchung ließ sich jedenfalls kein auffälliger Wandel im quantitativen Ausmaß der untertänigen Mobilität erkennen. ${ }^{46}$

Das Überschreiten der Herrschaftsgrenzen war durchaus auch nach dem Dreißigjährigen Krieg verbreitet. Laut der im Jahre 1651 durchgeführten Bevölkerungszählung lebten im Gebiet der Pfarre Kapličky unter den 383 verzeichneten Personen (wobei nur Personen in einem Alter von über zehn Jahren erfasst wurden) zehn Männer und sechs Frauen, die einer anderen, benachbarten Herrschaft untertänig waren (also etwa vier Prozent der verzeichneten Personen). Diese waren nicht ausschließlich im Gesindedienst tätig, auch ledige und verheiratete Inwohner befanden sich darunter. So waren etwa der als Gemeindehirt angestellte Joseph Huisser und seine Frau Ursula keine Herrschaftsuntertanen. ${ }^{47}$ Umgekehrt lebten und arbeiteten in diesem Jahr auch zahlreiche Untertanen der Herrschaft Vyšší Brod in den benachbarten Herrschaften. Das Soupis poddanych von 1651 nennt leider bloß im Falle der Stadt Český Krumlov die Herkunftsorte der einer ,fremden Herrschaft untertänigen Personen - üblicherweise wurde nur die Zugehörigkeit zu einer anderen Herrschaft festgehalten. Immerhin lässt sich so aber erkennen, dass zwölf Mägde der Stadt und vier Gesellen (bzw. Lehrlinge) aus Vyšší Brod stammten. ${ }^{48} \mathrm{Zu}$ vermuten ist, dass sich noch wesentlich mehr Personen aus der Herrschaft Vyšší Brod in den ländlichen Gebieten der benachbarten Herrschaft Český Krumlov aufhielten. Eine Stichprobe bestätigt die Persistenz einer Herrschafts-

45 Svoboda, Trade. Vgl. zur rechtlichen Entwicklung der Reisefreiheit in Böhmen im 18. und 19. Jahrhundert: Stoklásková, Ausländergesetzgebung.

46 Vgl. Grulich/Zeitlhofer, Migrace; Vgl. außerdem den Überblick zur Geschichte der Migration in Böhmen seit dem 17. Jahrhundert, bei dem auch die in manchen Regionen Südwestböhmens relevante Zuwanderung kurz angesprochen wird, bei: Zeitlhofer, Tschechien.

47 NA Praha, Soupis poddanych. Vgl. zu dieser Quelle ausführlich Kapitel 2. Vgl. auch die ähnlichen Ergebnisse für andere Regionen Böhmens bei: Maur, Gutsherrschaft, 120.

48 Kokošková/Sedlačková/Zahradníková (Hg.), Soupis poddaných, Band 2, 289 ff. Außerdem kamen weitere 19 Personen aus verschiedenen Regionen des heutigen Österreich. 
grenzen und Provinzgrenzen überschreitenden Mobilität für die zweite Hälfte des 18. Jahrhunderts: Im Archiv der Herrschaft Rožmberk haben sich aus den Jahren von 1751 bis 1778 insgesamt 67 individuell ausgestellte ,Losbriefe، von Personen erhalten, die in diesen Jahren von außerhalb kommend in die Untertänigkeit der Herrschaft wechselten. Von diesen 67 stammten unter anderem 19 Personen (oder etwa 28 Prozent) aus der Herrschaft Vyšší Brod und zumindest fünf Personen aus verschiedenen Gebieten Oberösterreichs. ${ }^{49}$

Häufig waren sowohl die Gesindemobilität wie auch die Migration aus Gründen einer Heirat. Jedenfalls zeigen die Herkunftsangaben der Personen in den Grundund Kirchenbüchern, dass zum Zwecke der Verehelichung während des 17. und 18. Jahrhunderts sowohl die Herrschaftsgrenzen als auch die Landesgrenze zu Oberösterreich jeweils in beide Richtungen überschritten wurden. ${ }^{50}$ Trotz der angeblich deutlichen Verschlechterung der Lebensbedingungen in rechtlicher und sozialer Hinsicht kam die Zuwanderung insbesondere aus bayerischen und österreichischen Gebieten nach Südböhmen nie völlig zum Erliegen. ${ }^{51}$ Eine Stichprobe aus der Familienrekonstitution von Kapličky zeigt etwa, dass zwischen 1670 und 1699 unter den 69 von auswärts in die Pfarre einheiratenden Frauen zumindest zwölf von außerhalb der Herrschaft kamen: drei aus Oberösterreich und neun aus anderen Gebieten Böhmens (1700-1749: 21 von insgesamt 135 Frauen; fünf aus Oberösterreich und 16 aus anderen Teilen Böhmens). ${ }^{52}$ Im Einzugsgebiet der Stadt Český Krumlov wurden zwischen 1800 und 1820 jährlich etwa 150 bis 200 Reisebewilligungen für Handwerker erteilt. Bis in die 1840er Jahre stieg dieser Wert auf etwa 400 erteilte Bewilligungen jährlich. ${ }^{53}$ Für das 19. Jahrhundert ist für mehrere Orte Südböhmens, darunter auch für die benachbarte Herrschaft Český Krumlov, die Praxis belegt, die eigenen Kinder zwecks Spracherwerbs über die Sprachgrenze hinweg in den Gesindedienst zu schicken. Dabei tauschten manchmal tschechisch- und deutschsprachige Familien (selbst die wohlhabenden unter ihnen) ihre Kinder aus. ${ }^{54}$

49 Auch eine Person aus der nordböhmischen Herrschaft Frýdlant war darunter. Vgl. SOA Třeboň, VS Rožmberk, kart. č. 94.

50 Eine Untersuchung zur Frage der grenzüberschreitenden Migration zwischen Südböhmen und Oberösterreich im 17. und 18. Jahrhundert auf der Basis von Losbriefen hat J. Záloha am Beispiel der Vyšší Brod benachbarten Herrschaft Č. Krumlov durchgeführt, vgl. Záloha, Bevölkerungsemigration.

51 Vgl. etwa die Erwähnungen bei Rubner, Bevölkerung, 557 ff.; Gallistl, Heimatkunde, 92; Markus, Oberplan, 26; Sturm, Oberpfalz. In der Herrschaft Nové Hrady wurde 1840 das Holzfällerdorf Wilhelmsberg mit protestantischen Zuwanderern aus der Region Hannover gegründet. Vgl. Blau, Hausindustrie (Bd.1), 63.

52 Quelle: Rodový Katastr. Ausgewertet wurde hier der Geburtsort der Frauen, der in den meisten Fällen im Trauungsbuch angeführt wurde.

53 Trachtová, Zünfte, 127.

54 Vgl. etwa Mardetschläger, Budweis, 325. 
Die saisonale Arbeitsmigration auch in entfernte Gebiete stellte in Südböhmen keine neue Erscheinung des industriellen Zeitalters dar. Sie wurde jedenfalls nicht durch die zunehmende De-Industrialisierung des südböhmischen Raumes und dessen Peripherisierung im Zuge der Hochindustrialisierung ausgelöst, sondern reicht zumindest in ihren Anfängen bis weit in eine Zeit zurück, in der ein Teil der untersuchten Bezirke von einer ausgeprägten Proto-Industrialisierung erfasst war, und damit in die Zeit der Gutsherrschaft mit ihren vermeintlich restriktiven Mobilitätsbeschränkungen. 1771 wurde an den Hofkriegsrat in Wien über den Budweiser Kreis (zu dem auch der südliche Böhmerwald gehörte) berichtet: „Im Frühjahr gehen viele Familienväter in die Nachbarländer und kommen erst zu Allerheiligen oder Martini zurück" 55 Häufig wurden die dafür benötigten Genehmigungen von den Herrschaften individuell ausgestellt, sodass das gesamte Ausmaß dieser Migrationen nachträglich schwer rekonstruierbar ist; selten vorliegende vollständige Verzeichnisse für südböhmische Kleinstädte des frühen 19. Jahrhunderts deuten aber auf zahlenmäßig relevante Bevölkerungsanteile (mit zum Teil über fünf Prozent der Einwohner), die jährlich eine Reisebewilligung beantragten. Für die Kleinstadt Netolitz/Netolice (Herrschaft Vimperk) ist für den Zeitraum von 1793 bis 1838 eine recht rege saisonale Arbeitsmigration - mit bis zu 70 Personen jährlich - dokumentiert. Die überwiegend in den österreichischen Raum (um Wien) gerichtete Wanderbewegung war einerseits von Bauhandwerkern und Ziegelarbeitern getragen, andererseits auch von Hausierern und Wandermusikanten. ${ }^{56}$

Der Hausierhandel hatte in den südwestlichen Böhmerwaldbezirken eine lange Tradition, die unter anderem eng mit der Vielfalt der Holzverarbeitung verbunden war. Hier waren kleinräumig - oft nur auf der Ebene eines Dorfes - zahlreiche heimgewerbliche Produktionsformen konzentriert, deren Produkte häufig im Hausierhandel abgesetzt wurden: darunter etwa die Holzschuherzeugung, die Korbflechterei, die Produktion von Hinterglasbildern mit religiösen Motiven, die Heiligenbildschnitzerei, etc. ${ }^{57}$ Böhmische Wandermusikanten - etwa aus dem Böhmerwald - waren bis weit ins 20. Jahrhundert hinein in vielen Regionen Zentraleuropas speziell bei Hochzeiten sehr begehrt. ${ }^{58}$

55 Zitiert nach Blau, Hausindustrie (Bd. 2), 7.

56 Starý, Migration. Vgl. zu den ähnlichen Zielregionen und Berufsgruppen südböhmischer Migranten im frühen 20. Jahrhundert meinen Aufsatz: Zeitlhofer, Bohemian Migrants.

57 Einen ausgezeichneten Überblick zur Vielfalt und lokalen Verbreitung der Hausindustrie im Böhmerwald bietet Blau, Hausindustrie (Bd. 1).

58 Für den Böhmerwald ist festzustellen, dass zunächst eher Einzelpersonen oder Kleingruppen (von maximal drei Personen) als Musiker unterwegs waren, und erst im 19. Jahrhundert allmählich größere Gruppen in Erscheinung traten. Vgl. Helm, Grenzgänge, 87. Mehrere Wandermusikanten werden auch in einem Verzeichnis für Vimperk aus dem Jahr 1830 erwähnt. Vgl. De Angelis, Winterberg, $69 f$. 
Die saisonale Arbeitsmigration dürfte im südlichen Böhmerwald früh einen wichtigen Bestandteil familialer Überlebensstrategien - insbesondere für die landarmen Bevölkerungsschichten - gebildet haben. Die Verbindung einer kleinen Landwirtschaft mit der Garnerzeugung und der Arbeitswanderung ist hier bereits für das späte 18. Jahrhundert naheliegend. Die unterschiedlichen saisonalen Rhythmen von Spinnen und Arbeitsmigration förderten eine Kombination: fand das Garnspinnen überwiegend im Winter statt, so hatten mehrere der wichtigsten Berufe der südböhmischen Migranten (Maurer, Ziegelarbeiter) ihren Schwerpunkt von Frühjahr bis Herbst. Im 19. Jahrhundert waren viele Arbeitsmigranten während der Wintermonate in anderen Sparten der Heimarbeit tätig..$^{59}$ Auch die ,Fortgeher aus der Region um Vyšší Brod, die nicht nur nach Süden sondern teilweise auch in nordböhmische Regionen gingen, verbanden zumindest im späten 19. Jahrhundert saisonale Migration mit Heimarbeit im Winter. ${ }^{60}$

Die süd- und südwestböhmischen Grenzbezirke wiesen auch in anderer Hinsicht eine lange Tradition hoher Mobilität auf. Während der frühen Neuzeit hatten die waldreichen Gebiete des Böhmerwaldes zahlreichen sozialen Randgruppen und vagierenden Bevölkerungsschichten als Rückzugsgebiet gedient. ${ }^{61} \mathrm{Im}$ 18. (und selbst noch im 19.) Jahrhundert entzogen sich Teile dieser Region einer dauerhaften effektiven Kontrolle durch die Obrigkeiten. In diesem Rückzugsgebiet lebten (und überlebten) bis ins frühe 19. Jahrhundert soziale Randgruppen und Vagierende, die zum Teil von der Grenze, das heißt vom Schmuggel über die Grenze lebten. Es handelt sich dabei um Personen, die in der typischen ,Kirchenbuchpopulation' von Dorfstudien, die auf einer Familienrekonstitution basieren, meist übersehen werden. Hinweise auf diese Gruppen finden sich in der Regionalliteratur für den gesamten Raum des Böhmerwaldes. ${ }^{62}$ Überwiegend wurden diese Gruppen in den Quellen als ,Zigeuner', in späterer Zeit auch als ,Schörgen' bezeichnet, ob es sich aber tat-

59 Die ältere Regionalliteratur berichtet etwa über den Ort Schweinitz/Trhově Sviny (bei Budweis), dass zahlreiche junge, unverheiratete Frauen im Frühjahr als ,Maurermädchen ' in die Städte zogen, während sie im Winter Zwirnknöpfe fertigten. Vgl. Josef Blau, Hausindustrie (Bd. 2), 193. Nach dem Niedergang der ,klassischen' proto-industriellen Textilgewerbe (Flachsverarbeitung und Leinenweberei) hatten sich seit der Mitte des 19. Jahrhunderts zahlreiche neue Heimgewerbe etabliert. Um 1900 wurden in dieser Region des Budweiser Handelskammerbezirkes etwa 2.000 Menschen in der Handschuherzeugung gezählt; 900 Personen waren heimgewerblich mit der Strumpfstrickerei beschäftigt und alleine in der Region um Gratzen/Nové Hrady arbeiteten etwa 600 Personen in der Hemdknopferzeugung. Die Zahlen nach dem ,Bericht der k. k. Gewerbeinspectoren über die Heimarbeit in Österreich: 1900/1901'. Zit. in: Kahle, Hausindustrie, 55f, 69; Teichl, Herrschaft, 449.

60 Vgl. hierzu speziell: Wohlschläger, Von Häuslern.

61 Vgl. Praxl, Dreiländerberg.

62 Vgl. etwa Blau, Von Räubern; Ders., Hausindustrie (Bd. 1), 99; Berger, Leidensgeschichte, 98. 
sächlich um Roma oder Sinti handelte, ist ziemlich unsicher. ${ }^{63}$ Einige Hinweise in den Kirchenbüchern deuten auch auf desertierte Soldaten hin. Dolzer, der nach 1900 selbst Pfarrer im nahen Frymburk war, setzte ,Schörg' mit ,Schwärzer' und ,Zigeuner' gleich. ,Schwärzer ‘ meint Leute, die vom Grenzschmuggel lebten. Über die Präsenz von ,Schwärzern' im 18. und 19. Jahrhundert im nahen Dreiländereck von Böhmen, Bayern und Österreich liegen zahlreiche Berichte vor. ${ }^{64}$ Auf dem Gebiet der Pfarre Kapličky gab es ein bestimmtes Waldstück (im nördlichen Teil der Pfarre), in dem sich Angehörige dieser Gruppen zu Beginn des 18. Jahrhunderts bevorzugt aufhielten. Phasenweise handelte es sich dabei sicherlich um mehrere Dutzend Personen. Bis gegen Ende des 18. Jahrhunderts tauchen Personen mit den bisher genannten Bezeichnungen auch in den Kirchenbüchern immer wieder auf, im Todesfall oder wenn sie ein Kind taufen ließen. Zwar ist keine einzige der mit einem auf eine vagierende Lebensweise deutenden Attribut versehenen Familien durch die Familienrekonstitution vollständig erfasst, bei einzelnen Familien verweist die mehrfache Erwähnung im Kirchenbuch allerdings doch auf einen etwas längerfristigen Aufenthalt im Pfarrgebiet. Gabriel und Katharina Gstuer etwa, in den Kirchenbüchern als ,Zigeuner' bezeichnet, ließen 1713 und 1715 ein Kind in der Pfarre Kapličky taufen. Dass diese stark mobilen Gruppen auch Sozialbeziehungen zu den Ortsansässigen unterhielten, ist an den Paten ihrer Kinder ablesbar. ${ }^{65}$ So erscheint etwa der im Pfarrdorf Martinkov wohnhafte und später zwangsweise versetzte herrschaftliche Jäger Kaspar Gafko um 1710 häufig als Taufpate der Kinder dieser Personen. ${ }^{66}$ Vagierende Gruppen hatten demnach offenbar eine Reihe sozialer Kontakte zu den Ortsansässigen. Im Mai 1715 gab es im Pfarrgebiet von Kapličky eine zwei Tage andauernde Militäraktion gegen die als ,Zigeuner' bezeichneten Gruppen, bei der unter Beteiligung der lokalen Bevölkerung nicht weniger als zwölf Personen getötet wurden. ${ }^{67}$ Obwohl die ,Zigeuner in Böhmen bereits 1697 per kaiserlichem Dekret für ,vogelfrei‘ und damit für rechtlos erklärt wurden (ein

63 In einer Ortsgeschichte des nahen Marktortes Horní Plana aus dem 19. Jahrhundert findet sich ein Hinweis darauf, dass mit dem Terminus „Zigeuner“ in dieser Region möglicherweise alle Herumziehenden gemeint sein konnten - unabhängig von ihrer ,ethnischen` Zugehörigkeit. Vgl. Markus, Oberplan, 27.

64 Dolzer, Friedberg, 86f. Vgl. auch Greipl, Böhmerwaldheimat, 224; Praxl, Dreiländerberg, 140 ff. Einen kurzen Einblick in den Einfallsreichtum, mit dem die Leute verschiedenste Waren unversteuert und unbemerkt über die Grenze zwischen Bayern und Böhmen brachten, bietet etwa der Bericht von Georg Weisel (verst. 1873): Ders, Weisel, Kuriositäten.

65 Neuere Studien zur Verfolgung vagierender Gruppen während der frühen Neuzeit in anderen Regionen Südböhmens betonen die hohe Bedeutung sozialer Netzwerke zur sesshaften Bevölkerung, da dies im Notfall überlebenswichtig sein konnte. Vgl. Dibelka, Migrace Cikánů.

66 Vgl. dazu Tobner, Zigeunerwald, 6.

67 Vgl. dazu: Svátek, Culturhistorische Bilder, bes. 291-293; Kaindl, Zisterzienserstift Hohenfurt, 90f. 
Dekret, das 1721 wiederholt wurde) ${ }^{68}$, ist an diesem grausamen Ereignis doch der Tathergang - nämlich die aktive Einbindung der lokalen Bevölkerung in die Jagd auf eine gesellschaftlich verfemte Bevölkerungsgruppe - einigermaßen bemerkenswert. ${ }^{69}$ Nicht weniger bemerkenswert erscheint die Art der lokalen Überlieferung des historischen Geschehens. ${ }^{70}$ Auch in späteren Jahren versuchten die südböhmischen Herrschaften die mobile Armut (den Bettel) - wenn freilich auch mit weniger drastischen Methoden - zu unterbinden. Die Herrschaften Rožmberk und Nové Hrady etwa beschäftigten ab 1780 mehrere permanent angestellte,Wachposten` zur Kontrolle der herumziehenden Vagabunden und Bettler. Wenn diese Personen aufgegriffen wurden, drohte ihnen eine Gefängnisstrafe. ${ }^{71}$

So mobil die vormoderne Gesellschaft nunmehr auch gezeichnet wird, ist dieses Bild genauer besehen auch in neueren Arbeiten klar auf bestimmte Per-

68 Dies bedeutete für die meisten männlichen Mitglieder dieser Gruppen den Tod, während die Frauen und Kinder nach einer Verstümmelung (Abschneiden eines Ohres) des Landes verwiesen wurden. Vgl. etwa: Svátek, Culturhistorische Bilder, $288 \mathrm{ff}$.

69 Die aktive Beteiligung der Bevölkerung an den gewaltsamen Übergriffen könnte auch die Folge einer schrittweisen Eskalation der Ereignisse gewesen sein. Jedenfalls ist auffällig, dass das Kloster Vyšší Brod in den Jahren 1713 und 1714 als Präventivmaßnahme gegen ein Übergreifen der in einigen Regionen Zentraleuropas in dieser Zeit grassierenden Pest (der letzten Pestepidemie Böhmens) auf das Herrschaftsgebiet an der Grenze zu Oberösterreich insgesamt elf Personen als ,Pest-Wachen' angestellt hatte, die die Mobilität an der Grenze kontrollieren sollten. Mit Christoph Donner und Augustin Nagel befanden sich auch zwei Personen aus der ländlichen Unterschicht der Pfarre Kapličky unter den Wachen. Durch diese Maßnahmen gerieten die besonders mobilen Bevölkerungsgruppen sicherlich verstärkt ins Visier von Verdächtigungen. Mit dem 31.1.1715 begannen dann die Berichte des Klosters Vy̌šś Brod an das königliche Kreisamt in Budweis, die schließlich in der Entsendung des Militärs mündeten.

70 Die Ereignisse bilden etwa den Kern des Ende des 19. Jahrhunderts verfassten Romans ,Der Zigeunerwald des Mönchs Zephyrin Tobner, einem Mitglied des Konvents von Vyšší Brod. Die Schilderung der Ereignisse stützt sich dabei (ebenso wie bei Svátek) auf Materialien aus dem Klosterarchiv. Tobners Roman erschien ursprünglich in Fortsetzungen in der südböhmischen Zeitschrift ,Der Landbote؛ Der Roman erlebte während des 20. Jahrhunderts mehrere Auflagen als Monographie, die noch in den 1980er Jahren vor allem in den Kreisen der aus dem südlichen Böhmerwald vertriebenen und in der Bundesrepublik Deutschland lebenden deutschsprachigen Bevölkerung gerne gelesen wurden. Für die Neuausgabe von 1987 in Beilngries/Bayern lagen bereits zahlreiche Vorbestellungen vor, wie im Vorwort der Ausgabe berichtet wird. Zu betonen ist allerdings auch, dass sowohl Tobner als auch Kaindl (der Verfasser einer ausführlichen Geschichte von Vyšší Brod), die historischen Ereignisse sehr verharmlosen, in dem beide bloß die Ermordung des ,Anführers' der ,Zigeuner berichten. Lediglich Svátek beschreibt diese Ereignisse in der Pfarre Kapličky in seinem Kapitel über die ,Zigeuner in Böhmen als ein ,Blutbade', das nach einer zweitägigen Menschenjagd insgesamt zwölf Menschenleben forderte.

71 Vgl. SOA Třeboň, VS N. Hrady, kart. č. 1220, nr. 6010.,Instruktion für die zur Abstellung der Betteley und Abhaltung aller Vagabunden auf der Herrschaft Gratzen und Rosenberg angestellten Nachseher. Vgl. zur neueren Literatur bezüglich der Verfolgung der,Zigeuner' im deutschsprachigen Raum etwa den knappen Überblick bei: Ammerer, Vaganten, bes. 172f. 
sonengruppen begrenzt, während andere nach wie vor davon ausgenommen scheinen. Anders als Ledige und Besitzlose werden verheiratete Personen und Hausbesitzer tendenziell als immobil und sesshaft angesehen. Mobilität während der frühen Neuzeit auch auf dem Lande wird beinahe ausschließlich den landlosen Gruppen (Gesinde, Handwerkergesellen, Bettler, etc.) unter der ländlichen Bevölkerung zugeschrieben. ${ }^{72}$ Christian Pfister spricht im Zusammenhang mit Mobilität von den „weniger bodengebundenen Schichten“", ${ }^{73}$ Wolfgang von Hippel verwendet die Formulierung von der „mobilen Armut“ und betont „die entschieden höhere regionale Mobilität der Unterschichten“ ${ }^{74}$ Häufig wird Mobilitätsbereitschaft auch als eng an bestimmte Lebensphasen gebunden gedacht. Migration vor der Eheschließung in Form von Gesinde- oder Heiratsmobilität wird berücksichtigt, ${ }^{75}$ die Heirat gilt aber als Beginn der Sesshaftigkeit. Dies wird etwa bei Paul Münch besonders deutlich, wenn er schreibt: „Nach der Eheschließung folgte in der Regel eine lebenslange Stabilität an dem Ort, an dem

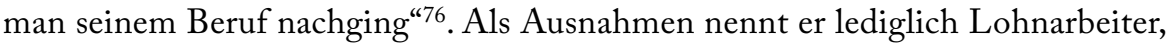
Wanderhandwerker und Kaufleute.

Wie im Falle der bisher erwähnten Gesinde-, Gesellen- und der Heiratsmobilität bereits angedeutet, müssen in Fragen nach der Mobilitätsbereitschaft ländlicher Gesellschaften stärker als bisher lebenszyklische Aspekte berücksichtigt werden. Sesshaftigkeit und Mobilität stellten keine einander strikt ausschließenden Lebensentwürfe dar, einzelne Personen waren vielmehr gezwungen, immer wieder zwischen diesen beiden Polen zu pendeln. ${ }^{77}$ In den südböhmischen Dörfern waren insbesondere solche Personen von einem Abgleiten in die Nicht-Sesshaftigkeit (vor allem im Alter) bedroht, die zeitlebens nie Hausbesitzer waren und auch keine Haus besitzenden Familienangehörigen hatten. Nicht nur die Mobilität dieser Personen ist kaum erforscht, generell ist die Frage eines Ortswechsels im Alter, etwa nach dem Rückzug aus der Hausinhaberschaft, aufgrund eines übermächtigen, doch einseitigen Bildes einer im Hofverband mitlebenden älteren Generation ein Desiderat der Forschung geblieben. ${ }^{78}$

72 Unter den zahlreich vorliegenden Studien zu den Vagierenden vgl. z.B.: Kienitz, Frauen; zur Bedeutung der Gesellenwanderung etwa Ehmer, Tramping artisans.

73 Pfister, Bevölkerungsgeschichte, 47.

74 Hippel, Armut, 72, 89 ff.

75 Vgl. etwa zum Gesinde Lundh, Servant Migration; Wilcox, Marriage. Als Beispiel für die Analyse von Heiratsmobilität vgl. etwa Hudson/King, Industrializing, und Štěrbová, Vývoi.

76 Münch, Lebensformen, 225.

77 Vgl. etwa die Beispiele bei: Kienitz, Frauen, 46.

78 In Kapitel 9 gehe ich auf den Aspekt des Ortswechsels nach der Übergabe des Grundbesitzes etwas genauer ein. 
Sozial differenziert betrachtet, deutete der Hinweis auf eine saisonale Arbeitsmigration in der Region bereits an, dass abgesehen von den erwähnten vagierenden und besitzlosen Bevölkerungsgruppen nicht alle anderen sozialen Schichten des Dorfes unbesehen als ,immobil ' eingestuft werden dürfen. Selbst die räumliche Stabilität und Hausgebundenheit der bäuerlichen Landbevölkerung unterlag einem historischen Wandel. ${ }^{79}$

Bei den in dieser Region besonders zahlreichen Inwohnern war aufgrund ihrer Mittellosigkeit und der Annahme, dass es sich bei ,Inwohnern' um eine lebenszyklische Position handelt, eine hohe Mobilität naheliegend. Auch andere Studien haben die hohe Mobilität der Inwohner betont. ${ }^{80}$ Für oberösterreichische Gebiete liegen etwa Zahlen vor, nach denen nur knapp die Hälfte der Inwohner länger als ein Jahr im selben Haus verblieb und nur sehr wenige länger als fünf Jahre. ${ }^{81}$ Dies war in Kapličky ähnlich: In Handrobotverzeichnissen der Herrschaft aus den Jahren 1675 bis 1677, die überwiegend nur Inwohner nannten, findet sich ein Viertel der 49 im Jahr 1675 genannten Personen im Jahre 1677 nicht mehr. ${ }^{82}$ Das Inwohnerdasein war in dieser Region aber nur zum Teil lebenszyklisch geprägt. $\mathrm{Zu}$ den Inwohnern wurden in dieser Region neben den relativ zahlreichen Altenteilern und verwitweten Personen auch zahlreiche junge Ehepaare gerechnet. Die Verknüpfung individueller personenbezogener Angaben aus unterschiedlichen Quellen gibt uns Auskunft über die Dauerhaftigkeit des Inwohner-Status. So lässt sich bei vielen Familien, die die Familienrekonstitution als offenbar längerfristig ortsansässig ausweist, durch die Kombination mit den Grundbüchern feststellen, dass diese zeitlebens nie Hausbesitzer waren, sondern immer im Inwohner-Status verblieben. Gregor und Margareth Wagner beispielsweise, er wurde bei der Heirat 1685 als Holzknecht bezeichnet, ließen alle ihre sechs Kinder in der Pfarre taufen und wurden beide hier begraben. Auch deren Sohn Philip Wagner (Heirat 1730), sowie dessen Sohn Anton (Heirat 1770) lebten als verheiratete Inwohner bis zu ihrem Tod im Pfarrgebiet, hatten jeweils mehrere Kinder, waren aber nie Hausbesitzer. Für die Pfarre lässt sich für einige Inwohnerfamilien eine Ansässigkeit über drei Generationen oder mehr nachweisen. In einzelnen englischen Pfarren war eine derart langfristige Pfarrgebundenheit offenbar selbst bei Bauernfamilien relativ selten. Für die ziemlich große englische Pfarre Odiham (273 Haushalte) etwa ließen sich im Zeitraum zwischen 1539 und 1820 lediglich 43 Familien nachwei-

79 Vgl. dazu ausführlicher Kapitel 7.8.

80 Mitterauer, Arbeitsteilung, 56f.

81 Vgl. Sandgruber, Gesindestuben, 121.

82 Archiv Kláštera Vy̌šší Brod, kart. č. 397, 5/3. 
sen, die drei Generationen oder mehr hier ansässig waren. ${ }^{83}$ Der Inwohner-Status war also nicht für alle bloß eine Phase im Lebenslauf und bei Weitem nicht alle sind als besonders mobil zu bezeichnen.

Trotzdem wechselte ein Teil der Inwohner aber relativ häufig die Unterkunft. Ägidius Schiepane etwa, ein „weichender“ Bauernsohn aus dem Dorf Hodoň, wohnte im Jahre 1651 gemeinsam mit seiner Frau als Inwohner auf einem anderen Hof dieses Dorfes, 1652 allerdings im Dorf Mlýnská, einige Zeit später dann in Lipova. Noch 1675 sind sie in der Pfarre nachweisbar. Inwohner konnten demnach auch sehr ortsgebunden sein. Auf Grund der wenigen für die Pfarre vorhandenen Haushaltslisten lassen sich nur im Einzelfall und nicht systematisch Aussagen über die Zirkulation der Inwohner zwischen den einzelnen Häusern oder Dörfern der Pfarre treffen. Es gab aber jedenfalls in dieser Region eindeutig eine Gruppe lebenslang in der Pfarre im Inwohnerstatus lebender Personen, auch wenn es ein Großteil der als Inwohnerkinder geborenen Personen vorzog, die Pfarre im Laufe ihres Lebens zu verlassen.

Zusammenfassend bleibt festzuhalten, dass in dieser Region jedenfalls auch bereits während der frühen Neuzeit und unter den Bedingungen gutsherrschaftlicher Strukturen Migration immer auch eine von mehreren Handlungsoptionen für die ländliche Bevölkerung darstellte. Migration (in Form eines Wegzugs aus der Pfarre) stellte hier etwa für,weichende' Erben eine Alternative zur Besitznachfolge dar, für andere aber konnte Migration gerade erst die Option des Bleibens eröffnen, wenn - wie dies etwa im 19. Jahrhundert in der Region weit verbreitet war - eine saisonale Arbeitstätigkeit auswärts erst die Basis dafür schuf, um vor Ort eine dauerhafte Existenz mit nur marginalem Grundbesitz führen zu können. Die Option einer temporären oder dauerhaften Migration widerspricht nicht zuletzt nachdrücklich allen Konzepten, die mit einem engen Zusammenhang von Bevölkerungszahl und vorhandenem Nahrungsspielraum operieren, da diese im-

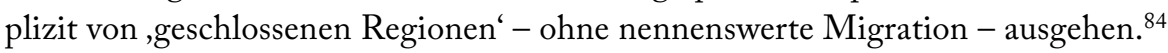

\subsection{Zur Entwicklung der Besitzrechte in der Region}

In weiten Teilen Böhmens blieben die Besitz- und Nutzungsrechte der Untertanen am Land während der gesamten Neuzeit - trotz der sich seit dem Ende des 16. Jahrhunderts allmählich ausbreitenden ,Erbuntertänigkeit - unverändert. ${ }^{85}$ Weit-

83 Vgl. Stapleton, Family Strategies, 387.

84 Vgl. dazu ausführlicher Kapitel 8.

85 Cerman/Maur/Zeitlhofer, Wirtschaft, 280-84; Maur, Erbrecht. 
gehend vorherrschend waren freie Leiheformen mit der Möglichkeit zur erblichen Weitergabe des Gutes. Bezeichnet wird dieses Besitzrecht als Erbzinsrecht, Erbpacht oder ,Emphyteuse ${ }^{6}{ }^{86}$ Im Vergleich zu manchen weiter westlich gelegenen Regionen und Ländern ist dies als sehr günstiges Besitzrecht zu bezeichnen. Die Haus- und Grundbesitzer, die in den Quellen teilweise auch explizit als,Erbnutzer ${ }^{6}$ und ,Emphyteut bezeichnet wurden ${ }^{87}$, waren damit Untereigentümer ihrer Anwesen und des Bodens, den sie bewirtschafteten. Die Persistenz dieser Besitzrechte stellt einen wesentlichen Unterschied zu zahlreichen anderen Gebieten Ost-Europas dar, in denen die sogenannte, zweite Leibeigenschaft ${ }^{\prime}$ Hand in Hand mit der Ausbreitung instabiler, bzw. nicht kodifizierter Besitz- und Nutzungsrechte ging. ${ }^{88}$

Günstige Besitzrechte bestanden in weiten Teilen Böhmens und Mährens schon seit dem Hochmittelalter. ${ }^{89}$ Während der Periode vom späten 14. bis zum 16. Jahrhundert breitete sich das Erbzinsrecht in Böhmen weiter aus. ${ }^{90}$ Eine gewisse Ausnahme bildete dabei aber Südböhmen, wo das Erbzinsrecht überwiegend erst im 16. Jahrhundert eingeführt wurde und die Untertanen damit das Recht erhielten, ihre Anwesen frei zu vererben und zu verkaufen. Es kam hier also zu Beginn der Neuzeit zu einer Stärkung der Besitzrechte der Untertanen. Davor war in zahlreichen Gebieten Südböhmens das Recht der freien Vererbung der Güter auf einen eingeschränkten Personenkreis innerhalb der Verwandtschaft beschränkt gewesen. Gab es keine nahen Verwandten, trat der sogenannte „Totenfall“ („odúmrt“) in Kraft: „... wenn einer ohne Leibeserben starb, der halbe Theil seines Gutes der herrschaftlichen Kammer zufiel; die andere Hälfte blieb der hinterlassenen Witwe...", hieß es in einer das Gericht Kapličky betreffenden Urkunde. ${ }^{91}$

86 Vgl. dazu: Enders, Besitzrechte, 1025f., die allerdings in traditioneller Sichtweise davon ausgeht, dass sich das ,in den hochma. Landesausbaugebieten des mittleren und östl. Deutschland (...) ebenso in den Neusiedelgebieten Polens, Böhmens, Ungarns' im Spätmittelalter feststellbare günstige ,Erbzinsrecht' nach dem Dreißigjährigen Krieg in vielen Gebieten, darunter ,Böhmen und Mähren' aufgrund der Machtverhältnisse verschlechtert habe.

87 So etwa im bereits erwähnten gemeinsamen Vertrag der Dominikalisten von Zadní Výtoň/HinterHeuraffl mit der Herrschaft anlässlich der Umwandlung ihrer Besitzrechte. Vgl. SOA Třeboň, fond C Vyšší Brod, PK č. 553, lose Beilage.

88 Wetherell/Plakans, Intergenerational transfers. Siehe auch den Überblick zu den Besitzrechten der Untertanen unter den Bedingungen der Gutsherrschaft bei: Kaak, Gutsherrschaft, 224.

89 Gerstorffer, Hintersassen, 81.

90 Maur, Erbrecht, 96; Čechura, Struktur, $126 \mathrm{ff}$.

91 Zitiert bei: Schmidt, Agrar- und Colonisationsgeschichte, 83. Einzelne Dörfer, wie das Kapličky benachbarte Gericht Studánky im Jahr 1418, hatten bereits früher emphyteutisches Besitzrecht erhalten. Es gehörte damals noch zum Dominium der Rosenberger und kam erst im Jahr 1515 zu Vyšší Brod. Vgl. Schmidt, Agrar- und Colonisationsgeschichte, 83. Gedruckt ist diese Befreiung bei: Pangerl, Urkundenbuch, 257. 
Die in Südböhmen vor allem während des 16. Jahrhunderts erfolgte Einführung des Erbzinsrechtes ging auf Betreiben der Herrschaften vor sich. Eine derartige Veränderung wurde ganz überwiegend nicht für einzelne Häuser, sondern immer für ganze Dörfer vollzogen. Für später im Dorf hinzukommende Häuser galt dieses Recht aber nicht automatisch. Die südböhmischen Herrschaften boten ihren Untertanen einen Handel an, der durch das Bedürfnis der Herrschaften, ihre Einnahmen zu steigern, motiviert wurde: Im Austausch für eine Verdoppelung der zu zahlenden Zinse sowie eine Anhebung der Robotpflichten wurde jeweils dorfweise das Erbzinsrecht eingeführt. Die Herrschaft Vyšší Brod gehörte zu den letzten in Südböhmen, die diese Umwandlung vollzog. Für die Dörfer der Pfarre Kapličky erfolgte dies im Jahre 1574. ${ }^{92}$

Wie häufig während des Spätmittelalters aufgrund der Bestimmung des, Totenfalls' tatsächlich Teile der untertänigen Güter an die Herrschaft zurückfielen, ist nicht zu bestimmen. Grundbücher existieren für diese Zeit nicht, deren Anlage war ja gerade eine Folge der Befreiung vom Totenfall. ${ }^{93}$ Der Einfluss derartiger Regelungen auf die Entwicklung der Besitzstrukturen sollte jedenfalls nicht überbewertet werden. Eine häufige Anwendung der Totenfallbestimmungen hätte tendenziell zu einer starken Besitzzersplitterung der Anwesen führen müssen. Die bereits für das Hochmittelalter feststellbare deutliche Variation in den Besitzgrößen der untertänigen Anwesen konnte allerdings sehr unterschiedliche Ursachen haben und sollte, wie etwa Markus Cerman zeigt, keineswegs vorschnell auf Besitzteilungen im Mittelalter zurückgeführt werden. ${ }^{94}$ Jedenfalls kann es in der Herrschaft Vy̌šší Brod zumindest während des 16. Jahrhunderts kaum zu Teilungen von Anwesen gekommen sein, da ein Vergleich der Häuserzahlen des Urbars aus dem Jahre 1530, also mehrere Jahrzehnte vor Abschaffung des Totenfalls, mit denen im 17. Jahrhundert für die meisten Dörfer die gleichen Zahlen bzw. in einigen Fällen sogar für das 1530 höhere Werte ergibt. ${ }^{95}$

Der Prozess der Umwandlung der Totenfälligkeit der Güter zu emphyteutischem Besitzrecht hatte sich im 16. Jahrhundert zwar auf einen Großteil, aber nicht auf alle südböhmischen Dörfer erstreckt. So blieben im Gebiet der Herrschaft Vyšší Brod etwa die Dörfer rund um den Marktort Hořice ausgeschlossen, diese erhielten die Befreiung vom Totenfall erst im Jahr 1779. ${ }^{96}$ Auch in der Herrschaft Český Krumlov hatten um 1700 keineswegs alle Dörfer die Befreiung vom

92 Schmidt, Agrar- und Colonisationsgeschichte, 92.

93 So auch dezidiert: Pangerl, Geschichte, $156 \mathrm{f}$.

94 Cerman, Diss., $211 \mathrm{ff}$.

95 Vgl. Schmidt, Urbar, 171-75.

96 Schmidt, Agrar- und Colonisationsgeschichte, 93; Schmidt, Urbar, 237. 
Totenfall erhalten. Interessant ist für diese Herrschaft besonders auch die weitere Differenzierung: zwar hatten alle ,befreiten' Gerichte das Recht der freien Vererbung, doch nur ein Teil dieser Gerichte hatte auch das Recht, sein Vermögen an herrschaftsfremde Personen zu vermachen. ${ }^{97}$

Mehrere der nach 1650 neu errichteten Häuser hatten in unterschiedlichem Maße etwas stärker eingeschränkte Verfügungsrechte. Hatten diese den Grund für ihr Haus von den Dorfgemeinden oder von einem Bauern erhalten, sicherten sich die Verkäufer für den Fall eines Weiterverkaufs zumeist eine „Vorkaufsklausel“, so insbesondere für den Fall eines Weiterverkaufs des Anwesens an Dorffremde. Prinzipiell konnten aber auch die meisten Inhaber der neu errichteten Anwesen diese erblich weitergeben (für Ausnahmen siehe weiter unten). ${ }^{98}$ Selbst die auf grundherrschaftlichem Boden angesiedelten sogenannten „Dominikalisten“, eine in vielen Teilen Böhmens im 18. Jahrhundert weit verbreitete Sozialform, bekamen zum größeren Teil ihr Haus/den Grund zur freien Vererbung. Nur das Land, auf dem diese lebten, blieb weiter im Besitz der Herrschaft. ${ }^{99}$

\subsubsection{Die Entstehung der Leiberpacht im 18. Jahrhundert}

Je nach Herrschaft recht unterschiedlich verbreitet war in Südböhmen während des 18. Jahrhunderts die Praxis, den auf Dominikalland neu angesiedelten Untertanen Grund und Boden nur mit einer temporären Befristung zu überlassen. Damit fand eine für die untertänige Bevölkerung deutlich ungünstigere Besitzrechtsform neuerlich Verbreitung, die eigentlich zu den ältesten Besitzformen untertäniger europäischer Bauern zu zählen ist: die befristete Leiberpacht. ${ }^{100}$ In der Pfarre Kapličky wurden seit der Mitte des 18. Jahrhunderts aber nur einige wenige neu errichtete Häuser (insgesamt sechs) zur ,Leiberpacht' ausgegeben. Mit einer Ausnahme handelte es sich dabei immer um eine Pacht auf ,drei Leiber', die ausschließlich die innerfamiliale Weitergabe des Anwesens vom Mann zur Frau sowie zu einem Kind erlaubte, also de facto auf die Dauer von zwei Generationen ausgelegt war. In anderen Teilen der Herrschaft fand sich vereinzelt auch die Pacht auf sechs Leiber. Im weiter östlich gelegenen Herrschaftsdorf Bukovsko (Buggaus) war die Leiberpacht bereits um 1713 häufig. ${ }^{101}$

97 Vgl. dazu ausführlich: Himl, Die ,armben Leüt', $57 \mathrm{f}$.

98 Vgl. auch Cerman, Diss.

99 Vgl. Schmidt, Siedlungs-Geschichte, 61.

100 Vgl. zur Diskussion verschiedener bäuerlicher Leiheformen am Beispiel Bayerns: Beck, Unterfinning, 400-412 sowie auch Lanzinger, Das gesicherte Erbe, bes. $219 \mathrm{ff}$.

101 SOA Třeboň, C Vyšší Brod, PK č. 553, fol. 32. 
In anderen Herrschaften Südböhmens war die Leiberpacht während des 18. Jahrhunderts zum Teil weit stärker verbreitet als in der Herrschaft Vyšší Brod. In der Herrschaft Nové Hrady, an der Grenze zu Niederösterreich etwa, wurden gegen Ende des 18. Jahrhunderts mehrere neue Siedlungen ausschließlich auf Basis der Leiberpacht errichtet. Die zunächst ebenfalls auf eine Dauer von ,drei Leibern' angelegten Verträge wurden in den 1830er Jahren häufig in Pachtverträge mit 70-jähriger Dauer umgewandelt. ${ }^{102}$ In Kapličky wurden auch bei neu errichteten Häusern auf herrschaftlichem Grund und auch bei einzelnen auf bäuerlichem Grund errichteten derartige Leibgedinge-Regelungen getroffen. Die Bauern wie die Herrschaft trachteten offenbar danach, ihre Besitzungen nicht endgültig abzugeben.

Im Bestand der Grundbücher von Kapličky hat sich auch die Abschrift eines solchen Kontraktes zwischen der Klosterherrschaft und einem gewissen Dominik Sommerauer aus dem Jahre 1754 erhalten. Dieser möglicherweise nichtrepräsentative Vertrag deutet - etwas überraschend - auf komplexe, gegenseitige Verpflichtungen, die eingegangen wurden. Sommerauer verpflichtet sich darin, für die Überlassung einer ,Haarstube‘ am Rande des Marktortes Vyšší Brod als Wohnhaus sowie zweier Äcker und Wiesen und einem Obstgarten nicht nur einen relativ hohen Kaufpreis von 500 Gulden zu zahlen, sondern auch den bereits in der Haarstube wohnenden ,klösterlichen Zimmermeister' Gregor Griebl solange wohnen zu lassen, so lange dieser in Diensten des Klosters stand - im Gegenzug verpflichtet sich das Kloster unter anderem, ihm durch zur Robot verpflichtete Arbeiter jährlich das Getreide einbringen zu lassen. ${ }^{103}$

Mehrere sozialhistorische Studien haben in den letzten Jahren allerdings gezeigt, dass trotz unterschiedlicher Rechtstitel der Besitzungen in der Praxis kaum Unterschiede für die auf diesen Gütern lebenden Personen bestehen mussten. Unterschiedliche Besitzrechte mussten weder hinsichtlich der Besitzdauer auf den einzelnen Anwesen noch in der Möglichkeit der innerfamilialen Weitergabe des Hauses besondere Auswirkungen haben. Beck hat dies am bayerischen Beispiel in der Gegenüberstellung von Emphyteuse und Freistift betont, Harnisch für ostelbische Zeit- und Erbpächter. ${ }^{104}$ Für die hier untersuchten Gebiete des südlichen Böhmerwaldes ist dagegen festzuhalten, dass in diesen Aspekten zwar tatsächlich kaum Unterschiede zwischen den Erbzinspächtern einerseits und den Dominikalisten andererseits festzustellen sind, die zeitlich befristete Leiberpacht dagegen hatte in dieser Region aber sehr wohl konkrete Auswirkungen auf die Besitznachfolge. $\mathrm{Zu}$ Leiberpacht vergebene Anwesen konnten, wie die Grundbücher für Kapličky

102 Vgl. Teichl, Herrschaft, 10f.

103 SOA Třeboň, C Vyšší Brod, PK č. 480, lose Beilage.

104 Beck, Unterfinning, 411f.; Harnisch, Ökonomie, 92. 
zeigen, mit Ausnahme des Ehepartners tatsächlich nur an leibliche Nachkommen weitergegeben werden. In der Pfarre Kapličky fielen diese Häuser nach Ablauf der gesetzten Frist außerdem tatsächlich wieder an den Obereigentümer (in der Regel die Herrschaft) zurück. Was geschah aber danach mit diesen Häusern? Eruierbar ist, dass einige der zu Leiberpacht vergebenen Häuser nach Ablauf der Frist weder in den Grundbüchern noch in den Dominikalistenverzeichnissen aufscheinen, sodass diese entweder nicht mehr als Wohnstätten genutzt oder nur mehr an Inwohner (also zu noch weit stärker befristeten Bestimmungen) vergeben wurden. Es finden sich allerdings auch einzelne Fälle, in denen die Häuser offenbar neuerlich in befristeter Pacht an die vormaligen Leibpächter ausgegeben oder diesen das Anwesen schließlich auch verkauft wurde. Ein solches Beispiel findet sich etwa im folgenden zwischen verwandten Untertanen vereinbarten Leiberpacht-Vertrag: Im Dorf Lipova hatte im Jahre 1697 der Bauer Georg Prieschl seiner Tochter und dem Schwiegersohn Ferdinand Woisetschläger eine an der Moldau nahe Nové Domky gelegene Wiese zu Leiberpacht überlassen, damit diese sich darauf ein Haus bauen konnten. Die Vereinbarung bezog sich ursprünglich (im Gegensatz zu allen anderen Fällen in der untersuchten Pfarre, die immer auf ,drei Leiber' abgeschlossen wurden) lediglich auf zwei Leiber, also auf die Lebenszeit des Schwiegersohnes und seiner Frau. Danach sollte der Grund mit dem Haus wieder an den genannten Bauernhof zurückfallen. Gegen diese Vereinbarung schritt allerdings die Herrschaft nachträglich ein und verlängerte die Dauer der Leiberpacht auch auf die Lebenszeit eines Kindes und dessen Ehepartner. Nach Ablauf dieser - nun auf vier „Leiber“ festgelegten - Frist im Jahre 1746 verkaufte jedoch der nunmehrige Inhaber des Bauernhofes dieses Anwesen an Franz Woisetschläger, dem Enkel von Ferdinand, auf „ewige Zeit“, wie es hieß.105

Insgesamt lassen sich in der Region neben der zahlenmäßig dominanten Rechtsform der Emphyteuse zwar einige verschiedene Abstufungen in den Besitzrechten erkennen, generell kann aber für die Periode nach dem Dreißigjährigen Krieg sicher nicht von ungünstigeren Besitzrechten der unterbäuerlichen Häuser oder der nach dem Dreißigjährigen Krieg neu entstandenen, landarmen Liegenschaften gesprochen werden, wie dies von manchen Autoren für Böhmen im 17. Jahrhundert angenommen wurde. ${ }^{106}$ Die Besitzrechte der Untertanen blieben im Gegenteil in der untersuchten Herrschaft, wie auch in zahlreichen anderen Gebieten Böhmens, auch in der Zeit der „verschärften Erbuntertänigkeit“ im Allgemeinen günstig und die bestehenden Rechtstitel wurden nicht angetastet.

105 SOA Třeboň, C Vyšší Brod, PK č. 559, fol. 61; PK č. 479, fol. 332.

106 Wright, Neo-Serfdom, 248. Vgl. dazu auch Markus Cerman, Proto-Industrialisierung, 181. 


\section{DIE PRAKTIKEN DES BESITZWECHSELS ${ }^{1}$}

\subsection{Die Prinzipien der Besitzweitergabe im südlichen Böhmerwald}

Im Untersuchungsgebiet des südlichen Böhmerwaldes galt, wie in den meisten Regionen Böhmens, das Prinzip der Unteilbarkeit der Güter. ${ }^{2}$ In der deutschsprachigen Forschung werden alle Formen der ungeteilten Weitergabe von Land und Haus an einen einzigen Nachfolger zumeist undifferenziert mit dem ,Anerbenrecht' gleichgesetzt. Demgegenüber werden Gebiete mit der Praxis einer gleichen Teilung auch des Landbesitzes unter allen Kindern (manchmal auch nur der männlichen) als Gebiete mit ,Realteilung' bezeichnet. Dies suggeriert, dass auch in der frühen Neuzeit ein formalisiertes Erbrecht bestanden habe und impliziert eine Ungleichbehandlung der Nachkommen durch die Bevorzugung des ,Haupterben'. Bis weit ins 18. Jahrhundert hinein bestimmten in vielen Gebieten Südböhmens wie auch in manchen anderen Regionen jedoch nichtstaatliche Rechtsvorschriften, sondern lokale Normen und Gebräuche die Praxis der Besitzweitergabe. ${ }^{3}$ Normative Regelungen auf staatlicher Ebene setzten erst ab der zweiten Hälfte des 18. Jahrhunderts ein. Die Dichotomie von Realteilung und Anerbenrecht übersieht die hohe Vielfalt unterschiedlicher lokaler Praktiken unter den Bedingungen der Unteilbarkeit, die keineswegs immer eine eindeutige Bevorzugung eines Kindes gegenüber seinen Geschwistern bedeuten musste.

In der internationalen Forschung wird die Praxis, Haus und Land ungeteilt an eine einzige Person weiterzugeben, als ,impartible inheritance' bezeichnet, während ,partible inheritance' das Pedant der deutschsprachigen, Realteilung' darstellt. Ähnlich wie auch beim in der deutschsprachigen Forschung ebenfalls bis heute gängigen Begriff ,Erbschaftspraktiken`wird damit bereits in der verwendeten Be-

1 Dieses Kapitel beruht in einigen Abschnitten auf meinem Aufsatz: Zeitlhofer, Besitztransfer, wurde hier aber sehr deutlich erweitert.

2 Vgl. dazu genauer weiter unten. Regionen innerhalb Böhmens, in denen die Praxis einer geschlossenen Weitergabe von Land nicht oder möglicherweise nicht strikt eingehalten wurde, werden genannt bei: Maur, Erbrecht, 114f. und Cerman/Maur/Zeitlhofer, Wirtschaft.

3 Verordnungen der lokalen Gutsherrschaft zur Besitzweitergabe und zur Erbschaftspraxis, wie sie aus einzelnen anderen Herrschaften Böhmens bekannt sind, konnten für diese Herrschaft nicht gefunden werden. 
grifflichkeit der Aspekt der,Erbschaft' im Zusammenhang mit dem Besitzwechsel in besonderer Weise betont. Da jedoch im vorliegenden Fall - wie gezeigt wird einerseits die Güter gekauft wurden, und andererseits häufig auch nichtverwandte Personen die Nachfolge antraten, erscheint es wenig sinnvoll und zum Teil sogar irreführend, im Kontext der Besitzweitergabe von ,Erbe‘ oder von ,Erbschaftsprak-

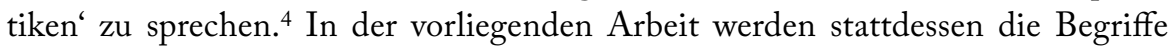
,Besitzwechsel' bzw. ,Besitztransfer 'verwendet. Von , ungeteilter Weitergabe' oder von ,Unteilbarkeit der Güter' wird in Abgrenzung zum nicht mit dem vorliegenden Fall identischen System des Anerbenrechts gesprochen. ${ }^{5}$

In dieser Region des südlichen Böhmerwaldes fand, wie auch in zahlreichen anderen Gebieten Böhmens, jeder Eigentumswechsel prinzipiell in der Form von Kauf und Verkauf statt. Die Besitznachfolger, egal ob es sich um eine fremde Person oder um ein leibliches Kind des Vorbesitzers handelte, hatten das Anwesen zu kaufen. Ganz überwiegend erfolgte die Zahlung des Kaufpreises in Form jährlicher Ratenzahlungen. Trotz der Unteilbarkeit der Güter bestand in dieser Region, ebenso wie in anderen Gebieten Böhmens, kein Anerbenrecht. Das hier verfolgte Prinzip der Unigenitur bedeutete nicht eine prinzipielle und eindeutige Bevorzugung eines einzigen Nachfolgers. Obwohl eine Einzelperson das Haus und den gesamten Landbesitz erhielt, beinhaltete diese Regelung der Besitzweitergabe zahlreiche egalitäre Elemente.

Zumindest in den Fällen, in denen der Besitztransfer als Teil einer Erbschaftsübertragung erfolgte, wurde die Kaufsumme unter allen erbberechtigten Familienmitgliedern des Vorbesitzers zu gleichen Teilen aufgeteilt, wobei der verkaufende Elternteil den gleichen Anteil wie ein Kind erhielt. Im Fall des Schusters und Kleinhäuslers Mathias Kern etwa, der 1696 von seiner verwitweten Mutter das elterliche Anwesen zum Preis von 70 Gulden kaufte, sah die Verteilung so aus: ${ }^{6}$

\section{Fallbeispiel 3: Aufteilung der Kaufsumme}

Der Käufer selbst

Schwester Rosina (37 Jahre), verheiratet

Schwester Margareth (28 Jahre), verheiratet

Bruder Hans (35 Jahre), ledig

Mutter
1696: 14 Gulden

1696: 14 Gulden

1696: 14 Gulden

1701: 7 Gulden, 1702: 7 Gulden

1704: 14 Gulden

4 Dies ist auch an der in der Studie von Dana Štefanová über nordböhmische Regionen verwendeten Terminologie zu kritisieren. Vgl. Štefanová, Erbschaftspraxis, passim.

5 Ähnlich auch die Argumentation bei: Ehmer, House.

6 SOA Třeboň, fond C Vyšší Brod, PK č. 453, fol. 340. Seinen eigenen Anteil lies sich Mathias Kern ,abschreiben', er bezahlte daher nur 56 Gulden. 
Die Anteile der Witwe und der Kinder wurden ratenweise aus der Summe beglichen, die der neue Hofbesitzer für die Liegenschaft bezahlte. ${ }^{7}$ Bei dieser Form der Aufteilung des Kaufpreises handelte es sich um die in der Region übliche, idealtypische Regelung. ${ }^{8}$ Die tschechischsprachige Literatur nennt dieses System folgerichtig nicht ,Anerbenrecht', sondern treffender - im Gegensatz zur realen Teilung - ,ideelle Teilung“. ${ }^{9}$ Der in Süd- und Mittelböhmen üblichen Aufteilung der Kaufsumme in gleiche Anteile für alle Familienmitglieder (Teilung in capita), ist das System des Witwendrittels in Nordböhmen und der systematischen Bevorzugung der männlichen Familienmitglieder (in Form höherer Anteile) in Teilen Westböhmens (etwa um Cheb und Loket) gegenüberzustellen. ${ }^{10}$ So weit bisher bekannt ist, erhielten in allen böhmischen Regionen die ,weichenden Erben' einen Anteil. ${ }^{11}$

Das Merkmal des Kaufes und Verkaufes der Güter steht in Widerspruch zu allen Klassikern der deutschsprachigen Sozialgeschichte. Bedeuten ,kaufen ' und ,verkaufen' nicht in irgendeiner Form Marktbeziehungen? Gerade der Markt kam in den traditionellen Vorstellungen über vorindustrielle ländliche Gesellschaften nicht vor. Bäuerliche Höfe wurden demnach ,vererbt', vom Grundherrn gestiftet oder allenfalls im Zuge des Landesausbaus neu angesiedelt. In Otto Brunners Vorstellungen über die „alteuropäische Ökonomik“ etwa verfügte das ,ganze Haus kaum über Marktbeziehungen, sondern zog sich immer wieder auf sein eigentliches Ziel, die Subsistenzsicherung, zurück. Nach seinem Konzept wurde innerhalb des Hauses nicht abgerechnet. ${ }^{12}$ Die hier vorzufindende Praxis, dass auch der Bauernsohn den Hof von seinen Eltern kaufte, bestärkt dagegen neuere sozialhistorische Annahmen, wonach die Dichotomie von Markt und Familie, von Emotionen und materiellen Interessen künstlich und nicht angemessen ist. ${ }^{13}$

Die Besitzweitergabe mittels Kaufvertrag und unter Aufteilung der Kaufsumme unter den Familienmitgliedern des Vorbesitzers war während der frühen Neuzeit auch außerhalb Böhmens weiter verbreitet als meist angenommen. Dass dies etwa

7 Identisch wird dieses System auch für die benachbarte Herrschaft Český Krumlov beschrieben. Vgl. Himl, Die, armben Leüt', 61.

8 Dieses strukturell egalitäre System bot in der Praxis, wie Einzelfälle zeigen, allerdings auch Raum für eine eventuelle Bevorzugung einer einzelnen Person (siehe unten).

9 Maur, Erbrecht, 102f.; Procházka, Nemovitost. Vgl. auch die kritischen Anmerkungen zur Anwendbarkeit des Begriffes ,Anerbenrecht' auf die böhmischen Verhältnisse etwa bei Štefanová, Zur Stellung der Untertanen, 215.

$10 \mathrm{Vgl}$. Maur, Erbrecht, $104 f$.

11 Auch in Niederösterreich erhielt bei Gütergemeinschaft des Besitzerpaares der überlebende Elternteil die Hälfte der Kaufsumme, während der Rest der Summe durch die Zahl der Kinder dividiert wurde, vgl. Feigl, Erbrecht, 169.

12 Brunner, Haus.

13 Vgl. Medick/Sabean, Emotionen. 
auch in vielen Gebieten Ober- und Niederösterreichs oder in Teilen Bayerns so gehandhabt wurde, ist bis heute wenig bekannt. ${ }^{14}$ Selbst Josef Demleitner, in den 1930er Jahren ein Verfechter des ,deutschen Erbhofgedankens' und außerdem Mitherausgeber eines einflussreichen Handbuches zur Erstellung von sogenannten Dorfsippenbüchern, ${ }^{15}$ gibt in einer Studie über die Hofübergabe im südbayerischen Raum einige Kaufverträge aus dem frühen 18. Jahrhundert wortwörtlich wieder, die eine sehr ähnliche Praxis zeigen: Auch in der von ihm untersuchten Region wurden die Höfe, selbst von den ehelichen Söhnen, in Form jährlicher Ratenzahlungen (,immer an Lichtmeß“) gekauft. ${ }^{16}$ Die Diktion von Demleitners begleitendem Text freilich zielte nicht auf die sachlichen und rationalen Aspekte dieser ökonomischen Beziehung, sondern war stark ideologisch verbrämt: die Form der Hofübergabe in der Region entspringe einer „uralten Stammesgewohnheit, die sich in Sorge um Haus und Hof, um Blut und Boden instinktmäßig herausgebildet hat" ${ }^{17}$

Am Beispiel eines Aufsatzes von Helmuth Feigl aus dem Jahr 1967 über die in wesentlichen Aspekten ähnlichen Besitzweitergabemodalitäten in Niederösterreich ${ }^{18}$ lassen sich im Folgenden einige häufig in der Literatur zu findende interpretatorische Probleme dieses Typs eines Besitzweitergabesystems, der den gängigen dichotomen Vorstellungen von Kauf versus Erbschaft bzw. von Einzelnachfolge versus ,gleichen Anteilen' widerspricht, diskutieren. Feigl hielt einerseits recht unmissverständlich fest:

„Es wäre jedoch unrichtig, in Niederösterreich von einem Anerbenrecht zu sprechen, denn der Übernehmer des Hofes sollte gegenüber den übrigen Anspruchsberechtigten keinen finanziellen Vorzug genießen, sondern seinen Miterben den gleichen Betrag zahlen, den sie beim Verkauf des Hofes an einen Fremden erhalten würden“, und einige Seiten später: „Auch die Übergabe des Hofes zu Lebzeiten des oder der Besitzer an einen Erbberechtigten ... erfolgte in der Form eines regelrechten Kaufvertrages. ${ }^{\text {19 }}$

Feigl betonte hier, dass der Besitztransfer prinzipiell in Form von Kauf und Verkauf erfolgte und hält am Beispiel der im Todesfall des Besitzers durchgeführten Schätzung des Besitzes fest, , aber wesentlich unter dem Verkaufswert blieb

14 Dies ist jedoch deutlich aus verschiedenen Dorfstudien ablesbar. Vgl. etwa Ardelt, Edelbruck, 92; Wasmayr, Ulrichsberg, 202; Feigl, Erbrecht.

15 Vgl. dazu etwa: Weiss /Münchow, Bestandsverzeichnis, 31f.

16 Demleitner, Hofübergabe.

17 Demleitner, Hofübergabe, 60.

18 Feigl, Erbrecht.

19 Ebda, 173. In Niederösterreich erfolgte eine Veränderung dieses Systems hin zu einem Anerbenrecht erst 1938 mit Inkrafttreten des Reichserbhofgesetzes, bzw. nach dessen Aufhebung im Jahr 1945 mit der erneuten Einführung des Anerbengesetzes im Jahre 1958. 
der Schätzwert nicht“. Andererseits trug Feigl selbst zur Aufrechterhaltung von Missverständnissen bei, da er in seiner Terminologie bei den Worten „Erbfall“, „Erbanteile“, „Erblasser“, etc. blieb und das Wort „Verkauf“ nicht in den Fällen von Verkäufen zwischen Eltern und Kindern, sondern lediglich bei Verkäufen an $\mathrm{Fa}^{-}$ milienfremde verwendete. Wenn er etwa wenige Zeilen später von der „Abneigung gegen den Verkauf" bei Bauern und Grundherrn schreibt, klingt dies in Anbetracht seiner zuvor geschilderten Rahmenbedingungen zunächst unlogisch. ${ }^{20}$ Erst am Ende des Absatzes wird deutlich, was er meint: „Die bäuerlichen Erblasser selbst aber wünschten, daß der Hof in der Familie blieb...". Entgegen der zeitgenössischen Terminologie hatte sich Feigl entschieden, eine begriffliche Trennung einzuführen und im Falle einer innerfamilialen Lösung der Besitzweitergabe nicht von Kauf, sondern von Übergabe zu sprechen. ${ }^{21}$ Feigl konnte sich letztlich, wie viele andere auch, nicht ausreichend vom in seiner Zeit dominanten Bild von traditionalen europäischen Bauern lösen.

Velková hat auf der Basis ihrer detaillierten Fallstudie über das westböhmische Štáhlavy zu Recht argumentiert, dass es sich bei dem in Böhmen herrschenden Muster der Besitzweitergabe mittels Kaufvertrag nicht um Markttransfers handelte. Weder würde der bezahlte Kaufpreis den Marktwert des Gutes darstellen noch sei eine freie Auswahl des Käufers gegeben, da in jedem Fall das Erbrecht berücksichtigt werden müsse. In der von ihr untersuchten Region wurde offenbar das regional dominante Muster der Weitergabe an den jüngsten Sohn nur in sehr seltenen Fällen nicht eingehalten. In ihrem Fallbeispiel findet sich häufig auch eine ,unbeglichene Übertragung' (ohne Bezahlung eines Kaufpreises), nämlich dann wenn es sich beim Nachfolger um das einzige Kind der Familie handelte. ${ }^{22}$ Insofern unterscheidet sich diese westböhmische Region doch merklich von der Situation in Kapličky, wo in keinem Fall eine unentgeltliche Weitergabe stattfand und außerdem vielfach die Ansprüche der Kinder auf das Haus unberücksichtigt blieben. Auch in einigen nordwestdeutschen Regionen kamen neben entgeltlichen häufig auch unentgeltliche Transfers vor, Georg Fertig betrachtet gerade dies als die signifikante Differenz von Markt und Erbschaft. ${ }^{23}$

20 Auch der ebenfalls in seiner Abhandlung zu findende Satz „Von der Möglichkeit der Lösung des Erbschaftsproblems durch Verkauf des Hofes und Aufteilung des Erlöses unter den Anspruchsberechtigten wurde in Niederösterreich im allgemeinen nur dann Gebrauch gemacht, wenn kein überlebender Ehegatte und kein Erbe vorhanden war, der den Hof übernehmen konnte oder wollte“ (ebda., 167) kann in dieser Hinsicht zu Verwirrung führen, da tatsächlich ja auch an Erben verkauft wurde.

21 In späterer Zeit revidierte Feigl offenbar auch seine Sichtweise zur Frage der Existenz eines Anerbenrechtes im frühneuzeitlichen Niederösterreich. Vgl. die kurzen Bemerkungen in: Feigl, Heiratsbriefe, 96.

22 Velková, Staatliches Eingreifen, bes. 163f. Vgl. auch ausführlich: Velková, Krutá vrchnost.

23 Fertig, Äcker, Wirte, Gaben, 78f. 
Dass auch im Falle einer innerfamilialen ,Vererbung' des Anwesens dieses nicht einfach kostenfrei weitergegeben, sondern ebenfalls bezahlt werden musste, hatte vor allem damit zu tun, dass erst die Entrichtung des Kaufpreises die Auszahlung der weichenden Geschwister ermöglichte. ${ }^{24}$ Unter anderem verlangte schon die Mobilität der ,weichenden' Geschwister eine Monetarisierung ihrer Ansprüche. Wie die Grundbucheinträge zeigen, musste der Besitznachfolger, und nicht der Vorbesitzer, die ,weichenden' Geschwister ausbezahlen. Wesentlich ermöglicht wurde ihm dies auch dadurch, dass seine Braut eine Mitgift in die Ehe mitbrachte. ${ }^{25}$ Der sicherlich oftmals bestehende Zusammenhang von Mitgift und Abbezahlung des Kaufpreises sollte freilich nicht zur Annahme verleiten, dass Heirat und Besitzantritt deshalb auch zeitlich immer eng beieinander lagen. ${ }^{26}$ In der untersuchten Region erscheinen jedenfalls die Beziehungen zwischen den Generationen in hohem Maße vertraglich geregelt. Gaben - auch zwischen Eltern und ihren Kindern - erscheinen nicht als Geschenke, sondern eher als Gegenstand und Folge von Verhandlungen. Derart versachlichte Generationenbeziehungen würde man sicherlich eher in der Gegenwart als in der frühen Neuzeit vermuten. ${ }^{27}$

Auch aus anderen Regionen Zentraleuropas, in denen das Prinzip der Unteilbarkeit der Anwesen galt, ist bekannt, dass die weichenden Geschwister Anteile erhielten, doch erfolgte die Weitergabe des Besitzes in Form einer bloßen „Übergabe" ohne Kauf. ${ }^{28}$ Selbst in den eigentlichen Anerbenregionen gingen die wei-

24 In vielen Regionen war das erbliche Besitzrecht ursprünglich dem Grundherrn abgekauft worden. Vielleicht mussten deshalb alle nachfolgenden Besitzer dieses Recht ebenfalls ihrem Vorgänger abkaufen. Für die hier untersuchten südböhmischen Gesellschaften lässt sich die Einführung des Erbzinsrechtes im 16. Jahrhundert eher als Tauschgeschäft mit den Grundherren auffassen. Während des Mittelalters wurde in vielen Regionen Böhmens dem Grundherrn das erbliche Besitzrecht aber tatsächlich abgekauft, vgl. Cerman/Maur/Zeitlhofer, Wirtschaft.

25 In der vorliegenden Studie können die Zusammenhänge von Hausübernahme, Abzahlung der Raten des Kaufpreises, Ausbezahlung des Heiratsgutes an die Kinder und der Mitgift der Frau nicht im Detail analysiert werden. Die Studie beschränkt sich in dieser Hinsicht auf jene Aspekte, die in den Grundbüchern verzeichnet waren.

26 Vgl. dazu genauer Kapitel 8.

27 Vgl. auch die theoretischen Überlegungen zum Themenkomplex Solidarität zwischen den Generationen versus Versachlichung dieser Beziehungen bei Godelier, Gabe, 295. Godelier weist auf die auch theoretische Unmöglichkeit einer vollständigen Umwandlung der Sozialbeziehungen zwischen den Generationen in vertraglich ausgehandelte und versachlichte Bindungen hin. Natalie Zemon Davis verweist auf den interessanten Umstand, dass sich im Frankreich der Renaissance Geschenke von Käufen/Verkäufen vor allem durch die sozialen Rollen, die Geber und Nehmer einnahmen, unterschieden: Während Käufe/Verkäufe zwischen gleichrangigen Personen vorkamen, erfolgten Geschenke eher zwischen Personen, bei denen eine sozial niedriger als die andere stand. Vgl. Davis, Schenkende Gesellschaft, 86.

28 Schlumbohm, Lebensläufe, 379. 
chenden Geschwister nicht völlig leer aus, sie wurden nicht „enterbt“. Zumindest erhielten sie bei der Heirat eine Mitgift. Bourdieu betont, dass die Mitgift eine Gegenleistung für deren Verzicht auf den Boden darstellte. ${ }^{29}$ In der Literatur weit verbreitet war jedoch die Einschätzung, dass die Höhe dieser Summe als geringfügig eingestuft wurde. Manchmal wurde auch behauptet, dass es sich dabei ohnehin nur um „symbolisch“ aufgefasste Ansprüche gehandelt hätte, die zwar im Grundbuch eingetragen, tatsächlich aber kaum in Geld abgegolten wurden. Tatsächlich finden sich Regionen, in denen die Nichtausbezahlung von Ansprüchen zu bestimmten Zeit eine gängige Praxis war. ${ }^{30}$ Häufiger scheinen aber doch die Beispiele von Regionen mit Unteilbarkeit zu sein, für die die Forschung die Bedeutung der Ansprüche der ,weichenden' Geschwister lange Zeit unterschätzt hat. ${ }^{31}$

Eine andere, in der Literatur zu findende Annahme lautet, dass sich die Höhe der Auszahlungen an die Geschwister des neuen Inhabers an der wirtschaftlichen Leistungsfähigkeit des Hofes orientiert hätte. ${ }^{32}$ Bei einer großen Kinderzahl wäre so für die jüngstgeborenen Kinder nur mehr eine sehr geringe Summe übrig geblieben. Für den südlichen Böhmerwald traf dies jedenfalls nicht zu. Die Höhe des Anteils aller lebenden Kinder war hier ab dem Zeitpunkt des Verkaufs festgelegt, lediglich dessen Auszahlung konnte sich verzögern.

\subsection{Die Rolle der Herrschaft beim Besitzerwechsel}

Der tatsächliche Einfluss der Gutsherrschaft auf den Alltag der Untertanen im Bereich der Besitzweitergabepraktiken in Böhmen während der Periode der „Verschärfung der Erbuntertänigkeit“ ist erst seit wenigen Jahren Gegenstand

29 Bourdieu, Boden, 267.

30 In der Obersteiermark war dies etwa zu Ende des 19. Jahrhunderts tatsächlich der Fall. In dieser Region verzichteten die Kinder überwiegend auf ihre Anteile, die ohnehin nur bei einer Heirat auszubezahlen gewesen wären. Die Möglichkeiten zur Eheschließung waren aber gerade in dieser Region und in diesem Zeitraum sehr stark erschwert. Die Anteile minderjähriger Kinder, die rechtlich nicht verzichten konnten, wurden im Grundbuch vermerkt. Jährlich hätten sie daraus einen Anspruch auf vier Prozent an Zinsen gehabt, auch diese wurden aber zumeist nicht ausbezahlt. Ich danke Gudrun Hopf für diese Hinweise. Auch aus anderen Regionen Österreichs wird berichtet, dass nur Geschwister, die sich verehelichten, Ansprüche auf Anteile erwarben. Vgl. Seiser, On the importance of being the last one, 100. Der unter englischsprachigen Historikern weit verbreitete, aber auch häufig kritisierte Begriff der, disposessed children' ist deshalb nicht völlig aus der Luft gegriffen. Er ist allerdings in seinem zu stark verallgemeinerten Gebrauch für weite Regionen Zentraleuropas missverständlich und letztlich falsch.

31 Vgl. etwa Fertig, Hofübergabe, bes. 81-83.

32 Beispielsweise bei Khera, Stratification, 816, für österreichische Gebiete. 
historischer Studien. Lange Zeit wurde oft vorschnell aus normativen Quellen eine beinahe ,Allmacht' der Gutsherrschaft abgeleitet. Unzweifelhaft bedurfte jeder Besitzwechsel im frühneuzeitlichen Böhmen der Zustimmung der jeweiligen Gutsherrschaft. Auch in den Grundbüchern von Kapličky findet sich immer wieder formelhaft der Hinweis auf den „obrigkeitlichen Konsens“ zur getroffenen Vereinbarung. ${ }^{33}$ In welchem Maße die Herrschaft allerdings auch tatsächlich ihre Möglichkeiten zu Eingriffen in die zwischen den Untertanen getroffenen Vereinbarungen wahrnahm (oder nicht), ist nur sehr schwierig zu beurteilen. Gegen die Annahme etwaiger seitens der Herrschaft rigide durchgesetzter Nachfolgeregelungen spricht sowohl die kontinuierlich hohe Vielfalt an unterschiedlichen Lösungsvarianten in der Besitznachfolge, die auf Wahlmöglichkeiten der Untertanen verweist, als auch der im Zeitverlauf feststellbare deutliche Wandel dieser Praktiken. Die Untertanen hatten Optionen, sie konnten entscheiden, ob sie schon zu Lebzeiten oder erst nach dem Tode, in jüngerem oder späterem Alter ihren Besitz abgaben; neben dem Zeitpunkt der Besitzweitergabe war auch die Person des Nachfolgers nicht vorgegeben.

Die Gutsherrschaft fungierte beim Besitztransfer im Wesentlichen als Kontrollinstanz. Sie überwachte vor allem das Prinzip der Unteilbarkeit der landwirtschaftlichen Betriebseinheiten und kontrollierte zudem von Zeit zu Zeit die korrekte Führung der Grundbücher. Indem sie etwa die Aufteilung der Kaufsumme überprüfte, konnten eventuelle beabsichtigte oder unabsichtliche (Rechenfehler!) Benachteiligungen aufgespürt werden. ${ }^{34}$ Die Herrschaft sanktionierte (nachweisbar vor allem für das 17. Jahrhundert) unerwünschtes Verhalten (insbesondere Fälle vor- und außerehelicher Sexualität) ihrer Untertanen dadurch, dass sie Geldstrafen aus dem Fundus der noch auszuzahlenden Anteile der einzelnen Familienmitglieder einhob (vgl. Kapitel 7.3). ${ }^{35}$ Die Funktion der Herrschaft als kontrollierende Instanz wurde von den Untertanen nicht nur akzeptiert, sondern von diesen manchmal auch aktiv für die eigenen Zwecke angerufen. Beispielsweise ist die Eingabe eines Bauernsohnes aus dem weiter nördlich gelegenen Herrschaftsdorf Rojov an die Herrschaft aus dem Jahre 1799 überliefert, in der er darauf aufmerksam machte, dass seiner Mutter nach dem Tode des Vaters zugestanden worden war, noch weitere vier Jahre zu wirtschaften, um danach den Hof an ihn zu übergeben.

33 Die Formel vom ,obrigkeitlichen Konsens‘ stellt keine Folge der Verschärfung der Erbuntertänigkeit während des 17. Jahrhunderts dar, sondern ist zumindest in Teilen Böhmens bereits bei Übergaben des 16. Jahrhunderts zu finden, vgl. Cerman, Gutsherrschaft, 97.

34 Solche Überprüfungen erfolgten tatsächlich nur in größeren Zeitabständen.

35 Vgl. dazu genauer am Beispiel der benachbarten Herrschaft Český Krumlov/Krumau: Himl, Die ,armben Leüte', $62 \mathrm{f}$. 
Die Frist von vier Jahren sei nun aber bereits seit einem halben Jahr verstrichen, ohne dass sie sich zurückgezogen hätte. Er appellierte deshalb an die "Amtspflicht“ der „löblichen Obrigkeit“, darauf zu sehen, dass er „ehe baldigst zu seinem Recht gelange".36

Die Grundbucheintragungen selbst erfolgten zumeist durch einen herrschaftlichen Verwalter, mehrfach finden sich aber auch Eintragungen durch den jeweiligen Dorfrichter. Eine ähnliche Situation wird auch für die benachbarte Herrschaft Český Krumlov berichtet: obwohl die Grundbuchführung nach dem Dreißigjährigen Krieg im Allgemeinen bei der Herrschaft lag, scheinen einige Dörfer - so etwa Přední Výton/Vorder-Heuraffl - ihre Grundbücher bis weit in das 18. Jahrhundert hinein selbstständig geführt zu haben. ${ }^{37}$

Ein besonderes Interesse der Herrschaft an häufigem Besitzwechsel bestand in dieser Region nicht. Während in vielen Gebieten Österreichs bei einem Besitzwechsel unter Lebenden eine spezielle Gebühr (,Laudemium') zu entrichten war ${ }^{38}$, wurde in dieser Herrschaft keine derartige Abgabe an den Grundherrn gefordert. Dies geht sehr deutlich aus der Durchsicht all jener Grundbucheinträge hervor, die eine genaue Aufschlüsselung der Aufteilung der Kaufsumme beinhalten. Bei der Ansiedlung von Erbpächtern auf den Gründen des aufgelassenen Meierhofes Zadní Výtoň im Jahr 1783 wurde der Verzicht auf ein Laudemium auch explizit festgehalten. ${ }^{39}$ Besitzwechselgebühren dürften in Böhmen generell eher selten vorgekommen sein; weder im nordböhmischen Frýdlant/Friedlant noch im südwestmährischen Telč/Teltsch waren diese bekannt. ${ }^{40}$ In den nahe gelegenen österreichischen Gebieten hatten solche Gebühren dagegen eine große Bedeutung. In der Herrschaft des Stiftes Schlägl im Oberen Mühlviertel war diese „Freigeld“ genannte Gebühr seit 1615 mit einer Höhe von zehn Prozent der liegenden und fahrenden Habe festgelegt. ${ }^{41}$ Auch in der an der niederösterreichischen Grenze gelegenen südböhmischen Herrschaft Nové Hrady/Gratzen wurde beim Besitzwechsel eine Gebühr von zwei Prozent verlangt. ${ }^{42}$ In der Herrschaft Vyšší Brod bestand die einzige Abgabe nur in einer eher geringen Schreibgebühr. Am Beginn des ältesten erhaltenen Grundbuches der Pfarre Kapličky (beginnend mit dem Jahr

36 Archiv Klaštera Vy̌̌ší Brod, kart. č. 414, unpag.

$37 \mathrm{Vgl}$. Himl, Amtstage, $12 \mathrm{f}$.

38 Mitterauer, Formen, 313.

39 Vgl. SOA Třeboň, PK č. 480, loses Blatt. Vgl. zu diesem Fall auch Kapitel 5.5.

40 Chocholač, Güterpreise, 100.

41 Für die Herrschaft bedeutete das Freigeld daher eine lukrative Einnahme, allein im Jahre 1769 konnte sie unter diesem Titel 2.444 Gulden verbuchen, vgl. Wasmayr, Ulrichsberg, 202. Vgl. für Bayern: Beck, Unterfinning, $406 \mathrm{ff}$.

42 Vgl. Teichl, Herrschaft, 14. 
1580) findet sich eine Festlegung der Höhe des „Einschreibgeldes“ nach der Formel „von jedem Gulden ein halber Kreutzer“. Dies würde einem Anteil von 0,83 Prozent an der jeweiligen Kaufsumme entsprechen. ${ }^{43}$

Eingriffe der Gutsherrschaft in die tatsächliche Gestaltung der Besitzweitergabe (wer wird zu welchen Konditionen Nachfolger) dürften kaum vorgekommen sein. ${ }^{44}$ Nur bei einer sehr geringen Anzahl der Verträge deuten bestimmte Formulierungen oder Ergänzungen im Grundbuch auf einen Eingriff durch die Herrschaft hin, ${ }^{45} \mathrm{da}$ aus den Grundbucheintragungen ja immer nur die Ergebnisse von Entscheidungsprozessen abzulesen sind. Wer an den diesen Entscheidungen vorangehenden Diskussionen beteiligt war und welche Konflikte diesen möglicherweise vorausgegangen waren, ist nicht verzeichnet. Anhand einiger in den Grundbüchern dokumentierter Ausnahmefälle lassen sich die Bedingungen, unter denen sich die Herrschaft beim Besitzwechsel aktiv einschaltete, näher erläutern: Im Jahre 1649 etwa hatte Mathias Stockinger seinen Hof mit Taverne im Ort Kapličky an Martin Hutter verkauft. Trotz bereits erfolgten Eintrags im Grundbuch ratifizierte die Gutsherrschaft diesen Kaufvertrag nicht, sondern setzte Gallus Eschenlohner "pro interim“ als neuen Besitzer ein. Möglicherweise ausschlaggebend für den Eingriff der Herrschaft war, dass Mathias Stockinger völlig verarmt war und ihn das Kloster bereits monatelang auf vielfältige Weise - finanziell und mit Nahrungsmitteln - unterstützt hatte. Unklar ist, ob die Taverne dadurch nicht de facto bereits der Herrschaft gehörte. ${ }^{46}$

Vor allem in den 1640er Jahren "fielen“ einzelne Anwesen an die Herrschaft „heim“, weil diese verlassen waren. In einzelnen Fällen lassen sich aber auch Abstiftungen von Bauern durch die Herrschaft finden. 1695 war etwa Christoph Donner, Besitzer von Kapličky Nr. 5, ,weil er einen gar schlechten würth“ abgegeben hatte, abgestiftet worden. Dass in diesem Fall die Meinung der Verwandtschaft eine Rolle spielte, kann hier nur vermutet werden. Donner, der Sohn eines Holzfällers, hatte Maria geehelicht, die Tochter des Müllers Gregor Viehböck

43 Vgl. SOA Třeboň, fond C Vyšší Brod, PK č. 445. Tatsächlich lassen sich aber durch Auf- und Abrundungen verursachte kleinere Schwankungen im Anteil des Schreibgeldes an der Kaufsumme feststellen.

$44 \mathrm{Zu}$ einem ähnlichen Ergebnis kommen auch andere Fallstudien zum Besitztransfer in Regionen der ,ostelbischen Gutsherrschaft'. Vgl. Štefanová, Erbschaftspraxis; Velková, Staatliches Eingreifen; Wetherell/Plakans, Intergenerational transfers, $342 \mathrm{f}$.

45 Grundbucheinträge dokumentieren lediglich die Ergebnisse der erfolgreich verlaufenden Aushandlungen zwischen allen beteiligten Parteien und verzeichnen eventuell auch Einsprüche und Verbote; verhinderte oder verworfene Pläne dagegen in der Regel nicht.

46 Vgl. SOA Třeboň, fond C Vyšší Brod, PK č. 453, fol. 163. Letztendlich blieb Eschenlohner bis zu seinem Tod Besitzer der Gastwirtschaft, danach folgte ihm sein Schwiegersohn nach. 
aus dem Dorf Mlýnská, der - da er zugleich auch über größeren landwirtschaftlichen Grund verfügte - zu den wohlhabendsten Bewohnern der Pfarre zählte. 1687 hatten sie den Hof in Kapličky durch Kauf von einem nicht verwandten Vorbesitzer erworben. Offenbar hatten die beiden aber Schwierigkeiten mit der Abbezahlung des Kaufpreises. Bemerkenswert ist nun, dass Philip Draxl, neuer Besitzer nach der Abstiftung von Christoph Donner durch die Herrschaft, wiederum ein Schwiegersohn von Gregor Viehböck war. ${ }^{47}$ Dem Schwiegervater war bei der Lösung dieses Falles sicherlich eine gewichtige Mitsprache zugekommen, so dass nicht ohne Weiteres von einem Willkürakt der Herrschaft gesprochen werden kann. Bereits 1654 hatte das Schicksal der Abstiftung auch Hans Zanner aus dem in der Nachbarpfarre gelegenen Dorf Studánky ereilt. In seinem Fall lässt sich allerdings eine besondere Ursache für die Absetzung erkennen. Er war als Anstifter einer breit angelegten kollektiven Protestaktion der Herrschaftsuntertanen gegen das Kloster, insbesondere gegen überhöhte Robotforderungen, angesehen worden. ${ }^{48}$

Die geringe Zahl an verzeichneten Eingriffen der Herrschaft, die jeweils auf außerordentliche Konstellationen verweisen, scheint für die These einer weitgehenden Nichteinmischung der Herrschaft in die Besitzweitergabe zu sprechen.

7.3 Die „Wehrungen“ und Variationen in der Aufteilung der Kaufsumme

In Kapličky wurde zum Zeitpunkt des Besitztransfers nicht nur die Höhe der Kaufsumme festgelegt, sondern - zumindest im 17. Jahrhundert - auch die jährlichen Raten, die sogenannte „Wehrung“ (tschechisch: vejrunk), und manchmal auch die Fristen, binnen der diese abbezahlt werden mussten. Im Normalfall bildete dabei die erste Rate die höchste und die zweite die zweithöchste Summe. $\mathrm{Ab}$ der dritten Rate wiesen die jährlichen Zahlungen dann zumeist eine gleichbleibende Höhe auf. ${ }^{49}$ Die tatsächliche Abzahlung der vereinbarten Rate wurde jeweils im Grundbuch notiert. ${ }^{50}$ Speziell für das 17. Jahrhundert sind die Grundbucheintragungen äußerst detailliert und erlauben für jeden Besitztransfer eine sehr genaue Rekonstruktion der Aufteilung der Kaufsumme (vgl. Fallbeispiel

47 SOA Třeboň, fond C Vyšší Brod, PK č. 453, fol. 147.

48 Kienzl, Geschichte, 32. Mehrere Akten zu diesem Fall, unter anderem auch eine Beschwerdeschrift des Hans Zanner gegen seine Abstiftung, finden sich in: NA Praha, NM (Nove Manipulace), H 115, 1, Nr. 30, 31, 56 sowie in: Archiv Klaštera Vy̌šší Brod, kart. č. 405, 47/5.

49 Dies war genauso in der Herrschaft Chýnov der Fall. Vgl. Grulich, Poddanská, 41.

50 Dies bedeutet, dass auch die Ausbezahlung der Kinder im Grundbuch festgehalten wurde. Diese Praxis war in Böhmen weit verbreitet. Vgl. dazu: Tlapak, Poddanské. 
4). Im 18. Jahrhundert ist für die Pfarre Kapličky eine gewisse Änderung dieses Systems der Ausbezahlung der Anteile festzustellen, insofern deutlich seltener tatsächliche jährliche Raten bezahlt wurden, sondern die Anteile der Geschwister häufig in einem, etwa als Heiratsgut, ausbezahlt wurden. Auch wurde in den Grundbüchern dieser Zeit zumeist keine Frist, bis zu der der Hof vollständig abbezahlt werden sollte, festgelegt.

Fallbeispiel 4: Die Abzahlung des Kaufpreises nach dem Verkauf des Anwesens Kapličky Nr. 1 im Jahr 1644

1644: Nach Ableben des bisherigen Inhabers Simandl Koller wird das Anwesen samt allem zugehörigen Vieh geschätzt auf einen Wert von 174fl. Diese Summe bildet damit den aktuellen Kaufpreis.

Die Summe der vorhandenen Schulden beträgt: 133 fl. 11x. Die Schulden verteilen sich auf zahlreiche Gläubiger, elf von diesen werden namentlich genannt, überwiegend stehen sie in einem engen Verwandtschaftsverhältnis zum Verstorbenen:

Margaretha Leitner (19f 35x, sambt dem zins')

Waise Anna im Dorf Adámky (28f 35x, sambt dem zins')

Sobn Georg (21 fl.)

Sohn Michael (4f 30x)

Tochter Sara (7 fl.)

Schwiegersohn Michael Draxl (6 fl.)

Schwiegersobn Thoman Iglpeck (16 f)

Bruder Martin Koller im Dorf Einsiedel (3 $f$ )

Balthasar Cappeller, ein Pate des Verstorbenen (7f 30x).

Simon Koller (8f)

Lorentz Stockinger in Frantoly (2fl)

, allerley kleine schulden'(10f).

Die Beifügung ,sambt dem Zins` bei einer gewissen Margaretha sowie bei der,Waise Anna' deutet an, dass es sich jeweils um bereits länger bestehende Schulden handelt. Das Verhältnis des Verstorbenen zu jenen Gläubigern, bei denen keine verwandtschaftliche Verbindung angeführt wurde, bleibt unklar. ${ }^{51}$

51 Das Fallbeispiel liegt zeitlich am Beginn der Untersuchungsperiode, sodass auch aus diesem Grund viele verwandtschaftliche Netze nicht eruiert werden können. 
Angeführt wird weiters: die schulden von der schatzung verbleibn der wittib Barbara mit den drei khinder Georg, Michael undt Sara in gleich zu theilen: 40fl. 49x', khemt sich: $10 \mathrm{fl}$ $12 x$. Nach Abzug der Schulden, die am Anwesen lasten, bleiben zur Verteilung unter den hinterbliebenen Familienangehörigen 40 Gulden und 49 Kreutzer, pro Person ergibt dies einen Anspruch auf: 10f 12x. Sohn Georg Koller wird als neuer Besitzer des Anwesens eingetragen, er hat sich ,umb die stifft angenohmen:

Bei diesem Eintrag 1644 wird auch bereits festgelegt, nach welchem Schema Georg Koller die vorhandenen Schulden sowie die verbleibende Differenz auf den Kaufpreis abzuzahlen hat:

,zu Georgi 1644: 50 fl., ,ander jabr': 20 fl., im dritten jabr: 15 fl, dann bis zur völligen abbezablung 10 fl jährlich.'

Gemäß dieser Vereinbarung im Grundbuch wäre das Anwesen nach 12 Jahren (im Jahr 1656) vollständig abbezahlt gewesen.

Diesen Einträgen im Grundbuch unmittelbar anschließend ist nun die tatsächlich erfolgte ratenweise Abbezahlung des Kaufpreises detailliert festgehalten:

,Ao. 644 Zu Georgi legt Georg Koller erst mahl seinem gött Blasius Cappeller 7 f 30, der waisen Anna 9 fl., Margaretha $2 f .30 x$, khlein schulden $10 \mathrm{fl}$ undt ibme selbst $21 \mathrm{fl}$.

Georg Koller erfüllt damit die festgehaltene Bedingung, wonach er im ersten Jahr 50 Gulden zu bezahlen hat, exakt. Nicht unwesentlich dabei ist aber sicherlich, dass er mehr als ein Drittel dieser Summe (seine Forderung von 21 Gulden an den Vater) ohne Barzahlung in die Gleichung einbringen kann. Es fällt außerdem auf, dass er zunächst sowohl die bereits längere Zeit wartenden Gläubiger (Waise Anna, Margaretha) bedient als auch entfernt verwandte Gläubiger gegenüber denen aus der Kernfamilie vorzieht.

Entgegen der festgeschriebenen Vorgangsweise finden sich dann in den weiteren Jahren keine Einträge - Georg Koller war offenbar nicht in der Lage, die weiteren Raten des Kaufpreises für das elterliche Haus fristgerecht zu bezahlen. In den letzten Jahren des Dreißigjährigen Krieges war dieses Unvermögen keineswegs ungewöhnlich, es kam aber auch in Friedenszeiten in der Region oft vor. Weitere Einträge finden sich ab dem Jahre 1650: 
,Ao. 650 legt Georg dem Iglpeckh 16 fl, dem Johann Leitner wegen seines Weibs Margaretha $20 f$.'

Nachdem Georg Koller fünf Jahre keine Raten zahlte, kann er nun mit insgesamt 36 Gulden eine deutlich größere Summe als die ursprünglich vereinbarte Höhe der zweite Rate abbezahlen. Er kann nicht nur die Schulden an seinen Schwager Thoman Iglpeck vollständig (ohne Zinsen!) ausbezahlen, sondern auch die ausstehende Summe an Margaretha Leitner (inklusive der neuerlich aufgelaufenen Zinsen).

,Ao. 651 legt Georg der Sara vier fl., dem Simandl Koller drei fl., der waysen Anna 6 flox:

Im darauffolgenden Jahr zahlt Georg Koller die dritte Rate, die mit insgesamt 13 Gulden 10 Kreutzern, fast die vereinbarte Höhe seiner dritten Rate erreicht. Erstmals erhält mit seiner Schwester Sara auch eines seiner Geschwister eine Teilrückzahlung.

,Ao. 652 legt Georg der wayßen Anna 10fl, dem Simon Koller 2fl 10x:

,Ao. 653 legt Georg dem Simon Koller 3 fl., dem Michael Koller 3 fl., der waißen Anna 5 fl.

Mit seiner vierten und fünften Ratenzahlung liegt Georg Koller nun jeweils etwas (12 Gulden 10 Kr.; bzw. 11 Gulden) über der vereinbarten Höhe der Ratenzahlung, die ja ab der vierten Rate nur mehr 10 Gulden jährlich betragen sollte.

Auch in den Folgejahren zahlt Georg Koller jährliche Raten von jeweils rund zehn Gulden, so dass er es ihm tatsächlich gelingt (bis auf eine geringe Summe), das Anwesen wie vereinbart fristgerecht bis 1656 abzubezahlen.

Quelle: SOA Třeboň, fond C Vyšší Brod, PK č. 453, fol. 133.

Im genannten Fallbeispiel zeigt sich, dass zunächst die vorhandenen Schulden getilgt und erst danach die Anteile an die ,weichenden Geschwister' ausbezahlt wurden. Eine zeitlich stark verzögerte Ausbezahlung, wie dies in manchen Perioden überaus häufig vorkam, war für die weichenden Geschwister natürlich von Nachteil. Chocholač hat etwa für südwestmährische Regionen festgestellt, dass während des Dreißigjährigen Krieges die Auszahlung der Raten der Weichenden auf ein Maximum verzögert wurde. ${ }^{52}$ In der Pfarre Kapličky verfielen aber jedenfalls die Anteile einzelner Personen nicht - auch dann nicht, wenn sie sehr lange liegen blieben, sondern mussten nach und nach abbezahlt werden. Nicht ausbezahlte „Wehrun-

52 Chocholač, Selské peníze, 181. Ausführlich zu den „Wehrungen“ auch: Chocholač, Güterpreise. 
gen" wurden nicht etwa als ,stille Teilhaberschaft" am Haus aufgefasst, sondern als ausstehende Schulden. Nach Möglichkeit wurden diese Schulden - wenn auch zum Teil mit großer Verzögerung - nach und nach abbezahlt. Beispielsweise hatte beim neuerlichen Verkauf des nicht fertig abbezahlten Hofes Frantoly Nr. 1 im Jahre 1750 ein gewisser Martin Martetschläger vom vorhergehenden Besitztransfer im Jahr 1730 noch einen Anteil von 12 Gulden zu erhalten. Beim nächsten Besitzerwechsel am Hof im Jahre 1766 betrug sein noch ausstehender Anteil dagegen nur mehr vier Gulden. ${ }^{53}$ Wie viele Besitzer ihre Anwesen tatsächlich während ihrer Inhaberschaft des Hauses vollständig abbezahlten, wurde nicht systematisch ermittelt. Entsprechende Angaben sind aus den Grundbüchern auch nicht für sämtliche Phasen des Untersuchungszeitraums zu gewinnen. ${ }^{54}$ Nach einer für zwei Dörfer (Mnichovice und Hodoň) durchgeführten vorsichtigen Schätzung (Basis: 111 Besitzweitergaben) dürften nur knapp mehr als 30 Prozent der Inhaber das ,solutum‘ - jene Formulierung, mit dem nach vollständiger Abbezahlung des Kaufpreises der jeweilige Grundbuchakt geschlossen wurde - zu ihren Lebzeiten erreicht haben. Freilich gab es hier im Zeitverlauf deutliche Unterschiede. Während der zweiten Hälfte des 17. Jahrhunderts lag dieser Anteil durch die häufig nur sehr kurze Besitzdauer natürlich deutlich niedriger als im 18. Jahrhundert. Auch aus den für Kapličky erhalten gebliebenen Verlassenschaften aus der Periode $1672-1760^{55}$ ist ersichtlich, dass viele Personen zum Zeitpunkt ihres Todes, auch wenn dieser viele Jahre nach der Übergabe lag, ihre finanziellen Ansprüche noch nicht zur Gänze erhalten hatten. Für den Käufer des Anwesens war es offenbar entscheidend, in den ersten Jahren nach dem Kauf zumindest einen hohen Prozentsatz der vereinbarten Kaufsumme abzubezahlen; sobald ihm dies gelungen war, hatten auch mehrmalige Versäumnisse der jährlichen Fristen kaum Folgen. Der Grundbucheintrag wurde in diesen Fällen nicht annulliert.

In der Regel wurde die Kaufsumme in Geld und nicht etwa in Sachäquivalenten abbezahlt, jedenfalls finden sich keine Hinweise auf eine gegenteilige Praxis. Lediglich im Falle eines außerhalb der Untersuchungspfarre gelegenen Anwesens - eines kleinen Eisenhammers im benachbarten Dorf Studánky - findet sich die Aufzeichnung, dass der Käufer die jährlichen Raten während der 1660er Jahre

53 SOA Třeboň, fond C Vy̌̌ší Brod, PK č. 465.

54 Zunehmend wurden im 18. Jahrhundert die zumeist recht detaillierten Aufzeichnungen, an wen welcher Geldbetrag zu welchem Zeitpunkt tatsächlich ausbezahlt wurde, nicht mehr in den Grundbüchern selbst verzeichnet, sondern in separat geführten Büchern, die in der vorliegenden Arbeit nicht analysiert werden konnten. In einzelnen, besonders komplex gelagerten Fällen wurde auch schon im 17. Jahrhundert auf separat geführte Aufzeichnungen verwiesen, so etwa beim Transfer des Anwesens Hodoň Nr. 1, bei dem lediglich angeführt wurde:, wem die kaufsumme gebühret sieh invent. fol. 148، 55 SOA Třeboň, fond C Vyšší Brod, PK č. 559. 
immer in Leinwand und nicht in Geld bezahlte. Empfänger dieser Leistungen war in diesem Fall die Klosterherrschaft selbst (als Vorbesitzerin des Anwesens), die offenbar diese Variante der Bezahlung einer Geldleistung vorzog. ${ }^{56}$

Obwohl die in dieser Region verfolgten Prinzipien der Besitzweitergabe zahlreiche egalitäre Elemente enthielten, muss letztlich offenbleiben, ob dieses System tatsächlich als egalitär oder gar als ,gerecht ${ }^{`} \mathrm{zu}$ bezeichnen ist, da die in dieser Hinsicht relevanten Fragen kaum eindeutig zu beantworten sind. Wie sich der Kaufpreis zum Marktwert des Besitzes verhielt, ist sehr schwer zu bestimmen. Wäre der Kaufpreis systematisch niedriger als der Marktwert angesetzt worden, hätte dies eine Benachteiligung der ,weichenden' Geschwister bedeutet. ${ }^{57}$ Über den Marktwert der Anwesen wissen wir jedoch nichts. Dass sich die Kaufsumme bei einigen Häusern jahrzehntelang nicht veränderte, lässt darauf schließen, dass zumindest die Preisgestaltung bisweilen anderen als Marktprinzipien folgte. Egalitär wäre dieses System außerdem nur dann zu nennen, wenn die weichenden Geschwister ihre Geldanteile ohne wesentliche zeitliche Verzögerung ausbezahlt bekamen. Tatsächlich kam es aber, trotz (vor allem im 17. Jahrhundert) grundbücherlich vereinbarter Termine der Ratenzahlungen, in zahlreichen Fällen zu Zahlungsrückständen, so dass viele Anwesen zum Zeitpunkt des Todes ihres Besitzers noch nicht vollständig abbezahlt waren. Die Auszahlung der Anteile der,weichenden' Geschwister konnte sich also bedeutend verzögern; deren Anteile dürften daher - schon inflationsbedingt - jedenfalls nicht in jedem Fall den gleichen Wert wie die vom kaufenden Kind erworbenen Besitzungen gehabt haben.

In vielen Fällen sind keine Unterschiede in der Kaufsumme bei Verkäufen an Fremde oder an die eigenen Kinder zu bemerken. Bei einigen Häusern fällt jedoch auf, dass bei einer Weitergabe an ein leibliches Kind die Kaufsumme manchmal gleich hoch wie beim vorangehenden Transfer war. Wurde das Anwesen aber an Nichtverwandte verkauft, erfolgte eine (zumeist geringfügige) Erhöhung dieser Summe. Mehrmals wurde eine auffällig hohe Kaufsumme aber auch mit dem Argument begründet, dass ein Gebäude gerade neu errichtet worden sei. Auch die gute oder schlechte Ausstattung der Höfe mit Arbeitsgeräten bildete ein Argument. Andere Studien konnten keine Unterschiede in der Preisbildung zwischen Verkäufen an verwandte oder an nichtverwandte Personen feststellen, gehen dennoch aber nicht von einem Marktpreis, sondern von einem „sozial definierten“ Preis

56 SOA Třeboň, fond C Vyšší Brod, PK č. 453, fol. 88.

57 In der zeitgenössischen, aus dem frühen 19. Jahrhundert stammenden Arbeit von Neuber, Verhältnisse, 7, findet sich die Behauptung, dass in Niederösterreich der volle Wert der Anwesen habe bezahlt werden müssen, in Böhmen dagegen nicht. 
aus. ${ }^{58}$ In der süddeutschen Region Hohenlohe, einem Gebiet mit Unteilbarkeit der Güter hieß dieser „soziale“ Preis, der zumeist deutlich unter dem Marktpreis lag, „Kindskauf" ${ }^{59}$ Sicherlich ist auch für den südlichen Böhmerwald im Wesentlichen von einem sozialen Preis auszugehen. Ein gewinnorientierter Handel mit den untertänigen Häusern und Bauernhöfen lässt sich für diese Pfarre jedenfalls bis ins beginnende 19. Jahrhundert weitgehend ausschließen. In der Marktordnung von Vyšši Brod aus dem Jahre 1608 findet sich sogar eine Bestimmung, die den Verkauf der Anwesen „theurer oder überiger gewinn“ ausschließen sollte. Darauf hätten die jeweils nächsten Nachbarn zu achten. ${ }^{60}$

In vielem scheint das in dieser Region vorzufindende Muster mit den von Martine Segalen für eine Region in der Bretagne beschriebenen Verhältnissen vergleichbar. ${ }^{61}$ Auch dort wurden die Höfe gekauft. Überwiegend, aber nicht ausschließlich, erhielt nur ein Kind den Hof mitsamt allen Grundstücken. Die weichenden Geschwister hatten Anspruch auf gleiche finanzielle Anteile. Oft erhielten sie allerdings auch Grundstücke. Wie im Böhmerwald/Šumava lebten die Geschwister manchmal jahrelang in der Erwartung der Auszahlung der noch ausständigen Anteile. Der aus dieser Region stammende charakteristische Ausspruch "ich habe noch meinen Teil da unten"62 würde auch die Situation in Kapličky treffend skizzieren. Dass die weichenden Geschwister auch Landanteile erhalten konnten, war allerdings in Südböhmen nicht möglich.

$\mathrm{Ob}$ für die Untersuchungsregion tatsächlich auch in der Praxis von einer faktischen Gleichstellung oder aber einer „nachgeordneten Versorgung “63 der Nebenerben gesprochen werden muss, kann eigentlich nur von Fall zu Fall entschieden werden. Ob die weichenden Kinder des Vorbesitzers trotz der prinzipiell egalitären Teilung tatsächlich eine relevante Geldsumme erhielten oder nicht, war von sehr vielen Faktoren abhängig: zunächst vom Wert und damit auch von der Größe des Anwesens; davon, ob ihnen ihr Anteil rasch und vollständig ausbezahlt wurde, oder ob sich dies verzögerte; ob Schulden vorhanden waren oder nicht; von der Anzahl der lebenden Geschwister.

58 Štefanová, Zur Stellung der Untertanen, 226f. Ähnlich auch Pazderová, Herrschaft, 53f., für eine nordostböhmische Herrschaft, auch Hans Medick bezeichnet den Kaufpreis für seine Untersuchungsregion der Schwäbischen Alb als weder symbolisch noch als marktorientiert, sondern als, sozialen Preis'. Vgl. Medick, Weben, 330.

59 Robisheaux, Rural Society, 82; Trossbach, Bauern, 34.

60 Schlesinger, Dorfweisthümer, 325.

$61 \mathrm{Vgl}$. Segalen, Geschwisterbeziehungen. Medick/Sabean, Einleitung, 20, beschreiben diese Verhältnisse in der Bretagne als, Realteilung.

62 Segalen, Geschwisterbeziehungen, 198.

63 Mooser, Ländliche Klassengesellschaft, 195. 
In Kapličky bot das strukturell egalitäre System in der Praxis allerdings immer auch Raum für eine Bevorzugung einer einzelnen Person (ob Verkäufer, Käufer oder eines der Kinder). Dies geschah etwa dadurch, dass Teile des Besitzes, etwa Vieh, von der vereinbarten Kaufsumme ausgenommen und zusätzlich gesondert verrechnet wurden. Mehrfach kam es etwa vor, dass dem Käufer des Anwesens zwei Ochsen extra verrechnet wurden - so etwa im Jahre 1788, als Johann Edelbauer den Hof Vyšína Nr. 1 von seiner verwitweten Mutter kaufte. ${ }^{64}$ Bei der Festsetzung der Höhe des Preises bestand also ein nicht unbeträchtlicher Spielraum, um den die beteiligten Personen oft wohl lange verhandelten, und der durchaus auch die Möglichkeit bot, etwa den im Besitz nachfolgenden Sohn gegenüber seinen Geschwistern zu bevorzugen. Allerdings finden sich auch Fälle, in denen nicht der Besitznachfolger, sondern eines der weichenden Kinder bei der Aufteilung der Kaufsumme ausdrücklich besser gestellt wurde. Töchter etwa erhielten mehrfach zuzüglich zu ihrem Anteil an der Kaufsumme auch nicht-monetäre Anteile, etwa Bettwäsche, Kleidung oder eine Kuh. Bei solchen Fällen freilich ist zu bedenken, dass die Weitergabe von Haus und Land Teil des umfassenderen und komplexeren Vererbungsprozesses von einer Generation zur nächsten war. Um die Gleichbehandlung bzw. Ungleichbehandlung von Geschwistern tatsächlich beurteilen zu können, müssten wir allerdings auch alle zu anderen Zeitpunkten möglicherweise stattfindenden innerfamilialen Transfers (Mitgiften bei einer Heirat; Aufteilung von Verlassenschaften) kennen. Diese Informationen stehen uns jedoch in keinem Fall vollständig zur Verfügung.

In bestimmten Fällen war es offenbar möglich, mit Hilfe einer besonderen Begründung den Anteil eines weichenden Kindes gegenüber den anderen zu erhöhen. Die klassische Form, eine Sonderregelung festzulegen, erfolgte mittels testamentarischer Verfügung. ${ }^{65}$ Freilich mussten, wie die Durchsicht einzelner aus der Region vorliegender derartiger Akten zeigte, ${ }^{66}$ auch die Bestimmungen eines Testaments nicht zwingend eingehalten werden. Wie bereits Sabean gezeigt hat,

64 SOA Třeboň, fond C Vyšší Brod, PK č. 464, fol. 1, pag. 389. Der Kaufpreis des Anwesens lag damit 1788 mit 312 Gulden deutlich höher als beim vorherigen Verkauf 1756 (263 Gulden) und beinahe doppelt so hoch wie beim vorletzten 1714 (160 Gulden). Im Vergleich dazu war der Kaufpreis des Nachbaranwesens Vyšína Nr. 4 zwischen 1707 und 1776 von 300 Gulden auf 440 Gulden gestiegen, der des Anwesens Vyšína Nr. 5 zwischen 1722 und 1779 nur von 160 Gulden auf 190 Gulden.

65 Vgl. für die Analyse dieser Quellen: Langer-Ostrawsky, Generationenbeziehungen.

66 Archiv Klaštera Vyšší Brod, Kart. č. 414, unpag., z. B. Testamentsbrief des Albert Meyer aus dem Dorf Roiden, 1794. Mehrfach versuchten in der Region Grundbesitzer per Testament festzulegen, wie lange ihre Frau nach ihrem Tod den Hof weiterführen dürfe, ehe sie an ein Kind (aus erster Ehe des Mannes) übergeben sollten. Der Vergleich mit den Grundbüchern zeigt jedenfalls, dass diese Fristen nicht in jedem Fall tatsächlich immer eingehalten wurden. 
konnten testamentarische Verfügungen auch abgeändert werden, wenn sich alle Anspruchsberechtigten über eine andere Lösung einig wurden. ${ }^{67}$ In den späteren Phasen des Untersuchungszeitraums kam es auch mehrmals vor, dass der Großteil der Kaufsumme den Vorbesitzern (also etwa den Eltern) verblieb. Als Wentzel Hutter das Anwesen Frantoly Nr. 1 an seinen Sohn Jacob verkaufte, erhielten Jacob und seine Schwester Gertraud je einen Anteil von 23 Gulden an der Kaufsumme, die restlichen 385 Gulden gingen dagegen an den Vater Wentzel. ${ }^{68}$ Insgesamt war aber eine Aufteilung in gleiche Teile die üblichste Lösung.

Lasteten auf dem Anwesen hohe Schulden, dann fielen die Anteile der Anspruchsberechtigten in der Praxis sehr gering aus, da vom zuvor festgelegten Kaufpreis zunächst die Schulden abgezogen wurden, ${ }^{69}$ erst danach wurde der verbleibende Rest der Kaufsumme als Anspruch der Mitglieder der Vorbesitzerfamilie in gleichen Teilen aufgeteilt. In solchen Fällen nahmen die Anteile, die die Geschwister erhielten, manchmal tatsächlich den Charakter eines symbolischen Betrages an.

\subsection{Muster des Besitztransfers in Kapličky}

Welche Auswirkungen hatte das beschriebene System der Besitzweitergabe mittels vertraglich fixiertem Kauf auf die Besitzdauer der Anwesen und auf die Bindung der Familien an ihre Besitzungen? Welche Bedeutung hatte die Weitergabe von Land und Anwesen innerhalb der Familie und der Verwandtschaft beim Besitztransfer von einer Generation zur nächsten? In der internationalen Literatur werden Besitzwechsel und Generationenwechsel oft unhinterfragt als ausschließlich innerfamiliale Angelegenheit zwischen Eltern und ihren Kindern betrachtet, sonstige Relationen zwischen den Besitzern und ihren Nachfolgern werden nicht gesehen. Dies kommt etwa in den in diesem Zusammenhang verwendeten Termini, wie „family strategies“, ${ }^{70}$ oder auch in den Diskussionen um die Verbreitung von „stem families" ${ }^{\text {"71 }}$ zum Ausdruck.

67 Sabean, Property, 251.

68 Welche Ursachen dies hatte, lässt sich nicht eruieren. Möglich wäre, dass der Vater im Gegenzug auf ein Ausnehmen beim Hof verzichtet hatte. Die in separaten Büchern geführten Ausgedinge-Verträge sind jedoch für den fraglichen Zeitraum nicht vorhanden.

69 Dies war auch in der südböhmischen Herrschaft Chýnov der Fall. Vgl. Grulich, Aspekte, 28.

70 Vgl. zu diesem Konzept Baud/Engelen, Introduction; Moch, Family Strategy.

71 Z. B. Berkner, The Stem family. 


\subsubsection{Die Unteilbarkeit der Güter als Konstante}

Als erstes wichtiges Ergebnis der empirischen Analyse der Grundbücher von Kapličky ist festzuhalten, dass das Prinzip der Unteilbarkeit der Anwesen beim Besitztransfer in dieser Region während des gesamten Untersuchungszeitraumes eine Konstante darstellte. In sämtlichen untersuchten Fällen erfolgte die Weitergabe eines Anwesens unter Einschluss des gesamten dazugehörigen Landbesitzes. Die Unteilbarkeit der Güter leitete sich - dies lässt sich nicht nur für die Untersuchungsregion, sondern auch für andere Gebiete feststellen - nicht aus einem Erbrecht oder einer traditionell eingebürgerten Übergabepraxis ab, sondern aus dem Besitzrecht. ${ }^{72}$ Auch das in vielen anderen Regionen vorzufindende Anerbenrecht war eine Folge der Unteilbarkeit der Güter, ${ }^{73}$ oder wie Kretschmer und Piegler für den österreichischen Raum festhielten, war „für das bäuerliche Erbrecht ... nicht das Anerbenrecht, sondern der Güterschluss primär ursächlich “. ${ }^{74}$ In der Literatur wird dieser Zusammenhang häufig nicht klar genug betont. Allem Anschein nach war es in zahlreichen Regionen so, dass erst der Rechtsstatus der Unteilbarkeit des Hofes und aller dazugehörigen Gründe dazu geführt hatte, dass sich ein System herausbildete, bei dem ein einzelner Nachfolger alleiniger Besitznachfolger wurde. ${ }^{75}$ Aufbauend auf dem Faktor der unteilbaren Anwesen konnten sich dann unterschiedliche Formen der Besitzweitergabe entwickeln.

In der Pfarre Kapličky wurde zwischen 1640 und 1840 das Prinzip der Unteilbarkeit beinahe ohne Ausnahme strikt eingehalten. Darauf achtete offenbar die Grundherrschaft äußerst genau. Die Unteilbarkeit der Güter sicherte ihr eine unveränderliche Zahl an bäuerlichen Betriebseinheiten und fixierte damit auch die Zahl der Abgabeeinheiten. ${ }^{76}$ Nicht zuletzt war ja auch das Ausmaß der Robotbelastung der Untertanen im Prinzip von der Besitzgröße des Anwesens abhängig. Zur vollen, „großen“ Robot, d.h. zu drei Tagen Arbeitsverpflichtung pro Woche für eine Person samt einem Ochsengespann, waren nur die sogenannten „spannfähigen“ Bauern verpflichtet. Alle anderen hatten nur Handrobot zu leisten. Die Herrschaft hatte daher großes Interesse, die Zahl der spannfähigen Bauern konstant zu halten. Für die benachbarte Herrschaft Český Krumlov findet sich nicht nur eine Herrschaftsinstruktion aus den Jahren 1707/08, die ein Verbot der Teilung von

72 Vgl. dazu Kapitel 6.3.

73 Schlumbohm, Lebensläufe, 379.

74 Kretschmer/Piegler, Erbrecht, 10.

75 Diesen auch zeitlichen Zusammenhang betont ebenso Schlumbohm, Lebensläufe, 379, für eine Region im Norden Deutschlands.

76 Vgl. auch: Maur, Gutsherrschaft, 210. 
Anwesen festhielt, sondern ebenso eine Instruktion von 1642, die explizit auch ein Verbot des Verkaufs einzelner Feldparzellen festhielt. ${ }^{77}$ Größere Höfe konnten im Vergleich mit kleineren in der Regel auch überproportional höher mit grundherrlichen Abgaben belastet werden. Die Teilung eines größeren Hofes in zwei Anwesen barg für den Grundherrn jedenfalls die Gefahr, dass unterhalb einer bestimmten Wirtschaftsgröße des untertänigen Anwesens eine Spannviehhaltung nicht mehr sinnvoll war. ${ }^{78}$

Lediglich gegen Ende des Untersuchungszeitraumes kam es im Fall eines hoch verschuldeten Bauernhofes im Dorf Frantoly zur tatsächlichen Teilung des Anwesens in mehrere neue Höfe. Allerdings erfolgte auch bei diesem Hof nicht etwa eine Aufteilung des Grundbesitzes unter mehreren Kindern des Besitzerpaares; vielmehr wurden zweimal (beide Male nicht im Zuge eines Besitzerwechsels) größere Grundflächen vom Anwesen losgelöst und auf den getrennten Flächen jeweils ein neues bäuerliches Anwesen errichtet. Vielleicht fand der Besitzer Wentzel Prieschl, Inhaber des Anwesens - das er von seinem Vater gekauft hatte - seit dem Jahr 1831 keinen Käufer, der bereit gewesen wäre, den gesamten Hof mitsamt den Schulden zu übernehmen. 1839 waren jedenfalls elf Joch Grund und 1847 28 Joch Grund vom Anwesen abgetrennt und verkauft worden. Zwei nicht mit dem Vorbesitzer verwandte Käufer erhielten so jeweils mehrere Hektar Grund und errichteten darauf ein neues Anwesen. Da Prieschl weiterhin Wirtschaftsflächen besaß, waren somit aus vormals einem bäuerlichen Anwesen nun drei entstanden. ${ }^{79}$ Durch den Kauf des im Jahr 1847 von Prieschel verkauften Grundes war der Häuslersohn Bernhard Füxl aus demselben Dorf zum Bauern aufgestiegen. Lediglich in einem Fall aus dem 17. Jahrhundert wurden das Wirtschaftsgebäude (eine Mühle im Dorf Lipova) und der dazugehörige Landbesitz im Zuge eines Besitztransfers in zwei verschiedene Einheiten getrennt. Der Müller und Bauer Wolf Kastner konnte mit dieser Regelung zweien seiner Söhne eine Existenz sichern. ${ }^{80}$ Es war dies der einzige Fall einer tatsächlichen Güterteilung im Zuge eines Besitzerwechsels im gesamten Untersuchungszeitraum. Da die Mühle bei dieser Lösung aber völlig landlos blieb, kann allerdings auch dieser Fall nicht direkt als Verletzung des Prinzips der Unteilbarkeit der Güter bewertet werden.

Trotz der strikten Unteilbarkeit der Anwesen im Zuge des Besitzerwechsels kam es aber nicht zu einer Konservierung der bestehenden sozialen Differenzierung in der Pfarre durch eine bloße beständige Reproduktion der Besitzgrößen-

77 Vgl. Himl, Die, armben Leüt', 61.

$78 \mathrm{Vgl}$. Achilles, Landwirtschaft, 33.

79 Vgl. SOA Třeboň, C Vyšší Brod, PK č. 464, fol. 40f.

80 Vgl. SOA Třeboň, C Vyšší Brod, PK č. 453, fol. 211. 
unterschiede, denn abseits des Besitzwechsels bestanden mehrfach - in begrenztem Rahmen - Spielräume für Veränderungen im Umfang des Grundbesitzes (vgl. Kapitel 3 und 5). Nicht nur bei Errichtung neuer Häuser auf bäuerlichem Grund wurden manchmal kleine Grundstücke aus den bäuerlichen Besitzungen gelöst und diesen neuen Häusern zugeschlagen, auch die Grundbesitzer selbst kauften oder verkauften in wenigen Einzelfällen ein einzelnes Feld. Dies war - anders als in Český Krumlov - in dieser Region mit Genehmigung der Herrschaft offenbar möglich, obwohl es sich um Teile der Hausgründe handelte. In Kapličky lassen sich Verkäufe einzelner Grundstücke sowohl für das 16. als auch für das 17. und 18. Jahrhundert belegen. ${ }^{81}$ Die Landausstattung der neu errichteten Kleinhäuser war zumindest zum Zeitpunkt ihrer Gründung äußerst bescheiden. In vielen Fällen gelang es diesen Häusern jedoch im Laufe der Jahrzehnte kleinere Grundstücke dazuzukaufen, darunter insbesondere neu gerodete Flächen aus dem Besitz der Herrschaft. Die über mehrere Generationen im Dorf Kapličky ansässige Schneider- und Häuslerfamilie Wabro etwa konnte zumindest zweimal einen Acker kaufen. Das Anwesen Hodoň Nr. 8, lange Zeit hindurch sicherlich ein für die Region typisches Kleinhaus, wurde im Stabilen Kataster 1826 schließlich sogar als bäuerliche Stelle kategorisiert. Derart markante Veränderungen in der Besitzstruktur eines Anwesens waren aber selten. In zwei Fällen bestand ein Ausgedinge-Haus mit geringem Grundbesitz für mehrere Jahrzehnte als selbstständige Einheit, ehe dieses wieder vom Hof, von dem es losgelöst worden war, zurückgekauft wurde. Insgesamt trugen alle genannten Beispiele im Laufe der Jahrzehnte doch zu merkbaren Veränderungen in der Grundbesitzstruktur der Pfarre bei. Zu betonen ist, dass alle diese Fälle von nachweisbaren Veränderungen in der Besitzgrößenstruktur der Anwesen jeweils nicht im Zuge eines Besitzwechsels stattfanden, sondern außerhalb von diesem. ${ }^{82}$

\subsection{Die Besitzdauer}

Trotz der Stabilität der Rahmenbedingungen ist für Kapličky in mehrfacher Hinsicht ein bemerkenswerter Wandel in den Praktiken der Besitznachfolge während

81 Vgl. als Nachweis für das 16. Jahrhundert etwa einzelne derartige Nachträge im Urbar des Jahres 1530, z.B.: Schmidt, Urbar, 197.

82 Stärkere Schwankungen in ihrer Größe als die emphyteutischen Besitzungen wiesen freilich die tatsächlich bewirtschafteten Flächen pro Anwesen auf, da hier auch die zusätzlich von beinahe jedem Haus der Pfarre von der Gutsherrschaft gepachteten, Zinsreuter berücksichtigt werden müssen. Vgl. dazu Kapitel 5.6. 
des Untersuchungszeitraums nachweisbar. Dieser wird insbesondere für das frühe 18. Jahrhundert fassbar, daher wird im Folgenden bei der Darstellung der empirischen Ergebnisse eine Zweiteilung der Untersuchungsperiode in eine erste Phase von 1651 bis 1720 und eine zweite Phase von 1721 bis 1840 gewählt.

In der ersten Phase von 1651 bis 1720 war die durchschnittliche Besitzdauer auf den Anwesen der Pfarre eher kurz. In der Hälfte aller Fälle lag sie bei weniger als 20 Jahren, in beinahe einem Viertel der Fälle bei weniger als zehn Jahren (Tabelle 28). Fast ein Drittel der landarmen Häuser wechselte in dieser Zeit nach weniger als zehn Jahren wieder den Besitzer. ${ }^{83}$ Es gab vor allem einzelne Anwesen, die nie über einen längeren Zeitraum hinweg von ein und derselben Familie bewirtschaftet wurden, sondern immer wieder bereits nach wenigen Jahren weiterverkauft wurden. Ursache dafür waren offenbar die schwierigen ökonomischen Bedingungen. Die wirtschaftliche Krise nach dem Krieg hatte auch hier dazu geführt, dass das ökonomische Potenzial vieler Häuser nicht ausreichte, ein Einkommen zu erwirtschaften, um sowohl das Überleben der Familie zu gewährleisten als auch allen finanziellen Anforderungen nachzukommen. Letztere bestanden vor allem darin, die Kaufsumme vollständig abzubezahlen, die Abgaben an die Herrschaft zu leisten und den finanziellen Verpflichtungen gegenüber den ,weichenden' Geschwistern nachzukommen. Beispielsweise verkaufte im Jahr 1679 Andreas Leitner (1674-1679) sein Anwesen Kapličky Nr. 4 aus ,Armut und Unvermögen'. Schon sein Vorgänger Michl Draxler (1656-1674) hatte aus „Unvermögenheit“ verkauft, nachdem er bereits 1668 ein Nebengebäude an M. Iglbeck abgegeben hatte, der dafür seine Schulden übernahm. Zacharias Wagner verkaufte Kapličky Nr. 11 im Jahre 1700 aus „höchster Noth und Unvermögen“, 1697 Philip Pichler Kapličky Nr. 9 aus ,Unvermögenheit'; Thomas Iglbeck (1650-1665) sagte aus „Unvermögenheit" das Anwesen Kapličky Nr. 8 der Obrigkeit „heim“. Sein Nachfolger Reichard Reischl (1665-1675) verkaufte, weil er der „Stift nicht mehr vorstehen konnte“. ${ }^{84}$ Im Dorf Kapličky mit zumeist mittelgroßen bäuerlichen Wirtschaften (zwischen 10 und 22 Strich Aussaat), deren Besitzer häufig auch zusätzlich ein Gewerbe ausübten, hatten sechs der elf Grund besitzenden Anwesen in der Zeit von 1640 bis 1670, die in etwa einer Generationsspanne entspricht, jeweils zwischen vier und fünf verschiedene Besitzer. Vertraut man, wie dies etwa Sabean tut, ${ }^{85}$ der Aussa-

83 Für einige südmährische Dörfer lässt sich dagegen auch für die zweite Hälfte des 17. Jahrhunderts eine durchschnittliche Besitzdauer von etwas über 20 bzw. von mehr als 25 Jahren nachweisen. Vgl. Chocholač, Güterpreise, 113.

84 SOA Třeboň, fond C Vyšší Brod, PK č. 453, fol. 144, fol. 158. In den lokalen Quellen wurde das Anwesen/der Hof häufig als „Stift“ bezeichnet.

85 Vgl. Sabean, Property, 260. 
gekraft solcher in den Grundbüchern enthaltenen Anmerkungen zu den Ursachen der Besitzabgabe, wie „Unvermögen“, „Armut“, etc., dann finden sich in etwa zehn Prozent aller Fälle der zweiten Hälfte des 17. Jahrhunderts Formulierungen, die auf bedeutende ökonomische Schwierigkeiten der Besitzer verweisen, für die späteren Jahrzehnte sind derartige Anmerkungen dagegen bedeutend seltener. ${ }^{86}$

Tabelle 28: Verteilung der Besitzdauer in der Pfarre Kapličky, 1651-1840

\begin{tabular}{lcccccccc}
\hline In Jahren & \multicolumn{4}{c}{ Bauern } & \multicolumn{5}{c}{ Landarme } \\
& \multicolumn{1}{c}{$1651-1720$} & \multicolumn{1}{c}{$1721-1840$} & \multicolumn{1}{c}{$1651-1720$} & \multicolumn{1}{c}{$1721-1840$} \\
\hline & $\mathrm{N}$ & $\%$ & $\mathrm{~N}$ & $\%$ & $\mathrm{n}$ & $\%$ & $\mathrm{~N}$ & $\%$ \\
$0-9$ & 38 & 21,2 & 28 & 11,2 & 20 & 32,8 & 22 & 12,7 \\
$10-19$ & 48 & 26,8 & 38 & 15,1 & 13 & 21,3 & 29 & 16,8 \\
$20-29$ & 30 & 16,8 & 60 & 23,9 & 15 & 24,6 & 35 & 20,2 \\
$30-39$ & 47 & 26,3 & 79 & 31,5 & 9 & 14,8 & 51 & 29,5 \\
$40+$ & 16 & 8,9 & 46 & 18,3 & 4 & 6,6 & 36 & 20,8 \\
\hline Summe & 179 & 100,0 & 251 & 100,0 & 61 & 100,0 & 173 & 100,0 \\
\hline
\end{tabular}

Anmerkung: Für die Periode vor 1720 mussten einzelne Fälle ausgeschlossen werden, da im 17. Jahrhundert bei einzelnen Transfers die Angabe eines genauen Datums fehlt.

Quelle: SOA Třeboň, fond C Vy̌ší Brod, Pozemkove knihy.

Insgesamt lag die Häufigkeit der Besitzerwechsel in der Pfarre im 17. Jahrhundert zeitweise bei über fünf Prozent jährlich (jeweils im Dekaden-Durchschnitt) ${ }^{87}$ und damit deutlich über den Werten, die einige Autoren als , ungestörte Generationenabfolge" bezeichnet haben. ${ }^{88}$ In den Jahrzehnten zwischen 1710 und 1769 bewegte sich dagegen der Anteil der Besitzwechsel in der Pfarre Kapličky überwiegend um die zwei Prozent pro Jahr und überschritt nie die vier Prozent-Marke. Die Unterschiede zwischen den einzelnen Dörfern waren in diesem Punkt aber nicht

86 Hier ist jedoch zu betonen, dass derartige Angaben in den Grundbüchern wohl zu keiner Zeit vollständig angeführt wurden, da diese Anmerkungen nicht zu den Informationen zählten, die sich zwingend im Grundbuch finden sollten.

87 Berechnet wurde der Anteil der Transfers pro Jahr an der Gesamtzahl aller Anwesen. Die so erzielten Werte sind nicht direkt mit den in der neueren internationalen Literatur zur Geschichte des Bodenmarktes diskutierten, jährlichen Besitzwechselraten`vergleichbar, die den Prozentanteil der jährlich verkauften Fläche in einer Region messen. Vgl. dazu etwa: Bavel van/Hoppenbrouwers, Landholding, $28 \mathrm{ff}$.

88 Schlögl, Krise, 150 f., nahm einen Wert von drei bis vier Prozent jährlich als ,normal' an, da dies einer Generationenabfolge von 30 Jahren entsprechen würde. 
unbeträchtlich. Für einige der beinahe ausschließlich agrarisch geprägten Dörfer, wie Martinkov oder Dobřin, war kaum eine Häufung der Besitzwechsel zu beobachten. Noch deutlich höher als in diesem südböhmischen Gebiet lag mit sieben bzw. sogar 15 Prozent jährlich ${ }^{89}$ die Besitzwechselfrequenz in den Jahren 1656 und 1675 in einigen Dörfern der nordböhmischen Herrschaft Frýdlant.

Um die Mitte des 17. Jahrhunderts waren manche Höfe, wie in den Grundbüchern öfter angemerkt wird, sowohl in Bezug auf die vorhandenen Arbeitsgeräte als auch den baulichen Zustand der Häuser offenbar in einer sehr schlechten Lage, so dass auch aus diesem Grunde keine optimale Wirtschaftsführung gewährleistet war. Bei einzelnen Besitzweitergaben um die Mitte des 17. Jahrhunderts wurde der geringe Kaufpreis explizit damit begründet, dass außer den landwirtschaftlichen Gründen und den Gebäuden nichts vorhanden sei. Gleichzeitig war es offenbar schwer, Kredite zu erhalten. Anders als im 16. Jahrhundert oder in der zweiten Hälfte des 18. Jahrhunderts begegnen in den Grundbüchern kaum nichtverwandte oder auswärtige Gläubiger. ${ }^{90}$ Für untertänige Bauern der benachbarten Herrschaft Český Krumlov sind für das 16. Jahrhundert zum Teil sehr intensive Kreditkontakte nachgewiesen, manchmal auch bis nach Bayern und Oberösterreich. In Einzelfällen erreichten diese Kredite sogar die Höhe des Kaufpreises einiger kleinstädtischer Bürgerhäuser. ${ }^{91}$ Hinter der relativ hohen Besitzmobilität zu dieser Zeit verbarg sich dennoch sicherlich nicht durchgängig ein äußerer Zwang zum Verkauf, sondern auch konkrete individuelle Planung und die Verfolgung bestimmter Strategien..$^{92}$ Die hohe Besitzfluktuation hatte zum Teil wohl auch eine Ursache darin, dass vor allem unmittelbar nach 1648 viele Anwesen relativ günstig zu erwerben waren. Zwar sind Veränderungen im Kaufpreis der einzelnen Häuser aus verschiedenen Gründen schwierig zu interpretieren. Vergleicht man etwa die Kaufpreise von Gütern, die sowohl in den 1640er Jahren als auch in den 1660er verkauft wurden, so fällt auf, dass diese in den 1660er Jahren durchgehend zumeist um etwa 10 bis 20 Prozent niedriger lagen als in den 1640er Jahren..$^{93}$ Andere Studien haben für einige Gebiete in Ostböhmen einen Rückgang des Kaufpreises der Anwesen zu Ende des Dreißigjährigen Krieges um bis zu 50 Prozent nachgewiesen..${ }^{94}$ Auch in Kapličky dürften relativ günstige Kaufpreise eine Begründung

89 Štefanová, Herrschaft und Untertanen, 202.

90 Zur Frage der Verschuldung der Anwesen vgl. Chocholač, Selské peníze, und Štefanová, Zur Stellung der Untertanen.

91 Stejskal, Bauer, 223.

92 Vgl. dazu ausführlich Kapitel 7.9.

93 Als Beleg dafür können etwa die Verkäufe der Häuser Nr. 1, Nr. 3 und Nr. 6 im Pfarrdorf Kapličky in den 1660er Jahren dienen.

94 Vgl. etwa, Lancinger, K otáce studia. 
dafür gewesen sein, dass es für junge Leute, für Inwohner oder für Personen von auswärts relativ leicht möglich war, in den Besitz eines Hauses zu kommen. ${ }^{95} \mathrm{Ge}-$ org und Susanna Wagner beispielsweise wurden in der Bevölkerungszählung des Jahres 1651 als junges Inwohnerpaar im Dorf Martinkov geführt, im Jahre 1654 kauften sie dann ein Anwesen mit geringem Grundbesitz im Dorf Adámky, welches sie bis 1669 inne hatten. Die relativ günstigen Möglichkeiten zum Erwerb eines Hauses drückten sich auch darin aus, dass in den Dörfern der Herrschaft Vyšší Brod im Jahre 1651 mehr als ein Drittel der 20-24-Jährigen bereits Hausinhaber waren.

In der zweiten Periode - nach 1720 - dagegen lag die Besitzdauer in bäuerlichen und unterbäuerlichen Schichten in etwa der Hälfte der Fälle bei über 30 Jahren. Eine Besitzdauer von unter zehn Jahren war nun eher selten geworden, Unterschiede zwischen den Schichten gab es beinahe überhaupt nicht mehr. Die Besitzdauer auf den einzelnen Häusern der Pfarre erhöhte sich im Untersuchungszeitraum deutlich (von durchschnittlich ca. 21 Jahren zwischen 1640 und 1680 auf etwa 27 Jahre zwischen 1681 und 1770). ${ }^{96}$

Der registrierte signifikante Wandel in der Besitzdauer in der untersuchten Pfarre hatte unterschiedliche Ursachen. Er hing sowohl mit Veränderungen in der Lebenserwartung und den äußeren ökonomischen Bedingungen zusammen (siehe dazu die Kapitel 4 und 5.7) als auch mit einem Wandel der Übergabepraktiken. Festzuhalten ist dabei der scheinbar paradoxe Umstand, dass der deutliche Anstieg der durchschnittlichen Besitzdauer trotz offenbar gleichzeitig zunehmender Bedeutung des Rückzugs zu Lebzeiten beider Inhaber (von Mann und Frau) möglich war (siehe Kapitel 9) - Bedingungen, die tendenziell eigentlich eine Verkürzung der Besitzdauer bewirken sollten.

Eine genaue Analyse der Einzelfälle mit einer außergewöhnlich langen Besitzdauer zeigt einschränkend allerdings, dass in manchen Fällen auch die spezifischen Praktiken der Aufzeichnungen in den Grundbüchern zu bedenken sind. In mehreren Fällen war der männliche Inhaber nämlich bereits längere Zeit verstorben, die Witwe führte das Anwesen aber noch einige Zeit weiter, ehe es zu einem neuerlichen Eintrag eines Besitzerwechsels kam. Martin Leitgöb etwa hatte den Hof Krasné Pole Nr. 6 im Jahre 1779 im Alter von 28 Jahren von seinen Eltern gekauft und bewirtschaftete diesem bis zum seinem Tod im Jahre 1821 (im Alter von 70 Jahren), also insgesamt 42 Jahre lang. Nicht 1821, sondern erst $1827 \mathrm{kam}$ es in diesem Fall aber zu einem Eintrag eines neuen Besitzers ins Grundbuch. Seine Witwe Maria hatte den Hof noch so lange weitergeführt, bis das zweitgeborene Kind (der

95 Ein ähnlicher Befund bei Schlögl, Bauern, $102 \mathrm{ff}$.

96 Bei dieser Berechnung wurden nur die 1640 bereits existierenden Häuser berücksichtigt. 
älteste Sohn) Johann 25 Jahre alt geworden war. Die aus den Quelleneinträgen errechnete Besitzdauer beträgt in diesem Fall daher 48 Jahre (1779 bis 1827). Der große Altersabstand zwischen Martin Leitgöb und seinem Sohn Johann erklärt sich wiederum dadurch, dass Martin nicht zum Zeitpunkt der Übernahme 1779, sondern erst im Jänner 1799 geheiratet hatte - erst nach dem Tod seines Vaters $(† 1797)$ und seiner Mutter $(\dagger 1798)$. Er war damit zum Zeitpunkt seiner Eheschließung bereits im 48 sten Lebensjahr. ${ }^{97}$

Bartholomäus Fixl wiederum hatte den Hof Frantoly Nr. 51734 im Alter von nur 23 Jahren von seinem Vater erhalten und leitete diesen 47 Jahre lang. 1781, im Alter von 70 Jahren übergab er den Hof an seinen 33-jährigen Sohn Karl. ${ }^{98}$ Sowohl der zuvor erwähnte Martin Leitgöb als auch Bartholomäus Fixl waren jeweils die jüngsten noch lebenden Söhne ihrer Eltern gewesen; beide hatten - zum Teil jüngere, zum Teil ältere - Schwestern. In diesen Fällen hatte also auch die (in der Region nicht universell gültige) Bevorzugung des jüngsten Kindes in der Besitznachfolge ${ }^{99}$ (verbunden mit einem eher späten Rückzug der Eltern auf das Ausgedinge) die besonders lange Besitzdauer mit verursacht. In ähnlicher Weise wurde für die norddeutsche Pfarre Belm der Anteil von 15 Prozent aller Besitzer, die 40 Jahre oder länger gewirtschaftet hatten, mit dem dort vorherrschenden Minorat in Verbindung gebracht. ${ }^{100}$

7.6 Die Besitznachfolger: Kinder, Verwandte, Fremde?

\subsubsection{Zur Rekonstruktion von Besitzerfolgen und Verwandtschaftsbeziehungen}

Die in dieser Region übliche Regelung des Besitztransfers mittels Kaufvertrag (vgl. Kapitel 7.1) deutet eine strukturelle Ähnlichkeit mit modernen und anonymisierten Bodenmärkten an. Kann in diesem historischen Fall tatsächlich von einem Bodenmarkt gesprochen werden? Welche Bedeutung hatte unter den Bedingungen eines Kaufes die Weitergabe von Land und Anwesen innerhalb der Familie von

97 Quelle: SOA Třeboň, fond C Vyšší Brod, PK č. 475, fol. 38. Nicht wahrscheinlich ist dagegen die Vermutung, dass es sich bei dieser Eheschließung in Wahrheit bereits um seine zweite Ehe handelte, die erste aber nicht verzeichnet worden war. Eine frühere Heirat außerhalb der Pfarre erscheint unplausibel und wäre wohl auch im Kirchenbuch vermerkt worden. Da Martin Leitgöb seit 1779 Inhaber eines Hofes in der Pfarre war, wird er kaum während dieser Zeit für eine längere Periode außerhalb der Pfarre gelebt haben.

98 SOA Třeboň, fond C Vyšší Brod, PK č. 465, fol. 207.

99 Vgl. dazu Kapitel 7.6.

100 Schlumbohm, Lebensläufe, 480. Da für Belm jede Wiederverehelichung als Besitzwechsel gewertet wurde, sind die Werte bezüglich der durchschnittlichen Besitzdauer nicht direkt vergleichbar. 
einer Generation zu nächsten? Lässt sich innerhalb des Untersuchungszeitraumes von etwa 200 Jahren ein Wandel in den diesbezüglichen Praktiken feststellen? Auch wenn es in dieser Region eine Reihe verschiedener Einkommensmöglichkeiten gab, stellte doch Landbesitz - insbesondere bei den größeren Höfen -, wie auch in anderen Regionen, eine der zentralen ökonomischen Ressourcen für das Überleben einer ganzen Gruppe von Personen bereit; entsprechend begehrt waren diese Anwesen wohl. ${ }^{101}$ Wer erhielt durch die jeweilige Nachfolgeregelung Zugang zu diesen Ressourcen und wer verlor gleichzeitig etwaige Ansprüche? Die ökonomische und soziale Bedeutung der Auswahlprozesse und Entscheidungsfindungen, die einem Besitzwechsel vorausgingen, sind dementsprechend hoch einzuschätzen.

Um die Relation der Vorbesitzer zu ihren jeweiligen Nachfolgern darzustellen, wurden aus den Grundbüchern anhand aller während der Untersuchungsperiode verzeichneten Besitzerwechsel der Pfarre Kapličky die Besitzerfolgen der einzelnen Häuser für die Jahre 1639 bis 1840 vollständig rekonstruiert. Mittels nominativer record linkage dieser Quelle mit dem, rodovy katastr' ließen sich danach jeweils die Verwandtschaftsbeziehungen zwischen den Besitzern und ihren Nachfolgern eruieren. Bei der tabellarischen Darstellung der Ergebnisse sind auch die jeweils gerade neu errichteten Anwesen, bei denen es sich nicht um Besitzerwechsel im eigentlichen Sinne handelte, inkludiert. Diese wurden bei der folgenden Analyse der Besitzweitergaben als , neu errichtet' ohne Relation zu einem Vorbesitzer gewertet. ${ }^{102}$

Ziel der Rekonstruktion der Verwandtschaftsverhältnisse war es, einerseits die Bedeutung von Generationenabfolgen und Ressourcentransfers innerhalb der Kernfamilien festzustellen und dabei insbesondere auch die geschlechtsspezifischen Präferenzen (Bevorzugung der Vater-Sohn-Abfolge bis hin zur strikten Befolgung der männlichen Abstammungslinie versus Weitergaben über die Töchter) herauszuarbeiten. Darüber hinaus wurde auch versucht, nahe Verwandtschaftsverhältnisse außerhalb der Eltern-Kind-Gruppe von nicht offensichtlich durch Ver-

101 Vgl. dazu auch die Bemerkungen bei: Trossbach, Haus, 311.

102 Genau betrachtet hatten die Grundstücke, auf denen neue Anwesen errichtet wurden, natürlich auch bereits davor einen Besitzer, entweder die Herrschaft selbst, die Dorfgemeinde oder eine bäuerliche Familie - je nachdem, von welchem Land die neue Parzelle abgetrennt worden war (vgl. dazu Kapitel 3. 4). Zu beachten ist auch, dass die Addition der Zahl der zu Beginn des Untersuchungszeitraumes bestehenden Häuser mit der Zahl der in den folgenden Tabellen als während des Untersuchungszeitraums ,neu errichtet' klassifizierten Einträge in den Grundbüchern nicht völlig identisch ist mit der Summe der zu Ende des Untersuchungszeitraumes bestehenden Häuserzahl, da einzelne der neuen Anwesen im Laufe der Jahrzehnte aus unterschiedlichen Gründen auch wieder verschwanden. 
wandtschaft geprägten Beziehungen zwischen Käufer und Verkäufer analytisch zu unterscheiden. Die Unterscheidung in Verkäufe innerhalb einer näheren Verwandtschaft und in solche außerhalb davon kann einen Hinweis auf die Existenz von Bodenmärkten und auf die Art und Weise geben, wie ökonomische Beziehungen innerhalb der lokalen Gesellschaft wahrgenommen wurden. Dabei wurde die Bipolarität von Markt und Verwandtschaft in der neueren Literatur in Zweifel gezogen. ${ }^{103}$ Die Unterscheidung in ,Familie' einerseits und ,Verwandtschaft ${ }^{\text {' an- }}$ dererseits wiederum ist relevant, da zentraleuropäische Gesellschaften seit dem Hochmittelalter bekanntermaßen überwiegend in Kernfamilien und Zwei- bis Drei-Generationenhaushalten lebten und nicht in größeren Verwandtschaftsgruppen (wie etwa Clans). Eine solche Differenzierung kann daher unterschiedliche Interessen und Strategien der Kleingruppe ,Familie“ wie der Großgruppe ,Verwandtschaft' sichtbar machen. ${ }^{104}$

Die Bedeutung von Verwandtschaft als gesellschaftlicher Strukturierungsfaktor wurde für vormoderne Gesellschaften West- und Mitteleuropas, ähnlich wie für die modernen industriellen Gesellschaften, durch die Forschung lange Zeit als vergleichsweise gering eingestuft. Modernisierungstheoretische Ansätze assoziierten eine von verwandtschaftlichen Bindungen geprägte Gesellschaft überwiegend mit dem Begriff der „Rückständigkeit“. ${ }^{105}$ Für das Verständnis traditionaler außereuropäischer Gesellschaften dagegen wurden Struktur und Funktion der Verwandtschaftssysteme lange Zeit als Basiskategorie der Gesellschaft gedacht. Von Claude Levi-Strauss, im Feld der Verwandtschaftssoziologie international mit Sicherheit einer der bedeutendsten Anthropologen, ist die Äußerung überliefert, dass ,in archaischen Gesellschaften die sozialen und politischen Aktivitäten in der ,Kloake der Verwandtschaft" verborgen seien“" ${ }^{106}$ Nachdem in den 1970er und 1980er Jahren interessanterweise verwandtschaftsstrukturelle Studien innerhalb der Sozialanthropologie immer stärker kritisiert und abgelehnt wurden, erlebte eine neue Art von Verwandtschaftsstudien in den 1990er Jahren einen bedeutenden Aufschwung. ${ }^{107}$ Diese Studien fragten nun nicht mehr nach den formalen Bedeutun-

103 Vgl. Cerman, Bodenmärkte, bes. 148; Rouette, Erbrecht, $160 f$.

104 Dies ist auch kritisch gegenüber Studien einzuwenden, die Besitzweitergaben nur in den Kategorien, verwandt' bzw. ,nicht-verwandt' differenziert analysieren und auf eine separate Betrachtung der Eltern-Kind-Gruppe weitgehend verzichten. Siehe etwa Štefanová, Zur Stellung der Untertanen.

105 Vgl. dazu die Bemerkungen bei: Schnyder, Alltag, $79 \mathrm{ff}$.

106 Zit. nach: Sabean, Kinship, 3.

107 In dieser Zeit einer deutlichen Abkehr von Studien zur Verwandtschaft gingen einzelne Sozialanthropologen, die selbst jahrzehntelang Verwandtschaftsstudien durchgeführt hatten, sogar so weit, die Existenz von Verwandtschaft in jeglicher menschlichen Kultur generell zu leugnen. Vgl. dazu den informativen Überblick bei: Schweitzer, Introduction. 
gen, sondern vielmehr nach der sozialen Funktion von Verwandtschaft. Getragen wurde dieser neue Trend nicht nur von Anthropologen, sondern zum Teil auch von Sozialhistorikern (wie etwa David Sabean).

Unter HistorikerInnen ist in den letzten Jahren die Gleichsetzung von Verwandtschaft mit traditionalen, vormodernen Gesellschaften deutlich ins Wanken geraten. ${ }^{108}$ Gerade das beginnende industrielle Zeitalter im 19. Jahrhundert erscheint nun in einigen sozialen Bereichen durch eine zunehmende Bedeutung von Verwandtschaftsbindungen charakterisierbar. ${ }^{109}$ Die lange zu geringe Beachtung verwandtschaftlicher Bindungen im frühneuzeitlichen West- und Mitteleuropa durch die SozialhistorikerInnen hatte auch mit der Dominanz der quantifizierenden Historischen Familien- und Haushaltsforschung seit den 1960er Jahren zu tun, die beinahe ausschließlich auf Basis von Haushaltslisten arbeitete und vor allem an der Größe und Struktur der Haushalte und Familien interessiert war. ${ }^{110}$ Wie insbesondere von auch historisch arbeitenden Sozialanthropologen kritisiert wurde, haben die SozialhistorikerInnen in ihrem Fokus auf das Haus und den Haushalt als ökonomische und soziale Einheit die Beziehungen, die zwischen den untersuchten Haushalten bestanden (etwa über verwandtschaftliche Verbindungen) weitgehend ignoriert. ${ }^{111}$ Die neuere sozialanthropologisch inspirierte sozialhistorische Forschung sieht, Verwandtschaft' freilich weder auf die ideologisch verbrämte patrilineare Abstammungslinie verkürzt, noch als ahistorische gesellschaftliche Konstante. Von Außenstehenden rekonstruierbar sind zunächst bloß genealogische Verbindungen zwischen Menschen, diese können nicht a priori mit verwandtschaftlichen gleichgesetzt werden. Ob genealogische Verbindungen auch verwandtschaftliche Rollen produzierten, ob und welche soziale Bedeutung diese Verbindung hatte, oder ob die genealogisch rekonstruierte Gruppe nur ein hypothetisches Konstrukt des Genealogen bildet, gilt es erst herauszufinden. ${ }^{112} \mathrm{Zu}$ fragen ist daher, wie die Individuen und Familien von Verwandtschaft Gebrauch

108 Vgl. dazu den Band Lanzinger/Saurer, Politiken.

109 Sabean hat das 19. Jahrhundert für Mitteleuropa als eine Blütezeit des Heiratens unter Verwandten bezeichnet. Vgl. Sabean, Heiratsallianzen158. Vgl. zur zunehmenden Bedeutung des Zusammenlebens im 19. Jahrhundert von Verwandten auch: Schlumbohm, Lebensläufe, 168.

$110 \mathrm{Zu}$ nennen sind in diesem Zusammenhang vor allem die Arbeiten der sogenannten Cambridge Group um Peter Laslett. Siehe z.B.: Laslett/Wall, Household; Wall/Robin/Laslett, Family forms.

111 Vgl. dazu: Reay, Kinship 89; Seiser, On the Importance of being the last one. Vgl. bereits die kritische Auseinandersetzung bei: Trossbach, Bauern, bes. 92 ff.; Ders., Ganzes Haus, bes. 309.

112 Plakans, Kinship, 76f., 90f., 190. Die jeweiligen Dorfbewohner der Vergangenheit oder der Gegenwart selbst hatten in der Regel ein anderes Verwandtschafts-System als die sie analysierenden Sozialwissenschaftler oder Genealogen. Vgl. Faragó, Kinship, 316. 
machten. ${ }^{113}$ So wurden etwa in christlich geprägten Kulturen die durch Heirat konstituierten Affinalverwandtschaften mit ähnlichen Heiratsverboten wie eine Blutsverwandtschaft belegt. ${ }^{114}$ In welchem Maße Formen fiktiver Verwandtschaft, wie Patenschaft, etc., oder in manchen Kulturen auch Verwandtschaftsbindungen zu mythischen Vorfahren von Bedeutung waren, variierte räumlich und zeitlich in erheblichem Maße.

In dieser Arbeit wird die Bedeutung von Verwandtschaftsrollen mit Hilfe einer Familienrekonstitution auf Basis der Analyse genealogischer Beziehungen untersucht. In der sozialhistorischen Forschung der letzten Jahrzehnte über die vorindustriellen Gesellschaften Europas wurden verwandtschaftliche Beziehungen zwischen Menschen manchmal auch auf der Basis von Personenstandslisten behauptet oder beruhten überhaupt nur auf Vermutungen aufgrund der Namensgleichheit zweier Personen. Letzteres Verfahren kann „systematisch in die Irre“ führen, wie bereits Jürgen Schlumbohm gewarnt hat. ${ }^{115}$ Auch an englischen Beispielen des Spätmittelalters und der frühen Neuzeit wurde gezeigt, dass ein bloßer Abgleich der Familiennamen von Vorbesitzer und Nachfolger zu einer sehr deutlichen Unterschätzung der Besitzweitergabe innerhalb der Verwandtschaft führen kann. Sreenivasan demonstrierte anhand zahlreicher Beispiele, dass sich auch hinter Besitztransfers zwischen nicht-namensgleichen Personen fast immer - wenn auch häufig entfernte - Verwandtschaftsverhältnisse verbargen. ${ }^{116}$

In methodischer Hinsicht ist auch anzumerken, dass in der vorliegenden Studie nur die in den Grundbüchern verzeichneten Ereignisse analysiert wurden. Etwaige personelle Änderungen auf den Anwesen, die nicht zu einem Eintrag im Grundbuch führten, konnten nicht berücksichtigt werden. Dies bedeutet konkret, dass sämtliche Weitergaben von Haus und Land durch die Wiederverehelichung einer Witwe einen eigenen Fall darstellen, die Wiederverehelichungen verwitweter männlicher Hausbesitzer dagegen nicht! Nur die erste Konstellation fand einen Niederschlag in den Grundbüchern, die zweite dagegen nicht. Den zeitgenössischen patriarchalen Auffassungen folgend wurde bis ins frühe 19. Jahrhundert trotz der regional offenbar bereits davor verbreiteten ehelichen Gütergemeinschaft - jeweils nur der Mann ins Grundbuch eingetragen. Da bis Ende des 18. Jahrhunderts nur Männer ein Anwesen besitzen konnten, hatte sich im Falle der Zweitheirat des Mannes für das zeitgenössische Verständnis nichts verändert; bei der

113 Medick/Sabean, Emotionen, 49.

114 Zwischen affinal verwandten Personen galt in Mitteleuropa ein kirchliches Heiratsverbot bis zum dritten Grad. Vgl. Theibault, German Villages, 90.

115 Schlumbohm, Lebensläufe, 281.

116 Sreenivasan, Land-family bond, $14 f$. 
Wiederverehelichung einer Witwe dagegen wurde in der Regel nicht sie, sondern ihr zweiter Mann als Besitzer im Grundbuch verzeichnet. ${ }^{117}$

\subsubsection{Empirische Ergebnisse: zunehmende land-family bond}

Tabelle 29 verdeutlicht zunächst die große Vielfalt der Lösungen in der Nachfolgeregelung. Zu keiner Zeit stellte die Weitergabe von Haus und Land ausschließlich eine Angelegenheit innerhalb der Eltern-Kind-Gruppe dar. Entfernter verwandte Personen oder in keinem verwandtschaftlichen Verhältnis zum Vorbesitzerpaar stehende Personen kamen während des gesamten Untersuchungszeitraums als Besitznachfolger vor. Die in der Tabelle unter ,Keine Relation/Unbekannt' firmierenden Käufer sind als ,nicht verwandt' einzustufen bzw. lässt sich aus unterschiedlichen Gründen kein Verwandtschaftsverhältnis nachweisen. ${ }^{118}$

Wie die Tabelle 29 aber auch anzeigt, vollzog sich während des Untersuchungszeittraums ein nicht unbedeutender Wandel. War in der Periode vor 1720 die Bindung der Familien an ihr Land in dieser Pfarre kaum ausgeprägt, so war diese Bindung in der zweiten Periode deutlich stärker. Seit dem Ende des 17. Jahrhunderts änderten sich einige Rahmenbedingungen der Besitzweitergabe allmählich. Die ökonomische Situation der Anwesen hatte sich deutlich stabilisiert. Langsam bildete sich als dominantes Muster die Weitergabe an die eigenen Kinder heraus. Zwischen 1721 und 1840 erfolgten mehr als zwei Drittel aller Übergaben in direkter Linie von den Eltern an die Kinder. Insbesondere der Anteil der Besitztransfers vom Vater auf den Sohn stieg im Untersuchungszeitraum kontinuierlich an, bis er während der ersten Hälfte des 19. Jahrhunderts (1800-1840) beinahe drei Viertel aller Fälle ausmachte (Tabelle 30). Es kam also insbesondere zu einer Stärkung der männlichen Primogenitur. Zahlreiche Anwesen wurden ab dem 18. Jahrhundert über mehrere Generationen immer vom Vater an den Sohn weiterge-

117 Diese Anmerkung ist auch für die Vergleichbarkeit der hier erzielten Ergebnisse wichtig, da manche Autoren nämlich entweder die Wiederverehelichung verwitweter Hausbesitzerinnen mit dem Argument wegließen, dass dies keinen vollständigen Generationenwechsel darstelle (vgl. Schlögl, Bauern, 100). Andere Autoren wiederum haben aufgrund der Verwendung anderer Quellen grundsätzlich alle Wiederverehelichungen (auch die der männlichen Besitzer) als Besitzwechsel gewertet. Siehe: Schlumbohm, Lebensläufe.

118 Die in der vorliegenden Studie durchgeführte Rekonstruktion verwandtschaftlicher Verbindungen unterliegt zwangsweise mehreren Begrenzungen: erstens konnten quellenbedingt durch den Fokus auf eine kleine lokale Untersuchungseinheit nur verwandtschaftliche Netze innerhalb des Pfarrgebiets rekonstruiert werden, wie dies überwiegend auch bei allen anderen auf lokalen Kirchenbüchern beruhenden internationalen Studien der Fall ist. Zweitens beschränkte sich die Rekonstruktion der Verwandtschaftsverhältnisse auf die engeren Verwandtschaftsgrade. Siehe genauer Kapitel 2.2.1. 
geben. Obwohl die land-family bond deutlich stärker wurde, wurde in Kapličky die Besitznachfolge nie zu einer ausschließlich innerfamilialen Angelegenheit, andere Lösungen der Besitzweitergabe blieben immer möglich. Zwischen 1651 und 1720 dagegen erfolgte etwa die Hälfte aller Besitztransfers zwischen nicht verwandten oder nur entfernt verwandten Personen, nur in etwa 40 Prozent der Fälle wurde an die eigenen Kinder verkauft. Der Verkauf des Anwesens an Familienfremde war in der ersten Periode häufig, und zwar auch dann, wenn eigene Kinder vorhanden waren. Witwen warteten etwa die Volljährigkeit eines minderjährigen Kindes nicht ab und verehelichten sich nochmals, wodurch die Ansprüche des Kindes aus erster Ehe auf das Haus verloren gingen. Es war in der Folge gezwungen, dieses zu verlassen. In zahlreichen Fällen wurden auch die Schwiegersöhne oder entfernte Verwandte den eigenen Söhnen als Nachfolger vorgezogen. Während der zweiten Hälfte des 17. Jahrhunderts bestand zwischen den Hausbesitzern eine hohe Fluktuation, sowohl Land besitzende Familien als auch landarme wechselten öfter mittels Kauf und Verkauf ihre Besitzungen innerhalb der untersuchten Pfarre von einem Anwesen zum nächsten (vgl. dazu Kapitel 7.5).

Tabelle 29: Verwandtschaftsbeziehungen in der Besitznachfolge, Pfarre Kapličky $1651-1840$

\begin{tabular}{lrrrr}
\hline & \multicolumn{2}{c}{$1651-1720$} & \multicolumn{2}{c}{$1721-1840$} \\
Stellung zum Vorbesitzer & $\mathrm{N}$ & $\%$ & $\mathrm{~N}$ & \multicolumn{1}{c}{$\%$} \\
\hline Sohn & 82 & 30,15 & 257 & 57,49 \\
Schwiegersohn & 35 & 12,87 & 38 & 8,50 \\
Bruder & 4 & 1,47 & 4 & 0,89 \\
Witwenheirat & 35 & 12,87 & 41 & 9,17 \\
Stiefsohn & - & - & 19 & 4,26 \\
Witwe & 4 & 1,47 & 5 & 1,11 \\
Tochter & - & - & 3 & 0,67 \\
Andere Verwandte* & 10 & 3,69 & 5 & 1,11 \\
Neu errichtet & 25 & 9,19 & 20 & 4,47 \\
Keine Relation/unbekannt & 77 & 28,31 & 55 & 12,30 \\
\hline Summe & 272 & 100,00 & 447 & 100,00 \\
\hline
\end{tabular}

* Geschwister, Kinder der Geschwister, Enkelkinder, angeheiratete Verwandte, etc.

Quelle: Datenverknüpfung Grundbücher und Familienrekonstitution (Státní oblastní archiv Třeboň, Sbírka jihočeskych matrik, Farní úřad Kapličky č. 9; fond C Vyšší Brod, Pozemková kniha č. 453, č. 464, č. 465 č. 465 , č. 475 , č. 479 , č. 480 und č. 553$)$. 
Differenziert man die Weitergabe der Besitzungen danach, ob es sich um bäuerliche oder landarme Anwesen handelte (Tabelle 31), so zeigen sich nur relativ geringe Unterschiede zwischen diesen beiden Gruppen. Es erscheint bemerkenswert, dass das Merkmal einer häufigen Weitergabe innerhalb der Familie in der zweiten Periode (1721-1840) auf die unterbäuerlichen Häuser im selben Maße wie auf die bäuerlichen zutraf. Besitzstabilität und familiale Kontinuität waren bei den landarmen (und landlosen) Häusern dieser Region deutlich höher ausgeprägt als in zahlreichen anderen Regionen. ${ }^{119}$ In manchen anderen europäischen Gebieten galt dagegen: je größer der Hof, desto eher wurde innerhalb der Familie übergeben; je kleiner, desto eher wurde auf dem ,Markt' verkauft. ${ }^{120}$ Auch M. Mitterauers Arbeiten über den österreichischen Raum haben nachgewiesen, dass landlose Hausbesitzer in weit geringerem Maße intergenerationelle Besitzkontinuitäten entwickelten. ${ }^{121}$ Für Kapličky traf dies nicht zu. Zwar übergaben Bauern ihre Anwesen hier in beiden Perioden etwas häufiger an ihre eigenen Kinder als die landarmen, die Anteile der Nicht-Verwandten unter den Besitznachfolgern unterschieden sich aber kaum. Im 18. und frühen 19. Jahrhundert blieben zahlreiche Kleinhäuser der Pfarre über Generationen hinweg innerhalb derselben Familie. Die wenigen Häuser, die bloß unter den rechtlichen Bedingungen einer Leiberpacht vergeben worden waren und denen deshalb ausschließlich die innerfamiliale Weitergabe erlaubt war, beeinflussen aufgrund ihrer geringen Anzahl dieses Ergebnis nicht in signifikanter Weise. ${ }^{122}$ Die Stabilität der landarmen Häuser der Region gründete sich vielmehr darauf, dass überhaupt ein relevanter Besitz vorhanden war, der weitergegeben werden konnte, und hatte insbesondere mit der ,Landanbindung' dieser Anwesen etwa durch von der Herrschaft gepachtete Wiesen zu tun. Dadurch verfügten selbst landlose Häuser über ein agrarisches Standbein und konnten in der Regel zumindest eine Kuh halten (vgl. genauer Kapitel 5.6). Landbesitz und stabile Einkommensverhältnisse können allgemein als Vorbedingung innerfamilialer Kontinuität bei unterbäuerlichen Anwesen angesehen werden. ${ }^{123}$ Für andere Regionen Böhmens, in denen - wie in der Herrschaft Frýdlant - die unterbäuerlichen Gruppen weitgehend losgelöst vom agrarischen Kontext waren, wurde eine deutlich höhere Besitzfluktuation beobachtet. ${ }^{124}$

119 Vgl. etwa Sieder /Mitterauer, Reconstruction, 312.

$120 \mathrm{Vgl}$. Stone/Stone, Country houses 86f.

121 Vgl. etwa Sieder/Mitterauer, Reconstruction, 312; Mitterauer, Auswirkungen, 88. Ähnliche Verhältnisse wie in Kapličky schildert dagegen Schöne, Kultur, 45 ff., $85 f$.

122 Alle von diesen insgesamt sechs Häusern wurden entweder nach wenigen Jahrzehnten nicht mehr bewohnt oder erhielten im Laufe der Zeit emphyteutisches Besitzrecht. Die Gesamtzahl der Besitztransfers unter den Bedingungen der Leiberpacht ist daher nur gering.

$123 \mathrm{Vgl}$. Ehmer, Sozialgeschichte, $32 \mathrm{ff}$.

124 Vgl. Štefanová/Zeitlhofer, Alter, bes. 238. 
Tabelle 30: Verwandtschaftsbeziehungen in der Besitznachfolge im zeitlichen Wandel, Pfarre Kapličky 1651-1840

\begin{tabular}{lrrrrrrrr}
\hline Stellung zum & \multicolumn{2}{c}{$1651-1700$} & \multicolumn{2}{c}{$1701-1750$} & \multicolumn{2}{c}{$1751-1800$} & \multicolumn{2}{c}{$1801-1840$} \\
Vorbesitzer & \multicolumn{1}{c}{ N } & \multicolumn{1}{c}{$\%$} & \multicolumn{1}{c}{ N } & $\%$ & N & $\%$ & N & $\%$ \\
\hline Sohn & 62 & 31,5 & 83 & 42,4 & 95 & 50,0 & 99 & 72,8 \\
Schwiegersohn & 23 & 11,7 & 23 & 11,7 & 20 & 10,5 & 7 & 5,2 \\
Witwenheirat & 25 & 12,7 & 20 & 10,2 & 25 & 13,2 & 6 & 4,4 \\
Stiefsohn & 0 & 0,0 & 6 & 3,1 & 11 & 5,8 & 2 & 1,5 \\
Neu errichtet & 22 & 11,2 & 5 & 2,6 & 14 & 7,4 & 4 & 2,9 \\
Andere Verwandte* & 10 & 5,1 & 17 & 8,6 & 7 & 3,5 & 2 & 1,5 \\
Keine Relation/ & & & & & & & & \\
unbekannt & 55 & 27,9 & 42 & 21,4 & 18 & 9,5 & 16 & 11,8 \\
\hline Summe & 197 & 100,0 & 196 & 100,0 & 190 & 100,0 & 136 & 100,0 \\
\hline
\end{tabular}

* Geschwister, Kinder der Geschwister, Enkelkinder, angeheiratete Verwandte, etc.

Quelle: Datenverknüpfung Grundbücher und Familienrekonstitution (Státní oblastní archiv Třeboň, Sbírka jihočeskych matrik, Farní úřad Kapličky č. 9; fond C Vyšší Brod, Pozemková kniha č. 453, č. 464, č. 465 č. 465 , č. 475 , č. 479 , č. 480 und č. 553).

Tabelle 31: Verwandtschaftsbeziehungen in der Besitznachfolge nach sozialer Differenzierung, Pfarre Kapličky 1651-1840

\begin{tabular}{|c|c|c|c|c|c|c|c|c|}
\hline \multirow{3}{*}{$\begin{array}{l}\text { Stellung zum } \\
\text { Vorbesitzer }\end{array}$} & \multicolumn{4}{|c|}{ Bauern } & \multicolumn{4}{|c|}{ Landarme } \\
\hline & \multicolumn{2}{|c|}{$1651-1720$} & \multicolumn{2}{|c|}{$1721-1840$} & \multicolumn{2}{|c|}{$1651-1720$} & \multicolumn{2}{|c|}{$1721-1840$} \\
\hline & $\mathrm{N}$ & $\%$ & $\mathrm{~N}$ & $\%$ & $\mathrm{~N}$ & $\%$ & $\mathrm{~N}$ & $\%$ \\
\hline Sohn & 67 & 36,4 & 162 & 64,5 & 15 & 23,8 & 95 & 54,0 \\
\hline Schwiegersohn & 23 & 12,5 & 17 & 6,8 & 12 & 19,0 & 21 & 11,9 \\
\hline Witwenheirat & 24 & 13,0 & 23 & 9,2 & 11 & 17,5 & 18 & 10,2 \\
\hline Stiefsohn & 0 & 0,0 & 14 & 5,6 & 0 & 0,0 & 5 & 2,8 \\
\hline Andere Verw. & 14 & 7,6 & 10 & 4,0 & 4 & 6,4 & 8 & 4,7 \\
\hline $\begin{array}{l}\text { Keine Relation/ } \\
\text { unbekannt }\end{array}$ & 56 & 30,4 & 25 & 10,0 & 21 & 33,3 & 29 & 16,5 \\
\hline Summe & 184 & 100,0 & 251 & 100,0 & 63 & 100,0 & 176 & 100,0 \\
\hline
\end{tabular}

Quelle: Státní oblastní archiv Třeboň, Sbírka jihočeskych matrik, Farní úřad Kapličky č. 9; fond C Vyšší Brod, Pozemková kniha č. 453, č. 464, č. 465 č. 465, č. 475, č. 479 , č. 480 und č. 553.

Wie die Tabellen 29 bis 31 zeigen, lassen sich für das Untersuchungsgebiet im Zeitverlauf deutliche Veränderungen in den Besitztransfermustern feststellen. Wie noch näher zu erläutern sein wird, erscheint es sinnvoll, eine Zäsur in den Jahren 
um etwa 1720 anzusetzen. In dieser Zeit kam es in mehrfacher Hinsicht zu einigen Veränderungen bei der Weitergabe von Land und Haus. Zwischen 1651 und 1720 erfolgte in der Pfarre etwa die Hälfte aller Besitztransfers zwischen nicht verwandten oder nur entfernt verwandten Personen, nur in etwas mehr als 40 Prozent der Fälle wurde an die eigenen Kinder übergeben. In der zweiten Phase nach 1720 hatte sich vor allem die Häufigkeit der Weitergabe an die eigenen Kinder deutlich erhöht, in etwa drei von vier Fällen blieb der Besitz innerhalb der Verwandtschaft.

Im 17. Jahrhundert war die innerfamiliale Weitergabe der Besitzungen in der Pfarre Kapličky relativ selten und kann für diese Zeit nicht als typisch angesehen werden. Unter den Bedingungen einer relativ hohen Besitzmobilität war ein sozialer Auf- und Abstieg und der Verkauf des Hauses an Fremde keine Seltenheit. Manche Besitzer verkauften, zum Teil aus Verschuldung, ihr Anwesen und kauften sich dafür ein anderes in der Pfarre - einige blieben danach auch im Inwohnerstand (vgl. dazu genauer Kapitel 8.7). Möglicherweise wurde zu dieser Zeit in einigen Fällen auch die ökonomisch eher unsichere Existenz als Inwohner und Tagelöhner der Bewirtschaftung eines nur wenig rentablen Hofes vorgezogen. Freilich muss in dieser Hinsicht sicherlich zwischen den relativ gut situierten Höfen, die weiterhin begehrt waren, und ,abgewirtschafteten' Höfen deutlich unterschieden werden. ${ }^{125}$ Jedenfalls schuf die ökonomische und demographische Instabilität dieser Zeit zwangsweise einen Häuser- und Boden-,markt', der nicht ausschließlich durch verwandtschaftliche Netze bestimmt wurde.

Während der Untersuchungsperiode lässt sich somit für Kapličky eine sehr deutliche Zunahme der Bindung der Familien an ihr Land feststellen. ${ }^{126}$ Der Besitztransfer an die eigenen Söhne wurde immer häufiger, bis er im beginnenden 19 . Jahrhundert schließlich beinahe drei Viertel aller Fälle umfasste. Zahlreiche Häuser blieben nunmehr über viele Generationen hinweg innerhalb derselben Familie. Dass die Stabilität der Familien - auch der bäuerlichen - auf ihren Anwesen einem zeitlichen Wandel unterliegen konnte, wurde bisher kaum gesehen. Im deutschsprachigen Raum wird zumeist unhinterfragt eine starke Orts- und Hausgebundenheit der Grund besitzenden Bevölkerung angenommen. Anders in England: hier gab es eine Diskussion über das Ausmaß der Bindung der Familien an ihr Land, die so genannte land-family bond. Ausgelöst durch die Thesen Alan Macfarlanes ${ }^{127}$ über den Kontrast zwischen einer angeblich stark individualistischen Gesellschaft Eng-

125 Solche den gängigen Vorstellungen sozialer Schichtung deutlich widersprechende Beispiele schildert anschaulich Christiansen, Hofübernahme.

126 Vgl. zum Folgenden auch den deutlich kürzeren Abschnitt in meinem Aufsatz: Zeitlhofer, Besitztransfer.

127 Macfarlane, Origins. 
lands und den peasant societies auf dem Kontinent mit über die Generationen an ihr Land gebundenen Bauern wurde von einigen seiner Kritiker festgestellt, dass auch in England während der frühen Neuzeit das Band zwischen den Familien und deren Land weit stärker war als von McFarlane behauptet. ${ }^{128}$ Jürgen Schlumbohm, der diese Diskussion über die land-family bond aufgriff, kam für eine deutsche Region zu dem Schluss, dass es für die Bauern, obwohl sie sehr häufig das Land der Eltern oder Vorfahren bewirtschafteten, nicht in jeder Situation oberste Priorität war, das ererbte Land innerhalb der Familie zu halten. ${ }^{129}$

Gründe für die Zunahme der land-family bond in Kapličky sind nicht so einfach zu benennen. Keineswegs darf die zweite Hälfte des 17. Jahrhunderts vorschnell als atypische Phase, etwa aufgrund der Auswirkungen des Dreißigjährigen Krieges, gesehen werden. Diese waren in der Region vergleichsweise marginal, es gab zu Ende des Krieges kaum verödete Häuser (vgl. Kapitel 3). Eher hatte die im 17. Jahrhundert geringe Bindung der Familien an ihr Haus eine weiter zurückreichende Tradition. Betrachtet man etwa nur die Abfolge der Familiennamen der Besitzer der Anwesen im ältesten Grundbuch der Pfarre aus dem späten 16. Jahrhundert, so deutet dies zumindest nicht auf besonders viele Übergaben vom Vater an den Sohn hin. ${ }^{130}$

Der beschriebene Wandel in den Praktiken der Besitzweitergabe ergab sich trotz zahlreicher konstanter struktureller Bedingungen, so blieben etwa die günstigen Besitzrechte der Untertanen auch unter den Bedingungen einer „verschärften Erbuntertänigkeit" unangetastet (vgl. Kapitel 6.3). ${ }^{131}$ Die innerfamiliale Besitzkontinuität wurde auch aus demographischen Gründen leichter möglich. Das durchschnittliche Sterbealter der im 18. Jahrhundert Geborenen lag deutlich über dem der während der zweiten Hälfte des 17. Jahrhunderts Geborenen. ${ }^{132}$ Bei den Männern hatten die Geburtsjahrgänge 1731-1770 ein um etwa vier Jahre höheres Sterbealter als die Geburtsjahrgänge 1651-1690, bei den Frauen betrug

128 Vgl. Sreenivasan, Land-family bond, bes. 9f; Razi, Myth; Mitson, Significance, bes. 71f.

129 Schlumbohm, Land-family bond.

130 SOA Třeboň, fond C Vyšší Brod, PK č. 445. Eine genaue Auswertung dieser Quelle ist in mehrfacher Hinsicht erschwert: erstens fehlen in dieser Periode noch die Kirchenbücher, zweitens sind viele Hausbesitzer bloß mit dem Vornamen im Grundbuch eingetragen, so dass in einigen Fällen selbst die Möglichkeit eines Vergleichs des Familiennamens des Vorbesitzers und dessen Nachfolger unterbleiben muss. In den Fällen, in denen Familiennamen genannt sind, fällt jedenfalls auf, dass Käufer und Verkäufer der Anwesen großteils unterschiedliche Familiennamen aufweisen, es sich also wohl nicht um eine Übergabe vom Vater an den Sohn handelte.

131 Für manche Regionen Böhmens findet sich zur Mitte des 17. Jahrhunderts vorübergehend eine gegenteilige Entwicklung. Vgl. Maur, Erbrecht, 97.

132 In die Berechnung einbezogen wurden jeweils nur Personen, die das 15. Lebensjahr erreicht hatten. 
der Anstieg ein Jahr (vgl. dazu Kapitel 5.7). Dieselbe Tendenz einer deutlichen ,demographischen Alterung' der untersuchten Gesellschaft während des Beobachtungszeitraumes zeigt die Analyse der erhalten gebliebenen Bevölkerungsverzeichnisse (vgl. auch Kapitel 3.1): während für viele südböhmische Gebiete des 16. und 17. Jahrhunderts von einem im internationalen Vergleich auffällig geringen Anteil höherer Altersgruppen auszugehen ist, hatten sich diese Anteile bis zum späten 18. Jahrhundert deutlich erhöht. Im Jahre 1651 waren weniger als zwei Prozent der dörflichen Bevölkerung der Herrschaft Vyšší Brod älter als 60 Jahre. ${ }^{133} \mathrm{Im}$ zur selben Herrschaft gehörigen, benachbarten Gericht Studánky ist dagegen für das Jahr 1798 ein Anteil der Personen über 60 Jahre an der Bevölkerung von 13, 9 Prozent nachweisbar. ${ }^{134}$ Dieser demographische Wandel brachte es unter anderem mit sich, dass zu Ende des 18. Jahrhunderts der plötzliche Tod der Hausinhaber seltener als zuvor eine frühzeitige Neuregelung der Besitzverhältnisse erzwang.

Der Wandel hin zu einer Präferenz familialer Besitzkontinuitäten muss auch als Antwort auf sich wandelnde Rahmenbedingungen gesehen werden. Demographischer Wandel und ökonomische Stabilisierung führten beide zu einer Reduktion der Zahl an jährlichen Transaktionen im Laufe des 18. Jahrhunderts. Die nur in begrenzter Anzahl in der Pfarre existierenden, agrarischen Einheiten' waren aber begehrter geworden. Auch ein vergleichsweise kleiner landwirtschaftlicher Betrieb bot, wenn gut geführt, die attraktive Perspektive einer langfristig relativ sicheren ökonomischen Basis - und sei es auch nur als eine langfristige Teilabsicherung, die permanent einen Zuverdienst erforderte. Gerade die zunehmende Begrenzung der verfügbaren $Z a h l$ an solchen erwerbbaren Häusern führte wohl zu sozialen Abschottungstendenzen der bäuerlichen Besitzer, was wiederum zur Folge hatte, dass derartige Anwesen nur mehr selten aufgegeben wurden und damit auch kaum mehr außerhalb der familialen Netze erwerbbar waren.

Darüber hinaus bot der familiale Transfer auch in ökonomischer Hinsicht einige Vorteile gegenüber dem Erwerb eines Anwesens auf dem Markt. Blieb etwa der im Besitz nachfolgende Sohn permanent als Arbeitskraft im Haus, so war dies für den Betrieb billiger als eine familienfremde Arbeitskraft, da dessen Arbeit mit zukünftigen Ansprüchen abgegolten wurde. Auch konnte die als Jugendlicher am elterlichen Hof erworbene genaue Kenntnis der spezifischen Bedingungen im elterlichen Besitz (von der Bodenqualität der einzelnen Felder über detaillierte Erfahrungswerte im Gedeihen bestimmter Kulturpflanzen auf einem bestimmten

133 Unterdurchschnittlich geringe Altenanteile in südböhmischen Gebieten des späten 16. Jahrhunderts sind dokumentiert bei Grulich/Zeitlhofer, Lebensformen, 44.

134 Archiv Klaštera Vyšší Brod, kniha č. 225. 
Hang bis hin zu den erworbenen sozialen Kompetenzen in der in dieser Region im Jahresrhythmus gar nicht so selten notwendigen Kooperation mit den Nachbarn) von gravierender ökonomischer Bedeutung sein. ${ }^{135}$ Geringere Bedeutung dürfte dagegen eine ,familiale Ideologie' innegehabt haben, die sich in der Hochbewertung einer langen Abfolge möglichst vieler Generationen im Besitz als Quelle von Ansehen und Prestige äußerte. Diese verbreitete sich, ausgehend vom Adel, seit dem 18. Jahrhundert langsam, dürfte sich aber, wenn überhaupt, im bäuerlichen Milieu der meisten zentraleuropäischen Regionen jedoch erst im späten 19. und frühen 20. Jahrhundert allmählich als Leitmotiv durchgesetzt haben. ${ }^{136}$

\subsubsection{Geschlecht und Geburtsrang der Nachfolger}

In den Fällen einer Weitergabe von Anwesen an die eigenen Kinder lassen sich einige Kriterien unterscheiden, die die Wahrscheinlichkeit, die Besitznachfolge anzutreten, erhöhten oder aber deutlich verschlechterten. Dazu ist etwa das Geschlecht des Kindes zu zählen. Grundsätzlich wurden in der Pfarre Söhne beim Besitztransfer gegenüber Töchtern bevorzugt. Dieses Merkmal erweist sich aber weder als im Zeitverlauf konstant, noch war es bei allen Häusern der Pfarre gleich stark ausgeprägt. War während der zweiten Hälfte des 17. Jahrhunderts eines von vier der zur Besitznachfolge ausgewählten Kinder eine Tochter, so hatte sich dieses Verhältnis zu Beginn des 19. Jahrhunderts mit eins zu zwölf deutlich zugunsten der Söhne verschoben (vgl. die Tabellen 29 - 31). ${ }^{137}$ Bei den Bauern ist bereits im 17. Jahrhundert eine klare Bevorzugung der Söhne zu erkennen, bei den landarmen Häusern dagegen kaum. Dass bei Kleinhäuslern der Besitz häufiger über die Töchter weiterging, ist auch aus anderen Regionen bekannt. ${ }^{138}$ Allerdings gab es auch bäuerliche Anwesen, bei denen die Weitergabe an die Schwiegersöhne eine sehr große Rolle spielte. Der Hof Hodoň Nr. 4 wurde zwischen 1683 und 1733 stets - d. h. dreimal in Folge - an die Tochter und den Schwiegersohn übertragen (wobei nur beim ersten Mal gesichert ist, dass kein Sohn vorhanden war). Im Jahre 1775 wurde das Haus zum ersten Mal seit dem späten 16. Jahrhundert direkt von einem Vater an seinen Sohn weitergegeben, was danach allerdings bis zur Mitte des 19. Jahrhunderts durchgängig der Fall war.

135 Vgl. die ähnlichen Überlegungen bei: Kennedy, Farm Succession, $494 \mathrm{f}$.

136 Vgl. dazu: Ehmer, Generationen, 63, 69.

137 Eine ähnliche Entwicklung hin zu einer allmählichen weitgehenden Durchsetzung des Vorrangs der

Söhne hält auch Schlumbohm - allerdings nur im Falle der Großbauern - fest. Vgl. Schlumbohm, Lebensläufe, 383.

138 Mittterauer, Formen, 314. 
Aussagekräftig ist ein Vergleich zwischen den Besitzweitergaben an Söhne oder an Töchter vor allem dann, wenn dieser vor dem Hintergrund der jeweiligen familialen Konstellation betrachtet wird. Konnten die Töchter nur dann die Nachfolge auf den Gütern antreten, wenn kein männlicher Nachkomme vorhanden war, wie dies einige Autoren betont haben ?139 Das breite Spektrum von ,Ausnahmefällen“ zeigt, dass weder die Bedeutung des Geschlechtes noch der Verwandtschaft für die Besitznachfolge absolut gesetzt werden darf. Mehrmals wurde nämlich auch eine Tochter einem Sohn vorgezogen. Diese Form der Flexibilität wurde auch für andere Regionen Mitteleuropas festgestellt. ${ }^{140}$ Hinter derartigen Regelungen standen oft handfeste ökonomische Überlegungen. So konnte etwa der einheiratende Schwiegersohn den Hof finanziell entlasten. Freilich waren in Kapličky in der Mehrzahl dieser Fälle die Söhne zum Zeitpunkt der Übergabe noch nicht im übernahmefähigen Alter, die Töchter jedoch schon.

Ein Fall, bei dem eine Tochter auch erwachsenen Söhnen vorgezogen wurde, stellt dagegen die Besitznachfolge nach dem Bauern Mathias Martetschläger und seiner Frau Regina im Dorf Krasná Pole Nr. 6 im Jahre 1700 dar. Deren älteste Tochter Barbara hatte bereits 1689 den Bauernsohn Franz Pichler geheiratet (wo diese nach der Hochzeit lebten, ist nicht bekannt). Nach dem Tod der Regina im Jahre 1695 verehelichte sich der Vater nicht mehr, übergab allerdings zunächst seine Besitzungen noch nicht. Möglicherweise plante er zu diesem Zeitpunkt noch, an einen der beiden unverheirateten Söhne Georg und Thomas, die zu diesem Zeitpunkt beide bereits älter als 20 Jahre waren, zu übergeben. Im Jahre 1700 schließlich verkaufte M. Martetschläger sein Anwesen doch seiner Tochter und deren Mann F. Pichler. Wir wissen nicht, warum die Söhne nicht zum Zuge kamen, ob ihnen die finanziellen Mittel zum Kauf des Hofes fehlten, oder ob sie zu dieser Zeit keine geeigneten Partnerinnen finden konnten. Zumindest Sohn Georg war jedenfalls nachweislich geeignet, ein bäuerliches Anwesen zu leiten, da er im Jahr 1707 durch die Heirat mit einer Witwe doch in den Besitz eines Bauernhofes kam (sein Bruder Thomas wechselte nach seiner Heirat 1706 in den Inwohnerstand). Vielleicht war auch das Drängen der eventuell seit dem Tod der Mutter im Hause mitwohnenden Tochter und ihres Mannes ausschlaggebend für diese Lösung. ${ }^{141}$

Die Wahl des Nachfolgers hing neben dessen Eignung in starkem Maße auch vom Zeitpunkt der Übergabe ab. Auch wenn ursprünglich ein bestimmter Nachfolger (etwa ein Sohn) vorgesehen war, konnten plötzliche Todesfälle oder Erkrankungen diese Pläne zunichte und eine rasche Übergabe an jemand anderen erfor-

139 So etwa: Bourdieu, Boden, 271.

140 Vgl. Schlumbohm, Lebensläufe, 401 ff; Schlögl, Bauern, 343.

141 Quelle: SOA Třeboň, fond C Vyšší Brod, PK č. 453, fol. 322 und Familienrekonstitution. 
derlich machen. Der Bauer Martin Schiepani und seine Frau Maria in Hodoň Nr. 5 mochten den Verkauf an einen ihrer Söhne geplant haben. Selbst als ihr Sohn Paul $1695 \mathrm{im}$ 20. Lebensjahr verstarb, blieb noch der zu diesem Zeitpunkt siebenjährige Georg. Doch 1703 zogen sich beide auf das Ausgedinge zurück und übergaben an ihre Tochter Margareth. Vermutlich erfreute sich der zu diesem Zeitpunkt 58-jährige Martin Schiepani nicht mehr der besten Gesundheit (er starb fünf Jahre später), so dass ein Abwarten, bis der inzwischen 15-jährige Georg zur Übernahme bereit war, nicht aussichtsreich erschien. Es fanden sich außerdem Fälle, bei denen der Sohn zugunsten weiter entfernter Verwandter übergangen wurde. Der Chalupner Georg Mörxbauer und seine Frau übergaben 1734 an einen Sohn von Mörxbauers Schwester, während ihr eigener Sohn, 26 Jahre alt, übergangen wurde. ${ }^{142}$

Allein während der ersten Hälfte des 18. Jahrhunderts lassen sich zumindest acht Verkäufe von Anwesen feststellen, bei denen neben dem Besitzerpaar auch noch zumindest eines ihrer Kinder am Leben war und dennoch die Weitergabe außerhalb des engeren Familienkreises erfolgte. Die Weitergabe an entfernte Verwandte oder an Familienfremde war in dieser Pfarre also keineswegs generell nur durch Kinderlosigkeit begründet.

Bei den wenigen Übergaben in seitlicher Linie (an die Geschwister des Besitzers oder an ein Kind der Geschwister) spielte offenbar weder das Geschlecht des Nachfolgers noch der Wunsch nach Aufrechterhaltung der männlichen Abstammungslinie eine entscheidende Rolle. Dies beweist etwa der Fall des kinderlosen bäuerlichen Paares Urban und Ursula Weimüller in Krasné Pole Nr. 2. Diese verkauften ihr Anwesen 1706 an eine Tochter der Schwester von Urban. Sowohl ein 22-jähriger Sohn seines Bruders wie auch ein 25-jähriger Sohn einer weiteren Schwester wären zu diesem Zeitpunkt ebenfalls im übernahmefähigen Alter gewesen, wurden aber nicht berücksichtigt. ${ }^{143}$

Nicht die Ideologie von Abstammungslinien, sondern individuelle und ökonomische Strategien scheinen in manchen Fällen eine entscheidende Bedeutung gehabt zu haben. In zwei Fällen des Weiterverkaufs an den jeweiligen Bruder wollten die bisherigen Besitzer offenbar ihre Position als landwirtschaftliche Grundbesitzer aufgeben und zu nichtlandwirtschaftlichen Einkommensformen wechseln. Michael Hoffmann etwa verkaufte seinen Hof Kapličky Nr. 10 (den er nur etwa ein Jahr innegehabt hatte) an seinen Bruder; er lässt sich dann einige Jahre später als Lehrer und Mauteinnehmer im Dorf nachweisen. ${ }^{144}$ Auch der 45-jährige Wentzel Martetschläger, Besitzer des kleinbäuerlichen Anwesens Mnichovice Nr. 3, und seine 54-jährige

142 SOA Třeboň, fond C Vyšší Brod, PK č. 465, fol. 15.

143 SOA Třeboň, fond C Vyšší Brod, PK č. 453, fol. 317.

144 Vgl. dazu auch die in Kapitel 7.3 geschilderten Fälle. 
Frau dürften sich im Jahr 1705 aus freien Stücken aus ihrer Existenz als Kleinbauern zurückgezogen haben, indem sie das Anwesen an Wentzels Bruder Paul verkauften. Sie ließen sich dafür - neben dem weiteren Wohnrecht im Haus - ein im Verhältnis zur Größe des Anwesens beachtlich umfangreiches Ausgedinge zusichern, das Anteile an mehreren Wiesen, die Haltung einer Kuh und einer Ziege, den Anbau von Leinsamen, die Nutzung von „Krautäckern“, etc. inkludierte. Mit diesem lebenslang garantierten Ausgedinge war das ökonomische Überleben der beiden zwar sicherlich noch nicht völlig abgesichert, doch hatten sie sich jedenfalls auch ohne Besitz eines landwirtschaftlichen Betriebes einen sehr wichtigen dauerhaften ökonomischen Polster, der noch durch weitere, uns unbekannte, Einkommensformen ergänzt werden musste, geschaffen. Der Deal des Paares mit Wentzels Bruder Paul, hinkünftig faktisch gemeinsam von den Erträgnissen der kleinen Landwirtschaft zu leben, war wohl für beide Seiten akzeptabel, sonst wäre er nicht zustande gekommen. In erbrechtlicher Hinsicht ging dieses Arrangement jedenfalls auf Kosten der direkten Nachkommen von Wentzel Martetschläger. Die drei im Jahre 1705 allesamt bereits über 20 Jahre alten Töchter des Ehepaares sowie der 16-jährige Sohn gelangten nie mehr in die Besitznachfolge auf diesem Haus: dieses ging später an einen Sohn des Bruders Paul. Dass in solchen Einzelfällen eigentlich ursprünglich, weichende Geschwister, wie der Bruder des Besitzers, schließlich doch in den Besitz des Anwesens kamen, deutet an, dass unsere gewohnt dichotomische Gegenüberstellung von ,weichenden " und , nicht-weichenden' (oder gar von, erbenden' und, nicht-erbenden') Geschwistern nicht zu strikt gedacht werden darf. Es finden sich auch in dieser Hinsicht Übergänge, Schnittmengen und Vermischungen.

Insgesamt gab es während der gesamten Untersuchungsperiode zwei nachweisbare Fälle, in denen der ehemalige Besitzer das Anwesen neuerlich übernahm - er also Nachfolger seines eigenen Nachfolgers wurde (und dies auch so im Grundbuch festgehalten wurde). Auch wenn die Beweggründe für diese ungewöhnlichen Lösungen für uns weitgehend im Verborgenen bleiben, so verdeutlicht doch einer der beiden Fälle eindrücklich den vorhandenen Handlungsspielraum der beteiligten Personen in der Lösung der Besitznachfolge: Joachim Weimüller verkaufte im Jahre 1696 seinen Hof Frantoly Nr. 6 an seine Tochter und deren Mann Josef Leitgöb. Der zu diesem Zeitpunkt mit 25 Jahren in einem geeigneten Übernahmealter stehende Sohn Mathias kam nicht zum Zug. Ließe sich zunächst über eine mögliche Nichteignung des Sohnes zur bäuerlichen Wirtschaftsführung vortrefflich spekulieren, so nimmt der Fall nach drei Jahren eine überraschende Wendung: 1699 verzichtet der Schwiegersohn Josef Leitgöb nämlich, aus Unvermögen' (wie im Grundbuch vermerkt) auf den noch nicht abbezahlten Hof und gibt diesen wieder an Joachim Weimüller zurück. Der Schwiegervater führt das Anwesen danach neuerlich vier Jahre lang, ehe er es im Jahr 1703 schließlich an seinen nun 32-jäh- 
rigen Sohn Mathias verkaufte. Warum Mathias nicht bereits 1696 oder im Jahre 1699 die Nachfolge antrat, bleibt offen. Ein prinzipieller Mangel an der Fähigkeit zur Wirtschaftsführung kann kaum die Ursache gewesen sein. Mathias leitete den Bauernhof nämlich schließlich noch insgesamt 33 Jahre lang. ${ }^{145}$ Dieser Fall scheint damit die prinzipielle Option, die Tochter auch einem erwachsenen und zur Wirtschaftsführung befähigten Sohn vorzuziehen, eindeutig zu bestätigen.

Trotz der erkennbar zunehmenden Präferenz der patrilinealen Abstammungslinie zeigt das breite Spektrum der Ausnahmefälle, dass weder die Bedeutung des Geschlechts noch der Abstammung für die Auswahl des Besitznachfolgers absolut gesetzt werden darf. Die Weitergabe innerhalb der Verwandtschaft blieb trotz ihrer deutlich zunehmenden Bedeutung immer nur eine Variante unter mehreren. Die genannten Beispiele verdeutlichen vor allem den hohen Entscheidungsspielraum der Untertanen in der Regelung der Besitznachfolge. Die Grundherrschaft gab den Haus- und Grundbesitzern keine starren Richtlinien vor, wann und an wen diese ihre Anwesen und wirtschaftlichen Betriebseinheiten weitergeben sollten.

Der Geburtsstand des Kindes (ob ehelich oder unehelich geboren) bildete in dieser Region offenbar ein entscheidendes Kriterium für die Möglichkeit, je zu Haus- oder Grundbesitz zu gelangen. In der untersuchten Pfarre finden sich jedenfalls zwischen der Mitte des 17. und dem beginnenden 19. Jahrhundert keine unehelich geborenen Kinder, die ihren Eltern (oder auch Großeltern) direkt im Besitz nachgefolgt wären. ${ }^{146} \mathrm{Nicht}$ erschöpfend zu analysieren ist dabei allerdings die Frage, ob unter denjenigen Personen, die als ,nicht-verwandte', von außerhalb der Pfarre kommende Käufer Besitznachfolger wurden, Personen unehelicher Geburt zu finden waren. In ländlichen alpinen Gebieten Österreichs finden sich für diesen Zeitraum durchaus (wenn auch nicht besonders zahlreich) Besitzweitergaben an illegitim geborene Kinder. ${ }^{147}$ Auffallend ist für Kapličky auch, dass sich in der Pfarre insgesamt nur relativ wenige unehelich geborene Personen auch verehelichten; wenn doch, dann verblieben sie im Inwohnerstand.

In manchen Gebieten des vorindustriellen Europa übte auch der Geburtsrang eines Kindes einen sehr hohen Einfluss auf dessen weiteren Lebensweg aus, insbe-

145 Quelle: SOA Třeboň, fond C Vyšší Brod, PK č. 453, fol. 290 und Familienrekonstitution.

146 Eine mögliche Ausnahme von diesem Prinzip könnte lediglich ein Fall aus dem Jahre 1647 darstellen, der - da er in den Beginn des Untersuchungszeitraums fällt - leider nicht vollständig rekonstruierbar ist. Laut Grundbucheintragung verkaufte in diesem Jahr ein Hans Weisgramer seinen Hof an seinen Sohn Georg Daschil. Die Tatsache, dass der Sohn in diesem Fall nicht den Familiennamen seines Vaters trug, könnte auf eine außer- oder uneheliche Geburt des Sohnes schließen lassen. In dieser Frühzeit der Kirchenbuchführung kann auch die Heranziehung der Matriken nichts zur Rekonstruktion dieser Konstellation beitragen.

147 Mitterauer, Familienformen, 137. 
sondere auch auf die Möglichkeit, Landbesitz zu erwerben. ${ }^{148}$ Für manche deutsche Region mit Unteilbarkeit der Güter wurde die Bedeutung des ,Zufalls der Geburt' besonders hervorgehoben, da die Person des ,Anerben“ und damit die des Nachfolgers im elterlichen Besitz bereits von Geburt an durch dessen Geburtsrang festgelegt war. ${ }^{149}$ Je nach lokaler oder regionaler Gewohnheit bildete entweder der ältestgeborene (Majorat) oder aber der jüngstgeborene Sohn (Minorat) den designierten Nachfolger. Dieser wurde von Kindheit an auf die Rolle als zukünftiger Besitzer vorbereitet und entsprechend erzogen. Er blieb bis zu seiner Heirat am elterlichen Hof und arbeitete mit. ${ }^{150}$ In manchen europäischen Gebieten gab es sogar eine begriffliche Unterscheidung zwischen dem ,Stammhalter und dessen jüngeren Geschwistern. ${ }^{151}$ Interessant erscheinen dabei auch regionale Unterschiede im Detail: In bestimmten Regionen Schleswig-Holsteins beispielsweise sah die Rechtsgrundlage das Minorat vor - verstarb allerdings der Jüngste, war vorgesehen, dass an seiner Stelle der Älteste, und nach diesem der Zweitälteste übernehmen sollte. ${ }^{152}$ Schlumbohm wiederum berichtet von spezifischen Hoftraditionen, die von der eigentlich regional dominanten Norm abwichen: trotz des lokal überwiegenden Minorats gab es in seinem Untersuchungsgebiet einige Höfe, die ausschließlich die Tradition des Majorats pflegten. ${ }^{153}$ Ein starres Festhalten am Geburtsrang ohne Ansehen der Persönlichkeit und der Fähigkeiten des Kindes barg die Gefahr in sich, nicht immer die ökonomisch bestmögliche Lösung darzustellen. Deshalb wurden derartige lokale Gewohnheiten in der Bevorzugung eines Kindes aufgrund des Geburtsranges häufig auch recht flexibel gehandhabt, d. h. in vielen Fällen nicht befolgt. ${ }^{154}$ Oft wird die Bedeutung regionaler Gewohnheitsrechte in diesem Punkt wohl auch überbetont. In vielen Regionen fehlten derartige Festlegungen offenbar völlig oder es ließen zumindest die empirischen Studien zur tatsächlichen Weitergabepraxis keine eindeutige Präferenz für eines der Kinder erkennen. ${ }^{155}$ In anderen Gebieten wiederum hatte derjenige Sohn die besten Chancen den Hof zu erhalten, der gerade dann volljährig wurde, wenn sein Vater

148 Vgl. etwa Brennan/James/Morril, Inheritance, 289.

149 Trossbach, Bauern, 97.

150 Harnisch, Ökonomie, 83; Schlumbohm, Lebensläufe, 387; Begemann, Lebensbedingungen, $118 \mathrm{ff}$.

151 Vgl. etwa Segalen, Teil, 182f.

152 Gehrmann stellte daher in seiner Untersuchung fest, dass erst mit der sinkenden Mortalitätsrate des 19. Jahrhunderts das Minorat voll zur Geltung kam. Vgl. Gehrmann, Leezen, 50-52.

153 Schlumbohm, Lebensläufe, 393.

154 Dies war etwa in Teilen Irlands der Fall. Vgl. Kennedy, Farm Succession $485 \mathrm{ff}$.

155 So etwa in der Westlausitz oder in Teilen Bayerns. Vgl. etwa: Schöne, Kultur, 46; Breit, Leichtfertigkeit, 63f.; Robisheaux, Rural Society, 129. 
verstarb oder dieser aber gerade willens war sich zurückzuziehen. ${ }^{156}$ Wenig untersucht ist, ob sich diese regionalen Normen oder Gewohnheitsrechte im Laufe der Zeit auch ändern konnten. Aus dem westlichen Mühlviertel gibt es etwa Berichte, wonach im frühen 19. Jahrhundert eher die Weitergabe an den ältesten Sohn präferiert wurde, im 20. Jahrhundert dagegen eher an den jüngsten. ${ }^{157}$

Für das frühneuzeitliche Böhmen geht die Literatur trotz eines weitgehenden Fehlens empirischer Studien üblicherweise von einer in weiten Teilen des Landes herrschenden Dominanz des Minorats aus. ${ }^{158}$ Tatsächlich empirisch nachgewiesen wurde dieses Weitergabemuster bisher aber nur in wenigen Fällen, so etwa für eine westböhmische Region im 17. und 18. Jahrhundert. Gerade in diesem Gebiet kam es gegen Ende des 18. Jahrhunderts allerdings aufgrund geänderter rechtlicher Rahmenbedingungen zu einem Wandel hin zum ältesten Sohn. ${ }^{159}$ Für das sehr kleine südböhmische Dorf Záblatí wurde dagegen eine gewisse Bevorzugung des Zweitgeborenen festgestellt, ${ }^{160}$ und für die Herrschaft Chýnov lässt sich keine eindeutige Präferenz erkennen. ${ }^{161}$

Auch in Kapličky ist weder zur Mitte des 17. noch zu Beginn des 19. Jahrhunderts eine klare Präferenz für einen bestimmten Sohn zu erkennen, wie Tabelle 32 zeigt. Hier änderte auch die zunehmende Dominanz einer Weitergabe vom Vater an den Sohn nichts an einer offenbar flexibel und situationsbedingt gehandhabten Auswahl des jeweiligen nachfolgenden Kindes. Sowohl der älteste, der jüngste als auch ein mittlerer Sohn konnten zum Zuge kommen.

Angesichts der Vielzahl an weiteren Optionen in der Besitznachfolge (an den Schwiegersohn; Wiederverehelichung der Witwe; Verkauf an nicht-verwandte Personen) trat die Bedeutung des Geburtsranges stark in den Hintergrund. Auch die relativ hohe Sterblichkeitsrate lässt vielmehr ein möglichst langes Offenhalten der Nachfolgeregelung sinnvoll erscheinen. Auch bei den wenigen überlieferten Testamenten der Pfarre, die als Bestandteil von Verlassenschaften erhalten sind, fällt auf, dass nicht ein bestimmtes Kind als Nachfolger tituliert wird, sondern sich Vermerke, wie „einer seiner Söhne“ solle die Nachfolge antreten, zu finden sind. Dies war etwa beim Schmied von Kapličky im Jahre 1800 (er hatte zu diesem Zeitpunkt drei lebende Söhne, wie die Familienrekonstitution zeigt) sowie beim Kleinhäusler Simon Draxler im Jahre 1806 der Fall. ${ }^{162}$

156 Cole/Wolf, Die unsichtbare Grenze, 241.

157 Kretschmer/Piegler, Erbrecht, 15.

158 Maur, Erbrecht, bes. 16.

159 Velková, Besitztransfer; Dies., Staatliches Eingreifen, $164 f$.

160 Horská, Rodinná strategie.

161 Vgl. Grulich, Aspekte, 37.

162 SOA Třeboň, fond C Vyšší Brod, PK č. 475, fol. 53. 
Tabelle 32: Der Geburtsrang des im Besitz nachfolgenden Sohnes (ausgewählte Dörfer der Pfarre Kapličky)

\begin{tabular}{lcc}
\hline Rang des Sohnes: & nach 1651 & beginnendes 19. Jht. \\
\hline Ältester & 10 & 13 \\
Jüngster & 7 & 18 \\
Einziger & 4 & 19 \\
Mittlerer & 1 & 7 \\
unbekannt & 8 & 7 \\
\hline Summe & 31 & 64 \\
\hline
\end{tabular}

Quelle: Datenverknüpfung Grundbücher, Familienrekonstitution und Soupis poddaných.

Anmerkung: Einerseits wurden sämtliche im Verzeichnis von 1651 genannten Besitzer, die später an einen Sohn weitergaben, nach dem Geburtsrang dieses Sohnes überprüft. Die Stichprobe für das beginnende 19. Jahrhundert basiert auf den jeweils ersten Besitzwechsel im neuen Jahrhundert in den Dörfern Frantoly, Krasné Pole und Nové Domky. Berücksichtigt wurden nur die jeweils zum Zeitpunkt des Besitztransfers lebenden Söhne.

Natürlich kam es aber in einigen Fällen auch vor, dass eine Festlegung auf einen Nachfolger doch bereits mehrere Jahre vor der Übergabe erfolgte. Die Verknüpfung der Grundbücher mit dem Bevölkerungsverzeichnis von 1651 lässt nur diesen Schluss zu: es zeigt sich nämlich, dass beinahe alle der im Jahr 1651 noch im elterlichen Haushalt mit lebenden und über 20 Jahre alten Söhne in den darauffolgenden Jahren auch Besitznachfolger auf diesem Haus wurden. Dies scheint die mehrfach formulierte These, wonach der übernehmende Sohn zu Hause blieb und am Hof mitarbeitete, zu bestätigen. ${ }^{163}$

\subsubsection{Witwen und Interimsbesitzer ${ }^{164}$}

Auch eine andere, qualitative Änderung war für die zunehmende Bedeutung der Weitergabe in der männlichen Abstammungslinie in Kapličky wichtig, nämlich die Einführung der Position des Interimsbesitzers. Die besitz- und erbrechtliche Stellung von Frauen in Südböhmen war der in vielen westeuropäischen Gebieten durchaus vergleichbar. Die Wirtschaftsführung durch Witwen, etwa bis ein Sohn ein entsprechendes Alter erreicht hatte, kam im 17. wie im 18. Jahrhundert öfter vor, wurde häufig aber nicht im Grundbuch eingetragen. Ein Eintrag der Witwe

163 Mitterauer, Sozialgeschichte, 99.

164 Vgl. dazu auch den gleichnamigen, aber deutlich kürzeren Abschnitt in meinem Artikel: Zeitlhofer, Besitztransfer. 
als Besitzerin im Grundbuch (vgl. Tabelle 7.1) musste allerdings etwa dann erfolgen, wenn die Ehe kinderlos geblieben war und die Witwe fortan allein das Haus bewohnte. Die Witwe war in historischen Zeiten oft eine Schlüsselfigur im Prozess der Besitzerabfolgen. Ihre Bedeutung wurde in älteren Arbeiten jedoch häufig zugunsten der Vater-Sohn-Abfolge vernachlässigt. ${ }^{165}$ Entscheidend für die Rolle, die der Witwe im Prozess der Besitznachfolge zukam, war, ob in der Region das Modell (das Recht) der ,ehelichen Gütergemeinschaft' oder das der ,Gütertrennung etabliert war. Beim System der ,ehelichen Gütergemeinschaft', wie es in den meisten Teilen Südböhmens die Regel war, ${ }^{166}$ konnte der überlebende Ehepartner den Besitz des verstorbenen Partners (anteilig) übernehmen, bei ,Gütertrennung gab es auch während der Ehe getrennte Besitzungen und nach dem Tod fiel der Besitz der verstorbenen Personen wieder an deren Herkunftsfamilien zurück. ${ }^{167}$ Bei Gütergemeinschaft konnte die Witwe daher im Besitz nachfolgen und diesen nach einer neuerlichen Heirat auch an einen anderen Mann weitergeben, bei Gütertrennung hatten weder Witwe noch Witwer ein Nachfolgerecht.

Insgesamt war im südböhmischen Untersuchungsgebiet dennoch der Anteil der von Witwen geleiteten Haushalte geringer als in anderen Regionen, ${ }^{168}$ da Frauen nach der Verwitwung oft ins Ausgedinge wechselten. Der Prozentsatz an Besitzweitergaben durch die Wiederverehelichung von Witwen lag zwischen 1651 und 1800 bei etwa 10 bis 13 Prozent aller Besitzwechsel, danach sank dieser Anteil deutlich. Für einige europäische Gebiete sind bisher ähnliche Werte festgestellt worden, ${ }^{169}$ in vielen Regionen lagen diese aber weitaus höher. ${ }^{170}$ Ein besonderes Interesse der Herrschaft an häufigen Besitztransfers durch Wiederverehelichungen bestand nicht. In dieser Herrschaft wurden keine Besitzwechselgebühren eingefordert (vgl. Kapitel 7.2).

Im Falle einer Wiederverehelichung von Witwen wurde in Kapličky während des 17. Jahrhunderts kaum auf die Wahrung von Ansprüchen der Kinder aus erster Ehe auf das Anwesen geachtet. Eine Witwenheirat schuf daher tendenziell Konflikte innerhalb der Familien. Die Kinder aus erster Ehe verloren in diesen Fällen ihre prinzipiell bestehenden Ansprüche auf das Haus (nicht aber auf eine Erbschaft) und mussten dieses oft auch mit relativ jungem Alter verlassen. Bei-

165 Rouette, Erbrecht, 164.

166 Vgl. Schmidt, Gutsübergabe und Ausgedinge, 267.

167 Vgl. dazu Lanzinger, Das gesicherte Erbe, 21 ff., 224; Brauneder, Erbrecht, 414.

168 Zur These eines in Böhmen allgemein geringen Anteils an weiblichen Haushaltsvorständen vgl. Ogilvie/Edwards, Women.

169 Vgl. etwa Whittle, Inheritance, 38, für eine englische Pfarre im frühen 16. Jahrhundert.

170 Höhere Anteile etwa bei Breit, Leichtfertigkeit 62 für zwei bayerische Orte oder bei Sieder/Mitterauer, Reconstruction, 312, 315, für die Pfarre Rappoltenkirchen in Niederösterreich. 
spiele dafür lassen sich mehrfach finden. Als etwa der Bauer Andreas Petermüller in Hodoň Nr. 6 im Jahre 1648 frühzeitig verstarb, ehelichte dessen zu diesem Zeitpunkt sicherlich noch relativ junge Witwe Anna (sie lebte noch weitere 37 Jahre) einen gewissen Georg Stockinger. Das Haus ging später dann an einen gemeinsamen Sohn aus dieser zweiten Ehe. Mathias Petermüller, der Sohn der Anna aus erster Ehe, war zum Zeitpunkt des Todes seines Vaters erst vier Jahre alt gewesen; er hatte keine Ansprüche auf das Haus und wurde später Inwohner in Frantoly. Als Gregor Leitgöb 1693 die Witwe des L. Stipl in Lipová ehelichte, verloren die drei lebenden Töchter des letzteren (im Alter zwischen fünf und vierzehn Jahren) ihre Ansprüche auf den Hof. ${ }^{171} \mathrm{Zu}$ Ende des 16. Jahrhunderts war von Ansprüchen der Kinder erster Ehe auf das Haus wohl keine Rede, vielmehr wurde bei einigen Übergabeverträgen im Grundbuch explizit festgehalten, dass der einheiratende zweite Mann der Witwe bei Androhung einer Geldstrafe verpflichtet sei, seinen Stiefkindern eine angemessene „Erziehung“ angedeihen zu lassen. ${ }^{172}$ Offenbar wurden zu dieser Zeit die Kinder aus erster Ehe bei einer neuerlichen Heirat in den Status von Ziehkindern zurückgestuft. ${ }^{173}$ Zur Mitte des 17. Jahrhunderts ist für Kapličky in einzelnen Fällen, in denen nach dem Tod des Hausbesitzers anstelle einer Wiederverehelichung der Witwe eine Übergabe an noch sehr junge Söhne erfolgte, eine Tendenz zur Vermeidung einer Zweitehe der Witwe zu vermuten. Wie die Familienrekonstitution zeigt, gelangten um 1700 in zwei Fällen die Enkel aus der ersten Ehe der Witwe schließlich noch in den Besitz des Hauses. Nach dem Zweitmann der Witwe und dessen Sohn folgte also ein Enkelkind des Erstmannes im Besitz nach. Ob diese Lösung auf bloßem Zufall beruhte oder ob dies so oder ähnlich zu irgendeinem Zeitpunkt vereinbart worden war, ist nicht zu klären, da dazu keine schriftlichen Aufzeichnungen überliefert wurden.

$\mathrm{Zu}$ Beginn des 18. Jahrhunderts kam es in dieser Hinsicht zu einer wichtigen Änderung. Die Ansprüche der Kinder aus erster Ehe wurden nun deutlich aufgewertet. ${ }^{174}$ Auf Basis individueller Vereinbarungen bei Heirat wurde ab dem frühen 18. Jahrhundert vielen zweiten Ehemännern von Witwen lediglich der Status eines Interimsbesitzers in Vertretung eines Kindes aus erster Ehe zuerkannt. Mit Besitzantritt wurden diese Vereinbarungen ins Grundbuch eingetragen. Die erste derartige Regelung begegnet im Jahre 1707 bei einem der wohlhabendsten Anwe-

171 SOA Třeboň, fond C Vyšší Brod, PK č. 453, fol.. 18.

172 Vgl. SOA Třeboň, fond C Vyšší Brod, PK č. 447.

173 Vgl. dazu auch Sieder, Strukturprobleme, 192.

174 Eine ähnliche Entwicklung beobachtet Hohkamp, Wer will erben? In anderen Regionen konnte es während der Neuzeit jedoch auch zu einer Aufwertung der Position des eingeheirateten Zweitmannes der Witwe kommen. Vgl. auch Trossbach, Bauern, 35. 
sen der Pfarre im Ort Lhota. Zu diesem Haus gehörte eine Mühle, eine Säge und Grund im Ausmaß eines durchschnittlichen Bauernhofes der Region. Zusätzlich war 1643 ein herrschaftliches Feld vom Kloster dazugekauft worden. Auch die für die lokalen Verhältnisse außerordentlich hohe Zahl von acht Ochsen beim Haus, die anlässlich der Besitzübertragung im Jahre $1691 \mathrm{im}$ Grundbuch dokumentiert wurden, belegt die ökonomische Wohlhabenheit des Anwesens. Von den 1640er Jahren beginnend bis zumindest ins Jahr 1757 hatte der jeweilige Inhaber des Anwesens auch das Amt des Dorfrichters, von denen es in der gesamten Pfarre nur zwei gab, inne. Als nun der Inhaber des Hauses, Georg Leitgöb, im Herbst 1706 starb, hinterließ er zwei Söhne und eine Tochter. Der älteste Sohn Johann war zu diesem Zeitpunkt 17 Jahre alt, Simon erst sieben und Tochter Maria drei Jahre. ${ }^{175}$ Die Witwe Elisabeth heiratete im darauffolgenden Jahr den von auswärts gebürtigen Henrich Scheuchenstuhl. Auch dieser war Sohn eines Müllers und Sägewerksbesitzers. ${ }^{176}$ Durch eine, laut Grundbuch auch bei Gericht festgehaltene Regelung wurde anlässlich der Hochzeit vereinbart, dass Henrich Scheuchenstuhl „iner 18 Jahres Fruest" das Anwesen an ,aynen von den Leitgoebischen Zwey Soehne ... mit allem was obbeschribn /: exciepto ds Ausnehmbn :/ ..." ${ }^{177}$ wieder zu übergeben habe. Tatsächlich übergab er nach 18 Jahren an Johann Leitgöb und ging mit seiner Frau Elisabeth ins Ausgedinge. Die in diesem Zusammenhang aufgesetzte Ausgedingevereinbarung ist die mit Abstand detaillierteste aller für die Pfarre erhaltenen - und außerdem die einzige, die einen Nachtrag, übrigens zugunsten des neuen Inhabers, erfuhr. ${ }^{178}$ Offenbar war der konkrete Umfang des Ausgedinges bereits bei der Eheschließung festgelegt worden und Henrich Scheuchenstuhl hatte für seinen frühzeitigen Verzicht auf das Gut einen hohen Preis gefordert. Auch Henrich Scheuchenstuhl bekleidete das Amt des Dorfrichters.

Erst Regelungen wie diese machten es möglich, dass beim Tod des Vaters noch minderjährige Kinder später den Hof übernehmen konnten. Daher finden sich ab dem 18. Jahrhundert auch Stiefsöhne als Besitznachfolger; für das 17. Jahrhundert lässt sich dies nicht nachweisen (vgl. Tabelle 7.2). In der Regel wurde dem zweiten Mann der Witwe in dieser Region durch Grundbucheintrag die Wirtschaftsführung auf die Dauer von 18 oder 20 Jahren zugesichert (in zwei Einzelfällen betrug diese Zeitspanne auch 15 bzw. 22 Jahre). Danach hatte er an ein Kind aus erster Ehe der Frau zu übergeben. Im Gegenzug erhielt er bereits bei der Heirat ein Aus-

175 Mehrere Kinder aus dieser Ehe waren bereits früh verstorben.

176 Laut Kirchenbuch war sein Elternhaus der,Steindlhammer, ein an der Moldau gelegenes großes Einzelanwesen in der Pfarre Vyšší Brod, zu dem auch ein Hammerwerk gehörte.

177 SOA Třeboň, fond C Vyšší Brod, PK, č. 453, fol. 172ff.

178 SOA Třeboň, fond C Vyšší Brod, PK, č. 565, fol. 341ff 
gedinge am Hof zugesichert. Insgesamt gab es zwar nur 19 Weitergaben an den Stiefsohn während des gesamten Untersuchungszeitraums, phasenweise kam dieser Lösung der Nachfolgeregelung dennoch eine recht hohe Bedeutung zu: Zwischen 1751 und 1800 etwa wurde in mehr als zehn Prozent aller Fälle, bei denen nicht der Sohn die Nachfolge antrat, an den Stiefsohn übergeben (Tabelle 7.2). Während der ersten Hälfte des 18. Jahrhunderts lassen sich zunächst fünf derartige Regelungen, die allesamt eher wohlhabende Häuser der Pfarre betrafen, feststellen. Im Jahre 1745 wurde ein solches Abkommen aber auch bei einem landarmen Haus getroffen.

Für viele Regionen, auch innerhalb Böhmens, wurde festgestellt, dass die Dauer der Interimswirtschaft sich am Alter der präsumptiven Hoferben orientierte. ${ }^{179}$ In Kapličky war dies nicht der Fall, da es einen solchen zumeist nicht gab (siehe oben). Hier wurde manchmal offenbar der Zeitpunkt abgewartet, zu dem alle lebenden Kinder „übernahmefähig“ waren. Als beispielsweise Florian Hoffmann im Jahre 1766 Anna, die Witwe des Bauern Jacob Hutter in Frantoly Nr. 1, ehelichte, wurde die Dauer seiner Wirtschaftsführung mit 22 Jahren festgelegt. Der Zusammenhang zwischen dieser Fristvereinbarung und dem Alter des Jüngsten der zu diesem Zeitpunkt fünf lebenden Kinder aus der ersten Ehe der Anna ist bei diesem Beispiel besonders deutlich. Von den vier lebenden Söhnen war einer 15 Jahre alt, einer 13 und einer 11 Jahre, der jüngste aber erst ein Jahr. Die Zeitspanne war also für Florian Hoffmann sehr großzügig bemessen. Es wurde darauf geachtet, dass auch der Letztgeborene eine Chance zur Übernahme hatte und dass trotz der relativ hohen Kindersterblichkeit zumindest ein Sohn zum Zeitpunkt des Transfers im übernahmefähigen Alter war. Auch im zuvor erwähnten Fall der Familie Leitgöb war trotz des hohen Altersunterschieds zwischen den beiden Söhnen anscheinend noch keine Entscheidung gefallen, wer Besitznachfolger werden sollte. Die 18-Jahres-Frist sollte vielmehr sicherstellen, dass auch der zweite Sohn altersmäßig in der Lage war, die Nachfolge anzutreten.

Die Einsetzung eines Interimsbesitzers erfolgte in Kapličky im Unterschied zu anderen Regionen ${ }^{180}$ aber auch im 18. und frühen 19. Jahrhundert nicht in allen Fällen einer Besitzweitergabe durch Wiederverehelichung. Es ist auffällig, dass die Interimslösung hier lediglich bei einer Wiederverehelichung einer Witwe, nicht aber eines Witwers getroffen wurde, und zwar überwiegend nur dann, wenn der verstorbene Mann ,Hoferbe' gewesen war, die nun verwitwete Frau eingeheiratet hatte und ein Sohn aus erster Ehe vorhanden war. War dagegen die Frau ,Hoferbin' gewesen, verstarb sie vor ihrem Mann und dieser verehelichte sich nochmals,

179 Vgl. dazu etwa Velková, Besitztransfer. Vgl. auch Begemann, Lebensbedingungen, 123.

180 Schlumbohm, Familie, $148 \mathrm{ff}$. 
wurde (mit Ausnahme eines Falles) keine Interimsregelung getroffen. Die Anwendung dieser Regelung förderte demnach vor allem die Wahrung des Besitzes in der männlichen Abstammungslinie.

$\mathrm{Ob}$ die Kinder aus erster oder zweiter Ehe der Witwe die Besitznachfolge antraten, war regional höchst unterschiedlich geregelt. In mehreren Gebieten Österreichs wurden üblicherweise die Kinder aus der letzten Ehe bevorzugt. ${ }^{181}$ In anderen deutschsprachigen Regionen, etwa in Bayern oder in norddeutschen Gebieten, hatten dagegen die Kinder aus erster Ehe den Vorrang. ${ }^{182}$ Im norddeutschen Belm finden sich in einigen Fällen auch Ausnahmen von dieser Regel. ${ }^{183}$ Und es gibt Beispiele dafür, dass auf informellem Wege - etwa über den Druck der Verwandtschaft - die Nachfolge der Kinder aus erster Ehe gesichert wurde. ${ }^{184}$ Auch wird berichtet, dass Witwen manchmal bewusst einen Mann ohne Vermögen wählten, da ein solcher, weil er nichts in die Ehe eingebracht hatte, nach ihrem Tod keinen Anspruch auf das Anwesen stellen konnte. ${ }^{185}$ In einigen Gebieten wurden trotz der Institution eines „Setzwirtes“ die Kinder aus erster Ehe häufig übergangen. ${ }^{186}$ Umgekehrt konnten regional selbst ohne formales Bestehen einer Interimsposition die Kinder aus erster Ehe durchaus in den Besitz des Hauses gelangen. ${ }^{187}$

Ein gutes Beispiel dafür, wie sich die Position der Kinder aus erster Ehe im Kontext einer neuerlichen Verehelichung der Witwe zu Beginn des 18. Jahrhunderts allmählich veränderte, bildet die Besitzerfolge des Bauernhofes Lipová Nr. 4.

\section{Fallbeispiel 5: Besitzerfolge Haus Lipová Nr. 4}

1651-1684 Hans Leitgöb (Schwiegersohn)

1684-1722 Gregor Hehenberger (Witwenheirat)

1722-1742 Mathias Leitgöb (Witwenheirat, auf 20 Jahre befristet)

1742-1779 Simon Hehenberger (Stiefsohn; Sohn des G. Hehenberger)

Quellen: SOA Třeboň, fond C Vy̌šíí Brod, PK, č. 453, č. 465, č. 475.

Erläuterung: Hans Leitgöb kam 1651 durch Heirat mit der Tochter dieses Hauses auf den Hof. Nach dem Tod seiner Frau verehelichte er sich nochmals - mit Susanna Kapeller (geboren im oberösterreichischen Mühlviertel). Als er selbst im Jahre 1684 verstarb, hinterließ er sowohl aus erster wie aus zweiter

181 Feigl, Erbrecht, 170; Sieder/Mitterauer, Reconstruction, 342.

182 Beck, Frauen, 175; Mooser, Ländliche Klassengesellschaft, 187.

183 Schlumbohm, Lebensläufe, 382; Ders., Land-Family Bond, 466.

184 Hohkamp, Wer will erben, 335; Mayr, Heiratspraktiken, 45.

185 Mayr, Heiratspraktiken, 40.

186 Gehrmann, Leezen, $51 f$.

187 Dies ist mehrfach anhand der rekonstruierten Besitzerfolgen des Ortes Ulrichsberg im österreichischen Mühlviertel ersichtlich: Wasmayr, Ulrichsberg, $394 \mathrm{ff}$. 
Ehe Kinder. ${ }^{188}$ Die Witwe Susanna, deren Alter unbekannt ist, verehelichte sich nun im Jahr 1684 nochmals, ohne dass eine Bestimmung zugunsten der Kinder des Hans Leitgöb getroffen worden wäre. Sie heiratete den 27-jährigen weichenden Bauernsohn Gregor Hehenberger von Martinkov Nr. 4. Auch aus dieser Ehe gingen mehrere Kinder hervor. Nachdem Susanna im Jahre 1701 verstarb, verehelichte sich der nun 43-jährige Gregor Hehenberger ein zweites Mal (mit Klara Binder aus der benachbarten Pfarre Malšín). Als Gregor Hehenberger im Jahre 1722 ebenfalls verstarb, bestand dieselbe Situation wie beim Tod seines Vorbesitzers Hans Leitgöb: es waren Kinder aus beiden Ehen des Vorbesitzers am Leben und die Witwe verehelichte sich nochmals. Als Klara Hehenberger (Binder) nun zum zweiten Mal heiratete, wurde ihrem Mann, Mathias Leitgöb, nur mehr eine auf 20 Jahre befristete Wirtschaftsführung zugestanden. Danach habe er zugunsten von Simon (19 Jahre) oder Heinrich (sechs Jahre), den beiden noch lebenden Kindern aus der Ehe von Gregor und Klara Hehenberger (also aus der zweiten Ehe der Witwe!), zu verzichten. Dafür wurde ihm bereits bei der Eheschließung ein Ausgedinge beim Hof zugesichert. Anders als beim vorangegangenen Besitzerwechsel im Jahre 1684 wurde nun also eine Vereinbarung zugunsten der Kinder des verstorbenen Vorbesitzers getroffen und tatsächlich wurde der Stiefsohn Simon zwanzig Jahre später als mittlerweile 39-jähriger als neuer Besitzer in das Grundbuch eingetragen. An der konkreten Personenkonstellation dieses Hofes sind allerdings noch weitere Aspekte interessant: Die drei lebenden Kinder aus der ersten Ehe des Gregor Hehenberger wären zum fraglichen Zeitpunkt (1722) bereits alt genug für die Besitzübernahme gewesen: die ledige Helena, 24 Jahre alt; die bereits verheiratete Theresia, 27 Jahre und der ledige Sohn Martin, 30 Jahre alt. Ihre Ansprüche auf das Haus hatten sie aber wohl bereits mit der neuerlichen Eheschließung ihres Vaters im Jahre 1701 verloren. Der Sohn Martin beispielsweise ehelichte 1734 im Alter von bereits 42 Jahren eine weichende Bauerntochter aus Dobřin und verblieb zeitlebens im Inwohnerstand.

Darüber hinaus ist an diesem Fallbeispiel natürlich die Abfolge von mehreren Wiederverehelichungen bemerkenswert, die anhand der im Grundbuch eingetragenen Besitzerabfolge gar nicht sichtbar ist und erst rekonstruiert werden musste. Solche Ketten an Wiederverehelichungen waren jedoch in der Region gerade im frühen 18. Jahrhundert eher selten. Auch der Anteil an Zweitehen von Frauen war in der Pfarre relativ niedrig. Besonders wenige $Z$ weitehen von Frauen scheint es in Kapličky jedenfalls in den Jahren zwischen 1721 und 1740 gegeben zu haben (siehe Tabelle 33). Dies hatte wohl mit der besonderen Häufigkeit von Ausgedingeregelungen in dieser Phase zu tun. In diesen 18 Jahren, die in die Zeitperiode fallen, in der sämtliche Ausgedingeverträge erhalten sind, wechselten immerhin 38 Frauen alleine oder gemeinsam mit ihrem Mann ins Altenteil (zwischen 1701 und 1720 waren es 20 gewesen). Für verwitwete Frauen war der Wechsel ins Ausgedinge eine Alternative zur Wiederverehelichung. Anders als bei den Männern verehe-

188 Im vorliegenden Fall ist die Existenz von Kindern nicht nur durch die Familienrekonstitution rekonstruierbar, diese sind vielmehr auch namentlich im Grundbuch genannt: Aus erster Ehe des Hans Leitgöb war ein Sohn bereits länger verehelicht, die Tochter Susanna (ebenfalls aus erster Ehe) heiratete in diesem Jahr 1684 nach Přední Vyton, also außerhalb der Herrschaft. Aus der zweiten Ehe mit Susanna waren zu diesem Zeitpunkt zumindest noch ein neun- und ein fünfjähriger Sohn sowie dreijährige Zwillinge am Leben. 
lichte sich keine einzige im Altenteil lebende Frau nochmals. Wenn der Anteil der Zweitehen von Frauen nach 1740 wieder anstieg, könnte dies auch auf weniger Ausgedingeregelungen in der nachfolgenden Periode schließen lassen, für die Zeit nach 1738 kann deren genaue Zahl aber nicht mehr rekonstruiert werden. Der neuerliche Rückgang ab 1780 liegt dagegen im allgemein beobachtbaren Trend. Sowohl für eine Pfarre Südböhmens als auch für viele andere europäische Gebiete ist eine rückläufige Tendenz der Wiederverheiratung von Frauen ab dem beginnenden 19. Jahrhundert nachgewiesen. ${ }^{189}$ Es gab allerdings auch Gebiete, in denen ein deutlicher Rückgang der Zahl der Wiederverehelichungen von Witwen bereits ab der Mitte des 17. Jahrhunderts einsetzte. ${ }^{190}$

Tabelle 33: Anteil der Zweitehen an allen Eheschließungen, Pfarre Kapličky

1701-1820

\begin{tabular}{ccccc}
\hline Heiratskohorte & \multicolumn{2}{c}{ Männer } & \multicolumn{2}{c}{ Frauen } \\
& Anteil Zweitehen & $\mathrm{N}$ & Anteil Zweitehen & $\mathrm{N}$ \\
\hline $1701-1720$ & 13,9 & 72 & 7,5 & 80 \\
$1721-1740$ & 10,9 & 92 & 4,2 & 72 \\
$1741-1760$ & 17,5 & 80 & 7,7 & 78 \\
$1761-1780$ & 21,7 & 92 & 8,9 & 90 \\
$1781-1800$ & 14,5 & 110 & 5,5 & 109 \\
$1801-1820$ & 18,0 & 89 & 4,5 & 89 \\
\hline
\end{tabular}

Quelle: Rodovy katástr, Pfarre Kapličky.

Anm.: Nur im Ort geborene Personen wurden berücksichtigt; Drittehen blieben ausgeklammert. , $\mathrm{N}^{\text {‘ }}$ steht für die gesamte Zahl an eheschließenden Personen in dieser Periode.

$\mathrm{Zu}$ betonen ist außerdem, dass es sich bei der in Kapličky gefundenen Lösung der Befristung der Wirtschaftsführung für den Zweitmann der Witwe rechtlich nicht um eine institutionalisierte Interimswirtschaft handelte. Stiefväter galten in Böhmen um 1800 rechtlich nicht als Interimswirte. ${ }^{191}$ Während in anderen Regionen auch innerhalb Böhmens - unterschiedliche Personen, wie entfernte Verwandte, die Geschwister des vorgesehenen Nachfolgers oder andere die Vertreterposition bis zur Großjährigkeit des vorgesehenen ,Anerben“ einnehmen konnten, ${ }^{192}$ war dies in der

189 Šterbová, Vývoj, bes. 108; Mitterauer, Agrarrevolution, 53 ff; allgemein: Ehmer, Life stairs, $61 \mathrm{f}$.

190 Maisch, Unterhalt, $224 \mathrm{ff}$.

191 Rößler, Ausgedinge, 38.

192 Schlumbohm, Lebensläufe, 399; Velková, Besitztransfer. 
Pfarre Kapličky nicht der Fall. Weder stand der vorgesehene Nachfolger fest, noch konnten andere Personen (mit einer Ausnahme) die Vertreterrolle übernehmen, hier wurde lediglich die Besitzdauer des zweiten Mannes der Witwe zeitlich zugunsten der Kinder aus erster Ehe begrenzt. Der einzige im Grundbuch verzeichnete Fall einer zeitlich begrenzten Wirtschaftsführung in Vertretung eines bestimmten Kindes war jener der Witwe Sophia Mautner. Auf dem bäuerlichen Anwesen Kapličky Nr. 9 wurde sie im Jahre 1799 als Inhaberin „in Verwaltung bis zur Großjährigkeit des Sohnes“ Michael im Grundbuch eingetragen. Michael, ein gemeinsames Kind aus ihrer Ehe mit dem Vorbesitzer Adalbert Mautner, trat die Nachfolge im Jahre 1813 im Alter von 20 Jahren an. Bei dieser Regelung ist also auch die Festsetzung der zeitlichen Befristung - auf 14 Jahre - atypisch. Da Michael Mautner zum Zeitpunkt des Besitzantritts relativ jung war, hatte er in Gestalt des Bauern Paul Draxler aus demselben Ort einen Vormund. Die Gesetzgebung Josephs II sah im Falle ,minderjähriger' Übernehmer einen solchen vor. In unseren Quellen begegnet ein Vormund des Besitznachfolgers ab dem beginnenden 19. Jahrhundert öfter. Der erwähnte Paul Draxler hatte, wohl auch aufgrund seiner gesellschaftlichen Position er war nicht nur einer der größeren Bauern der Pfarre, sondern bekleidete zeitweise auch kommunale Ämter ${ }^{193}$, um 1810 in mehreren Fällen diese Funktion inne. Das ,Amt' des Vormundes (in der lokalen Terminologie: der,Gerhaber') brachte auch Vorteile: Der Gerhaber verwaltete die an die Minderjährigen ratenweise ausbezahlten Kauf- und Erbanteile und lieh sich daraus Geld „auf Interesse“. ${ }^{194}$ Die Institution des „Vormundes“ war in dieser südböhmischen Region offenbar sehr ähnlich wie in südwestdeutschen Gebieten geregelt. Die Überprüfung der Einzelfälle legt nahe, dass dieses Amt, ähnlich wie auch in Neckarhausen, etwa mit dem Erreichen des 25. Lebensjahrs des Kindes befristet war. ${ }^{195}$

\subsection{Besitztransfermuster im regionalen Vergleich}

Es stellt sich nun die Frage, wie typisch das für die Pfarre Kapličky vorgefundene Muster einer hohen Vielfalt unterschiedlicher Lösungsmöglichkeiten der Besitzweitergabe sowie einer gleichzeitig zunehmend deutlichen Stärkung der innerfamilialen Weitergabe im überregionalen Vergleich war? Schon früh haben Mitterauer und Sieder die hohe Vielfalt unterschiedlicher Lösungen in der Praxis

193 In der Pfarrfassion von 1797 ist er als „Dorfgeschworener“ genannt (Archiv Klaštera Vyšší Brod, kart. 219).

194 Dies ist auch für Oberösterreich dokumentiert, vgl. Mayerhofer, Quellenerläuterungen, 46.

195 Vgl. Sabean, Kinship, 30f. 
der Besitznachfolge, die entgegen gängiger Annahmen weit über die unterstellte Exklusivität der Eltern-Kind-Nachfolge (vor allem: Vater-Sohn) hinausging, aufgezeigt. ${ }^{196}$ Die geringe Bedeutung blutsverwandtschaftlicher Bindungen in zahlreichen österreichischen Regionen ist etwa daran erkennbar, dass nicht selten auch die in den Haushalt aufgenommenen Ziehkinder als Besitznachfolger eingesetzt wurden. ${ }^{197}$ Andererseits hat aber etwa Rainer Beck anhand seiner überaus detailreichen bayerischen Mikrostudie festgehalten: „Wer in Unterfinning mit einem Erben versehen war, der vermachte diesem auch seinen Besitz". ${ }^{198}$ Nur bei Kinderlosigkeit, einem Häusertausch oder wenn jemand ausnahmsweise zwei Häuser inne hatte seien dort Haus- und Grundbesitz nicht an die leiblichen Kinder gegangen.

Insbesondere wenn Besitzerabfolgen über längere Zeiträume und mehrere Generationen hinweg verfolgt werden, zeigt sich häufig eine nur sehr geringe Konstanz familialer Kontinuitäten. In englischen Studien über das 16. und 17. Jahrhundert war zum Teil festgestellt worden, dass kaum ein Haus im Verlauf eines Jahrhunderts (drei Generationen oder mehr) innerhalb derselben Familie geblieben war. ${ }^{199}$ In modernisierungstheoretischer Sicht werden aufkommende kapitalistische Marktbeziehungen, wie sie für England typisch gewesen seien, als verbunden mit einem geringen Grad an innerfamilialen Übergaben gesehen, während die traditionalen Gesellschaften Kontinentaleuropas vom familialen Erbe lange geprägt geblieben seien. ${ }^{200}$

Demgegenüber verweisen mehrere neuere Studien darauf, dass für zahlreiche Regionen Mitteleuropas eine Bedeutungszunahme von Familie und Verwandtschaft seit dem 18. Jahrhundert angenommen werden kann. ${ }^{201}$ In diesen Befund passen nicht nur die empirischen Ergebnisse für Kapličky, auch in anderen Teilen Böhmens und Südböhmens dürfte sich die Besitzweitergabe innerhalb der Kernfamilie während des frühen 18. Jahrhunderts allmählich deutlicher durchgesetzt haben. Für die Region um Třeboň etwa liegen Daten aus dem 16. Jahrhundert vor, die auf zahlreiche Käufe und Verkäufe außerhalb des Familienkreises deuten, während im 18. Jahrhundert die innerfamiliale Besitzweitergabe dominierte. ${ }^{202}$ Eine zunächst sehr ähnliche Entwicklung wie in Kapličky fand auch im westböh-

196 Vgl. insbesondere Sieder/Mitterauer, Reconstruction.

197 Mitterauer, Formen; Ehmer, House, 75.

198 Beck, Unterfinning, 412.

199 Vgl. etwa Stapleton, Family Strategies, 387.

200 Doch sind hier auch die Ergebnisse für England zu differenzieren. Im Ort Earls Colne etwa wurden im 16. und 17. Jahrhundert 45,7 Prozent der Anwesen innerhalb der Verwandtschaft weitergegeben. Vgl. Sreenivasan, Land-family bond, 5 , 9 .

201 Vgl. etwa Sabean, Kinship.

202 Horský, Vererbungspraxis. 
mischen Štáhlavy (nahe Pilsen) statt. Nach einem zu Ende des 17. Jahrhunderts ähnlich hohen Niveau an Verkäufen zwischen nichtverwandten Personen sank hier deren Bedeutung im 18. Jahrhundert in etwa demselben Ausmaß wie in Kapličky, stieg jedoch im frühen 19. Jahrhundert auf etwa ein Drittel aller Fälle an (Zeitraum 1821-1850). Velková führt diesen neuerlichen Wandel auf eine steigende Mobilität der Hausbesitzer zurück. Faktisch waren die Weitergaben an die eigenen Kinder genauso häufig wie im 18. Jahrhundert; ein größerer Teil der Besitzenden war jedoch dazu übergegangen, mehrmals im Leben ihre Anwesen durch Kauf und Verkauf (an Nichtverwandte) zu wechseln. ${ }^{203} \mathrm{Zu}$ fragen wäre, ob dieser regionale Unterschied mit der Nähe von Štáhlavy zur sich im beginnenden 19. Jahrhundert bereits rapide urbanisierenden Stadt Pilsen erklärbar ist. Ähnlich wie in Kapličky waren jedenfalls auch in Štáhlavy die Unterschiede zwischen bäuerlichen und unterbäuerlichen Anwesen gering. ${ }^{204}$ Für die ebenfalls südböhmische Herrschaft Chýnov wurden noch weitaus höhere Anteile an Verkäufen zwischen nichtverwandten Personen ermittelt (zwischen 1625 und 1710 in etwa 80 Prozent aller Fälle), aber auch hier ging dieser Anteil im 18. Jahrhundert sehr deutlich zurück. ${ }^{205}$ Ähnlich verliefen die Besitzweitergaben in der nordböhmischen Herrschaft Frýdlant, in der zwischen 1558 und 1648 etwa 73 Prozent aller Besitzwechsel zwischen nichtverwandten Personen stattfanden (zwischen 1651 und 1750: etwa 68 Prozent). ${ }^{206}$ Für die beiden letztgenannten Fallbeispiele ist jedoch einschränkend nicht nur festzuhalten, dass der Untersuchungszeitraum teilweise deutlich früher ansetzt und damit auch die Phase des Dreißigjährigen Krieges inkludiert, sondern auch, dass jeweils Verwandtschaftsangaben nur auf Basis der Grundbucheintragungen rekonstruiert wurden und nicht auf Familienrekonstitutionen basieren. Daher sind auch deutlich höhere Anteile an unentdeckt gebliebenen verwandtschaftlichen Verbindungen (wohl außerhalb der Eltern-Kind-Relation) in beiden Fällen anzunehmen. Ein genauer Vergleich der Ergebnisse für Kapličky mit den beiden Studien von Velková und Grulich über andere böhmische Regionen zeigt mehrfach Ähnlichkeiten, doch waren im westböhmischen Fallbeispiel die Weitergaben über die Witwe noch deutlich seltener und dafür Verwandte als Nachfolger weitaus häufiger (Tabelle 34).

In Innichen in Südtirol dagegen fand der Prozess einer Stärkung der familialen Besitzstabilität vor allem erst im 19. Jahrhundert statt. ${ }^{207}$ Im norddeutschen Belm

203 Vgl. dazu im Detail: Velková, Familie und Besitzinteressen, $126 \mathrm{ff}$.

204 Vgl. Velková, Familie und Besitzinteressen, 132 f.

205 Grulich, Populační, 303f.

206 Štefanová, Erbschaftspraxis, $95 f$.

207 Lanzinger, Das gesicherte Erbe, 230, 253ff.; Dies., , Aus khainer gerechtigkeit', 25. 
(Tabelle 35) sind Entwicklungslinien nicht auf den ersten Blick klar erkennbar, während der frühen Neuzeit erfolgten immer etwa zwischen einem Drittel und knapp der Hälfte aller Weitergaben an den Sohn, allerdings steigt der Anteil dieser Übergaben vom 18. ins 19. Jahrhundert doch an. ${ }^{208}$ Weitergaben durch eine neuerliche Eheschließung der Witwe hatten hier im Vergleich zum südlichen Böhmerwald kontinuierlich eine sehr hohe Bedeutung. Noch wichtiger war die Besitzweitergabe über die Witwe im 16. Jahrhundert etwa im südwestdeutschen Langenburg (Region Hohenlohe): in beinahe einem Viertel der Übergaben innerhalb der Verwandtschaft ging das Anwesen an den neuen Mann der Witwe. ${ }^{209}$

Tabelle 34: Verwandtschaftsbeziehungen in der Besitznachfolge im innerböhmischen Vergleich

\begin{tabular}{lccrrrr} 
& Sohn & $\begin{array}{c}\text { Schwie- } \\
\text { gersohn }\end{array}$ & $\begin{array}{c}\text { Witwen- } \\
\text { heirat }\end{array}$ & $\begin{array}{c}\text { andere } \\
\text { VW }\end{array}$ & Sonstige & N \\
\hline Vřesce, 1625-1825 & 45,9 & 10,0 & 11,0 & 3,2 & 29,9 & 290 \\
Štáhlavy, 1700-1787 & 28,5 & 10,9 & 3,8 & 24,4 & 22,4 & 618 \\
Štáhlavy, 1788-1850 & 37,5 & 10,5 & 2,3 & 22,5 & 27,2 & 778 \\
Kapličky, 1651-1720 & 30,2 & 12,9 & 12,9 & 6,7 & 37,5 & 272 \\
Kapličky, 1721-1840 & 57,5 & 8,5 & 9,2 & 8,0 & 16,8 & 447 \\
\hline
\end{tabular}

Quellen: Grulich, Populační, 303f; Velková, Familie und Besitzinteressen, 129.

Während damit zahlreiche der bisher vorliegenden Fallstudien für den mitteleuropäischen Raum eine relativ einheitliche Tendenz einer Stärkung der familialen Kontinuität im Übergang in die Moderne andeuten, lässt sich in anderen Regionen Europas offenbar ein gegenteiliger Trend beobachten. Im schwedischen Scania herrschten in der zweiten Hälfte des 18. Jahrhunderts durchaus vergleichbare Merkmale mit einer mehrheitlich innerhalb der Verwandtschaft stattfindenden Übergabe (davon etwa zu einem Drittel an die eigenen Kinder), ab etwa 1830 dagegen kam es zu einem deutlichen Rückgang der Weitergaben an die eigenen Kinder. Diese Lösung wurde nur mehr dann gewählt, wenn man als Altenteiler beim Haus

208 Besitztransfermuster in Gebieten mit Unteilbarkeit der Güter sind mit jenen in Gebieten mit Realteilung nur sehr bedingt zu vergleichen, da in letzteren ja keine Einzelperson ausgewählt wurde. Sabean stellte für Neckarhausen etwa fest, dass in 40 Prozent aller Fälle, in denen einzelne Grundparzellen ihren Besitzer wechselten, Käufer und Verkäufer nicht miteinander verwandt waren. Vgl. Sabean, Kinship, 94.

209 Robisheaux, Society, 132. 
bleiben wollte; viel häufiger gaben nun aber Hausbesitzer ihre Anwesen auf, um auf dem Markt ein anderes zu erwerben. ${ }^{210}$ Auch in Pinkenhof (heutiges Lettland) ging der Anteil der Besitztransfers an den Sohn wie auch an andere Verwandte nach etwa 1830 deutlich zurück. ${ }^{211}$ Wie der Rückgang familialer Kontinuitäten in einigen Teilen (Nord-)Europas vermutlich eine Folge eines sich herausbildenden Bodenmarktes und damit ein Ergebnis neuer sozio-ökonomischer Bedingungen war, so scheint auch der in vielen Teilen Mitteleuropas verstärkte Aufbau familialer Besitzkontinuitäten nicht Ausdruck einer traditionellen Kultur als vielmehr Teil einer spezifischen Modernisierungsstrategie gewesen zu sein.

Tabelle 35 : Verwandtschaftsbeziehungen in der Besitznachfolge, Belm 1681-1860

\begin{tabular}{lcccccc}
\hline & Sohn & $\begin{array}{c}\text { Schwieger- } \\
\text { sohn }\end{array}$ & $\begin{array}{c}\text { Mann }+2 . \\
\text { Frau }\end{array}$ & $\begin{array}{c}\text { Witwen- } \\
\text { heirat }\end{array}$ & Sonstige & \\
\hline $1681-1710$ & 42,6 & 14,9 & 14,9 & 13,9 & 13,9 & $100 \%$ \\
$1711-1740$ & 34,6 & 11,8 & 21,3 & 19,7 & 12,6 & $100 \%$ \\
$1741-1770$ & 31,4 & 13,7 & 19,4 & 18,9 & 16,6 & $100 \%$ \\
$1771-1800$ & 35,9 & 17,4 & 20,0 & 14,9 & 11,8 & $100 \%$ \\
$1801-1830$ & 42,9 & 11,7 & 23,4 & 11,7 & 10,2 & $100 \%$ \\
$1831-1860$ & 44,5 & 11,6 & 15,5 & 15,5 & 12,9 & $100 \%$ \\
$\mathrm{~N}$ & 370 & 131 & 202 & 151 & 128 & 982 \\
& $(37,7)$ & $(13,3)$ & $(20,6)$ & $(15,4)$ & $(13,0)$ & $100 \%$ \\
ohne Zweit- & 370 & 131 & - & 151 & 128 & 780 \\
ehen des & $(47,4)$ & $(16,8)$ & - & $(19,4)$ & $(16,4)$ & $100 \%$ \\
Mannes* & & & & & & \\
\hline
\end{tabular}

Quelle: Schlumbohm, Lebensläufe, 385.

*) Eigene Berechung.

Vergleicht man die Besitztransfermuster in europäischen Regionen mit Studien über den außereuropäischen Raum, so ist als signifikanter Unterschied die in Zentraleuropa bestehende Möglichkeit zur Weitergabe außerhalb des Verwandtenkreises festzustellen. In manchen russischen Regionen etwa musste in solchen Fällen zuvor mittels Adoption ein ,künstliches 'Verwandtschaftsverhältnis zwischen dem Vorbesitzer und dessen Nachfolger hergestellt werden. ${ }^{212}$

210 Dribe/Lundh, Retirement, 175 f.

211 Wetherell/Plakans, Networks, 661.

212 Vgl. etwa die Studie von Bohac, Strategies. Eine Studie über den nordostchinesischen Raum im 


\subsection{Der Wandel der räumlichen Stabilität bei der Haus besitzenden Bevölkerung}

Während in der sozialhistorischen Literatur heute - anders als in früheren Jahrzehnten - ein Bild der vorindustriellen ländlichen Gesellschaften gezeichnet wird, das insgesamt durchaus sehr vielfältige Formen und Typen von Mobilität in der frühen Neuzeit erkennen lässt, ${ }^{213}$ wird im Falle der Grund besitzenden Bevölkerung dieser Zeit nach wie vor eine überzeitlich gültige starke Orts- und Hausgebundenheit unhinterfragt angenommen. Wie sesshaft und an ihr Haus gebunden waren aber die Bauern und die anderen ländlichen Hausbesitzer während der frühen Neuzeit? Waren sie immer im selben Ausmaß immobil? Das als überzeitlich angenommene Bild des an seine Scholle gebundenen Bauern, der „in Generationen denkt" und dessen oberstes Prinzip es ist, den Hof in der Familie zu erhalten, wirkte offenbar zu stark, um sich solche Fragen überhaupt zu stellen. Bauern gelten im deutschsprachigen Raum geradezu als Prototyp einer sesshaften und stabilen Bevölkerung, landarme oder landlose Hausbesitzer dagegen nicht. Im schweizerischen Langnau etwa veränderten gerade die Haushalte der untersten Steuerklassen im 18. Jahrhundert überaus häufig ihren Wohnsitz innerhalb der Gemeinde. ${ }^{214}$

Für alle sozialen Gruppen unter den Hausbesitzern der Pfarre Kapličky wurde während des Untersuchungszeitraums eine Zunahme der durchschnittlichen Besitzdauer festgestellt. Diese Entwicklung hatte, wie erwähnt, durchaus unterschiedliche Ursachen. ${ }^{215}$ Sieht man sich aber sämtliche Kurzzeitbesitzer (d.h. unter zehn Jahre Besitzdauer) der ersten Zeitperiode (1651-1720) genauer an und fragt nach den Ursachen des Besitzendes, so zeigt sich, dass weder die Demographie (infolge eines niedrigen Sterbealters) noch die Bedeutung bestimmter sozialer Praktiken wie die weite Verbreitung von Inter Vivos-Transfers ausreichende Erklärungsfaktoren für das vorzeitige Ende der Hausinhaberschaft darstellen. Lediglich bei 36 Prozent dieser Fälle war der Tod die Ursache des Besitzendes (und nur etwa zehn Prozent wechselten ins Altenteil, vgl. Tabelle 36). Eine Mehrheit dieser kurzzeitigen Hausbesitzer dagegen gab in dieser Periode ihr Haus aus anderen Gründen auf und wechselte ihren Wohnort (inner- oder außerhalb der Pfarre). Dem Ortswechsel konnte ein Leben als besitzloser Inwohner oder als neuerlicher

19. Jahrhundert zeigt, dass auch dort die Weitergabe über die Witwe, selbst wenn ein Sohn vorhanden war, häufig möglich war. Besitztransfers an nichtverwandte Personen kamen dagegen nicht vor.

Vgl. Lee/Campell, Succession.

213 Vgl. dazu genauer Kapitel 6.2.

214 Pfister, Bevölkerungsgeschichte, 48. Auch Mooser, Ländliche Klassengesellschaft, $201 \mathrm{ff}$., betont die Sesshaftigkeit der bäuerlichen Gruppen im Gegensatz zur Mobilität der unterbäuerlichen Gruppen und widmet diesem Gegensatz ein ganzes Kapitel.

215 Vgl. Kapitel 7.6.2. 
Haus- oder Hofbesitzer folgen. Bei einigen dieser Fälle lag die Ursache des Ortsund Positionswechsels sicherlich an finanziellen Problemen, etwa im Unvermögen, den Kaufpreis des erworbenen Hauses tatsächlich vollständig abzubezahlen. Diese Personen führten danach überwiegend ein Leben als besitzlose Inwohner. Während diejenigen, die die Pfarre verließen, nicht weiter verfolgt werden können, zeigen die Fälle der in der Pfarre Verbleibenden, dass im 17. Jahrhundert mehrere Besitzer ihr Haus auch verkauften und anstelle dessen ein anderes innerhalb der Pfarre erwarben. Hinter diesen Entscheidungen verbarg sich sicherlich nicht durchgängig ein äußerer Zwang zum Verkauf, sondern auch konkrete individuelle Planung und die Verfolgung bestimmter Strategien. Einzelne wiederholten dies mehrmals in ihrem Leben (vgl. das Beispiel von J. und H. Zanner). Zwischen 1637 und 1720 gab es feststellbar 16 derartige Fälle, danach nur mehr sechs. Es handelt sich dabei jedenfalls um eine Mindestanzahl, da es nicht in allen Fällen gelungen ist, identische Besitzernamen zweifelsfrei als identische Personen zu identifizieren, und die Zahl derjenigen, die außerhalb der Pfarre neuerlich ein Haus erwarben, im Dunkeln bleibt. In manchen anderen europäischen Regionen scheint ein Wohnungs- oder Wohnortwechsel der abtretenden Besitzer dagegen weitgehend unbekannt gewesen zu sein. ${ }^{216}$ Dagegen war es auch in einigen westmährischen Herrschaften im 17. Jahrhundert eine weit verbreitete Praxis, dass Hausbesitzer ihr Anwesen verkauften, um sich danach ein größeres oder kleineres zu kaufen. ${ }^{217}$ Wie die im Anhang ausgewiesenen Fälle illustrieren, lassen sich für die erste Periode mehrere Typen unterscheiden: sozialer Aufstieg, ein möglicherweise lebenszyklisch bedingter Wechsel auf ein kleineres Anwesen, Verschuldung als Ursache. Interessant erscheint, dass in mehreren Fällen das Haus einem Bruder überlassen wurde. Auch ein Tausch der Höfe/Häuser zwischen zwei Besitzern lässt sich im 17. Jahrhundert einige Male beobachten. Acht Personen tauschten zwischen 1637 und $1708 \mathrm{ihr}$ Anwesen. Rein quantitativ waren diese Fälle eines Stellenwechsels oder Häusertausches nicht zahlreich. Dennoch ist im Vergleich mit der Periode nach 1720 ein qualitativer Wandel erkennbar. Die Wechsel des Hauses durch Verkauf gehen zahlenmäßig deutlich zurück. Einen Häusertausch gibt es nach 1708 überhaupt nicht mehr. Dies deutet auf den Verlust einer Option hin. Zudem repräsentieren die wenigen Fälle eines Häuserwechsels nach 1720 beinahe ausschließlich den Typus eines gelungenen sozialen Aufstiegs.

Eine verbreitete Praxis des Häusertausches lässt sich sowohl für mehrere Regionen in Böhmen als auch für deutschsprachige Gebiete zwischen dem 16. und dem

216 Siehe jedoch die bei Trossbach, Haus, 311, erwähnten Berichte aus der Uckermark und aus dem spätmittelalterlichen Westfalen.

217 Chocholač, Selské penize, 182. 
frühen 18. Jahrhundert nachweisen. Dies scheint in besonderem Maße auf eine geringe „emotionale“ Bindung an das eigene Haus und Land zu deuten. Während der Häusertausch in der südböhmischen Herrschaft Chýnov noch während des 18. Jahrhunderts sehr häufig war, scheint er in zahlreichen anderen Regionen zu dieser Zeit kaum mehr vorzukommen. Insgesamt handelt es sich aber um ein Phänomen, das noch ungenügend untersucht ist. ${ }^{218}$

Für die Zeit vor etwa 1720 muss die Bindung der Familien an ihr Haus bei allen Schichten der Pfarre als gering betrachtet werden. Es kam durchaus auch vor, dass Personen von außerhalb der Herrschaft ein Anwesen kauften. So stammten beispielsweise einige Hauskäufer aus dem der benachbarten Herrschaft Rožmberk untertänigen Marktort Frýmburk oder auch aus Oberösterreich. In anderen böhmischen Herrschaften scheinen dagegen Hauskäufer aus benachbarten Herrschaften überhaupt nicht auf. . $^{219}$

Mit dem beginnenden 18. Jahrhundert verstärkte sich dann die Immobilität der Hausbesitzer deutlich. Wer einmal zu Hausbesitz gelangt war, wechselte seinen Wohnsitz zeitlebens nicht mehr. Dieser Wandel verweist darauf, dass die gängige Vorstellung von stark an Haus und Boden gebundenen Bauern keine überzeitliche Konstante ausdrückt, sondern häufig bloß eine ideologische Rückprojektion späterer Verhältnisse darstellt.

Angesichts des deutlich erkennbaren historischen Wandels im Grad der Sesshaftigkeit bei allen Gruppen von Hausbesitzern in dieser dörflichen Gesellschaft erscheint es auch kaum angemessen, für diese Region ein duales Gesellschaftsmodell - bei dem der immobilen Gesellschaft der Besitzenden die „unstabile Gesellschaft" der Armen und Landlosen gegenübergestellt wird - anzuwenden, wie dies andere Autoren vorgeschlagen haben. ${ }^{220}$ Landarme Hausbesitzer und ein Teil der Inwohnerbevölkerung verhielten sich in dieser Hinsicht der bäuerlichen Bevölkerung sehr ähnlich. Bei aller Bedeutung einer Betonung der lange übersehenen hohen Mobilität in der frühen Neuzeit in der neueren Literatur sollte allerdings auch nicht vergessen werden, dass es zu allen Zeiten auch zahlreiche Menschen gab, deren Ortsgebundenheit und Sesshaftigkeit stark ausgeprägt war.

218 Vgl. Grulich, Migrationsstrategien; Štefanová, Zur Stellung der Untertanen. Breit, Leichtfertigkeit, 62, kann dieses Phänomen in allen drei untersuchten oberbayerischen Dörfern im Zeitraum von 1670 bis 1808 nachweisen.

219 Štefanová, Erbschaftspraxis, 228.

220 Vgl. Collins, Mobility, bes. 572f. 
Tabelle 36: Hausbesitzer mit einer Besitzdauer von weniger als 10 Jahren (1651-1720)

\begin{tabular}{lcc}
\hline Besitzaufgabe wegen & N & $\%$ \\
\hline Tod des Besitzers & 21 & 36,2 \\
Wechsel ins Altenteil & 6 & 10,3 \\
Häusertausch & 5 & 8,6 \\
Neukauf eines Anwesens & 6 & 10,3 \\
Verlassen der Pfarre & 9 & 15,5 \\
Inwohner in anderem Pfarrdorf & 2 & 3,4 \\
Verkauf bei Verbleib im Dorf & 3 & 5,2 \\
Unklar & 6 & 10,3 \\
\hline Summe & 58 & 100,0 \\
\hline
\end{tabular}

Quelle: Datenverknüpfung Grundbücher und Familienrekonstitution (Státní oblastní archiv Třeboň, Sbírka jihočeskych matrik, Farní úřad Kapličky č. 9; fond C Vyšší Brod, Pozemková kniha č. 453, č. 464, č. 465 č. 465 , č. 475 , č. 479 , č. 480 und č. 553$)$.

Übersicht 1: Hausbesitzer der Pfarre Kapličky, die ihr Anwesen wechselten

\section{Durch Verkauf des Hauses und Kauf eines neuen Hauses}

1637/47/48/54 J. Zanner - Kapličky $6 \rightarrow$ Kapličky $8 \rightarrow$ Kapličky $4 \rightarrow$ Kapličky 11

Jacob und Helena Zanner besaßen seit 1637 den Hof Nr. 6 (9 Strich Ackerland) und verkauften diesen um 135 fl.. 1647 erwarben sie Hof Nr. 8 (18 Strich) um 240 fl., den sie bereits ein Jahr später um 187 fl. verkauften und um 100 fl. auf Nr. 4 (12 Strich) wechselten. Ein weiteres Jahr später, 1649, veräußerten sie diesen Besitz um 140 fl.. In der Volkszählung 1651 waren sie als Inwohner im Dorf genannt, 1654 aber erwarben sie die Gastwirtschaft mit Nr. 11 (10 Strich) um 156 fl., die sie 1666 übergaben und ins Ausgedinge gingen.

1639 J. Weimüller - Krasné Pole $2 \rightarrow$ Hvězda 1

Nach der Übergabe des Hofes in Krasné Pole an den Sohn kaufte Weimüller ein Kleinhaus in Hvězda.

1639/41 M. Krepper - Lipová $2 \rightarrow$ Lipová 6

Der Bauer von Nr. 2 errichtete sich 1639 Kleinhaus Nr. 6, in das er nach Übergabe an den Schwiegersohn 1641 zog. Nr. 6 übergab er später an einen zweiten Sohn. 
$1641 / 49$

1648

1648

$1656 / 68$

1665

1666

1675

1679

$1679 / 80 / 95$

1690

1695
L. Saumer - Mnichovice $4 \rightarrow$ Frantoly 6

Nach dem Verkauf des Hofes in Mnichovice 1641, erwarb Saumer 1649 den neuen Hof in Frantoly.

M. Nimmervoll - Adámky $1 \rightarrow$ Komařice

Der Chalupner war nach dem Verkauf seiner Wirtschaft Grundbesitzer im ca. 50 Kilometer entfernten, ebenfalls zur Klosterherrschaft gehörigen Dorf Komařice.

S. Koller - Krasné Pole $1 \rightarrow$ Krasné Pole 4

Nach dem Verkauf des Bauernhofs Nr. 1 kaufte Koller die Chalupnerstelle Nr. 4.

M. Draxler - Hřbitek $2 \rightarrow$ Kapličky 4

Nachdem er seit 1640 Kleinhäusler in Hřbitek war, kaufte er 1656 den Hof in K., den er bis 1674 innehatte. Das Kleinhaus verkaufte er 1668.

M. Draxler - Krasné Pole $3 \rightarrow$ Kapličky 3

Er verkaufte nach 35 Jahren seinen Bauernhof in Krasné Pole, um den Hof Kapličky Nr. 3 zu kaufen, wo er noch 1 Jahr Bauer war. Er starb 1666.

G. Wagner - Adámky $2 \rightarrow$ Kapličky 11

Nach 12 Jahren auf Chalupnerstelle erwarb er den Bauernhof mit Gastwirtschaft in Kapličky von J. Zanner (siehe erster Fall).

J. Hutter - Hodoň $7 \rightarrow$ Mnichovice 2

Der Bauernsohn von Mnichovice Nr. 2 kaufte nach seiner Heirat das Kleinhaus in Hodoň. Ein halbes Jahr später verkaufte er und übernahm den elterlichen Hof.

Th. Mautner - Vyšina $1 \rightarrow$ Vyšina 6

Kaufte nach Übergabe des Bauernhofes Nr. 1 die Kleinstelle Nr. 6.

M. Hoffmann - Kapličky $10 \rightarrow$ Kapličky 12

Weichender Bauernsohn von Nr. 2 kaufte 1679 Hof Nr. 10, den er 1680 an den Bruder weitergab. Ab 1695 als Dorflehrer im Kleinhaus Nr. 12 belegt. Dazwischen war er möglicherweise Inwohner. H. Hoffmann - Adámky $4 \rightarrow$ Kapličky 14

Wechselte durch Kauf von einem landarmen Haus zum nächsten. Ch. Nimmervoll - Hodoň $3 \rightarrow$ Hodoň 10

Der bäuerliche Hoferbe (Nr. 3) verkaufte nach 2 Jahren an seinen Bruder und errichtete ein landloses Haus. 
1722

1741/43/45 A. Koller - Kapličky $12 \rightarrow$ Krasné Pole $7 \rightarrow$ Adámky 1

War in Folge Inhaber zweier landarmer Häuser, dann Kleinbauer in Adámky.

$1761 / 68$

1779

1832

\section{Durch Häusertausch}

zwischen

1630-1637

1664

$1671 / 73$

1708

B. Schimpl - Hodoň $8 \rightarrow$ ?

Nach 18 Jahren als Kleinstellenbesitzer verkaufte er das Haus. Fünf Monate später bereute er seine Entscheidung und bekam gegen eine Strafzahlung sein Haus, das er in Folge weitere 17 Jahre innehatte, zurück.

A. Tweraser - Dobřin $7 \rightarrow$ ? $\rightarrow$ Adámky 4

Verkaufte 1761 nach 7 Jahren das landlose elterliche Weberhaus an den Bruder; war ab 1768 durch Witwenheirat Inhaber eines Kleinhauses in Adámky.

A. Dobringer - Hřbitek $1 \rightarrow$ Kapličky 2

Verkaufte eine Kleinstelle an seinen Bruder und erwarb den bäuerlichen Hof in Kapličky.

J. Fischböck - Hvězda $3 \rightarrow$ Vyšší Brod

Veräußerte Haus mit geringem Grundbesitz und wurde Hausbesitzer im Marktort.

S. Hutter, U. Hoffmann - Kapličky $2 \leftrightarrow$ Adámky 4

Kleinhäusler und Bauer tauschten ihre Anwesen. Hoffmann übergab den so erworbenen Hof in Kapličky im Jahr 1645 an seinen Sohn.

G. Kastner, S. Hutter - Lipová $5 \leftrightarrow$ Kapličky 5

Nachdem beide erst wenige Jahre (4 bzw. 7) gewirtschaftet hatten, tauschten sie ihre relativ gleichwertigen Höfe.

G. Koller, A. Kern - Kapličky $1 \leftrightarrow$ Hřbitek 1

Der ca. 50-jährige Koller tauschte nach 27 Jahren seinen Hof in Kapličky gegen eine Kleinstelle. Der sicher jüngere Kern starb 1673, worauf Koller mit der Witwe Kern wiederum Haus tauschte. H. Leitgöb, W. Merxbauer - Martinkov $3 \leftrightarrow$ Mnichovice 6

H. L. verkaufte das bäuerliche Anwesen Martinkov Nr. 3 nach 12 Jahren und kaufte ein Kleinhaus, auf dem er noch 36 Jahre Besitzer war. W. M. war nach 8 Jahren im Kleinhaus 21 Jahre lang Bauer in Martinkov. 
7.9 Typen unterschiedlicher Strategien des Besitzerwerbs und -erhalts

Im Pfarrgebiet von Kapličky bestand während des Untersuchungszeitraums ein sehr hoher Spielraum für unterschiedliche Lösungsmöglichkeiten der Besitznachfolge: Haus und Land konnten zu Lebzeiten oder nach dem Tod an ein leibliches Kind, an Verwandte oder an familienfremde Personen gehen. Dieses weite Feld der Möglichkeiten erlaubte es den handelnden Personen, unterschiedliche Interessen und Strategien zu verfolgen. Die einen Besitzerwechsel aushandelnden Personen hatten bei ihrer Entscheidung über die Person des Besitznachfolgers wie bei der Festsetzung des Kaufpreises zumeist wohl ,rationale wie emotionale Motive gleichzeitig. Die Grundbücher geben im Allgemeinen jedoch nur ökonomische Konstellationen wieder, über andere Motive enthalten sie keinerlei Auskunft. Es ist eine Besonderheit, wenn sich in einzelnen Fällen etwa durch außergewöhnliche Formulierungen doch Verweise auf die emotionale Seite des Generationentransfers finden. Als die verwitwete Anna Maria Petermueller 1789 ihr Dominikalhaus in Sand, einem Ortsteil von Vyšší Brod, ihrer „anverwandten“ Susanna Eibl verkaufte, wurde der auffallend geringe Kaufpreis ausdrücklich mit der „fleissigen und getreuen Dienstleistung durch mehrere Jahre" begründet. 1790 erließ sie ihr die restliche Kaufsumme ganz. ${ }^{221}$

Seit dem frühen 18. Jahrhundert war eines der Ziele der Haus besitzenden Bevölkerung, ihren Besitz an die eigenen Kinder/Söhne weiterzugeben. Dafür kam dem Zeitpunkt des Besitztransfers eine hohe Bedeutung zu. Der plötzliche und vorzeitige Tod eines Teils des Besitzerpaares erforderte eine rasche Neuregelung in der Wirtschaftsführung und konnte damit die Pläne, ein leibliches Kind als Nachfolger einzusetzen, gefährden. Der rechtzeitige Rückzug bereits zu Lebzeiten bei einer gleichzeitigen Übergabe an den Sohn (oder an ein anderes Kind) war eine sichere Möglichkeit, das Anwesen im Besitz der Familie zu halten. Die Einrichtung eines Ausgedinges für die abtretenden Besitzer war dabei ein wichtiger Bestandteil dieses Plans, wenn auch keinesfalls in allen Fällen einer Ausgedingeregelung das Ziel einer familialen Kontinuität am Hof verfolgt wurde. ${ }^{222}$ Auch die seit dem frühen 18. Jahrhundert praktizierte Interimsregelung für den zweiten Mann der Witwe ermöglichte es auch in diesen Fällen, das Anwesen den Kindern zu erhalten. ${ }^{223}$ Für Lorenz Fischböck beispielsweise, der in den 1760er Jahren die Witwe Gertraud Weimüller geehelicht hatte, ermöglichte erst eine derartige Interimsregelung, dass der Hof Frantoly Nr. 6 von 1766 weiterhin (dann ununterbrochen bis mindestens zur Mitte des 19. Jahrhunderts) letztlich in der männlichen Abstam-

221 SOA Třeboň, fond C Vyšší Brod, PK, č. 553, fol. 25.

222 Vgl. ausführlich Kapitel 9.

223 Vgl. Kapitel 7.6.5. 
mungslinie der Familie Weimüller verblieb. Eine hohe Kontinuität in der Patrilinie war also manchmal auch trotz ,Brüchen' möglich.

Sicherlich war es auch eine Intention besitzender Eltern, alle Kinder möglichst gut zu versorgen. Dazu mussten die ,weichenden' Kinder, die das Elternhaus nicht erhielten, entsprechend finanziell gut ausgestattet wurden, um ihnen die Möglichkeit zu bieten, in ein anderes Haus einheiraten zu können. Dieses „zuwiheiraten“ wird in einer Monographie über diese Region aus dem späten 19. Jahrhundert ausdrücklich als „Glücksfall“ bezeichnet. ${ }^{224}$ Vor allem die Töchter wurden deshalb beim Heiratsgut öfter, vor allem mittels Naturalleistungen, in Einzelfällen allerdings auch bereits beim Anteil am Kaufpreis, bevorzugt. ${ }^{225}$ In einigen Fällen waren die Bemühungen, den eigenen Kindern die Einheirat auf einem anderen Hof zu ermöglichen, auch sehr erfolgreich. So gelangten etwa vier Kinder von Mathias Draxler, Besitzer eines durchschnittlich großen Bauernhofes in Krasné Pole, zu Beginn des 18. Jahrhunderts ebenfalls in den Besitz eines Hofes innerhalb der Pfarre. Eine derartige Strategie, die auch für andere Fälle in anderen Regionen belegt ist, brachte der Familie überdies Einfluss im Dorf und vermutlich auch finanzielle Unterstützung in schwierigen Situationen. ${ }^{226}$

Die gute soziale Platzierung möglichst vieler Kinder war ein erstes zentrales Prinzip. Erfolgreich gehandhabt, konnte dies dazu führen, dass allmählich einzelne Familien mehrere Anwesen in ihren Besitz brachten. Den Mitgliedern der Familie Mautner z.B. gelang es nicht nur, ihre Häuser über Generationen hinweg in der männlichen Abstammungslinie weiterzugeben, sondern auch Besitzdynastien auf mehreren Häusern zu entwickeln. So waren schließlich zur Mitte des 19. Jahrhunderts etwa fünf Bauernhöfe der Pfarre im Besitz der männlichen Nachkommen von Erhard Mautner, der zwischen 1671 und 1700 Bauer im Pfarrdorf Martínkov gewesen war (vgl. Abbildung 1). Zur Perennität der Höfe in der Region trat zunehmend auch eine Perennität der Familien.

In Ansätzen entwickelte die Haus besitzende Bevölkerung ein endogames Heiratssystem, um den Besitz unter sich zu halten. Mittels wechselseitiger Heiraten der Kinder zweier Familien/Häuser konnten etwa mehrere Kinder mit Haus und Grund ,versorgt' werden. Ein sicherlich erwünschter Nebeneffekt derartiger Regelungen zwischen zwei Bauernhöfen war de facto eine Einsparung der Mitgift. Auch bei Heiraten zwischen affinal verwandten Personen konnte es sich ergeben, dass eine zuvor ausbezahlte Mitgift wieder an den Hof zurückkam. ${ }^{227}$ So fand am

224 Märten, Heimatkunde, 202.

225 Vgl. auch Begemann, Lebensbedingungen, 171; Sabean, Property, 252.

226 Vgl. Harnisch, Ökonomie, 86.

227 Vgl. dazu Sabean, Kinship, bes. 236. 
Abbildung 1: Hausbesitz in der Familie Mautner bis in die Mitte des 19. Jahrhunderts

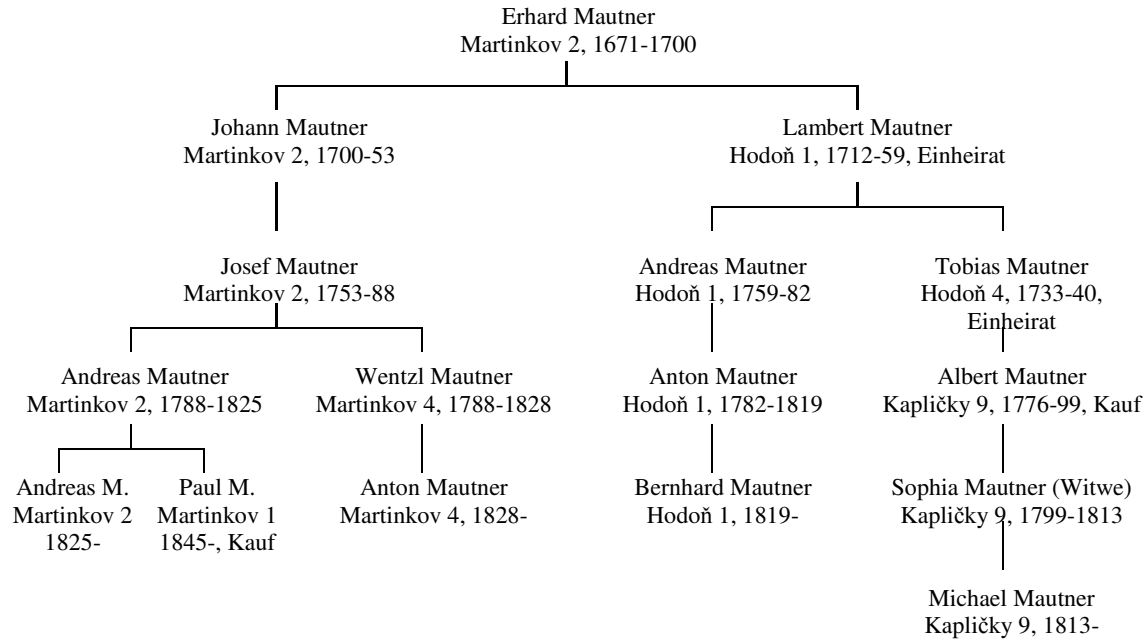

Quelle: Datenverknüpfung Grundbücher und Familienrekonstitution

Anmerkung: Jeder Besitzer ist jeweils mit Adresse und Besitzdauer gelistet. Bei dieser Darstellung wurden nur die Haus besitzenden und nicht alle Nachkommen angeführt. ,Einheirat' meint eine Verehelichung mit der Tochter des Vorbesitzerpaares.

13. Oktober 1788 in der Pfarrkirche von Kapličky eine Trauung von drei Paaren gleichzeitig statt. Alle drei lebenden Kinder von Josef Mautner aus der erwähnten Familie Mautner, Bauer in Martinkov Nr. 2, verehelichten sich am selben Tag. Sohn Andreas heiratete Maria Hehenberger, sein Bruder Wentzl deren Halbschwester Katharina Hehenberger. Beide Frauen waren die Töchter des Nachbarn Martin Hehenberger, Bauer auf Martinkov Nr. 4. Gleichzeitig verehelichte sich Maria Mautner, die Schwester der beiden Bräutigame von Martinkov Nr. 2, mit Bernhard Leitgöb, dem übernehmenden Sohn von Martinkov Nr. 1. Maria Hehenberger und Andreas Mautner erhielten dadurch den Hof Nr. 2, Katharina und Wentzl Mautner wurden Besitzer von Nr. 4. Die beiden großjährigen Kinder von Nr. 4 waren dadurch ebenso versorgt wie alle drei Kinder von Nr. 2. Bereits zuvor hatte auch eine Verbindung zwischen den Höfen Nr. 4 und Nr. 1 bestanden. Martin Hehenberger (Besitzer Nr. 4) hatte nämlich Jahre zuvor Maria Leitgöb, eine ältere Schwester des Bernhard Leitgöb, geheiratet - sie war somit die Mutter der sich nun verehelichenden Maria Hehenberger. Bernhard Leitgöb heiratete daher die Schwester des Mannes seiner Nichte. Es entstanden mit dieser Lösung recht 
komplexe und vielfache Verflechtungen zwischen den Bewohnern dreier benachbarter Häuser. ${ }^{228}$

Wechselseitige Eheschließungen zwischen zwei Familien waren auch bei den besonders wohlhabenden Familien der Region verbreitet - so etwa zwischen den beiden großen Leinenverleger- und -händlerfamilien in der nahen Umgebung (allerdings in beiden Fällen außerhalb des Herrschaftsgebietes des Klosters Vyšší Brod gelegen). Eine Tochter des Adalbert Greipl, des Begründers des großen Handelshauses in Frýmburk an der Moldau, heiratete 1788 den verwitweten Leinenverleger J. P. Löffler im nicht weit entfernten Weissenbach im Mühlviertel, der übrigens ebenfalls aus Frymburk stammte. ${ }^{229}$ Maria Theresia, Löfflers Tochter aus erster Ehe, wiederum heiratete Mathias Greipl, den Sohn und Erben des Handelshauses Adalbert Greipl. Das Ehepaar Mathias und Maria Theresia Greipl selbst scheint bei der Verheiratung ihrer Kinder relativ strikte ökonomische und politische Interessen verfolgt zu haben: Zwei Töchter wurden jeweils mit einem Verwalter der Schwarzenbergischen Güter in Südböhmen verehelicht, eine weitere heiratete im frühen 19. Jahrhundert den nunmehrigen Besitzer des Löffler-Gutes in Weissenbach. Adalbert Stifter dagegen hatte um die Hand von Fanni, einer weiteren Tochter des Hauses, angehalten, wurde jedoch aufgrund seiner „Mittellosigkeit" von ihren Eltern abgewiesen. 230

Einen etwas anderen Typus stellt die Heirat zwischen miteinander verschwägerten Personen dar. Die Darstellung in Abbildung 2 illustriert einen solchen Fall aus dem frühen 18. Jahrhundert. An diesem Beispiel wird auch besonders deutlich, dass eine Heirat zwischen verschwägerten Personen strategisch eingesetzt wurde, um ein bestimmtes Anwesen zu erlangen. Das Anwesen Krasné Pole Nr. 6 war zuvor im Besitz der Familie Martetschläger gewesen, danach ging es an die Tochter Barbara und deren Mann Philip Stipl. Die Ehe von Philip und Barbara Stipl, geb. Martetschläger, blieb in der Folge allerdings kinderlos. Die beteiligten Personen verständigten sich wohl auf ein Arrangement im engsten Kreis der affinalen Verwandten, um sich den wegen Kinderlosigkeit frei werdenden Hof Nr. 6 gleichsam zu teilen. Im Zentrum standen dabei die beiden bereits verheirateten Geschwister der Frau des Hauses: der selbst einen Hof leitende Bruder Georg Martetschläger, sowie die ebenfalls bereits verehelichte Schwester Sophia Martetschläger (verehel. Leitgöb). Die Schwester der Frau des Bruders (Sophia Draxler) und der Bruder

$228 \mathrm{Ob}$ in diesem Zusammenhang auch kirchliche Heiratsverbote, die sich ja auch auf Heiratsverwandtschaft bezogen, mittels Ansuchen um Dispens aufgehoben wurden, konnte nicht näher untersucht werden. Vgl. dazu Goody, Entwicklung, 70 ff. und an einem regionalen Fallbeispiel Theibault, German Villages, 90.

229 Vgl. dazu Kapitel 4.5.

230 Vgl. Dolzer, Stifterkreise; Berger, Bayer, 167 ff.; Komlosy, Industrie-Kultur, 200. 
Abbildung 2: Heiraten zwischen verschwägerten Personen

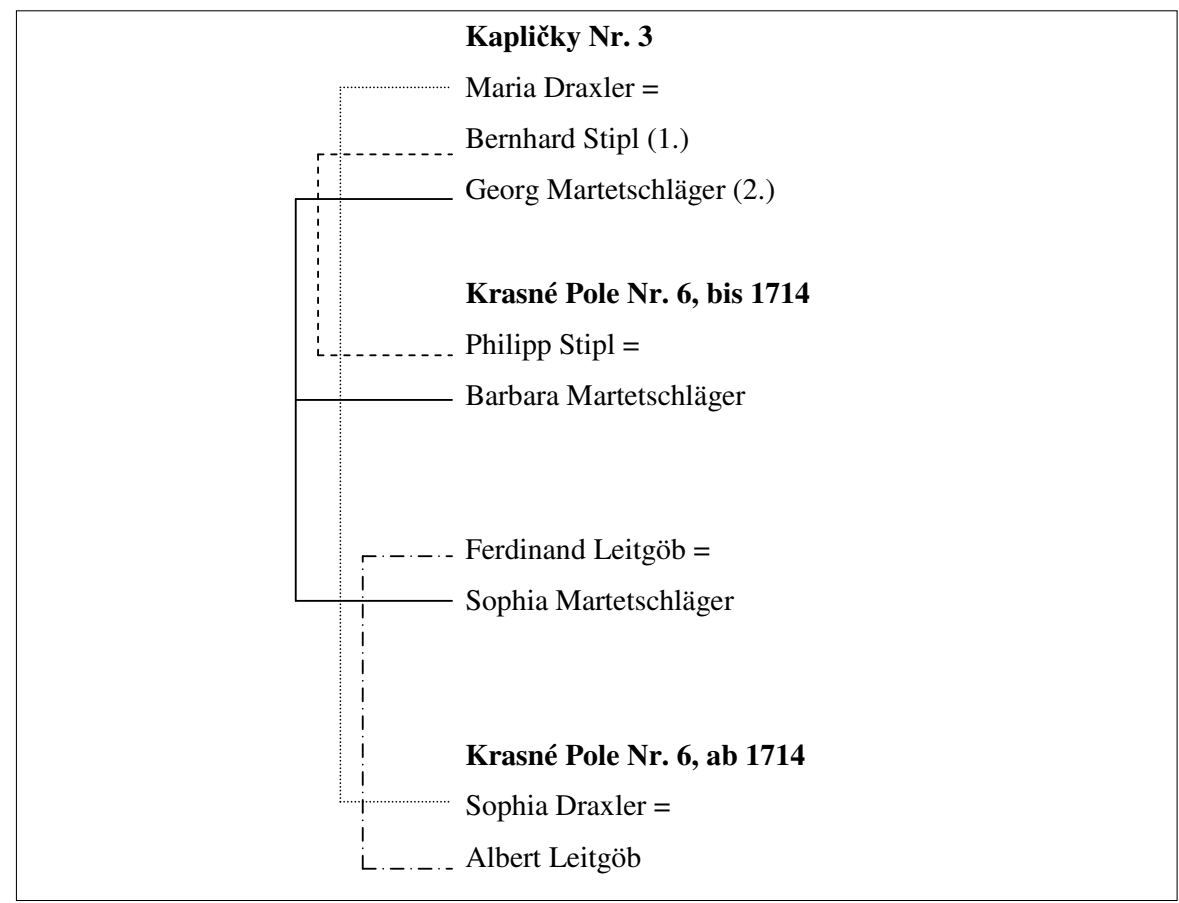

Quelle: Datenverknüpfung Grundbücher und Familienrekonstitution

Anm.: Alle jeweils durch eine Linie verbundenen Personen sind Geschwister.,=“ bedeutet Ehe, in Klammern stehende Zahlen beziehen sich auf Erst- und Zweitehe.

des Mannes der Schwester (Albert Leitgöb) verehelichten sich und kauften das Anwesen. Die Ehefrau von Georg Martetschläger war außerdem zuvor bereits mit einem Bruder des Philip Stipl verheiratet gewesen. Ohne die Geldflüsse in diesem Fall detailliert nachvollziehen zu können (belegt sind im Grundbuch bis zumindest 1739 Zahlungen der neuen Besitzer an Philip Stipl), liegt die Vermutung nahe, dass die getroffene Lösung (beide Ehepartner waren mit beiden Teilen des Vorgängerpaares verwandt) auch dazu verwendete wurde, um verschiedene finanzielle Verpflichtungen leichter auflösen zu können. Zumindest führte diese Lösung dazu, dass die jährlich zu zahlenden Raten der Kaufsumme und die Mitgiften innerhalb eines sehr engen Kreises von bereits miteinander verwandten Personen blieben. Beachtenswert ist, dass in diesem Fall ein Abstammungs- oder Liniendenken keine Rolle gespielt haben dürfte. Es war offenbar kein Ziel, das Haus Nr. 6 im Besitz der Familie Martetschläger zu halten. 


\author{
8. DIE HEIRAT: EIN ,SOZIALES PRIVILEG‘ \\ DER BESITZENDEN? \\ EUROPEAN MARRIAGE PATTERN, ,VOLLSTELLEN'- \\ THEORIE, UND DIE LOKALEN VERHÄLTNISSE ${ }^{1}$
}

Erfolgreiche wissenschaftliche Theorien durchlaufen in ihrer Rezeptionsgeschichte manchmal einen erstaunlichen Wandel. Eine häufige, aber manchmal unkritische Zitierung kann dazu führen, dass zentrale Aussagen einer Theorie in den Hintergrund rücken und stattdessen unter einem erfolgreichen Etikett andere Inhalte transportiert werden. In der deutschsprachigen sozialhistorischen Forschung scheint mir dies bei John Hajnals Konzept eines spezifischen ,European Marriage Pattern' der Fall zu sein. Unter Berufung auf diesen Terminus werden häufig insbesondere in der deutschsprachigen Forschung - die Annahmen des Modells der sogenannten ,Vollstellentheorie' (bzw. der ,agrarischen Bevölkerungsweise') vertreten. In diesem Kapitel werden daher die Unterschiede zwischen ,European Marriage Pattern' und,Vollstellentheorie' diskutiert sowie zentrale Aussagen der ,Vollstellentheorie‘ über das Heiratsverhalten in vorindustrieller Zeit am Beispiel der lokalen Fallstudie zur südböhmischen Pfarre Kapličky überprüft. Dabei wird gezeigt, dass diese Theorie keine Gültigkeit zur Erklärung des traditionalen Heiratsverhaltens beanspruchen kann.

John Hajnals „nahezu kanonisierte These“ ${ }^{2}$ von der Einzigartigkeit eines europäischen Heiratsmusters (European Marriage Pattern, EMP) beruht in erster Linie auf einem empirischen Befund: Hajnal wies nach, dass sich um 1900, vermutlich aber bereits seit Beginn der frühen Neuzeit, die Bevölkerung West- und Mitteleuropas in ihrem Heiratsverhalten stark von ost- und außereuropäischen Gesellschaften unterschied. Westlich einer fiktiven Linie, die etwa von St. Petersburg bis Triest gezogen werden könnte, heiratete man kontinuierlich erst relativ spät, und ein nicht unbedeutender Prozentsatz der Bevölkerung blieb zeitlebens ledig. ${ }^{3} \mathrm{Haj}-$ nals Überlegungen über die Ursachen dieses Musters stellen eher die Skizzierung eines Forschungsproblems dar, denn den Entwurf einer ausformulierten Theorie

1 Dieses Kapitel beruht auf einer Überarbeitung meiner beiden Aufsätze: Zeitlhofer, „Eiserne Ketten“, und: Zeitlhofer, Aspekte.

2 Schlumbohm, Sozialstruktur, 323.

3 Hajnal, European marriage patterns; Hajnal, Two kinds. 
des Heiratsverhaltens; ${ }^{4}$ er sprach aber mit dem Gesindedienst und der Dominanz der Kernfamilie zweifelsohne wichtige Einflussfaktoren an. Konstitutives Merkmal für Hajnals eigene Begründung des EMP ist die Bindung der Eheschließung an die Gründung eines eigenen Haushalts: „[A]fter marriage a couple are in charge of their own household“. ${ }^{5}$ In der lebhaften internationalen Diskussion kristallisierten sich danach unterschiedliche Erklärungsmodelle für das EMP heraus. ${ }^{6}$ Beide bringen die Heirat mit der Errichtung eines eigenen Haushaltes durch das frisch vermählte Paar in Verbindung. Das erste Modell, das überwiegend auf die ,individualistische“ vorindustrielle Gesellschaft Englands angewendet wird, nimmt neolokale Haushaltsgründung an und operiert mit einem neo-malthusianischen Erklärungsmuster. Die Möglichkeiten zur Eheschließung werden vor allem in Abhängigkeit von der Lohn- und Preisentwicklung gesehen. ${ }^{7}$ Im zweiten Modell, das für die ,familistischen' Gesellschaften des vorindustriellen Kontinentaleuropa entwickelt wurde, wird überwiegend mit der Existenz eines ,Nischenmechanismus argumentiert: ${ }^{8}$ Eheschließung und Fortpflanzung seien an den Besitz einer ,ökonomischen Nische‘ geknüpft gewesen.

Beide Modelle dienen als Begründung dafür, dass im vorindustriellen Europa, vermittelt über Heiratsalter und Heiratshäufigkeit, ein demo-ökonomisches Gleichgewicht (,homöostatisches Regime') bestanden habe, das ein allzu rasches Bevölkerungswachstum verhindert habe. ${ }^{9}$

Die Debatte über das EMP erlebte in der Forschung mehrfach Aktualisierungsschübe, in den 1990er Jahren etwa warfen Ostöffnung und bevorstehende EUErweiterung die Frage nach,where does Europe end?‘ auf. Manchen Sozialhistori-

4 Vgl. Fertig, Hajnal hypothesis.

5 Hajnal, Two kinds, 69.

6 Vgl. Ehmer, Heiratsverhalten, 15-82; Schlumbohm, Lebensläufe, bes. 96-99; Schlumbohm, MicroHistory and the Macro-Models; Fertig, Hajnal hypothesis.

7 Ein gutes Beispiel für diesen Ansatz stellt etwa die Sammlung an empirischen Fallstudien dar: Devos/Kennedy, Marriage.

$8 \mathrm{Zu}$ dieser idealtypischen Unterscheidung vgl. etwa: Schofield, Family Structure, bes. 284 f. Die Argumentation, dass Landbesitz oder das Erreichen bestimmter sozio-ökonomischer Positionen eine Vorbedingung für die Eheschließung gewesen sei, findet sich in der internationalen Literatur etwa auch bei: Alter, New perspectives, 1-5; Dribe, Leaving home; Van Poppel/Nelissen, Opportunities, 174.

9 Ähnliche Modelle demographischer Autoregulation wurden auch in der französischen Demographie entwickelt. Vgl. dazu sowie zu einer grundsätzlichen Kritik an den Prämissen des, homöostatischen Paradigmas' Ehmer, Heiratsverhalten, 64-67. Einige englische Autoren sehen das demographischökonomische Regelsystem in Europa als bis ins Mittelalter zurückreichend und dessen Etablierung als spezifische Reaktion auf die schweren Pestepidemien der Jahre 1348 und 1349. Vgl. dazu etwa Herlihy, Tod. 
kern schien sich das EMP als passende Antwort der Geschichte auf diese aktuelle Frage anzubieten.

\subsection{Die Persistenz der,Vollstellentheorie‘ in der deutschsprachigen Forschung}

Das für das vorindustrielle Kontinentaleuropa als Begründung des EMP häufig angeführte Nischenmodell findet in den beiden klassischen Texten von Hajnal praktisch keine Entsprechung. Wie zu zeigen sein wird, geht dieses im Kern auf das ältere Konzept der ,agrarischen Bevölkerungsweise ${ }^{10}$ des deutschen Ökonomen Gerhard Mackenroth zurück, dessen Thesen seit den 1970er Jahren ${ }^{11}$ auch international rezipiert wurden. Im Modell der ,agrarischen Bevölkerungsweise، wird mit der Existenz eines ,Stellenmechanismus' argumentiert. Eheschließung und Fortpflanzung seien an den Besitz einer, ökonomischen Vollstelle‘ geknüpft gewesen: „Die Zweiteilung der Arbeitsplätze in Vollstellen mit Familiengründung und Nicht-Vollstellen mit generativer Sterilisierung ihrer Inhaber durch Ehelosigkeit ist im ganzen vorindustriellen West- und Mitteleuropa im agrarischen wie im gewerblichen Bereiche die soziale Institution, durch die Bevölkerung und Wirtschaft entscheidend miteinander verknüpft sind“.. ${ }^{12}$ Die Zahl solcher Stellen sei begrenzt und wenig veränderbar gewesen. Heiratswillige hätten auf das Freiwerden einer ,Stelle' warten müssen, die im Wesentlichen nur durch die Erbfolge erworben werden konnte. Die viel zitierte eiserne ,Kette zwischen Fortpflanzung und Erbschaft' (Tilly/Tilly), also der Mechanismus der Generationenabfolge auf den ,Stellen', bezeichnet den zentralen Aspekt dieses Modells. Kennzeichnend für Mackenroth ist, dass er das Heiratsverhalten als „Element eines obrigkeitlich abgesicherten Ordnungssystems" 13 sieht: die Obrigkeiten zwangen mittels ihrer „Herrenrechte [...] Ehe- und Erbregelungen auf, die die Überzähligen zur Ehelosigkeit verurteilen“, sie setzten „die Bindung der Proliferation an eine ,Stelle“ der Sozialordnung auf Grund ihrer politischen Macht durch. “14 „Nur diese bäuerlichen und handwerklichen Vollstellen werden von Mackenroth als, generativ vollwertig' bezeichnet, alle anderen sozialen Positionen unter- oder außerhalb des Kreises der Vollstelleninhaber dagegen der,Gruppe demographisch nicht vollwer-

10 Mackenroth, Bevölkerungslehre, bes. S. 421-432.

11 Vgl. z. B. Schofield, Family Structure, 280. In der Theorie der Proto-Industrialisierung bildete die ,agrarische Bevölkerungsweise' das Gegenstück zur postulierten proto-industriellen Bevölkerungsweise. Vgl. Kriedte/Medick/Schlumbohm, Industrialisierung,122 ff.

12 Mackenroth, Bevölkerungslehre, 432.

13 Ehmer, Heiratsverhalten, 42.

14 Mackenroth, Bevölkerungslehre, 427. 
tiger Arbeitsplätze‘ zugeschlagen.“ ${ }^{15}$ „Im ,Stellenprinzip“ ist die Tragfähigkeit eben nicht an die Arbeitskapazität gebunden, sondern an den Besitz. " ${ }^{16}$ Konstitutiv ist die Existenz von „ökonomischen Nicht-Vollstellen“, die nicht zu Heirat und Reproduktion befähigten. ${ }^{17}$ In dieser theoretischen Traditionslinie ist „[I]n den ständischen Gesellschaften der frühen Neuzeit [...] das Recht zur Eheschließung ein Privileg. " 18

Mackenroths Modell idealisiert eine untergegangene Sozialordnung, die durch eine polarisierte Sichtweise auf eine stark hierarchisch gegliederte und zweigeteilte ländliche vorindustrielle Gesellschaft und eine deutlich positive Bewertung von feudaler Herrschaft zu charakterisieren ist. Sein Konzept beruht auf einer Bauernund Handwerkerideologie und einer tiefen Skepsis gegenüber den „untersten Sozialschichten, die ohne Zwang keine Bevölkerungsweise ausbilden würden "19, die als ,Randbestand', ,Zusatzbevölkerung' und als ,Überschuss', der wieder abstirbt, gesehen werden. Die soziale Zweiteilung der Gesellschaft garantiere ein Gleichgewicht von Bevölkerung und Nahrungsspielraum, sodass eine bestimmte Konsumnorm aufrechterhalten werden könne. Die Herstellung eines derartigen Gleichgewichts sei eine gesellschaftliche Leistung, die nicht allen Kulturen und Völkern gelungen sei. Mackenroths ,agrarische Bevölkerungsweise‘ wurde ursprünglich von Gunther Ipsen in den 1930er Jahren theoretisch ausgearbeitet. ${ }^{20}$ Für Ipsen etwa war die über Heiratsbeschränkungen vermittelte demographische Autoregulation eine Errungenschaft des deutschen Volkes. Die Ostvölker (Slawen) dagegen hätten diese Leistung nicht vollbracht und daher beständig zu Verarmung und Verelendung tendiert. Die ,Stelle' als zentrale Denkfigur dieser Konzeption geht auf kameralistische Ordnungsvorstellungen des 18. Jahrhunderts und auf Johann Peter Süßmilch, den ersten deutschsprachigen Demographen, zurück. ${ }^{21}$

Im auffälligen Kontrast zur Häufigkeit der Bezugnahme auf diese theoretischen (Vor-) Annahmen in der sozialhistorischen Literatur steht der Mangel an empirischen Belegen für die Existenz eines ,Stellenmechanismus'. Konkrete Studien, die zeigen, wie dieser in der Praxis historischer Gesellschaften funktioniert hätte, lagen

15 Medick, Weben, 298.

16 Gehrmann, Verhältnis, 25.

17 Mackenroth, Bevölkerungslehre, 431f.

18 Pfister, Bevölkerungsgeschichte, 24.

19 Mackenroth, Bevölkerungslehre, 427. Vgl. dazu bereits Ehmer; Bevölkerungsgeschichte, 67. Ähnliche Sichtweisen noch bei Linde, Proto-Industrialisierung, 112, der in den Unterschichten bloß eine ,arbeitswirtschaftliche Beifügung der bäuerlichen Höfe“ sah; Conze sprach von „Ausschussbevölkerungen“, vgl. Medick, Weben, 299.

20 Vgl. zu Ipsen: Ehmer, Heiratsverhalten; Ehmer, Bevölkerungsgeschichte.

21 Fertig, Autoregulation. 
bis in jüngste Zeit nicht vor. Bisher ist das Modell vor allem in seinen theoretischen Prämissen kritisiert worden. ${ }^{22}$ Im angenommenen Modell bildet der Haushalt den eigentlichen Konnex von Heirat und Ökonomie. Systematische Überprüfungen der behaupteten Zusammenhänge von Heirat und Haushaltsgründung auf der Mikroebene konkreter Haushalte, Individuen und Lebensläufe sind aber sehr aufwendig und daher bis heute selten. Weder Schlumbohm noch Fertig konnten in ihren Fallstudien die behaupteten Zusammenhänge bestätigen. ${ }^{23}$ Überdies nimmt das Modell des ,Stellenmechanismus" offensichtlich nur auf Systeme der Besitzweitergabe mit Unteilbarkeit der Güter Bezug; für Realteilungsgebiete mit ständiger Teilung der ,Stellen' beim Besitztransfer kann es keine Gültigkeit beanspruchen.

In der deutschsprachigen Forschung ist die Vorstellung der Bindung der Heirat an einen ,Stellenmechanismus' in vorindustrieller Zeit bis heute weit verbreitet. Hajnals überaus erfolgreiche These wird zwar auch in der deutschsprachigen Forschung rezipiert, dabei kommt es aber zuweilen zu bemerkenswerten Vermischungen unterschiedlicher theoretischer Erklärungsmodelle. Christian Pfister etwa verweist auf Hajnals EMP, „dessen konstitutives Merkmal die Bindung der Eheschließung an die Gründung eines eigenen Haushalts war", um anschließend ausführlich auf verschiedene Formen obrigkeitlicher, staatlicher oder kommunaler Ehebeschränkungen sowie die Begrenzungen durch das Erbrecht einzugehen. Außerdem sei durch ökonomische Zugangsbeschränkungen „ein beträchtlicher Teil der Bevölkerung von der Eheschließung ausgeschlossen“ worden, die anderen heirateten relativ spät. „Die späte Heirat war durch die Knappheit der Stellen bedingt, die von einer Generation auf die andere übertragen wurden“. Die Konsequenz daraus: „Über den Mechanismus der ,freien Stellen' folgte das ,mittlere' (mediane) Heiratsalter dem demographischen Wachstumsspielraum“. ${ }^{24}$ Pfister hat mit dieser Argumentationslinie jedoch nicht Hajnals EMP wiedergegeben, sondern Mackenroths , agrarische Bevölkerungsweise'. Dabei wird an keiner Stelle der Name Mackenroth oder das Konzept der ,agrarischen Bevölkerungsweise‘ erwähnt. Der einzige Autor, auf den Bezug genommen wird, ist Hajnal.

In Hajnals Schriften lässt sich eine vergleichbare Argumentation nicht finden. Analogien der Ansätze von Mackenroth und Hajnal bestehen bloß im Bezug auf die Bedeutung von Heiratsalter und Heiratshäufigkeit für die Begrenzung des

22 Vgl. Ehmer, Heiratsverhalten, 64-67; Fertig, Autoregulation.

23 Vgl. Schlumbohm, Lebensläufe; Schlumbohm, Micro-History; Fertig, Lokales Leben, 319-325; Fertig, Heirat. Zu einem ähnlichen Ergebnis kommen neuerdings auch: Küpker, Weber, bes. 433 und Szołtysek/Rzemieniecki, Perspective, 156.

24 Vgl. Pfister, Bevölkerungsgeschichte, 24-28. 
Bevölkerungswachstums. ${ }^{25}$ Weder die Privilegierung bestimmter sozialer Positionen noch obrigkeitliche Ehebeschränkungen kommen in Hajnals Aufsätzen vor. In seiner Sichtweise war die Heirat an die Gründung eines Haushalts gebunden, dass deren Zahl in irgendeiner Form begrenzt gewesen sei, erwähnt er nicht. Hajnal definierte Haushalte explizit als ,housekeeping units' (als Einheiten der Koresidenz und Konsumption) und betont mehrmals, dass diese nicht notwendigerweise Produktionseinheiten sein mussten. ${ }^{26}$ Dagegen ist für Mackenroth „die vorindustrielle Familie [...] eine ökonomische Einheit, und zwar Erzeugungs- und

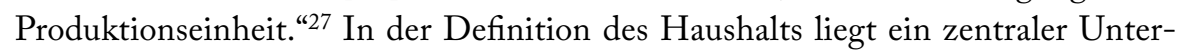
schied der beiden Konzepte. Insbesondere durch die Elemente ,herrschaftliche Eheverbote' sowie eine weitgehend ,begrenzte Zahl an zur Eheschließung befähigende sozio-ökonomische Positionen' ist Mackenroths Modell als ungleich restriktiver als Hajnals Überlegungen anzusehen. Formulierungen wie, „[e]ine solche Hausstandsgründung habe Besitz und Status, also eine unterhaltssichernde Bauern- oder Meistereigenschaft vorausgesetzt. Besitzerwerb, Verselbständigung und Eheschließung seien, so Hajnal, im vorindustriellen Westeuropa untrennbar verbunden gewesen ${ }^{28}$ oder das Postulat, dass Hajnal seine Befunde in einen Erklärungsansatz integriert habe, wonach „die Möglichkeit zur Eheschließung an die Verfügbarkeit der notwendigen ökonomischen Ressourcen zum Erhalt einer Familie gebunden [war], das heißt an die Übergabe einer Hofstelle oder eines Handwerksbetriebs ${ }^{\text {“29 }}$ zeigen daher selbst im Falle ansonsten sehr sorgfältig durchgeführter Studien ein deutliches Eindringen Mackenroth'scher Theorieelemente in die Hajnal-Rezeption.

Obwohl im Widerspruch zu einer vor allem seit den 1970er Jahren zunehmend größeren Zahl an empirischen Studien bezüglich der zahlenmäßigen Stärke der ländlichen Unterschichten in der Vormoderne (vgl. Kapitel 5), wurde und wird die ,Vollstellentheorie‘ von zahlreichen deutschen Historikern weiterhin vertreten. „Diskutabel wurde die Heirat allerdings erst, wenn [...] eine Hofstelle oder ein Betrieb frei wurde“"30, schrieb R. van Dülmen über die Eheschließung in der frühen Neuzeit. Friedburg behauptet, dass „vielen Ehesuchenden die Möglichkeit zur Ehe verwehrt ... “ [worden sei], wenn sie „keine Nahrungsstelle besaßen“. ${ }^{31}$ „Breite Schichten, denen [...] eine Eheschließung gänzlich verwehrt war", wie Paul Münch

25 Vgl. Medick, Weben, 299.

26 Hajnal, Two kinds, 67.

27 Mackenroth, Bevölkerungslehre, 362.

28 Mantl, Heirat, 16.

29 Gestrich, Geschichte, 76. Ganz ähnlich auch die Argumentation im Artikel: Gestrich, Heirat.

30 Van Dülmen, Kultur, 134; vgl. auch: Imhof, Familienstrukturen, 206, 228.

31 Friedeburg, Lebenswelt, 12. 
in ähnlicher Weise betonte, ${ }^{32}$ wurden aber bisher nur in sehr wenigen der zahlreich vorliegenden quantifizierenden Forschungen zur frühen Neuzeit nachgewiesen. Im Gegenteil zeigte sich, dass frühneuzeitliche Agrargesellschaften schon seit dem 16. Jahrhundert durch eine hohe und zumeist stark zunehmende soziale Differenzierung gekennzeichnet waren. ${ }^{33}$ Eine bedeutende Zahl an landarmen oder landlosen Familien gab es in den meisten ländlichen Regionen Europas. In vielen Gebieten bildeten sie noch während der frühen Neuzeit auch zahlenmäßig die Mehrheit der Anwesen. Die Annahme einer weitgehend stabilen Anzahl an ,familientragenden Stellen' während der frühen Neuzeit ist daher seit längerer Zeit eindeutig widerlegt. Dass „viele Gesellen, Taglöhner, Knechte und Mägde sowie Geschwister, die nach den Bestimmungen des Anerbenrechts keinen Anteil erhielten, [...] zeitlebens nicht an eine Heirat denken ${ }^{\text {“34 }}$ konnten, wurde nicht bestätigt. Die in großer Dichte vorliegenden Studien zur historischen Familienforschung wiesen nach, dass es in der Regel keine sozialen Positionen mit permanentem Ledigenstatus gab. ${ }^{35}$ Die Möglichkeit zur Heirat lässt sich lediglich für einzelne Regionen zu bestimmten Phasen innerhalb des Verbreitungsgebietes des EMP als ,Privileg' bezeichnen ${ }^{36}$, aber jedenfalls nicht für dessen gesamtes Verbreitungsgebiet während der gesamten frühen Neuzeit. Dennoch sah vor wenigen Jahren etwa Rolf Gehrmann das ,Stellenprinzip“ als Erklärungselement innerhalb der Forschungsdebatten zur Entwicklung des Heiratsalters in den letzten Jahren wieder gestärkt. ${ }^{37}$

\subsection{Heirat und ,Stelle in Kapličky}

Im Folgenden werden am Beispiel der südböhmischen Pfarre Kapličky, bzw. der Herrschaft Vyšší Brod, einige Aspekte des Konzepts der ,agrarischen Bevölkerungsweise' systematisch diskutiert. Die zentrale empirische Basis der Untersuchung bildet die Verknüpfung der Informationen aus den Grundbüchern mit den Daten der Familienrekonstitution.

32 Münch, Lebensformen, 48.

33 Unter der Fülle an Literatur vgl. etwa Kriedte, Spätfeudalismus, 179-181; Trossbach, Bauern, 36-44; Ehmer, Heiratsverhalten, 68; regionale Beispiele für das Wachstum der Unterschichten: Schlumbohm, Lebensläufe; Beck, Unterfinning; Peters, Landarmut.

34 Rödel, Entwicklung, 32.

35 Vgl. z. B. Mitterauer, Formen; Mitterauer, Arbeitsteilung.

36 Vgl. etwa Mantl, Heirat.

37 Gehrmann, Heiratsverhalten. 


\subsubsection{Zum Wandel der Heiratsmuster in Südböbmen}

Zur Mitte des 17. Jahrhunderts lassen sich in der Herrschaft Vyšší Brod, wie in vielen anderen Gebieten Böhmens ${ }^{38}$, sehr hohe Verheiratetenanteile in der Altersgruppe der 25-29-Jährigen feststellen (Tabelle 37). Eine überwiegende Mehrheit sowohl der Männer als auch der Frauen dieser Altersgruppe war verheiratet. Einige wenige für Südböhmen existierende Daten verweisen darauf, dass dieses Muster hoher Verheiratetenanteile bereits zu Ende des 16. Jahrhunderts bestand und nicht etwa eine kurzfristige Folge des Dreißigjährigen Krieges darstellte. ${ }^{39}$ Für 1798 zeigen die Werte für das der Pfarre Kapličky unmittelbar benachbarte Gericht Studánky ein im Vergleich zu 1651 völlig konträres Bild. Vor dem 30. Lebensjahr verheiratete Menschen waren nun zur Ausnahme geworden. Auch andere aus Südböhmen für das 18 . Jahrhundert bisher vorliegende Daten zeigen gegenüber dem 17. Jahrhundert bei den 25-29-Jährigen durchgängig deutlich geringere Verheiratetenanteile. Wie sich für die Herrschaften Třeboň und Chýnov belegen lässt, verschlechterte sich, insbesondere für die Männer, die Möglichkeit zur Eheschließung in relativ jungem Alter während der frühen Neuzeit kontinuierlich (Tabelle 38 und 39). Offenbar ist diese Entwicklung nicht auf die ungünstige ökonomische Situation nach dem Dreißigjährigen Krieg zurückzuführen ${ }^{40}$, sondern stellt einen langfristigen Trend dar. Noch zu Ende des 19. Jahrhunderts wies der südliche Böhmerwald die geringsten Verheiratetenanteile in der Altersgruppe der 25-29-Jährigen innerhalb Böhmens auf. ${ }^{41}$

Tabelle 37: Verheiratetenanteile nach Altersgruppen, Herrschaft Vyšší Brod (in Prozent)

a) Herrschaft Vyšší Brod Dörfer 1651

\begin{tabular}{lcccccc}
\hline $\begin{array}{l}\text { Alters- } \\
\text { gruppe }\end{array}$ & \multicolumn{2}{c}{ Männer } & \multicolumn{3}{c}{ Frauen } \\
\hline $25-29$ & 75,6 & 24,4 & 90 & 90,9 & 9,1 & 99 \\
$45-49$ & 90,0 & 10,0 & 40 & 60,0 & 40,0 & 20 \\
\hline
\end{tabular}

Anm.: ,led./w.' meint, ledig' oder,verwitwet'. Die Quelle differenziert nicht durchgängig zwischen diesen beiden Kategorien. Berücksichtigt wurde nur der territorial geschlossene Zentralteil der Herrschaft. In diesem Gebiet lebten zur Mitte des 17. Jahrhunderts etwa 2. 000 Personen.

Quelle: NA Praha, SM, R 109/45, Bech. 5.

38 Vgl. Cerman, Mitteleuropa.

39 Ćáňová/Horská/Maur, Les listes nominatives; Grulich/Zeitlhofer, Lebensformen.

40 Dies wurde etwa von Maur, $\mathrm{K}$ demografickým aspektům, 29f. angenommen.

$41 \mathrm{Vgl}$. Ehmer, Heiratsverhalten, $139 \mathrm{ff}$. 
b) Gericht Studánky 1798

\begin{tabular}{lcccccc}
\hline \multirow{2}{*}{$\begin{array}{l}\text { Alters- } \\
\text { gruppe }\end{array}$} & \multicolumn{2}{c}{ Männer } & \multicolumn{4}{c}{ Frauen } \\
\hline $25-29$ & 24,0 & 76,0 & 25 & 25,8 & 74,2 & 31 \\
$45-49$ & 95,2 & 4,8 & 21 & 70,0 & 30,0 & 30 \\
\hline
\end{tabular}

Quelle: Archiv Klaštera Vyšší Brod, Knihá č. 225.

Tabelle 38: Verheiratetenanteile in den Dörfern der Herrschaft Třeboň, Altersgruppe 25-29 Jahre (in Prozent)

\begin{tabular}{lcccc}
\hline & \multicolumn{2}{c}{ Männer } & \multicolumn{2}{c}{ Frauen } \\
& $\mathrm{N}$ & verheiratet & $\mathrm{N}$ & verheiratet \\
\hline $1586^{*}$ & 39 & 82,1 & 68 & 89,7 \\
1753 & 391 & 56,0 & 488 & 56,0 \\
1800 & 428 & 44,0 & 348 & 53,0 \\
\hline
\end{tabular}

* Nur ein Teil der Dörfer.

Quelle: Dudáček, Age Structure, 116; Grulich/Zeitlhofer, Lebensformen, 45.

Tabelle 39: Verheiratetenanteile in den Dörfern der Herrschaft Chýnov, Altersgruppe 25-29 Jahre (in Prozent)

\begin{tabular}{crcrc}
\hline & \multicolumn{2}{c}{ Männer } & \multicolumn{2}{c}{ Frauen } \\
& $\mathrm{N}$ & verheiratet & $\mathrm{N}$ & verheiratet \\
\hline 1651 & 99 & 87,9 & 83 & 81,9 \\
1725 & 159 & 48,4 & 231 & 55,0 \\
1775 & 208 & 50,5 & 240 & 59,6 \\
\hline
\end{tabular}

Quelle: Wiener Datenbank zur europäischen Familiengeschichte (Soupis poddaných und Mannschaftsbücher Chýnov).

Anmerkung: Tabelle 38 und 39 jeweils einschließlich verwitweter Personen.

Auch das durchschnittliche Alter bei der Erstheirat lag in der Pfarre Kapličky in der Periode von 1680 bis 1840 (Tabelle 40) für die Männer durchwegs um die 30 Jahre, für die Frauen zumeist nur geringfügig darunter. Nicht nur im böhmischen, sondern auch im internationalen Vergleich sind diese Werte als hoch zu bezeich- 
nen. ${ }^{42} \operatorname{Im}$ 18. und 19. Jahrhundert entsprach das Alter bei der Erstheirat in Böhmen in der Regel etwa dem in anderen Regionen West- und Mitteleuropas. Im Dorf Břevnov (bei Prag) lag es etwa zwischen 1700 und 1750 bei 26, 1 Jahren für Männer und bei 24,7 für Frauen; danach geringfügig niedriger. In der westböhmischen Stadt Domažlice betrug das durchschnittliche Alter bei der Erstheirat dagegen bereits vor 1700 29, 3 Jahre für Männer und 26, 5 Jahre für Frauen. Während des 18. Jahrhunderts wurde für die Männer kontinuierlich ein Wert von über 30 Jahren ermittelt, für die Frauen Werte um die 25 Jahre. ${ }^{43}$ Entgegen einem häufig in Mitteleuropa zu beobachtenden Trend, ${ }^{44}$ sank um 1800 in der Pfarre Kapličky das Heiratsalter (der Männer, das der Frauen bereits etwas früher) wieder etwas ab.

Tabelle 40: Durchschnittliches Alter bei der Erstehe, Pfarre Kapličky 1681-1840

\begin{tabular}{ccccc}
\hline $\begin{array}{c}\text { Heirats- } \\
\text { periode }\end{array}$ & Männer & \multicolumn{2}{c}{ Frauen } \\
\hline $1681-1700$ & 28,5 & $\mathrm{~N}$ & Alter & $\mathrm{N}$ \\
$1701-1720$ & 30,6 & 62 & 25,4 & 50 \\
$1721-1740$ & 30,4 & 82 & 28,2 & 74 \\
$1741-1760$ & 30,5 & 66 & 28,2 & 69 \\
$1761-1780$ & 31,9 & 72 & 30,1 & 72 \\
$1781-1800$ & 30,9 & 94 & 29,1 & 82 \\
$1801-1820$ & 28,0 & 73 & 27,7 & 103 \\
$1821-1840$ & 28,6 & 94 & 27,0 & 89 \\
\hline
\end{tabular}

Anm: Sämtliche Erstehen von Frauen und Männern. Die Fallzahlen stagnieren ab etwa 1800, da ab dem Jahre 1787 das Dorf Vyšína nicht mehr zum Pfarrgebiet gehörte.

Quelle: SOA Třeboň, Sbírka jihočeských matrik, Farní uřad Kapličky č. 9.

Die Daten für das Gericht Studánky von 1798 (Tabelle 37b) verweisen aber auf ein spezifisches Muster des Heiratsverhaltens in der Region: während nur sehr wenige Männer unter 30 Jahren bereits verehelicht waren, war dies bei beinahe allen in der Altersgruppe der 45-49-Jährigen der Fall - ein im Vergleich mit westeuropäischen Regionen der frühen Neuzeit durchaus hoher Wert. In dieser Region wurde zwar spät geheiratet, aber nur relativ wenige Menschen blieben zeitlebens ledig.

42 Vgl. etwa die Zusammenstellung der Daten aus deutschen Regionen bei Schlumbohm, Sozialstruktur. 43 Vgl. Mužík, Obyvatelstvo; Ćáňová/Horská, Obyvatelstvo.

44 Cerman, Mitteleuropa. 


\subsubsection{Was ist eine, Stelle'?}

War die späte Heirat in der Pfarre Kapličky durch eine Bindung der Heiratsmöglichkeit an den Besitz einer ,familientragenden Stelle und an einen ,Stellenmechanismus' bedingt, wie dies die ,Vollstellentheorie' besagt? Stellt man sich diese Frage, so muss zunächst diskutiert werden, wie ,Stellen' (oder ,ökonomische Nischen`) für diese Region definiert werden können. In der Literatur herrscht darüber keineswegs Konsens. ${ }^{45}$ Wird eine ,Stelle“ mit Landbesitz gleichgesetzt, wie das manche Autoren explizit tun ${ }^{46}$, scheint eine empirische Überprüfung einfach. Schwieriger wird die Überprüfung hingegen, wenn von einer „Nahrungsstelle “47 oder einer „Erwerbsstelle, die ihrem Inhaber und seiner Familie ein gesichertes Auskommen bieten sollte“48, die Rede ist. Die Begriffe ,gesichertes Auskommen“ und ,Nahrungsstelle' müssten erst einmal genauer definiert werden. Selbst bei Mackenroth findet sich einmal die Einschränkung, dass „die westliche Sozialordnung immer Raum gehabt hat für eine gewisse Zahl an Halb- und Viertelhüfnerstellen [...]. Auch sie sind aber wenigstens immer noch Herdstellen und erfordern ein Haus für eine Familie [...]. " 49 Demnach könnte schon der Hausbesitz als soziale Untergrenze für die Möglichkeit zu Heirat und Fortpflanzung gelten. Wollte man hingegen alle Arbeitsgelegenheiten pauschal als ,Stellen' betrachten ${ }^{50}$, so würde das die Erklärungsmacht des Modelles, das von einer „sozialen Wachstumskontrolle“ ausgeht ${ }^{51}$, außer Kraft setzen, denn ungeachtet aller Unterschiede im Detail impliziert jede Argumentation mit ,Stellen' die Existenz von anderen Positionen, die eben keine Stellen sind. Gerade diese Zweiteilung habe die Begrenzung des Bevölkerungswachstums garantiert.

Was bildete nun in der Pfarre Kapličky die zur Familiengründung erforderliche Untergrenze: Land- oder Hausbesitz, ökonomische Unabhängigkeit oder ein gesichertes Auskommen? Gab es soziale oder ökonomische Positionen, die nicht zur Heirat befähigten? Der Steuerkataster des Jahres 1654 zeigt zunächst tatsächlich einen sehr hohen Anteil an grundbesitzenden Häusern. Allerdings sind deutliche Abstufungen in der Besitzverteilung zu erkennen. Das Spektrum der Besitzgrößen

45 Ähnlich unklar ist die Definition des in der demographischen Theoriebildung ebenfalls zentralen Begriffs der, Tragfähigkeit', der den Zusammenhang von Bevölkerung und Wirtschaft auf der MakroEbene umschreibt. Vgl. Gehrmann, Verhältnis.

46 Vgl. etwa die Formulierungen bei Alter, New Perspectives, 1 und Dribe, Leaving home, 65.

47 Vgl. etwa Werkstetter, Auskommen, 177.

48 Marschalk, Bevölkerungsgeschichte Deutschlands, 17.

49 Mackenroth, Bevölkerungslehre, 425.

50 Dies tut etwa: Fischer, Bevölkerung, 35.

51 Vgl. etwa Kriedte/Medick/Schlumbohm, Industrialisierung, 159. 
reichte von ausreichend Landbesitz, um eine Familie davon ernähren zu können, über landwirtschaftliche Betriebseinheiten, die eine Nebenbeschäftigung erforderlich machten, bis zu einer nur minimalen Landausstattung der Häuser: von den 67 genannten Anwesen bewirtschafteten 39 (58 Prozent) zwischen fünf und zehn Hektar Ackerland, 23 (34, 5 Prozent) zwischen einem und fünf Hektar und fünf Anwesen (7, 5 Prozent) weniger als ein Hektar Ackerland (vgl. Kapitel 5.4). Neben den genannten Anwesen gab es um 1654 einzelne weitere landlose Häuser, die im Kataster nicht erfasst wurden. Setzt man überdies die Zahl der verheirateten Paare, die weit höher lag, mit der Zahl der landbesitzenden Anwesen in Verbindung, ergibt sich ein den Annahmen der,Vollstellentheorie“ deutlich widersprechendes Bild der sozialstrukturellen Zusammensetzung der Bevölkerung. Die staatliche Bevölkerungszählung von 1651 nennt 107, eine Liste des Pfarrers aus demselben Jahr 104 Ehepaare. Bereits zu dieser Zeit lebte ein hoher Prozentsatz der Familien als Inwohner ohne Land- und Hausbesitz. Für manche war der Inwohnerstatus eine lebenszyklische Position, da auch Altenteiler dazugerechnet wurden. Ein nominative record linkage der Grundbücher mit der Familienrekonstitution zeigt aber, dass zur Mitte des 17. Jahrhunderts zahlreiche Inwohner entweder zeitlebens ohne Hausbesitz blieben oder erst Jahre nach der Heirat ein Haus erwarben. Offensichtlich ist, dass in der Untersuchungsregion die Heirat weder an Land- noch an Hausbesitz gebunden war. Während zahlreiche Ehepaare ohne klare ökonomische Basis nachzuweisen sind, finden sich in der Pfarre, wie auch in anderen Regionen, ${ }^{52}$ keine durch einen lebenslangen Zölibat gekennzeichneten ,ökonomischen Nicht-Vollstellen'. Die einzige soziale Position, die den Ledigen-Status voraussetzte, war der Gesindedienst, der aber eindeutig eine alterszyklische Lebensphase zwischen Kindheit und eigener Familiengründung umfasste. Während der frühen Neuzeit nahm in der Pfarre die Zahl der Familien, die über wenig oder kein Land verfügten oder aber nicht einmal ein Kleinhaus ihr Eigen nannten, deutlich zu. Die Häuserzahl in der Pfarre Kapličky lag nach den Eintragungen in den Grundbüchern im Jahre 1797 bei 115, 1840 bei 119. 1783 lassen sich in der Pfarre 142 Ehepaare nachweisen; in etwa jedem dritten Haus lebte neben der Besitzerfamilie auch eine Inwohnerfamilie. ${ }^{53}$ Weder die Zahl der Häuser und noch die der Ehepaare wurde - ob durch im Hintergrund wirkende Regelmechanismen oder durch herrschaftlichen Druck - im Verlauf der frühen Neuzeit konstant gehalten.

In der Pfarre Kapličky gab es zahlreiche Ehepaare, deren Auskommen nicht auf einer fixen ,Stelle', sondern auf der Kombination verschiedener Einkommensfor-

52 Vgl. z.B. Schlumbohm, Lebensläufe, 190.

53 Archiv Klaštera Vyšší Brod, Kart. č. 219, Nr. III. Nicht mitgezählt wurden die Altenteiler, die in dieser Quelle gesondert genannt sind. 
men beruhte (vgl. Kapitel 4.3). Sowohl Lohnarbeit als Holzknecht oder auf den Gutshöfen der Herrschaft (etwa als ,Hofdrescher') als auch die Produktion von Leinengarn hatten in der Region über Jahrhunderte hinweg einen hohen Stellenwert als Einkommensmöglichkeiten für Inwohner und kleine Landbesitzer. Holzverarbeitende Gewerbe, wie das Schindelmachen, die Erzeugung hölzerner landwirtschaftlicher Geräte und von hölzernem Geschirr verlangten nur geringe spezielle Kenntnisse und die Produkte konnten auch in Eigenregie abgesetzt werden. Auf der nahen Moldau hatte die Flößerei einen hohen Stellenwert.

Die Vielfalt an unterschiedlichen Einkommensmöglichkeiten mochte im Untersuchungsgebiet besonders ausgeprägt sein, sie ist aber keineswegs untypisch für vorindustrielle ländliche Gesellschaften. ${ }^{54}$ Die,Vollstellentheorie‘ geht implizit von autarken bäuerlichen Betriebseinheiten und isolierten Wirtschaftsräumen ohne wesentliche Marktbeziehungen aus. Diesen Annahmen ist auf mehrfache Weise zu widersprechen. Für bäuerliche Familienwirtschaften war aufgrund des saisonal stark schwankenden Bedarfs an Arbeitskräften, der nur durch temporäre Beschäftigung von ansonsten nicht im landwirtschaftlichen Bereich tätigen Personen gedeckt werden konnte, die Arbeitskraft der ländlichen Unterschichten wohl überall funktional notwendig. Außerhalb der saisonalen Spitzen mussten diese nicht-agrarische Erwerbsmöglichkeiten suchen. Möglichkeiten dazu fanden sie nicht nur in dörflichen, sondern auch in überregionalen Zusammenhängen. Weiträumige ökonomische Kontakte sind keine Innovation der frühen Neuzeit, sondern stellten einen integralen Bestandteil der ländlichen vorindustriellen Welt dar. Die völlige Autarkie des bäuerlichen Hofes und der abgeschlossene Wirtschaftsraum des vorindustriellen Dorfes sind allein aufgrund naturräumlicher Besonderheiten eine Fiktion. Naturräumliche Unterschiede schufen die Basis regional unterschiedlicher Wirtschaftsweisen, ${ }^{55}$ die früh selbst isolierte bäuerliche Familien zu potenziellen Kunden überregionaler Marktbeziehungen werden ließen.

Gegen das Konzept des Stellenmechanismus sind am Beispiel der Pfarre Kapličky weitere Einwände zu erheben. Die Annahme unveränderlicher ökonomischer Einheiten, die den Familien lebenslang zur Verfügung standen, erweist sich - trotz der strikten Unteilbarkeit des Landes beim Besitzwechsel - als falsch. $\mathrm{Zu}$ - und Verkäufe einzelner Grundparzellen kamen manchmal vor. Vor allem bewirkte aber die verbreitete Praxis, von der Herrschaft neu gerodete Flächen zu pachten, Veränderungen im Ausmaß des tatsächlich bewirtschafteten Landes. Die

54 Eindrucksvoll zu den vielfältigen Formen des Wanderhandels als Teil der Einkommensgrundlage der Unterschichten Beck, Unterfinning, 374 ff. Vgl. auch Mitterauer, Formen, 206f; Mitterauer, Arbeitsteilung, $50 \mathrm{ff}$.

55 Grundlegend dazu Mitterauer, Formen. 
Anlage neuer ,Stellen' bedeutete nicht immer eine Zunahme der Eheschließungen, da auch bereits verheiratete landlose Paare angesiedelt wurden. Auch eine lebenslange Bindung der Familien an ihren Landbesitz kann nicht a priori angenommen werden, die räumliche Stabilität der bäuerlichen Grundbesitzer unterlag vielmehr einem historischen Wandel (vgl. Kapitel 7.8). Ebenso traf die Annahme, dass frei gewordene ,Nischen' stets rasch aufgefüllt worden seien, ${ }^{56}$ nicht für alle Zeitperioden zu. Für die südböhmische Herrschaft Chýnov lässt sich feststellen, dass 1654 85 der 540 Häuser und Höfe (knapp 16 Prozent) leer standen, obwohl die drei Jahre zuvor erstellte staatliche Zensusliste etwa fünf Prozent der Gesamtbevölkerung als junge (unter 40 Jahre alte) verheiratete Inwohnerpaare ohne Land- und Hausbesitz ausweist. ${ }^{57}$ Diese waren also nicht automatisch in die ,leeren Stellen nachgerückt. In der hier untersuchten Region mussten die Anwesen gekauft werden, und trotz der zur Mitte des 17. Jahrhunderts stark gesunkenen Kaufpreise konnten - oder wollten - offenbar nicht alle den Kaufpreis aufbringen. ${ }^{58}$ Trotzdem hatten diese Paare heiraten können!

\subsection{Der Besitztransfer als Regulativ im Nischenmodell}

Die Praxis des intergenerationellen Besitztransfers wird im Nischenmodell zum zentralen Regulativ erklärt. Diesem sei eine zugleich verzögernde und selektive Funktion zugekommen: Die junge Generation habe auf den Zeitpunkt des Transfers warten müssen und nur „so viele aus der jungen Generation konnten jeweils durch Einheirat oder Übergabe in Stellen einrücken, wie aus der alten abtraten" ${ }^{\text {"59. }}$. Den Übrigen, in erster Linie den sogenannten,weichenden' Geschwistern der Hofübernehmer, sei eine Eheschließung verwehrt geblieben. In der Untersuchungsregion weichen die Modalitäten des Generationenwechsels aber in mehreren wesentlichen Punkten deutlich von diesem behaupteten Muster ab. Trotz der

56 Mackenroth, Bevölkerungslehre, 423.

57 Der Steuerkataster von 1654 führt auch die seit dem Dreißigjährigen Krieg leer stehenden Häuser an. Die Pfarre Kapličky kann dabei nicht als Beispiel herangezogen werden, da es hier 1654 keine unbewohnten Häuser gab. Die Berechnungen für Chýnov wurden auf Basis der in der,Wiener Datenbank zur europäischen Familiengeschichte'vorliegenden maschinenlesbaren Datensätze (Soupis poddaných 1651 und Berní rula 1654) durchgeführt.

58 Ein Vergleich der beiden Listen von 1651 und 1654 zeigt, dass auch in anderen böhmischen Herrschaften, beispielsweise in Frýdlant und Liberec in Nordböhmen, zahlreiche Familien zur Miete lebten, obwohl gleichzeitig viele Häuser und Höfe leer standen. Vgl. Cerman/Štefanová, Wirtschaft, 75.

59 Schlögl, Bauern, 99. Vgl. Mackenroth, Bevölkerungslehre, 423: „, [...] nachgeborene Bauernsöhne können nicht $[\ldots]$ heiraten, sie leben als Knechte ehelos [...]“. 
Unteilbarkeit des Landbesitzes und der Weitergabe an eine einzelne Person folgte der Besitztransfer hier prinzipiell egalitären Prinzipien. Wie auch in zahlreichen anderen Gebieten Böhmens und in Teilen Bayerns und des heutigen Österreich war jeder Besitztransfer ein Kauf. Das Prinzip der Unteilbarkeit des Landes (und des Hauses) war mit dem Grundsatz der gleichen Teilung von dessen Geldwert verbunden. Die Kaufsumme wurde in der Regel unter allen erbberechtigten Familienmitgliedern des Vorbesitzers aufgeteilt, wobei der verkaufende Elternteil den gleichen Anteil wie ein Kind erhielt (vgl. Kapitel 7). Die behauptete selektive Funktion erfüllte der Besitztransfer damit offensichtlich nicht. Das hier praktizierte System der Besitzweitergabe schloss Personen, die nicht in den Besitz eines Anwesens gelangten, nicht von der Heirat aus.,Weichende' Geschwister erhielten gleichwertige Anteile und heirateten beinahe ebenso häufig wie jene, die ein elterliches Anwesen übernahmen. Insgesamt blieb, wie zumindest im Falle der Männer die Anteile der Verheirateten in der Altersgruppe der 45-49-Jährigen (Tabelle 37) zeigen, nur ein sehr geringer Prozentsatz der Gesamtbevölkerung zeitlebens unverheiratet. Die Lebenswege der, weichenden' Geschwister verliefen aber sehr unterschiedlich: Viele konnten in bestehende Häuser einheiraten, einigen wenigen gelang es, neue Häuser zu errichten, und zahlreiche weichende Geschwister wurden Inwohner.

Selbst eine verzögernde Funktion kam dem Besitztransfer nur mit Einschränkungen zu. Die Modelle beruhen auf der Annahme, dass die Heirat erst nach Besitzantritt habe stattfinden können: „Bei der Eheschließung musste „der Bräutigam [...] die Nachfolge auf dem Hof oder im Gewerk des Vaters angetreten haben."60 Im 17. Jahrhundert war jedoch der zeitliche Zusammenhang zwischen Heirat und der Übernahme eines Anwesens eher lose. Viele heirateten, bevor sie, häufig Jahre später, zu Haus- und Grundbesitz gelangten (Tabelle 41). Maria Wagner zum Beispiel war die einzige überlebende Tochter einer bäuerlichen Familie, die anderen Kinder waren als Säuglinge verstorben. Sie heiratete 1671, erst sechs Jahre später übernahm sie mit ihrem Mann Peter das Anwesen ihres Vaters. Bei Thomas und Sophia Lind verstrichen gar 14 Jahre nach ihrer Heirat (1721), bevor sie das Haus seiner Eltern übernahmen (1735). ${ }^{61}$ Auch im westböhmischen Štáhlavy verehelichten sich zwischen 1730 und 1839 mehr als 20 Prozent der ,übernehmenden“ Söhne zumindest drei Jahre vor ihrem Besitzantritt. ${ }^{62}$

60 Rödel, Entwicklung, 32.

61 Umgekehrt konnte in manchen Fällen auch nach dem Besitzantritt noch einige Zeit verstreichen, bis das Haus besitzende Paar vor den Traualtar schritt. Andreas und Katharina Hutter etwa hatten den Hof von seinem Vater am 24.3.1669 erworben und verehelichten sich am 12.5.1671.

62 Velková, Eingriffe, 170. 
Tabelle 41: Zeitlicher Zusammenhang von Heirat und Besitzantritt, Pfarre Kapličky 1651-1730

\begin{tabular}{lrrrrrr}
\hline & \multicolumn{3}{c}{$1651-1690$} & & \multicolumn{3}{c}{$1691-1730$} \\
Heirat & & & Prozent & & $\mathrm{N}$ & Prozent \\
\hline mehr als 1 Jahr vor Antritt & 21 & 15,4 & $(25,3)$ & 14 & 9,0 & $(13,2)$ \\
bis 1 Jahr davor & 13 & 9,6 & $(15,7)$ & 9 & 5,8 & $(8,5)$ \\
nach Antritt & 49 & 36,0 & $(59,0)$ & 71 & 45,5 & $(67,0)$ \\
unklar* & 53 & 40,4 & & 50 & 32,1 & \\
\hline & 136 & 100 & $(100)$ & 156 & 100 & $(100)$ \\
\hline
\end{tabular}

* Ausreichende Angaben fehlen, da entweder kein exaktes Datum in den Grundbüchern genannt ist oder die Personen von auswärts einheirateten.

Quelle: Datenverknüpfung Grundbücher und Familienrekonstitution.

Im frühen 18. Jahrhundert wird der zeitliche Zusammenhang zwischen Eheschließung und Besitzantritt allerdings deutlich enger (Tabelle 41). Dieser Wandel war zum Teil dadurch bedingt, dass man zunehmend Wert darauf legte, das Land in der Familie zu halten (vgl. Kapitel 7.6.2). Die Bindung der Familien an ihr Land wurde deutlich enger: Abgetretene Besitzer, die im 17. Jahrhundert öfter ein anderes Haus erworben oder anderswo zur Miete gelebt hatten, blieben nun als Altenteiler im Haus. Zahlreiche Anwesen wurden ab dem 18. Jahrhundert über Generationen hinweg innerhalb der Familie gehalten, und Heiratsallianzen zwischen den hausbesitzenden Familien gewannen an Bedeutung. Im 17. Jahrhundert war es noch mehreren Inwohnerpaaren gelungen, nach der Verehelichung ein Anwesen auf dem ,Markt' zu erwerben. Diese Möglichkeit ging nun stark zurück. Eine Heirat ohne Hausbesitz bedeutete daher zunehmend, lebenslang im Inwohnerstatus zu bleiben. Von den im Verzeichnis des Jahres 1783 als Inwohner genannten Personen schaffte es keine mehr, später zu Hausbesitz zu gelangen.

Auch der Zusammenhang von Eheschließung und sozialer Positionierung wurde damit enger. Aus diesem Grund wurde es für Hofübernehmer zunehmend notwendig, mit der Heirat bis zur Übergabe zu warten. Für sie gewann also der ,Nischenmechanismus' stark an Bedeutung. Haus und Land konnten häufig nur mehr mittels vertraglich fixiertem Austausch zwischen den Generationen erworben werden: „,contractual retirement [...] kept large numbers of young people waiting for land". ${ }^{63}$ Die Heirat der Jungen und der Verbleib der Alten wurden so im 18. Jahrhundert zu eng zusammengehörigen Elementen des Besitztransfers.

63 Crenshaw, Demographic regime, 184. 
Die Heirat der weichenden Geschwister dagegen war zwar finanziell, nicht aber zeitlich an den Transfer des Elternhauses gebunden. Sie benötigten ihren Anteil an der Kaufsumme als Heiratsgut; gleichwohl konnten sie auch schon vor der Übergabe des elterlichen Hauses heiraten. Sie erhielten dann entweder einen Teil ihres finanziellen Anspruchs im Voraus oder lebten in Erwartung ihrer Anteile. ${ }^{64}$

Für Personen, die zeitlebens nie Haus oder Land besaßen, dennoch aber verheiratet waren, und die selbst bereits aus Inwohnerfamilien stammten, spielte weder der Generationenwechsel im elterlichen Haushalt noch das Freiwerden eines Anwesens eine Rolle. Anton Wagner etwa, der im Jahre 1770 die Inwohnertochter Maria Prieschl heiratete, stammte aus einer Familie, die bereits seit mehreren Generationen - seit Ende des 17. Jahrhunderts - ohne Haus- und Grundbesitz als Inwohner in der Pfarre gelebt hatte. Die Haushaltsgründung dieses Paares war neolokal, und die ökonomische Basis ihrer Ehe bestand wohl überwiegend in Lohnarbeit.

Generell vernachlässigt das Konzept des ,Stellenmechanismus' die neolokale Haushaltsgründung der Unterschichten. ${ }^{65}$ Wenn einige Autoren - mit Hajnal - die Regel der neolokalen Haushaltsgründung betonen, ${ }^{66}$ so steht dies im Widerspruch zur behaupteten Bindung der Verehelichung an einen ,Stellenmechanismus', der in erster Linie von Patrilokalität ausgeht.

\subsection{Die Rolle der Herrschaft bei der Eheschließung}

In der Theorie der ,agrarischen Bevölkerungsweise‘ nimmt die obrigkeitliche Einflussnahme auf die Heiratsmöglichkeiten der Untertanen einen zentralen Stellenwert ein (vgl. oben). Neuere Studien zeigen dagegen, dass Heiratsverbote kaum für die traditionale Gesellschaft charakteristisch waren, sondern häufig erst im späten 18. und im 19. Jahrhundert und damit im Übergang zur industriellen Gesellschaft ihre schärfste Ausprägung erfuhren. ${ }^{67}$ Bereits in der frühen Neuzeit existierende herrschaftliche Verordnungen zur Heirat der Untertanen bezogen sich zumeist bloß auf mit der Eheschließung verbundene Abgaben oder auf Mobilitätsbeschrän-

64 In der tschechischsprachigen Forschung wird vielfach der transitionale Inwohner-Status der vybití (ein Begriff, der die bereits ausbezahlten und verheirateten Kinder bezeichnet) angesprochen, die entweder im Elternhaus oder anderswo zur Miete lebten, bis sie eine eigene Unterkunft fanden. Vgl. Horská, Rodinná Strategie; Cerman, Mitteleuropa.

$65 \mathrm{Vgl}$. Mitterauer, Formen, 320.

66 Vgl. z.B. Gestrich, Geschichte, 76.

67 Vgl. Ehmer, Heiratsverhalten, 46ff., 85; Ehmer, Marriage, 290f.; Mantl: Heirat, 137; Kaschuba/Lipp, Dörfliches Überleben, 299, 312; Schlumbohm, Lebensläufe, 111. 
kungen, nicht aber auf generelle Heiratsverbote für bestimmte Bevölkerungsgruppen. Ehmer vertritt die These, dass das Interesse von Grund- wie Gutsherren eher „in der Förderung als in der Beschränkung der Eheschließungen “68 lag. Dennoch blieb Mackenroths Theorie auch in dieser Hinsicht bis heute einflussreich: es sei ein „Grundelement" der Heiratsmuster im vorindustriellen Deutschland gewesen, dass „die Heirat von der Erlaubnis obrigkeitlicher Instanzen abhängig [war]“, 69 und erst „mit der Aufhebung der behördlichen Ehebeschränkungen zu Beginn des 19. Jahrhunderts“ sei ,vielen das Schicksal des Zwangszölibats erspart" geblieben. ${ }^{70}$

Bereits im 16. Jahrhundert war in Böhmen der grundherrliche Ehekonsens formell eingeführt worden. ${ }^{71}$ Es ist aber nicht erkennbar, dass die Herrschaften diese Bestimmungen dazu genutzt hätten, die Eheschließung von Untertanen ohne Haus- und Landbesitz prinzipiell zu verhindern. Zwar wurden in einzelnen böhmischen Herrschaften, wie im Berauner Kreis, seit der Mitte des 17. Jahrhunderts sogar eigene ,Ehekonsens'-bücher geführt, die belegen, dass die Bewilligung durch die Herrschaft für alle Untertanen obligatorisch war und dafür auch eine Gebühr eingehoben wurde. Dass diese Bewilligung für vermögenslose Personen aber unentgeltlich erfolgte, deutet bereits an, dass der herrschaftliche Ehekonsens hier nicht unbedingt im Sinne der "Stellentheorie' angewandt wurde. ${ }^{72}$ Aus der südböhmischen Herrschaft Český Krumlov datiert aus dem Jahr 1720 tatsächlich eine herrschaftliche Instruktion, wonach die Eheschließung der „unpossessionierten Inleute" verwehrt werden sollte, falls diese über keine ausreichende Existenzgrundlage verfügten. Letztlich wurden die lokalen Dorfrichter und -geschworenen angehalten, den betroffenen Personen die Heirat ,auszureden“ ${ }^{73}$ Angesichts der überaus hohen Zahl an verheirateten Inwohnern in dieser Region zu jener Zeit ist fraglich, ob diese Instruktion in der Praxis eine hohe Bedeutung hatte. Über die Zahl an Ablehnungen ist nichts bekannt. Das Kloster Vyšší Brod jedenfalls setzte als Gutsherrschaft zwar auf vielfältige Weise die Rahmenbedingungen für die Haushaltsgründung seiner Untertanen: Jeder Transfer von Haus und Land, aber auch die Errichtung neuer Häuser oder die Aufnahme von Inwohnern in die Hausgemeinschaft musste formell genehmigt werden. ${ }^{74}$ Die Gutsherrschaft selbst

68 Ehmer, Heiratsverhalten, 243. Ähnlich argumentiert Maur, Gutsherrschaft, 117f., der zahlreiche Beispiele aus der zweiten Hälfte des 17. Jahrhunderts für den herrschaftlichen Druck zur Eheschließung anführt.

69 Pohlmann, Industriegesellschaft, 122.

70 Rödel, Entwicklung, 32.

71 Vgl. Stark, Ursprung, 60f.

72 Vgl. Maur, Gutsherrschaft, 116.

73 Vgl. Himl, Die armben Leüt, 73, 78.

74 Schlesinger, Dorfweisthümer, bes. S. 324 (Marktordnung von Vyšší Brod aus dem Jahre 1608). 
benötigte aber die Arbeitskraft der Unterschichten. Zahlreiche Taglöhner waren auf ihren Meierhöfen tätig, andere arbeiteten als Holzfäller in ihren ausgedehnten Wäldern. ${ }^{75}$ Die Herrschaft war an der Gründung neuer Häuser aktiv beteiligt und stärkte durch die Ausgabe von Pachtgründen die agrarische Basis der landarmen Häuser. Für das Kloster war nicht die Begrenzung der Zahl der landlosen und landarmen Bevölkerungsgruppen von Interesse, sondern die Erhaltung der mit zahlreichen Abgaben und Verpflichtungen behafteten grundbesitzenden Anwesen in ihrer Zahl und Größe. Die Gutsherrschaft achtete strikt auf die Unteilbarkeit der Güter und setzte bei schlechter Wirtschaftsführung vereinzelt auch Inhaber der Anwesen ab. Ein direkter Eingriff in das Heiratsverhalten der Untertanen ist dagegen auf Basis der hier untersuchten Quellen nicht nachweisbar.

Abgesehen von der erwähnten Instruktion aus der Herrschaft Český Krumlov aus dem Jahre 1720 beziehen sich alle bisher für das 17. und 18. Jahrhundert bekannten restriktiven Eheverordnungen aus dem südlichen Böhmerwald auf Heiratsverbote für das Gesinde, ${ }^{76}$ oder darauf, dass die Eheschließung nur innerhalb der Wohnsitzpfarre stattfinden sollte, wie dies etwa für die Vyšší Brod benachbarte Pfarrre Malšiny nachweisbar ist, nicht aber auf generelle Verehelichungsverbote für besitzarme/-lose Personen. Statistische Daten, die durchwegs hohe Anteile an landlosen Familien belegen, würden eine solche Politik auch nicht als besonders wirksam erscheinen lassen. In der Frage der Ansiedlung landarmer Bevölkerungsgruppen vertraten die Gemeinden Südböhmens wohl eine restriktivere Position als die Herrschaften. ${ }^{77} \mathrm{Wie}$ sich für Kapličky zeigen lässt, hatten diese ein Interesse, den Zugang zu den Gemeindeweiden zu begrenzen, hier entstanden zwischen 1681 und 1840 auf Gemeindegrund lediglich sieben neue Häuser, auf bäuerlichem Grund aber 15 und auf dominikalem 16 (vgl. Kapitel 5.5). 1820 beschloss die Gemeinde Horní Plana, Inwohnern nur mehr dann die Ehebewilligung zu erteilen, wenn sie jemanden aus dem Ort ehelichten, ${ }^{78}$ insgesamt aber hatte die Haltung der Gemeinden eher Auswirkungen auf die Häufigkeit der Errichtung neuer (viehhaltender) Anwesen, kaum jedoch auf die Zahl der Eheschließungen.

75 Vgl. etwa: Archiv Klaštera Vy̌̌ší Brod, Kart. č. 397, 5/3 (Handrobotverzeichnisse der Jahre 16751677).

76 Šterbová, Vývoj, 115 ff.

77 Dies betont auch Blau, Hausindustrie, 21 für das beginnende 19. Jahrhundert. Mehrere südböhmische Marktorte hatten bereits seit dem 17. Jahrhundert das Recht, Ehekonsense zu erteilen.

78 Vgl. Essl, Oberplan, 237. 


\subsection{Die Bedeutung des Gesindedienstes für das Heiratsalter}

Ein zur ,agrarischen Bevölkerungsweise‘ alternatives Erklärungsmodell für das Muster später Heirat betont die Bedeutung des lebenszyklischen Gesindedienstes vor der Eheschließung. ${ }^{79}$ Demnach wird der weithin beobachtbare Anstieg des Heiratsalters in vielen mitteleuropäischen Regionen während des 18. und 19. Jahrhunderts auf die Zunahme der Erwerbstätigkeit in solchen Positionen zurückgeführt. Der südliche Böhmerwald lässt sich aufgrund der Dominanz der Viehzucht und der Flachsverarbeitung, die beide einen permanent hohen Arbeitskräftebedarf erforderten, als ,Gesindegesellschaft ${ }^{80}$ bezeichnen. Im innerböhmischen Vergleich war der Gesindeanteil im Jahre 1651 in der Herrschaft Vyšší Brod auffällig hoch: ${ }^{81}$ mehr als die Hälfte der ländlichen Anwesen der Dörfer beschäftigte Gesindepersonen. Auch die Ansätze einer Gesindehierarchie (mit je nach Alter und Arbeitstätigkeit bis zu drei unterschiedlichen Bezeichnungen für jedes Geschlecht) ${ }^{82}$ können als Indikator für die Bedeutung dieser sozialen Position gelten. 1651 werden für Vyšší Brod neben den eigentlichen Knechten und den ,Dienstbuben' auch sogenannte ,Menner', die den Knechten untergeordnet waren, genannt. ${ }^{83}$ Über die quantitative Entwicklung der Gesindezahlen in Südböhmen in der Zeit nach 1651 existiert bisher nur sehr wenig Material. Für die Herrschaft Chýnov ist aber bis 1692 eine deutliche Zunahme des Anteils des Gesindes an der Bevölkerung nachweisbar. ${ }^{84}$

Tabelle 42: Altersaufbau des Gesindes in der Herrschaft Vyšší Brod

\begin{tabular}{lcccccc}
\hline & \multicolumn{3}{c}{ männlich } & & weiblich \\
& $<$ 20 Jahre & $\geq 20$ Jahre & \% der & $<20$ Jahre & $\geq 20$ Jahre \\
$(\%)$ & $(\%)$ & Bev. & $(\%)$ & $(\%)$ & $\begin{array}{c}\% \text { der } \\
\text { Bev. }\end{array}$ \\
\hline V. Brod Dörfer 1651 & $102(66,7)$ & $50(33,3)$ & 20,0 & $99(73,3)$ & $36(26,7)$ & 17,3 \\
Studánky 1798 & $21(53,2)$ & $18(46,8)$ & 13,2 & $21(40,4)$ & $31(59,6)$ & 14,9 \\
\hline
\end{tabular}

Anmerkung: Es wurden jeweils nur Personen ab 10 Jahren berücksichtigt.

Quelle: siehe Tabelle 37.

79 Vgl. Ehmer, Heiratsverhalten. Vgl. dazu bereits Hajnal, Two kinds.

80 Vgl. Mitterauer, Formen.

81 Vgl. die Daten bei Maur, Gesinde, 124.

82 Vgl. Mitterauer, Formen, $200 \mathrm{ff}$.

83 Diese Differenzierungen lassen sich in der Region sowohl im 17. als auch im 19. Jahrhundert nachweisen.

84 War das Verhältnis der Anzahl der Gesindepersonen zur Zahl der Anwesen 1651 hier etwa 1:3, so lag es 1692 beinahe bei 1:1. Eigene Berechnung nach Placht, Lidnatost a společenská, 151. 
Für Kapličky liegen aus späterer Zeit keine systematischen Daten zum Gesinde vor, ergänzend können wieder Informationen für Studánky 1798 herangezogen werden (Tabelle 42). Im Vergleich zu 1651 lassen sich dabei wesentliche Unterschiede erkennen: 1798 lag der Anteil des Gesindes an der Gesamtbevölkerung niedriger; auch die Alters- und Geschlechterstruktur hatte sich gegenüber 1651 gewandelt. Der 1798 geringere Anteil der Dienstboten ist mit Veränderungen in der regionalen Arbeitsorganisation erklärbar. Der hohe Bedarf an Gesinde im 17. Jahrhundert ergab sich zum Teil auch aus den Verpflichtungen gegenüber der Gutsherrschaft. Die spannfähigen Bauern mussten drei Tage pro Woche Robot leisten. Im Durchschnitt war daher pro Hof etwa eine halbe Arbeitskraft zusätzlich zu versorgen, die für die Herrschaft zu arbeiten hatte. Aus lokalen Quellen ist bekannt, dass die Bauern oft Gesindepersonen zum Frondienst sandten. ${ }^{85}$ In den 1780er Jahren wurde die Robot abgeschafft und in Geldabgaben umgewandelt, die Bauern ersparten sich danach die Beschäftigung dieser halben Arbeitskraft.

Der Zusammenhang mit den Robotverpflichtungen dürfte auch den Wandel in der Geschlechterproportion des Gesindes erklären: 1651 ist für die Dörfer um Vyšší Brod, wie für zahlreiche Gebiete Böhmens, ein Überhang des männlichen Gesindes festzustellen. Dieses für ländliche Gebiete eher untypische Muster wurde mit den Frondienstverpflichtungen der Bauern in Böhmen begründet. ${ }^{86}$ 1798, nach Wegfall der Robot, überwiegen in Studánky dagegen die Mägde. 1798 war außerdem eine Mehrheit des Gesindes älter als 20 Jahre. Insbesondere die weiblichen Dienstboten waren noch in der Altersgruppe der 25-29jährigen stark vertreten. Zur Mitte des 17. Jahrhunderts dagegen waren mehr als zwei Drittel des Gesindes der Dörfer von Vyšší Brod jünger als 20 Jahre.

Mackenroths Konzept liegt, in Analogie zu Otto Brunners ,ganzem Haus ' ${ }^{87}$ das Bild einer weitgehend autarken „väterlichen Produktionswirtschaft“ ${ }^{88}$ zugrunde. In Kapličky hatte jedoch ein großer Teil der Haushalte mit dem angeblich auf der „lohnlosen Mitarbeit der Familienmitglieder" 89 beruhenden ,ganzen Hauses“ (wozu auch Inwohner und Gesinde gezählt werden), nur wenig zu tun. Knechte und Mägde, und manchmal sogar die leiblichen Kinder der Bauern, erhielten eine Entlohnung für ihre Mitarbeit: ${ }^{90}$ Als 1738 Balthasar Wolffschläger sein Anwesen in Kapličky an seinen Sohn verkaufte und sich aufs Ausgedinge zurückzog, wurde

85 Ein Hinweis in: NA Praha, ED inv. č. 193, kart. 20. Exaequatorium Dominicale Closter Hohenfurth', 1749.

86 Vgl. Maur, Gesinde in Böhmen, 91.

87 Brunner, Haus; Darauf hat bereits Fertig, Autoregulation, 95, hingewiesen.

88 Mackenroth, Bevölkerungslehre, 363.

89 Brunner, Haus, 107.

90 Die Grundbücher nennen bei zahlreichen Besitztransfers den ausständigen ,Lidlohn` für das Gesinde. 
im Grundbuch vermerkt, dass er seiner Tochter noch den ,Lidlohn“ schulde. ${ }^{91}$ Anhand von Einzelfällen kann gezeigt werden, dass auch die Kinder der Inwohner Gesindedienst leisteten: $:{ }^{92} \mathrm{Um} 1712$ waren etwa die Geschwister Philip und Maria Wagner, Inwohnerkinder aus Lipová, auf dem Anwesen ihres Cousins mütterlicherseits Lhota Nr. 2 im Dienst. Beide verehelichten sich später und lebten zeitlebens als Inwohner in der Pfarre. Philip war bei seiner Hochzeit 1730 knapp 35 Jahre alt, Maria bei ihrer Heirat 1745 sogar bereits 48 Jahre. Auch Veit Fixl, der 1798 als Knecht in Vyšina genannt ist, stammte aus einer Inwohnerfamilie, heiratete um 1807 mit etwa 27 Jahren (außerhalb der Pfarre) und lebte später mit seiner Frau als Inwohner in Frantoly. Die Verdienstmöglichkeiten als Gesinde schufen für Kinder landloser Familien die Voraussetzungen für eine (späte) Heirat.

\subsection{Optionen und Strategien statt Mechanismen}

In der untersuchten Pfarre war das im Durchschnitt relativ hohe Heiratsalter nicht durch eine Bindung der Heirat an einen Mechanismus der ,Stellen'verursacht. Die Annahmen der ,Vollstellentheorie“ erweisen sich in mehrfacher Hinsicht als nicht zutreffend. Keineswegs besaßen allein Bauern und Handwerker ,demographische Vollwertigkeit'. Im Untersuchungsgebiet gab es während der gesamten Neuzeit eine zahlenmäßig starke haus- und landlose, dennoch aber verheiratete Bevölkerungsgruppe. Wer in dieser Region nicht in den Besitz eines landwirtschaftlichen Anwesens gelangte, blieb nicht unverheiratet, sondern heiratete in der Regel in die Unterschicht. Die Interessen der Obrigkeiten waren, entgegen den Annahmen der Theorie, nicht darauf ausgerichtet, das Entstehen landarmer/-loser Bevölkerungsgruppen zu verhindern. Auch wirkte die Praxis des Besitztransfers nicht als Regulativ, der die einen mit ihrer Heirat auf das Freiwerden einer ,Stelle' warten ließ, während die anderen zur Ehelosigkeit verurteilt waren. Für die Heirat und Haushaltsgründung von landlosen Paaren war der ,Stellenmechanismus' ohne Bedeutung. Da bei steigender Bevölkerungszahl die Zahl der landbesitzenden Anwesen weitgehend stabil blieb, wurde für die Grundbesitzenden der Wunsch nach Behauptung ihrer tatsächlich knappen sozialen Positionen zunehmend wichtiger.

91 SOA Třeboň, fond C Vyšší Brod, PK č. 479, fol. 38.

92 Da das Soupis poddaných Knechte und Mägde nur mit dem Vornamen verzeichnete, kann diese Frage nicht systematisch untersucht werden. In den Grundbüchern sind die Dienstboten in einigen Fällen namentlich genannt. Falls sie nicht von außerhalb der Pfarre kamen, lässt sich mit Hilfe der Familienrekonstitution feststellen, aus welchen Familien sie stammten. 
Dies hatte in vielen Fällen einen deutlichen Aufschub der Heirat zur Folge. ${ }^{93}$ Das hohe Heiratsalter der landarmen/-losen Bevölkerung wiederum ist vor allem mit der Bedeutung des Gesindedienstes zu erklären, der dazu diente, einen Heiratsfonds anzusparen. ${ }^{94}$ Trotz der Vielfalt der Einkommensmöglichkeiten in der Region blieb die bäuerliche Arbeitsorganisation auch für die Unterschichten prägend.

Freilich erweisen sich die historischen Verhältnisse häufig als komplexer als von den in der Literatur gängigen Konzepten angenommen. Sowohl die ,Vollstellentheorie' als auch Ansätze, welche die Heiratschancen ausschließlich mit konjunkturellen Entwicklungen der Löhne und Preise erklären, greifen letztlich zu kurz, da sie die Optionen und Praktiken der handelnden Menschen nicht ausreichend berücksichtigen. Wurden mit einer Heirat soziale Strategien verfolgt, wie die Bildung von Allianzen zwischen Häusern und Verwandtschaftsgruppen, so beeinflusste dies auch die Wahl des Zeitpunktes der Eheschließung (vgl. Kapitel 7). ${ }^{95}$ Auch waren ein mehrjähriger Gesindedienst oder Taglohn für ärmere Personen nicht die einzigen Möglichkeiten, zu einem Heiratsfonds zu kommen. Für das Untersuchungsgebiet liegen mehrfach Berichte vor, dass ärmere Bräute in den Wochen vor der Hochzeit in der Umgebung von Haus zu Haus gingen (bis zu 16 Tage lang) und um die sogenannte ,Haussteuer' baten. Sie erhielten Nahrungsmittel, Flachs oder einen Geldbetrag. Es handelte sich dabei um einen deutlich ritualisierten Brauch (,d'Braut geht sauma'), der auch gewissen Kontrollmechanismen unterlag. Eine zweite Frau musste mit ihr mitgehen, sie als Braut vorstellen und danach Fragen nach dem Namen und dem Herkunftsort beantworten. ${ }^{96}$ Zukünftige Studien zum Heiratsverhalten sollten daher der Entwicklung von Strategien und kulturellen Praktiken und deren Relation zu den lokalen Normen besondere Bedeutung beimessen.

\subsection{Auswirkungen auf die Sozialstruktur: die Lebenswege der, weichenden“ Geschwister}

Die Frage nach den Auswirkungen des Besitztransfers auf die demographische und sozialstrukturelle Entwicklung in einer Region mit Unteilbarkeit der Anwesen zielt in erster Linie auf die vorhandenen Möglichkeiten für die ,weichenden' Geschwister der Haus- und Hofbesitzer ab. Diese konnten entweder darauf hoffen, durch

93 Ähnlich die Argumentation bei Ehmer: Heiratsverhalten, 69 und Schlumbohm, Sozialstruktur, $329 f$. 94 Vgl. Mooser, Ländliche Klassengesellschaft, 89.

95 Vgl. Ehmer, Marriage, bes. 292-297. Vgl. auch: Duhamelle/Schlumbohm, Einleitung.

96 Vgl. Schramek, Böhmerwaldbauer, 218; Markus, Oberplan, 31f.. 
,Einheirat' in den Besitz eines Anwesens zu kommen, oder darauf, dass ihnen im Ausnahmefall der Neubau eines Hauses gestattet wurde. Ansonsten hätten sie, so die gerade im deutschsprachigen Raum lange Zeit vorherrschende Annahme, entweder lebenslang unverheiratet bleiben müssen oder allenfalls durch einen Wegzug aus der Region versuchen können, anderswo zu Hausbesitz zu gelangen. Insbesondere in der Tradition der älteren deutschen Bevölkerungsgeschichte nach Ipsen und Mackenroth dominierte die Vorstellung eines lebenslangen Zwangszölibats für große Teile dieser Bevölkerungsgruppe. ${ }^{97}$ Indirekt wurde diese Annahme zwar bereits vor längerer Zeit und auf vielfältige Weise widerlegt, ${ }^{98}$ dennoch hielt sich die Sichtweise bis in die jüngste Zeit. Dass weichende Geschwister tatsächlich nur selten in ihrer Herkunftspfarre heiraten konnten und daher entweder zeitlebens unverheiratet blieben oder wegzogen, wurde bisher aber nur für sehr wenige $\mathrm{Ge}$ biete tatsächlich nachgewiesen. ${ }^{99}$

Andere Autoren betonten dagegen vor allem, dass die ,weichenden“ Bauernkinder im Allgemeinen einen sozialen Abstieg erlebten und in die landlose und landarme Schicht (Inwohner, Heuerlinge o. Ä.) wechselten ${ }^{100}$ Die „nachgeordnete Versorgung“ der weichenden Geschwister sei eine „Funktion der Stabilität des bäuerlichen Besitzes“ und der Preis des Anerbenrechtes gewesen. ${ }^{101}$ Je nach Standpunkt werden in der Literatur unterschiedliche Terminologien für die Geschwister der Besitznachfolger gebräuchlich: diese werden entweder als,weichende Erben (da sie zumeist fortziehen mussten), als ,Nebenerben' oder als ,benachteiligte Erben', und im Extremfall auch als ,nicht erbende Geschwister' oder gar als ,Enterbte bezeichnet. ${ }^{102}$ Wenn ein Kind den Hof und damit auch die soziale Position ,erbte', die Geschwister jedoch in die ländliche Unterschicht abstiegen, so müsste dies zur Konsequenz haben, dass Verwandtschaftsbeziehungen unter den Bedingungen der Unteilbarkeit häufig schichtübergreifend waren. $\mathrm{Zu}$ fragen wird sein, ob die scheinbar vorgezeichneten und schroff unterschiedlichen Lebenswege der Geschwister auch in der sozialen Praxis tatsächlich so deutlich vorgegeben waren.

Jürgen Schlumbohm hat etwa festgestellt, dass zwar viele Bauernkinder zu Heuerlingen wurden, diese aber nur einen kleinen Anteil aller Heuerlinge stellten. ${ }^{103}$

\footnotetext{
97 Vgl. dazu die kritische Zusammenfassung bei Ehmer, Heiratsverhalten, $40 \mathrm{ff}$.

98 Vgl. etwa die zitierten Arbeiten von M. Mitterauer. Zahlreiche Studien zur historischen Familienforschung zeigten, dass es in der Regel keine soziale Position mit permanentem Ledigenstatus gab.

99 Dies stellt etwa Bonnain, Houses, 278 fest. Vgl. auch Mantl, Heirat, bes. $32 \mathrm{ff}$.

100 Trossbach, Bauern, 37; Ebeling/Klein, System, 32f.; Mooser, Soziale Mobilität, 189 ff.

101 Mooser, Ländliche Klassengesellschaft, 195, 198.

102 Rebel, Peasant Classes, spricht von den ,disinherited siblings'; Mantl, Heirat, 57 von den ,nicht erbenden Geschwistern“

103 Schlumbohm, Lebensläufe, 582.
} 
Zuletzt haben etwa Hohkamp und Lünnemann betont, dass auch unter den Bedingungen der Unteilbarkeit Ressourcenflüsse nicht einmalig, sondern mehrfach im Lebenslauf erfolgten. ${ }^{104}$ Zwischen den Geschwistern etablierten sich oft langfristige Reziprozitätsbeziehungen, die in komplexen gegenseitigen Unterstützungsund Versorgungsansprüchen bestehen konnten, sodass die Effekte des Systems der Unteilbarkeit auf die Strukturierung der Geschwisterbeziehungen möglicherweise weniger eindeutig waren als bisher angenommen. Christine Fertig hat in einer detaillierten Lokalstudie den Einfluss sozialer Netzwerke - wie der Verwandtschaft, der Nachbarschaft und vor allem der Patenschaft - auf sozialen Auf- oder Abstieg hin untersucht. Sie weist dabei insbesondere der Patenschaft und damit indirekt auch dem sozialen Prestige im Dorf eine wichtige Rolle zu. ${ }^{105}$

Bei einem beispielhaften Vergleich der Lebenswege von Geschwistern in der Pfarre Kapličky zeigt sich ein durchaus differenziertes Bild: Bei der wohlhabenden bäuerlichen Mühle ,Weyermühl' in Martinkov Nr. 5, die Mathias Hofmann 1688 von seinem Vater kaufte, wurde sein jüngerer Bruder Johann schließlich durch Einheirat Schuster und Besitzer eines Kleinhauses in Hodoň Nr. 7, seine Schwester Maria durch Einheirat aber Bäuerin in Vyšina Nr. 4. Alle weiteren Geschwister verstarben entweder unverheiratet (zwei davon im Erwachsenenalter) oder verließen die Pfarre. Als dann Albert Hofmann das Anwesen, Weyermühl' 1722 von seinem Vater Mathias kaufte, war sein älterer Bruder bereits verstorben (mit 23 Jahren), seine beiden Schwestern Maria und Margareth heirateten jeweils die Besitzer (klein-)bäuerlicher Anwesen in Mnichovice bzw. in Martinkov. Der jüngere Halbbruder Johann wurde 1745 durch Einheirat Bauer in Dobřín Nr. 4. Die wenigen Beispiele dieses Anwesens scheinen somit darauf hinzuweisen, dass ein deutlicher sozialer Abstieg der ,weichenden' Geschwister eher selten vorkam und es die meisten schafften, wiederum in einem bäuerlichen Anwesen unterzukommen. Betrachten wir noch das Kleinhaus Hvězda Nr. 2 (mit äußerst bescheidenem agrarischen Eigenbesitz, doch waren mehrere herrschaftliche Zinsreuter langfristig zugepachtet): Georg Schober kaufte dieses Haus 1739 von seinem Vater. Seine Schwester Elisabeth heiratete den faktisch landlosen Kleinhäusler Mathias Kern in Kapličky. Der Bruder Johann dagegen war 1737 durch Heirat mit einer Bauerntochter in den Besitz des bäuerlichen Hofes Kapličky Nr. 9 gelangt. Zu diesem Anwesen gehörten immerhin etwa sechs Hektar Ackerland an Eigenbesitz. Nachdem der einzige Sohn als Kleinkind verstorben war, hatten beim Anwesen Kapličky Nr. 9 nur drei Töchter überlebt. Mathäus, ein weiterer Bruder, wird 1742 durch Kauf Besitzer eines landarmen Kleinhauses in Kapličky Nr. 12. Der Lebensweg zweier

104 Hohkamp, Wer will erben, 331; Lünnemann, Besitztransfer.

105 Fertig, Rural Society. 
weiterer Geschwister des Georg Schober ist nicht rekonstruierbar, da diese offenbar die Pfarre verließen. Das Beispiel dieses Hauses zeigt damit, dass in Einzelfällen durchaus auch sozialer Aufstieg möglich war - sofern man der konventionellen sozialhistorischen Sichtweise zustimmen möchte, wonach mehr Landbesitz grundsätzlich eine bessere sozio-ökonomische Position indiziert als weniger Landbesitz.

In welchem Maße ermöglichte im Untersuchungsgebiet der phasenweise recht rege, phasenweise aber kaum durchgeführte Neubau von Häusern (siehe Kapitel 5.5) den weichenden Geschwistern der Haus- und Hofinhaber die Etablierung einer eigenständigen Existenz? In der Pfarre Kapličky war dies nicht besonders häufig der Fall. Wenn neue Häuser errichtet wurden, dann wurden dadurch oftmals nicht bisher noch unverheiratete Bauernkinder angesiedelt, sondern bereits seit längerer Zeit im Inwohnerstatus befindliche, verheiratete Personen. Dies lässt sich etwa am Beispiel des im Jahre 1690 neu angelegten Dominikalisten- und Holzfällerdorfes Nové Domky gut dokumentieren. Zwei waren zwar Bauernkinder gewesen, hatten aber bereits längere Zeit verehelicht im Inwohnerstand gelebt; auch beim dritten handelte es sich um einen verheirateten Inwohner aus der Pfarre. Die Namen von drei weiteren Neusiedlern finden sich in einem Verzeichnis aus dem Jahre 1677 unter den ,Tagwerkern' des direkt angrenzenden, aber nicht mehr zur Pfarre gehörigen Herrschaftsdorfes Slupečna. Zwei weitere kamen aus Dörfern nördlich von Vyšší Brod. Die Familienrekonstitution zeigt, dass fast alle mit Frau und mehreren Kindern ins neu gegründete Dorf übersiedelten. Zwei der Hausbesitzer verstarben im darauf folgenden Jahrzehnt, ein dritter nach elf Jahren. Zum Zuge kamen also primär eher ältere Inwohner, ähnlich wie dies auch bereits für mehrere frühneuzeitliche Dorfgründungen in Österreich nachgewiesen wurde. ${ }^{106}$ Auch wenn neue Häuser auf bäuerlichem Grund entstanden, waren es nur selten die Kinder oder Geschwister des Hausbesitzers, die die Möglichkeit zur Errichtung eines Anwesens erhielten. In der Pfarre selbst hatten demnach nur sehr wenige Geschwister von Hausübernehmern die Chance, durch die Neugründung eines Anwesens selbst zu Hausbesitz zu gelangen. Möglicherweise wichen jedoch einige in benachbarte Herrschaften aus, wo die Siedlungstätigkeit zum Teil weit bedeutender war (Kapitel 6.1).

Rekrutierten sich daher die Inwohner der Pfarre vornehmlich aus den weichenden Kindern der Haus- und Hofbesitzer? Von den 43 in einem Abgabenverzeichnis des Pfarrers aus dem Jahr 1783 verzeichneten männlichen Inwohnern ist lediglich für 14 nachweisbar, dass sie aus einer Haus besitzenden Familie stammten. Bei diesen handelte es sich also um ,weichende' Bauern- oder Häuslerkinder. 15 hatten dagegen Eltern, die selbst bereits lebenslang Inwohner in der Pfarre gewesen wa-

106 Mitterauer, Arbeitsteilung, 42. 
ren. Bei weiteren 13 ist die Position ihrer Eltern unbekannt, ganz überwiegend deshalb, weil diese außerhalb der Pfarre gelebt hatten. ${ }^{107}$ Es ist daher anzunehmen, dass sich während der zweiten Hälfte des 18. Jahrhunderts - nicht unähnlich den Erkenntnissen Schlumbohms (siehe oben) - zwar ein Teil der Inwohner aus den ,Nebenerben' der Hausbesitzer zusammensetzte, ein ähnlich hoher Anteil aber bereits selbst in Inwohnerfamilien geboren war. Die Lebenswege der ,weichenden“ Kinder verliefen daher in dieser Region sehr unterschiedlich: Viele konnten in ein anderes Haus einheiraten, nur einigen wenigen gelang es, ein neues Haus zu errichten, zahlreiche weichende Geschwister wurden Inwohner.

Unter der Bedingung der Unteilbarkeit der Anwesen gelangten in dieser Region also tatsächlich zahlreiche weichende Geschwister nie zu Haus- und Landbesitz. Verursacht wurde dies jedoch nicht durch die Unteilbarkeit an sich, sondern durch phasenweise Verbote eines Neubaus von Häusern. Der Anteil der Inwohner an der Gesamtbevölkerung der Pfarre war so auch kontinuierlich sehr hoch. Im Jahre 1783 lebten etwa in 30,3 Prozent aller Haushalte verheiratete Inwohnerpaare mit (wobei Ausnehmer und alleinstehende Inwohner nicht mitgezählt sind). ${ }^{108} \mathrm{Zu}$ betonen ist dagegen, dass während der gesamten Untersuchungsperiode die Möglichkeit zur Eheschließung für weitgehend alle Menschen kontinuierlich aufrechtblieb, auch wenn sich während dieser Zeit die Heiratsmuster stark wandelten. Zur Mitte des 17. Jahrhunderts heirateten die Menschen in der Untersuchungsregion - wie auch in anderen Gebieten Böhmens - im interregionalen Vergleich relativ früh, wie die überaus hohen Verheiratetenanteile bei den 25- bis 29-Jährigen zeigen (siehe dazu Kapitel 8.2.1). Auch wenn danach das Heiratsalter stieg, war den meisten Menschen nicht die Heirat an sich verwehrt, sondern nur die Möglichkeit zur frühen Eheschließung.

Die Anwesen wurden zunehmend im innerfamilialen Generationenwechsel erworben; die Heiratskreise unter den besitzenden Familien schlossen sich stärker nach außen hin ab und neue Anwesen wurden nur selten errichtet. Für Personen, die nicht in eine der haus- und grundbesitzenden Familien der Pfarre geboren waren, wurde es dadurch immer schwieriger, jemals zu Hausbesitz zu gelangen. ${ }^{109}$ Weil außerdem kaum neue Anwesen errichtet wurden, wurden insgesamt aber die Möglichkeiten außerhalb des innerfamilialen ,Erbgangs' oder einer Einheirat Hausbesitzer werden zu können, deutlich geringer.

Dies veränderte während des 18. Jahrhunderts den Charakter des Inwohnerstandes. Die starke Zunahme der innerfamiliären Besitzweitergaben hatte auch

107 Ein weiterer Inwohner, der davor selbst Hausbesitzer gewesen war, wurde hier nicht berücksichtigt.

Vgl. die Erläuterungen zur Quelle in Kapitel 3.4.

108 Vgl. Kapitel 3. 4.

109 Vgl. die ähnliche Entwicklung bei Sabean, Background, 118f. 
eine schärfere Trennung der sozialen Schichten zur Folge. Wer ohne Haus- und Grundbesitz geheiratet hatte, verblieb nunmehr lebenslang in dieser Position. Im 17. Jahrhundert war dies noch anders gewesen; in dieser Zeit ist in mehreren Fällen ein Wechsel vom Inwohner- in den Hausbesitzerstatus nachweisbar.

Die Seelenbeschreibung des Pfarrers Pater Mathias Mark aus dem Jahre 1651110 verzeichnete insgesamt 42 verheiratete Inwohnerpaare (Tabelle 43). Zieht man von dieser Zahl die neun ab, die in Wahrheit nicht Inwohner, sondern Besitzer eines Kleinhauses waren ${ }^{111}$, und verfolgt die Lebenswege der restlichen 33 Paare mit Hilfe zusätzlicher Quellen wie den Grundbüchern und der Familienrekonstitution, zeigt sich, dass beinahe ein Drittel entweder zuvor im Besitz eines Hauses gewesen war oder diese Position in einem späteren Lebensabschnitt erlangte: Als Altenteiler, ehemalige Hausbesitzer, die nach dem Verkauf in die Inwohnerposition gewechselt hatten, oder aber als junge Inwohner, die später noch zu Hausbesitz gelangten. Zusätzlich lebten die Hirten und der Schmied jeweils in einem von der Gemeinde Kapličky gepachteten Haus. Das Dorf Kapličky verkaufte seine Schmiede laut Grundbuch erst im Jahre 1723 an den damaligen Pächter. 1651 gab es auch drei ehemalige Hausbesitzer, die nach dem Besitztransfer nicht im ehemals eigenen Haus weiter mitwohnten, sondern als Inwohner in einem anderen Haus der Pfarre. Dagegen schaffte es keine der im Verzeichnis des Jahres 1783 als Inwohner genannten Personen, in den nachfolgenden Jahren zu Hausbesitz zu gelangen, und nur eine war davor Inhaber eines Anwesens gewesen.

Die Familienrekonstitution weist zahlreiche Familien aus, die über viele Jahre hinweg von der Heirat über die Taufe mehrerer Kinder bis zum Tod der Ehepartner in der Pfarre ortsansässig, jedoch, wie die Analyse der Grundbücher zeigt, nie Hauseigentümer waren. Es handelte sich also um Inwohner. Blasius Hoffmann, Bauernsohn und Bäcker, war zweimal verheiratet (erstmals 1776) und ließ in der Pfarre Kapličky neun Kinder taufen, auch sein Sterbeeintrag findet sich in den Matriken - Hausbesitzer war er allerdings nie. Zahlreiche Nachfahren des Chalupnerpaares Georg und Susanna Wagner (er verstarb 1679) aus Adámky verblieben in der Pfarre; die meisten von ihnen lebenslang im Inwohnerstatus. Ihr Sohn Gregor, vor seiner Heirat 1685 mit der Bauerntochter Margareth Kroyher Holzknecht im Dorf Lipová, ließ alle seine sechs Kinder in der Pfarre taufen und wurde

110 Archiv Kláštera Vyšší Brod, Kart. č. 219, Nr. 5.

111 Alle neun zahlten jedenfalls laut Zinsregister des Jahres 1643 einen Hauszins. Soweit diese Häuser auch im Grundbuch aufscheinen, lässt sich kein Hinweis darauf finden, dass diese ihre Anwesen bis 1651 verkauft hätten. Allerdings waren zu dieser Zeit nicht alle existierenden Kleinhäuser im Grundbuch verzeichnet, ein Eintrag erfolgte im 17. Jahrhundert in Einzelfällen auch erst mit einer jahrzehntelangen Verzögerung. 
auch in Kapličky begraben. Auch Philip Wagner (Heirat 1730), der Sohn des Gregor, sowie dessen Sohn Anton (Heirat 1770) lebten als verheiratete Inwohner bis zu ihrem Tod im Pfarrgebiet und hatten jeweils mehrere Kinder, waren aber nie Hausbesitzer. Der Inwohner-Status war demnach nicht für alle bloß eine Phase im Lebenslauf, im Laufe des 18. Jahrhunderts war er fast durchwegs zu einer lebenslangen Position geworden.

Tabelle 43: Die als ,Inwohner' bezeichneten Ehepaare der Seelenbeschreibung des Jahres 1651

\begin{tabular}{lcc}
\hline & $\mathrm{N}$ & $\%$ \\
\hline tatsächlich Besitzer eines Kleinhauses & 9 & 21,4 \\
Gemeindehirten & 3 & 7,1 \\
Gemeindeschmied & 1 & 2,4 \\
Ehemalige Hausbesitzer u. Ausnehmer & 5 & 11,9 \\
Andere ehemalige Hausbesitzer & 3 & 7,1 \\
Spätere Hausbesitzer & 5 & 11,9 \\
Lebenslang Inwohner & 16 & 38,1 \\
\hline Summe & 42 & 100,0 \\
\hline
\end{tabular}

Quelle: Datenverknüpfung Grundbücher und Seelenbeschreibung; Archiv Kláštera Vyšší Brod, Kart. 219 , Nr. 5 (Seelenbeschreibung). 


\section{DAS AUSGEDINGE : PRIVILEG DER LÄNDLICHEN OBERSCHICHTEN ODER SOZIALER ABSTIEG ? ERZWUNGENER RÜCKZUG ODER STRATEGISCHER WECHSEL?}

In vielen Gebieten Europas mit Unteilbarkeit der Güter fanden Besitzweitergabe und -nachfolge häufig bereits inter vivos statt. In diesen Fällen wurde oft ergänzend zum Kauf- oder Übergabevertrag ein ,Ausgedinge'-Vertrag abgeschlossen. Die im ländlichen Raum in manchen Regionen bereits seit dem 13. Jahrhundert nachweisbare rechtliche Institution des Ausgedinges (auch Altenteil, Ausnahme etc. genannt; tschechisch: výmènek) basierte entweder auf einer mündlichen Abmachung oder auf einem schriftlich fixierten Zusatz zu den Übergabe- und Kaufverträgen. Ausgedingevereinbarungen regelten die Frage, wer in welchem Ausmaß weiterhin Zugang zu den Ressourcen des Hauses hatte. Die Koppelung der Ausgedingevereinbarung an den Besitztransfer bedeutete auch, dass nur ehemalige Hausbesitzer derartige Verträge abschließen konnten.

Das wissenschaftliche Interesse am bäuerlichen Altenteil war lange Zeit hindurch stark von sozialpolitischen Wertungen motiviert. „Die unter dem Industrialisierungsschock einsetzende konservative Familienforschung des 19. Jahrhunderts sah in der bäuerlichen Dreigenerationenfamilie eine vorbildliche Lösung der Altenversorgung. "1 Diese auf Wilhelm Heinrich Riehl und andere zurückgehende unkritisch positiv bewertete Sichtweise des Ausgedinges als einer Altersversorgung innerhalb einer traditionellen, inzwischen aber im Zerfall befindlichen bäuerlichen Großfamilie war bis weit in das 20. Jahrhundert hinein äußerst einflussreich. Andererseits war gegen Ende des 19. Jahrhunderts in mehreren europäischen Ländern auch eine breite sozialreformerisch motivierte Strömung gegen das Ausgedinge entstanden. Ihre Forderungen nach einer staatlichen Altersversicherung für Bauern versuchten die Vertreter dieser Richtung mit einer Betonung der negativen Auswirkungen des Ausgedinges zu unterstreichen. Diese Bewegung betonte den drohenden ökonomischen Ruin zahlreicher bäuerlicher Wirtschaften durch eine zumeist überaus hohe ökonomische Belastung der Höfe und verschwieg auch keineswegs die hohe Konfliktträchtigkeit derartiger Regelungen zwischen den Generationen.

1 Sieder, Sozialgeschichte, 67. 
Im Rahmen dieser politischen Kampagne entstanden auch einige wichtige, noch heute häufig als Quellen herangezogene, empirische Arbeiten zum Ausgedinge. ${ }^{2}$

In Österreich entstanden seit den 1970er Jahren im Zusammenhang mit Studien aus dem Bereich der historischen Familienforschung einige sozialhistorische Arbeiten zum Themenbereich des Ausgedinges. Diese Arbeiten wurden vor allem auf der Quellenbasis von Seelenbeschreibungen durchgeführt und nur relativ selten anhand von Ausnehmerverträgen. ${ }^{3}$ Die Ergebnisse dieser Studien aus dem Umkreis Michael Mitterauers lassen sich etwa folgendermaßen zusammenfassen: Die reale Verbreitung des Ausgedinges wird für die frühe Neuzeit als nicht besonders hoch eingeschätzt. ${ }^{4}$ Die quantifizierende sozialhistorische Forschung konnte nachweisen, dass in vielen Regionen „das Ausgedinge-Verhältnis eher die Ideologie des generationellen Tausches prägte als tatsächliche Reziprozität zwischen den Generationen implizierte“. ${ }^{5}$ Das Ausgedinge ist nicht als familiale, sondern als hauswirtschaftliche Form der Altersversorgung zu sehen, ${ }^{6}$ da es nicht selten auch zwischen nicht-verwandten Personen abgeschlossen wurde. Ausgedinge und Wiederverehelichung werden als alternative, einander ausschließende Lösungsmöglichkeiten angesehen. Die verhältnismäßig geringe Zahl an derartigen Regelungen sei eine Folge der ökonomischen Belastung gewesen, die die Versorgung einer mitlebenden, jedoch nicht mehr produktiv tätigen - gleichsam im Ruhestand befindlichen - Person für ein Anwesen bedeutete. Deshalb wird für die Zeit vor dem 19. Jahrhundert eine weitgehende Begrenzung dieser Institution auf wohlhabende bäuerliche Höfe angenommen. ${ }^{7}$ Den landlosen oder landarmen Schichten habe die ökonomische Basis gefehlt, um es den Hausinhabern zu ermöglichen, sich zu Lebzeiten zurückzuziehen und sich von den Erträgen des Anwesens weiterhin mitversorgen zu lassen. In manchen Regionen waren Ausgedingeverträge bereits im 16. Jahrhundert verbreitet, in anderen waren sie in dieser Zeit aber noch unbekannt und setzten sich erst ab dem 18. Jahrhundert durch. Eine steigende Ertragslage der bäuerlichen Wirtschaften im Gefolge der Agrarrevolution des frühen 19. Jahrhunderts habe

2 In Böhmen trat etwa Stephan Richter mit Vortragsreisen durch das ganze Land gegen das Ausgedinge auf, vgl. Richter, Ausgedinge. Die wichtigste empirische Arbeit aus dieser Zeit: Horáček, Ausgedinge.

3 Vgl. neben den diversen familienhistorischen Arbeiten Mitterauers, die das Thema,Ausgedinge' häufig mitbehandeln, vor allem Ostrawsky, Hausgemeinschaften; Kogler, Ausgedinge.

4 So das Resümee einer Arbeit anhand von Materialien aus dem österreichischen Raum von Held, Ausgedinge.

5 Held, Ausgedinge, 183.

6 Dies betonen auch Sieder, Sozialgeschichte, 65 und Ehmer, Sozialgeschichte, 29.

7 Van Dülmen, Kultur, 204: „...eine so starke Belastung, dass ihr nur große Höfe entsprechen konnten.“ Vgl. auch Mitterauer/Sieder, Patriarchat; Mitterauer, Problemfelder, 22. 
dann die Möglichkeit der Mitversorgung von mehr Menschen am bäuerlichen Hof vergrößert und allgemein zu einem Anstieg der Zahl der Übergaben unter Lebenden, bei gleichzeitigem Rückgang der Wiederverehelichungen, und zu einem starken Anstieg der Zahl der im Ausgedinge lebenden Menschen geführt. ${ }^{8}$ Dieser Prozess wurde auch die Diffusion des Ausgedinges genannt. ${ }^{9}$ In der tschechischen Historiographie existieren sozialhistorische Arbeiten über das Ausgedinge erst seit jüngster Zeit. Überwiegend haben sich nur Rechtshistoriker damit befasst. ${ }^{10}$ Eine Ausnahme bildet aber die Monographie von Vladimír Procházka, der anhand einer Reihe von Einzelfällen aus verschiedenen Regionen versuchte, verallgemeinernde Aspekte des Ausgedinges in Böhmen zusammenzufassen. ${ }^{11}$ Neben dem mitteleuropäischen Raum war das Ausgedinge während der frühen Neuzeit auch in Skandinavien weit verbreitet. ${ }^{12}$

So sehr einerseits die gängige Beschreibung des Ausgedinges als einer angeblich „von Arbeit entlasteten Altersphase ... ${ }^{13}$ eine Einschätzung als soziales Privileg der besitzenden ländlichen bäuerlichen Oberschichten nahelegt, wird andererseits immer wieder auch der Positions- und Statusverlust, der mit einem Wechsel auf das Ausgedinge angeblich häufig einherging, betont. Bauern, als Besitzer zumeist angesehene Mitglieder der dörflichen Oberschicht, hätten sich als Altbauern im Ausgedinge häufig plötzlich auch als verarmte Bittsteller und sogar als Gespött der Kinder wiedergefunden. Kontrovers gesehen wird daher die Frage, ob die Hausbesitzer der frühen Neuzeit frühzeitig, gerne und freiwillig ins Ausgedinge wechselten oder ob erst ein von mehreren Seiten ausgeübter sozialer Druck sie zur Aufgabe ihrer bisherigen Position bewegte. Ein solcher Druck sei einerseits von den prospektiven Nachfolgern, etwa den eigenen Kindern, ausgeübt worden, anderseits zum Teil auch vom Grundherrn, der Interesse an einem zeitgerechten Rückzug der Hofinhaber haben musste, weil er leistungsfähige Wirtschaftsbesitzer benötigte. ${ }^{14}$

$8 \mathrm{Zu}$ diesen Zusammenhängen siehe vor allem Mitterauer, Formen, 312f.

9 Ehmer, Life stairs, 60.

10 Vgl. bereits Rößler, Ausgedinge.

11 Procházka, Nemovitost.

12 Vgl. als einige der wichtigsten internationalen Studien zum Thema: Berkner, Stem Family; Gaunt, Property; Goody, Erbschaft. An neueren internationalen Studien sind etwa zu nennen: Kopczyński, Old Age; Moring, Family Strategies.

13 Sieder, Sozialgeschichte, 31.

14 Vgl. Mitterauer/Sieder, Patriarchat, 188-190. 


\subsection{Zur Verbreitung des Ausgedinges in der Pfarre Kapličky}

Ausgedingeverträge waren in der Pfarre Kapličky zumindest seit dem Beginn des 18. Jahrhunderts bei den wohlhabenden Bauern wie bei den landarmen Hausbesitzern sehr zahlreich. Für den Zeitraum von 1699 bis 1738 scheint die Überlieferung dieser Verträge vollständig erhalten zu sein, da die insgesamt 77 Verträge dieses Zeitraums gesammelt in einem herrschaftsweit geführten ,Ausnehmerbuch ${ }^{15}$ verzeichnet sind. Das ,Ausnehmerbuch“ der Herrschaft Vyšší Brod, das als Quellentypus sicherlich eine Besonderheit darstellt, umfasst für die Jahre von 1699 bis 1738 schätzungsweise etwa 400 bis 500 Altenteilerverträge aus allen Dörfern der Herrschaft. Alleine für die Jahre von 1731 bis 1738 sind es 157 Verträge (davon betreffen lediglich 17 die Pfarre Kapličky). ${ }^{16}$

In Kapličky kamen Ausgedingeverträge zwischen 1699 und 1738 bei einer Mehrheit aller Land besitzenden Anwesen sowie bei etwa der Hälfte aller landarmen Häuser vor (Tabelle 44). Bei 66,4 Prozent aller Besitzwechsel dieser Zeit (ohne den Besitzweitergaben durch Wiederverehelichungen von Witwen) wurde ein Ausgedinge vereinbart, in ca. 40 Prozent dieser Fälle waren bei der Übergabe noch beide Ehepartner am Leben. Die untersuchten Ausgedingeverträge dieses Zeitraums verteilten sich auf 65 der insgesamt etwa 100 Häuser der Pfarre. Das Altenteil war in diesem Gebiet daher eine auch in der Praxis häufig genutzte Sozialform und stellte nicht bloß ein potenziell existierendes Modell dar, wie dies für andere Gebiete festgestellt wurde. ${ }^{17}$ Für andere Gebiete wurde die Zunahme von Altenteilerverträgen eher mit der Ertragssteigerung der bäuerlichen Betriebe im Zuge der Agrarrevolution des beginnenden 19. Jahrhunderts in Zusammenhang gebracht. ${ }^{18}$ Insgesamt scheint das Altenteil in Böhmen im 17. und 18. Jahrhundert weiter als in vielen anderen Regionen Mitteleuropas verbreitet gewesen zu sein. ${ }^{19}$

15 SOA Třeboň, fond Vyšší Brod, PK č. 565 ,Kniha Výměnkářskác. Dass alle diese Verträge in einem von der Herrschaft geführten Buch zentral verzeichnet wurden, verdeutlicht die besondere Rolle des Klosters als Kontrollorgan der Überwachung der zwischen den Generationen geschlossenen Verträge.

16 Für die Dörfer der größeren benachbarten Pfarre Vyšší Brod sind alleine für die acht Jahre zwischen 1731 und 173843 solcher Verträge verzeichnet, d. h. pro Jahr durchschnittlich etwas mehr als fünf. Das Buch beinhaltet dabei keine Ausgedingeverträge aus den beiden Marktorten der Herrschaft. Eine Ursache dafür dürfte darin zu suchen sein, dass die Marktorte, die anders als die Dörfer häufig das Recht hatten, eigenständig Grundbücher zu führen, auch die Einhaltung der Ausgedinge-Vereinbarungen selbstständig überwachten.

17 Vgl. Ehmer, House, 69 und Held, Retirement, $249 \mathrm{f}$.

18 Vgl. Mitterauer, Formen, $312 \mathrm{f}$.

19 Vgl. Klášterská, Forma; Štefanová, Ausgedinge. 
Tabelle 44: Besitzerwechsel und Ausgedinge nach Verwandtschaft und Schicht, Pfarre Kapličky 1699-1738 ( $\mathrm{N}=116)$

\begin{tabular}{lrrrrrrrrrr}
\hline & \multicolumn{3}{c}{ Landbesitzende Anwesen } & \multicolumn{3}{c}{ Landarme Anwesen } \\
& Ausgedinge & \multicolumn{2}{c}{$\begin{array}{c}\text { kein } \\
\text { Ausgedinge }\end{array}$} & gesamt & Ausgedinge & $\begin{array}{c}\text { kein } \\
\text { Ausgedinge }\end{array}$ & gesamt \\
\hline Neuer Besitzer & $\mathrm{n}$ & $\%$ & $\mathrm{~N}$ & $\%$ & $\%$ & $\mathrm{n}$ & $\%$ & $\mathrm{~N}$ & $\%$ & $\%$ \\
\hline Sohn & 28 & 53,9 & 8 & 44,4 & 51,4 & 15 & 60,0 & 7 & 33,3 & 47,8 \\
Schwiegersohn & 7 & 13,5 & 1 & 5,5 & 11,4 & 4 & 16,0 & 5 & 23,8 & 19,6 \\
Stiefsohn & 2 & 3,9 & 1 & 5,5 & 4,3 & - & 0,0 & - & 0,0 & 0,0 \\
Bruder & - & 0,0 & 1 & 5,5 & 1,4 & 1 & 4,0 & - & 0,0 & 2,2 \\
Sonstige & 6 & 11,5 & 1 & 5,5 & 10,0 & 2 & 8,0 & 1 & 4,8 & 6,5 \\
Verwandte & & & & & & & & & & \\
Familienfremd & 9 & 17,3 & 6 & 33,3 & 21,4 & 2 & 8,0 & 7 & 33,3 & 19,6 \\
Unbekannt & - & 0,0 & - & 0,0 & 0,0 & 1 & 4,0 & 1 & 4,8 & 4,3 \\
\hline Summe & 52 & 100,0 & 18 & 100,0 & 100.0 & 25 & 100.0 & 21 & 100,0 & 100,0 \\
\hline
\end{tabular}

Anm.: Zur sozialen Kategorisierung der Anwesen vergleiche Kapitel 3.3.

Auch aus den wenigen erhalten gebliebenen Bevölkerungsverzeichnissen der Pfarre lässt sich ein durchaus hoher Anteil an Ausnehmern ablesen. Sowohl im Jahr 1651 als auch 1783 lebten in mehr als 17 Prozent aller Haushalte von Kapličky Ausnehmer mit. Dies stellt jedenfalls einen höheren Wert dar, als er für eine Vielzahl an österreichischen Orten der frühen Neuzeit ermittelt wurde. ${ }^{20}$ Für Kapličky sind einige Altenteilerverträge bereits aus dem späten 16. Jahrhundert (sowie auch aus dem 17. Jahrhundert) erhalten; ${ }^{21}$ deren Zahl stieg aber fraglos im frühen 18. Jahrhundert an, insbesondere unter den ärmeren sozialen Gruppen. ${ }^{22} \mathrm{Im}$ Zeitraum von 1699 bis 1720 wurden in der Pfarre im Durchschnitt etwa 1,5 Verträge abgeschlossen, zwischen 1721 und 1738 durchschnittlich aber 2,4. Ebenso stieg die Häufigkeit eines Ausgedinges für beide Ehepartner an. Bemerkenswert erscheinen

20 Held, Retirement.

21 Schon in der Zeit davor wurden in den seit dem späten 16. Jahrhundert vorhandenen Grundbüchern immer wieder auch einige Ausgedinge-Verträge vermerkt - es ist nicht mit Bestimmtheit zu klären, ob in dieser Zeit alle diese Verträge auch im Grundbuch verzeichnet wurden. Für die Zeit nach 1738 jedenfalls finden sich nur mehr sehr vereinzelt solche Verträge; in einer etwas größeren Zahl gibt es in den Grundbüchern aber immer wieder Hinweise auf ein beim jeweiligen Haus gerade bestehendes Ausgedinge.

22 Die wenigen verzeichneten Verträge des 17. Jahrhunderts betreffen durchgehend Land besitzende Anwesen. 
die zahlreichen Ausgedinge-Verträge bei den landarmen Häusern. Die Besitzübergabe zu Lebzeiten und ein Rückzug auf das Ausgedinge war in dieser Region demnach keineswegs ein Privileg der Oberschichten, sondern kam selbst bei den kleinsten Anwesen vor. Zwar waren die meisten Kleinhäuser dieser Region nicht völlig landlos, sondern verfügten über zumindest marginalen Grundbesitz, der Basis der Arrangements zwischen den Generationen werden konnte. Manchmal diente aber auch der bloße Besitz eines kleinen landlosen Hauses bereits als Quelle, um sich für den eigenen Lebensabend etwa ein permanentes Wohnrecht auszuhandeln. Auch in anderen Regionen Böhmens lassen sich im 17. und 18. Jahrhundert Altenteiler-Verträge in den Unterschichten nachweisen, ${ }^{23}$ ebenso waren Ausgedinge-Regelungen um 1800 unter den Bandwebern (und Kleinhausbesitzern) der Westlausitz weit verbreitet. ${ }^{24}$

In dieser Region bestand das Ausgedinge, wie in vielen anderen Regionen auch, im Anspruch gegenüber dem Hof und nicht gegenüber der Person des neuen Inhabers des Anwesens. ${ }^{25}$ Die Bindung an den Hof im Untersuchungsgebiet ist schon daraus ersichtlich, dass im Falle eines Besitzwechsels auf das Vorhandensein eines Ausgedinges beim Haus im Grundbuch extra hingewiesen wurde. Bei einem neuerlichen Besitzwechsel gingen die Verpflichtungen gegenüber den im Ausgedinge befindlichen Personen an den neuen Inhaber über. Solche Konstellationen sind auch mehrfach nachweisbar. In zumindest 12 Fällen lebten die Ausnehmer auch noch beim Nachfolger ihres Nachfolgers mit, in einem Fall sogar noch bei seinem dritten Besitznachfolger. Die Bindung an den Hof wird außerdem durch die formale Gestaltung der ,Verträge' deutlich. Die Ansprüche der Vorbesitzer wurden gegenüber dem Anwesen formuliert („bei diesem Haus hat der N.N. folgendes Ausnehmen:"), mehrfach wurde der Besitznachfolger dabei nicht einmal namentlich genannt. (Es handelte sich also nur in eingeschränktem Sinne um ,Verträge‘ zwischen Übergeber und Übernehmer).

In den Verträgen erscheinen die Generationenbeziehungen in hohem Maße versachlicht und verrechtlicht. Genau vertraglich geregelt wurden nicht nur die diversen Sachleistungen, die die Vorbesitzer beanspruchen konnten, häufig wurden auch Zusatzregelungen für den Konfliktfall vereinbart. Diese zielten vorwiegend

23 Vgl. Klášterská, Forma; Štefanová, Ausgedinge; Grulich, Aspekte; Štefanová/Zeitlhofer, Alter. Vgl. zur Verbreitung in anderen Gebieten: Trossbach, Bauern, 34.

24 Schöne, Kultur.

25 Als Ausnahme von dieser Regel findet sich ein einzelner Fall für die im Norden anschließende Pfarre Malšin, bei dem im Jahr 1714 vereinbart wurde, dass der ins Ausgedinge wechselnde Besitzer seine bereits länger als Ausnehmerin lebende Mutter von der ihm zugesicherten Leistung künftig mit zu versorgen habe. SOA Třeboň, fond C Vyšší Brod, PK č. 565, fol. 94. 
auf eine stärkere räumliche Separierung der Ausnehmer. ${ }^{26}$ Außerdem finden sich oft Regelungen des Anteils, der der Witwe eines Ausnehmers verbleiben sollte, im Falle, dass dieser vor ihr sterben sollte. Letztlich steckten die Ausgedinge-Verträge wohl nur einen rechtlichen Rahmen ab, auf den sich beide Teile im Konfliktfall berufen konnten. Anhand eines Vergleichs der Grundbücher mit dem Ausnehmerbuch lässt sich in Einzelfällen nachweisen, dass vereinbarte Leistungen in der Realität manchmal auch erst sehr spät erfüllt wurden. ${ }^{27}$

Variierte in Kapličky die Verbreitung von Ausgedingeverträgen nur relativ wenig zwischen den einzelnen sozialen Gruppen der Land besitzenden Bauern und der landarmen und landlosen Häusler, so waren diese Unterschiede hinsichtlich der Leistungen, die den Vorbesitzern weiterhin zugesichert wurden, weit stärker: Das bäuerliche Paar ging üblicherweise zu zweit ins Ausgedinge (Tabelle 45) und beanspruchte, hinkünftig in einem separaten Kleinhaus zu wohnen (Tabelle 46).

Besitzer landarmer Haushalte dagegen wechselten zumeist allein, häufig in weit fortgeschrittenem Alter und/oder in Reaktion auf den Tod des Ehepartners, in das Altenteil. ${ }^{28}$ Hier lebten die Altenteiler im Haus des Nachfolgers mit (entweder in einem eigenen Raum oder nur in einer ihnen zugewiesenen Ecke eines Raums) und erhielten überwiegend keine für das Überleben notwendige Versorgung. Die Verträge in dieser Gruppe sind oft äußerst knapp und unspezifisch gehalten. ${ }^{29}$ Der Ausgedingevertrag des verwitweten Thomas Leitgöb beispielsweise - Inhaber eines Kleinhauses, zu dem laut Kataster 1713 lediglich ca. 0,2 Hektar Grund gehörten und als Viehstand nur eine einzige Kuh verzeichnete, und der noch im selben Jahr nach dem Verkauf des Anwesens an seine 41 Jahre alte Tochter und deren Mann auf das Altenteil wechselte, - bestand lediglich in einem einzigen Satz: ,lebenslang das frewe bleiben und die betrewung vom jetzig stüffter zuhabn“. ${ }^{30}$ Diese unspezifische Formulierung verweist auf eine sehr schwache Position im Haushalt des

26 Beispielsweise „... und wan sie sich miteinand nit vertragn können, so soll der stiffter umb seine aigene Bezahlung ein newes Heißl vor dem Ausnehmber bawn laßn." (SOA Třeboň, fond C Vyšší Brod, PK č. 565, fol. 70).

27 So hatte der Kleinhäusler Thomas Lind bei der Übernahme des Hauses 1735 von seiner Mutter einen Preisnachlass unter der Voraussetzung erhalten, ihr dafür eine Unterstandsmöglichkeit für die Haltung einer Kuh zu erbauen (SOA Třeboň, fond C Vyšší Brod, PK č. 565, fol. 445). Laut Grundbuch erfüllte er diese Bedingung allerdings erst nach 14 Jahren im Todesjahr seiner Mutter.

28 Die Verwitwung der Frau als auslösendes Moment für den Rückzug auf das Altenteil scheint in vielen Regionen häufig gewesen zu sein. Vgl. Ostrawski, Hausgemeinschaften, 220; Krabička, Übergabemuster, 55; Kogler, Ausgedinge, 231.

29 Auch für niederösterreichische Regionen wird berichtet, dass die Regelungen für die Altenteiler umso geringer und wenig detailliert gehalten waren, je kleiner der Besitz war. Vgl. Langer-Ostrawski, Generationenbeziehungen, 268.

30 SOA Třeboň, fond C Vyšší Brod, PK č. 565, fol. 78. 
Nachfolgers. Die konkrete Bedeutung der unspezifisch formulierten ,Betreuung;, die Thomas Leitgöb zu erwarten hatte, hing wohl weitgehend vom Gutdünken seines Nachfolgers ab.

Manchmal wurde auch dezidiert festgehalten, dass sich die Person im Altenteil „um den Rest selbst kümmern müsse“31; vereinzelt wurde sogar bestimmt, dass ein Ausnehmer für eine Leistung zu bezahlen hätte: Mathias Sultzbacher etwa war vertraglich verpflichtet, seinem nicht-verwandten Nachfolger Ludwig Woisetschläger im Gegenzug für das relativ großzügig bemessene Ausgedinge beim landarmen Kleinhaus Nové Domky Nr. 9 (Haltung einer Kuh, Nutzung der halben Hauswiese und zweier Gemüseäcker) „dem stüffter 24 kreutzer zinss zu hilf“ zu zahlen. ${ }^{32}$

Tabelle 45: Personen im Ausgedinge, Pfarre Kapličky 1699-1738

\begin{tabular}{lrrrr}
\hline & \multicolumn{2}{c}{ Bauern } & \multicolumn{2}{c}{ Unterbäuerliche } \\
& $\mathrm{n}$ & $\%$ & $\mathrm{n}$ & $\%$ \\
\hline Witwer & 4 & 7,7 & 8 & 32,0 \\
Witwe & 17 & 32,6 & 8 & 32,0 \\
Witwe mit zwei Kindern & 1 & 1,9 & - & 0,0 \\
Ehepaar & 27 & 51,9 & 8 & 32,0 \\
Ehepaar mit einem Kind & 3 & 5,8 & 1 & 4,0 \\
\hline Summe & 52 & 100,0 & 25 & 100,0 \\
\hline
\end{tabular}

Quelle: SOA Třeboň, fond C Vyšší Brod, PK č. 565.

Ausgeprägt waren die Unterschiede zwischen den besitzenden und den besitzarmen Anwesen bei den Wohnformen im Ausgedinge (vgl. Tabelle 46). Die Abmachungen bezüglich der räumlichen Unterbringung der abtretenden Generation wiesen eine hohe Bandbreite auf. Neben unbestimmten Formulierungen wie, freies Bleiben beim Haus' reichen sie von der konkreten Festlegung eines, Ecks in der Stuben' oder eines ,Winckels in der Kammer' über die Benutzung eines separaten ,Stübls ${ }^{33}$ bis hin zum Vorbehalt eines eigenen Ausnehmerhauses.

31 SOA Třeboň, fond C Vyšší Brod, PK č. 565, fol. 44 (1707).

32 SOA Třeboň, fond C Vyšší Brod, PK č. 565, fol. 368 .

33 Das ,Ausnehmerstübl' war im österreichischen Waldviertel weit verbreitet, vgl. Mitterauer, Formen, 237. 
Tabelle 46: Wohnformen im Ausgedinge, Pfarre Kapličky 1699-1738

\begin{tabular}{lcccc}
\hline & \multicolumn{2}{c}{ Bauern } & \multicolumn{2}{c}{ Unterbäuerliche } \\
& $\mathrm{n}$ & $\%$ & $\mathrm{n}$ & $\%$ \\
\hline Haus & 25 & 48,1 & 1 & 4,0 \\
Stübl & 12 & 23,1 & 9 & 36,0 \\
Mitwohnen & 15 & 28,8 & 14 & 56,0 \\
ohne Angabe & - & 0,0 & 1 & 4,0 \\
\hline Summe & 52 & 100,0 & 25 & 100,0 \\
\hline
\end{tabular}

Quelle: SOA Třeboň, fond C Vy̌šší Brod, PK č. 565.

Auch wenn in Einzelfällen nachweisbar ist, dass einige Ausnehmer die vorhandenen Räumlichkeiten gar nicht beanspruchten, hing die Möglichkeit, ob sich beide Ehepartner aufs Ausgedinge zurückziehen konnten oder nicht, auch mit den räumlichen Gegebenheiten zusammen. In diese Richtung deutet jedenfalls der Umstand, dass die Vereinbarung, ein eigenes Hauses bzw. ein Stübl zu bewohnen, mehrheitlich von Ehepaaren beansprucht wurde, das Mitleben in den Räumen der neuen Besitzer dagegen in etwa zwei Dritteln der Fälle alleinstehende Altenteiler betraf. Allerdings hatte auch ca. ein Drittel der Ehepaare im Ausgedinge lediglich ein Recht, sich mit dem neuen Besitzerpaar die Räumlichkeiten des Hauses zu teilen. Bei den landarmen Häusern bestand nur sehr selten die Möglichkeit, abgesonderte Wohneinheiten zu benutzen. Wie prekär hier die räumliche Nähe oft war, zeigt sich etwa in der Vereinbarung, dass dem neuen Inhaber der Gang durch das ,Ausnehmerstübl' in den Stall gewährt werden müsse. Diese Räume für Ausnehmer waren häufig ohne eigene Heizmöglichkeit und wurden daher oft direkt an den Stall angebaut, der eine gewisse natürliche Wärme bot. In anderen Fällen wurden Altenteiler auch in unmittelbarer Nähe des Herdes oder des Backofens untergebracht. ${ }^{34}$

Im Untersuchungsgebiet lassen sich für den Zeitraum von 1699 bis 1738 bei immerhin 25 Anwesen separate Ausgedinge-Häuser nachweisen. 18 dieser Nebenhäuser gehörten zu den zwei- oder mehrspännigen Bauernhöfen, sieben zu den einspännigen, keines jedoch zu den Gütern ohne Zugvieh. Bei einem Hof sind zwei bewohnbare Nebenhäuser nachweisbar. Auch wenn offensichtlich ein Zusammenhang zwischen der Größe des Grundbesitzes und dem Vorhandensein eines Ausnehmerhauses bestand, verfügten viele der größeren Bauerngüter über

34 Vgl. Schramek, Böhmerwaldbauernhaus, 20. 
kein solches, während andererseits durchaus auch bei Häusern mit relativ geringem Grundbesitz ein Nebengebäude für Altenteiler vorkam.

Der hohe Verbreitungsgrad eigener Ausnehmerhäuser in dieser eher kleinbäuerlich strukturierten Gesellschaft mag überraschen. Ein Nebenhaus konnte aber zeitweise auch an Miete zahlende Inwohner vergeben werden. Die wechselweise Unterbringung von Inwohnern und Ausnehmern in den Nebenhäusern wird auch in der Regionalliteratur betont. ${ }^{35}$ Ein finanzieller Beitrag durch mitlebende Inwohner war sicherlich gerade auch für weniger wohlhabende Anwesen von Vorteil.

Die Häuser für Ausnehmer oder Inwohner waren im Regelfall wohl nur von sehr bescheidener Größe. Noch Ende des 19. Jahrhunderts wurden diese durchgehend aus Holz gebaut. ${ }^{36}$ Ein Großteil dieser Nebengebäude wurde erst im Untersuchungszeitraum errichtet. Mehrfach wird erwähnt, dass sich die abtretenden Besitzer vor der Übergabe ein solches für das eigene Altenteil extra erbaut hatten. Teilweise findet sich in den Ausgedingeverträgen aber auch die Bestimmung, dass der neue Besitzer ein solches Gebäude erst errichten müsse. Die dabei anfallenden Kosten trugen häufig die Besitznachfolger, manchmal auch beide Parteien. Die zu Beginn des 18. Jahrhunderts zunehmende Zahl von Ausnehmerhäusern verweist auf eine steigende Bedeutung des Ausgedinges in dieser Zeit. Interessant ist, dass sich die Anzahl dieser Nebenhäuser in späterer Zeit offenbar kaum mehr erhöhte. Vergleicht man diese Periode mit dem Verzeichnis der Häuser, das im Zuge der Erstellung des Stabilen Katasters im Jahr 1826 angelegt wurde, so kam offenbar nur mehr ein solches Nebengebäude hinzu. ${ }^{37}$ Der Vergleich zeigt, dass es in der Mehrzahl in beiden Perioden dieselben Häuser waren, die über solche Nebengebäude verfügten, nur bei einigen wenigen ist ein solches entweder nur im frühen 18. oder nur im frühen 19. Jahrhundert nachweisbar. Die Anwesen Martinkov Nr. 5 (die ,Weihmühle') und Kapličky Nr. 3 etwa hatten zwar um 1720 ein Ausgedingehaus dabei, im 19. Jahrhundert aber nicht mehr. Beim Haus Lipová Nr. 1 dagegen wird ein solches zwar im Jahre 1826 genannt, nicht aber im 18. Jahrhundert.

Die Existenz zahlreicher Ausnehmerhäuser ist für die gesamte Region des südlichen Böhmerwaldes sowie des angrenzenden österreichischen Mühlviertels vor allem für das 19. Jahrhundert gut dokumentiert. Die ältere volkskundlich orientierte deutschsprachige Literatur Südböhmens sprach im Zusammenhang mit der Ent-

35 Schramek, Böhmerwaldbauernhaus, 4; Bürger, Entwicklung, 11.

36 Schramek, Böhmerwaldbauernhaus, 21.

37 In den ersten Jahrzehnten des 18. Jahrhunderts lassen sich im Pfarrgebiet (ohne das Dorf Vyšína, das im 19. Jahrhundert nicht mehr zur Pfarre gehörte) 22 solche Häuser nachweisen, im Jahre 1826 laut den Verzeichnissen des Stabilen Katasters 23. Vgl. NA Praha, Stabilní Katastr 221 Operat, 323 Operat. 
stehung solcher Häuser von einem Prozess: Zunächst sei durch Nachrodung und Ertragssteigerung die Errichtung derartiger Zusatzhäuser ermöglicht worden, ${ }^{38}$ in einer späteren Phase seien dann diese Nebenhäuser häufig baulich wieder mit dem Hof verbunden worden. Im 19. Jahrhundert verfügten bei einigen reichen Bauernhöfen in Südböhmen die Ausnehmerhäuser sogar über einen eigenen Stall. ${ }^{39}$

Im Ausnahmefall konnte der Status solcher Häuser (ob Nebengebäude oder eigenständiges Haus) auch schwanken, wie das folgende Beispiel zeigt: Michl Krepper, bis 1641 Inhaber eines bäuerlichen Anwesens in Lipová Nr. 2 erbaute dieses Ausnehmergebäude im Jahre 1639. Zwei Jahre später behält er sich dieses anlässlich der Übergabe aber nicht nur für sich selbst als Ausnehmerhaus vor, sondern auch für seine Nachkommen. Im Grundbuch wird es in der Folge als selbstständige Einheit geführt und geht später an einen Sohn des Michl Krepper über. Erst zu Ende des 17. Jahrhunderts - nach dem Tod des Sohnes - wird es vom nunmehrigen Inhaber des bäuerlichen Anwesens Lipová Nr.2, Gregor Leutgöb, wieder zurückgekauft, dem es ab 1729 ebenfalls als Ausnehmerwohnung dient. ${ }^{40}$

Das Merkmal eigener Ausnehmerhäuser erscheint als ein regionales Muster von hoher zeitlicher Konstanz. Einzelne Regionen Oberösterreichs etwa wiesen kontinuierlich von der frühen Neuzeit bis ins 20 Jahrhundert eine hohe Verbreitung derartiger Gebäude auf. ${ }^{41} \mathrm{Im}$ südlichen Böhmerwald erlaubte die Siedlungsstruktur der Dörfer (kleine Weiler) solche Nebengebäude. Auch die Haus- und Hofformen bildeten so eine wichtige Voraussetzung für die hohe Verbreitung von Altenteilregelungen in der Region. Allerdings musste das Vorhandensein zahlreicher bewohnbarer Nebengebäude in einer Region noch keineswegs bedeuten, dass diese überwiegend auch als Wohnräume für Altenteiler genutzt wurden. In der großbäuerlich geprägten norddeutschen Pfarre Belm gab es etwa bereits im 17. Jahrhundert zahlreiche derartige Gebäude. Ganz überwiegend wurden diese aber von Heuerlingen und nicht von Altenteilern bewohnt. In anderen Regionen wiederum - wie etwa im 18. Jahrhundert in der Region um Höchstadt an der Aisch in Franken - war zwar das Ausgedinge durchaus verbreitet; spezielle Austragshäuser sind jedoch nicht nachweisbar. ${ }^{42}$

Schlumbohm stellte fest, dass die Altenteiler vor allem dann in einem eigenen Haushalt lebten, wenn die Besitznachfolger nicht mit ihnen verwandt waren. Handelte es sich bei den neuen Besitzern jedoch um die eigenen Kinder, dann lebte die

38 Blau, Hausindustrie, 160f., Pröll, Bauernhaus, 11, Schramek, Böhmerwaldbauernhaus, 4.

39 Schramek, Böhmerwaldbauernhaus, 38.

40 SOA Třeboň, fond C Vyšší Brod, PK č. 453, fol. 202, 337f; č. 565, fol. 379.

$41 \mathrm{Kretschmer} /$ Piegler, Ausgedinge, 8.

42 Endres, Altersvorsorge, 476. 
Elterngeneration mit diesen im Haupthaushalt mit. ${ }^{43}$ Eine solche Differenzierung lässt sich für Kapličky nicht feststellen; hier nutzten die Ausnehmer fast durchwegs die Nebengebäude, falls solche vorhanden waren.

\subsection{Das Ausgedinge und die familialen Kontinuitäten ${ }^{44}$}

Die zentrale Funktion von Altenteilerregelungen bestand darin, die weiteren Ansprüche der Vorbesitzer am Haus zu regeln, wobei die Altersversorgung nicht zwangsläufig Bestandteil solcher Vereinbarungen sein musste. Darüber hinaus konnte das Ausgedinge aber eine Vielzahl an weiteren Funktionen erfüllen. Es konnte dazu dienen, familiale Kontinuitäten am Haus zu sichern und/oder den Aufbau einer soliden ökonomischen Existenz eines bestimmten Kindes durch den rechtzeitigen Verzicht auf die Hausinhaberschaft durch die Vorgänger gewährleisten. Es konnte aber auch dazu genutzt werden, um die ökonomische Basis des Besitzer(-paares) selbst zu ändern und neu auszurichten.

Eine Ausgedinge-Vereinbarung mit den eigenen Kindern war weitaus häufiger als bei familienfremden Nachfolgern. Trotzdem gibt es auch zahlreiche Beispiele für Ausgedingeverträge zwischen nichtverwandten Personen. In 12 der untersuchten 77 Fälle lässt sich keine verwandtschaftliche Verbindung zwischen Altenteilern und Besitznachfolgern feststellen. ${ }^{45}$ Haushaltskonstellationen mit Ausgedinge sind mit dem Konzept von „stem families“ nicht adäquat zu erfassen. ${ }^{46}$ Trotzdem zeigt sich eine eindeutige Tendenz, ein Ausgedinge eher bei den eigenen Kindern als bei familienfremden Personen anzutreten. War der Nachfolger ein Sohn, dann wurde in beinahe 80 Prozent der Fälle auch ein Ausgedinge für den/die Vorbesitzer vereinbart. Die Übergabe inter vivos erlaubte die Planung der Besitznachfolge und förderte die Etablierung familialer Besitzkontinuitäten. ${ }^{47}$ Durch die bewusste Wahl des Zeitpunktes des Besitzerwechsels konnte Einfluss auf die Auswahl des Nachfolgers genommen werden. Der demographische Wandel ermöglichte es der Mehrzahl der untertänigen Besitzer im 18. Jahrhundert, anders als in vergangenen Zeiten, relativ lange Hausbesitzer zu bleiben und einen für sich selbst und für den Nachfolger günstigen Zeitpunkt für die Übergabe zu wählen. Die Wahl des rich-

43 Schlumbohm, Lebensläufe, 256.

44 Vgl. zum Folgenden auch die entsprechenden Abschnitte in meinem Aufsatz: Zeitlhofer, Succession. 45 Auch für mehrere österreichische Regionen des 17. Jahrhunderts sowie für eine Region in Polen ließen sich zahlreiche Ausgedingeregelungen bei familienfremden Personen nachweisen. Vgl. Mitterauer, Arbeitsteilung, 186f und Kopczyñski, Old Age, $96 f$.

46 Ehmer, House.

47 Ehmer, Life stairs, 61. 
tigen Zeitpunktes für die Übergabe war dabei von entscheidender Bedeutung. $\mathrm{Zu}$ lange damit zu warten, inkludierte immer die Gefahr, dass ein plötzlicher Todesfall eine rasche Lösung erforderlich machte und auch ein vielleicht wenig erwünschter Nachfolger akzeptiert werden musste. Dieser Fall konnte etwa eintreten, wenn zum Zeitpunkt des Todes des Besitzers einige seiner Kinder bereits auswärts verehelicht und die anderen noch zu jung für eine Nachfolge waren (siehe etwa die in Kapitel 7.6.3 angeführten Beispiele). Ein frühzeitiger Rückzug auf das Ausgedinge bei einer gleichzeitigen Übernahme durch das vorgesehene Kind konnte dem entgegenwirken. Die Heirat der Nachfolger, die Besitzweitergabe und der Verbleib der Alten im Ausgedinge wurden deshalb im Verlauf des frühen 18. Jahrhunderts zu zeitlich eng zusammengehörigen Elementen des Besitztransfers. Haus und Land wurden häufig nur mehr mittels vertraglich fixiertem Austausch zwischen den Generationen erworben. Im 17. Jahrhundert war es noch weit häufiger vorgekommen, dass Heirat und Besitzantritt zeitlich weit auseinander lagen; auch war es keinesfalls durchgängig der Fall gewesen, dass die abtretenden Besitzer weiter im Haus blieben.

Das Altenteil bildete in Regionen mit Unteilbarkeit der Güter ein wichtiges Element, um eine graduelle Weitergabe von Besitz zu ermöglichen. Im Unterschied zur Realteilung impliziert Unteilbarkeit der Güter einen Transfer des gesamten Besitzes zu einem einzigen Zeitpunkt an den/die Nachfolger. Eine Besitzweitergabe inter vivos mittels Ausgedinge schuf einen wesentlichen zusätzlichen Moment des Transfers und erfüllte damit insbesondere eine wichtige Funktion in der Versorgung der Jüngeren, die damit nicht erst bis zum Tod der Vorgängergeneration auf eine Ressourcenübertragung warten mussten. ${ }^{48}$

In mehreren Fällen übergaben die bisherigen Inhaber ihre Kontrolle über das Anwesen zu einem erstaunlich frühen Zeitpunkt, der einen altersbedingten Rückzug in unserem heutigen Verständnis eher ausschließt. Obwohl über die jeweiligen Motive im Einzelfall nichts ausgesagt werden kann, sprechen in mehreren Fällen zahlreiche Indizien dafür, dass ein freiwilliger Rückzug auf das Ausgedinge von den Besitzern bewusst angestrebt wurde. Möglicherweise hatte das Ausgedinge als soziale und ökonomische Alternative zum Status eines Hausbesitzers in dieser Region auch positive Aspekte. Eventuell ermöglichte es der Wechsel auf das Ausgedinge, den vielfältigen Verpflichtungen, denen Grundbesitzer in Böhmen zu dieser Zeit ausgesetzt waren, zu entkommen. $\mathrm{Zu}$ der zumeist Jahrzehnte andauernden Abzahlung des Kaufpreises und der Ausbezahlung der Geschwister kamen noch die zahlreichen monetären wie nicht-monetären Verpflichtungen gegenüber dem

48 Dies kann zumindest für das den elterlichen Betrieb übernehmende Kind so gesehen werden, die ,weichenden Geschwister' erhielten auch bei ihrer Heirat ein ,vorgezogenes Erbe'. 
Grundherrn. Insbesondere ist dabei die ,Robot' zu erwähnen, die für Grund besitzende Anwesen die Abstellung eines Arbeiters sowie eines Gespannes für etwa drei Tage pro Woche bedeutete. Die ,Robot'-Pflichten der Landlosen (dies inkludierte auch die Ausnehmer) dagegen beliefen sich in der Region nur auf etwa 16 Tage pro Jahr (vgl. Kapitel 2.3).

Dass manche einen Wechsel in das Ausgedinge als einen Wechsel in eine andere Form des ökonomischen Auskommens (vgl. den Abschnitt zu den Arbeitstätigkeiten im Ausgedinge) nutzten, scheint nicht zuletzt auch durch das Alter zum Zeitpunkt des Antritts des Ausgedinges plausibel (vgl. Tabelle 47). Zwar ließ sich für etwa 42 Prozent aller Ausnehmer von Kapličky kein Alter rekonstruieren, immerhin waren aber 14 von 38 Frauen und sechs von 29 Männern mit bekanntem Alter jünger als 50 Jahre, als sie sich auf das Ausgedinge zurückzogen. Der jüngste männliche Ausnehmer war lediglich 33 Jahre alt und im Falle zweier Ehepaare waren jeweils beide Partner jünger als 40 Jahre. Bei landarmen und landlosen Häusern waren die meisten Ausnehmer dagegen deutlich älter (viele auch bereits über 70 Jahre), als sie sich zurückzogen. Auch aus einigen anderen Regionen Zentraleuropas wissen wir (überwiegend aus Daten für das 19. Jahrhundert), dass das Altenteil häufig in der Lebensphase zwischen 50-65 Jahren angetreten wurde. ${ }^{49}$

Die Witwen von Hausbesitzern verehelichten sich ab einem gewissen Alter oftmals nicht neuerlich, sondern zogen es stattdessen vor, das Anwesen weiterzugeben und sich auf das Ausgedinge zurückzuziehen. Es war ihnen aufgrund ihrer Sozialisation und der unterschiedlichen Rollenbilder eher als den Männern möglich, alleine zu leben. Männer benötigten dagegen in der Regel jemanden zum Kochen und Wäsche waschen. Falls sie im Ausgedinge über eine kleine Landwirtschaft verfügten und eventuell auch andere Einkommensmöglichkeiten hatten, waren sie ökonomisch nur begrenzt vom neuen Inhaber des Anwesens abhängig. Beispielsweise heiratete nach dem Tod ihres Mannes die 49 Jahre alte Witwe Agnes Lang aus dem Dorf Hodoň nicht mehr, sondern verkaufte 1728 an ihren Sohn. Im Ausgedinge behielt sie zwei Kühe, sie hatte das Recht, Leinsamen im Ausmaß von zwei böhmischen Vierteln auszusäen und im Hausgarten Kraut anzubauen. Ihr Sohn war verpflichtet, das für ihre zwei Kühe benötigte Heu nicht von irgendeiner, sondern von einer ganz bestimmten Wiese bereitzustellen. ${ }^{50} \mathrm{Die}$ Witwe verfügte auch nach der Besitzweitergabe durchaus über eine gewisse Autonomie.

49 Vgl. Ehmer, Life Stairs, 63.

50 SOA Třeboň, fond C Vyšší Brod, PK č. 565, fol. 368. 
Tabelle 47: Alter bei Antritt des Ausgedinges, Pfarre Kapličky, 1699-1738

\begin{tabular}{lcccc}
\hline Altersgruppe & Witwen & Witwer & Ehemänner & Ehefrauen \\
\hline $30-39$ & - & 1 & 4 & 3 \\
$40-49$ & - & 4 & 2 & 6 \\
$50-59$ & - & 4 & 7 & 8 \\
$60-69$ & 3 & 5 & 7 & 5 \\
$70-$ & 3 & 2 & 3 & - \\
unklar* & 6 & 10 & 16 & 17 \\
Summe & 12 & 26 & 39 & 39
\end{tabular}

* Aufgrund fehlender Altersangaben

Anm.: Jüngere Personen könnten überrepräsentiert sein, da einzelne Personen mit fehlendem Geburtsdatum möglicherweise bereits vor Beginn der Kirchenbücher (1642) geboren worden waren.

Quelle: Rodovy katastr, Pfarre Kapličky.

Eine weitere Funktion des Ausgedinges war die Vorsorge für noch unversorgte Kinder der Ausnehmer. Insgesamt wurden in 15 Verträgen (überwiegend bei bäuerlichen Anwesen) auch Kinder berücksichtigt. Etwa die Hälfte dieser Fälle bezog sich lediglich auf bestimmte Naturalleistungen des neuen Inhabers, die ihnen bei der Heirat zustehen sollten. Sechs erhielten auch ein Bleiberecht beim Haus garantiert, welches in vier Fällen unbefristet war (vgl. Tabelle 45). Bei genauer Betrachtung des Einzelfalls stellt sich heraus, dass diese besonderen Regelungen vor allem dann getroffen wurden, wenn die Etablierung eines eigenen Haushalts durch die Betroffenen - etwa aus gesundheitlichen Gründen - nicht erwartet werden konnte. Überwiegend bezogen sich diese Fälle auf Kinder, die einen körperlichen Mangel aufwiesen, oder bereits relativ alt, aber noch unverheiratet waren. Deutlich wird das auch an der Beifügung, dass das Bleiberecht bei einer allfälligen Verheiratung hinfällig wäre. ${ }^{51}$ Im Jahr 1726 enthielt der Ausnehmer-Vertrag von Paul Schwendtner und seiner Frau die folgende Klausel: „NB wais Helena soll wegen ihres üblen gehörs das stete verbleiben beim Haus haben, wenn sie sich aber verheiratet, ist ihr der stifter nichts schuldig“. ${ }^{52}$ Für den Besitznachfolger bedeuteten diese zusätzlichen Verpflichtungen nicht unbedingt eine allzu große Bürde, da er im Gegenzug Anspruch auf den Anteil der Helena am Kaufpreis hatte. $\mathrm{Zu}$ berücksichtigen ist, dass derartige Regelungen lediglich den Angehörigen ehemaliger Hausbesitzer offen standen; nur diese hatten die Möglichkeit zu einem Abschluss eines solchen Vertrages.

51 Vgl. etwa SOA Třeboň, fond C Vyšší Brod, KV, fol. 10. In diesem Dokument wird von einem ,Leibsdefect, des Kindes mit Bleiberecht gesprochen.

52 SOA Třeboň, fond C Vyšší Brod, Pozemková kniha č. 465, fol. 20. 
Eine Wiederverehelichung im Ausgedinge wurde in dieser Region offenbar über einen längeren Zeitraum hinweg gestattet, jedenfalls für diejenigen Ausnehmer, die bereits als verheiratetes Paar ins Ausgedinge gewechselt waren. Insgesamt sind sieben Ausnehmer nachweisbar, die sich im Ausgedinge nach dem Tod ihrer Ehepartnerin neuerlich verehelichten. Keine einzige der verwitweten Ausnehmerinnen heiratete dagegen nochmals.

Durch Wiederverehelichung und die Geburt weiterer Kinder konnte es zu mitunter sehr komplexen Personenkonstellationen kommen, wie das folgende Fallbeispiel 6 zeigt. Nachweisbar ist eine Wiederverehelichung von im Ausgedinge lebenden Personen in mehreren Fällen aus der Zeit um 1700, dürfte aber in späterer Zeit - so etwa bei allen nach 1720 abgeschlossenen Ausnehmerverträgen - nicht mehr vorgekommen sein.

\section{Fallbeispiel 6: Markus Schimpl: Komplexe und langfristige Haushaltskonstellationen mit Ausgedinge}

Der aus dem Dorf Studánky in der Nachbarpfarre Vyšší Brod gebürtige Markus Schimpl wird 1670 durch Heirat mit Ursula Leitgöb, der Tochter des eben verstorbenen Vorbesitzers, neuer Besitzer des Anwesens Mlýnska Nr. 2. Im Theresianischen Kataster 1713 wurde bei diesem kleinbäuerlichen Anwesen Grundbesitz im Ausmaß von 20 böhmischen Strich angegeben (knapp sieben ha). Als Viehbestand wurden zwei Ochsen, eine Kuh sowie ein Galtvieh genannt. Außerdem war dem Haus ein herrschaftliches Zinsreut unbekannter Größe ,zugeschrieben‘. Damit kann das Anwesen als durchaus typisch für die Mehrzahl der bäuerlichen Höfe in der Region angesehen werden.

Aus der ersten Ehe von Markus und Ursula Schimpl gingen vier Töchter hervor. Wann genau Ursula verstarb, ist - vermutlich aufgrund der Lücken in der Überlieferung der Kirchenbücher gerade für die 1690er Jahre (vgl. Kapitel 2.2.1) - nicht feststellbar. Im Februar 1700 verehelicht sich Markus Schimpl jedenfalls ein zweites Mal mit Annamaria Stadler. Noch im selben Jahr kommt Martin, das einzige Kind aus der zweiten Ehe, zur Welt. Am 6.8.1701 heiratet Barbara, die erst 19-jährige jüngste Tochter aus erster Ehe, den zuvor im Pfarrdorf Lhota wohnhaften Inwohner Gallus Gehfort. Mittels Familienrekonstitution ist rekonstruierbar, dass sie zum Zeitpunkt ihrer Hochzeit wohl bereits etwa drei Monate schwanger war. Im September 1701 stirbt die älteste Tochter aus erster Ehe des Markus Schimpl.

Wie alt Markus Schimpl im Jahre 1704 war, als er nach 34 Jahren Bewirtschaftung des Hofes das Anwesen schließlich an seinen Schwiegersohn Gallus Gehfort verkaufte und sich mit seiner zweiten Frau auf das Ausgedinge zurückzog, wissen wir infolge seiner Herkunft aus der Nachbarpfarre nicht. Falls er sich in einem regional 
üblichen Alter erstmals verehelichte, kann davon ausgegangen werden, dass er 1704 wohl bereits gegen 60 Jahre zählte. Seine (zweite) Frau war zu diesem Zeitpunkt jedenfalls 42 Jahre alt. Die beiden erhielten als Ausgedinge, neben dem Bleiberecht im Haus, die Nutzung des Hausgartens und eines Ackers, an Lebensmitteln jährlich ein bestimmtes Quantum an verschiedenen Getreidesorten sowie im ersten Jahr zusätzlich noch den ,Genuss' der halben Wintersaat. Zusätzlich wurde einem weiteren noch lebenden Kind aus erster Ehe, der zu diesem Zeitpunkt 28-jährigen Rosina, das lebenslange Bleiberecht im Haus schriftlich zugesichert (sie verstarb sechs Jahre später). Martin, der inzwischen 4-jährige Sohn aus zweiter Ehe wird dagegen im Ausgedingevertrag nicht genannt, er hat also kein lebenslanges Bleiberecht beim Haus, doch ist davon auszugehen, dass er die Phase der Kindheit bei seinen Eltern im Ausgedinge verbringt.

Die zweite Ehefrau Annamaria stirbt um 1705 (wiederum ist kein exaktes Sterbedatum verzeichnet). 1706 verehelicht sich der Ausnehmer Markus Schimpl zum dritten Mal - nun mit der 35-jährigen Apolonia Koller, Tochter eines Kleinbauern aus Krasná Pole. Auch seiner dritten Frau wird - mittels nachträglicher Ergänzung im Ausnehmerbuch (ein Akt, der ansonsten nicht nachweisbar ist) - das lebenslange Wohnrecht im Haus garantiert.

1706 und in den folgenden Jahren leben bei diesem Haus somit im Ausgedinge: das Ehepaar Schimpl mit dem minderjährigen Sohn Martin aus zweiter Ehe, sowie die erwachsene Tochter Rosina aus erster Ehe (stirbt 1710). 1711 kommt Lorenz, das einzige Kind aus der dritten Ehe, dazu.

Als Markus Schimpl nach 14 Jahren im Ausgedinge im Jahre 1718 stirbt, ist Lorenz, sein Sohn aus dritter Ehe, gerade 7 Jahre alt. Dieser wird sicherlich auch danach noch bei seiner Mutter im Ausgedinge mitleben. Wie lange Martin, der inzwischen 18-jährige Sohn aus zweiter Ehe im Haus blieb, wissen wir nicht. Gerade er aber kauft weitere sieben Jahre später (1725) - im Alter von nur 25 Jahren - seiner Halbschwester und ihrem Mann diesen Hof ab. Der inzwischen 51-jährige Gallus Gehfort und seine 44-jährige Frau mussten das Anwesen wegen Verschuldung, wie das Grundbuch explizit vermerkte, aufgeben. Die Vermutung ist wohl berechtigt, dass zu dieser Verschuldung nicht unwesentlich die ungewöhnlich lange Belastung durch ein für mehrere Personen zu leistendes Ausgedinge mit beitrug.

Faktisch tauschten die beteiligten Personen mit dem Vertrag von 1725 aber nur ihre Positionen im Haus: Während Martin Schimpl und seine Frau (er hat im August desselben Jahres geheiratet) Inhaber des Anwesen wurden, wechselten seine Halbschwester Barbara und ihr Mann Gallus Gehfort nun in die Position der Ausnehmer im Haus. Daneben hatte weiterhin Apolonia, die Stiefmutter des Martin, ein Wohnrecht. Wann deren Sohn, der inzwischen 13-jährige Lorenz, den Hof verließ, ist nicht bekannt. 
Alle drei durch Ausgedingeverträge auf dem Hof „wohnberechtigten“ Personen lebten jedenfalls noch längere Zeit: Gallus Gehfort starb 1737 im Alter von 63 Jahren (nach 12 Jahren im Ausgedinge), seine Frau Barbara wurde knapp 80 Jahre alt und lebte damit 36 Jahre als Ausnehmerin am Hof (von 1725 bis 1761). Apolonia Schimpl starb 1740 und verbrachte 34 Jahre bei diesem Anwesen im Ausgedinge. Martin Schimpl, der neue Besitzer, dagegen blieb anders als seine Vorgänger sehr lange Hofbesitzer, noch in den 1770er Jahren ist er in den Grundbüchern als über 70-Jähriger als Inhaber geführt. Dem Anwesen fehlten nun vermutlich die Mittel, um auch ihm ein frühzeitiges Ausgedinge zu ermöglichen.

Das Fallbeispiel steht für eine in erster Linie durch die Wiederverehelichungsmöglichkeit im Ausgedinge herbeigeführte überaus komplexe und lange andauernde Ausgedinge-Konstellation. Verschärft wurde diese für die Ökonomie des eher kleinen Anwesens sicherlich nicht leichte Konstellation überdies durch ein Bleiberecht für Dritte sowie durch den individuellen Faktor einer vergleichsweise hohen Lebenserwartung einiger der beteiligten Personen. Obwohl im konkreten Fallbeispiel keine entsprechenden Hinweise vorhanden sind, ist anzunehmen, dass wohl nicht alle am Hof lebenden Personen ausschließlich von der bei diesem Anwesen vorhandenen Landwirtschaft ernährt werden konnten. Die beteiligten Personen mussten sich sicherlich auch auf ergänzende Einkommensquellen stützen. Natürlich ist dabei in erster Linie an die in der Region massiv betriebene Garnproduktion zu denken, weitere Einkommensformen sind aber nicht auszuschließen.

Quellen: Datenverknüpfung Grundbücher, Ausnehmerbuch, Familienrekonstitution, Theresianischer Kataster.

9.3 Arbeit und Alter bei der hausbesitzenden und der landlosen Bevölkerung: Die Erwerbstätigkeit im Alter zwischen eigenem Besitz und den Zwängen einer ,Ökonomie des Auskommens ${ }^{\text {53 }}$

Die ,historische Altersforschung، der letzten Jahrzehnte hat aufgezeigt, dass der Rückgang der Erwerbsquoten im Alter ein säkularer Trend ist, der in den westlichen Industriestaaten im späten 19. Jahrhundert einsetzte und sich seitdem kontinuierlich verstärkte. Dieser Prozess scheint eng mit der Ausbreitung von Industriekapitalismus und Lohnarbeit sowie mit dem Ausbau des Sozialstaates verbunden

53 Dieser Abschnitt ist eine gekürzte und überarbeitete Version meines Aufsatzes: Zeitlhofer, Arbeit und Alter. 
zu sein, und führte im Ergebnis zu einer ,Institutionalisierung des Lebenslaufs ${ }^{\star}$ mit klaren Zäsuren, darunter einer deutlich abgegrenzten Alters- und Ruhestandsphase. ${ }^{54}$ Trotz des Booms, den die historische Forschung zu den Themenbereichen ,Alter' und ,Altern' in den letzten Jahren und Jahrzehnten erlebt hat, ist eine längerfristige - in die Vormoderne zurückblickende - Perspektive weitgehend ein Desiderat der Forschung geblieben. Bezogen auf die vorindustrielle Zeit dominieren in der ,historischen Altersforschung' kulturgeschichtliche Ansätze. Dagegen gibt es bis heute nur wenige Studien zur Arbeitsbeteiligung älterer Menschen in früheren Zeitabschnitten. Dies erstaunt insbesondere angesichts der gegenwärtigen gesellschaftspolitischen Aktualität des Themas (siehe die gesellschaftlichen Debatten über das Rentenantrittsalter, bzw. den Zeitpunkt des Ausscheidens aus dem Arbeitsprozess im Alter).

Für die Vormoderne ist zunächst zu betonen, dass es weder eine klare Trennung von Erwerbs- und Reproduktionsarbeit noch eine klar abgrenzbare Altersphase gab. Nicht nach Erwerbsquoten, sondern generell nach dem Ausmaß an Arbeitstätigkeiten unterschiedlichster Art ist deshalb für diesen Zeitraum zu fragen. In der Literatur wird überwiegend festgestellt, dass es in der vorindustriellen Arbeitswelt keinen Ruhestand gegeben hätte ${ }^{55}$ und daher „nur Invalidität im Alter ein Ausscheiden aus dem Arbeitsprozess begründet" habe. ${ }^{56}$ Es wird angenommen, dass der Großteil der älteren Menschen nicht bis zum Erreichen eines bestimmten Zeitpunkts im Lebenslauf arbeitete, sondern „solange es ging. ${ }^{\text {“. }}{ }^{57}$ Das ,Altenteil allerdings wurde von vielen Historikern als Vorläufer des modernen Ruhestands betrachtet. ${ }^{58}$ Trotzdem hat die Forschung bisher für die Zeit der Vormoderne ganz überwiegend vor allem das Problem der ,Altersversorgung' in den Mittelpunkt ge-

54 Vgl. Conrad, Ruhestand; Vgl. auch Borscheid, Industriearbeit; Ehmer, Lohnarbeit; Johnson, Workers; Johnson, Employment.

55 Allerdings entstehen bereits im 18. Jahrhundert, zunächst in der Habsburgermonarchie im Jahre 1781, dann auch in anderen Staaten, mit der Einführung von staatlichen Pensionssystemen für Staatsbeamte Vorformen einer staatlichen Altersrente. Vgl. Ehmer, Sozialgeschichte, 41; freilich betraf dies die ländliche Bevölkerung kaum. Bereits in den 1760er Jahren wurde allerdings auf den großen, überwiegend in Südböhmen liegenden Herrschaften der Fürsten Schwarzenberg ein Pensionsfonds für die herrschaftlichen Beamten eingerichtet, in dessen Genuss durchaus auch einzelne Landbewohner kamen. Vgl. Paleczek, Modernisierung.

56 Mitterauer/Sieder, Patriarchat, 197.

57 Ehmer, Altersversorgung; Johnson, Historical Readings, 6; Vgl. etwa auch: Van Dülmen, Kultur, 201: "Grundsätzlich arbeiteten ein Mann oder eine Frau, solange die Kräfte reichten.“

58 So etwa die Einschätzung bei: Sieder, Sozialgeschichte, 31; vgl. auch Johnson, Historical Readings, 7 : „retirement shows that the deliberate withdrawal from an active life before the onset of physical incapacity - is not an invention of the twentieth century“. Ähnliche Schlussfolgerungen ebenso bei: Dribe/Lund, Retirement. 
rückt. Allenfalls wurde noch - als Kontrast eines Scheiterns der Versorgung - die Altersarmut im Kontext einer Geschichte des ,Bettels‘ und der ,mobilen Armut thematisiert. Freilich kommt das Thema ,Alter in der Fülle an Literatur zur Historischen Armutsforschung zwar immer wieder vor, wird dabei aber nicht eindeutig als eigenständiges Problemfeld eingegrenzt, sondern bleibt ein zumeist nur vage bestimmbarer Faktor einer allgemein gesellschaftlich weit verbreiteten Armut. ${ }^{59}$

Im Rahmen einer Geschichte der, Altersversorgung، wurde die Unterstützung nicht mehr arbeitsfähiger, alter Menschen durch die Familie, bzw. des ,Ganzen Hauses', gegenüber anderen Unterstützungsformen (wie kommunaler oder kirchlicher Institutionen) oder aber einer Selbstversorgung der Alten durch eigene Arbeit - speziell in der deutschsprachigen Forschungstradition - lange Zeit deutlich überbetont. In der durch die Historische Familienforschung der 1970er Jahre wiederentdeckten Riehl'schen und Brunner'schen Denkfigur des ,Ganzen Hauses ${ }^{60}$ galt die vorindustrielle Hauswirtschaft nicht nur als eine Wohn- und Arbeitsgemeinschaft, sondern auch als eine "Solidargemeinschaft“. ${ }^{61}$ Dem ,Ganzen Haus“ wurde eine integrative soziale Funktion zugesprochen, die allen ihren Mitgliedern, vom Kind über die Magd und den Knecht bis hin eben zur älteren Generation Schutz, Versorgung und Pflege bot. ${ }^{62}$

Eine solche Sichtweise ist harmonisierend, da sie den Blick auf all jene verstellt, die in Folge der Unabwägbarkeiten der Demographie und der hohen Mobilität in der frühen Neuzeit nicht auf Familienangehörige zählen konnten. ${ }^{63}$ Für das England des 17. und 18. Jahrhunderts beispielsweise wurde errechnet, dass ungefähr die

59 Vgl. Bräuer, Altersarmut; An neueren Publikationen zur Geschichte der Armut vgl. etwa Gestrich/ Raphael, Inklusion/Exklusion, und Gestrich/King/Raphael, Being Poor. Einen Überblick zum Forschungsstand bietet: Hippel, Armut, der allerdings auch darauf hinweist, wie sehr eine nach Lebensphasen differenzierte historische Zugangsweise zum Problembereich ,Armut' bis heute ein Forschungsdesiderat geblieben ist (113 f.). Da auch die Geschichte der Armut lange Zeit vorwiegend als Geschichte von Institutionen wahrgenommen wurde, stand überwiegend die städtische Armut der frühen Neuzeit im Blickpunkt, kaum aber die am Lande. Dies zeigt etwa auch die Durchsicht des ersten, der Vormoderne gewidmeten, Bandes von Sasse/Tennstedt, Armenfürsorge.

60 Brunner, Haus. Die historische Familienforschung griff auf das, Ganze Haus` als bloß funktionales Forschungskonzept zurück und stand zu zahlreichen Aspekten der Überlegungen von Riehl oder Brunner in kritischer Distanz. Vgl. die kritische Würdigung des Konzepts bei Trossbach, Haus, bes. $284 \mathrm{ff}$.. Zur Kritik an den ideologischen Prämissen - insbesondere von Brunners Konzept des ,Ganzen Hauses' - vgl. Derks, Faszination.

61 Van Dülmen, Kultur, 52.

62 Van Dülmen, Kultur, 201: „Ohne das ,ganze Haus‘ zu idyllisieren, hatten die Alten in der Regel einen festen Platz und konnten nicht ohne weiteres aus dem Hause vertrieben werden (... $)^{4}$, sie waren in den Arbeitsprozess des Hauses einbezogen und partizipierten an der ,Nahrung، " Vgl. auch Münch, Lebensformen, $184 f$.

63 Ehmer, Altersversorgung. 
Hälfte aller alten Menschen keine Kinder hatte, die in ihrer unmittelbaren Nähe wohnten und sie hätten unterstützen können. ${ }^{64}$ Das Haus war - was seine personelle Zusammensetzung betrifft - in der frühen Neuzeit keineswegs jener Ort der hohen Kontinuität und Stabilität. All zu oft führte die Allgegenwart des Todes zu einer plötzlichen Auflösung einer Haushaltsgemeinschaft und ließ Einzelpersonen alleine zurück. Tatsächlich verblieben nur relativ wenige Mitglieder des Hauses in diesem auch ein Leben lang. Nicht nur die mit im Hausverband lebenden Inwohner und das Gesinde, dessen Zugehörigkeit zum Haus ohnehin zeitlich sehr befristet war, sondern auch die weichenden Erben verließen diesen früher oder später und manchmal selbst das Hausbesitzerpaar. ${ }^{65}$ Eine Versorgung durch die Familie oder durch das Haus im Alter ließ sich außerdem nicht einfach aus der bloßen Zugehörigkeit zu einer Familie ableiten; vielmehr wurden die Rechte und Ansprüche aller Beteiligten - häufig etwa im Zuge eines Besitzerwechsels - mühsam ausgehandelt. Ansprüche auf eine lebenslange Versorgung (oder zumindest ein lebenslanges Wohnrecht) ergaben sich dabei vor allem für die ehemaligen Besitzer. Insgesamt scheinen jedenfalls nicht nur in England, sondern auch in den ,familistischen' Gesellschaften des vorindustriellen Kontinentaleuropa weitaus weniger Menschen als oft angenommen im Alter durch ihre Familienmitglieder (Kinder) versorgt worden zu sein. Familie bildete eine wichtige Ressource für soziale Sicherung, Pflege und Betreuung, trotzdem darf die Ausdehnung und Tragfähigkeit des familialen Netzes nicht überschätzt werden. ${ }^{66}$

In der Literatur zur frühen Neuzeit wird unter dem Begriff Altersversorgung gleichzeitig ,Pflege‘ (etwa im Falle von Bettlägerigkeit) und ,materielle Absicherung، (etwa im Falle von Arbeitsunfähigkeit) verstanden. Dies ist deswegen irreführend, weil hier auch der Begriff der materiellen Absicherung mit einer ausschließlich passiven Rolle des alten Menschen assoziiert wird. Dadurch wird ausgeblendet, dass materielle Absicherung oft aus eigener Arbeit oder einem $\mathrm{Ne}$ beneinander von eigener Arbeitstätigkeit und unterschiedlichen Unterstützungsformen bestand. Die beiden Aspekte ,Versorgung' bzw. ,eigene Arbeit' wurden offensichtlich als einander gegenseitig ausschließend betrachtet, und deren vielfältige Überschneidungen wurden lange nicht wahrgenommen. Die bis weit ins 20 . Jahrhundert hinein charakteristische Kombination von familialer und/oder auch

64 Thane, Ältere Menschen und ihre Familien, 75f.

65 Durch die hohe Zahl an Zweit- und Drittehen änderte sich die personelle Zusammensetzung eines bäuerlichen Anwesens häufig, da etwa die Kinder aus erster Ehe dieses frühzeitig verlassen mussten. Auch war die räumliche Stabilität ländlicher Familien keineswegs immer so hoch wie im 19. oder 20. Jahrhundert (vgl. dazu Kapitel 7.8).

66 Ehmer, Altersversorgung, 281. 
kommunaler Unterstützung mit mehr oder minder starker eigener Arbeitsleistung, wird in der Literatur unter verschiedenen Bezeichnungen häufig thematisiert. ${ }^{67}$

Mit vorliegendem Kapitel soll die Vielfältigkeit der ökonomischen (Selbst-) Versorgung alter Menschen ausgehend von Fallbeispielen aus dem südböhmischen Raum diskutiert werden.

\subsubsection{Arbeit im Alter bei der haus- und grundbesitzenden Bevölkerung}

In welchem Ausmaß die eigene Arbeitstätigkeit zur Überlebenssicherung in der letzten Lebensphase notwendig war, hing insbesondere von den Besitzverhältnissen ab. Unabhängig davon, ob es zu einem Rückzug aus der Wirtschaftsführung zu Lebzeiten kam oder nicht, erlaubte Besitz - in welcher Form auch immer eine je nach individuellem Bedarf nötige Verlagerung oder Reduktion der eigenen Arbeitstätigkeit im Alter. Zwischen den beiden Varianten einer Besitzweitergabe zu Lebzeiten oder einer Wirtschaftsführung bis zum Tode gab es durchaus eine individuelle Wahlmöglichkeit, wenn diese auch von regional unterschiedlich ausgeprägten Präferenzen und Normen beeinflusst war. Die konkrete Gestaltung von Zeitpunkt und Bedingungen eines Besitzerwechsels auf einem Anwesen war nicht starr vorgegeben, sondern das Produkt eines Verhandlungsprozesses zwischen den beteiligten Personen. ${ }^{6}$

\subsubsection{Besitzweitergabe zu Lebzeiten: das Ausgedinge als Vorwegnahme des} modernen Ruhestandes? Die Arbeits- und Erwerbstätigkeit der Ausnehmer

Die im ländlichen Raum verbreitete Institution des ,Altenteils‘ (,Ausgedinges`) bildet ein Beispiel für die überaus komplexen Beziehungen zwischen Altersversorgung und Fortführung bzw. Veränderung der eigenen Arbeitsbeteiligung. Durch die vorherrschende Interpretation des Altenteils als einer den Lebensunterhalt garantierenden Versorgungsinstitution ${ }^{69}$ für den oder die ehemaligen Besitzer wurde

67 Der von Olwen Hufton stammende Ausdruck, economy of makeshifts‘ ist längst zum Standardterminus der internationalen Forschung avanciert. Vgl. Hufton, Poor, bes. 69-127. Als eine der zahlreichen neueren Studien, die mit diesem Konzept operieren, vgl. etwa Williams, Earnings. Den in der deutschsprachigen Forschung häufig als ,Ökonomie des Notbehelfs', manchmal auch als, Ökonomie des Überlebens' übersetzten Termius, economy of makeshifts' möchte ich hier mit, Ökonomie des Auskommens' übertragen. Vgl. neuerdings auch den ähnlich gebrauchten Begriff, mixed economy of welfare‘ bei: Green/Owens, Introduction, 5. Für das Fortleben des Musters eines Mischeinkommens bei breiten Schichten bis ins frühe 20. Jahrhundert vgl. Conrad, Incomes.

68 Vgl. etwa Sabean, Property; Schlumbohm, Lebensläufe.

69 Mitterauer, Problemfelder, bes. 21. 
dieses häufig mit einer hohen ökonomischen Belastung für die ländlichen Anwesen gleichgesetzt, die in der frühen Neuzeit nur von wohlhabenden bäuerlichen Anwesen geleistet werden konnte.

Zahlreiche neuere lokale Fallstudien zum ,Altenteil ${ }^{\circ}$ - etwa aus dem deutschsprachigen und ostmitteleuropäischen Raum - deuten jedoch zum Teil auf eine weite Verbreitung dieser Praxis auch in ärmeren, unterbäuerlichen Schichten hin und lassen eine Relativierung des Versorgungsaspekts angebracht erscheinen. ${ }^{70} \mathrm{Im}$ Folgenden soll daher gezeigt werden, dass auch in der sozialen Position des ,Altenteilers' der ,Arbeit' in unterschiedlicher Art und Weise eine bedeutende Rolle zukam, wobei nicht nur schichtspezifische Unterschiede, sondern auch regionale Besonderheiten berücksichtigt werden müssen.

Die Funktion des Altenteils als Altersversorgung (im Sinne einer Versorgung von im arbeitsfreien Ruhestand befindlichen alten Menschen) ist für diese Region in mehrfacher Hinsicht anzuzweifeln. In der überwiegenden Mehrzahl der Fälle handelte es sich weder um einen von Arbeit entlasteten Ruhestand noch um eine vollständige Versorgung der Altenteiler. Auch waren es nicht durchgängig Menschen in fortgeschrittenem Alter, die in den Genuss solcher Regelungen kamen.

Bei den eigentlichen Bauern mit ausreichend Landbesitz ging üblicherweise das Ehepaar gemeinsam ins Altenteil und behielt sich auch nach dem Rückzug aus der Leitung der Hauswirtschaft neben dem Wohnrecht und der Nahrung weiterhin Teile der Wirtschaft zurück. Das Paar lebte oft in einem separaten Haus. Neben der Haltung von Tieren (überwiegend nur eine Kuh, manchmal zwei; oft auch Hühner, vereinzelt Schafe etc.) behielten sich viele bäuerliche Altenteiler auch Grundflächen zurück. Darunter konnte die Mitbenutzung des Hausgartens zu verstehen sein, etwa wenn der Anbau von Kraut, Möhren oder Rüben vorbehalten wurde. Beinahe alle der insgesamt 59 Altenteilerverträge bei Häusern mit dazugehörendem Grundbesitz beinhalteten aber tatsächlich weiterhin einen Anspruch auf Ackerflächen oder häufiger noch Wiesen. Besonders die zusätzlich zu den Hausgründen von der Herrschaft gepachteten Flächen wurden dafür verwendet. Die in der Pfarre übliche eigene kleine Landwirtschaft der bäuerlichen Altenteiler war nur auf herrschaftlichen Pachtgründen möglich, da diese nicht zur unteilbaren Besitzeinheit gehörten. Welchen Anteil die ausgenommenen Parzellen der Altenteiler an den Gesamtflächen der Anwesen hatten, ist nur schwer einzuschätzen. Am Viehstand lässt sich aber ablesen, dass manche der Ausgedinge-Wirtschaften im Vergleich zur Landwirtschaft der unterbäuerlichen Häuser einen beträchtlichen Umfang erreichten.

70 Vgl. an solchen neueren Studien etwa: Štefanová/Cerman, Lebensunterhalt; Velková, Fenomén; Grulich, Ausgedinge; Fertig/Lünnemann/Fertig, Inheritance,; Begemann, Lebensbedingungen. 
Das in Kapličky vorzufindende Ausmaß an Viehhaltung der Ausnehmer entspricht in etwa auch der Bestimmung des Gemeinde-Taidings des nahen Marktortes Frymburk/Friedberg (in der Herrschaft Rožmberk/Rosenberg) aus dem Jahre 1672, die besagte, dass jeder Altenteiler nur eine Kuh und ein Kalb zur Viehherde treiben dürfe. ${ }^{71} \mathrm{Im}$ Ausnahmefall konnte eine solche Ökonomie aber auch ein größeres Ausmaß erreichen. Eine Verlassenschaft eines Ausnehmers für das nicht zur Pfarre, aber zu einem Teil zur Herrschaft gehörige Dorf Svinilavy/Zwineschlag aus dem Jahre 1709 verzeichnete als dessen Besitz vier Ochsen, zwei alte Kühe, drei Schafe, bestimmte Mengen an Leinsamen, Flachs, Leinwand sowie noch ausstehende Geldforderungen in der Höhe des Preises eines kleinen bäuerlichen Anwesens. ${ }^{72}$ Auch die 49-jährige Witwe Agnes Lang von Hodoň/Hornschlag Nr. 5 in der Pfarre Kapličky, die sich nicht mehr verehelichte, wollte im Jahre 1728 auf ihre eigene Kleinlandwirtschaft nicht verzichten: Sie behielt sich die Haltung einer Kuh und eines Kalbes vor; außerdem auch eine Fuhr Heu jährlich vom zum Haus gehörigen Zinsgereut und den Anbau von 0,5 Strich Leinsamen. ${ }^{73}$

Für viele der bäuerlichen Ausnehmer ergibt sich daher ein Bild, das auf eine auch nach der Übergabe des Hauses relative Wohlhabenheit hindeutet. Etwa zwei Kühe halten zu können, war ja mehr als viele Häusler hatten. Es hat den Anschein, als ob sich manche dieser Ausnehmer jedenfalls in einer deutlich besseren Lage befanden als die Neuübernehmer, denn erstere konnten sich mit der Übergabe aller Verpflichtungen des Hofes der Abzahlung der Schulden und der Ausbezahlung der noch unverheirateten Kinder entledigen. Die jüngere Generation dagegen nahm mit der Übernahme der Verpflichtung zur Ausgedinge-Leistung normalerweise auch eine lange Periode der Verantwortung für das Haus auf sich.

Neben Viehhaltung und der Bewirtschaftung von Äckern und Gemüsegärten bauten fast alle bäuerlichen Altenteiler auch Flachs an und verarbeiteten diesen zu Leinengarn. Eine solche separate Ökonomie bedeutete faktisch eine befristete Zweiteilung des Anwesens. Einige der Verträge enthielten sogar sehr detaillierte Bestimmungen über den Rückbehalt von für die Verrichtung von Arbeit notwendigen Gegenständen. In einem Fall wurde ein Fuhrwagen ausbedungen. ${ }^{74} \mathrm{Im}$ Falle einer Mühle wurde festgelegt, an welchen Wochentagen das Mühlwasser für das Altenteilerpaar zu fließen habe. ${ }^{75}$ Auch die in einem anderen Fall vorzufindende

71 Vgl. Stark, Abhängigkeitsverhältnisse, 372.

72 Archiv Klaštera Vyšší Brod, Karton č . 414, unfoliert.

73 SOA Třeboň, fond C Vyšší Brod, PK č. 565, fol. 368 (1728).

74 SOA Třeboň, fond C Vyšší Brod, PK č. 565, fol. 70 (1712).

75 SOA Třeboň, fond C Vyšší Brod, PK č. 565, fol. 342 (1725). 
Vereinbarung, dass für die Altenteilerin ein neuer Viehstall gebaut werden müsse, ${ }^{76}$ stellt eine Formulierung dar, aus der sich die tatsächliche Arbeitstätigkeit der Altenteiler erschließen lässt. Die überwiegende Mehrheit der bäuerlichen Altenteiler dieser Region setzte sich also nicht zur Ruhe, sondern entschied sich für eine reduzierte Fortführung ihrer landwirtschaftlichen und sonstigen Tätigkeiten. Zwar ist im Einzelfall nicht festzustellen, ob die Altenteiler den zurückbehaltenen Besitz auch selbst bewirtschafteten oder diesen durch ihre Nachfolger bearbeiten ließen. Häufig vorkommende Formulierungen in den Verträgen, die regeln sollten, welche Arbeiten die Nachfolger zu verrichten hätten, scheinen aber darauf hinzudeuten, dass die nicht genannten Tätigkeiten von den Altenteilern selbst durchgeführt wurden. Sehr häufig wurde etwa festgehalten, dass die Besitznachfolger die Felder der Altenteiler düngen sollten.

Bei den landarmen Häusern erhielten die Altenteiler in der Regel keine das Überleben sichernden Zuwendungen. Bei diesen Schichten stand die Sicherung des Wohnrechtes nach der Hausübergabe deutlich im Vordergrund. Bei den landarmen Häusern waren die vereinbarten Leistungen in der Regel eindeutig zu gering, um ausschließlich davon leben zu können; sie waren also unbedingt auf eine eigene Arbeitsleistung angewiesen. Welche Einkommensmöglichkeiten sie hatten, lässt sich oft nicht im Detail eruieren. Nicht nur bäuerliche Ausnehmer, auch die meisten ehemaligen Besitzer landarmer Häuser strebten danach, nach ihrem Rückzug aus der Hausinhaberschaft weiterhin Flachs anzubauen und zu verspinnen. Von den 77 aus dem Zeitraum von 1699 bis 1738 in der Pfarre Kapličky erhaltenen Ausgedingeverträgen beinhalten mehr als 80 Prozent den Vorbehalt der ehemaligen Besitzer, weiterhin Flachs anbauen zu dürfen. Ein Großteil behielt sich vor, zumindest auf einem böhmischen Viertel (ca. 0,14 Hektar) Flachs anzubauen. ${ }^{77}$ Zweifellos haben sie diesen häufig auch selbst zu Garn weiterverarbeitet. In den wenigen erhalten gebliebenen Verlassenschaftsabhandlungen von Altenteilern finden sich mehrmals auch Hinweise auf unterschiedlich hohe Mengen an Garn. ${ }^{78}$ Mit dem Garnspinnen verfügten die Altenteiler der Region über ein Zusatzeinkommen, sodass sie nicht ausschließlich vom vereinbarten Altenteil leben mussten. Diese Möglichkeit zu einem Zusatzeinkommen war wohl auch ein Grund dafür, dass Ausgedingeverträge hier auch bei landarmen Häusern so häufig vorkamen.

76 SOA Třeboň, fond C Vyšší Brod, PK č. 565, fol. 445 (1735).

77 Diese Fläche ist im Vergleich zu den etwa 0.5 Hektar, die im Steuerkataster von 1713 als typisch für den Flachsanbau der größeren Bauern der Region genannt werden, nicht so gering. Vgl. NA Praha, TK Spisy 619, fol. 65.

78 SOA Třeboň, fond C Vyšší Brod, PK č. 559, beispielsweise fol. 67; PK č. 414. 
Bemessungsgrundlage für die den Altenteilern zugesprochenen Leistungen war in Kapličky (und anderswo) „nicht der angenommene Bedarf, auch nicht der ehemalige Status [...], sondern die Größe, genauer: die Leistungsfähigkeit des Hofes“. ${ }^{79}$ Eine vollständige Versorgung der ehemaligen Besitzer war aufgrund der geringen ökonomischen Möglichkeiten eines Anwesens oft nicht möglich. Dies bedeutete jedoch nicht, dass auf eine Altenteilerregelung verzichtet wurde, vielmehr wurde oft nur eine Teilabsicherung (etwa nur das Wohnrecht) vereinbart. Viele Altenteiler mussten daher zusätzlich durch verschiedenste Formen der Lohnarbeit ihr Überleben sichern.

Auch die südböhmischen Gutsherren stuften die Altenteiler nicht ausschließlich als arbeitsunfähige Menschen ein, eher waren sie den Inwohnern gleichgestellt. Von diesen wie auch von den Altenteilern wurden sowohl in Südböhmen als auch in den angrenzenden österreichischen Gebieten Abgaben und Dienste verlangt. In der großen südböhmischen Herrschaft Český Krumlov/Böhmisch Krumau der Fürsten Schwarzenberg, zu der auch ein umfangreicher Waldbesitz gehörte, waren die Altenteiler verpflichtet, Waldarbeiten als Robot zu leisten. Sie mussten etwa ein Drittel der Menge Holz verhacken, die den Inwohnern vorgeschrieben war. ${ }^{80}$ Auch in den Robotverzeichnissen der Herrschaft Vyšší Brod ${ }^{81}$ wurden Altenteiler geführt, es ist aber zu sehen, dass viele von ihnen de facto nicht mehr zur Robotarbeit herangezogen wurden.

Dass der Wechsel ins Ausgedinge nicht den Beginn einer ,unproduktiven' Lebensphase darstellte, lässt sich oft indirekt erschließen: Seit Beginn des 18. Jahrhunderts existierte in der Herrschaft Vy̌šś Brod ein ,Mühlenzwang, der per herrschaftlicher Verordnung die untertänigen Anwesen jeweils ganzer Dörfer einer bestimmten Mühle als ,Kunden' zuteilte. Laut dem Zinsregister des Jahres 1712 zählten dazu ausdrücklich auch die Altenteilerwirtschaften der jeweiligen Dörfer. ${ }^{82}$ Die Altenteiler ließen also das wenige Getreide, das sie ernteten, selbstständig mahlen - es war von der Ernte der eigentlichen bäuerlichen Wirtschaft getrennt.

Auch in anderen Gebieten Böhmens, des heutigen Österreichs und Deutschlands waren in der frühen Neuzeit Ausgedingewirtschaften verbreitet. ${ }^{83}$ Für man-

79 Täger, Altenteil, 46. Diese Abhängigkeit der Ausstattung des Altenteils von Größe und Leistungsfähigkeit des Hofes und Agrarkonjunktur wird in der Literatur immer wieder betont. Vgl. Trossbach, Bauern, $33 \mathrm{f}$.

80 Blau, Hausindustrie (Bd. 1), 58. Ähnlich dürfte die Situation in vielen anderen Teilen Böhmens gewesen sein. Vgl. Stark, Abhängigkeitsverhältnisse, 372.

81 Archiv Klaštera Vyšší Brod, kart. 397, Publikum 5/3.

82 Archiv Klaštera Vyšší Brod, kart. 245, Nr. 17.

83 Štefanová/Cerman, Lebensunterhalt; Grulich, Aspekte, 46; Klášterská, Forma. Auch für das norddeutsche Calenberg wurde festgestellt, dass die Altenteiler eine eigene Wirtschaft führten. Vgl. Bege- 
che benachbarte österreichische Gebiete sowie für eine westböhmische Region nahe der bayerischen Grenze ist für das 18. und 19. Jahrhundert sogar dokumentiert, dass die Ausnehmerhäuser baulich zum Teil wie kleine Bauernhäuser errichtet waren. Diese umfassten nicht nur Wohnräume, sondern hatten auch einen eigenen Viehstall und eine eigene Scheune. ${ }^{84}$ Für das westböhmische Gebiet der Choden wird berichtet, dass sich die Bauern bei der Übergabe immer eine kleine Landwirtschaft zurückbehielten. Die Ausgedingehäuser waren hier so groß, dass sie sogar über Wohnraum für eine zusätzlich mitwohnende Inwohnerfamilie verfügten. ${ }^{85}$ Altenteilerverträge, die auf großen Arbeitsaufwand für die abtretenden Besitzer hindeuten, sind bisher vor allem aus dem oberösterreichischen Raum für die 1570er und 1580er Jahre bekannt. Georg Grüll fand für diese Zeit zahlreiche Verträge aus verschiedenen Teilen Oberösterreichs, die auf die Verbreitung umfangreicher Altenteilerökonomien (etwa die Haltung von bis zu fünf Kühen) hinweisen, oder sich überhaupt den vierten Teil des gesamten Grundbesitzes zurückbehalten hatten. ${ }^{86}$ Im österreichischen Mühlviertel konnten Ausnehmer die von ihnen bewirtschafteten Felder und Wiesen auch weiterverkaufen, da diese rechtlich,Überlandgründe“ darstellten, die nicht Teil des unteilbaren Hofbesitzes waren. Im Salzburger Dorf Berndorf beschäftigen im 17. Jahrhundert einige Altenteiler auch eigene Gesindepersonen, ${ }^{87}$ was ebenfalls auf eine größere Wirtschaftsführung schließen lässt.

Die Weiterführung produktiver Tätigkeiten oder die Ausübung von Lohnarbeit nach dem Wechsel auf das Altenteil war nicht auf den agrarischen Bereich beschränkt. Für den ebenfalls zur Herrschaft Vyšší Brod gehörigen kleinen Marktort Hořice/Höritz wurde in einem nur fünf Personen umfassenden Verzeichnis der Handelsleute des Ortes auch ein „Ausnehmer und Krämer“ genannt. ${ }^{88}$ In der ,protoindustriellen' Kleinstadt Gmünd in Niederösterreich arbeiteten Ausnehmer öfter als Weber und bildeten in diesem Beruf auch Lehrlinge aus. ${ }^{89}$ Bandweber aus der Westlausitz ließen sich im 18. und frühen 19. Jahrhundert häufig vertraglich die räumlichen Voraussetzungen zusichern, um ihr Gewerbe weiter ausüben zu können: genügend Platz zum Aufstellen eines Bandwebstuhls und zur Aufbewahrung des Flachses. Waren die Weberhäuser zu klein, wurden für die Altenteiler kleine

mann, Lebensbedingungen. Einzelne Beispiele dafür finden sich außerdem in: Czerannowski, Altenteil, z.B. 87.

84 Schramek, Böhmerwald-Bauernhaus, 38.

85 Blau, Freibauern, 374.

86 Grüll, Bauer, 97 ff. Vgl. dazu auch Rebel, Peasant Stem Families, 271 ff..

87 Mitterauer, Familienstruktur, 164.

88 Archiv Klaštera Vyšší Brod, Kart. 410 Camerale 7/1.

89 Mitterauer, Formen, 321. 
Anbauten errichtet. ${ }^{90}$ Aus dem sächsischen Erzgebirge ist der Altenteilervertrag eines Posamentierer-Meisters überliefert, der festhielt, dass genügend Hausraum zur Verfügung gestellt werden müsse, um weiterhin einen Gesellen beschäftigen zu können. ${ }^{91}$ Naheliegend erscheint die Annahme einer weiteren Erwerbstätigkeit auch im Falle eines Altenteilers im niederösterreichischen Maria Langegg, der sich ausdrücklich sein Holzfällerhandwerkszeug vorbehielt. ${ }^{92}$ Hermann Rebel spricht in seiner Studie den oberösterreichischen Ausnehmern des 16. Jahrhunderts vor allem eine wichtige Funktion als innerdörfliche Geldverleiher zu. ${ }^{93}$

Sicherlich waren die regionalen Praktiken hinsichtlich der Häufigkeit und des Inhalts von Altenteilerverträgen während der frühen Neuzeit sehr unterschiedlich. Nicht überall war eine eigene Altenteilerökonomie so weit verbreitet wie in Südböhmen oder in Oberösterreich. Der Inhalt der Verträge und der Zeitpunkt im Leben, zu dem Altenteilerverträge abgeschlossen wurden, waren stark von regional unterschiedlichen Normen abhängig. War es etwa üblich, erst nach der Verwitwung ins Altenteil zu wechseln, konnte die Führung einer vom Haupthaus getrennten Ökonomie weniger wahrscheinlich sein. ${ }^{94}$ Gerade die Textilverarbeitung war aber in sehr vielen Regionen unter Altenteilern weit verbreitet. Vielfach war diese die letzte Verdienstmöglichkeit für alte Leute. ${ }^{95}$ Neueste Studien über das Altenteil in Norwegen und Finnland betonen die Mitarbeit der verwitweten Altenteilerinnen im Haushalt des Nachfolgers; neben der Textilverarbeitung spielten diese insbesondere bei der Beaufsichtigung der Kinder eine wichtige Rolle. ${ }^{96}$

Das Altenteil erfüllte jedenfalls vielfältige Funktionen und kann keineswegs generell als ein von Arbeit entlasteter Ruhestand gedeutet werden. Durch die Wahl des Zeitpunktes des Rückzugs konnte es etwa der Entwicklung von Besitzweitergabestrategien dienen und bedeutete in jedem Fall einen Rollenwechsel für die bisherigen Inhaber. Die Versorgung der abtretenden Besitzer konnte mit dem Abschluss eines solchen Vertrages intendiert sein. Dies war aber keineswegs

90 Schöne, Kultur, bes. $85 \mathrm{ff}$.

91 Schöne, Posamentierer, 144.

92 Mitterauer, Formen, 321.

93 Rebel, Peasant Stem Families, 262.

94 Dies scheint etwa in der Region Höchstadt an der Aisch in Franken im 18. Jahrhundert der Fall gewesen zu sein. Der von der verwitweten Person im Altenteil zurückbehaltene Grundbesitz diente als Faustpfand für den Konfliktfall, die zurückbehaltene Kuh musste vom Nachfolger gefüttert werden. Vgl. Endres, Altersvorsorge. In einer Studie zu Dinslaken im Ruhrgebiet findet sich zwar eine Weiterführung der Arbeit von Altenteilern selten, mehrfach kam jedoch der, Regierungsvorbehalt' der abtretenden Generation am Anwesen vor. Vgl. Schäfer, Übernahme.

95 So etwa auch in der nordböhmischen Herrschaft Starkenbach im 18. Jahrhundert oder in Westfalen. Vgl. Donth, Rochlitz, 17; Sauermann, Hofidee.

96 Moring, Retirement Contracts. 
zwingend. Noch weniger bedeutete ein Altenteil eine das Überleben vollständig sichernde materielle Absicherung. Häufig wurden während der frühen Neuzeit auch Altenteilerverträge mit nur geringfügigen Leistungen abgeschlossen, die nicht vor Verarmung schützten. ${ }^{97}$

Wurde bisher in der Literatur eine Zunahme der Zahl an Altenteilerregelungen als Folge der Produktivitätssteigerungen bäuerlicher Ökonomien im Zuge der Agrarrevolution zu Beginn des 19. Jahrhunderts betont ${ }^{98}$, ist hinzuzufügen, dass es zeitgleich in vielen Gebieten zu einer Re-Agrarisierung der ländlichen Unterschichten, etwa durch den Wegfall proto-industrieller Erwerbstätigkeiten, kam, ${ }^{99}$ wodurch die Möglichkeiten eines Nebenverdienstes für landarme oder landlose Bevölkerungsgruppen deutlich eingeschränkt wurden. Für landarme Kleinhäuser reduzierte sich dadurch die Chance auf die Einrichtung eines Altenteils sicherlich drastisch. Ein Wechsel ins Ausgedinge bedeutete in diesen Regionen fortan, dass die Betroffenen wohl auch tatsächlich von den zugesagten Leistungen leben mussten. Dies wäre eine Erklärung dafür, dass es im 19. Jahrhundert zu einer ,Verbäuerlichung' des Altenteils kam.

\subsubsection{Die Wirtschaftsführung bis zum Tod}

Die bei der besitzenden Landbevölkerung in unterschiedlichem Maße anzutreffende Praxis einer Wirtschaftsführung bis zum Tod kann als eine Form der Arbeitstätigkeit im Alter angesehen werden. Bei bäuerlichen Haushalten oder ländlichen Gewerbebetrieben wurde dies manchmal trotz schwindender Leistungsfähigkeit des Haushaltsvorstandes aufgrund einer größeren Zahl an zur Verfügung stehenden Arbeitskräften ermöglicht. Mitlebende und -arbeitende erwachsene Kinder, Gesindepersonen oder Gesellen erlaubten einen Rückzug auf die Leitungsfunktionen bei gleichzeitiger Delegierung der körperlich besonders anstrengenden Tätigkeiten. Hohe Wiederverehelichungsraten - häufig mit großen Altersunterschieden - führten außerdem oft dazu, dass zumindest ein Teil des bäuerlichen Paares noch rüstig genug für anstrengende körperliche Arbeit war. Je nach Region und Zeitperiode waren in der frühen Neuzeit bis zu einem Drittel (und vereinzelt auch mehr) aller Eheschließungen Zweit- und Drittheiraten von verwitweten Personen. ${ }^{100} \mathrm{Da}$

97 Dies wird auch aus den weiter unten behandelten Armenlisten ersichtlich, die auch mehrere Altenteiler erfassten. Vgl. dazu auch Buquoy, Die Armen.

98 Mitterauer, Problemfelder, 22.

99 Vgl. dazu etwa Hoffmann, Agrarisierung.

100 Vgl. Imhof, Wiederverheiratung. Im 19. Jahrhundert ging dieser Anteil dann zurück. Zu Wiederverehelichung als Rollenergänzung in der bäuerlichen Familienwirtschaft vgl. Mitterauer, Formen, $261 \mathrm{ff} .$. Siehe auch Wunder, Frauen, $49 \mathrm{f}$. 
Frauen überwiegend nur nach der Verwitwung ökonomisch selbstständig waren, indem sie die Geschäfte ihres verstorbenen Mannes weiterführten und allein ihrem Haushalt vorstanden, konnte für sie hohes Alter auch einen Gewinn an Autonomie und Autorität bedeuten. ${ }^{101}$

Eine Alternative zur Reduktion der eigenen Arbeitsleistung durch Delegierung war die Anpassung der bewirtschafteten Grundfläche an die verminderte Körperkraft. Dies konnte auf unterschiedliche Weise geschehen. In Realteilungsgebieten variierte die Größe der besessenen und bewirtschafteten Fläche aufgrund eines sukzessiven Prozesses des Erbens und Vererbens ohnehin je nach Lebensalter deutlich: Durch Erbschaften stieg der Grundbesitz beständig bis zu den mittleren Lebensjahren an, danach setzte der umgekehrte Prozess ein: Feld für Feld wurde wieder an die Kinder abgegeben, sodass der Höchststand an Landbesitz zumeist in den mittleren Altersgruppen erreicht wurde. ${ }^{102}$ Ein anderer Weg war es, das eigene Anwesen aufzugeben und sich im Alter auf ein kleineres zurückzuziehen. Fälle, in denen Bauern ihren Hof verkauften, um unmittelbar danach in der Region einen kleineren zu erwerben, waren in manchen Regionen etwa im 17. Jahrhundert weitaus öfter als in späteren Jahrhunderten anzutreffen. Auch die vereinzelt anzutreffende Praxis, einen großen Hof samt der dazugehörigen Besitzungen im Alter gegen ein kleineres Anwesen (eventuell mit einer geringen finanziellen Vergütung) einzutauschen, ist in diesem Kontext zu verorten. Ein Tausch von Häusern und Bauernhöfen zwischen zwei Besitzern war während der frühen Neuzeit offenbar in vielen Regionen eine Option, die später dann verloren ging (Kapitel 7. 8).

Regional bestanden sicherlich sehr große Unterschiede in der Verbreitung der ökonomischen Selbstständigkeit bis zum Tod. Das frühneuzeitliche England kann als geradezu klassisches Beispiel der selbstständigen Haushaltsführung bis zum Tod gelten. Als grober Annäherungswert für die Häufigkeit dieser Praxis können die Anteile der Haushaltsvorstände in der Altersgruppe der über 60-Jährigen dienen. In Mitteleuropa fand sich dieses Muster im Allgemeinen auf dem Land seltener als in der Stadt. In Salzburger Landgemeinden des 17. Jahrhunderts waren etwas mehr als die Hälfte der über 60-Jährigen Haushaltsvorstände. ${ }^{103} \mathrm{Im}$ frühneuzeitlichen Böhmen, wo die Besitzweitergabe zu Lebzeiten und damit der Rückzug auf das Altenteil weit verbreitet waren, lag dagegen der Prozentsatz derer, die im Alter in der Position des Haushaltsvorstands verblieben, im Vergleich zu vielen ande-

101 Vgl. dazu auch Hahn, Frauen.

102 In David Sabeans Studie zu Neckarhausen wurde der Höchststand an Landbesitz in der Altersgruppe der 45-54-Jährigen erreicht. Vgl. Sabean, Property, bes. 256-258.

103 Ehmer, Sozialgeschichte, 175; Ehmer, Altersversorgung. 
ren Regionen deutlich niedriger. In den Dörfern der südböhmischen Herrschaften Vyšší Brod und Chýnov/Chejnow etwa, bildeten im Jahre 1651 die Haushaltsvorstände unter den über 60-jährigen Männern nur eine Minderheit (Tabelle 48).

Tabelle 48: Prozentsatz der Haushaltsvorstände an der Altersgruppe der über 60-jährigen Bevölkerung in den Dörfern ausgewählter böhmischer Herrschaften (im Jahre 1651 bzw. 1586)

\begin{tabular}{lcccc}
\hline & Weiblich & Anzahl & Männlich & Anzahl \\
\hline Třeboň 1586 & $40,0 \%$ & 10 & $70,0 \%$ & 10 \\
Vy̌šś Brod 1651 & $40,0 \%$ & 5 & $36,7 \%$ & 30 \\
Chýnov 1651 & $37,5 \%$ & 8 & $40,0 \%$ & 5 \\
Liberec 1651 & $31,3 \%$ & 15 & $67,4 \%$ & 58 \\
Děčín 1651 & $22,4 \%$ & 33 & $74,0 \%$ & 174 \\
\hline
\end{tabular}

Anm.: Es wurden jeweils nur die ländlichen Regionen der Herrschaft berücksichtigt.

Quelle: Eigene Berechnungen auf Basis der Bestände der,Wiener Datenbank zur Europäischen Familiengeschichte'.

Zwar bot auch Haus- oder Landbesitz bzw. eine durch die Abgabe von Besitz eingetauschte Unterstützung keineswegs zwingend ausreichenden Schutz vor Verarmung im Alter, doch gewährte dieser zumindest eine Teilabsicherung (wenn eventuell auch nur in der minimalen Form eines Wohnrechtes), die all jenen, die zeitlebens nicht zu Haus- und/oder Grundbesitz gelangt waren, fehlte.

Welche Perspektiven abtretende Hausbesitzer hatten, die kein Ausgedinge erhielten, ist bisher in der Literatur kaum diskutiert. Auch in Kapličky kamen solche Fälle vor; auch hier lassen sich aber nur wenige Belege über den weiteren Lebensweg dieser Personen finden. Während des 17. Jahrhunderts wechselten mehrere Bauern im Alter mittels Kauf oder Häusertausch in ein Kleinhaus. Manche lebten danach auch als Inwohner auf anderen Höfen. Dies lässt sich etwa für Mathias Moherndl nachweisen. Dieser hatte 1766 auf einen bäuerlichen Hof in Kapličky eingeheiratet. In die Ehe brachte er einen (vermutlich bereits erwachsenen) Sohn mit. Nach nur fünf Jahren verkaufte er den inzwischen stark verschuldeten Hof an diesen Sohn. Da der Sohn die vorhandenen Schulden übernahm, aber auch weil im zugehörigen Ausnehmerhaus noch der Schwiegervater des Mathias Moherndl lebte, wurde ihm und seiner Frau kein Ausgedinge zugestanden. Mathias Moherndl und seine Frau lebten stattdessen im Jahre 1783 - nur wenige Meter entfernt auf der gegenüberliegenden Straßenseite - als Inwohner im Nebengebäude des Anwesens von Mathias Hoffmann. Hier war das Ausnehmerhaus nach dem 
Tod der Mutter des Bauern, Sophia Hoffmann, im Jahre 1766 frei geworden. ${ }^{104}$ Das genannte Beispiel mahnt so insbesondere in methodischer Hinsicht vor übereilten Zuordnungen: Nicht alle als Inwohner lebenden ehemaligen Bauern waren Ausnehmer und nicht bei allen in einem Ausgedinge-Haus lebenden Personen handelte es sich um die ehemaligen Hofbesitzer.

\subsubsection{Arbeit im Alter bei den Besitzlosen: eine Ökonomie des Auskommens}

Alte Menschen ohne einen Rückhalt durch eigenen Besitz und jene, die nicht ausreichend durch ein Altenteil oder eine andere Form der Unterstützung abgesichert waren, waren im Alter auf die eigene Arbeitsleistung angewiesen. Solange sie arbeiten konnten, bildete Lohnarbeit die Basis ihrer Existenzsicherung. Manche Autoren nehmen sogar an, dass Taglohn in der frühen Neuzeit unter älteren Menschen stärker verbreitet war als in anderen Altersgruppen. ${ }^{105}$ Auch im frühneuzeitlichen Dorf gab es - entgegen älterer Annahmen ${ }^{106}$ - durchaus Bedarf an Lohnarbeit, vor allem in der Form von Taglohn (vgl. Kapitel 4).

Für einige Regionen lässt sich feststellen, dass manche Berufe und Formen der Erwerbstätigkeit in den höheren Altersgruppen weiter verbreitet waren als unter den Jüngeren. Im niederösterreichischen Waldviertel etwa sattelten um 1800 viele Bauern mit zunehmendem Alter auf die Weberei um. ${ }^{107}$ Während das Verspinnen der Baumwolle - für das Gelenkigkeit der Hände und Geschmeidigkeit der Finger wichtig waren - tendenziell von Jüngeren ausgeübt wurde, war das Spinnen von grobem Leinengarn in sehr vielen Regionen eine Tätigkeit, die auch von denjenigen älteren Menschen noch ausgeübt wurde, die zahlreiche andere Arbeiten nicht mehr verrichten konnten. ${ }^{108}$

Darüber hinaus gab es vielfach auch spezifische ,Marginaltätigkeiten', die während der frühen Neuzeit dem Alter vorbehalten waren. Dazu zählten unter anderem etwa Wächter- und Botendienste, Holzschneiden, Futterschneiden, Ofenkehren und Leichen waschen. Häufig boten die Kirchen älteren Pfarrbewohnern

104 Das Fallbeispiel wurde rekonstruiert auf Basis der Grundbücher, der Familienrekonstitution, dem Hausbesitzer- und Inwohnerverzeichnis von 1783 sowie dem im Zuge der Erstellung des Stabilen Katasters entstandenen Kartenmaterial.

105 Mitterauer/Sieder, Patriarchat, 195: „Arbeit um Taglohn war überhaupt eine gerade für alte Menschen spezifische Form, das Leben zu fristen.“

106 Das Konzept des, Ganzen Hauses" etwa präsentierte ein Bild von weitgehend als autark angesehenen bäuerlichen Hauswirtschaften, die auf der „lohnlosen Mitarbeit der Familienmitglieder“ beruhten (wozu auch Inwohner und Gesinde gezählt werden). Vgl. Brunner, Haus, bes. 107.

107 Mitterauer, Formen, 321.

108 Komlosy, Webwaarenindustrie, 111. 
Verdienstmöglichkeiten als Mesner, Totengräber oder Pfarrdiener an. ${ }^{109} \mathrm{Im}$ Böhmerwald etwa war es zumindest im frühen 19. Jahrhundert Sitte, dass jeweils die ältesten Leute des Dorfes als ,Leichenansager' (,Leichensäger') ausgesandt wurden. Im Todesfall suchten sie die Verwandten der verstorbenen Person auf, um die Einladung zur Begräbnisfeier zu verkünden. Diese geschlechtsspezifisch differenzierte Tätigkeit - bei einem männlichen Toten wurde ein männlicher Berichterstatter ausgesandt - erfüllte eine nicht zu unterschätzende Versorgungsfunktion, da die ,Leichenansager' in jedem Haus reichlich bewirtet und beschenkt wurden. ${ }^{110}$

Die landlosen Unterschichten, wie die Inwohner, die schon oft zum Leben zu wenig hatten, als sie jung und arbeitsfähig waren, standen bei Nachlassen ihrer Arbeitskraft vor großen Problemen. Das Problem der kaum vermeidbaren allmählich sinkenden Arbeitsfähigkeit (bis hin zur völligen Arbeitsunfähigkeit) führte früher oder später dazu, dass die Verdienstmöglichkeiten aus dem Taglohn nicht mehr ausreichten und die meisten besitzlosen Alten gleichzeitig auf mehrere Quellen der Unterhaltssicherung angewiesen waren. Kombinationen aus Lohnarbeit, Unterstützung und/oder Bettel waren in jeder denkbaren Form möglich. Die familiale Unterstützung war bei den Besitzlosen auf dem Lande keine voraussetzbare Größe und wenn es sie gab, reichte sie jedenfalls nicht zur Existenzsicherung. Neben der Versorgung durch die Familie wird in der Literatur häufig auch der Rückhalt alter Menschen in der Gemeinde betont. ${ }^{111}$ In der Habsburgermonarchie beispielsweise hatten die Kommunen ab dem 18. Jahrhundert dezidiert die Verpflichtung, die in ihren Zuständigkeitsbereich fallenden Armen zu versorgen. Unterstützung erhielt, wer in der Gemeinde das sogenannte ,Heimatrecht' hatte. Dieses stand Personen $\mathrm{zu}$, die entweder in der Gemeinde geboren waren, oder sich mindestens zehn Jahre dort aufgehalten hatten oder - im Falle von Frauen - dieses durch Verheiratung erworben hatten. In der Praxis haben diese Regelungen aber vielfach zu Konflikten geführt, denn die Gemeinden versuchten, sich in vielen Fällen der Verpflichtung zu entziehen und die Person an eine andere Zuständigkeitsinstanz zu verweisen. Die kommunale Versorgung alter Menschen geschah häufig in Form der sogenannten ,Einlege'. Wurde alten Menschen der Status eines ,Einlegers' zuerkannt, zogen sie als Gemeindearme von Hof zu Hof, wo sie nach einem vorgegebenen gemeindeinternen Schema (häufig nach der Hofgröße variierend) für eine bestimmte Zeit (Tage, Wochen oder Jahre) Beherbergung und Verköstigung erhielten. ${ }^{112}$

109 Vgl. Göckenjan, Moralökonomien, 4; Ehmer, Sozialgeschichte, 35.

110 Vgl. den Bericht bei Rank, Böhmerwald, 111.

111 Vgl. etwa die Formulierung „Rückhalt in Familie und Gemeinde“ bei Troyansky, 18. Jahrhundert. Besonders betont wird die Bedeutung der Gemeinde etwa auch bei:Tennstedt, Sozialgeschichte, z.B. 18.

112 Ehmer, Sozialgeschichte, 36; Ammerer, Versorgung, 174; Ortmayr,,Oarbeits‘. 
Wenn das Überleben durch Lohnarbeit, die familiale und die kommunale Versorgung nicht gesichert war oder wenn Versorgungsansprüche von der Gemeinde nicht anerkannt wurden, waren arme Personen auf die ,Wohltätigkeit' unterschiedlicher Institutionen angewiesen, deren Leistungen für Bedürftige in Südböhmen im 16. Jahrhundert als Reaktion auf die Reformation vielfach deutlich erweitert worden waren. ${ }^{113}$ Für eine eng begrenzte Zahl an Personen gab es die Möglichkeit einer Versorgung als Pfründer in einem der vielfach im Mittelalter gegründeten regionalen Spitäler. Das bereits seit 1371 bestehende Klosterspital von Vyšší Brod versorgte 16 Arme mit Kost, Kleidung und ,allem nothwendigen'. Auch das bürgerliche Spital im Ort hatte 16 Plätze. ${ }^{114}$ Seit 1773 existierte im Ort Vyšší Brod außerdem eine kleine private Armenstiftung, die ebenfalls vom Kloster verwaltet wurde: jährlich wurden dabei drei Gulden unter den Ortsarmen verteilt. ${ }^{115}$

Darüber hinaus bestand gerade in Südböhmen mit den ,Pfarrarmeninstituten“ seit dem späten 18. Jahrhundert eine weitere Form der offenen Armenfürsorge, die zum Vorbild für die Reorganisation des Armenwesens in Wien und Niederösterreich wurde und ab 1783 in der gesamten Habsburgermonarchie eingeführt wurde. Eine Auswertung von mehreren der in diesem Zusammenhang erstellten, zahlreich erhaltenen südböhmischen Pfarrarmenverzeichnisse des späten 18. und frühen 19. Jahrhunderts zeigt, dass diese als Armenfürsorge bezeichnete Unterstützung in erster Linie eine Altersversorgung darstellte, da eine deutliche Mehrheit der unterstützten Personen über 50 Jahre alt war (etwa die Hälfte war älter als 60 Jahre). Daneben wird auch die Häufigkeit einer aus unterschiedlichen Quellen bestehenden ,mixed economy' im Alter sichtbar, die sich aus drei oder mehr Ressourcen zusammensetzte; zahlreiche alte Personen kombinierten z.B. die Unterstützung durch die kommunalen Pfarrarmeninstitute mit eigener Erwerbstätigkeit, mit Bettel und mit verschiedenen anderen Unterstützungsformen, wie etwa gelegentlichen Zuwendungen durch die eigenen Kinder. ${ }^{116}$

Auf den Bettel als zusätzliche oder alleinige Erwerbsform waren zahlreiche Menschen immer wieder angewiesen. Bettel war in dieser Zeit ein Massenphänomen, wie die seltenen Fälle, in denen Zahlen vorliegen, zeigen. In Oberösterreich etwa wurden im Jahr 172725.896 und im Jahr 172923.728 Bettler gezählt. ${ }^{117}$ Dieser Erwerbsform bedienten sich Alte wie Junge, Frauen wie Männer, kurzfristig Erwerbslose wie Arbeitsunfähige, Sesshafte wie Vagierende. Gelegentlicher

113 Vgl. Tönsmeyer, Adel, 485 ff.

114 Quelle: NA Praha, APA I, sign. B14/22.

115 Ladenbauer, Das Sociale Wirken, 276.

116 Vgl. dazu ausführlicher: Zeitlhofer, Arbeit, bes. 48-52.

117 Ammerer, Versorgung, 173. 
Bettel diente unterschiedlichsten Berufsgruppen und Milieus als Überlebensstrategie, beispielsweise auch alternden Handwerkern, wenn sie im erlernten Beruf über längere Zeiträume hinweg keine Arbeit finden konnten. ${ }^{118}$ Umgekehrt boten herumziehende Invalide oder Bettler teilweise auch Waren zum Verkauf an oder übernahmen kurzfristige Taglohnarbeiten, wenn sich dazu die Gelegenheit bot. ${ }^{119}$

Fundamental für das Verständnis der Frage nach Ausmaß und Form der Arbeits- und Erwerbstätigkeit älterer Menschen der frühen Neuzeit erscheint damit eine Differenzierung in Besitzende (Haus- und/oder Landbesitz) einerseits und Besitzlose andererseits. Besitz erwies sich als zentral, weil sich aus den Erträgnissen des Besitzes ein (zumindest bescheidener) Beitrag zur eigenen materiellen Absicherung im Alter gewinnen ließ. Unterschieden werden muss zwischen Personen, die zeitlebens nie die Möglichkeit hatten, zu Haus- (und eventuell Land-)Besitz zu gelangen und jenen, die den erlangten Besitz entweder bis zum Tod beibehielten oder diesen erst in ihrer letzten Lebensphase wieder aufgaben. Während sich für erstere im hohen Alter die Lebensumstände bei abnehmender Arbeitsfähigkeit und ohne Versorgungsansprüche häufig sehr dramatisch entwickelten und bis zum Verlust dauerhafter Wohnmöglichkeiten führen konnten, hatten letztere zumindest prinzipiell die Wahlmöglichkeit, die ökonomische Selbstständigkeit und die soziale Position als Besitzer und Haushaltsvorstand bis zum Tode aufrechtzuerhalten oder aber diese Position an die nächste Generation weiterzugeben und sich dafür im Gegenzug einen (Teil-)Unterhalt zu sichern. ${ }^{120}$ Unter Umständen konnte schon der Besitz eines bescheidenen Häuschens oder einer einzigen Kuh das Angewiesensein auf die eigene Arbeitsfähigkeit im Alter soweit entscheidend verringern, dass Verarmung und Verelendung vermieden werden konnten.

So sehr Besitz als relevantes Differenzierungskriterium für die Möglichkeiten einer sozialen Absicherung im Alter erscheint, so falsch wäre gleichzeitig eine bloß dichotome Unterscheidung zwischen einer besitzenden Schicht unter den Älteren einerseits und besitzlosen Alten andererseits. In vielen ländlichen Regionen der frühen Neuzeit existierte keine scharfe Trennlinie zwischen Land besitzenden und landlosen Haushalten; die Abstufungen zwischen Landbesitz, Landarmut und Landlosigkeit waren vielmehr sehr fließend - ,feine Unterschiede anstelle von schroffen Gegensätzen kennzeichneten das breite Spektrum an sozialen Abstufungen in der ländlichen Gesellschaft. Dementsprechend abgestuft erwies sich auch die Bedeutung von Besitz für die Absicherung der materiellen Existenz im Alter.

118 Vgl. dazu bes. Bräuer, Bettler.

119 Ammerer, Versorgung, 164.

120 Vgl. dazu auch Ehmer, Sozialgeschichte, $165 \mathrm{ff}$. 
Ein Rückzug aus der Arbeitstätigkeit im Alter erfolgte vielfach nur sehr graduell. Für die individuell sehr unterschiedlich lange Phase eines, Nachlassens', einer langsamen Aufgabe der bisher ausgeübten Tätigkeiten, scheint eine Kombination heterogener Einkommens- und Unterstützungsformen konstitutiv. Dass dabei auch die eigene Erwerbstätigkeit der älteren Menschen eine zentrale Rolle spielte, hat eine stark von den Sichtweisen des 20. Jahrhunderts geprägte Geschichtsforschung, die dem Alter eine vorwiegend passive Rolle zuschrieb, lange Zeit nicht gesehen. ${ }^{121}$

121 So bereits: Ottaway, Elderly, 415. 


\section{ZUSAMMENFASSUNG UND SCHLUSSFOLGERUNGEN}

Die vorliegende Arbeit behandelt mehrere Teilbereiche der aktuellen sozialhistorischen Diskussionen. Sie steht im Kontext neuerer Ansätze, die versuchen, mittels lokaler Fallstudien oder mikrogeschichtlicher Zugangsweisen die in ihren Aussagen häufig sehr weitreichenden Theorie- und Modellbildungen traditionellerer sozialhistorischer Ansätze an konkreten Beispielen zu überprüfen und kritisch zu hinterfragen. In dieser Arbeit geschieht dies vor allem im Hinblick auf die häufig thematisierten Zusammenhänge von Besitztransfer, Generationenbeziehungen, Heiratsverhalten und sozialstruktureller Entwicklung. Die Analyse der lokalen Praktiken der Besitztransfermuster hat allerdings auch einen eigenständigen Charakter. Es werden dadurch etwa sich im Zeitverlauf wandelnde Verhaltensweisen der Menschen sichtbar, die geeignet sind, neue Fragestellungen in der aktuellen Forschungsdiskussion aufzuwerfen. Relativ neu ist auch die Einbeziehung einer Region aus dem Geltungsbereich der sogenannten ,ostelbischen Gutsherrschaft ${ }^{6}$ in die Diskussionsstränge über die Entwicklung vorindustrieller ländlicher Gesellschaften, die sich bisher vorwiegend nur auf Gebiete der westeuropäischen Grundherrschaften bezogen.

Die vorliegende Arbeit unterstützt zunächst Aussagen der neueren Forschung, die die Entstehung einer, verschärften Erbuntertänigkeit' in Böhmen eher als langfristige kontinuierliche Entwicklung verstehen und die früher in diesem $\mathrm{Zu}-$ sammenhang meist angenommene hohe Bedeutung des Dreißigjährigen Krieges zurückweisen. ${ }^{1}$ Die Annahmen der tschechischen Historiographie bezüglich der großen Zäsur, die der Dreißigjährige Krieg dargestellt habe, ließen sich nicht bestätigen. Diese Feststellung bezieht sich nicht nur auf die Entwicklung der,Gutsherrschaft', sondern auch auf weitere gesellschaftliche Phänomene. Die hier untersuchte Gesellschaft wandelte sich in vielerlei Hinsicht offenbar vor allem im 18. Jahrhundert, nicht aber - wie oft angenommen - bereits im 17. Jahrhundert. In vielen strukturellen Merkmalen scheint das 17. Jahrhundert in diesem südböhmischen Gebiet dem 16. Jahrhundert weit ähnlicher gewesen zu sein als dem 18. Jahrhundert. $^{2}$

1 Vgl. Cerman, Gutsherrschaft vor dem, Weißen Berg.

2 Vgl. dazu Grulich/Zeitlhofer, Lebensformen. 
Die lokale Herrschaft hatte in dieser Region in vielerlei Hinsicht eine zentrale Stellung und einen hohen Einfluss auf das Leben und die Handlungsmöglichkeiten ihrer Untertanen. Falsch wäre jedoch die Annahme, dass dieser Einfluss ausschließlich in den Dimensionen der Repression, Kontrolle und einer Beschneidung der Freiräume der lokalen Bevölkerung zu interpretieren ist. Zwar kann für manche gesellschaftlichen Bereiche diese Einschätzung der Rolle der Herrschaft wohl bestätigt werden, gleichzeitig war deren Einfluss auf das alltägliche Leben der Menschen in vielen Aspekten aber auch erstaunlich begrenzt. Es gab mehrere weitgehend obrigkeitsfreie Sphären und in vielfältiger Weise auch Formen der Unterstützung der Untertanen durch die Obrigkeit. Gerade den Inhabern der besitzenden Anwesen kamen in weiten Bereichen auch Freiheiten zu. Da sie die ,Kosten, (Abgaben, Robot) des Systems der ,verschärften Erbuntertänigkeit, trugen, hatten sie eine entscheidende Rolle im Funktionieren dieses Sozialsystems inne. ${ }^{3}$

Die Herrschaft verfügte als Besitzer eines sehr großen Teils der in der Region vorhandenen Grundflächen auch indirekt über hohe Einflussmöglichkeiten auf die ökonomische und sozialstrukturelle Entwicklung. Wenn es mehrere lang andauernde Phasen einer Stagnation im Siedlungsausbau gab, so ist dies insgesamt wohl weniger auf die Haltung der Klosterherrschaft selbst zurückzuführen. Vielmehr lag die Verhinderung eines allzu raschen sozialen Wandels wohl im Interesse eines Teils der untertänigen Besitzer selbst, die etwa vermittelt über die Organisation der Dorfgemeinden den Zugang zum kommunalen Weideland beschränkt wissen wollten.

In den Phasen eines raschen Siedlungsausbaus war es jedenfalls gerade die Herrschaft, die dafür ihr Land zur Verfügung stellte. Auch in den anderen Perioden gab sie zahlreiche Parzellen aus ihrem Dominikalbesitz ab, um die agrarische Basis der untertänigen Anwesen zu stärken. Gleichzeitig beeinflusste die Grundherrschaft damit die wirtschaftliche und soziale Entwicklung in ihrem Herrschaftsgebiet wesentlich. Durch die Ausgabe dominikalen Landes an die Untertanen verhalf sie insbesondere den landarmen Häusern zu einer Stärkung ihres agrarischen Standbeins und verhinderte so eine durchgehende proto-industrielle Transformation der Gesellschaft, wie dies in einigen anderen Regionen stattfand. Wie bereits öfter nachgewiesen wurde, konnte ein in der Bevölkerung weit verbreiteter, wenn auch geringer Landbesitz die Dynamisierung der proto-industriellen Entwicklung einer Region deutlich bremsen. ${ }^{4}$

Die ökonomische und sozialstrukturelle Entwicklung in der Region war beständig von einer hohen Vielfalt an unterschiedlichen Einkommensformen gekenn-

3 Diese Position bestätigt neuerdings auch Velková, Manor, die auch die teilweise Übereinstimmung der Interessen von Grundherrschaft und Bauern betont.

4 Vgl. Kriedte/Medick/Schlumbohm, Sozialgeschichte. 
zeichnet. Die Unterschiede zwischen den einzelnen Häusern der untersuchten Pfarre waren sowohl hinsichtlich ihres Landbesitzes als auch ihrer außeragrarischen Einkommen weniger von scharfen Gegensätzen, sondern vor allem von graduellen Unterschieden geprägt. Nur sehr wenige Familien lebten gänzlich von ihrer Landwirtschaft und hatten keinerlei heimgewerbliche Einkommen. Umgekehrt gab es nur sehr wenige Häuser, die keinerlei landwirtschaftliche Anbindung besaßen - zumindest eine Kuh oder Kleinvieh wurde von den allermeisten Anwesen gehalten.

Die Besitzrechte der Untertanen waren trotz der Bedingungen der,verschärften Erbuntertänigkeit, sehr günstig. Starke Besitzrechte der Untertanen und mächtige Grundherrn sind daher kein Widerspruch. Grundherrschaft und Besitzrechte waren wesentliche Determinanten der konkreten Übergabepraktiken. ${ }^{5}$ Die eigentlichen Entscheidungen in den untertänigen Besitzweitergaben fanden aber im Wesentlichen außerhalb der Einflussnahme der Grundherrschaft statt. Die Herrschaft beschränkte sich weitgehend auf eine Kontrollfunktion, eine Art Schlichtungsstelle, und griff nur selten direkt in die Gestaltung der Übergabe ein. Die Verhandlungsposition neu antretender Hofbesitzer gegenüber der Gutsherrschaft blieb auch unter den Bedingungen einer, verschärften Erbuntertänigkeit' stark. Für die Herrschaft entscheidend war im Zusammenhang mit dem Besitztransfer die Aufrechterhaltung des Prinzips der Unteilbarkeit der untertänigen Anwesen, darauf achtete sie sehr genau. Trotz der Unteilbarkeit des Landbesitzes beinhaltete der Besitztransfer nicht nur in seiner formalen Gestaltung, sondern auch in der Praxis der handelnden Menschen zahlreiche Elemente der Teilbarkeit. Letztendlich lässt sich nur schwer entscheiden, ob das in der Untersuchungsregion vorherrschende Muster der Besitzweitergabe einem ,Anerbenrecht' oder einer ,Realteilung' näherkam. Auch anderswo existierten Systeme der Besitzweitergabe, die sowohl zahlreiche Momente der Teilbarkeit als auch der Unteilbarkeit enthielten.

Die vorliegende Arbeit kann zu einer weiteren Aufweichung der angeblichen Unterschiedlichkeit der lange Zeit als Gegenpole betrachteten Prinzipien Realteilung, bzw. geschlossene Besitzweitergabe beitragen. Für französische Regionen wurde bereits auf die breite Skala an Zwischenstufen von egalitären und nichtegalitären Systemen hingewiesen. ${ }^{6}$ Auch Berkner und Mendels beschreiben die hohe Bandbreite an Zwischenformen zwischen den Prinzipien der Unteilbarkeit und jenen der Realteilung, haben diese aber in erster Linie als Folgeerscheinungen ökonomischer und demographischer Einflussfaktoren gesehen. ${ }^{7}$ Nach wie vor wird in

5 Fertig, Autoregulation, 95.

6 Segalen, Die Familie, $98 \mathrm{ff}$.

7 Berkner/Mendels, Inheritance Systems. 
der Literatur zu häufig undifferenziert von historischen Regionen mit herrschendem Anerbenrecht ausgegangen, bzw. werden die Verhältnisse des 19. und frühen 20. Jahrhunderts einfach auf frühere Zeiten rückprojiziert. Allerdings ist die Auflösung einer dichotomen Auffassung der Besitzweitergabesysteme auch aus der anderen Richtung zu betreiben. Es gab in frühmoderner Zeit zahlreiche Realteilungsgebiete, in denen es weit verbreitet war, dass nur ein Kind das Haus und den Grund übernahm und seine Geschwister ausbezahlte. ${ }^{8}$ Im Realteilungsgebiet rund um den deutschen Ort Heuchelheim galten die landwirtschaftlichen Betriebseinheiten offenbar als derart ,unveränderlich', dass für die Jahre 1721 bis 1740 keinerlei Käufe oder Verkäufe einzelner Grundparzellen nachgewiesen werden konnten. ${ }^{9}$ In mehreren Gebieten mit Unteilbarkeit der Güter, wie etwa im südböhmischen Kapličky, wurde dies dagegen keineswegs so strikt gehandhabt. Andererseits gab es Regionen, in denen etwa die althergebrachten Normen der Unteilbarkeit der Besitzungen durch unterschiedliche Praktiken abgelöst wurden, die einer Realteilung nahekamen. Im Zürcher Oberland entstanden dadurch, dass allmählich auch die weichenden Geschwister ihre Wohnstätten beim elterlichen Haus errichten konnten, zunehmend Teil- und Doppelhäuser. ${ }^{10}$

Die Analyse der Besitzweitergabepraktiken zeigt, dass es in der Pfarre Kapličky im 18. Jahrhundert zu wichtigen Veränderungen kam. Der Anteil an Eigentümern mit längerer Besitzdauer erhöhte sich, zunehmend wurde der Besitz nur mehr innerhalb der Familie weitergegeben. Ende des 18. Jahrhunderts gab es kaum Haushaltsvorstände, die jünger als 35 Jahre waren, während im Jahre 1651 etwa ein Drittel der Altersgruppe der 20- bis 24-Jährigen bereits Hausbesitzer gewesen war. Konnten im 17. Jahrhundert noch etliche Inwohner zu Hausbesitz gelangen, war dies in späterer Zeit nur mehr in seltenen Fällen möglich. Andere, grundlegende Merkmale des Besitztransfers - wie die Einzelnachfolge - wandelten sich jedoch nicht. Auch verweisen die Verheiratetenanteile bei den unter 30-Jährigen auf eine zur Mitte des 17. Jahrhunderts allgemein frühe Heirat, während das durchschnittliche Heiratsalter ab dem beginnenden 18. Jahrhundert auf sehr hohem Niveau lag.

Eindeutige Schlussfolgerungen aus dem Prinzip der Unteilbarkeit der Häuser auf die Verheiratetenanteile in einer Bevölkerung, auf die Höhe des Heiratsalters und damit auch auf das Ausmaß des Bevölkerungswachstums sowie auf die Verbreitung komplexer Familienformen erscheinen aufgrund dieses Ergebnisses nicht legitim. Die Folgen bestimmter Besitztransferformen waren vielmehr in entscheidendem Maße von einer Vielzahl an Einflussfaktoren abhängig. Das Prinzip der

8 Vgl. etwa Theibault, German Villages, 94; Tanner, Spulen, 10.

9 Schmidt, Hofgröße, 697.

10 Braun, Industrialisierung, $166 \mathrm{ff}$. 
Unteilbarkeit der Güter konnte sowohl mit einem allgemein niedrigen als auch mit einem hohen Heiratsalter verbunden sein. In dieser Region war die Eheschließung kontinuierlich nicht an den Besitztransfer gebunden. Die Haus- und Grundbesitzer folgten einem Gleichheitsgedanken in Bezug auf die Ausstattung der Kinder. Ziel war, dass alle Kinder gleiche Anteile aus dem Erbe erhielten, nach Möglichkeit sollte allen eine ausreichende Existenzbasis gesichert werden und alle sollten heiraten können. Die Formen des Besitztransfers beeinflussten in dieser Region die demographische Entwicklung nicht in dem von den Klassikern der sozialhistorischen Theoriebildung angenommenen Sinne. Die weichenden Geschwister waren überwiegend nicht von Heirat und Fortpflanzung ausgeschlossen, wie dies Ipsen, Mackenroth und auch noch Pfister annahmen. Kontinuierlich bestand eine Heiratsmöglichkeit auch für Personen, die nicht zu Hausbesitz gelangten. Auch für die Besitznachfolger war der Zusammenhang zwischen dem Zeitpunkt von Besitzweitergabe und Heirat, vor allem in den frühen Phasen der Untersuchungsperiode, keineswegs besonders eng.

Während des Untersuchungszeitraums erfuhr die Besitzweitergabe vom Vater an den Sohn einen ganz deutlichen Aufschwung, wie dies für die frühe Neuzeit ansonsten noch selten nachgewiesen wurde. Freilich erscheint der Wandel hier auch deshalb so markant, weil im 17. Jahrhundert noch eine recht hohe Besitzfluktuation herrschte. Diese Veränderung hatte jedenfalls auf die Möglichkeiten für Frauen, im Besitz nachzufolgen, negative Auswirkungen. Töchter (und Schwiegersöhne) kamen zunehmend seltener in den Besitz des elterlichen Hauses. Auch die Weitergabemöglichkeiten der Witwe wurden in bestimmten Fällen eingeschränkt. Scheint die Bindung der Familien an ihr Haus im 17. Jahrhundert in manchen Fällen, in denen der Hausbesitz zugunsten anderer Wohn- und Einkommensformen aufgegeben wurde, noch recht gering, wurden im 18. und frühen 19. Jahrhundert offenbar vielfältige Strategien angewandt, um das Anwesen im Familienbesitz zu halten.

Erklären lässt sich die Bedeutungszunahme der Weitergabe an ein leibliches Kind (insbesondere an den Sohn), die sich etwas später - im 19. Jahrhundert auch in zahlreichen anderen Regionen Zentraleuropas nachweisen lässt, sowohl kulturgeschichtlich als auch ökonomisch. Die Betonung langer familialer Kontinuitäten als eine Quelle von sozialem Prestige und Legitimation für gesellschaftliche Macht verbreitete sich ausgehend vom Adel im 18. Jahrhundert allmählich auch im Bürgertum und unter den Bauern. Die Anlage von Stammbäumen und Abstammungslinien, die sich vereinzelt auch als Beilage im untersuchten lokalen Quellenbestand fand, wurde allmählich Teil einer öffentlich zelebrierten Erinnerungskultur. ${ }^{11}$ Eine plausible ökonomische Erklärung der Bevorzugung von Fami-

11 Vgl. Ehmer, Generationen, 63. 
lienmitgliedern in der Besitznachfolge bieten die Überlegungen von Liam Kennedy. ${ }^{12}$ Demnach war die Arbeitskraft des prospektiven leiblichen Nachfolgers, der in der Regel ja auch vor der Besitzübernahme (in seiner Kindheit und Jugend) am Hof mitarbeitete, in jedem Fall günstiger als Lohnarbeit, da dessen Arbeit häufig bloß mit ,zukünftigen Ansprüchen' abgegolten wurde. Hinzukommen mochte in vielen Fällen eine besondere Motivation des nachfolgenden Kindes und sein spezifisches, genau auf den elterlichen Betrieb und dessen Felder abgestimmtes umfangreiches Detailwissen. Die Vorteile familialer Arrangements gegenüber bloßen Marktbeziehungen sind außerdem auch in deren Möglichkeit, überaus komplexe und langfristige Austauschbeziehungen zu knüpfen, zu sehen. Die Reziprozität von Ressourcenflüssen musste nicht unbedingt in ein und derselben Generation erfolgen, sondern konnte auch deutlich später eintreten. Eine Vorbedingung innerfamilialer Lösungen der Besitznachfolge war freilich ein Mindestmaß an demographischer und ökonomischer Stabilität, die eine längerfristige Zukunftsplanung überhaupt erst sinnvoll erscheinen ließ. ${ }^{13}$ Dies war im Untersuchungsgebiet offenbar nicht zu allen Zeiten der Fall.

Häufig erfolgte in dieser Region ein Besitzerwechsel nicht mit dem Tod, sondern bereits zu Lebzeiten des Besitzers, für den nach seinem Rückzug häufig, keineswegs aber in allen Fällen, ein Ausgedinge eingerichtet wurde. Dass in diesem Gebiet das Ausgedinge häufig auch bei den landarmen Häusern vorkam und überdies oft bei familienfremden Besitznachfolgern angetreten wurde, ist im überregionalen Vergleich bemerkenswert. Die Einrichtung eines Ausgedinges war nicht an wirtschaftlich leistungsfähige Höfe geknüpft und diente häufig auch nicht einer vollständigen Versorgung der Vorbesitzer. Das Ausgedinge erfüllte vielmehr vielfältige soziale Funktionen; häufig gewährte es nur eine minimale Unterstützung und sicherte insbesondere die Anbindung an ein bestimmtes Haus und bewahrte so vor einem Absturz in eine vagierende Lebensweise. Weder für die wohlhabenden ehemaligen Bauern unter den Altenteilern noch für Altenteiler aus der unterbäuerlichen Schicht bedeutete das Ausgedinge eine ausschließlich arbeits- und erwerbslose Lebensphase.

Der bäuerliche Hof - in Gestalt des ,ganzen Hauses' - wurde oft als unveränderliches Grundelement der alteuropäischen Gesellschaft beschrieben. Innerhalb dieses ganzen Hauses habe das tatsächlich wirtschaftende Paar („das regierende

12 Kennedy, Farm Succession, bes. $494 \mathrm{ff}$.

13 Ein Nachteil der familialen Besitzübertragung liegt freilich in der engen Verzahnung von ökonomischen Interessen und persönlichen wie verwandtschaftlichen Bindungen, die ein großes Konfliktpotenzial in sich birgt. Der Generationenkonflikt ist bereits seit der Zeit um 1800 ein zentrales Motiv einer breit gefächerten Literatur. Vgl. etwa Göckenjan, Alter, 246-262. 
Paar") eine sehr hohe Verfügungsgewalt gehabt. ${ }^{14}$ Gegen diese Sichtweise ergeben sich aus der vorliegenden Arbeit in mehrfacher Hinsicht bedeutende Einwände: erstens erfolgte eine Aufwertung des Hofes hier erst im Laufe der frühen Neuzeit. Auch lässt sich einwenden, dass manchmal auch eine andere, zumeist ebenfalls als sehr beharrend erachtete Sozialform, nämlich die Verwandtschaft, in Konkurrenz zum „regierenden Paar" treten konnte. Die Interessen der Verwandtschaft konnten die Verfügungsgewalt des Paares auch stark begrenzen. ${ }^{15}$ Es gab im 18. Jahrhundert in Kapličky mehrere Bauern (nämlich etwa die ,Interimswirte'), die genau wussten, dass sie ihre Position nur befristet inne hatten; die manchmal auch wussten, wer bereits in wenigen Jahren diesen Hof - auf dem sie dann als Ausnehmer mitleben würden - leiten würde. Schon einige Jahre vor dem Rückzug aus ihrer Position werden sie daher wohl nicht alle ihre betriebswirtschaftlichen Entscheidungen ohne Mitsprache des zukünftigen Besitzers, bzw. der Personen, die die Interessen desselben vertraten, haben treffen können.

Die untersuchte Gesellschaft war durch eine zunehmende Stabilität gekennzeichnet. Neben der Stabilität der bäuerlichen Höfe, die zumindest seit dem 16. Jahrhundert bestand, und einer weitgehenden Stabilität der Besitzstrukturen trat schließlich auch die Stabilität der Familien, die auf diesen Häusern saßen. Diese Stabilität war jedoch das Ergebnis einer Beweglichkeit der Menschen in ihrem Alltag. ${ }^{16}$ Die Menschen erreichten diese Stabilität erst dadurch, dass sie ihre Netzwerke umbauten., Verwandtschaft ${ }^{\prime}$ wurde erst allmählich zu einem wichtigen sozialen Faktor. Die Entwicklung hin zu einem stärker von Familie und Verwandtschaft geprägten Muster der Besitzweitergabe hatte außerdem gravierende Auswirkungen auf die Lebenswege der,weichenden' Geschwister. Zwar blieben die Heiratschancen der ,weichenden' Geschwister in allen Phasen des Untersuchungszeitraums gewahrt; im 17. Jahrhundert gelang es diesen allerdings noch recht häufig, selbst zu Haus- oder Grundbesitz zu kommen, während dies im späten 18. Jahrhundert zunehmend verunmöglicht wurde. Da immer mehr Anwesen nur mehr innerhalb der Familie weiterverkauft wurden, verblieben nun viele ,weichende' Geschwister zeitlebens im Inwohner-Status. Diese soziale Position verwandelte sich so von einer ursprünglich lebenszyklischen Phase in eine lebenslange Stellung.

Neben den Merkmalen einer Stabilität gab es allerdings auch viele Faktoren des Wandels. Ein deutlicher Anstieg der Einwohnerzahl - getragen fast ausschließlich von einem Wachstum der landarmen und landlosen Bevölkerungsgruppen - war trotz der in der Region vorherrschenden Rigidität einer ,starren Agrarverfassung.

14 Brunner, Haus.

15 Trossbach, Haus, 310, 314.

16 Schnyder, Unterschiede, 165. 
möglich. Trotz der in der Pfarre strikt eingehaltenen ungeteilten Weitergabe allen Landbesitzes an eine Einzelperson, nahm die sozialstrukturelle Entwicklung in der Region nicht den angenommenen Verlauf. Nicht eine stark polarisierte Gesellschaft mit einer kleinen, stabilen Zahl an großen Grundbesitzern einerseits und einer breiten Masse an völlig landlosen Häusern andererseits, ist zu Ende der Untersuchungsperiode zu konstatieren, sondern neben diesen Gruppen auch ein durchaus breit gefächertes Spektrum an landarmen Klein- und Kleinstbesitzern, deren Anzahl im Lauf der Zeit noch größer geworden war. Ursache dieser Entwicklung war die Tatsache, dass es in der Region neben der Besitzweitergabe von einer Generation zur nächsten verschiedene andere Möglichkeiten des Landerwerbs gab. In einzelnen Phasen fand etwa ein recht bedeutender Siedlungsausbau statt. In der heimgewerblichen Textilproduktion der Region ergab sich während des späten 18. Jahrhunderts eine zunehmende regionale Arbeitsteilung und Spezialisierung. Wer auf solche Einkommensmöglichkeiten angewiesen war, musste stärker als zuvor auch gewisse Kenntnisse und Fähigkeiten vorweisen. Stabilität und Wandel können einander aber nicht einfach als Gegenpole gegenübergestellt werden. Der Großteil der neu entstandenen landarmen Häuser wurde etwa immer wieder über die Pacht herrschaftlicher Gründe stärker in den agrarischen Kontext integriert.

Insgesamt ist der deutliche soziale Wandel in der Region keineswegs monokausal, sondern nur aus den spezifischen Konstellationen verschiedener aufeinandertreffender Faktoren zu erklären. Das im Zeitverlauf jeweils unterschiedliche Verhältnis von beharrenden wie dynamisierenden Kräften wurde immer gleichzeitig von lokalen Bedingungen wie von überlokalen und überregionalen Einflussfaktoren mitgeformt.

Die idealtypischen Annahmen über die vorindustriellen ,peasant societies' in Europa, wonach die Größe des von den einzelnen Familien besessenen Landes unveränderlich gewesen sei, ${ }^{17}$ trafen hier nicht zu. In der Verteilung der Grundgrößen in der Region gab es durchaus auch Elemente der Flexibilität: ein Kauf und Verkauf einzelner Parzellen kam öfter vor, vor allem sorgte die Pacht herrschaftlicher Zinsgereuter für tatsächliche Veränderungen im Ausmaß der durch die einzelnen Anwesen bewirtschafteten Flächen. Die untertänigen Besitzer hatten das Recht des freien Verkaufes, die Besitzweitergabe selbst war als Kauf konzipiert. Die Strategien der Menschen verhinderten aber, dass ein Landmarkt in der Pfarre tatsächlich zur Entfaltung kam. So ließe sich in Anlehnung an anthropologische Konzepte formulieren, dass es während der frühen Neuzeit zunehmend nicht der Markt war, sondern die verwandtschaftlichen Strukturen, die den Zugang zu

17 Vgl. Berkner/Mendels, Inheritance Systems, 212f. 
Land- und Hausbesitz vermittelten. ${ }^{18}$ Allerdings handelte es sich dabei nur um eine zunehmend stärker werdende Tendenz und zu keiner Zeit um ein ausschließliches Prinzip. Die Besitzweitergabe innerhalb von Familie und Verwandtschaft blieb immer nur eine Variante unter mehreren. Ein zu einem großen Teil über verwandtschaftliche Strukturen organisierter Markt - also ein vermeintlich vormodernes Muster - wird so aber als Begleiter der Modernisierung einer Agrargesellschaft sichtbar. ${ }^{19}$ Es wäre daher sicherlich sinnvoll, hinkünftig in sozialhistorischen Forschungen über die ländlichen Sozialstrukturen der frühen Neuzeit die in der sozialanthropologischen Literatur wesentlich weiter fortgeschrittenen Diskussionen über Verflechtungen und Interdependenzen von verwandtschaftlichen und sozialen Strukturen stärker als bisher zu rezipieren.

Für das Zustandekommen bestimmter Muster des Besitztransfers waren in der lokalen Gesellschaft gültige kulturelle Werte grundlegend. Die Haus- und Grundbesitzer des südlichen Böhmerwaldes verfolgten als einen dieser maßgebenden Werte zunächst einen Gleichheitsgedanken in Bezug auf die Ausstattung der Kinder. Alle Kinder sollten gleiche Anteile erhalten, allen sollte möglichst eine ausreichende Existenzbasis gesichert werden und alle sollten nach Möglichkeit heiraten können. Dagegen verlangte das Prinzip der ,guten Haushaltung, letztlich das des Fortbestandes der bäuerlichen Ökonomie, ein gewisses Maß an Flexibilität. Den Besitz in der männlichen Abstammungslinie zu halten, wurde offenkundig erst spät zu einem hohen Wert.

Insgesamt war diese vorindustrielle Gesellschaft überaus flexibel. Den Menschen der Region standen recht unterschiedliche Gestaltungsmöglichkeiten ihrer Lebenswege und ihres Umgangs mit Besitz offen. Heirat war hier nicht prinzipiell an den Selbstständigenstatus gebunden. Immer wieder kam es vor, dass noch im Elternhaus lebenden erwachsenen Kindern die Eheschließung erlaubt wurde. Einfache kausale Schlüsse vom vorherrschenden System des Besitztransfers auf andere soziale Faktoren - wie das Heiratsalter der Menschen, die Formen des familialen Zusammenlebens oder das Bevölkerungswachstum - können also nicht gezogen werden. Von Relevanz waren nicht so sehr die Normen der Besitzweitergabe, sondern vielmehr auch der „Gebrauch“, den die Menschen davon machten..$^{20}$ Ökonomische und demographische Veränderungen hatten aber einen hohen Einfluss auf die tatsächliche Gestaltung der Übergabe.

18 Die These, dass in den traditionalen außereuropäischen Gesellschaften der Zugang zur materiellen Basis und zu anderen Ressourcen über die Verwandtschaftsverhältnisse vermittelt wird, geht zurück auf Maurice Godelier, vgl. Groh, Godelier.

19 Vgl. Trossbach, Anthropologie, 204.

20 Schlumbohm, Lebensläufe, 259. 
Die Formen des Besitztransfers beeinflussten in dieser Region die demographische Entwicklung nicht in dem von den Klassikern der sozialhistorischen Theoriebildung angenommenen Sinne. Die Auswirkungen der in dieser Region herrschenden Praxis des Besitztransfers auf die sozialstrukturelle Entwicklung waren unterschiedlich. Die Unteilbarkeit der Güter führte dazu, dass die Zahl der Bauern im Zeitverlauf weitgehend stabil blieb. Ob die,weichenden' Kinder aus den bäuerlichen Familien dagegen neue Häuser errichten konnten, ob sie in den Inwohnerstand heirateten oder ob sie ledig blieben, hatte mit den Praktiken des Besitztransfers nur indirekt zu tun. Dass sie Anteile an der Kaufsumme erhielten, erleichterte zwar ihre Heiratsmöglichkeiten. Ob sie zu Land- oder Hausbesitz gelangten, hing jedoch auch von Faktoren ab, die außerhalb der Besitzweitergabestrategien der Familien lagen.

Schließlich ist festzuhalten, dass den unterschiedlichen Mustern des Besitztransfers nicht jene hohe Bedeutung für die soziale und demographische Entwicklung der frühmodernen Gesellschaften zukam, wie lange Zeit angenommen wurde. Der Grund dafür ist, dass die Besitztransfermuster nicht per se bestimmte Auswirkungen hatten, sondern immer erst in Verbindung mit den politischen, rechtlichen, ökonomischen Rahmenbedingungen und mit den von den handelnden Menschen präferierten Optionen und Reaktionsweisen bestimmte Folgewirkungen nach sich zogen. Die Zahl der unterschiedlichen Einflussfaktoren war also hoch. Monokausale Erklärungen, wie sie die ältere Literatur präsentierte, sind daher zurückzuweisen. 


\section{QUELLEN- UND LITERATURVERZEICHNIS}

\section{Gedruckte Quellen und Literatur}

Achilles, Landwirtschaft $=$ Walter Achilles, Landwirtschaft in der Frühneuzeit, München 1991.

Allmann, Wald = Joachim Allmann, Der Wald in der frühen Neuzeit. Eine mentalitäts- und sozialgeschichtliche Untersuchung am Beispiel des Pfälzer Raumes $1500-1800$, Berlin 1989.

Alter, New Perspectives = George Alter, New Perspectives on European Marriage in the Nineteenth Century, in: Journal of Family History 16 (1991), 1-5.

Ammerer, Vaganten $=$ Gerhard Ammerer,,$\ldots$ dem müssigen Vaganten Leben zugethann'-Betrachtungen zur nichtsesshaften Bevölkerung, in: Stephan Wendehorst/Siegrid Westphal (Hg.), Lesebuch Altes Reich, München 2006, 168-175.

Ammerer, Versorgung = Gerhard Ammerer, Zur Versorgung von alten, arbeitsunfähigen Personen auf dem Land - Überlegungen und Hinweise zu kommunalen Defiziten von Regionalbeamten und Betroffenen, in: Helmut Bräuer (Hg.), Arme - ohne Chance? Protokoll der internationalen Tagung „Kommunale Armut und Armutsbekämpfung vom Spätmittelalter bis zur Gegenwart" vom 23. bis 25. Oktober 2003 in Leipzig, Leipzig 2004, 159-189.

Anderegg, Verhältnisse = Felix Anderegg, Die landwirtschaftlichen Verhältnisse im Böhmerwalde, Wien 1893.

Anonymus, Graphitbergbau = Anonymus, Der Graphitbergbau in Mugrau, in: Waldheimat. Monatsschrift für Geschichte, Kunst, Landes- und Volkskunde des Böhmerwaldes 5 (1928), 88-92.

Ardelt, Edelbruck = Rudolf Ardelt, Das Dorf Edelbruck im Mühlviertel. Ein agrar- und sozialgeschichtlicher Beitrag zur Grundlagenforschung des Landes Oberösterreich (Beiträge zur Landeskunde von Oberösterreich, Historische Reihe I/1), Linz 1972.

Arrizabalaga, The Stem Family in the French Basque Country = Marie-Pierre Arrizabalaga, The Stem Family in the French Basque Country: Sare in the Nineteenth Century, in: Journal of Family History 22 (1997), 50-69.

Arrizabalaga, Female Primogeniture $=$ Marie-Pierre Arrizabalaga, Female Primogeniture in the French Basque Country, in: Emiko Ochiai (Hg.), The Logic 
of Female Succession: Rethinking Patriarchy and Patrilineality in Global and Historical Perspective, Kyoto 2002, 31-52.

Balling, Bergbau = Friedrich Balling, Zur Geschichte des ehemaligen und jetzigen Bergbaues auf Gold, Silber, Graphit und Eisenstein bei Krumau in Böhmen, in: Österreichische Zeitschrift für Berg- und Hüttenwesen 14 (1855), 105-108, 114-117.

Banck, Bevölkerungszahl = Rudolf Banck, Die Bevölkerungszahl der Stadt Köln in der zweiten Hälfte des 16. Jahrhunderts, in: Beiträge zur Geschichte vornehmlich Kölns und der Rheinlande. Festschrift für Ernst Mevissen, Köln 1895, 299-332.

Baud/Engelen, Introducion = Baud Michael/Theo Engelen, Introduction: Structure or Strategy? Essays on Family, Demography, and Labor, in: The History of the Family 2 (1997), 347-354.

Bavel van, Organization = Bas Van Bavel, The Organization and Rise of Land and Lease Markets in Northern Europe and Italy, c. 1000-1800, in: Continuity and Change 23,1 (2008), 13-53.

Bavel van/Hoppenbrouwers, Landholding = Bas J.P. Van Bavel/Peter Hoppenbrouwers, Landholding and Land Transfer in the North Sea Area (late Middle Ages-19th Century), in: Bas J.P. Van Bavel, Peter Hoppenbrouwers (Hg.), Landholding and Land Transfer in the North Sea Area (late Middle Ages 19th Century), Brepols 2004, 13-43.

Béaur, Land Transmission = Gérard Béaur, Land Transmission and Inheritance Practices in France during the Ancient Regime: Differences of Degree or Kind?, in: David R. Green/Alastair Owens (Hg.), Family Welfare. Gender, Property, and Inheritance since the Seventeenth Century, Westport CT 2004, 31-46.

Béaur/Schlumbohm, Einleitung = Gérard Béaur/Jürgen Schlumbohm, Einleitung: Probleme einer deutsch-französischen Geschichte ländlicher Gesellschaften, in: Reiner Prass/Jürgen Schlumbohm/Gérard Béaur/Christophe Duhamelle (Hg.), Ländliche Gesellschaften in Deutschland und Frankreich, 18.-19. Jahrhundert (Veröffentlichungen des Max-Planck-Instituts für Geschichte, Bd. 187), Göttingen 2003, 11-29.

Beck, Frauen = Rainer Beck, Frauen in Krise. Eheleben und Ehescheidung in der ländlichen Gesellschaft Bayerns während des Ancien regime, in: Richard van Dülmen (Hg.), Dynamik der Tradition, Frankfurt/M. 1992, 137-212.

Beck, Unterfinning = Rainer Beck, Unterfinning, Ländliche Welt vor Anbruch der Moderne, München 1993.

Beck, Handwerkliche Produktion = Rainer Beck, Handwerkliche Produktion und dörfliche Gesellschaft im 18. Jahrhundert - ein bayerisches Beispiel, in: Reinhold Reith (Hg.), Praxis der Arbeit. Probleme und Perspektiven der handwerksgeschichtlichen Forschung, Frankfurt/M. 1998, 147-186. 
Begemann, Lebensbedingungen = Ulrike Begemann, Bäuerliche Lebensbedingungen im Amt Blumenau (Fürstentum Calenberg), 1650-1850, Hannover 1990.

Berger, Bayer $=$ Adolf Berger, Emanuel Bayer. Nekrolog, in: Mittheilungen des Vereins für Geschichte der Deutschen in Böhmen 12 (1874), 167-176.

Berger, Wittingshausen = Adolf Berger, Wittingshausen, in: Mittheilungen des Vereins für Geschichte der Deutschen in Böhmen 13 (1875), 105-126 und 14 (1876), 47-69.

Berger, Leidensgeschichte $=$ Adolf Berger, Zur Leidensgeschichte des Böhmerwaldes, in: Mittheilungen des Vereins für Geschichte der Deutschen in Böhmen 19 (1881), 89-106.

Berkner, Stem Family = Lutz K. Berkner, The Stem Family and the Developmental Cycle of the Peasant Household: an Eighteenth-Century Austrian Example, in: American Historical Review 77 (1972), 398-418.

Berkner, Inheritance, Land Tenure and Peasant Family Structure = Lutz Berkner, Inheritance, Land Tenure and Peasant Family Structure: a German Regional Comparison, in: Jack Goody/Joan Thirsk/Edward P. Thompson (Hg.), Family and Inheritance: Rural Society in Western Europe 1200-1800, Cambridge 1976, 71-95.

Berkner, Use and Misuse = Lutz K. Berkner, Use and Misuse of Census Data for the Historical Analysis of Family Structure, in: Journal of Interdisciplinary History 5 (1975), 721-738.

Berkner, Social Structure = Lutz K. Berkner, Family, Social Structure and Rural Industry: A Comparative Study of the Waldviertel and the Pays de Caux in the Eighteenth Century, Phil. Diss., Cambridge (Mass.) 1973.

Berkner/Mendels, Inheritance Systems = Lutz Berkner/Franklin Mendels, Inheritance Systems, Family Structure and Demographic Patterns in Western Europe, 1700-1900, in: Charles Tilly (Hg.), Historical Studies of Changing Fertility, Princeton 1978, 209-224.

Bietenhard, Langnau $=$ Benedikt Bietenhard, Langnau im 18. Jahrhundert. Die Biographie einer ländlichen Kirchengemeinde im Bernischen Ancien Régime, Thun 1988.

Blau, Kreuz = Josef Blau, Kreuz und Kelch, in: Mittheilungen des Vereins für Geschichte der Deutschen in Böhmen 52 (1914), 238-262.

Blau, Böhmerwaldreise = Josef Blau, Eine Böhmerwaldreise vor hundert Jahren, in: Südböhmische Volkszeitung 12, Nr. 37 (1912), 1-4.

Blau, Hausindustrie (Bd. 1) = Josef Blau, Böhmerwälder Hausindustrie und Volkskunst, Bd. 1: Wald- und Holzarbeit, Prag 1917.

Blau, Hausindustrie (Bd.2) = Josef Blau, Böhmerwälder Hausindustrie und Volkskunst. 2. Teil: Frauen-Hauswerk und Volkskunst, Prag 1918. 
Blau, Glasmacher = Josef Blau, Die Glasmacher im Böhmer- und Bayerwald in Volkskunde und Kulturgeschichte. 2 Bände, Kallmünz 1954/56.

Blau, Viehweiden = Josef Blau, Viehweiden in alter und neuer Zeit, Prag (2. Aufl.) 1913.

Blau, Inmann = Josef Blau, Inmann und Bauer in den Ortschaften der Pfarre Rothenbaum, in: Zeitschrift für österreichische Volkskunde 6 (1900), 145-154.

Blau, Von Räubern = Josef Blau, Von Räubern, Wildschützen und anderen Waldkindern (Schriften zu Gunsten des Böhmerwaldmuseums in Oberplan 8), Oberplan 1928.

Blau, Freibauern = Josef Blau, Geschichte der künischen Freibauern im Böhmerwalde, Pilsen o. J. [1932].

Blickle, Grundherrschaft = Peter Blickle, Grundherrschaft, in: Friedrich Jäger (Hg.), Enzyklopädie der Neuzeit. Bd. 4, Stuttgart 2006, Sp. 1159-1166.

Blickle, Scharwerk = Renate Blickle, Scharwerk in Bayern. Fronarbeit und Untertänigkeit in der Frühen Neuzeit, in: Geschichte und Gesellschaft 17 (1991), 407-433.

Böser, Ortssippenbücher = Wolfgang Böser, Ortssippenbücher. Erschließung einer genealogischen Sekundärquelle für die Sozialgeschichte, in: Blätter für deutsche Landesgeschichte 121 (1985), 1-48.

Bohac, Strategies = Rodney D. Bohac, Peasant Inheritance Strategies in Russia, in: Journal of Interdisciplinary History 16 (1985), 23-42.

Bonnain, Houses = Rolande Bonnain, Houses, Heirs, and Non-Heirs in the Adour Valley: Social and Geographic Mobility in the Nineteenth-Century, in: The History of the Family 1 (1996), 273-295.

Borscheid, Industriearbeit $=$ Peter Borscheid, Industriearbeit und Alter im Wilhelminischen Deutschland, in: Zeitschrift für Gerontologie 19 (1986), 228-234.

Bourdieu, Boden = Pierre Bourdieu, Boden und Heiratsstrategien, in: Ders., Sozialer Sinn. Kritik der theoretischen Vernunft, Frankfurt/M. 1987, 264-287.

Brakensiek, Generationengerechtigkeit = Stefan Brakensiek, Generationengerechtigkeit. Normen und Praxis im Erb- und Ehegüterrecht 1500-1850. Eine Einführung, in: Ders./Michael Stolleis/Heide Wunder (Hg.), Generationengerechtigkeit. Normen und Praxis im Erb- und Ehegüterrecht 1500-1850 (=Zeitschrift für Historische Forschung, Beiheft 37), Berlin 2006, 1-21.

Brakensiek, Gemeinheitsteilungen = Stefan Brakensiek (Hg.), Gemeinheitsteilungen in Europa. Die Privatisierung der kollektiven Nutzung des Bodens im 18. und 19. Jahrhunderts (=Jahrbuch für Wirtschaftsgeschichte 2, 2000).

Brakensiek, Grund und Boden - eine Ware? = Stefan Brakensiek, Grund und Boden - eine Ware? Ein Markt zwischen familialen Strategien und herrschaftlichen Kontrollen, in: Reiner Prass/Jürgen Schlumbohm/Gerard Beaur/Christophe Du- 
hamelle (Hg.), Ländliche Gesellschaften in Deutschland und Frankreich, 18.-19. Jahrhundert, Göttingen 2003, 269-290.

Brakensiek, Agrarreformen = Stefan Brakensiek, Agrarreform und ländliche Gesellschaft. Die Privatisierung der Marken in Nordwestdeutschland 1750-1850. Paderborn 1991.

Bräuer, Altersarmut = Helmut Bräuer, Altersarmut, in: Friedrich Jäger, et al. (Hg.), Enzyklopädie der Neuzeit, Bd. 1, Stuttgart 2005, 263-266.

Bräuer, Bettler = Helmut Bräuer, Arbeitende Bettler? Bemerkungen zum frühneuzeitlichen Bettler-Begriff, in: Comparativ 6 (1993), 79-91.

Braun, Industrialisierung $=$ Rudolf Braun, Industrialisierung und Volksleben . Veränderungen der Lebensformen unter Einwirkung der verlagsindustriellen Heimarbeit in einem ländlichen Industriegebiet (Zürcher Oberland) vor 1800, Göttingen (2. Aufl.) 1979.

Brauneder, Erbrecht $=$ Wilhelm Brauneder, Erbrecht, in: Friedrich Jäger, et al. (Hg.), Enzyklopädie der Neuzeit, Bd. 3, Stuttgart/Weimar 2006, 413-415.

Breit, Leichtfertigkeit = Stephan Breit, „Leichtfertigkeit“ und ländliche Gesellschaft. Voreheliche Sexualität in der Frühen Neuzeit (Ancien Regime, Aufklärung und Revolution 23), München 1991.

Brennan/James/Morril, Inheritance $=$ Edward R. Brennan/A. V. James/W. T. Morril, Inheritance, Demographic Structure and Marriage: A Cross-Cultural Perspective, in: Journal of Family History 7 (1982), 289-298.

Brunner, Haus = Otto Brunner, Das "ganze Haus“ und die alteuropäische Ökonomik, in: Ders., Neue Wege der Verfassungs- und Sozialgeschichte, Göttingen (2., verm. Aufl.) 1968, 103-127.

Buquoy, Die Armen = Margarethe von Buquoy, Die Armen auf dem Lande im späten 18. und frühen 19. Jahrhundert, in: Bohemia 26 (1985), 37-78.

Buquoy, Grafen = Margarethe von Buquoy, Die Grafen von Buquoy - Aspekte ihrer Herrschaft, in: Heimatkundlicher Verein für Südböhmen (Hg.), Deutsche Kulturlandschaft an Moldau und Maltsch, München 1986, 45-69.

Bürger, Bäuerliche Liegenschaftsübertragung = Erhard Bürger, Bäuerliche Liegenschaftsübertragung und Vererbung im Gebiete der Tschechoslowakei, in: Max Sering/Constantin von Dietze (Hg.), Die Vererbung des ländlichen Grundbesitzes in der Nachkriegszeit. Band 2. München/Leipzig 1930, 109-58.

Bürger, Entwicklung = Josef Bürger, Die Entwicklung des Bauernhauses im Böhmerwald, Oberplan 1938.

Čánová/Horská/Maur, Les listes nominatives = Eliška Čáňová/Pavla Horská/Eduard Maur, Les listes nominatives de la Bohême source de donnees pour l'histoire sociale et la demographie historique, in: Annales de Demographie Historique 1987, 295-312. 
Čánová/Horská, Obyvatelstvo = Eliška Čánová/Pavla Horská, Obyvatelstvo obce Břevnova v církevních pramenech $\mathrm{z}$ let 1652-1800 [Die Bevölkerung der Gemeinde Břevnov in den kirchlichen Quellen der Jahre 1652-1800], in: Acta Universitatis Carolinae. Philosophica et historica 3 (1972), 81-100.

Čapek, Soupis obyvatel = Josef F. Čapek, Soupis obyvatel na panství Hluboká nad Vltavou z roku 1651 [Das Bevölkerungsverzeichnis der Herrschaft Hluboká nad Vltavou aus dem Jahre 1651], in: Výběr 16 (1979), 10-15.

Čechura, Struktur = Jaroslav Čechura, Struktur der Grundherrschaft im mittelalterlichen Böhmen, Göttingen 1994.

Čechura, Monastères cisterciens = Jaroslav Čechura, Les monastères cisterciens en Bohême du XIIe au XVe siècle, in: Les Cisterciens dans le Royaume médiéval de Bohême (=Cîteaux 47) 1996, 35-41.

Čechura, Nejstarší český urbář = Jaroslav Čechura, Nejstarší český urbář - urbář kláštera ve Vyšším Brodě z konce sedmdesátých let 13. století [Das älteste böhmische Urbar - das Urbar des Klosters Vyšší Brod aus den Siebzigerjahren des 13. Jahrhunderts], in: Právněhistorické studie 27 (1986), 5-26.

Čechura, Bauernschaft $=$ Jaroslav Čechura, Die Bauernschaft in Böhmen während des Spätmittelalters, in: Bohemia 31 (1990), 283-311.

Čechura, Cechy rožmberských $=$ Jaroslav Čechura, Cechy rožmberských měst a městeček do poloviny 16. století [Die Zünfte der Rosenberger Städte und Marktorte bis zur Mitte des 16. Jahrhunderts], in: Jihočeský sborník historický 58 (1989), 113-123.

Čechura, Rozvoj cechù = Jaroslav Čechura, Rozvoj cechù na rožmberském dominiu po roce 1550: textilní řemesla [Die Entwicklung der Zünfte im Rosenberger Dominium nach dem Jahr 1550], in: Jihočeský sborník historický 58 (1989), 177-185.

Cerman, Diss. $=$ Markus Cerman, Proto-Industrialisierung und Grundherrschaft. Unpubl. Phil. Diss., Wien 1996.

Cerman, Proto-Industrialisierung $=$ Markus Cerman, Proto-Industrialisierung und Grundherrschaft. Sozialstruktur, Feudalherrschaft und Textilgewerbe in Nordböhmen (15. bis 17. Jahrhundert), in: Dietrich Ebeling/Wolfgang Mager (Hg.), Protoindustrie in der Region. Europäische Gewerbelandschaften vom 16. bis 19. Jahrhundert, Bielefeld 1997, 157-198.

Cerman, Klassenstruktur $=$ Markus Cerman, Agrarische Klassenstruktur und sozioökonomische Entwicklung in Böhmen im 17. und 18. Jahrhundert, in: Thomas Winkelbauer (Hg.), Kontakte und Konflikte. Böhmen, Mähren und Österreich: Aspekte eines Jahrtausends gemeinsamer Geschichte, Horn 1993, 215-230.

Cerman, Gutsherrschaft vor dem ,Weißen Berg ${ }^{\star}=$ Markus Cerman, Gutsherrschaft 
vor dem ,Weißen Berg. Zur Verschärfung der Erbuntertänigkeit in Nordböhmen 1380 bis 1620, in: Jan Peters (Hg.), Gutsherrschaftsgesellschaften im europäischen Vergleich, Berlin 1997, 91-111.

Cerman, Gutsherrschaft und untertäniges Gewerbe $=$ Markus Cerman, Gutsherrschaft und untertäniges Gewerbe: die Herrschaften Frýdlant und Liberec in Nordböhmen, in: Jahrbücher für Geschichte Osteuropas 47 (1999), 2-19.

Cerman, Rural Economy = Markus Cerman, Rural Economy and Society, in: Peter Wilson (Hg.), A Companion to Eighteenth-Century Europe, Oxford 2008, 47-65.

Cerman, Bodenmärkte und ländliche Wirtschaft $=$ Markus Cerman, Bodenmärkte und ländliche Wirtschaft in vergleichender Sicht: England und das östliche Mitteleuropa im Spätmittelalter, in: Jahrbuch für Wirtschaftsgeschichte 2 (2004), 125-148.

Cerman, Soziale Differenzierung = Markus Cerman, Soziale Differenzierung, proto-industrielle Entwicklung und Gutsherrschaft in Frýdlant und Liberec, 16.-18. Jahrhundert, in: Markus Cerman/Hermann Zeitlhofer (Hg.), Soziale Strukturen in Böhmen. Ein regionaler Vergleich von Wirtschaft und Gesellschaft in Gutsherrschaften, 16. - 19. Jahrhundert. Wien 2002, 174-191.

Cerman, Bohemia $=$ Markus Cerman, Bohemia after the Thirty Years' War: Some Theses on Population Structure, Marriage and Family, in: Journal of Family History 19 (1994), 149-75.

Cerman, Ursprünge $=$ Markus Cerman, Mittelalterliche Ursprünge der unterbäuerlichen Schichten, in: Markus Cerman/Robert Luft (Hg.), Untertanen, Herrschaft und Staat in Böhmen und im ,Alten Reich'. Sozialgeschichtliche Perspektiven (Veröffentlichungen des Collegium Carolinum, 99), München: Oldenbourg 2005, 323-350.

Cerman, Mitteleuropa $=$ Markus Cerman, Mitteleuropa und die, europäischen Muster. Heiratsverhalten und Familienstruktur in Mitteleuropa, 16.-19. Jahrhundert, in: Josef Ehmer/Tamara Hareven/Richard Wall (Hg.), Historische Familienforschung. Ergebnisse und Kontroversen, Frankfurt/M./New York 1997, 327-346.

Cerman/Matušíková/Zeitlhofer, Rozbor = Markus Cerman/Lenka Matušíková/ Hermann Zeitlhofer, Rozbor pramenù s použitím počítače: projekt „Sociální struktury v Čechách" [Quellenanalyse mit Hilfe des Computers: das Projekt „Soziale Strukturen in Böhmen“], in: Archivní časopis 49 (1999), 107-128, 171-190.

Cerman/Maur/Zeitlhofer, Wirtschaft = Markus Cerman/Eduard Maur/Hermann Zeitlhofer, Wirtschaft, Sozialstruktur und Besitztransfer in frühneuzeitlichen gutsherrschaftlichen Gesellschaften in vergleichender Perspektive: Ergebnisse 
des Projekts „Soziale Strukturen in Böhmen“, in: Markus Cerman/Hermann Zeitlhofer (Hg.), Soziale Strukturen in Böhmen. Ein regionaler Vergleich von Wirtschaft und Gesellschaft in Gutsherrschaften, 16. - 19. Jahrhundert. Wien 2002, 262-285.

Cerman/Maur, Entwicklung = Markus Cerman/Eduard Maur, Die wirtschaftliche und soziale Entwicklung im frühneuzeitlichen Böhmen aus mikro- und makrohistorischer Sicht, in: Cerman/Zeitlhofer (Hg.), Soziale Strukturen in Böhmen, 101-110.

Cerman/Štefanová, Wirtschaft = Markus Cerman/Dana Štefanová, Wirtschaft und Sozialstruktur in den Herrschaften Frýdlant und Liberec 1590-1750, in: Cerman/Zeitlhofer (Hg.), Soziale Strukturen in Böhmen, 70-87.

Cerman/Zeitlhofer, Fragestellungen = Markus Cerman/Hermann Zeitlhofer, Fragestellungen, Zugangsweisen und Quellen des Forschungsprojekts „Soziale Strukturen in Böhmen“, in: Cerman/Zeitlhofer (Hg.), Soziale Strukturen in Böhmen, 9-14.

Cerman/Zeitlhofer, Soziale Strukturen = Markus Cerman/Hermann Zeitlhofer (Hg.), Soziale Strukturen in Böhmen. Ein regionaler Vergleich von Wirtschaft und Gesellschaft in Gutsherrschaften, 16. - 19. Jahrhundert, Wien 2002.

Chalupa, Tereziánský katastr český = Aleš Chalupa, et al. (Hg.), Tereziánský katastr český [Der böhmische Theresianische Kataster]. Rustikal. 2 Bde., Praha 1964; 1966.

Chocholač, Güterpreise = Bronislav Chocholač, Güterpreise, Verschuldung und Ratensystem. Eine Fallstudie zu den finanziellen Transaktionen der Untertanen bei Besitzübertragungen in Westmähren im späten 16. und im 17. Jahrhundert, in: Markus Cerman/Robert Luft (Hg.), Untertanen, Herrschaft und Staat in Böhmen und im ,Alten Reich‘. Sozialgeschichtliche Perspektiven (Veröffentlichungen des Collegium Carolinum, 99), München: Oldenbourg 2005, 89-125.

Chocholač, Selské peníze = Bronislav Chocholač, Selské peníze. Sonda do finančního hospodaření poddaných na západní Moravě koncem 16. a v 17. století [Bauerngeld. Eine Sonde in die Finanzwirtschaft der Untertanen in Westmähren zu Ende des 16. und im 17. Jahrhundert], Brno 1999.

Christiansen, Hofübernahme = Palle Ove Christiansen, Die vertrackte Hofübernahme. Zur gutsherrlichen Rekrutierung von Bauern in der ländlichen Gesellschaft des östlichen Dänemark im 18. Jahrhundert, in: Historische Anthropologie 3 (1995), 144-164.

Clarke, The ,Land-Family Bond" = David R. Clarke, The ,Land-Family Bond' in East Sussex, c. 1580-1770, in: Continuity and Change 21 (2006), 341-369.

Cole/Wolf, The Hidden Frontier = John Cole/Eric Wolf, The Hidden Frontier: Ecology and Ethnicity in an Alpine Valley, New York 1974. 
Cole/Wolf, Die unsichtbare Grenze $=$ John Cole/Eric Wolf, Die unsichtbare Grenze. Ethnizität und Ökologie in einem Alpental, Wien 1995.

Collins, Mobility = James B. Collins, Geographic and Social Mobility in Early Modern France, in: Journal of Social History 24 (1990/91), 562-577.

Conrad, Ruhestand $=$ Christoph Conrad, Die Entstehung des modernen Ruhestandes. Deutschland im internationalen Vergleich 1850-1960, in: Geschichte und Gesellschaft 14 (1988), 417-447.

Conrad, Incomes $=$ Christoph Conrad, Mixed Incomes for the Elderly Poor in Germany 1880-1930, in: Michael B. Katz/Christoph Sachße (Hg.), The Mixed Economy of Social Welfare. Public/Private Relations in England, Germany and the United States, the 1870's to the 1930's, Baden-Baden 1996, 340-367.

Crenshaw, Demographic Regime = Edward Crenshaw, The Demographic Regime of Western Europe in the Early Modern Period: a Review of Literature, in: Journal of Family History 14 (1989), 177-189.

Davis, Schenkende Gesellschaft $=$ Natalie Zemon Davis, Die schenkende Gesellschaft. Zur Kultur der französischen Renaissance, München 2002.

De Angelis, Winterberg = Günther Hrabe de Angelis, Winterberg im Böhmerwald: Sozialstruktur und Volksleben - Tradition und neue Wege, Marburg 1990.

Demleitner, Hofübergabe = Josef Demleitner, Hofübergabe und Heirat im Bayerischen Alpenvorland, in: Georg Schreiber (Hg.), Volk und Volkstum (= Jahrbuch für Volkskunde, Bd.3), München 1938, 54-67.

Derks, Faszination $=$ Hans Derks, Über die Faszination des ,Ganzen Hauses', in: Geschichte und Gesellschaft 22 (1996), 221-242.

Devos/Kennedy, Marriage = Isabelle Devos/Liam Kennedy (Hg.), Marriage and Economy. Western Europe since 1400 (Corn Publication Series 3). Turnhout 1999.

Dibelka, Migrace Cikánů = Jaroslav Dibelka, „Kde my se máme podít, když nemáme naši zem ?" Migrace Cikánů v raném novověku a jejich reflexe v očích okolí [Where Are We to Go if We Don't Have Our Own Country?" The Migration of Romany Gypsies in the Early Modern Age and How it Was Viewed in Their Surroundings], in: Eduard Maur/Josef Grulich (Hg.), Dějiny migrací v českých zemích v novověku (=Historicka Demografie 30, Supplement 2006), 189-203.

Dipper, Übergangsgesellschaft $=$ Christof Dipper, Übergangsgesellschaft. Die ländliche Sozialordnung in Mitteleuropa um 1800, in: Zeitschrift für Historische Forschung 23 (1996), 57-87.

Ditz, Property and Kinship = Toby Ditz, Property and Kinship: Inheritance in Early Connecticut 1750-1820, Princeton 1986. 
Dokupil, Gebietssterblichkeit = Lumír Dokupil, Zu neueren Ergebnissen des Gebietssterblichkeitsstudiums, in: Anthropologie 27 (1979), 83-86.

Dokupil/Fialová/Maur/Nesládková, Přirozená = Lumír Dokupil/Ludmila Fialová/ Eduard Maur/Ludmila Nesládková, Přirozená měna obyvatelstva Českých zemí v 17. a 18. Století [Bevölkerungsentwicklung in den böhmischen Ländern im 17. und 18. Jahrhundert], Praha 1999.

Dolzer, Stifter-Kreise = Petrus Dolzer, Aus dem Stifter-Kreise. Die Familie Greipl in Friedberg, in: Festschrift Staatsgymnasium Krumau, Krumau 1921, 59-63.

Dolzer, Friedberg = Petrus Dolzer, Geschichte und Geschichten um Friedberg, Friedberg 1935.

Donth, Rochlitz = Hans H. Donth, Rochlitz an der Isar und Harrasdorf in der Frühen Neuzeit (Veröffentlichungen des Collegium Carolinum, 65), München 1993.

Doskočil, Berni Rula = Karel Doskočil, Popis čech. v r. 1654. Souborní index obcí k berní rule [Das böhmische Volk im Jahr 1654], Praha 1953/54.

Dribe, Leaving Home = Martin Dribe, Leaving Home in a Peasant Society. Economic Fluctuations, Household Dynamics and Youth Migration in Southern Sweden, 1829-1866, Lund 2000.

Dribe/Lundh, Retirement $=$ Martin Dribe/Christer Lundh, Retirement as a Strategy for Land Transmission. A Micro-Study of Pre-Industrial Rural Sweden, in: Continuity and Change 20 (2005), 165-192.

Dudáček, Age Structure = Karel Dudáček, et al., On Using the 1661-1839 Lists of Subjects of the Třeboň Dominion to Study the Age Structure of the Population, in: Historická demografie 13 (1989), 59-124.

Duhamelle/Schlumbohm, Einleitung = Christophe Duhamelle/Jürgen Schlumbohm, Einleitung: Vom ,europäischen Heiratsmuster' zu Strategien der Eheschließung?, in: Christophe Duhamelle/Jürgen Schlumbohm (Hg.), Eheschließungen im Europa des 18. und 19. Jahrhunderts, Göttingen 2003, 11-33.

Duroux, The temporary Migration = Rose Duroux, The Temporary Migration of Males and the Power of Females in a Stem Family Society: the Case of Nineteenth Century Auvergne, in: The History of the Family 6 (2001), 33-50.

Duroux, Emigration, Gender, and Inheritance = Rose Duroux, Emigration, Gender, and Inheritance: a Case Study of the High Auvergne, 1700-1900, in: David R. Green/Alastair Owens (Hg.), Family Welfare: Gender, Property, and Inheritance since the Seventeenth Century, Westport CT 2004, 47-71.

Ebeling/Klein, System = Dietrich Ebeling/Peter Klein, Das soziale und demographische System der Ravensberger Protoindustrialisierung, in: Ernst Hinrichs/ Henk van Zon (Hg.), Bevölkerungsgeschichte im Vergleich. Studien zu den Niederlanden und Nordwestdeutschland, Aurich 1988, 27-48. 
Ehmer, Heiratsverhalten = Josef Ehmer, Heiratsverhalten, Sozialstruktur, ökonomischer Wandel. England und Mitteleuropa in der Formationsperiode des Kapitalismus, Göttingen 1991.

Ehmer, Marriage $=$ Josef Ehmer, Marriage, in: David Kertzer/Marzio Barbagli (Hg.), The History of the European family. Bd. 2. New Haven, u. a. 2002, 282321.

Ehmer, Migration und Bevölkerung = Josef Ehmer, Migration und Bevölkerung. Zur Kritik eines Erklärungsmodells, in: Tel Aviver Jahrbuch für deutsche Geschichte 27 (1998), 5-29.

Ehmer, Bevölkerungsgeschichte = Josef Ehmer, Eine ,deutsche‘ Bevölkerungsgeschichte?, in: Demographische Informationen 1992/93, 60-70.

Ehmer, Sozialgeschichte $=$ Josef Ehmer, Sozialgeschichte des Alters, Frankfurt/M. 1990.

Ehmer, House $=$ Josef Ehmer, House and the Stem family in Austria, in: Antoinette Fauve-Chamaux/Emiko Ochiai (Hg.), House and Stem family in Eurasian Perspective (=Proceedings of the 12th International Economic History Congress in Seville, 1998), Kyoto 1998, 46-64.

Ehmer, Life Stairs = Josef Ehmer, The „Life Stairs“: Aging, Generational Relations, and Small Commodity Production in Central Europe, in: Tamara Hareven (Hg.), Aging and Generational Relations over the Life Course, Berlin 1996, 53-74.

Ehmer, Tramping Artisans = Josef Ehmer, Tramping Artisans in Nineteenth-Century Vienna, in: David Siddle (Hg.), Migration, Mobility and Modernization, Liverpool 2000, 164-185.

Ehmer, Generationen = Josef Ehmer, Generationen in der historischen Forschung: Konzepte und Praktiken, in: Harald Künemund/Marc Szydlik (Hrsg.), Generationen. Multidisziplinäre Perspektiven. Wiesbaden 2009, 59-80.

Ehmer, Alter $=$ Josef Ehmer, Alter und Generationenbeziehungen im Spannungsfeld von öffentlichem und privatem Leben, in: Josef Ehmer/Peter Gutschner (Hg.), Das Alter im Spiel der Generationen. Historische und sozialwissenschaftliche Beiträge, Wien, u.a. 2000, 15-48.

Ehmer, Altersversorgung = Josef Ehmer, Altersversorgung, in: F. Jäger, et al. (Hg.), Enzyklopädie der Neuzeit, Bd. 1, Stuttgart/Weimar 2005, Sp. 272-282.

Ehmer, Demographie $=$ Josef Ehmer, Bevölkerungsgeschichte und Historische Demographie 1800-2000, München 2004.

Ehmer, Lohnarbeit $=$ Josef Ehmer, Lohnarbeit und Lebenszyklus im Kaiserreich, in: Geschichte und Gesellschaft 14 (1988), 448-471.

Ehmer, Ökonomische Transfers = Josef Ehmer, Ökonomische Transfers und emotionale Bindungen in den Generationenbeziehungen des 18. und 19. Jahrhun- 
derts, in: Martin Kohli/Marc Szydlik (Hg.), Gesellschaftliche Generationen, familiale Generationen, Opladen 2000, 77-96.

Enders, Besitzrechte $=$ Lieselott Enders, Bäuerliche Besitzrechte, in: Friedrich Jäger (Hrsg), Enzyklopädie der Neuzeit. Bd.1, Stuttgart 2005, Sp. 1025 - 1027.

Enders, Uckermark = Liselott Enders, Die Uckermark. Geschichte einer kurmärkischen Landschaft vom 12. bis zum 18. Jahrhundert, Weimar 1992.

Endres, Altersvorsorge $=$ Rudolf Endres, Bäuerliche Altersvorsorge, in: Heinrich R. Schmidt/André Holenstein/Andreas Würgler (Hg.), Gemeinde, Reformation und Widerstand, Tübingen 1998, 475-483.

Essl, Oberplan = Rupert Essl, Oberplan: der Geburtsort Adalbert Stifters, München 1993.

Essl, Krummau = Rupert Essl, Der Kreis Krummau an der Moldau, Unterhaching 1983.

Exner, Hausindustrie $=$ Wilhelm Franz Exner, Die Hausindustrie Österreichs $:$ Ein Commentar zur hausindustriellen Abtheilung auf der Allgemeinen Land- und Forstwirtschaftlichen Ausstellung, Wien 1890.

Faragó, Kinship = Tamás Faragó, Kinship in Rural Hungary during the Eighteenth Century: the Findings of a Case Study, in: The History of the Family 3 (1998), 315-331.

Fauve-Chamoux/Arrizabalaga, Family Transmission = Antoinette Fauve-Chamoux $/$ Marie-Pierre Arrizabalaga (Hg.), Family Transmission in Eurasian Perspective (= The History of the Family 10, 3), Bern 2005.

Fegert, ,Fürstenhütte' $=$ Friedemann Fegert, Die ,Fürstenhütte' und ,die Mauth' am ,Goldenen Steig. Glashütte und Waldhufen - Gründung am alten Handelsweg nach Böhmen. Ein Beitrag zur Siedlungs- und Wirtschaftsgeographie des Passauer Abteilandes, in: Ostbairische Grenzmarken 37 (1995), 103-149.

Fegert, Zwölfhäuser = Friedemann Fegert, Zwölfhäuser. Eine junge Rodungssiedlung am „Goldenen Steig“. Ein Beitrag zur Siedlungs- und Agrargeographie des Passauer Abteilandes, in: Ostbairische Grenzmarken 33 (1991), 89-122.

Feigl, Erbrecht $=$ Helmuth Feigl, Bäuerliches Erbrecht und Erbgewohnheiten in Niederösterreich, in: Jahrbuch für Landeskunde von Niederösterreich N.F. 37 (1967), 161-183.

Feigl, Heiratsbriefe $=$ Helmuth Feigl, Heiratsbriefe und Verlassenschaftsabhandlungen als Quelle zur Alltagsgeschichte, in: Othmar Pick1/Helmuth Feigl (Hg.), Methoden und Probleme der Alltagsforschung im Zeitalter des Barock, Wien 1992, 83-99.

Fertig, Marriage and Economy = Georg Fertig, Marriage and Economy in Rural Westphalia, 1750-1870: a Time Series and Cross-Sectional Analysis, in: Isa- 
belle Devos/Liam Kennedy (Hg.), Marriage and Rural Economy: Western Europe since 1400, Brepols 1999, 243-271.

Fertig, Autoregulation $=$ Georg Fertig, Demographische Autoregulation in vorindustriellen Bevölkerungen, in: Beiträge zur historischen Sozialkunde 30 (2000), 93-99.

Fertig, Äcker, Wirte, Gaben = Georg Fertig, Äcker, Wirte, Gaben. Ländlicher Bodenmarkt und liberale Eigentumsordnung im Westfalen des 19. Jahrhunderts (= Jahrbuch für Wirtschaftsgeschichte, Beiheft 11), Berlin 2007.

Fertig, Lokales Leben $=$ Georg Fertig, Lokales Leben, atlantische Welt: Die Entscheidung zur Auswanderung vom Rhein nach Nordamerika im 18. Jahrhundert (Studien zur Historischen Migrationsforschung 7), Osnabrück 2000.

Fertig, Heirat = Georg Fertig, Wenn zwey Menschen eine Stelle sehen': Heirat, Besitztransfer und Lebenslauf im ländlichen Westfalen des 19. Jahrhunderts', in: Christophe Duhamelle/Jürgen Schlumbohm (Hg.), Eheschließungen im Europa des 18. und 19. Jahrhunderts: Muster und Strategien (Veröffentlichungen des Max-Planck-Instituts für Geschichte 197), Göttingen 2003, 93124.

Fertig, Gemeinheitsteilungen $=$ Georg Fertig, Gemeinheitsteilungen in Löhne: Eine Fallstudie zur Sozial- und Umweltgeschichte Westphalens im 19. Jahrhundert, in: Karl Ditt/Rita Gudermann/Norwich Rüße (Hg.), Landwirtschaft und Umwelt in Westfalen vom 18. bis zum 20. Jahrhundert. Forschungen zur Regionalgeschichte, Paderborn 2001, 393-426.

Fertig, Hajnal Hypothesis = Georg Fertig, The Hajnal Hypothesis? Which Hajnal hypothesis?, in: Theo Engelen/Arthur P. Wolf (Hg.), Marriage and the Family in Eurasia: Perspectives on the Hajnal Hypothesis, Amsterdam 2005, 37-50.

Fertig/Fertig, Bäuerliche Erbpraxis = Christine Fertig/Georg Fertig, Bäuerliche Erbpraxis als Familienstrategie. Hofweitergabe im Westfalen des 18. und 19. Jahrhunderts“, in: Stefan Brakensiek/Michael Stolleis/Heide Wunder (Hg.), Generationengerechtigkeit. Normen und Praxis im Erb- und Ehegüterrecht 15001850 (=Zeitschrift für Historische Forschung, Beiheft 37), Berlin 2006, 163-187. Fertig, Hofübergabe $=$ Christine Fertig, Hofübergabe im Westfalen des 19. Jahrhunderts: Wendepunkt des bäuerlichen Familienzyklus?, in: Christophe Duhamelle/Jürgen Schlumbohm (Hg.), Eheschließungen im Europa des 18. und 19. Jahrhunderts. Muster und Strategien (Veröffentlichungen des Max-PlanckInstituts für Geschichte 197), Göttingen 2003, 65-92.

Fertig, Rural Society $=$ Christine Fertig, Rural Society and Social Networks in Nineteenth-Century Westphalia: The Role of Godparenting in Social Mobility, in: Journal of Interdisciplinary History 39 (2009), 497-522.

Fertig/Lünnemann/Fertig, Inheritance $=$ Christine Fertig/Volker Lünnemann/ 
Georg Fertig, Inheritance, Succession and Familial Transfer in Rural Westphalia, 1800-1900, in: The History of the Family 10 (2005), 309-326.

Fischer, Naturereignisse $=$ Franz Fischer, Von Naturereignissen, von Wetter und von Ernten, in: Waldheimat. Monatsschrift für Geschichte, Kunst, Landes- und Volkskunde des Böhmerwaldes 4 (1927), 6-7.

Fischer, Bevölkerung $=$ Wolfram Fischer, Bevölkerung und Wirtschaft in historischer Perspektive, in: Bernhard Felderer (Hg.), Bevölkerung und Wirtschaft (Schriften des Vereins für Socialpolitik, Gesellschaft für Wirtschafts- und Sozialwissenschaften, N. F. 202), Berlin 1990, 29-49.

Floßmann, Nochilinga = Gerhard Floßmann, 1000 Nochilinga 990-1998. Die Geschichte einer Region. Über die Gemeinden Dorfstetten, Nöchling, St. Oswald und Yspertal, Dorfstetten, u.a. 1998.

Friedeburg, Taglöhner = Robert von Friedeburg, Bauern und Taglöhner : Die Entwicklung gesellschaftlicher Polarisierung in Schwalm und Knüll im Gewand der traditionellen Dorfgemeinde, 1737-1855, in: Zeitschrift für Agrargeschichte und Agrarsoziologie 39 ( 1991), 44-68.

Friedeburg, Lebenswelt = Robert von Friedeburg, Lebenswelt und Kultur der unterständischen Schichten in der Frühen Neuzeit (Enzyklopädie deutscher Geschichte 62), München 2002.

Fröhlich, Glashütten = Jiř́ Fröhlich, Die Glashütten des östlichen Böhmerwaldes, in: Ostbairische Grenzmarken 37 (1994), 89-94.

Fügedi, Demographic Landscape $=$ Eric Fügedi, The Demographic Landscape of East-Central Europe, in: Antoni Mączak/Henryk Samsonowicz/Peter Burke (Hg.), East-Central Europe in Transition, Cambridge 1985, 47-58.

Gallistl, Heimatkunde $=$ Thomas Gallistl, Heimatkunde des politischen Bezirkes Krummau, Winterberg 1887.

Gaunt, Formen = David Gaunt, Formen der Altersversorgung in Bauernfamilien Nord- und Mitteleuropas in: Michael Mitterauer/Reinhard Sieder (Hg.), Historische Familienforschung, Frankfurt/M. 1982, 156-192.

Gaunt, Property = David Gaunt, The Property and Kin Relationships of Retired Farmers in Northern and Central Europe, in: Richard Wall/Jean Robin/Peter Laslett (Hg.), Family Forms in Historic Europe, Cambridge 1983, 249-279.

Gehrmann, Leezen = Rolf Gehrmann, Leezen 1720-1870. Ein historisch-demographischer Beitrag zur Sozialgeschichte des ländlichen Schleswig-Holstein, Neumünster 1984.

Gehrmann, Heiratsverhalten $=$ Rolf Gehrmann, Heiratsverhalten als historisches Problem, in: Historical Social Research 28 (2003), 8-28.

Gehrmann, Verhältnis = Rolf Gehrmann, Das Verhältnis von Bevölkerung und Ressourcen als Problem der demographischen Theorie und historischen For- 
schung, in: Karl Ditt/Rita Gudermann/Norwich Rüße (Hg.), Agrarmodernisierung und ökologische Folgen: Westfalen vom 18. bis zum 20. Jahrhundert, Paderborn 2001, 23-45.

Gerstorffer, Hintersassen $=$ Helga Gerstorffer, Die Stellung der Hintersassen auf geistlichen Grundherrschaften in Böhmen vom 12. bis zum 14. Jahrhundert, Phil. Diss., Wien 1935.

Gestrich, Geschichte = Andreas Gestrich, Geschichte der Familie im 19. und 20. Jahrhundert (Enzyklopädie deutscher Geschichte 50), München 1999.

Gestrich, Heirat $=$ Andreas Gestrich, Heirat, in: Friedrich Jäger (Hg.), Enzyklopädie der Neuzeit, Bd. 5 (Stuttgart 2007), Sp. 345-350.

Gestrich/Raphael, Inklusion/Exklusion = Andreas Gestrich/Lutz Raphael (Hg.), Inklusion/Exklusion. Studien zu Fremdheit und Armut von der Antike bis zur Gegenwart, Frankfurt/M. 2004.

Gestrich/King/Raphael, Being Poor $=$ Andreas Gestrich/Steven King/Lutz Raphael (Hg.), Being Poor in Modern Europe. Historical Perspectives 1800-1940, Oxford 2006.

Göckenjan, Alter = Gerd Göckenjan, Das Alter würdigen. Altersbilder und Bedeutungswandel des Alters, Frankfurt/M. 2000.

Göckenjan, Moralökonomien = Gerd Göckenjan, Moralökonomien und Statuspassagen. Einleitende Bemerkungen, in: Gerd Göckenjan (Hg.), Recht auf ein gesichertes Alter? Studien zur Geschichte der Alterssicherung in der Frühzeit der Sozialpolitik, Augsburg 1990, 1-13.

Godelier, Gabe = Maurice Godelier, Das Rätsel der Gabe. Geld, Geschenke, heilige Objekte, München 1999.

Goody, Strategies = Jack Goody, Strategies of Heirship, in: Comparative Studies in Society and History 15 (1973), 3-19.

Goody, Inheritance, Property, and Women = Jack Goody, Inheritance, Property, and Women: Some Comparative Considerations, in: Jack Goody/Joan Thirsk/E.P. Thompson (Hg.), Family and Inheritance: Rural Society in Western Europe 1200-1800, Cambridge 1976, 10-36.

Goody, Erbschaft = Jack Goody, Erbschaft, Eigentum und Frauen. Einige vergleichende Betrachtungen, in: Michael Mitterauer/Reinhard Sieder (Hg.), Historische Familienforschung, Frankfurt/M. 1982, 88-122.

Gottschalk, Eigentum = Karin Gottschalk, Eigentum, Geschlecht, Gerechtigkeit. Haushalten und Erben im frühneuzeitlichen Leipzig, Frankfurt/M./New York 2003.

Gottsmich, Zur Erhaltung = Severin Gottsmich, Zur Erhaltung und Erschließung der alten Kirchenbücher, in: Sudetendeutsche Familienforschung 10 (1937/38), 41-46. 
Gottsmich/Pils, Hohenfurt $=$ Severin Gottsmich/Dionys Pils, Hohenfurt. Stift Hohenfurt und seine Pfarreien, in: Cistercienser-Chronik 77 (1970), 11-44.

Grassby, Kinship and Capitalism = Richard Grassby, Kinship and Capitalism: Marriage, Family, and Business in the English-Speaking World, 1580-1740, New York/Washington, DC 2001.

Green/Owens, Introduction = David R.Green/A. Owens, Introduction: Family Welfare and Welfare Family, in: David R.Green/A. Owens (Hg.), Family Welfare. Gender, Property, and Inheritance since the Seventeenth Century, Westport CT 2004, 1-30.

Greipl, Böhmerwaldheimat = Fanny Greipl, Böhmerwaldheimat. Erinnerungen an Friedberg an der Moldau, Deining 1990.

Gritt, Good Land = Andrew Gritt, Making Good Land from Bad: the Drainage of West Lancashire, c. 1650-1850, in: Rural History 19, 1 (2008), 1-27.

Groh, Godelier = Dieter Groh, Maurice Godelier: Verwandtschaftsstrukturen, Religion und Politik als Elemente von Produktionsverhältnissen, in: Ders., Anthropologische Dimensionen der Geschichte, Frankfurt/M. 1992, 27-34.

Grulich, Aspekte = Josef Grulich, Zu ausgewählten Aspekten des Familien- und Lebenszyklus. Ein Beitrag zur Geschichte des südböhmischen Landes im 17. und 18. Jahrhundert am Beispiel der Herrschaft Chýnov, in: Historická demografie 20 (1996), 9-56.

Grulich, Ausgedinge = Josef Grulich, Das ländliche Ausgedinge in der Frühen Neuzeit. Ein Beitrag zur Problematik der Wahrnehmung sozialer Kategorien im 17. und 18. Jahrhundert, in: Dana Štefanová/Vaclav Bůžek (Hg.), MenschenHandlungen-Strukturen. Historisch-anthropologische Zugangsweisen in den Geschichtswissenschaften (Opera historica 9), České Budějovice 2001,343-369. Grulich, Migrationsstrategien = Josef Grulich, Migrations- und Erbschaftsstrategien der untertänigen Bevölkerung (Südböhmen, Ende des 16. bis 18. Jh.), in: Markus Cerman/Robert Luft (Hg.), Untertanen, Herrschaft und Staat in Böhmen und im ,Alten Reich', München 2005, 127-151.

Grulich, Populační = Josef Grulich, Populační vývoj a životní cyklus venkovského obyvatelstva na jihu Čech v 16. až 18. století [Die demographische Entwicklung und der Lebenszyklus der ländlichen Bevölkerung in Südböhmen vom 16. bis zum 18. Jahrhundert], České Budějovice 2008.

Grulich, Poddanská = Josef Grulich, Poddanská nemovitost a dědické pravo na Táborsku. Vřesecká rychta v letech 1625-1825 [Die Liegenschaften der Untertanen und das Erbrecht im Gebiet von Tábor. Das Gericht Vřesce in den Jahren 1625-1825], in: Jihočeský sborník historický 65 (1996), 34-41.

Grulich, Motivace migrací = Josef Grulich, Motivace migrací a mobility venkovského obyvatelstva na jihu Čech v 17.-18. století [Motive der Migration und 
Mobilität der ländlichen Bevölkerung in Südböhmen im 17. und 18. Jahrhundert], in: Opera Historica 12 (2007), 255-290.

Grulich/Zeitlhofer, Lebensformen = Josef Grulich/Hermann Zeitlhofer, Lebensformen und soziale Muster in Südböhmen im 16. und 17. Jahrhundert, in: Jihočeský sborník historický 66-67 (1997/98), 26-50.

Grulich/Zeitlhofer, Migrace $=$ Josef Grulich/Hermann Zeitlhofer, Migrace jihočeského obyvatelstva v období před třicetiletou válkou a po jejím ukončení [Migration in der südböhmischen Bevölkerung im Zeitalter vor dem Dreißigjährigen Krieg und nach seinem Ende], in: Historická demografie 22 (1998), 79-105.

Grüll, Matrikeln in Oberdonau = Georg Grüll, Die Matrikeln in Oberdonau, 2. Teil (angegliederte Gebiete von Böhmen), Linz 1940.

Grüll, Walde = Georg Grüll, Die Leute im Walde. Ein Beitrag zur Geschichte des Freiwaldes, in: Oberösterreichische Heimatblätter 1 (1947), 209-219.

Grüll, Pergkirchen $=$ Georg Grüll, Pergkirchen. Beiträge zur Geschichte eines Dorfes, in: Heimatgaue 11 (1930), 121-168.

Grüll, Bauernhaus = Georg Grüll, Bauernhaus und Meierhof. Zur Geschichte der Landwirtschaft in Oberösterreich, Linz 1975.

Grüll, Bauer = Georg Grüll, Der Bauer im Lande ob der Enns am Ausgang des 16. Jahrhunderts, Wien 1969.

Habakkuk, Family Structure and Economic Change = John Habakkuk, Family Structure and Economic Change in Nineteenth-Century Europe, in: Journal of Economic History 15 (1955), 1-12.

Haan, In the Shadow of the Tree $=$ Henk de Haan, In the Shadow of the Tree: Kinship, Property and Inheritance Among Farm Families, Amsterdam 1994.

Hackel, Besiedlungsverhältnisse = Alfred Hackel, Die Besiedlungsverhältnisse des oberen Mühlviertels, in: Forschungen zur deutschen Landes- und Volkskunde 14 (1902), 7-77.

Hahn, Frauen = Sylvia Hahn, Frauen im Alter - alte Frauen?, in: Josef Ehmer/ Peter Gutschner (Hg.), Alter im Spiel der Generationen. Historische und sozialwissenschaftliche Beiträge, Wien 2000, 156-189.

Hajnal, European Marriage Patterns = John Hajnal, European Marriage Patterns in Perspective, in: David V. Glass/David E. C. Eversley (Hg.), Population in History, Chicago 1965, 101-143.

Hajnal, Two Kinds=John Hajnal, Two Kinds of Pre-Industrial Household Formation Systems, in: Richard Wall/Jean Robin/Peter Laslett (Hg.), Family Forms in Historic Europe, Cambridge 1983, 65-104.

Hansert, Erbschaft = Andreas Hansert, Die Erbschaft im Kontext familiärer Generationenbeziehungen, in: Frank Lettke (Hg.), Erben und Vererben. Gestaltung und Regulation von Generationenbeziehungen, Konstanz 2003, 143-155. 
Harnisch, Gutsherrschaft = Hartmut Harnisch, Die Gutsherrschaft. Forschungsgeschichte, Entwicklungszusammenhänge und Strukturmerkmale, in : Jahrbuch für die Geschichte des Feudalismus 9 (1985), 189-240.

Harnisch, Ökonomie = Hartmut Harnisch, Bäuerliche Ökonomie und Mentalität unter den Bedingungen der ostelbischen Gutsherrschaft in den letzten Jahrzehnten vor Beginn der Agrarreformen, in: Georg Iggers (Hg.), Ein anderer historischer Blick. Beispiele ostdeutscher Sozialgeschichte, Frankfurt/M. 1991, 70-92.

Held, Ausgedinge $=$ Thomas Held, Ausgedinge und Ländliche Gesellschaft. Generationsverhältnisse im Österreich des 17. bis 19. Jahrhunderts, in: Christoph Conrad/Hans-Joachim Kondratowitz (Hg.), Gerontologie und Sozialgeschichte, Berlin 1983, 151-185.

Helm, Grenzgänge = Winfried Helm, Grenzgänge - Pohraniční styky, in: Martin Ortmeier (Hg.), Bauernhäuser in Südböhmen, Passau 1992, 80-87.

Henningsen, Besitz = Uta Henningsen, Besitz und Einkünfte der Herren von Rosenberg in Böhmen nach dem Urbar von 1379/84, Marburg/Lahn 1989.

Herlihy, Tod = David Herlihy, Der schwarze Tod und die Verwandlung Europas. Berlin 1998.

Himl, Vrchnost a venkované = Pavel Himl, Vrchnost a venkované v myšlené poddanské společnosti na českokrumlovském panstvi v 17. a 18. století [Obrigkeit und Untertanen im Denken der Untertanengesellschaft der Herrschaft Český Krumlov im 17. und 18. Jahrhundert], in: Opera Historica 5 (1996), 639-660.

Himl, Die ,armben Leüt“ = Pavel Himl, Die „armben Leüte“ und die Macht: die Untertanen der südböhmischen Herrschaft Český Krumlov/Krumau im Spannungsfeld zwischen Gemeinde, Obrigkeit und Kirche (1680-1781), Stuttgart 2003.

Himl, Amtstage = Pavel Himl, Amtstage, Feste, Gericht. Tradition und Wandel in den Beziehungen von Obrigkeit und Untertanen im frühneuzeitlichen Böhmen (Herrschaften Český Krumlov/Krumau und Jindřichův Hradec/Neuhaus im 17. und 18. Jahrhundert), in: AKA-Newsletter 25 (2009), 3-18.

Hippel, Auswanderung = Wolfgang von Hippel, Auswanderung aus Südwestdeutschland, Stuttgart 1984.

Hippel, Armut = Wolfgang von Hippel, Armut, Unterschichten, Randgruppen in der Frühen Neuzeit (Enzyklopädie deutscher Geschichte 34), München 1995.

Hirsch, Streifzug = Lorenz Hirsch, Ein Streifzug durch Brief- und Kaufprotokolle der Herrschaft Freistadt zu Haus, in: Heimatgau 15 (1934), 157-169.

Hochfürstlich Schwarzenberg'scher Schematismus = Hochfürstlich Schwarzenberg'scher Schematismus für das Jahr 1846, Wien 1846. 
Hoensch, Geschichte = Jörg Hoensch, Geschichte Böhmens. Von der slavischen Landnahme bis zur Gegenwart, München (3. Aufl.) 1997.

Hoffmann, Wirtschaftsgeschichte = Alfred Hoffmann, Wirtschaftsgeschichte des Landes Oberösterreich, Band 1, Salzburg 1952.

Hoffmann, Agrarisierung = Alfred Hoffmann, Die Agrarisierung der Industriebauern in Österreich, in: Zeitschrift für Agrargeschichte und Agrarsoziologie 20 (1972), 66-81.

Hohkamp, Wer will erben? = Michaela Hohkamp, Wer will erben?, in: Jan Peters (Hg.), Gutsherrschaft als soziales Modell, München 1995, 327-341.

Holenstein, Bauern = André Holenstein, Bauern zwischen Bauernkrieg und Dreißigjährigem Krieg, München 1996.

Horáček, Ausgedinge = Cyril Horáček, Das Ausgedinge. Eine agrarpolitische Studie mit besonderer Berücksichtigung der böhmischen Länder, in: Wiener Staatswissenschaftliche Studien 5 (1904), 1-96.

Horská, Index = Pavla Horská, Index břevnovských matrik z 2. pol. 17. a 18 století [Index der Matriken Břevnovs in der 2. Hälfte des 17. und im 18. Jahrhundert], in: Historická demografie 5 (1971), 61-75.

Horská, Strategie = Pavla Horská, Rodinná strategie ve vesnici Záblatí na třeboňském panství (1661-1820) [Familienstrategie im Dorf Záblatí in der Herrschaft Třeboň, 1661-1820], in: Historická demografie 17 (1993), 131-149.

Horský/Maur, Die Familie = Jan Horský/Eduard Maur, Die Familie, Familienstrukturen und Typologie der Familien in der böhmischen Historiographie, in: Historická demografie 17 (1993), 7-35.

Horský/Sedláčková/Seligová, Demographisches Regime = Jan Horský/Iva Sedláčková/Marketa Seligová, „Ein einheitliches altes demographisches Regime“ oder die Bindung eines demographischen Verhaltens zu Ökotypen?, in: Historická demografie 20 (1996), 57-91.

Horský/Sládek, Rodinné = Jan Horský/Miloš Sládek, Rodinné, socialní a demografické poměry v poddanských vsích na panství Třeboň v letech 1586 a 1651 [Familiale, soziale und demographische Verhältnisse in den untertänigen Dörfern der Herrschaft Třeboň in den Jahren 1586 und 1651], in: Historická demografie 17 (1993), 71-109.

Hroch/Petrán, Krise = Miroslav Hroch/Josef Petrán, Das 17. Jahrhundert. Krise der feudalen Gesellschaft?, Hamburg 1981.

Hroch/Petrán, Länder = Miroslav Hroch/Josef Petrán, Die Länder der böhmischen Krone 1350-1650, in: Wolfram Fischer et al. (Hg.), Handbuch der Europäischen Wirtschafts- und Sozialgeschichte, Band 3, Stuttgart 1986, 968-1005.

Huber-Sperl, Inleute $=$ Rita Huber-Sperl, ,Jeder Hof hat noch ein Inhäusel'. Zur Geschichte der vergessenen ländlichen Schicht der Inleute in Bayern 1650-150, 
in: Ingrid Böhler/Werner Matt/Hanno Platzgummer (Hg.), Unterschichten und Randgruppen. Forschungsberichte - Fachgespräche, Dornbirn 2001, 19-40. Hudson/King, Industrializing = Pat Hudson/Steven King, A Sense of Place: Industrializing Townships in Eighteenth Century Yorkshire, in: René Leboutte (Hg.), Proto-industrialisation. Recherches Récentes et Nouvelles Perspectives, Geneve 1996, 181-210.

Hufton, Poor $=$ Olwen Hufton, The Poor of Eighteenth-Century France 17501789, Oxford 1974.

Huyer, Holzschwemme = Reinhold Huyer, Die Holzschwemme auf der Moldau, in: Waldheimat. Monatsschrift für Geschichte, Kunst, Landes- und Volkskunde des Böhmerwaldes 5 (1928), 37-40.

Imhof, Familienstrukturen = Arthur E. Imhof, Ländliche Familienstrukturen an einem hessischen Beispiel: Heuchelheim 1690-1900, in: Werner Conze (Hg.), Sozialgeschichte der Familie in der Neuzeit Europas, Stuttgart 1976, 197-230.

Imhof, Wiederverheiratung = Arthur E. Imhof, Wiederverheiratung in Deutschland zwischen dem 16. und dem Beginn des 20. Jahrhunderts, in: Rudolf Lenz (Hg.), Studien zur deutschsprachigen Leichenpredigt in der frühen Neuzeit, Marburg 1981, 185-222.

Irsigler, Turmberg = Franz Irsigler, Rund um den Turmberg. Chronik der Pfarrgemeinde Malsching im Böhmerwald, Beilngries 1987.

Jahresbericht der Handelskammer Budweis = Jahresbericht der Handelskammer Budweis für das Jahr 1853, Budweis 1854.

Jantke/Hilger, Die Eigentumslosen = Carl Jantke/Dietrich Hilger (Hg.), Die Eigentumslosen. Der deutsche Pauperismus und die Emanzipationskrise in Darstellungen und Deutungen der zeitgenössischen Literatur, Freiburg 1965.

John, Beschreibung $=$ Josef John, Statistische und topographische Beschreibung der fürstlich Schwarzenberg'schen Herrschaft Winterberg, Prag 1870.

Johnson, Historical Readings = Paul A. Johnson, Historical Readings of Old Age and Ageing, in: Paul Johnson/Pat Thane (Hg.), Old Age from Antiquity to Post-Modernity, London, u.a. 1998, 1-18.

Johnson, Workers = Paul A. Johnson, et al. (Hg.), Workers versus Pensioners. Intergenerational Justice in an Ageing World, Manchester 1989.

Johnson, Employment = Paul A. Johnson, The Employment and Retirement of Older Men in England and Wales, 1881-1981, in: Economic History Review 47 (1994), 106-128.

Jungwirth, Familienstrukturen $=$ Rudolf Jungwirth, Ländliche Familienstrukturen im 19. Jahrhundert am Beispiel einer oberösterreichischen Pfarrgemeinde. Unveröffentl. Hausarbeit Univ. Wien 1983. 
Kaak, Gutsherrschaft = Heinrich Kaak, Die Gutsherrschaft. Theoriegeschichtliche Untersuchungen zum Agrarwesen im ostelbischen Raum, Berlin 1991.

Kahle, Hausindustrie = Richard Kahle, Über Hausindustrie und Heimarbeit in Deutschland und Österreich. Unveröffentl. Diss., Halle 1903.

Kaindl, Zisterzienserstift Hohenfurt = Dominik Kaindl, Geschichte des Zisterzienserstiftes Hohenfurt in Böhmen, Krumau 1930.

Kann/Zděnek, Peoples = Robert A. Kann/David Zděnek, The Peoples of the Eastern Habsburg Lands, 1526-1918, Seattle 1984.

Kaser, Macht = Karl Kaser, Macht und Erbe. Männerherrschaft, Besitz und Familie im östlichen Europa (1500-1900), Wien 2000.

Kennedy, Farm Succession = Liam Kennedy, Farm Succession in Modern Ireland: Elements of a Theory of Inheritance, in: Economic History Review 44 (1991), 477-499.

Kaschuba/Lipp, Überleben = Wolfgang Kaschuba/Carola Lipp, Dörfliches Überleben. Zur Geschichte materieller und sozialer Reproduktion ländlicher Gesellschaft im 19. und frühen 20. Jahrhundert, Tübingen 1982.

Khera, Stratification = Sigrid Khera, Social Stratification and Land Inheritance among Austrian Peasants, in: American Anthropologist 75 (1973), 814-823.

Kienitz, Frauen $=$ Sabine Kienitz, Frauen zwischen Not und Normen. Zur Lebensweise vagierender Frauen um 1800 in Württemberg, in: Österreichische Zeitschrift für Geschichtswissenschaften 2 (1991), 34-58.

Kienzl, Geschichte = Othmar Kienzl (Hg.), Geschichte des Gerichtes Kaltenbrunn, [Graz] 1960.

Klášterská, Forma = Alice Klášterská, Forma sociálního zabezpečení na vesnici $\mathrm{v}$ 18. a v první polovině 19. století [Formen sozialer Absicherung in den Dörfern im 18. und in der ersten Hälfte des 19. Jahrhunderts], in: Historická demografie 21 (1997), 95-132.

Kleinhanns, Leinenweberei $=$ Günter Kleinhanns, Die geschichtliche Entwicklung der Mühlviertler Leinenweberei, in: Mühlviertler Heimatblätter 27 (1987), 3-13.

Klíma, Probleme $=$ Arnošt Klíma, Probleme der Leibeigenschaft in Böhmen, in: Vierteljahrsschrift für Sozial- und Wirtschaftsgeschichte 62 (1975), 214-228.

Klíma, Economy = Arnošt Klíma, Economy, Industry and Society in Bohemia in the 17th and 19th Centuries, Prag 1991.

Klima, Länder = Arnošt Klíma, Die Länder der böhmischen Krone 1648-1850, in: Wolfram Fischer et al. (Hg.), Handbuch der europäischen Wirtschafts- und Sozialgeschichte, Bd. 4, Stuttgart 1993, 688-719.

Klíma, Class Structure $=$ Arnošt Klíma, Agrarian Class Structure and Economic Development in Pre-industrial Bohemia, in: T. H. Ashton/C. Philpin (Hg.), The Brenner Debate, Cambridge 1988, 192-212. 
Knittler, Pferd oder Ochse = Herbert Knittler, Pferd und Ochse. Spanntiergrenzen in Niederösterreich um 1800, in: Jahrbuch für Landeskunde von Niederösterreich, N.F. 59 (1993), 147-164.

Knodel, Ortssippenbücher $=$ John Knodel, Ortssippenbücher als Quelle für die Historische Demographie, in: Geschichte und Gesellschaft 1 (1975), 288-324.

Knodel/Shorter, The Reliability = John Knodel/Edward Shorter, The Reliability of Family Reconstitution Data in German Genealogies (Ortssippenbücher), in: Annales de Démographie Historique 1976, 115-154.

Koch, Holzindustrien = Julius Koch, Kleine Holzindustrien in Südböhmen, in: Österreichische Monatsschrift für Forstwirtschaft 18 (1868), 446-487.

Köferl, Tachau = Josef Köferl, Der politische Bezirk Tachau, Geretsried, Neuauflage 1985.

Köllmann, Bevölkerungsgeschichte $=$ Wolfgang Köllmann, Bevölkerungsgeschichte, in: Wolfgang Schieder/Volker Sellin (Hg.), Sozialgeschichte in Deutschland, Band 2, Göttingen 1986, 9-31.

Kogler, Ausgedinge $=$ Leopold Kogler, Das Ausgedinge vom 17. Jahrhundert bis zur Gegenwart. Analyse zweier Bauerngemeinden: Seitenstetten und St. Peter/ Au. Unpubl. Diss., 2 Bde., Wien 1983.

Kokošková/Sedláčková/Zahradníková, Soupis poddanych = Zdeňka Kokošková/ Helena Sedláčková/Magda Zahradníková (Hg.), Soupis poddanych podle víry z roku 1651, Bechyňsko [Verzeichnis der Untertanen nach dem Glauben im Jahre 1651, Bechiner Kreis]. 3 Bde., Praha 1997.

Komlosy, Industrie-Kultur = Andrea Komlosy (Hg.), Industrie-Kultur. Mühlviertel - Waldviertel - Südböhmen, Wien 1995.

Komlosy, Webwaarenindustrie = Andrea Komlosy, Wo der Webwaarenindustrie so viele fleißige und geübte Hände zu Gebote stehen'. Landfrauen zwischen bezahlter und unbezahlter Arbeit, in: Birgit Bolognese-Leuchtenmüller/Michael Mitterauer (Hg.), Frauen-Arbeitswelten (= Historische Sozialkunde 3), Wien 1993, 105-132.

Komlosy, Fluß = Andrea Komlosy, Der Fluß als Wirtschaftsfaktor - Mühlen, Sägen und Hammerwerke an der niederösterreichischen Lainsitz, in: Herbert Knittler/Andrea Komlosy (Hg.), Die Lainsitz. Natur- und Kulturgeschichte einer Region (Forschungen zur Landeskunde von Niederösterreich 28), St. Pölten 1997, 103-130.

Komlosy, Grenze $=$ Andrea Komlosy, Grenze und ungleiche regionale Entwicklung. Binnenmarkt und Migration in der Habsburgermonarchie, Wien 2003.

Komlosy, Fallbeispiel $=$ Andrea Komlosy, Zur Geschichte der Waldviertler Textilindustrie: Ein Fallbeispiel abhängiger Entwicklung, in: Helmuth Feigl, et al. 
(Hg.), Versuche und Ansätze zur Industrialisierung des Waldviertels. Vorträge und Diskussionen des elften Symposions des Niederösterreichischen Instituts für Landeskunde. Weitra, 6.-8. Juli 1987 (Studien und Forschungen aus dem NÖ. Institut für Landeskunde 12), Wien 1990, 299-329.

Kopczyński, Old Age = Michal Kopczyński, Old Age Gives No Joy? Old People in the Kujawy Countryside at the End of the Eighteenth Century, in: Acta Poloniae Historica 78 (1998), 81-101.

Kopsidis, Entwicklung = Michael Kopsidis, Die regionale Entwicklung der Produktion und der Wertschöpfung im westfälischen Agrarsektor zwischen 1822/35 und 1878/82. Ein komparativ-statischer Vergleich, in: Jahrbuch für Wirtschaftsgeschichte 1 (1995), 131-169.

Kopsidis, Leistungsfähigkeit $=$ Michael Kopsidis, Die Leistungsfähigkeit der west fälischen Landwirtschaft am Vorabend der Agrarreformen 1822/35 (im statistischen Vergleich von 79 Abschätzungsverbänden), in: Westfälische Forschungen 54 (2004), 307-377.

Kreiner, Wirtschaftsleben $=$ Karl Kreiner, Wirtschaftsleben im Bayerisch-Böhmischen Waldgebiete. Wirtschafts- und sozialstatistische Studien aus Bayerns nordöstlichen Gauen, Leipzig 1919.

Kretschmer/Piegler, Ausgedinge = Ingrid Kretschmer/Josef Piegler, Ausgedinge, in: Österreichischer Volkskundeatlas, Kommentar, 2. Lieferung, Graz 1965, $1-15$.

Kretschmer/Piegler, Erbrecht $=$ Ingrid Kretschmer/Josef Piegler, Bäuerliches Erbrecht, in: Österreichischer Volkskundeatlas, Kommentar, 2. Lieferung, Graz 1965, 1-18.

Kriedte, Spätfeudalismus = Peter Kriedte, Spätfeudalismus und Handelskapital. Grundlinien der europäischen Wirtschaftsgeschichte vom 16. bis zum Ausgang des 18. Jahrhunderts, Göttingen 1980.

Kriedte/Medick/Schlumbohm, Industrialisierung $=$ Peter Kriedte/Hans Medick/ Jürgen Schlumbohm, Industrialisierung vor der Industrialisierung. Gewerbliche Warenproduktion auf dem Land in der Formationsperiode des Kapitalismus, Göttingen 1977.

Kriedte/Medick/Schlumbohm, Sozialgeschichte $=$ Peter Kriedte $/$ Hans Medick/ Schlumbohm Jürgen, Sozialgeschichte in der Erweiterung - Protoindustrialisierung in der Verengung?, in: Geschichte und Gesellschaft 18 (1992), 70-77, 231-255.

Krinzinger, Glashütten $=$ Florian Krinzinger, Das Stift Schlägel und seine Glashütten, in: Heimatgaue 2 (1921), 209-226.

Kropaček et al., Encyklopedie = Jiří Kropaček et al (Hg.), Encyklopedie Českých Budějovice [Enzyklopädie von Budweis], České Budějovice 1998. 
Kubíková, Panstvi Vyšší Brod = Anna Kubíková, Panstvi Vyšší Brod a Zlata Koruna ve světle berní ruly [Die Herrschaften Vyšší Brod und Zlata Koruna im Lichte der Berní Rula], in: Jihočeský sborník historický 51 (1982), 199-209.

Kubitschek/Schmidt, Wallern = Rudolf Kubitschek/Valentin Schmidt, Wallern und die Wallerer, Budweis 1921.

Küpker, Weber = Markus Küpker, Weber, Hausierer, Hollandgänger. Demografischer und wirtschaftlicher Wandel im ländlichen Raum: Das Tecklenburger Land 1750-1870, Frankfurt/M. 2008.

Kuhn, Geschichte = Walter Kuhn, Geschichte der deutschen Ostsiedlung in der Neuzeit, 2 Bde., Köln/Graz 1955-57.

Kurrein, Rosenberg = Viktor Kurrein, Rosenberg, in: Ročenka společènosti pro dějiny židù v Československé republice [Jahrbuch der Gesellschaft für Geschichte der Juden in der Čechoslovakischen Republik] 2 (1930), 485-488.

Ladenbauer, Das Sociale Wirken = Willibald Ladenbauer, Das Sociale Wirken der katholischen Kirche in der Diöcese Budweis (Königreich Böhmen) (= Das Sociale Wirken der katholischen Kirche in Österreich 9), Wien 1899.

Lancinger, $\mathrm{K}$ otáce studia = Luboš Lancinger, $\mathrm{K}$ otáce studia cen městských domů v Čechach do konce 18. Století [Zur Frage des Studiums der Preise der Stadthäuser in Böhmen bis zum Ende des 18. Jahrhunderts], in: Acta Universitatis Carolinae. Philosophica et Historica 1 (1971), 15-121.

Landsteiner, Leben = Erich Landsteiner, Leben und Arbeiten auf dem Lande. Wirtschaftsweise und Haushaltsformen im vorindustriellen Österreich I, in: Ernst Bruckmüller (Hg.), Alltagserfahrungen in der Geschichte Österreichs (Schriften des Institutes für Österreichkunde 61), Wien 1998, 92-110.

Landsteiner, Demesne $=$ Erich Landsteiner, Demesne Lordship and the Early Modern State in Central Europe. The Struggle for Labour Rent in Lower Austria in the Second Half of the 16th Century (Paper presented at the World Economic History Conference Utrecht 2009).

Landsteiner/Weigl, Krieg und lokale Gesellschaft = Erich Landsteiner/Andreas Weigl, ,Sonst finden wir die Sachen sehr übel aufm Land beschaffen ...' Krieg und lokale Gesellschaft in Niederösterreich (1618-1621), in: Benigna von Krusenstjern/Hans Medick (Hg.), Zwischen Alltag und Katastrophe. Der Dreißigjährige Krieg aus der Nähe (Veröffentlichungen des Max-Planck-Instituts für Geschichte 148), Göttingen 1999, 229-271.

Landsteiner/Langthaler, Ökotypus = Erich Landsteiner/Ernst Langthaler, Ökotypus Weinbau: Taglöhner- oder Smallholder-Gesellschaft, in: Erich Landsteiner/Franz X. Eder/Peter Feldbauer (Hg.), Wiener Wege der Sozialgeschichte. Themen - Perspektiven - Vermittlungen, Wien, u.a. 1997, 183-224. 
Langbein, Soziale Praxis = Ulrike Langbein, Geerbte Dinge. Soziale Praxis und symbolische Bedeutung des Erbens, Köln 2002.

Langer-Ostrawsky, Generationenbeziehungen = Gertrude Langer-Ostrawsky, Generationenbeziehungen im Spiegel von Testamenten und Übergabeverträgen, in: Josef Ehmer/Peter Gutschner (Hg.), Das Alter im Spiel der Generationen. Historische und sozialwissenschaftliche Beiträge, Wien 2000, 259-282.

Langer-Ostrawsky/Lanzinger, Begünstigt - benachteiligt? = Gertrude LangerOstrawsky/Margareth Lanzinger, Begünstigt - benachteiligt? Frauen und Männer im Ehegüterrecht. Ein Vergleich auf der Grundlage von Heiratskontrakten aus zwei Herrschaften der Habsburgermonarchie im 18. Jahrhundert, in: Grethe Jakobsen, et al. (Hg.), Less Favoured - More Favoured (Proceedings from a Conference on Gender in European Legal History, 12th-19th Centuries, Copenhagen September 2004), Online-Publikation, Copenhagen, The Royal Library 2005.

Lanzinger, Das gesicherte Erbe = Margareth Lanzinger, Das gesicherte Erbe. Heirat in lokalen und familialen Kontexten. Innichen 1700-1900, Wien 2003.

Lanzinger, Generationengerechtigkeit $=$ Margareth Lanzinger, Generationengerechtigkeit mittels Vertrag. Besitz- und Vermögensregelungen zwischen Reziprozität und Unterordnung, Ausgleich und Begünstigung (zweite Hälfte 18. Jahrhundert), in: Stefan Brakensiek/Michael Stolleis/Heide Wunder (Hg.), Generationengerechtigkeit? Normen und Praxis im Erb- und Ehegüterrecht 1500-1850, Berlin 2006 (Beiheft 37 der Zeitschrift für Historische Forschung), 241-263.

Lanzinger/Saurer, Politiken = Margareth Lanzinger/Edith Saurer (Hg.), Politiken der Verwandtschaft. Beziehungsnetze, Geschlecht und Recht, Wien 2007.

Laslett/Wall, Household = Peter Laslett/Richard Wall (Hg.), Household and Family in Past Time, Cambridge 1972.

Lausecker, Skizzen $=$ F. [riedrich] Lausecker, Skizzen aus dem Böhmerwalde, in: Mittheilungen des Vereins für Geschichte der Deutschen in Böhmen 10 (1872), 61-66.

Lee/Campell, Succession = James Lee/Cameron Campbell, Headship Succession and Household Division in Three Chinese Banner Serf Populations, in: Continuity and Change 13 (1988), 117-131.

Lettke, Erben = Frank Lettke (Hg.), Erben und Vererben. Gestaltung und Regulation von Generationenbeziehungen, Konstanz 2003.

Lettke, Vererbungsabsichten $=$ Frank Lettke, Vererbungsabsichten in unterschied lichen Familienformen. Ein Beitrag zur Institutionalisierung generationaler Kontinuität, in: Frank Lettke/Andreas Lange (Hg.), Generationen und Familien, Frankfurt/M. 2007, 96-129. 
Levi, Das immaterielle Erbe = Giovanni Levi, Das immaterielle Erbe. Eine bäuerliche Welt an der Schwelle zur Moderne, Berlin 1986.

Liedl, Greiplähnl = Josef Liedl, Der Greiplähnl, in: Glaube und Heimat. Monatsschrift der heimatvertriebenen Böhmerwäldler, Freunde des Böhmerwaldes und des Böhmerwaldmuseums Passau 12,11 (1960), 445.

Linde, Proto-Industrialisierung = Hans Linde, Proto-Industrialisierung. Zur Justierung eines neuen Leitbegriffs der sozialgeschichtlichen Forschung, in: Geschichte und Gesellschaft 6 (1980), 103-124.

List, Die Ackerverfassung = Friedrich List, Die Ackerverfassung, die Zwergwirtschaft und die Auswanderung, in: Carl Jantke/Dietrich Hilger (Hg.), Die Eigentumslosen. Der deutsche Pauperismus und die Emanzipationskrise in Darstellungen und Deutungen der zeitgenössischen Literatur, Freiburg 1965, 112-124 [Nachdruck aus: Deutsche Vierteljahrsschrift 4 (1842), 119-163].

Lundh, Servant Migration = Christer Lundh, Servant Migration in Sweden in the Early Ninteenth Century, in: Journal of Family History 24 (1999), 53-74.

Lünnemann, Besitztransfer = Volker Lünnemann, Familialer Besitztransfer und Geschwisterbeziehungen in zwei westfälischen Gemeinden (19. Jahrhundert), in: Historical Social Research 30 (2005), 31-48.

Macfarlane, The Origins of English Individualism = Alan Macfarlane, The Origins of English Individualism: the Family, Property and Social Transition, Oxford 1978.

Mackenroth, Bevölkerungslehre = Gerhard Mackenroth, Bevölkerungslehre. Theorie, Soziologie und Statistik der Bevölkerung. Berlin 1953.

Märten, Heimatkunde = Johann Märten, Heimatkunde des Bezirkes Kaplitz, Kaplitz 1894.

Mager, Protoindustrialisierung = Wolfgang Mager, Protoindustrialisierung und agrarisch-heimgewerbliche Verflechtung in Ravensberg während der Frühen Neuzeit, in: Geschichte und Gesellschaft 8 (1982), 435-474.

Maisch, Unterhalt = Andreas Maisch, Notdürftiger Unterhalt und gehörige Schranken, Stuttgart 1992.

Mantl, Heirat = Elisabeth Mantl, Heirat als Privileg. Obrigkeitliche Heiratsbeschränkungen in Tirol und Vorarlberg 1820 bis 1920, Wien 1997.

Mardetschläger, Budweis = Franz Mardetschläger, Kurzgefaßte Geschichte des Bisthums und der Diöcese Budweis. Zur Jubiläumsfeier seines 100jährigen Bestehens, Budweis 1885 .

Marks, Leinengewerbe $=$ Alfred Marks, Das Leinengewerbe und der Leinenhandel im Lande ob der Enns von den Anfängen bis in die Zeit Maria Theresias, in: Jahrbuch des Oberösterreichischen Musealvereins 95 (1950), 169-286.

Markus, Oberplan = Jordan Kajetan Markus, Oberplan, Plan de monte Vitkonis, 
Horní Plana, Plan: Historische, topographische und biographische Schilderungen, Wien 1883.

Markus, St. Thomas-Wittingshausen = Jordan Kajetan Markus, St. Thomas-Wittingshausen, Krumau 1882.

Marschalk, Bevölkerungsgeschichte Deutschlands = Peter Marschalk, Bevölkerungsgeschichte Deutschlands im 19. und 20. Jahrhundert, Frankfurt/M. 1984.

Mathieu, Agrargeschichte = Jon Mathieu, Eine Agrargeschichte der inneren Alpen. Graubünden, Tessin, Wallis 1500-1800, Zürich 1992.

Mathieu, From Ecotypes to Sociotypes = Jon Mathieu, From Ecotypes to Sociotypes: Peasant Households and State-Building in the Alps, Sixteenth - Nineteenth Centuries, in: The History of the Family 5 (2000), 55-74.

Mattmüller, Landwirtschaft $=$ Markus Mattmüller, Die Landwirtschaft der schweizerischen Heimarbeiter im 18. Jahrhundert, in: Zeitschrift für Agrargeschichte und Agrarsoziologie 31 (1983), 41-56.

Matušíková, Entwicklung = Lenka Matušíková, Die Entwicklung der Wirtschaftsund Sozialstrukturen in der Herrschaft Poděbrady, in: Cerman/Zeitlhofer (Hg.), Soziale Strukturen, 59-69.

Matušíková/Pazderová, Alterszusammensetzung = Lenka Matušíková/Alena Pazderová, Alterszusammensetzung der Kinder im Verzeichnis nach dem Glauben vom Jahre 1651, in: Historická demografie 17 (1993), 53-63.

Maur, Erbrecht = Eduard Maur, Das bäuerliche Erbrecht und die Erbschaftspraxis in Böhmen im 16. bis 18. Jahrhundert, in: Historická demografie 20 (1996), 93-118.

Maur, Gutsherrschaft = Eduard Maur, Gutsherrschaft und „zweite Leibeigenschaft" in Böhmen: Studien zur Wirtschafts-, Sozial- und Bevölkerungsgeschichte (14.-18. Jahrhundert), Wien 2001.

Maur, $\mathrm{K}$ demografickým aspektům = Eduard Maur, K demografickým aspektům tzv. druhého nevolnictví [Zu den demographischen Aspekten der sog. zweiten Leibeigenschaft], in: Historická Demografie 8 (1983), 7-43.

Maur, Gesinde = Eduard Maur, Das Gesinde in Böhmen nach dem Soupis poddaných podle víry aus dem Jahre 1651, in: Markus Cerman/Hermann Zeitlhofer ( $\mathrm{Hg}$.), Soziale Strukturen in Böhmen: ein regionaler Vergleich von Wirtschaft und Gesellschaft in Gutsherrschaften, 16. - 19. Jahrhundert, Wien 2002, $111-125$.

Maur, Structure démographique = Eduard Maur, La structure démographique de la Bohême après la Guerre de trente ans, in: Historická demografie 7 (1974), 29-98.

Maur, Problémy demografické = Eduard Maur, Problémy demografické struktury 
Čech v polovině 17. Století [Probleme der demographischen Struktur Böhmens zur Mitte des 17. Jahrhunderts], in: Českoslovenksý Časopis Historický 19 (1971), 839-870.

Maur, Populační = Eduard Maur, Populační vývoj českých komorních panství po válce třicetileté [Die Bevölkerungsentwicklung auf den böhmischen Kammergütern bis zum Dreissigjährigen Krieg], in: Acta Universitatis Carolinae 3 (1972), 9-80.

Maur, Gesinde in Böhmen = Eduard Maur, Das Gesinde in Böhmen in der frühen Neuzeit, in: Antoinette Fauve-Chamoux/Ludmila Fialová (Hg.), Le phénomène de la domesticité en Europe, XVI ${ }^{\mathrm{e}}-\mathrm{XX}^{\mathrm{e}}$ siècles, Praha 1997, 75-94.

Maur/Grulich, Dějiny migrací = Eduard Maur/Josef Grulich (Hg.), Dějiny migrací v českých zemích v novověku [Migrationsgeschichte der böhmischen Länder in der Neuzeit] (= Historicka Demografie 30, Supplement), Praha 2006.

Mayer, Anerben- und Teilungssystem $=$ Wilhelm Mayer, Anerben- und Teilungssystem dargelegt an den zwei pfälzischen Gemeinden Gerhardsbrunn und Martinshöhe (= Wirtschafts- und Verwaltungsstudien mit besonderer Berücksichtigung Bayerns, Bd. 5), Leipzig 1899.

Medick, Weben $=$ Hans Medick, Weben und Überleben in Laichingen, 16501900. Lokalgeschichte als Allgemeine Geschichte (Veröffentlichungen des Max Planck Instituts für Geschichte 126), Göttingen 1996.

Medick, Mikro-Historie = Hans Medick, Mikro-Historie, in: Winfried Schulze (Hg.), Sozialgeschichte, Alltagsgeschichte, Mikro-Historie. Eine Diskussion, Göttingen 1994, 40-53.

Medick/Sabean, Interest and Emotion $=$ Hans Medick/David W. Sabean (Hg.), Interest and Emotion: Essays on the Study of Family and Kinship, Cambridge 1984.

Medick/Sabean, Emotionen $=$ Hans Medick/David Sabean, Emotionen und materielle Interessen in Familie und Verwandtschaft: Überlegungen zu neuen Wegen und Bereichen einer historischen und sozialanthropologischen Familienforschung, in: Dies. (Hg.), Emotionen und materielle Interessen. Sozialanthropologische und historische Beiträge zur Familienforschung (Veröffentlichungen des Max Planck Instituts für Geschichte 75), Göttingen 1984, 27-54.

Medick/Sabean, Einleitung $=$ Hans Medick/David W. Sabean, Einleitung, in: Dies. (Hg.), Emotionen und materielle Interessen. Sozialanthropologische und historische Beiträge zur Familienforschung (Veröffentlichungen des Max Planck Instituts für Geschichte 75), Göttingen 1984, 11-24.

Meinharter/Ofner, Produktionsformen = Thea Meinharter/Franz Ofner, Frühindustrielle Produktionsformen am Beispiel der Groß- Sieghartser Bandweberei, 
in: Andrea Komlosy (Hg.), Spinnen - Spulen - Weben. Leben und Arbeiten im Waldviertel und anderen ländlichen Textilregionen, Krems 1991, 91-107.

Melton, Gutsherrschaft = Edgar Melton, Gutsherrschaft in East Elbian Germany and Livonia 1500-1800: a Critique of the Model, in: Central European History 21 (1988), 315-349.

Miaskowski von, Das Erbrecht $=$ August von Miaskowski, Das Erbrecht und die Grundeigentumsverhältnisse im Deutschen Reich. 2 Bde., Leipzig 1882-1884.

Mičanová, Deutsche Urkunden = Blanka Mičanová, Deutsche Urkunden des 14.-15. Jahrhunderts aus dem Umkreis des Klosters Vyšší Brod. Unpubl. Dipl.Arbeit, Univ. České Budějovice 1988 (in deutscher Sprache).

Michel/Schusser/Paloušová, Kapličky = Milan Michel/František Schusser/Zdena Paloušová, Kapličky na Vyšebrodsku [Kapličky bei Vyššý Brod], Český Krumlov 2001.

Mikowec, Cisterzienserstift Hohenfurt $=$ Ferdinand Mikowec, Das Cisterzienserstift Hohenfurt in Böhmen. Eine monografische Skizze, Wien/Olmütz 1858.

Millauer, Viehzucht $=$ Maximilian Millauer, Viehzucht des 14. Jahrhunderts im Süden Böhmens, in: Hesperus. Encyclopädische Zeitschrift für gebildete Leser 26 (1820), Nr. 28, 223-224.

Mitson, The Significance of Kinship Networks = Anne Mitson, The Significance of Kinship Networks in the Seventeenth Century: South-West Nottinghamshire, in: Charles Phythian-Adams (Hg.), Societies, Cultures, and Kinship, 15801850: Cultural Provinces and English Local History, London 1996, $24-76$.

Mitterauer, Agrarrevolution = Michael Mitterauer, Auswirkungen der Agrarrevolution auf die bäuerliche Familienstruktur in Österreich, in: Ders./Reinhard Sieder, Historische Familienforschung, Frankfurt/M. 1982, 241-270.

Mitterauer, Auswirkung = Michael Mitterauer, Auswirkung von Urbanisierung und Frühindustrialisierung auf die Familienverfassung an Beispielen des österreichischen Raums, in: Werner Conze (Hg.), Sozialgeschichte der Familie in der Neuzeit Europas, Stuttgart 1976, 53-146.

Mitterauer, Formen $=$ Michael Mitterauer, Formen ländlicher Familienwirtschaft im österreichischen Raum. Historische Ökotypen und familiale Arbeitsteilung im österreichischen Raum, in: Josef Ehmer/Michael Mitterauer (Hg.), Familienstruktur und Arbeitsorganisation in ländlichen Gesellschaften, Wien, u.a. 1986, 185-323.

Mitterauer, Sozialgeschichte $=$ Michael Mitterauer, Sozialgeschichte der Jugend, Frankfurt/M. 1986.

Mitterauer, Familienstruktur $=$ Michael Mitterauer, Zur Familienstruktur in länd lichen Gebieten Österreichs, in: Heimold Helczmanovski (Hg.), Beiträge zur Bevölkerungs- und Sozialgeschichte Österreichs, Wien 1973, 167-222. 
Mitterauer, Vorindustrielle Familienformen $=$ Michael Mitterauer, Vorindustrielle Familienformen, in: Wiener Beiträge zur Geschichte der Neuzeit 2 (1975), 123-185.

Mitterauer, Familienformen $=$ Michael Mitterauer, Familienformen und Illegitimität in ländlichen Gebieten Österreichs, in: Archiv für Sozialgeschichte 19 (1979), 123-188.

Mitterauer, Arbeitsteilung = Michael Mitterauer, Familie und Arbeitsteilung. Historischvergleichende Studien, Wien 1992.

Mitterauer, Problemfelder = Michael Mitterauer, Problemfelder einer Sozialgeschichte des Alters, in: Helmut Konrad (Hg.), Der alte Mensch in der Geschichte, Wien 1982, 9-61.

Mitterauer, Roggen = Michael Mitterauer, Roggen, Reis und Rohrzucker. Drei Agrarrevolutionen des Mittelalters im Vergleich, in: Markus Cerman/llja Steffelbauer/ Sven Tost (Hg.), Agrarrevolutionen. Verhältnisse in der Landwirtschaft vom Neolithikum zur Globalisierung (Querschnitte 24), Innsbruck 2008, 152-172.

Mitterauer/Sieder, Patriarchat $=$ Michael Mitterauer/Reinhard Sieder, Vom Patriarchat zur Partnerschaft. Zum Strukturwandel der Familie, München 1977.

Moch, Family Strategy = Leslie Page Moch, u. a., Family Strategy: a Dialogue, in: Historical Methods 20 (1987), 113-125.

Moch, Moving Europeans = Leslie Page Moch, Moving Europeans: Migration in Western Europe since 1650, Bloomington 1992.

Mooser, Ländliche Klassengesellschaft = Josef Mooser, Ländliche Klassengesellschaft 1770-1848: Bauern und Unterschichten, Landwirtschaft und Gewerbe im östlichen Westfalen, Göttingen 1984.

Mooser, Soziale Mobilität $=$ Josef Mooser, Soziale Mobilität und familiale Plazierung bei Bauern und Unterschichten. Aspekte der Sozialstruktur der ländlichen Gesellschaft im 19. Jahrhundert am Beispiel des Kirchspiels Quernheim im östlichen Westfalen, in: Neithard Bulst/Joseph Goy/Jochen Hoock (Hg.), Familie zwischen Tradition und Moderne. Studien zur Geschichte der Familie in Deutschland und Frankreich vom 16. bis zum 20. Jahrhundert, Göttingen 1981, 182-200.

Moring, Family Strategies $=$ Beatrice Moring, Family Strategies, Inheritance Systems and the Care of the Elderly in Historical Perspective-Eastern and Western Finland, in: Historical Social Research 23 (1998), 67-82.

Moring, Retirement Contracts = Beatrice Moring, Nordic Retirement Contracts and the Economic Situation of Widows, in: Continuity and Change 21 (3), 2006, 383-418.

Münch, Lebensformen = Paul Münch, Lebensformen in der Frühen Neuzeit, 1500-1800, Berlin 1998. 
Mužík, Obyvatelstvo = Petr Mužík, Obyvatelstvo města Domažlic v letech 16311830 [Bevölkerung der Stadt Domažlice in den Jahren 1631-1830], in: Sborník archivních prací 36 (1986), 103-208.

Myška, Proto-Industrialisierung = Milan Myška, Proto-Industrialisierung in Böhmen, Mähren und Schlesien, in: Markus Cerman/Sheilagh Ogilvie (Hg.), Protoindustrialisierung in Europa, Wien 1994,177-191.

Nenning, Materialien = Kajetan Nenning, Materialien zu einer Topographie von Hohenfurth in Böhmen im Budweiser Kreis, in: Hesperus. Encyclopädische Zeitschrift für gebildete Leser 26 (1820), Nr. 20, 153-158.

Neschwara, Grundbuch = Christian Neschwara, Grundbuch, in: Friedrich Jäger (Hrsg), Enzyklopädie der Neuzeit 4, Stuttgart 2006, Sp. 1157-1159.

Neuber, Verhältnisse = Neuber, Gedrängte Übersicht der Verfassung herrschaftlicher Wirthschaftsämter und der Verhältnisse zwischen Obrigkeiten und Unterthanen in Österreich unter der Enns, im Vergleich zu Böhmen, Wien 1813.

Novotný, Rozmíštění = Karel Novotný, Rozmístění manufakturní výroby v Čechách kolem r. 1790 [Räumliche Verteilung der Manufakturproduktion in Böhmen um das Jahr 1790], in: Hospodářské dějiny 11 (1983), 5-94.

Ogilvie, Zur ökonomischen Welt der Untertanen in Böhmen = Sheilagh Ogilvie, Zur ökonomischen Welt der Untertanen in Böhmen: eine Fallstudie zur Herrschaft Friedlant, in: Markus Cerman/Hermann Zeitlhofer (Hg.), Soziale Strukturen in Böhmen: ein regionaler Vergleich von Wirtschaft und Gesellschaft in Gutsherrschaften, 16. - 19. Jahrhundert, Wien 2002, 145-173.

Ogilvie, Institutionen = Sheilagh Ogilvie, Soziale Institutionen, Korporatismus und Protoindustrie: Die Württembergische Zeugmacherei, 1580-1797, in: Dietrich Ebeling/Wolfgang Mager (Hg.), Protoindustrie in der Region. Europäische Gewerbelandschaften vom 16. bis 19. Jahrhundert, Bielefeld 1997, 105-138.

Ogilvie, Communities = Sheilagh Ogilvie, Communities and the, Second Serfdom in Early Modern Bohemia, in: Past and Present 187 (2005), 69-119.

Ogilvie/Edwards, Women = Sheilagh Ogilvie/Jeremy Edwards, Women and the ,Second Serfdom‘: Evidence from Early Modern Bohemia, in: Journal of Economic History 60 (2000), 961-94.

Ortmayr, ,Oarbeits ${ }^{6}=$ Norbert Ortmayr, ,Oarbeits, sunst kemts ins Quartier ${ }^{6}$ : Alter und Armut am Land im frühen 20. Jahrhundert, in: Helmut Konrad/Michael Mitterauer (Hg.), ,... und i sitz' jetzt allein': Geschichte mit und von alten Menschen, Wien 1987, 71-91.

Ortmeyer, Bauernhäuser = Martin Ortmeyer, Bauernhäuser in Südböhmen Jihočeská lidová architektura, Passau 1992.

Ostrawsky, Hausgemeinschaften = Gertrude Ostrawsky, Die Zusammensetzung 
der Hausgemeinschaften in der Pfarre Maria Langegg im Dunkelsteinerwald, 1788-1875, Unpubl. Diss., Univ. Wien 1979.

Ottaway, Elderly = Susannah R. Ottaway, The Elderly in Eighteenth-Century England, in: Continuity and Change 13 (1998), 391-418.

Palacký, Popis království Českého = František Palacký, Popis království Českého, čili podrobné poznamenání všech dosavadních krajů, panství, statků, měst, městeček, vesnic, někdejších hradů a tvrzí, též samot a zpustlých osad mnohých $\mathrm{v}$ zemi české s udáním jejich obyvatelstva dle popisu r. MDCCCXLIII [1843] vykonaného v jazyku českém i německém [Die Bevölkerung des Königreichs Böhmen, ...], Praha 1848.

Paleczek, Modernisierung = Raimund Paleczek, Modernisierung des Großgrundbesitzes des Fürsten Johann Adolph zu Schwarzenberg in Südböhmen während des Neoabsolutismus, München 2006.

Palla,Lexikon= Rudi Palla,Lexikonderuntergegangenen Berufe,Frankfurt/M.1998. Pavel, Gelehrte, Schriftsteller, Künstler = Raphael Pavel, Gelehrte, Schriftsteller, Künstler und Kunsthandwerker des Stiftes Hohenfurth, in: Xenia Bernardina 3 (Beiträge zur Geschichte der Cisterzienser-Stifte), Wien 1891, 346-371.

Pangerl, Urkundenbuch $=$ Mathias Pangerl, Urkundenbuch des Cistercienserstiftes B. Mariae V. zu Hohenfurt in Böhmen (= Fontes Rerum Austriacarum, 2. Abtheilung, 23. Band), Wien 1865.

Pangerl, Geschichte $=$ Mathias Pangerl, Zur Geschichte von Unterhaid und die Unterhaider Marktordnung, in: Mittheilungen des Vereins für Geschichte der Deutschen in Böhmen 12 (1874), 152-166.

Pangerl, Choden = Mathias Pangerl, Die Choden zu Taus, in: Mittheilungen des Vereins für Geschichte der Deutschen in Böhmen 13 (1875), 144-187, 215-250. Pazderová, Herrschaft = Alena Pazderová, Die wirtschaftliche und soziale Entwicklung in der Herrschaft Poděbrady, in: Markus Cerman/Hermann Zeitlhofer (Hg.), Soziale Strukturen in Böhmen: ein regionaler Vergleich von Wirtschaft und Gesellschaft in Gutsherrschaften, 16. - 19. Jahrhundert, Wien 2002, 43-58.

Peters, Gutsherrschaftsgesellschaften = Jan Peters (Hg.), Gutsherrschaftsgesellschaften im europäischen Vergleich, Berlin 1997.

Peters, Landarmut $=$ Jan Peters, Ostelbische Landarmut. Sozialökonomisches über landlose und landarme Agrarproduzenten im Spätfeudalismus, in: Jahrbuch für Wirtschaftsgeschichte 3 (1967), 255-302.

Peters, Gutsherrschaft $=$ Jan Peters (Hg.), Gutsherrschaft als soziales Modell, München 1995.

Petraň, Poddaný = Josef Petraň, Poddaný lid na prahu třicetileté války [Das untertänige Volk vor Beginn des Dreissigjährigen Krieges], Praha 1964. 
Pfister, Bevölkerungsgeschichte $=$ Christian Pfister, Bevölkerungsgeschichte und Historische Demographie, 1500-1800, München 1994.

Pfister, Household = Ulrich Pfister, The Proto-Industrial Household Economy: Toward a Formal Analysis, in: Journal of Family History 17 (1992), 201-232.

Pierenkemper, Ländliche Sozialstruktur = Toni Pierenkemper, Zur ländlichen Sozialstruktur Preußens an der Wende zum 19. Jahrhundert, in: Hans-Jürgen Gerhard (Hg.), Struktur und Dimension. Festschrift für Karl Heinrich Kaufhold zum 65. Geburtstag. Band 1: Mittelalter und Frühe Neuzeit (VSWG Beiheft 132), Stuttgart 1997, 298-323.

Placht, Lidnatost a společenská = Otto Placht, Lidnatost a společenská skladba Českého státu v 16.-18. století [Bevölkerung- und Gesellschaftsstruktur der böhmischen Länder im 16. bis 18. Jahrhundert], Praha 1957.

Plakans, Retirement $=$ Andrejs Plakans, Retirement, Inheritance, and Generational Relations: Life-Course Analysis in Historic Eastern Europe, in: Tamara Hareven (Hg.), Aging and Generational Relations over the Life Course, Berlin/New York 1996, 140-157.

Plakans, Kinship = Andrejs Plakans, Kinship in the Past. An Anthropology of European Family Life, 1500-1900, New York 1984.

Pohlmann, Industriegesellschaft $=$ Friedrich Pohlmann, Die europäische Industriegesellschaft. Voraussetzungen und Grundstrukturen, Stuttgart 1997.

Popkin, The Rational Peasant $=$ Samuel Popkin, The Rational Peasant: the Political Economy of Rural Society in Vietnam, Berkeley 1979.

Prass/Schlumbohm/Beaur/Duhamelle, Ländliche Gesellschaften in Deutschland = Reiner Prass/Jürgen Schlumbohm/Gerard Beaur/Christophe Duhamelle (Hg.), Ländliche Gesellschaften in Deutschland und Frankreich, 18. - 19. Jahrhundert, Göttingen 2003.

Praxl, Dreiländerberg = Paul Praxl, Der Dreiländerberg. Grenzland Bayern - Böhmen - Österreich, Graufenau 1979.

Praxl, Leinwandhandlung $=$ Paul Praxl, Die Leinwandhandlung Greipl in Friedberg, in: Heimatkundlicher Verein für Südböhmen (Hg.), Deutsche Kulturlandschaft an Moldau und Maltsch, München 1986, 407-412.

Praxl, Holzhäuser = Paul Praxl, Die Wallerer Holzhäuser, in: Ostbairische Grenzmarken 34 (1992), 143-156.

Procházka, Nemovitost $=$ Vladimír Procházka, Česká poddanská nemovitost v pozemkových knihách 16. a 17. století [Die tschechische Untertanenliegenschaft in den Grundbüchern des 16. und 17. Jahrhunderts], Praha 1963.

Proschko, Cistercienser-Stift Hohenfurth = Franz Isidor Proschko, Das Cistercienser-Stift Hohenfurth, Linz 1859. 
Pröll, Bauernhaus = Laurenz Pröll, Das Obermühlviertler Bauernhaus, Linz-Urfahr 1902.

Pröll, Schlägl = Carl Pröll, Geschichte des Prämonstratenser-Stiftes Schlägl, Linz 1877.

Prügl, Schläg1 = Josef Prügl, Schlägl im Josephinismus, 1763-1816. Das Stift Schlägl u. seine Pfarreien unter den Äbten Siard II. Dengler (1763-1797) u. Wilhelm II. Waldbauer (1798-1816). Ein Beitrag zur Geschichte des Josephinismus im Lande ob d. Enns, Schlägl 1978.

Psíková, Rodové katastry = Jiřina Psíková, Rodové katastry uložené ve Státním oblastním archivu v Třeboni [Die Familienkataster im staatlichen Gebietsarchiv in Wittingau], in: Historická demografie 8 (1983), 75-80.

Purš, Struktur und Dynamik = Jaroslav Purš, Struktur und Dynamik der industriellen Entwicklung in Böhmen im letzten Viertel des 18. Jahrhunderts, in: Jahrbuch für Wirtschaftsgeschichte 1 (1965), 160-196, 2 (1965), 103-124, Supplement.

Rank, Böhmerwald = Josef Rank, Aus dem Böhmerwalde und volkskundliche Beiträge aus Ranks übrigen Werken (Beiträge zur deutsch-böhmischen Volkskunde 13), Prag 1917.

Razi, The Erosion of the Family-Land Bond = Zvi Razi, The Erosion of the FamilyLand Bond in the Late Fourteenth and Fifteenth Centuries: a Methodological Note, in: Richard Smith (Hg.), Land, Kinship and Life-Cycle, Cambridge 1984, 295-304.

Razi, Myth = Zvi Razi, The Myth of the Immutable English Family, in: Past and Present 140 (1993), 3-44.

Reay, Kinship = Barry Reay, Kinship and the Neighborhood in Nineteenth-Century Rural England: The Myth of the Autonomous Nuclear Family, in: Journal of Family History 21 (1996), 87-104.

Rebel, Peasant Stem Families = Hermann Rebel, Peasant Stem Families in Early Modern Austria: Life Plans, Status Tactics, and the Grid of Inheritance, in: Social Science History 2 (1978), 255-291.

Rebel, Peasant Classes = Hermann Rebel, Peasant Classes. The Bureaucratization of Property and Family Relations under Early Habsburg Absolutism 15111636, Princeton 1983.

Reith, Das alte Handwerk = Reinhold Reith (Hg.), Das alte Handwerk. Von Bader bis Zinngießer, München 2008.

Répásová, Das Archiv des Zisterzienserstiftes Hohenfurt = Marie Répásová, Das Archiv des Zisterzienserstiftes Hohenfurt in Pflege des Staatlichen Gebietsarchivs in Třeboň 1950 - 1994, in: Annalecta Cisterciensia 52 (1996), $204-223$. 
Richter, Ausgedinge $=$ Stephan Richter, Das bäuerliche Ausgedinge und dessen Ersatz durch eine Altersrente, Prag 1891.

Robisheaux, Rural Society $=$ Thomas Robisheaux, Rural Society and the Search for Order in Early Modern Germany, Cambridge 1989.

Rödel, Statistik = Walter G. Rödel, „Statistik“ in vorstatistischer Zeit. Möglichkeiten und Probleme der Erforschung frühneuzeitlicher Populationen, in: Kurt Andermann/Hermann Ehmer (Hg.), Bevölkerungsstatistik an der Wende vom Mittelalter zur Neuzeit, Sigmaringen 1990, 9-25.

Rödel, Entwicklung = Walter Rödel, Die demographische Entwicklung in Deutschland 1770-1820, in: Helmut Berding/Etienne Francois/Hans-Peter Ullmann $(\mathrm{Hg})$, Deutschland und Frankreich im Zeitalter der Französischen Revolution, Frankfurt/M. 1989, 21-41.

Roeck, Bayern = Bernd Roeck, Bayern und der Dreißigjährige Krieg. Demographische, wirtschaftliche und soziale Auswirkungen am Beispiel Münchens, in: Geschichte und Gesellschaft 17 (1991), 435-58.

Rößler, Ausgedinge = Emil F. Rößler, Über das Ausgedinge auf Bauerngütern, Prag 1842.

Rouette, Erbrecht und Besitzweitergabe = Susanne Rouette, Erbrecht und Besitzweitergabe. Praktiken in der ländlichen Gesellschaft Deutschlands, Diskurse in Politik und Wissenschaft, in: Prass/Schlumbohm/Beaur/Duhamelle, Ländliche Gesellschaften in Deutschland, 145-166.

Rubner, Bevölkerung = Heinrich Rubner, Die Bevölkerung des Böhmerwaldes in der Neuzeit, in: Dieter Albrecht (Hg.), Festschrift für Max Spindler zum 75. Geburtstag, München 1969, 553-576.

Rumlová, Demografická = Eva Rumlová, Demografická a sociální struktura obyvatelstva panství Dymokury v polovině 17. stoleti [Demographische und soziale Strukturen der Bevölkerung der Herrschaft Dymokury in der Mitte des 17. Jahrhunderts], in: Historická demografie 17 (1993), 153-199.

Sabean, Property $=$ David W. Sabean, Property, Production and Family in Neckarhausen, 1700-1870, Cambridge 1990.

Sabean, Kinship = David W. Sabean, Kinship in Neckarhausen, 1700-1870, Cambridge 1998.

Sabean, Heiratsallianzen = David W. Sabean, Die Ästhetik der Heiratsallianzen. Klassencodes und endogame Eheschließungen im Bürgertum des 19. Jahrhunderts, in: Josef Ehmer/Tamara K. Hareven/Richard Wall (Hg.), Historische Familienforschung. Ergebnisse und Kontroversen, Frankfurt/M./New York 1997, 157-170.

Sachße/Tennstedt, Armenfürsorge $=$ Christoph Sachße/Florian Tennstedt (Hg.), Geschichte der Armenfürsorge in Deutschland. Vom Spätmittelalter bis zum Ersten Weltkrieg, Stuttgart 1980. 
Saitz, Krumau = A. Saitz, Beschreibung der Fürst Adolf Josef zu Schwarzenbergschen Domaine Krumau, Prag 1898.

Sandgruber, Leben und Lebensstandard $=$ Roman Sandgruber, Leben und Lebensstandard im Zeitalter des Barock - Quellen und Ergebnisse, in: Othmar Pickl/Helmuth Feigl (Hg.), Methoden und Probleme der Alltagsforschung im Zeitalter des Barock (Österreichische Akademie der Wissenschaften, Veröffentlichungen der Kommission für Wirtschafts-, Sozial- und Stadtgeschichte 5), Wien 1992, $171-189$.

Sandgruber, Gesindestuben = Roman Sandgruber, Gesindestuben, Kleinhäuser, in: Lutz Niethammer (Hg.), Wohnen im Wandel. Beiträge zur Geschichte des Alltags in der bürgerlichen Gesellschaft, Wuppertal 1979, 107-131.

Sandgruber, Kartoffeln = Roman Sandgruber, Die Einführung der Kartoffeln in Österreich. Sozialgeschichtliche und volkskundliche Interpretation, in: Ernst Hinrichs/Günter Wiegelmann (Hg.), Sozialer und kultureller Wandel in der ländlichen Welt des 18. Jahrhunderts (Wolfenbütteler Forschungen 19), Wolffenbüttel 1982, 163-194.

Sauermann, Hofidee und bäuerliche Familienverträge = Dietmar Sauermann, Hofidee und bäuerliche Familienverträge in Westfalen, in: Rheinisch-westfälische Zeitschrift für Volkskunde 17 (1970), 58-78.

Schacherl, Kienberg = Anton Schacherl, Kienberg, in: Waldheimat. Monatsschrift für Geschichte, Kunst, Landes- und Volkskunde des Böhmerwaldes 2 (1925), 5-10.

Schacherl, Flachsbau $=$ Anton Schacherl, Der Flachsbau und die Flachsverarbeitung im südlichen Böhmerwalde, in: Zeitschrift für österreichische Volkskunde 19 (1913), 105-117.

Schäfer, Übernahme = Alisa Schäfer, Übernahme und Altenteil. Unpubl. Diss. jur., Univ. Bonn 1994.

Schaller, Topographie $=$ Jaroslav Schaller, Topographie des Königreiches Böhmen, Teil 13, Prag 1789.

Scheufler, Flößerei $=$ Vladimír Scheufler, Leben am Fluß. Die Flößerei auf den Oberläufen der südböhmischen Flüsse, in: Andrea Komlosy/Václav Bůžek/ František Svátek (Hg.), Kulturen an der Grenze. Waldviertel - Weinviertel Südböhmen - Südmähren, Wien 1995, 166-170.

Schissler, Agrargesellschaft $=$ Hanna Schissler, Preußische Agrargesellschaft im Wandel. Wirtschaftliche, gesellschaftliche und politische Transformationsprozesse von 1763-1847, Göttingen 1978.

Schläger, Kalsching = Karl Schläger, Kalsching im Böhmerwald, Ellwangen 1977. Schlesinger, Dorfweisthümer = Ludwig Schlesinger, Deutschböhmische Dorfweisthümer, Teil 2, in: Mittheilungen des Vereins für Geschichte der Deutschen in Böhmen 22 (1884), 281-330. 
Schlögl, Bauern = Rudolf Schlögl, Bauern, Krieg und Staat. Oberbayerische Bauernwirtschaft und frühmoderner Staat im 17. Jahrhundert, Göttingen 1988.

Schlögl, Krise = Rudolf Schlögl, Zwischen Krieg und Krise, in: Zeitschrift für Agrargeschichte und Agrarsoziologie 40 (1992), 133-167.

Schluchter, Gösgeramt = André Schluchter, Das Gösgeramt im Ancien Regime, Basel 1990.

Schlumbohm, Familie $=$ Jürgen Schlumbohm, Familie, Verwandtschaft und soziale Ungleichheit: Der Wandel einer ländlichen Gesellschaft vom 17. zum 19.Jahrhundert, in: Rudolph Vierhaus u.a. (Hg.), Frühe Neuzeit - Frühe Moderne?, Göttingen 1992, 133-156.

Schlumbohm, Sozialstruktur = Jürgen Schlumbohm, Sozialstruktur und Fortpflanzung bei der ländlichen Bevölkerung Deutschlands im 18. und 19.Jahrhundert. Befunde und Erklärungsansätze zu schichtspezifischen Verhaltensweisen, in: Eckart Voland (Hg.), Fortpflanzung: Natur und Kultur im Wechselspiel. Versuch eines Dialogs zwischen Biologen und Sozialwissenschaftlern, Frankfurt/M. 1992, 322-346.

Schlumbohm, Lebensläufe = Jürgen Schlumbohm, Lebensläufe, Familien, Höfe. Die Bauern und Heuerleute des Osnabrückischen Kirchspiels Belm in protoindustrieller Zeit, 1650-1860, Göttingen 1994.

Schlumbohm, Micro-History and the Macro-Models = Jürgen Schlumbohm, Micro-History and the Macro-Models of the European Demographic System in Pre-Industrial Times, in: The History of the Family 1 (1996), 81-95.

Schlumbohm, The Land-Family Bond = Jürgen Schlumbohm, The Land-Family Bond in Peasant Practice and in Middle Class Ideology: Evidence from the North-West German Parish of Belm, 1650-1860, in: Central European History 27 (1994), 461-77.

Schlumbohm, Mächtige Mythen = Jürgen Schlumbohm, Mächtige Mythen und flexible Praktiken. Erbfolge und Stammfamilie in Deutschland, in: Marie Koldinská/Alice Velková (Hg.), Historik zapomenutých dějin. Sborník př́spěvků věnovaných prof. dr. Eduardu Maurovi [Ein Historiker der vernachlässigten Geschichte. Festschrift für Eduard Maur], Praha 2003, 162-180.

Schlumbohm, Fluctuations = Jürgen Schlumbohm, Seasonal Fluctuations and Social Division of Labour: Rural Linen Production in the Osnabrück and Bielefeld Regions and the Urban Woollen Industry in the Niederlausitz, c. 1770 - c. 1850, in: Maxine Berg, et al. (Hg.), Manufacture in Town and Country before the Factory, Cambridge 1983, 92-123.

Schmidt, Hofgröße = Georg Schmidt, Hofgröße - Familiengröße - Vererbungsgewohnheiten. Eine Fallstudie über fünf Familien, in: Arthur Imhof (Hg.), His- 
torische Demographie als Sozialgeschichte, Bd. 2, Darmstadt/Marburg 1975, 687-707.

Schmidt, Gutsübergabe und Ausgedinge = Karl Schmidt, Gutsübergabe und Ausgedinge. Eine agrarpolitische Untersuchung mit besonderer Berücksichtigung der Alpen- und Sudetenländer, Wien/Leipzig 1920.

Schmidt, Urbar = Valentin Schmidt, Das Urbar des Stiftes Hohenfurt aus dem Jahre 1530, in: Cistercienser-Chronik 8 (1896), 129-137, 161-175, 193-200, 237-245, 266-272, 296-305, 328-340.

Schmidt, Urbar Rosenberg = Valentin Schmidt, Das Urbar der Herrschaft Rosenberg von 1598, in: Mittheilungen des Vereins für Geschichte der Deutschen in Böhmen 35 (1897), 175-208, 273-304, 401-429.

Schmidt, Stritschitzer Sprachinsel = Valentin Schmidt, Geschichtliches von der Stritschitzer deutschen Sprachinsel, in: Mittheilungen des Vereins für Geschichte der Deutschen in Böhmen 34 (1896), 380-400.

Schmidt, Gegenreformation = Valentin Schmidt, Zur Geschichte der Gegenreformation in Südböhmen, in: Mittheilungen des Vereins für Geschichte der Deutschen in Böhmen 40 (1902), 407-430.

Schmidt, Siedlungs-Geschichte = Valentin Schmidt, Versuch einer Siedlungs-Geschichte des Böhmerwaldes (Schriften zu Gunsten des Böhmerwaldmuseums in Oberplan 2), Budweis o. J. [1922/23].

Schmidt, Brauwesen = Valentin Schmidt, Zur Geschichte des Brauwesens, in: Mittheilungen des Vereins für Geschichte der Deutschen in Böhmen 38 (1900), 6-51, 162-197, 287-336.

Schmidt, Agrar- und Colonisationsgeschichte = Valentin Schmidt, Beiträge zur Agrar- und Colonisationsgeschichte der Deutschen in Südböhmen. Teil 3, in: Mittheilungen des Vereins für Geschichte der Deutschen in Böhmen 35 (1897), 83-94.

Schmidt, Urkunden = Valentin Schmidt, Alte agrarische Urkunden, in: Mittheilungen des Vereins für Geschichte der Deutschen in Böhmen 52,1 (1913), 176-178. Schmidt, Zünfte = Valentin Schmidt, Die Zünfte auf dem Gebiet der Herren von Rosenberg, in: Mittheilungen des Vereins für Geschichte der Deutschen in Böhmen 42 (1904), 442-457.

Schnabel, Grundkräfte = G[eorg] N. Schnabel, Die Grundkräfte der böhmischen Gewerbsindustrie, in: Encyclopädische Zeitschrift des Gewerbewesens 5, Teil 2 (1845), 472-493.

Schnyder, Unterschiede = Albert Schnyder, „Feine Unterschiede“ auf dem Dorf. Zur Analyse der Sozialstruktur der ländlichen Gesellschaft im schweizerischen Kernland des Ancien Regime, in: Albert Tanner/Anne-Liese Head-König (Hg.), Die Bauern in der Geschichte der Schweiz, Zürich 1992, 159-167. 
Schnyder-Burghartz, Lebensformen $=$ Albert Schnyder-Burghartz, Alltag und Lebensformen auf der Basler Landschaft um 1700, Basel 1992.

Schöne, Kultur $=$ Bernd Schöne, Kultur und Lebensweise Lausitzer Bandweber 1750-1850, Berlin 1977.

Schöne, Posamentierer $=$ Bernd Schöne, Posamentierer - Strumpfwirker - Spitzenklöpplerinnen. Zur Lebensweise von Textilproduzenten im Erzgebirge und Vogtland, 1750-1850, in: Rudolf Weinhold (Hg.), Volksleben zwischen Zunft und Fabrik, Berlin/DDR 1982, 107-164.

Schofield, Family Structure $=$ Roger Schofield, Family Structure, Demographic Behaviour, and Economic Growth, in: John Walter/Roger Schofield (Hg.), Famine, Disease and the Social Order in Early Modern Society, Cambridge 1989, 279-304.

Schramek, Böhmerwald-Bauernhaus = Josef Schramek, Das Böhmerwald-Bauernhaus (Beiträge zur deutsch-böhmischen Volkskunde 9/1), Prag 1908.

Schramek, Böhmerwaldbauer $=$ Josef Schramek, Der Böhmerwaldbauer (Beiträge zur deutsch-böhmischen Volkskunde 12), Prag 1915.

Schreiber, Elbogner Kreis = Rudolf Schreiber, Der Elbogner Kreis und seine Enklaven nach dem Dreißigjährigen Kriege, Prag 1935.

Schreyer, Fabriken = Joseph A. Schreyer, Über Commerz, Fabriken und Manufakturen des Königreiches Böhmen, Bd. 1, Prag 1790.

Schusser, Papírny Vltavský mlýn = František Schusser, Papírny Vltavský mlýn Loučovice 1884-1984 [Papierfabrik Moldaumühl in Loučovice 1884-1984], Praha 1984.

Schusser, Pfarrei $=$ František Schusser, Untergegangene Pfarrei Kapličky $<$ http:// www.ckrumlov.cz/de/region/histor/t_zafaka.htm> (20.5.2010).

Schusser, Ofensetzer $=$ František Schusser, Ofensetzer in Vy̌ší Brod im 16. Jahrhundert <http://www.encyklopedie.ckrumlov.cz/docs/de/region_histor_vbkam. $\mathrm{xml}>$ (20.5.2010).

Schweitzer, Introduction = Peter P. Schweitzer, Introduction, in: Peter P. Schweitzer (Hg.), Dividends of Kinship. Meanings and Uses of Social Relatedness. London - New York 2000, 1-16.

Segalen, Die Familie = Martine Segalen, Die Familie: Geschichte, Soziologie, Anthropologie, Frankfurt/M. 1990.

Segalen, Geschwisterbeziehungen = Martine Segalen, „Sein Teil haben“: Geschwisterbeziehungen in einem egalitären Vererbungssystem, in: Hans Medick/ David Sabean (Hg.), Emotionen und materielle Interessen. Sozialanthropologische und historische Beiträge zur Familienforschung (Veröffentlichungen des Max Planck Instituts für Geschichte 75), Göttingen 1984, 181-198.

Seiser, On the Importance of Being the Last One = Gertrud Seiser, On the Impor- 
tance of Being The Last One: Inheritance and Marriage in an Austrian Peasant Community, in: Peter P. Schweitzer (Hg.), Dividends of Kinship. Meanings and Uses of Social Relatedness, London 2000, 92-123.

Sering, Vererbung = Max Sering, Die Vererbung des ländlichen Grundbesitzes in Preußen, Berlin 1897-1908.

Sieder, Sozialgeschichte $=$ Reinhard Sieder, Sozialgeschichte der Familie, Frankfurt/M. 1987.

Sieder/Mitterauer, The Reconstruction = Reinhard Sieder/Michael Mitterauer, The Reconstruction of the Family Life Course. Theoretical Problems and Empirical Results, in: Richard Wall/Jean Robin/Peter Laslett (Hg.), Family Forms in Historic Europe, Cambridge 1983, 309-345.

Šimeček, Obchod jižních = Zdeněk Šimeček, Obchod jižních Čech s rakousy v 2. polovinì 15. a na počátku 16. století [Der Handel Südböhmens mit Österreich in der 2. Hälfte des 15 . und in der 1. Hälfte des 16. Jahrhunderts], in: Českoslovenksý časopis historický 19 (1971), 683-710.

Slavik, Böhmens Beschreibung = Franz Slavik, Böhmens Beschreibung nach dem 30jährigen Krieg, in: Mitteilungen aus dem Landesarchive des Königreichs Böhmen 3 (1910), 20-133.

Sommer, Königreich Böhmen = Johann G. Sommer, Das Königreich Böhmen: statistisch-topographisch dargestellt, Bd. 9, Prag 1841.

Sreenivasan, The Land-Family Bond = Govind Sreenivasan, The Land-Family Bond at Earls Colne (Essex) 1550-1650, in: Past and Present 131 (1991), 3-37. Stamm, Forstwirtschaft $=$ Fernand Stamm, Verhältnisse der Volks-, Land- und Forstwirthschaft des Königreiches Böhmen, Prag 1856.

Stapleton, Family Strategies = Barry Stapleton, Family Strategies. Patterns of Inheritance in Odiham, Hampshire, 1525-1850, in: Continuity and Change 14 (1999), 385-402.

Stark, Ackerbau = Werner Stark, Der Ackerbau der böhmischen Gutswirtschaften im 17. und 18. Jahrhundert, in: Zeitschrift für Agrargeschichte und -soziologie 5 (1957), 20-41.

Stark, Niedergang = Werner Stark, Niedergang und Ende des landwirtschaftlichen Großbetriebs in den böhmischen Ländern, in: Jahrbücher für Nationalökonomie und Statistik 146 (1937), 416-449.

Stark, Abhängigkeitsverhältnisse = Werner Stark, Die Abhängigkeitsverhältnisse der gutsherrlichen Bauern Böhmens im 17. und 18. Jahrhundert, in: Jahrbücher für Nationalökonomie und Statistik 164 (1952), 270-292, 348-373, 440-453. Stark, Ursprung = Werner Stark, Ursprung und Aufstieg des landwirtschaftlichen Großbetriebes in den böhmischen Ländern, Brünn 1934.

Starý, Migration = Václav Starý, Die Migration von Einwohnern der südböhmi- 
schen Stadt Netolitz nach Österreich in der ersten Hälfte des 19. Jahrhunderts, in: Thomas Winkelbauer (Hg.), Kontakte und Konflikte. Böhmen, Mähren und Österreich: Aspekte eines Jahrtausends gemeinsamer Geschichte, Horn 1993, 301-304.

Statní Archiv v Třeboni = Statní Archiv v Třeboni (Hg.), Průvodce po archivních fondech [Führer durch die Archivfonds], Bd. 1, Praha 1957.

Štefanová, Ausgedinge = Dana Štefanová, Ausgedinge und Besitztransfer. Gerechtigkeit zwischen den Generationen? Das Beispiel der Herrschaft Frýdlant in Nordböhmen, 1558-1750, in: Stefan Brakensiek/Michael Stolleis/Heide Wunder (Hg.), Generationengerechtigkeit? Normen und Praxis im Erb- und Ehegüterrecht 1500-1850, Berlin 2006 (Zeitschrift für Historische Forschung, Beiheft 37), 219-240.

Štefanová, Erbschaftspraxis = Dana Štefanová, Erbschaftspraxis, Besitztransfer und Handlungsspielräume von Untertanen in der Gutsherrschaft. Die Herrschaft Frydlant in Nordböhmen, 1558-1750 (= Sozial- und wirtschaftshistorische Studien 34), Wien, München 2009.

Štefanová, Zur Stellung der Untertanen = Dana Štefanová, Zur Stellung der Untertanen in einer gutsherrschaftlichen Gesellschaft in der Frühen Neuzeit. Die Herrschaft Frýdlant 1558-1750, in: Markus Cerman/Hermann Zeitlhofer (Hg.), Soziale Strukturen in Böhmen. Ein regionaler Vergleich von Wirtschaft und Gesellschaft in Gutsherrschaften, 16. - 19. Jahrhundert, Wien 2002,206227.

Štefanová, Herrschaft und Untertanen = Dana Štefanová, Herrschaft und Untertanen. Ein Beitrag zur Existenz der rechtlichen Dorfautonomie in der Herrschaft Frýdlant in Nordböhmen (1650-1700), in: Jan Peters (Hg.), Gutsherrschaftsgesellschaften im europäischen Vergleich, Berlin 1997, 199-210.

Štefanová/Cerman, Lebensunterhalt $=$ Dana Štefanová/Markus Cerman, Lebensunterhalt und Erwerb im Alter in ländlichen Gesellschaften der Frühen Neuzeit, in: Marie Koldinská/Alice Velková (Hg.), Historik zapomenutých dějin. Sborník př́spěvků věnovaných prof. dr. Eduardu Maurovi [Ein Historiker der vernachlässigten Vergangenheit. Festschrift für Eduard Maur], Praha 2003, 83-107.

Štefanová/Zeitlhofer, Alter = Dana Štefanová/Hermann Zeitlhofer, Alter und Generationenbeziehungen in Böhmen. Zum Ausgedinge in nord- und südböhmischen Dörfern 1650-1750, in: Josef Ehmer/Peter Gutschner (Hg.), Das Alter im Spiel der Generationen. Historische und sozialwissenschaftliche Beiträge. Wien-Köln-Weimar 2000, 231-258.

Steinmaß1, Massenarmut $=$ Franz Steinmaß1, Schlicht gesagt, Massenarmut. Die wirtschaftliche Lage der Untertanen der Herrschaft Weinberg auf der Grund- 
lage des Maria-Theresianischen Katasters, in: Mühlviertler Heimatblätter 28 (1988), 14-26.

Stejskal, Bauer $=$ Aleš Stejskal, Bauer - Beamter - Herr. Grundsätze des Kommunikationssystems auf dem Rosenbergischen Dominium in den Jahren 1550-1611, in: Jan Peters (Hg.), Gutsherrschaftsgesellschaften im europäischen Vergleich, Berlin 1997, 211-224.

Štěrbová, Vývoi = Blanca Štěrbová, Vývoi sňatečnosti v lokalitě Novosedly nad Nežárkou v letech 1686-1910 [Die Entwicklung der Eheschließungen im Pfarrsprengel Novosedly nad Nežárkou (Neusattel an der Naser) in den Jahren 1686-1910], in: Historická Demografie 11 (1987), 97-139.

Stifter, Waldgänger = Karl Konrad Polheim (Hg.), Adalbert Stifter. Der Waldgänger, Berlin 1990.

Stoklásková, Ausländergesetzgebung = Zdeňka Stoklásková, Ausländergesetzgebung und Ausländerbehandlung in Österreich 1750-1863 (Beispiel Mähren). Forschungsstand, in: Historica. Historical Sciences in the Czech Republic, Series Nova 11 (2004), 91-116.

Stone/Stone, Country houses = Lawrence Stone/Jeanne Stone, Country Houses and their Owners in Hertfordshire, 1540-1879, in: William Aydelotte et al. (Hg.), The Dimensions of Quantitative Research in History, Princeton 1972, 56-123.

Sturm, Oberpfalz $=$ Heribert Sturm, Eine Erhebung vom Jahr 1658 über die Abwanderungen aus der Oberpfalz nach Böhmen im Dreißigjährigen Krieg, in: Jahrbuch für fränkische Landesforschung 21 (1961), 59-78.

Svátek, Culturhistorische Bilder = Josef Svátek, Culturhistorische Bilder aus Böhmen, Wien 1879.

Svoboda, Trade $=$ George J. Svoboda, The Foreign Trade of Eighteenth Century Bohemia, in: Journal of European Economic History 20 (1991), 93-123.

Szołtysek, Perspective $=$ Mikołaj Szołtysek $/$ Konrad Rzemieniecki, Between ,Traditional' Collectivity and ,Modern' Individuality. An Atomistic Perspective on Family and Household astride the Hajnal Line (Upper Silesia and Great Poland at the End of the 18th Century), in: Historical Social Research 30 (2005), 130-170.

Täger, Altenteil $=$ Angela Täger, Der Kampf um den Status des Alters im agrarischen Bereich und die vielen Deutungen des Altenteils, in: Gerd Göckenjan (Hg.), Recht auf ein gesichertes Alter? - Studien zur Geschichte der Alterssicherung in der Frühzeit der Sozialpolitik, Augsburg 1990, 35-62.

Tanner, Spulen = Albert Tanner, Spulen - Weben - Sticken. Die Industrialisierung in Appenzell-Ausserrhoden, Zürich 1982.

Teichl, Herrschaft $=$ Anton Teichl, Geschichte der Herrschaft Gratzen mit Zugrundelegung des Urbars vom Jahre 1553, Gratzen 1899. 
Teichl, Stadt $=$ Anton Teichl, Geschichte der Stadt Gratzen mit theilweiser Berücksichtigung der Herrschaft Gratzen, Gratzen 1888.

Tennstedt, Sozialgeschichte $=$ Florian Tennstedt, Sozialgeschichte der Sozialpolitik in Deutschland. Vom 18. Jahrhundert bis zum Ersten Weltkrieg, Göttingen 1981.

Thane, Ältere Menschen und ihre Familien = Pat Thane, Es ist gut in der Nähe zu sein - aber nicht zu nah'. Ältere Menschen und ihre Familien in England seit dem 17. Jahrhundert, in: Margareth Lanzinger/Edith Saurer (Hg.), Politiken der Verwandtschaft. Beziehungsnetze, Geschlecht und Recht, Göttingen 2007, 73-98.

Theibault, German Villages = John Theibault, German Villages in Crisis. Rural Life in Hesse-Kassel and the Thirty Years War, New Jersey 1995.

Theibault, Demography $=$ John Theibault, The Demography of the Thirty Years War-Revisited. Günther Franz and his Critics, in: German History 15 (1997), $1-21$.

Tilly/Tilly, Agenda = Richard Tilly/Charles Tilly, Agenda for European Economic History in the 1970s, in: Journal of Economic History 31 (1971), 184-198.

Tlapak, Poddanské = Josef Tlapak, K nekterým otázkám poddanské nezákupní drzby v Čechach v 16.-18. století [ $\mathrm{Zu}$ einigen Fragen der untertänigen nichteingekauften Güter in Böhmen im 16. bis 18. Jahrhundert], Praha 1975.

Tobner, Zigeunerwald = Zephyrin Tobner, Der Zigeunerwald. Eine Geschichte aus dem dunklen Böhmerwalde (Sonderdruck aus: Der Landbote), Krumau 1923.

Tönsmeyer, Adel = Tatjana Tönsmeyer, Adel und Armenfürsorge in Böhmen (1848-1918), in: Bohemia 48 (2008), 480-491.

Trachtová, Zünfte = Jolande Trachtová, Zünfte und Handwerkerwanderungen. Zur Zusammenarbeit südböhmischer und österreichischer Handwerker vom 17. bis zum 19. Jahrhundert, in: Andrea Komlosy/Václav Bůžek/František Svátek (Hg.), Kulturen an der Grenze. Waldviertel - Weinviertel - Südböhmen - Südmähren, Wien 1995, 127-130.

Trajer, Historisch-statistische Beschreibung = Johann Trajer, Historisch-statistische Beschreibung der Diözese Budweis, Budweis 1862.

Trossbach, Bauern $=$ Werner Trossbach, Bauern 1648-1806 (Enzyklopädie Deutscher Geschichte 19), München 1993.

Trossbach, Haus = Werner Trossbach, Das „ganze Haus“ - Basiskategorie für das Verständnis der ländlichen Gesellschaft deutscher Territorien in der Frühen Neuzeit, in: Blätter für deutsche Landesgeschichte 129 (1993), 277-314.

Trossbach, Gutsherrschaft $=$ Werner Trossbach, Gutsherrschaft zwischen Elbe und Oder. Asymmetrische Agrarsysteme in wechselnden Perspektiven, in: Reiner Prass/Jürgen Schlumbohm/Gérard Béaur/Christophe Duhamelle (Hg.), Länd- 
liche Gesellschaften in Deutschland und Frankreich 18. - 19. Jahrhundert, Göttingen 2003, 31-52.

Trossbach, Anthropologie = Werner Trossbach, Historische Anthropologie und frühneuzeitliche Agrargeschichte deutscher Territorien, in: Historische Anthropologie 5 (1997), 187-211.

Troyansky, 18. Jahrhundert = David G. Troyansky, Das 18. Jahrhundert, in: Pat Thane (Hg.), Das Alter. Eine Kulturgeschichte, Darmstadt 2005, 175-209.

Ubel, Böhmerwald = Gustav Ubel, Der südliche Böhmerwald (das Flussgebiet der Obermoldau und der Maltsch), Budweis 1897.

Van der Linden, Household History = Marcel van der Linden, Connecting Household History and Labour History, in: International Review of Social History 38 (1993), 163-173.

Van Dülmen, Kultur = Richard van Dülmen, Kultur und Alltag in der Frühen Neuzeit. Bd. 1., München (2. Aufl.) 1995.

Van Poppel/Nelissen, Opportunities = Frans van Poppel/Jan Nelissen, Economic Opportunities and Age at Marriage: an Analysis of 19th Century Micro Data for the Netherlands, in: Isabelle Devos/Liam Kennedy (Hg.), Marriage and $\mathrm{Ru}-$ ral Economy: Western Europe since 1400, Brepols 1999, 152-178.

Vedder, Majorate = Ulrike Vedder, Majorate, Erbrecht und Literatur im 19. Jahrhundert, in: Sigrid Weigel/Ohad Parnes/Ulrike Vedder/Stefan Willer (Hg.), Generation. Zur Genealogie des Konzepts - Konzepte von Genealogie, München 2005, 91-107.

Velková, Staatliches Eingreifen = Alice Velková, Eingriffe des Staates in die Beziehung zwischen der Obrigkeit und den Untertanen und ihre Wirkung auf die Dorffamilie an der Wende des 18. zum 19. Jahrhundert, in: Markus Cerman/ Robert Luft (Hg.), Untertanen, Herrschaft und Staat in Böhmen und im ,Alten Reich', München 2005, 153-175.

Velková, Krutá vrchnost = Alice Velková, Krutá vrchnost, ubozí poddaní? Proměny venkovské rodiny a společnosti v 18. a první polovině 19. století na př́kladu západočeského panství Štáhlavy [Grausame Obrigkeit, arme Untertanen? Veränderungen der ländlichen Familie und Gesellschaft im 18. und in der ersten Hälfte des 19. Jahrhunderts], Praha 2009.

Velková, Fenomén = Alice Velková, Fenomén stáří ve venkovské společnosti na přelomu 18. a 19. století [Das Phänomen des Alters in der ländlichen Gesellschaft um die Wende des 18. zum 19. Jahrhundert].

Velková, Besitztransfer = Alice Velková, Der Besitztransfer untertäniger Anwesen in Štáhlavy im 18. und in der ersten Hälfte des 19. Jahrhunderts, in: Markus Cerman/Hermann Zeitlhofer (Hg.), Soziale Strukturen in Böhmen. Ein regio- 
naler Vergleich von Wirtschaft und Gesellschaft in Gutsherrschaften, 16.-19. Jahrhundert, Wien 2002, 228-239.

Velková, Besitzinteressen = Alice Velková, Familie und Besitzinteressen. Veränderungen in der Wahrung des Familieninteresses in der ländlichen Gesellschaft Böhmens im 18. und beginnenden 19.Jahrhundert, in: Inken Schmidt-Voges (Hg.), Ehe - Haus - Familie. Soziale Institutionen im Wandel 1750-1850, Köln, u. a. 2010, 121-141.

Velková, Manor = Alice Velková, The Role of the Manor in Property Transfers of Serf Holdings in Bohemia in the Period of the ,Second Serfdom', in: Social History 37 (2012), 501-521.

Viazzo, Upland Communities = Pier P. Viazzo, Upland Communities. Environment, Population and Social Structure in the Alps since the Sixteenth Century, Cambridge 1989.

Viazzo/Lynch, Anthropology = Pier P. Viazzo/Katherine Lynch, Anthropology, Family History, and the Concept of Strategy, in: International Review of Social History 47 (2002), 423-52.

Vogel, Ungleichheit $=$ Anna-Carolina Vogel, Zur geschlechtsspezifischen Ungleichheit vor dem Tod. Ergebnisse einer aggregativen Kirchenbuchauswertung, in: Zeitschrift für Agrargeschichte und Agrarsoziologie 56, 1 (2008), 66-72.

Vondruška, Zemědělská = Vlastimíl Vondruška, Zemědělská výroba na rustikálu v jižních Čechách na konci 18. a v 1. polovine 19. století [Landwirtschaftliche Produktion auf Rustikalland in Südböhmen zu Ende des 18. und in der 1. Hälfte des 19. Jahrhunderts], in: Jihočeský sborník historický 49 (1980), 225-245.

Wall/Roben/Laslett, Family Forms $=$ Richard Wall/Jean Robin/Peter Laslett (Hg.), Family Forms in Historic Europe, Cambridge 1983.

Waltenberger, Rosenberg = Hans Waltenberger, Ortskunde von Rosenberg, Budweis 1908.

Wasmayr, Ulrichsberg = Gustav Wasmayr, Ulrichsberg. Geschichte des Marktes und seiner Dörfer, Ulrichsberg 1971.

Wegge, To Part or not to Part $=$ Simone Wegge, To Part or not to Part. Emigration and Inheritance Institutions in Nineteenth-Century Hesse-Cassel, in: Explorations in Economic History 36 (1999), 30-55.

Weigl, Residenz = Andreas Weigl, Residenz, Bastion und Konsumptionsstadt: Stadtwachstum und demographische Entwicklung einer werdenden Metropole, in: Andreas Weigl (Hg.), Wien im Dreißigjährigen Krieg. Bevölkerung - Gesellschaft - Kultur - Konfession (=Kulturstudien. Bibliothek der Kulturgeschichte 32), Wien-Köln-Weimar 2001, 31-105.

Weigl, Ungleichheit $=$ Andreas Weigl, Soziale Ungleichheit vor dem Tod in einer 
werdenden Metropole, in: Sonia Horn/Susanne C. Pils (Hg.), Sozialgeschichte der Medizin - Stadtgeschichte und Medizingeschichte, Wien 1998, 116-135.

Weisel, Kuriositäten = Georg Weisel, Kuriositäten von der Grenze, in: Harald Salfellner (Hg.), LeseReise Böhmerwald, Furth im Wald 2005, 83-87.

Weiss/Münchow, Bestandsverzeichnis = Volkmar Weiss/Katja Münchow (Hg.), Bestandsverzeichnis der Abt. Deutsche Zentralstelle für Genealogie im Sächsischen Staatsarchiv Leipzig, Band 4: Ortsfamilienbücher mit Standort Leipzig in Deutscher Bücherei und Deutscher Zentralstelle für Genealogie (Genealogische Informationen 33), Neustadt/Aisch (2. Aufl.) 1998.

Weiß, Hollersbach $=$ Alfred Stefan Weiß, Leben in der Frühen Neuzeit. Das Dorf Hollersbach von ca. 1600-1816, in: Salzburg Archiv 23 (1997), 41-72.

Weitensfelder, Interessen $=$ Hubert Weitensfelder, Interessen und Konflikte in der Frühindustrialisierung. Dornbirn als Beispiel, Frankfurt/M. 1991.

Wenzig/Krejči, Böhmerwald = Josef Wenzig/Johann Krejči, Der Böhmerwald. Natur und Mensch, Prag 1860.

Werkstetter, Auskommen $=$ Christine Werkstetter, Auskommen: Arbeit und Nahrung, in: Stephan Wendehorst/Siegrid Westphal (Hg.), Lesebuch Altes Reich, München 2006, 176-188.

Wetherell/Plakans, Intergenerational Transfers $=$ Charles Wetherell/Andrejs Plakans, Intergenerational Transfers of Headships over the Life Course in an Eastern European Peasant Community, 1782-1850, in: The History of the Family 3 (1998), 333-349.

Whittle, Individualism and the Family-Land Bond = Jane Whittle, Individualism and the Family-Land Bond: a Reassessment of Land Transfer Patterns Among the English Peasantry c. 1270-1580, in: Past and Present 160 (1998), 25-63.

Whittle, Inheritance $=$ Jane Whittle, Inheritance, Marriage, Widowhood and Remarriage: a Comparative Perspective on Women and Landholding in NorthEast Norfolk, 1440-1580, in: Continuity and Change 13 (1998), 33-72.

Wilcox, Marriage $=$ Penelope Wilcox, Marriage, Mobility and Domestic Service, in: Annales de Demographie Historique 1981, 195-206.

Williams, Earnings =Samantha Williams, Earnings, Poor Relief and the Economy of Makeshifts: Bedfordshire in the Early Years of the New Poor Law, in: Rural History 16 (2005), 21-52.

Willkomm, Böhmerwald = Moritz Willkomm, Der Böhmerwald und seine Umgebungen. Ein Handbuch für Reisende, Prag 1878.

Winkelbauer, Glaserzeugung = Thomas Winkelbauer, Von Hüttenmeistern und Glasmachern, Aschenbrennern und Flußsiedern. Zur Geschichte der Glaserzeugung im böhmisch-österreichischen Grenzgebiet vom späten 16. bis ins frühe 19. Jahrhundert, in: Das Waldviertel 41 (1992), 225-252. 
Winkelbauer, Grundherrschaft = Thomas Winkelbauer, Grundherrschaft und bäuerliche Gemeinde im Waldviertel, in: Ulrike Kerschbaum/Erich Rabl (Hg.), Heimatforschung heute (Schriftenreihe des Waldviertler Heimatbundes 29, Krems/Donau-Horn 1988), 59-85.

Wohlschläger, Von Häuslern = Ernst Wohlschläger, Von Häuslern, Fortgehern und anderen kleinen Leuten, in: Heimatkundlicher Verein für Südböhmen (Hg.), Deutsche Kulturlandschaft an Moldau und Maltsch, München 1986, 437-441.

Wright, Neo-Serfdom $=$ William Wright, Neo-Serfdom in Bohemia, in: Slavic Review 34 (1975), 234-252.

Wunder, Frauen $=$ Heide Wunder, ,Er ist die Sonn, sie ist der Mond‘. Frauen in der frühen Neuzeit, München 1992.

Wunder, Acker $=$ Heide Wunder, Der Acker, in: Heinz-Gerhard Haupt (Hg.), Orte des Alltags, München 1994, 13-20.

Záloha, Průmyslove = Jiři Záloha, Průmyslové podnikání a řemesla v Budějovickém kraji na přelomu 18. a. 19. století [Industrieunternehmen und Gewerbe im Budweiser Kreis an der Wende vom 18. zum 19. Jahrhundert], in: Jihočeský sborník historický 57 (1988), 138-152.

Záloha, Bevölkerungsemigration = Jiři Záloha, Die Bevölkerungsemigration zwischen der Herrschaft Český Krumlov (Krumau, ČSFR) und Oberösterreich im 17. und 18. Jahrhundert, in: Jahrbuch des Oberösterreichischen Museal-Vereins 135 (1990), 135-140.

Zeithammer, Land = Leopold Zeithammer, Land und Leute des Böhmerwaldes, Winterberg 1896.

Zeitlhofer, Diss.= Hermann Zeitlhofer, Besitztransfer und sozialer Wandel in einer ländlichen Gesellschaft der Frühen Neuzeit. Das Beispiel der südböhmischen Pfarre Kapličky, 1640-1840, Unveröffentl. Dissertation Universität Wien 2001.

Zeitlhofer, Besitztransfer $=$ Hermann Zeitlhofer, Besitztransfer in frühneuzeitlichen ländlichen Gesellschaften: die südböhmische Pfarre Kapličky (Herrschaft Vyčší Brod), 1640-1840, in: Markus Cerman/Hermann Zeitlhofer (Hg.), Soziale Strukturen in Böhmen. Ein regionaler Vergleich von Wirtschaft und Gesellschaft in Gutsherrschaften, 16. - 19. Jahrhundert, Wien 2002, 240-261.

Zeitlhofer, Land, Family and the Transmission of Property = Hermann Zeitlhofer, Land, Family and the Transmission of Property in a Rural Society of South Bohemia, 1651-1840, in: Continuity and Change 22, 3 (2007), 519-544.

Zeitlhofer, Vielfalt $=$ Hermann Zeitlhofer, Ökonomische Vielfalt und soziale Differenzierung: die Herrschaft Vyšší Brod im 17. und 18. Jahrhundert, in: Markus Cerman/Hermann Zeitlhofer (Hg.), Soziale Strukturen in Böhmen: ein regionaler Vergleich von Wirtschaft und Gesellschaft in Gutsherrschaften, 16.-19. Jahrhundert, Wien 2002, 15-28. 
Zeitlhofer, Wandel = Hermann Zeitlhofer, Sozialer und demographischer Wandel im südböhmischen Kapličky 1640-1840: eine Fallstudie zur Flexibilität traditionaler ländlicher Gesellschaften, in: Zeitschrift für Agrargeschichte und Agrarsoziologie 52 (2004), 64-83.

Zeitlhofer, Heimgewerbe = Hermann Zeitlhofer, „Flachs, das Hauptinteresse eines Jeden ...". Zur Bedeutung des textilen Heimgewerbes im südlichen Böhmerwald, 16.-19. Jahrhundert, in: Jihočeský sborník historický 68 (1999), 63-80.

Zeitlhofer, Flachs = Hermann Zeitlhofer, Flachs und die lokale Ökonomie. Arbeitsbeziehungen und das Agro-System im südlichen Böhmerwald (17. bis 19. Jahrhundert), in: Rita Garstenauer/Erich Landsteiner/Ernst Langthaler (Hg.), Land-Arbeit. Arbeitsbeziehungen in ländlichen Gesellschaften Europas (17. bis 20. Jahrhundert), Innsbruck 2010, 20-35.

Zeitlhofer, Sesshaftigkeit $=$ Hermann Zeitlhofer, Formen der Seßhaftigkeit bei Hausbesitzern und Landlosen in der südböhmischen Pfarre Kapličky, 16401840, in: IMIS-Beiträge 18 (2001), 51-67.

Zeitlhofer, Tschechien $=$ Hermann Zeitlhofer, Tschechien und Slowakei, in: Klaus J. Bade/Pieter Emmer/Leo Lucassen/Jochen Oltmer (Hg.), Enzyklopädie: Migration in Europa. Vom 17. Jahrhundert bis zur Gegenwart, Paderborn 2007, 272-287.

Zeitlhofer, Bohemian Migrants = Hermann Zeitlhofer, Bohemian Migrants: Internal, Continental, and Transatlantic Migrations in Bohemia at the Beginning of the Twentieth Century, in: Annemarie Steid1/Josef Ehmer/Stan Nadel/Hermann Zeitlhofer (Hg.), European Mobility: Internal, International and Transatlantic Moves in the 19th and Early 20th Centuries, Göttingen 2008, 189-206.

Zeitlhofer, Arbeit $=$ Hermann Zeitlhofer, Arbeit und Alter in ländlichen Gesellschaften der Frühen Neuzeit. Die Erwerbstätigkeit im Alter zwischen eigenem Besitz und den Zwängen einer, Ökonomie des Auskommens', in: Jahrbuch für Wirtschaftsgeschichte 1 (2008), 31-54.

Zeitlhofer, „Eiserne Ketten“ = Hermann Zeitlhofer, Die „eisernen Ketten“ der Heirat. Eine Diskussion des Modells der „ökonomischen Nischen“ am Beispiel der südböhmischen Pfarre Kapličky, 1640-1840, in: Christophe Duhamelle/ Jürgen Schlumbohm (Hg.), Eheschließungen im Europa des 18. und 19. Jahrhunderts. Muster und Strategien (Veröffentlichungen des Max-Planck-Instituts für Geschichte 197), Göttingen 2003, 35-63.

Zeitlhofer, Aspekte $=$ Hermann Zeitlhofer, Sozialhistorische Aspekte des Heiratsverhaltens in Südböhmen, in: Markus Cerman/Robert Luft (Hg.), Untertanen, Herrschaft und Staat in Böhmen und im,Alten Reich ' [Veröffentlichungen des Collegium Carolinum 99], München 2005, 257-276. 
Zeitlhofer, Succession $=$ Hermann Zeitlhofer, Headship Succession and Retirement in South Bohemia 1640-1840, in: David R. Green/Alastair Owens (Hg.), Family Welfare. Gender, Property and Inheritance since the Seventeenth Century [Contributions in Family Studies 18], Westport CT 2004, 73-96.

Zeßner, Arbeitsverhältnis = Hans Zeßner, Das landwirtschaftliche Arbeitsverhältnis und die Arten landwirtschaftlicher Arbeiter in Böhmen, in: Der Arbeitsnachweis 5 (1912), 219-242.

Zimmermann, Traditionalismus $=$ Clemens Zimmermann, Bäuerlicher Traditionalismus und agrarischer Fortschritt in der frühen Neuzeit, in: Jan Peters (Hg.), Gutsherrschaft als soziales Modell, München 1995, 219-238.

Zückert, Allmende = Hartmut Zückert, Allmende und Allmendeaufhebung, Stuttgart 2005.

\section{Ungedruckte Quellen}

Národní archiv (NA) Praha

Berní rula (BR)

č. $2[1653 / 54]$

č. 30 [1682]

Nová manipulace (NM)

H 115/1, 30, 31, 56

Stará manipulace $(\mathrm{SM})$

SM R 109/45, Bechyňsko 5 [Soupis poddaných podle víri 1651]

Tereziánský katastr (TK)

Buděj. 46, Rustik. fasse. 43/8 [1725]

Buděj. 684 [1713]

Spisy 619 (Buděj. 44)

Josefinsky katastr (JK)

JK 2963, Obec Krasné Pole [1788]

Stabilní katastr (SK) [1827-1850]

SK 221 Operat [Steuergemeinde Münichschlag]

SK 323 Operat [Steuergemeinde Schönfelden]

SK Duplikat, 183 [Steuergemeinde Münichschlag]

SK Duplikat, 190 [Steuergemeinde Schönfelden]

Exaequatorium Dominicale (ED)

ED, i. č. 193, Kart. č. 20 [1749]

Archiv pražského arcibiskupství (APA) [Prager Erzbischöfliches Archiv]

sign. I B Consignatio paschalis. Vicariat Crumlov 
Ústřední zemědělsko-lesnický archiv (ÚZLA)

SB.ÚZLA, inv. č. 189 [Manufakturtabellen 1753]

Státní oblasntní archiv (SOA) Třeboň

Fond C Vyšší Brod, Pozemkové knihy (PK)

PK č. 453 [Gericht Kapellen 1639-1713]

PK č. 465 [Gericht Horuntschlag 1713-1777]

PK č. 479 [Gericht Stift 1713-177]

PK č. 480 [Dominikalbuch Gericht Neuhäuseln 1690-1777]

PK č. 475 [Gericht Schönfelden 1777-1878]

PK č. 464 [Gericht Minichschlag 1777-1880]

PK č. 553 [Dominikalbuch Gericht Neuhäuseln 1777-1878]

PK č. 565 [,Ausnehmerbuch`1699-1738]

PK č. 445 [,Kaufbuch`1580-1639]

PK č. 447 [,Alt Waisen- und Schatzungsbuch` 1585-1649]

PK č. 556 [,Reuterbuch' 1731-1869]

PK č. 559 [Verlassenschaften, etc. 1672-1782]

Fond Velkostatek (VS) Rožmberk

kart. č. 94

Fond Velkostatek (VS) Nové Hrady

kart. č. 1220

Fond Sbírka jihočeských matrik

Farní úřad Kapličky

kniha č. 1, č. 9 (rodový katastr)

Farní úruad Vyšší Brod

kniha č. 2, č. 3

Farní úřad Přidolí

kniha č. 14

Farní úřad Rožmberk

kniha č. 14

Státní okresní archiv (SOkA) Český Krumlov

C-84, Cech tkalců V. Brod

kniha č. 6

Spisy II/12

Archiv Kláštera Vyšší Brod

knihy č. 221, 225, 242, 245, 251, 397, 665

knihá č. 237 [Zinsregister 1643] 
knihá č. 245 [Zinsregister 1712]

kart. č. 219-222 [Pfarrarchiv Kapličky]

kart. č. 397, č. 399, č. 405, č. 409, č. 410, č. 414, č. 665-674

Elektronische Datensätze

Universität Wien, Institut für Wirtschafts- und Sozialgeschichte

Wiener Datenbank zur europäischen Familiengeschichte

(http://www.univie.ac.at/Wirtschaftsgeschichte/famdat/index-gr.html),

Daten des Projekts ,Soziale Strukturen in Böhmen':

Soupis poddaných Vyšší Brod 1651

Soupis poddaných Chýnov 1651

Berní rula Vyšší Brod 1654

Berní rula Vyšší Brod 1682

Tereziansky Katastr Vyčší Brod 1713

Mannschaftsbücher Chynov 1725

Mannschaftsbücher Chynov 1775 


\section{VERZEICHNIS DER TABELLEN, GRAPHIKEN UND KARTEN}

a) Verzeichnis der Tabellen

Tabelle 1: Häuser- und Einwohnerzahl der Dörfer und Weiler der Pfarre Kapličky im 19. Jahrhundert, S. 34

Tabelle 2: Altersaufbau der Bevölkerung der Pfarre Kapličky im Jahr 1651, S. 59

Tabelle 3: Altersaufbau der Bevölkerung des Marktes Vyšší Brod im Jahr 1651, S. 59

Tabelle 4: Altersaufbau der Bevölkerung der Dörfer der Herrschaft Vyšší Brod im Jahr 1651, S. 60

Tabelle 5: Das Alter der Bevölkerung in südböhmischen Regionen des 16. und 17. Jahrhunderts (ab 12 Jahren), S. 61

Tabelle 6: Altersaufbau der Bevölkerung in südböhmischen Regionen des 16. und 17. Jahrhunderts, S. 62

Tabelle 7: Geschlechterproportion in südböhmischen Regionen des 16. und 17. Jahrhunderts, S. 63

Tabelle 8: Entwicklung der Häuserzahl der Dörfer und Weiler der Pfarre Kapličky, S. 67

Tabelle 9: Sozialstrukturelle Differenzierung in der Pfarre Kapličky 1653/54 und 1682 (Quellenkategorien), S. 72

Tabelle 10: Differenzierung der Anwesen nach sozialer Kategorie in der Berní Rula, Herrschaft Vyšší Brod 1653/54, S. 72

Tabelle 11: Verteilung der gesamten Aussaat, Pfarre Kapličky 1653/54, S. 76

Tabelle 12: Sozialstrukturelle Entwicklung, Pfarre Kapličky 1654-1713 (nach Zugvieh), S. 77

Tabelle 13: Anzahl der Häuser, Haushalte und Ehepaare in der Pfarre Kapličky in verschiedenen Verzeichnissen, S. 81

Tabelle 14: Die Milchkuhhaltung bei den Anwesen der Pfarre Kapličky (1653/54 und 1682), S. 90

Tabelle 15: Die Milchkuhhaltung bei den Anwesen des Marktes Vy̌̌ší Brod (1653/54 und 1682), S. 90 
Tabelle 16: Anzahl des Zugviehs pro Anwesen, Markt Vy̌ší Brod 1653/54 und 1682, S. 91

Tabelle 17: Berufsangaben in den Staatlichen Katastern, Pfarre Kapličky (16541713), S. 93

Tabelle 18: Berufe im Marktort Vyšší Brod (1654-1753), S. 94

Tabelle 19: Berufsangaben im Handrobotverzeichnis 1675 (Gerichte Mnichovice und Lhota), S. 97

Tabelle 20: Berufsangaben im Handrobotverzeichnis 1677 (alle Gerichte der Herrschaft Vyšší Brod), S. 98

Tabelle 21: Einkommen der ,Wohnparteien“ der Gemeinden Krasné Pole und Mnicovice im Jahre 1846, S. 100

Tabelle 22: Orte mit der höchsten Anzahl an Leinenwebern in den südböhmischen Bezirken Český Krumlov und Kaplice im Jahre 1753, S. 105

Tabelle 23: Berufsangaben in den Staatlichen Katastern, Dorf Studánky (16541713), S. 112

Tabelle 24: Sozialstrukturelle Gliederung in den Dörfern der Herrschaft Český Krumlov, 1718, S. 129

Tabelle 25: Anzahl der neu errichteten Anwesen in der Pfarre Kapličky auf bäuerlichem, dominikalem und Gemeindeland, 1681-1840, S. 133

Tabelle 26: Entwicklung der agrarischen Produktion in der Pfarre Kapličky, 16541846, S. 148

Tabelle 27: Entwicklung des mittleren Sterbealters der erwachsenen Bevölkerung, Pfarre Kapličky (1651-1770), S. 150

Tabelle 28: Verteilung der Besitzdauer in der Pfarre Kapličky, 1651-1840, S. 197

Tabelle 29: Verwandtschaftsbeziehungen in der Besitznachfolge, Pfarre Kapličky 1651-1840, S. 206

Tabelle 30: Verwandtschaftsbeziehungen in der Besitznachfolge im zeitlichen Wandel, Pfarre Kapličky 1651-1840, S. 208

Tabelle 31: Verwandtschaftsbeziehungen in der Besitznachfolge nach sozialer Differenzierung, Pfarre Kapličky 1651-1840, S. 208

Tabelle 32: Der Geburtsrang des im Besitz nachfolgenden Sohnes (ausgewählte Dörfer der Pfarre Kapličky), S. 219

Tabelle 33: Anteil der Zweitehen an allen Eheschließungen, Pfarre Kapličky 1701-1820, S. 226

Tabelle 34: Verwandtschaftsbeziehungen in der Besitznachfolge im innerböhmischen Vergleich, S. 230

Tabelle 35: Verwandtschaftsbeziehungen in der Besitznachfolge, Belm 1681-1860, S. 231 
Tabelle 36: Hausbesitzer mit einer Besitzdauer von weniger als 10 Jahren (16511720), S. 235

Tabelle 37: Verheiratetenanteile nach Altersgruppen, Herrschaft Vyšší Brod, S. 250

Tabelle 38: Verheiratetenanteile in den Dörfern der Herrschaft Třeboň, Altersgruppe 25-29 Jahre, S. 251

Tabelle 39: Verheiratetenanteile in den Dörfern der Herrschaft Chýnov, Altersgruppe 25-29 Jahre, S. 251

Tabelle 40: Durchschnittliches Alter bei der Erstehe, Pfarre Kapličky 1681-1840, S. 252

Tabelle 41: Zeitlicher Zusammenhang von Heirat und Besitzantritt, Pfarre Kapličky 1651-1730, S. 258

Tabelle 42: Altersaufbau des Gesindes in der Herrschaft Vyšší Brod, S. 262

Tabelle 43: Die als, Inwohner bezeichneten Ehepaare der Seelenbeschreibung des Jahres 1651, S. 271

Tabelle 44: Besitzerwechsel und Ausgedinge nach Verwandtschaft und Schicht, Pfarre Kapličky 1699-1738, S. 276

Tabelle 45 : Personen im Ausgedinge, Pfarre Kapličky 1699-1738, S. 279

Tabelle 46: Wohnformen im Ausgedinge, Pfarre Kapličky 1699-1738, S. 280

Tabelle 47: Alter bei Antritt des Ausgedinges, Pfarre Kapličky, 1699-1738, S. 286

Tabelle 48: Prozentsatz der Haushaltsvorstände an der Altersgruppe der über 60-jährigen Bevölkerung in den Dörfern ausgewählter böhmischer Herrschaften (im Jahre 1651 bzw. 1586), S. 302

b) Verzeichnis der Abbildungen, Graphiken und Karten

Abbildung 1: Hausbesitz in der Familie Mautner bis in die Mitte des 19. Jahrhunderts, S. 240

Abbildung 2: Heiraten zwischen verschwägerten Personen, S. 242

Graphik 1: Durchschnittliche jährliche Zahl der Taufen, Begräbnisse und Eheschließungen pro Dekade, Pfarre Vyšší Brod 1610-1699, S. 69

Graphik 2: Die Entwicklung der Zahl der ,Kommunikanten“ in den Pfarren Kapličky und Vyšší Brod in ausgewählten Jahren, S. 126

Karte 1: Karte von Böhmen (mit Hervorhebung des Untersuchungsgebietes), S. 30 


\section{ORTS- UND SACHINDEX}

Agrarproduktion 86-91,116-124, 146-151

Agrarverfassung 116-151

Allmende 86,120-124,134-136

Alltag 273, 278, 309, 314

Altersstruktur $24 \mathrm{f}, 47 \mathrm{f}, 57-64,149 \mathrm{f}, 262 \mathrm{f}$, $285 \mathrm{f}, 301 \mathrm{f}$

Anerbenrecht 14, 16f, 20, 23, 174-178, 193, 217, 249, 266, $310 \mathrm{f}$

Arbeitsdienst (s. auch Robot) 51

Arbeitsmarkt 151

Arbeitsorganisation 111, 263, 265

Bayern 55, 70, 93, 105, 109, 111, 130, 154, $164 \mathrm{f}$, $171,177,182,198,224,257$

Belm 39, 125, 200, 224, 229, 231, 282

Bergbau 100,113f

Besiedlung 132-145, 152-157

Bettler/Bettel 98, 163-166, 291, 304-306

Bevölkerungsgeschichte 15f, 20 f, 29, 117, 157, 243-271

Bodenmarkt 19, 116f, 151, 197, 200, 202, 231

Česky Krumlov (Böhmisch Krumau) 32f, 38, 51f, 55, 71, 73f, 86f, 95, 100-107, 114, 128f, 136, 144, 153f, 159-162, 170, 176, $181 \mathrm{f}, 193$, 195, 198, 260 f, 297

Chalupner 71-75,78, 129, 214, 236, 270

Chýnov (Chejnow) 73, 160, 184, 192, 218, 229, 234, 250f, 256, 262, 302

Deutschland 20,125, 132, 169, 260, 307

Demographie 29, 58-71, 64, 118, 124-127, 148, $150,232,244,285 \mathrm{ff}$

Dominikalisten(bzw. Dominikalland) 135, 144, 152-156, 169, 171, 173, 268

Dorfgemeinde (s. auch Gemeinde) 79, 82, 93, 96, 121, 123, 135, 171, 201, 309

Dorfgründungen 132,152-157,268
Dreißigjähriger Krieg 47f, 50, 57-71, 92, 134, $138,153,158,186,210,250,256,308$

Ehekonsens 117, 259-261

Einkommen 48, 55, 91f, 95-100, 102, 106, 111-115, 215, 255 f, 265, 289, 293, 296, 307, 309 f, 312

Eisenverarbeitung $114 \mathrm{f}$

Emphyteuse 54, 135 f, 169-173

Epidemien 66, 68, 244

Erbuntertänigkeit 26f, 49-52, 158, 168, 173, 210, 308, 310

Erbzinsrecht 54,135, 168-171, 179

Familienforschung 203, 249, 266, 272f, 291

Familienwirtschaft 25, 27, 55,57, 104, 133, 255

Feudalabgaben 26f, 52-56,83, 120, 194, 196, $251,261,263,297,309$

Flurzwang 110, 116, 120-124

Frauenarbeit 111, 113, 141, 149, 163, 305

Freistadt 113, 145, 155, 161

Frydlant(Friedlant)64, 73, 92, 135, 144, 182, 198, 207, 229, 256

Frymburk nad Vltavou (Friedberg a. d. Moldau) 40, 105, $107 \mathrm{f}, 122,131,137,142,144,164$, 234,241

Gärtner 71-75, 78, 129

Garnerzeugung 92,104-111. 136, 163, 255, 289, 295 f, 303

Garnhandel 104-110

Geburten 37f, 70f, 216

Geburtsrang 16, 216-219

Gemeinde 35, 52, 79f, 83, 93, 96, 99, 120-123, 130f, 133-135, 138, 141, 148, 160, 171, 201, 232, 261, 271,295, 304f, 309

Generation(enwechsel) 13, 15, 19f, 25 f, 85, $135 \mathrm{f}, 166,179 \mathrm{f}, 192,201 \mathrm{f}, 207,228,245$, 
256-259, 269, 272 ff, 283 ff, 291, 295, 306, 313,315

Gericht 32, 42

Gerichtsherrschaft $51 \mathrm{f}$

Gesinde 51, 55, 57 f, 80, 104, 111, 113, 131, 134, 137, 160 f, 166, 244, 254, 261-265, 292, 298, 300

Glas $102 \mathrm{f}, 111 \mathrm{f}, 115,157,159,162$

Hajnal 16, 243-249, 259, 262

Handel 100 f, 106-108, 113, 145, 151, 190, 241, 298

Handwerk 48, 53, 78, 91-96, 99, 102, 112, 134, 136, $161 \mathrm{f}, 166,245 \mathrm{f}, 248,299,306$

Haushalt, Haushaltsstrukturen 15, 19, 25, 29, 47, 58f, 65, 80-83, 99 f, 111, 134, 203, 220, 244, 247 f, 259 f, 262 f, 269, 282 f, 287 ff, 299 , 311,316

Hausierhandel 162

Hausindustrie 96,102-111, 162, 279

Häusler 53,71-75, 82, 88, 96f, 99, 123, 137, 147, $156,195,212,268$ f, 278

Heimfall 54, $169 \mathrm{f}$

Heimgewerbe s. Hausindustrie

Hořice (Höritz) 31, 47, 52, 61 f, 66, 71, 73, 87, 94, 103, 105 f, 114, 122, 131, 157, 170, 298

Horni Plana (Oberplan) 52, 66, 74, 105, 108, $110,123,130,164,261$

Inter vivos-Übergabe 25, $192 \mathrm{ff}, 232,282 \mathrm{ff}$

Inwohner 41, 53, 55-59, 65, 79-83, 96 f, 99, $103 \mathrm{f}, 122,128-131,134,137,141,146$, 160, $167 \mathrm{f}, 173,199,209,213,216,221,225$, 232-235, 254-261, $268 \mathrm{ff}, 281,287,292,297$ f, 302 f, 304, 315, 317

Kartoffel(anbau) 91, 99, 110, 123 f, 130 f, 146, 149

Kaufpreis $42 \mathrm{f}, 172,175 \mathrm{f}, 178 \mathrm{f}, 184-192,198 \mathrm{f}$, 233, $238 \mathrm{f}, 256,284,286$

Kleinhäusler (s. Häusler)

Konflikt 24, 54, 102, 109, 112 f, 183, 220, 272, 277 f, 299, 304, 313

Kredit 137, 198

Landarmut $71 \mathrm{ff}, 127 \mathrm{ff}, 132 \mathrm{ff}, 232 \mathrm{ff}, 253 \mathrm{ff}$, $261 \mathrm{ff}, 306$
Landlose 57, 65, $71 \mathrm{ff}, 122,127 \mathrm{ff}, 132 \mathrm{ff}, 139 \mathrm{f}$, 166, 207, 232 f, $253 \mathrm{ff}, 261 \mathrm{ff}$

Landwirtschaft $86 \mathrm{ff}, 95 \mathrm{ff}, 116 \mathrm{ff}, 138 \mathrm{ff}$

Laudemium 182

Lebenslauf 24, 168, $200 \mathrm{ff}, 243 \mathrm{ff}, 283-290$

Ledige 14, 55, 160, 166, 225, $243 \mathrm{ff,} 317$

Leibeigenschaft (zweite) $49 \mathrm{ff}, 169$

Leinenhandel $106 \mathrm{ff}, 137$

Leinenweber 74, $104 \mathrm{ff}, 137,154,163$

Liberec (Reichenberg) 55, 64, 73, 92, 135, 256, 302

Lipno (Lippen) 98, 101

Lohnarbeit 50, 55, 73, 96, 99, 131, 158 f, 255, 259, 297 f, 303 ff, 313

Loučovice (Kienberg) 33, 35, 52, 67, 92, $100 \mathrm{f}$, 102, 114, 143, 156

Mackenroth, Gerhard 117f, 243, 264, 312

Mähren 169, 182, 187, 196, 233

Malthus, Thomas Robert 118, 153, $243 \mathrm{ff}$

Mannschaftsbücher 158, 251

Manufaktur 93, $104 \mathrm{ff}, 159$

Markt $12 \mathrm{f}, 18 \mathrm{f}, 87,103,107,113,137 \mathrm{f}, 150 \mathrm{f}$, $176 \mathrm{ff}, 189 \mathrm{f}, 200 \mathrm{f}, 207,209,211,228,231$, $255,258,313,315 \mathrm{f}$

Mikrogeschichte 19,28f, 308

Mortalität 39, 66, 71, 126f, 149f, 210, 217, 232

Mühlviertel 32, 68, 71, 86, 89, 102, $104 \mathrm{ff}, 113$, 124,241

Neckarhausen 125, 227, 230, 301

Niederösterreich $32,65,71,109,112,115,130$, 132, 144, $176 \mathrm{ff}, 220,278,298$ f, 303, 305

Nordböhmen 53, 55, 64, 73, 75, 79, 89, 92, 103, 108

Normen 16f, 119, 174, 218, 265, 293, 299, 311, 316

Nove Hrady (Gratzen) 103, 105 f, 114, 129, 144, $153 \mathrm{f}, 161,163,165,172,182$

Oberösterreich $31-33,38,52,68,71,79,84,86$, $95,101,103,111 \mathrm{f}, 130,137,142 \mathrm{f}, 153,155$, $161,165,167,198,224,234,282,298$ f, 305

Österreich 16, 80, 109, 123, 125, 132, $161 \mathrm{f}, 180$, $182,193,207,216,224,228,257,268,273$, $276,283,297 \mathrm{f}$ 
Pacht (auf 3 Leiber)131, 135 f, 153, 156, $171 \mathrm{ff}$, 207

Pest 66, 68, 70f, 165, 244

Prachatice (Prachatitz) $60 \mathrm{ff}$

Praha (Prag) 106 f, 252

Primogenitur 15, 205, 217

Proto-Industrialisierung 16, 74, $104 \mathrm{ff}, 115 \mathrm{f}$, 159, 162 f, 245, 298, 300, 309

Realteilung $14 \mathrm{ff}, 20 \mathrm{ff}, 174,176,190,230,247$, 284, 301, $310 \mathrm{f}$

Recht 12, 16 ff, 24-26, $41 \mathrm{ff}, 50,54,117,135$, $168 \mathrm{ff}, 173 \mathrm{ff}, 193,219$

Robot (s. auch Arbeitsdienste) $49 \mathrm{ff}, 76 \mathrm{f}, 83 \mathrm{f}, 96$, 102, 120, 133 f, 138, 170, 172, 184, 193, 263, 285, 297, 309

Rožmberk (Rosenberg a. d. Moldau) 33, 40, 52, 54, 68, 73, 94 f, 102, 105 f, 127, 161, 165, 234, 295

Rustikalland 42, 45, 84, 120 f, 136, 139, 141, 144, 148, $155 \mathrm{f}$

Rychnůvek (Dt. Reichenau) 32, 54, 74, 105 ff

Schlägl, Stift $52,68,112,145,153,155,182$

Schollenbindung 158

Schwemmkanal, Schwarzenbergischer 101, 154

Seelenbeschreibung 83, $270 \mathrm{f}$.

Spinnen 87, $104 \mathrm{ff}, 163,296,303$

Štahlavy (bei Pilsen) 178, 228 ff, 257

Staat 54, 120

Studánky (Kaltenbrunn) 47, 52-54, 97 f, 112 f, 134, 145, 156, 169, 184, 188, 211, $250 \mathrm{ff}, 262 \mathrm{f}$, 287
Taglöhner 56, 97, 134, 249, 261

Textilerzeugung 99, $104 \mathrm{ff}, 163,299,315$

Töpferei/Hafnerei 94f, $112 \mathrm{f}$

Třeboň (Wittingau) $60 \mathrm{ff}, 228,250$ f, 302

Ultimogenitur 15, 178, 200, 218

Vagierende $163 \mathrm{ff}, 305$

Verwandtschaft 12, 19, $21 \mathrm{f}, 37 \mathrm{f}, 44 \mathrm{f}, 107,169$, $189,276,283,314 \mathrm{ff}$

Waisen 51, $185 \mathrm{f}$

Wald, herrschaftlicher 55, 88, 97, $100 \mathrm{ff}, 108$, 120 f, 131, 138 ff, 146, 150, 152 ff, 163 f, 261, 297

Waldviertel 109, 111, 130, 146, 303

Weide 88, 91, 110,121ff, 131, 134, 138, 144, 146, 150, 261, 309

Wiederverehelichung 24, 27, 200, 204f, 218, $220 \mathrm{ff}, 273 \mathrm{ff}, 287 \mathrm{ff}, 300$

Witwer/Witwe 24, 45, 80, 129, $140 \mathrm{ff}, 167,169$, $175 \mathrm{f}, 199,204 \mathrm{ff}, 210,218 \mathrm{ff}, 227,229 \mathrm{ff}, 238$, 250 f, 275, 278 f, 285 f, 295, 299 f, 312

Zehent 56, 83

Zins 53, 82, 133, 170

Zins(ge)reuter 95 f, 138 ff, 146, 267, 287, 295, 315

Zlata Koruna (Goldenkron) 32, 73, $106 \mathrm{f}$

Zölibat 14, 245, 254, 260, 264, 266

Zunft $93 \mathrm{ff}, 105-107,109,112 \mathrm{f}$ 


\section{SOZIAL- UND WIRTSCHAFTSHISTORISCHE}

STUDIEN

HERAUSGEGEBEN VON CARSTEN BURHOP, MARKUS CERMAN, FRANZ X. EDER, JOSEF EHMER, PETER EIGNER, THOMAS ERTL, ERICH LANDSTEINER UND ANDREA SCHNÖLLER

EINE AUSWAHL

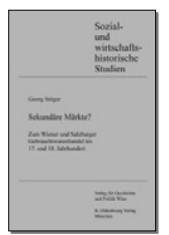

BAND 35

GEORG STÖGER

\section{SEKUNDÄRE MÄRKTE?}

ZUM WIENER UND SALZBURGER

GEBRAUCHTWARENHANDEL IM 17. UND

18. JAHRHUNDERT

2011. 298 S. 14 S/W-ABB., 10 GRAF. UND

7 TAB. BR.

$€ 39,80$ | ISBN 978-3-205-78678-8

BAND 34

DANA STEFANOVA

ERBSCHAFTSPRAXIS, BESITZ-

TRANSFER UND HANDLUNGS-

SPIELRÄUME VON UNTERTANEN

IN DER GUTSHERRSCHAFT

DIE HERRSCHAFT FRÝDLANT IN

NORDBÖHMEN, 1558-1750

2009. 341 S. BR.

$€ 49,80$ | ISBN 978-3-205-77936-O
BAND 33

MECHTHILD DUBBI

VOM K.U.K. HAUPTMANN ZUM

KOMMERZIALRAT.

KARL BITTNER (1871-1951)

ZWEI LEBENSENTWÜRFE IM SPIEGEL AUTOBIOGRAPHISCHER AUFZEICH-

NUNGEN

2008. 297 S. BR.

$€ 49,80$ | ISBN 978-3-205-77803-5

BAND 32

ELISABETH DIETRICH-DAUM

DIE „WIENER KRANKHEIT“

SOZIALGESCHICHTE DER TUBER-

KULOSE IN ÖSTERREICH

2007. 397 S. BR.

$€ 49,80$ | ISBN 978-3-7028-0431-2

BAND 31

ERNST BRUCKMÜLLER, FRANZX. EDER, ANDREA SCHNÖLLER (HG.)

HANNES STEKL

ADEL UND BÜRGERTUM IN DER HABSBURGERMONARCHIE 18. BIS 20. JAHRHUNDERT

HANNES STEKL ZUM 60. GEBURTSTAG GEWIDMET VON ERNST BRUCKMÜLLER, FRANZ EDER UND ANDREA SCHNÖLLER 2004. $312 \mathrm{~S}$.

$€ 49,80$ | ISBN 978-3-7028-0412-1

BÖHLAU VERLAG, WIESINGERSTRASSE I, A-IOIO WIEN, T: + 43 I 33024 27-O INFO@BOEHLAU-VERLAG.COM, WWW.BOEHLAU-VERLAG.COM | WIEN KÖLN WEIMAR 


\section{SOZIAL- UND WIRTSCHAFTSHISTORISCHE STUDIEN}

BAND 30

ANNEMARIE STEIDL

\section{AUF NACH WIEN!}

DIE MOBILITÄT DES MITTELEUROPÄISCHEN HANDWERKS IM 18. UND 19. JAHRHUNDERT AM BEISPIEL DER HAUPT- UND RESIDENZSTADT 2003. 233 S. BR.

$€ 49,80 \mid$ | ISBN 978-3-7028-0403-9

BAND 29

GERHARD AMMERER

HEIMAT STRASSE

VAGANTEN IM ÖSTERREICH DES ANCIEN REGIME

2003. 565 S. BR.

$€ 69,80$ | ISBN 978-3-7028-0402-2

BAND 28

MARKUS CERMAN,

HERMANN ZEITLHOFER (HG.)

SOZIALE STRUKTUREN IN BÖHMEN

EIN REGIONALER VERGLEICH VON WIRTSCHAFT UND GESELLSCHAFT IN GUTSHERRSCHAFTEN, 16.-19. JAHRHUNDERT

2002. 320 S. BR.

$€ 44,80$ | ISBN 978-3-7028-0392-6

\section{BAND 27}

ANDREA PÜHRINGER

\section{CONTRIBUTIONALE, OECONOMICUM} UND POLITICUM

DIE FINANZEN DER LANDESFÜRSTLICHEN STÄDTE NIEDER- UND OBERÖSTERREICHS IN DER FRÜHZEIT 2002. 320 S. BR.

$€$ 49,80 | ISBN 978-3-7028-0391-9
BAND 26

EDUARD MAUR

GUTSHERRSCHAFT UND ,ZWEITE LEIBEIGENSCHAFT" IN BÖHMEN

STUDIEN ZUR WIRTSCHAFTS-, SOZIALUND BEVÖLKERUNGSGESCHICHTE

(14.-18. JAHRHUNDERT)

2001. 247 S. BR.

$€ 39,80$ | ISBN 978-3-7028-0381-0

BAND 25

ADELIGE GRUNDHERRN ALS

UNTERNEHMER

ZUR STRUKTUR SÜDBÖHMISCHER

DOMINIEN VOR 1620

2000. 212 S. BR.

$€ 34,80 \mid$ ISBN 978-3-7028-0365-0

BAND 24

MARIA PAPATHANASSIOU

ZWISCHEN ARBEIT, SPIEL UND SCHULE DIE ÖKONOMISCHE FUNKTION DER KINDER ÄRMERER SCHICHTEN IN ÖSTERREICH 1880-1939 1999. 336 S. BR.

$€ 49,80$ | ISBN 978-3-7028-0360-5

BAND 23

ELISABETH MANTL

HEIRAT ALS PRIVILEG

OBRIGKEITLICHE HEIRATS-

BESCHRÄNKUNG IN TIROL UND

VORARLBERG 1820-1920

1997. 264 S. BR.

$€ 39,80$ | ISBN 978-3-7028-0350-6

BÖHLAU VERLAG, WIESINGERSTRASSE I, A-IOIO WIEN, T: + 43 I 33024 27-O INFO@BOEHLAU-VERLAG.COM, WWW.BOEHLAU-VERLAG.COM | WIEN KÖLN WEIMAR 
Hermann Zeitlhofer untersucht die Weitergabe von Haus und Grundbesitz zwischen den Generationen und die daraus resultierenden Folgen für die demographische, ökonomische und gesellschaftliche Entwicklung vormoderner Gesellschaften. Erst im lokalen Kontext lassen sich die Widersprüche der bisherigen Forschung in Bezug auf den postulierten Zusammenhang zwischen Besitzwechsel und sozialer Polarisierung auflösen und der gesellschaftliche Wandel auf einer neuen Grundlage erklären.

Hermann Zeitlhofer lebt und arbeitet als Sozialhistoriker und Bibliothekar in Wien. 